8-1967

\title{
A Pilot Study of Wichita Indian Archeology and Ethnohistory
}

Robert E. Bell

University of Oklahoma

Edward B. Jelks

Illinois State University

W., W. Newcombe

The University of Texas at Austin

Follow this and additional works at: https://scholarworks.sfasu.edu/ita

Part of the American Material Culture Commons, Archaeological Anthropology Commons, Environmental Studies Commons, Other American Studies Commons, Other Arts and Humanities Commons, Other History of Art, Architecture, and Archaeology Commons, and the United States History Commons

Tell us how this article helped you.

This Article is brought to you for free and open access by the Center for Regional Heritage Research at SFA ScholarWorks. It has been accepted for inclusion in Index of Texas Archaeology: Open Access Gray Literature from the Lone Star State by an authorized editor of SFA ScholarWorks. For more information, please contact cdsscholarworks@sfasu.edu. 


\section{A Pilot Study of Wichita Indian Archeology and Ethnohistory \\ Creative Commons License \\ (c) $($ ) $(9)$}

This work is licensed under a Creative Commons Attribution-NonCommercial 4.0 International License 


\section{A PILOT STUDY OF WICHITA INDIAN \\ ARCHEOLOGY AND ETHNOHISTORY}

Final Report To

THE NATIONAL SCIENCE FOUNDATION

Grant GS-964 
A PILOT STUDY OF

WICHITA INDIAN ARCHEOLOGY AND ETHNOHISTORY

Assembled by

Robert E. Bell

Edward B. Jelks

W. W. Newcomb

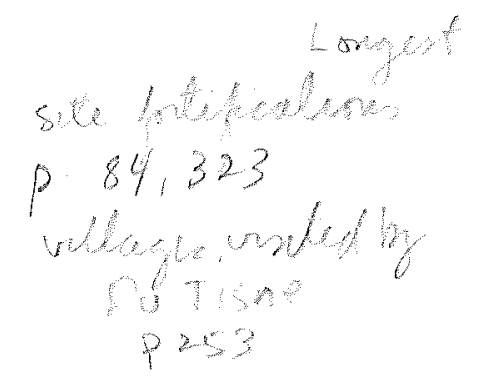

Contributors:

$\begin{array}{ll}\text { Tyler Bastian } & \text { Edward B. Jelks } \\ \text { Robert E. Bell } & \text { Harald P. Jensen, Jr. } \\ \text { Jay C. Blaine } & \text { Dessamae Lorrain } \\ \text { W. T. Field } & \text { David Lubell } \\ \text { Kathleen Gilmore } & \text { W.W. Newcomb } \\ \text { Inus M. Harris } & \text { C. A. Smith, Jr。 } \\ \text { R. K. Harris } & \text { J. Ned Woodall }\end{array}$

Final Report for Grant GS-964

NATIONAL SCIENGE FOUNDATION

August 1967 



\section{FOREWORD}

In 1965 several anthropologists drew up plans for a oneyear pilot study of the archeology and ethnohistory of the Wichita Indian tribes. After financial support had been gen erously provided by the National Science Foundation, the proposed research was carried out. This is a report on the results of that study.

The pilot study was designed to:

a) obtain a body of field data from the components

of the Spanish Fort sites, the largest and best-documented

of the historic Wichita sites in the Red River area;

b) make test excavations at several other sites in order that a problem-oriented program of future research can be accurately planned;

c) attempt to locate, by field reconnaissance, sites that relate to the Wichita occupation of the southern plains on both the historic and prehistoric time levels; d) make a survey of available ethnohistorical data in order (1) to compile a bibliography of documentary materials relevant to Wichita ethnohistory, (2) to make a detailed study of documents that relate specifically to the excavations being carried out at Spanish Fort and at the sites being tested, (3) to seek information that might lead to the field locations of other Wichita sites, and (4) to appraise those sources best suited for more extended examination.

The co-investigators of the project were Tyler Bastian of the Museum of the Great Plains, Robert E. Bell of The Uni= versity of Oklahoma, Edward B. Jelks of Southern Methodist University, and $W$. $W$. Newcomb of the Texas Memorial Museum at The University of Texas. Bastian supervised the arche= ological field work in Oklahoma under the direction of Bell. Jelks directed the archeological work in Texas. Newcomb directed the ethnohistorical research. Marvin E. Tong of the Museum of the Great Plains served the project as general coordinator.

The main part of the ethnohistorical study consisted of a thorough search of the archives at The University of Texas for documents relating to Wichita ethnohistory. The archeological work included extensive excavations at the Longest Site in Oklahoma and at the Upper Tucker and Coyote Sites in Texas. More limited excavations were carried out at the Glass and Gas Plant Sites in Texas. Several other archeo= logical sites were visited but not excavated beyond a test 
pit or two: the Devils Canyon and Wilson Springs Sites in Oklahoma, and the Gilbert, Stone, Vinson, and Womack sites in Texas. An effort was also made to locate several sites in Oklahoma and Texas which were reported in historical documents but which had not been located in the field.

After the library research and the archeological field work had been completed, a brief, general report could have been prepared to satisfy our contractual obligation to the National Science Foundation. It was felt, however, that the data which had been collected would be of interest to archeologists and ethnohistorians and, if possible, it should be made available to them in some detail without delay. Consequently, a series of descriptive papers was prepared instead of a summary report. Those papers are presented here.

Many people contributed in one way or another to the success of the project. The contributions of some are ac. knowledged in the section on archeological work in Oklahoma; there are also personal acknowledgments in some of the other papers. I wish here, however, to thank those who had a part in the archeological work in Texas and in the assembling and publishing of the final report:

Jo Ned Wooda11, formerly a Research Archeologist at Southern Methodist University, who supervised excavation of the Upper Tucker and Coyote Sites;

Dessamae Lorrain, Research Archeologist at Southern Methodist University, who supervised excavation of the Glass Site:

Harald $\mathrm{P}$ 。 Jensen, Jro, Research Archeologist at Southern Methodist Usiversity, who supervised excavation of the Gas Plant Site:

R。 Ko Harris, supervisor of the Archeology Laboratory at Southern Methodist University, who was in charge of the field laboratory at Spanish Fort, who participated in some of the reconnaissance, and who cowauthored the paper on trade beads: beads:

Inus Marie Harris, who co-authored the paper on trade

Jay C. Blaine, who wrote the section on gun parts and participated in the reconnaissance;

C.A.Smith, Jro, who prepared the report on reconnais. sance in Texas:

Kathleen Gilmore, graduate student at Southern Methodist 
University, who did the microscopic analysis of pottery and clays;

David Lubell, graduate student at Columbia University, who served as field assistant at the Upper Tucker and Coyote Sites, and who wrote the paper on chipped stone industries;

Dudley Varner of the Texas Memorial Museum, who assisted at the Gas Plant Site excavation.

I wish also to thank the landowners who generously pero mitted us to excavate on their property: Melvin Tucker, owner of the Upper Tucker and Coyote Sites; Hack Glass, owner of the Glass Site; and Edward Hicks, owner of the Gas Plant site.

Crew members who worked at sites in Texas were Doris Crow, Weldon Crow, Vernon Davie, David Glass, Arnold Goolsby, Charles Haney, Woody Hudson, Scott McKern, Arvind Patel, John Pig, Clyde Sewell, Bill Skinner, David West, and Bert Helm of the Tarrant County Archeological Society who volunteered a week of free work.

The field laboratory crew at Spanish Fort were Weldon Crow, Ruth Mann, and Adolph Witte。

Finally, I wish to express my gratitude to those whome working under continual pressure and harassment=-did the typing, drafting, preparation of photographic illustrations, proofreading, and other tasks involved in preparing the re port for printing. They are: typists Hazel Gilboe, Etoile Smith, and Inus Marie Harris; photographers Linda Smith and Gerald Humphreys; draftsman Marcia McGee; and editorial assistant Norma Hoffrichter, who edited manuscripts, typed, proofread, and offered many valuable suggestions.

Edward B。 Jelks

August, 1967 

TABLE OF CONTENTS

ARCHEOLOGICAL INVEST IGAT IONS IN TEXAS 1

THE TEXAS RED RIVER SITES 1

THE UPPER TUCKER SITE, by J. Ned Woodall 3

THE COYOTE SITE, by Jo Ned Woodall 15

THE GLASS SITE, by Dessamae Lorrain 24

THE GAS PLANT SITE, by Harald Po Jensen, Jr。 45

RECONNA ISSANCE IN TEXAS 50

ARCHEOLOGICAL RECONNAISSANCE ON THE TRINITY

AND BRAZOS RIVERS, by C.A. Smith, Jr。. 51

PRELIMINARY REPORT UPON EXCAVATIONS AT THE LONGEST

SITE, OKLAHOMA, by Robert E. Bell and Tyler

Bastian

54

SURVEY OF POTENT IAL WICHITA ARCHEOLOGICAL REMAINS

IN OKLAHOMA, by Robert E. Bell and Tyler Bastian 119

$\begin{array}{ll}\text { ART IFACTS } & 128\end{array}$

TRADE BEADS, PROJECT ILE POINTS, AND KNIVES,

by R. K。 Harris and Inus Marie Harris 129

GUNS, by Jay C。Blaine 163

MISCELLANEOUS EUROPEAN TRADE GOODS, by J. Ned Woodall

NAT IVE-MADE ART IFACTS FROM HISTORIC SITES, by Tyler Bastian

ART IFACTS FROM PREHISTORIC SITES, by Dessamae Lorrain

THE CHIPPED LITHIC INDUSTRIES FROM THE

LONGEST, GLASS, AND COYOTE SITES, by David

Lubel1

204

A MICROSCOPIC STUDY OF CERTAIN POTTERY TYPES AND CLAYS IN THE SOUTHERN PLAINS, by Kathleen Gilmore 
REFERENCES CITED IN ARCHEOLOGICAL REPORTS

AN ETHNOHISTORIC INVESTIGATION OF THE WICHITA INDIANS IN THE SOUTHERN PLAINS, by $W$. $W$ 。

Newcomb and $W$. T. Field

APPENDIX I: Synonymy 332

APPENDIX II: An Estimation of Wichita Population

340

BIBL IOGRAPHY

355

CONCLUDING STATEMENT

396

EXPLANATION OF FIGURES

397

FIGURES, TABLES, AND GRAPHS

FIGURES

Figures 1 through 75 follow page 401

\section{TABLES}

TABLE 1. Inventory of artifacts from the Upper Tucker site

TABLE 2。 Provenience of artifacts from the Coyote Site 22

TABLE 3. Provenience of artifacts at the Glass Site 43

TABLE 4. Provenience of artifacts, debitage, and biological specimens at the Gas Plant Site 48

\section{GRAPHS \\ (All graphs follow page 220。)}

GRAPH 1. Comparison of chipped stone tool sizes, Glass, Coyote, and Longest Sites.

GRAPH 2. Frequency distribution of chipped stone tool types, Glass, Coyote, and Longest Sites.

GRAPH 3. Cumulative frequency distribution of chipped stone tool types, Glass, Coyote and Longest sites. 
GRAPH 4. Cumulative frequency distribution of chipped stone tool types (arrow points and broken points excluded), Glass and Coyote sites.

GRAPH 5. Frequency distribution of chipped stone tool types (arrow points and broken points excluded), Glass and Coyote Sites. 


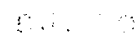




\section{ARCHEOLOG ICAL INVEST IGATIONS IN TEXAS}

In Texas, archeological excavations were carried out at three sites on the Red River in Montague County (the Upper Tucker, Glass, and Coyote Sites) and at the Gas plant Site on the Brazos River in McLennan County.

THE TEXAS RED RIVER STTES

Just northwest of the Spanish Fort Community in Montague county, Texas, the Red River makes a large bend (Figs. 2 and 3 ). The stretch of river valley embraced by the bend is some $7 \frac{1}{2}$ miles long (east-west) and about a mile wide. The major part of the valley inside the bend is taken up by an extensive alluvial terrace, the level surface of which stands approximately 20 meters above the river channel. The sandy soil of this terrace is very fertile and has been intensively cultivated by the Anglo-American farmers who have occupied the locality for the past century. At the top of the bend, the terrace breaks off and forms a bluff which overlooks the active flood plain lying between the terrace and the river channel to the north. Copious springs flow from the base of the bluff at several places.

Three archeological sites were excavated within this bend of the Red River as part of the research project reported here. Most work was done at the Upper Tucker Site (x41 MU 17), a late 18 th-century, Norteño Focus site attributable either to the Taovayas Indians or to one of the tribes affiliated with

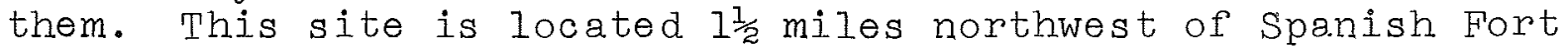
on the property of Melvin Tucker. It produced excellent architectural data and artifacts of both European and Indian provenience.

About four-tenths of a mile downstream (east) of the Upper Tucker Site is the Glass Site, a Henrietta Focus site dating from the late prehistoric period before the introduction of European trade goods into the area. Excavation at the Glass Site yielded the remains of one house and a good sample of artifacts.

Approximately six-tenths of a mile below the Glass site lies the Coyote Site, a Henrietta Focus component which was rather thoroughly explored. No houses were found at coyote, but several storage pits and a large midden produced a good collection of artifacts. 
One of the crucial problems of the Wichita study was to determine, if possible, who lived in the Red River area before the mid-18th century. Was the area part of the traditional Wichita homeland? or were the wichita newcomers to the region when first contacted there by Europeans in the 18th century? If they were newcomers, who lived there before them? It was in the hope of finding answers to some of these questions that the prehistoric Glass and goyote sites were investigated. Some partial answers resulted, as will be discussed later.

J. Ned Woodall supervised the work at Upper Tucker and at Coyote. Dessamae Lorrain supervised the Glass Site excavation. 
THE UPPER TUCKER STTE

by .J. Ned Woodall

The Upper Tucker Site (x41 MU 17) lies in and on the large alluvial terrace described above. It appears that at one time all the cultural remains were covered over with soil, evidently as a result of flood and wind deposition. In recent years, however, wind action, erosion, and intensive cultivation have removed the overlying soil mantle at several places, leaving cultural debris exposed on the surface. Particularly noteworthy are several exposures of bleached bison-bone fragments which are quite noticeable and which provide a clue to the presence of underlying midden deposits.

The terrace surface immediately around the site is almost level, the only contours being those produced by modern farming practices. Some 200 meters north of the area of major excavation the flat terrace drops sharply downward to the present flood plain of the river, which at that point flows almost due eastwest at the top of its bend. Several springs flow from the base of the downslope.

Although the exposed bison-bone fragments and other cultural debris lying on the surface have attracted artifact collectors for years, no systematic archeological excavations had been undertaken prior to the present work. The shifting sand and frequent plowing constantly turn up cultural materials; yet the number of artifacts obtained through the excavations was small compared to the many artifacts from Upper Tucker in local collections. Thus it appears that the site may have suffered significant loss of materials, although there are undoubtedly deeply buried features that remain as yet undisturbed.

\section{Excavations}

The Upper Tucker Site is large, and occupational debris is in evidence on the surface over at least four acres. Several areas of concentrated bone fragments are visible, ranging from 10 to 80 meters across. On the recommendation of $R$. K. Harris, who has made periodic surface collections from the site for many years, it was decided to begin work along the perimeter of one of the large bone concentrations near the north-eastern edge of the site. Ultimately all the work at Upper Tucker was devoted to that general area and to a somewhat smaller bone concentration immediately to the west (Fig. 4 ). 
Because of the unwieldly size of the site, it was divided into lots for purposes of recording information. Two lots were established: Lot A, 120 meters square, and Lot B (adjoining the southwestern edge of Lot A), 60 meters square. Each lot was subdivided by grid lines running north-south and east-west, true north being used in all instances. Trenches and pits were not always oriented with the grid lines, but were dug wherever investigation seemed most promising and plotted later on the site map by triangulating from nearby reference points. Vertical control was maintained by measuring depth below an iron nail driven in a large fence post to the northeast of the site. The height of this datum above sea level was not established.

The initial problem of excavation was viewed as deter mining the natural soil profile so that man-made disturbances of the geologic deposits could be recognized. Also it appeared necessary to determine the nature of the bone concentrations and their relation, if any, to cultural features. Soil profiles were obtained by digging small test pits beyond the area of concentrated bone, while long exploratory trenches about 80 centimeters wide were dug across the bone area. Several features-mouse pits, cache pits, and ash lenses-were found by the trenches: they appeared as anomalies in the tan sand once the plow zone was removed. The exploratory pits and trenches were dug with a minimum of vertical control until a feature was located; then the feature was excavated as a single unit, by natural strata, or by arbitrary levels, whichever was most appropriate in that particular case.

Soil removed from the test trenches was seldom screened, although any material found was bagged and labeled. with the appropriate trench number. Soil in and around the features, however, was sifted through screen of quarter-inch mesh. In addition, soil from the richest areas such as house floors and cache pits was bagged and sent to the field laboratory for washing though window screen. The latter process produced a sizable sample of tiny artifacts, especially glass beads. Pollen samples, carbon samples for radiocarbon analysis, and flotation samples were also obtained from the more crucial areas. Field records included drawings of soil profiles, level reports, maps, and written descriptive notes. Photographs were made of all the features as well as of the site in general. 


\section{Internal Site Structure}

Excavations at Upper Tucker revealed a simple internal structure, the chief soil contrast appearing between the dark, churned plow zone--generally about 15 centimeters thick--and the light-tan to yellow-tan sand which comprised the body of the alluvial terrace, extending to undetermined depth. While this lower zone changed slightly in color and texture about one meter below surface, this appeared to be a factor of moisture content unrelated to the archeological distribution of artifacts. Outside of the pit houses and cache pits, most of the cultural debris was contained in the plow zone. Occasionally, however, the debris extended below the plow zone to a depth of as much as 30 centimeters below the surface.

A helpful characteristic of the sand was its tendency to leave wash lines when deposited by water in depressions (Fig. 9). Such wash lines were often prominent in cache pits and house pits that were abandoned and then gradually filled in by rain-washed soil. Any disturbance through these wash lines--such as a house pit dug through an earlier, filledin one--were readily apparent. This aided greatly in establishing the relative ages of the respective features.

\section{Features}

Anomalies in the soil that seemed to be archeologically significant were assigned feature numbers when located. In those instances when it became necessary to subdivide a feature into components, a letter was suffixed to the number for each separate component. Eight features were excavated at Upper Tucker, comprising five house pits, four cache pits, and two hearths.

Feature 1

One of the test pits dug southeast of the major area of bone concentration encountered a zone of disturbed soil. When examined in profile (Fig. 6), the disturbed zone patently was fill that had accumulated inside a large pit, the south edge of which had been intercepted by the test pit. There were wash lines in the fill, indicating that the pit had lain open and was at least partially filled by rain washing.

The horizontal extent of the feature was traced by removing the plow zone, and an oval area of darkly stained soil emerged measuring some 15 meters long by 12 meters wide. A 
scallop-like irregularity in the eastern edge of the oval outline gave an indication that two intersecting house pits might be present. Subsequent excavation revealed that there were actually three house pits in the Feature 1 area: they were designated Features $1 \mathrm{~A}, 1 \mathrm{~B}$, and $1 \mathrm{C}$ respectively.

In the following descriptions, materials itemized under the heading Associations include only those objects found directly on the house floors, in post molds, or in fire basins.

\section{Feature 1A}

Type: Oval house pit

Dimensions: $11.85 \mathrm{~m}$. ENE-WSW, $5.3 \mathrm{~m}$. NNW-SSE, pit floor $65 \mathrm{~cm}$. below present surface

\section{Illustrations: Figures 5-8, 10}

Associations: 9 glass beads, 4 metal fragments, 9 stone fragments, 64 bone fragments, 58 clay lumps, 1 pipe fragment

Architecture: Feature IA was an oval house pit with the long axis running north-northeast and south-southwest. A packed ramp of sandy clay--evidently an entr ance passage $-\infty$ led down to the floor of the pit on its south side. An irregular-shaped, hard-baked area approximately 3.3 meters long by 1.5 meters wide lay near the center of the pit floor, its long axis paralleling that of the house. There was also a smaller (70 by 60 cm.) oval burned spot near the southeast corner of the house. Both burned places appear to be the remains of fireplaces.

Post molds averaging some 20 centimeters in diameter and 50 to 70 centimeters in depth were arranged around the walls inside the pit at about 1.5 -meter intervals. Sixteen such post molds probably go with Feature 1A, although the intersection with Feature IC at the east end made an exact count impossible. There were four center molds as well, two near each end of the house. An area about three meters square was cleared of topsoil immediately south of the house in search for exterior post molds, but none were found.

Apparently the original structure was an oval lodge built in an excavated pit, the roof supported by posts set around the inside edge of the pit and in its central area. Although archeological evidence is lacking, the superstructure 
was probably made of poles interlaced with branches, with a thatched roof and thatched or clay-daubed sides. An entrance ramp led down into the house on the south side. There was a large central hearth area and possibly a smaller one on the southeast side of the house.

Remarks: Owing to disruption by erosion and cultivation, the surface from which the house pit was dug could not be determined precisely; very probably, however, its original depth was greater than at present. The southern and eastern walls of the pit were much steeper and better defined than the western and northern ones, a circumstance resulting from intrusion by Features $1 B$ and $1 C$.

Although the low artifact yield from the house floor was disappointing, the fill of the house above the floor level was fairly productive. It appears that after the house was gone, a sizable depression was left in the surface of the ground which later was utilized as a trash depository.

\section{Feature 1B}

Type: Circular house pit

Dimensions: $6.9 \mathrm{~m} . \mathrm{N}-\mathrm{S} .7 .5 \mathrm{~m}$. E-W, original floor $65 \mathrm{~cm}$. below present ground surface

Illustrations: Figs. 5, 9, 9, 10

Associations: 7 metal artifacts, 63 metal fragments, $43 \mathrm{glass}$ beads, 2 bone artifacts, 1 potsherd, 1 flint flake, 275 bone fragments, numerous river pebbles.

Architecture: Feature $1 B$ was a smaller, more nearly circular pit than Feature 1A. It had an entrance ramp on the northeast side and a small (65 by $55 \mathrm{~cm}$.$) , basin-like,$ centrally located hearth. A series of post molds around the northern and western inside edges of the pit were spaced at intervals of about 1.5 meters. Each mold was approximately 20 centimeters in diameter and extended about 55 centimeters below the house floor. Although no post molds were found inside the eastern edge, the pit wall was clearly visible. Lying along the northern and western edges of the pit were charred beams which showed that the roof was made of stringers radiating out from the center of the house to the perimeter supports, with crosstimbers resting on the beams. In short, Feature $1 B$ seemed to represent a round house built over an excavated pit which was entered by means of a clay ramp on the northeast side. 
Remarks: As at Feature 1A, a depression was left in the surface of the ground at Feature $1 B$ after the house had disappeared. This depression was filled over a period of time by washed-in sand and discarded trash. Numerous metal objects, fragments of bone, and a quantity of charcoal were found in the fill. Indications are that the house at Feature $1 B$ was destroyed by fire.

Feature $1 \mathrm{C}$

Type: Oval or round house pit

Dimensions: More than $10 \mathrm{~m}$. in diameter, depth of original floor $50 \mathrm{~cm}$. below present ground surface

Illustrations: Figs. 8, 10

Associations: 1 glass bead, 1 metal fragment, 1 glass fragment, 53 smali bone fragments, 7 small unworked stones

Architecture: Because of disturbance by Features IA and 1B, the original plan of Feature lC could not be determined. The oldest of the three houses at Feature 1, it was also the shallowest and probably the largest as well. Originally the pit was either round or oval, with a diameter greater than 10 meters. There was a clay entrance ramp on the east side. Three post molds apparently belonged to the surviving portion of Feature IC: a possible wall post mold at the edge of the pit and two molds nearer the center of the house which probably were from roof supports.

Remarks: This house pit had already filled with sand before Features $I A$ and $I B$ were dug by the Indians. This was evidenced by the truncation of wash lines within Feature 1C at those places where it was intersected by the two other pits.

$$
* * * * * * * *
$$

Concerning Feature 1 as a whole, the absence of post molds around some sections of the pit perimeters posed questions about architectural details which were not answered satisfactorily. One possible explanation is that sound timbers from abandoned houses were sometimes salvaged and reused in other structures, leaving no wood to rot and stain the soil. 
Feature 2

Type: Bell-shaped cache pit

Dimensions: $1.2 \mathrm{~m}$. at top, constricting to $0.94 \mathrm{mo}$, and belling out to $1.58 \mathrm{~m}$. at the bottom; floor of pit $82 \mathrm{~cm}$. below surface

\section{Illustrations: Fig. II}

Associations: 83 glass beads, 3 glass fragments, 16 metal fragments, 3 flint flakes, 2,278 bones and bone fragments, pieces of mussel shell, animal teeth, stones, seeds

Description: This cache pit had a wide, flaring top which constricted before widening again, giving the feature an hourglass profile. All but one of the other cache pits described below expanded more or less uniformly from the original opening downward. Feature 2 also contained more cultural debris than the other pits, as well as numerous lenses of pure ash and charcoal. It obviously was used as a trash receptacle.

\section{Feature 3}

Type: Ash lens (hearth?)

Dimensions: $48 \mathrm{~cm}$. in diameter, $12 \mathrm{~cm}$. thick

Associations: None

Description: This was a light gray, homogeneous lens of pure ash, probably the residue of thoroughly burned bone, which lay 60 centimeters below the ground surface. The sand immediately beneath the ash showed signs of intense heat: it is probable, therefore, that this was a hearth. The soil underneath the .sh lens was disturbed to a depth of at least 72 centimeters, but no distinct pit edges could be seen.

\section{Feature 4}

Type: Hearth (?)

Dimensions: $2 \mathrm{~m}$. by $1.5 \mathrm{~m} ., 10 \mathrm{~cm}$. thick

Associations: Bone fragments, I flint flake, I turtle carapace fragment 
Description: This feature, badly disturbed by rodents, appeared to have been a shallow, oval fireplace. The sand beneath the ash was scorched to a dark orange color. No other occupational features were found in the immediate vicinity.

\section{Feature 5}

This large disturbed area was eventually found to comprise two complete house pits--designated Features 5A and 5B-plus a tiny remnant of a third which was excavated along with 5B.

\section{Feature 5A}

Type: Circular house pit

Dimensions: $6.18 \mathrm{~m} \cdot \mathrm{N}-\mathrm{S}, 5.32 \mathrm{~m}$. E-W, house floor $45 \mathrm{~cm}$. below present ground surface

\section{Illustrations: Figs. 10, 12-14}

Associations: 25 glass beads, several hundred metal fragments, 12 metal artifacts, 2 pipe fragments, 337 bone fragments, sandstone abraders, mussel shell fragments, 41 flint flakes, seeds, stones

Architecture: The plan of this house was revealed by the well-preserved post molds, the central hearth, and occasional bits of charred roof fall. The post molds-some of them still containing the burned post butts $-\infty$ were twelve in number: eight arranged at approximately two-meter intervals around the in terior edge of the pit, and four placed nearer the center where they apparently served as roof supports.

The hearth area, one meter in diameter, was in the center of the structure. A small hollowed-out spot 1.2 meters south of the hearth was found to contain a great number of metal, bone, and stone fragments.

Burned roof fall lay around most of the house perimeter. It consisted of medium-sized ( 15 to $25 \mathrm{~cm}$. diameter) charred sticks, usually resting with their long axis pointing toward the house center.

Judging from the evidence, Feature 5A represented a small circular pit house with its floor 45 centimeters or more below the surface. The roof consisted of wooden stringers extending 
from the center outward to the exterior posts. The roof, and possibly the sides as well, probably were covered with grass thatch.

No prepared entranceway was found. Because of the uninterrupted spacing of the exterior wall posts, the doorway seemingly was between two of them.

Remarks: This house was almost certainly destroyed by fire, a fact which has aided in the preservation of the associated wood material. Like all the houses at the Upper Tucker Site, the sunken area left after the house was gone became filled with washed-in sand and discarded trash.

Feature 5B

Type: Oval house pit

Dimensions: $11.0 \mathrm{~m}$. ENE-WSW; $6.7 \mathrm{~m}$. wide at $\mathrm{NE}$ end, tapering to $4.0 \mathrm{~m}$. near the $\mathrm{SW}$ end; floor 70 to $90 \mathrm{~cm}$. below present surface

Illustrations: Figs. 8, 10, 15

Architecture: Feature $5 \mathrm{~B}$ was a teardrop-shaped pit house. Like Features IA and 1B, it was constructed on the site of an earlier, shallower pit house, only a small remnant of which remained. Posts approximately 20 centimeters in diameter were set around the inside edge of the pit at two- to three-meter intervals; others, about 1.5 meters apart, were spaced along the central long axis of the house.

No hearths were found, nor was an entranceway positively identified although there may have been one near the southeast corner of the house. There was no burned roof fall.

Remarks: As previously mentioned, Feature 5B was originally dug through an earlier filled house pit, down to a level some 20 to 30 centimeters deeper than the floor of the earlier structure. No post molds were found inside Feature $5 \mathrm{~B}$ which did not appear to belong to the later house; thus it is probable that the posts of the earlier house were set less than 20 centimeters below its floor, and that the pit for Feature $5 \mathrm{~B}$ was excavated below those original post molds, destroying them. That the previous house employed vertically set wall posts is evidenced by five molds inside the small surviving remnant of its pit. 
The roof of Feature 5B must have been different from those of the other houses described above, as it was the only one with a center line of post molds. These center posts presumably carried a ridgepole which supported stringers running out to the exterior walls. If so, this house had a pitched rather than a dome-shaped roof.

\section{Feature 6}

Type: Bell-shaped cache pit

Dimensions: $1.4 \mathrm{~m}$. top diameter; $2.5 \mathrm{~m}$. bottom diameter; at least $2.2 m_{0}$ deep.

Associations: 1 mano fragment, reed matting, 1 seed, 1 she 1 fragment, 15 bone fragments

Description: This cache pit was the only one with evidence of a lining. The thoroughly carbonized remains of a mat made of reeds or grass lay on the pit bottom and ran about 20 centimeters up the wall.

The pit profile was asymmetrical, but originally it probably was bell shaped. The upper portion reached up into the plow zone, so the level from which it was dug could not be ascertained.

\section{Feature 7}

Type: Cache pit (?)

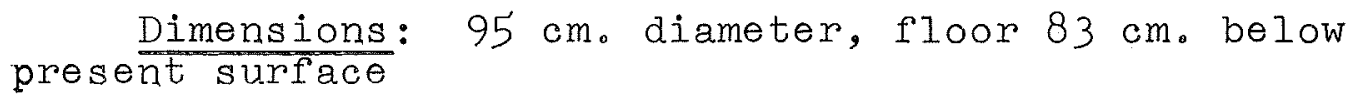

\section{Associations: None}

Description: This pit lay entirely within the path of an exploratory trench, and since the workman digging the trench did not detect the pit until the trench was 75 centimeters deep, no vertical profile was obtained. The pit was located in a large, poorly delineated, disturbed area, and numerous bone fragments and ashes were found around the general area of Feature 7 at a depth of 45 to 75 centimeters below surface. This scattered trash may have been "overflow" from using the pit for trash disposal (although there was no trash in the 
bottom of the pit); if so, the ground surface must have then been some 45 centimeters lower than now.

Although the walls of the excavated basal part of the pit were approximately vertical, the original pit, before being truncated by the test trench, could have been bell shaped.

\section{Feature 8}

Type: Bell-shaped cache pit

Dimensions: $1.65 \mathrm{~m}$. diameter at bottom, contracting to $1.2 \mathrm{~cm}$. at a point $40 \mathrm{~cm}$. above the bottom, and expanding again to a diameter of $1.35 \mathrm{~m}$. where truncated by a test trench.

Illustrations: Fig. 16

Associations: 6 glass beads, 18 complete or fragmentary bones, 1 metal fragment, 3 garfish scales, 1 flint flake, 1 snake spine, 2 unidentified seeds, 3 burned clay fragments, 1 unidentified animal tooth

Description: This feature, like Feature 7, was discovered entirely within an exploratory trench, so its original depth could not be determined because its top was removed before recording. It appeared to have an hourglass shape, with its lower walls angled sharply. Small ash lenses near the pit floor indicated that the pit was used as a trash receptacle. 
14

TABLE 1. Inventory of artifacts from the Upper Tucker Site. Items No. of Specimens

$\begin{array}{cr}\text { Metal Tools } & \\ \text { awls } & 1 \\ \text { scissors } & 1 \\ \text { arrow points } & 12 \\ \text { knives } & 3 \\ \text { Ornaments } & \\ \text { rings } & 4 \\ \text { hawk bells } & 1 \\ \text { tinklers } & 5 \\ \text { buttons } & 1\end{array}$

Gun Parts

frizzens 1

upper vise jaw I

Misc. Metal Artifacts

kettle fragments 5

pipe tomahawk 1

horse trappings $\quad 15$

chain links 4

Native-made Artifacts

potsherds 22

human figurines 2

unidentified figurines 8

pipe fragments, clay $\quad 11$

pipe fragments, stone $\quad 16$

tabular scrapers 27

grooved abraders 4

manos and fragments 7

grinding basins 5

possible abraders $\quad 37$

rubbing stones 1

paint palette 2

grooved mauls 3

hammerstones 4

toothed fleshers 1

shell artifacts 1 
THE COYOTE SITE

by J. Ned Woodall

Situated atop the bluff at the edge of the large, previously described alluvial terrace, the coyote Site commands the active flood plain of the Red River to the north. Springs flow from the base of the bluff nearby. Although prior to excavation there was virtually no surface indication of aboriginal habitation, the field party was attracted to the spot by the suitability of the terrain for human occupation. Tests proved that the site was, indeed, intensively occupied by peoples of late prehistoric times.

The bluff forms the north boundary of the site; the east and west boundaries are delineated by broad, shallow gullies draining downslope to the active flood plain. To the south the ground stretches almost perfectly flat for lic miles to the limits of the river valley. At present in pasture, the site has been cultivated intensively in the past.

Until recently a farmhouse had stood on the site. A concrete storm cellar still remained, and modern trash was scattered about the spot where the house had formerly been, both on the surface and buried a few centimeters in the soil. Fortunately one of the workmen on the field crew had lived in the house at one time and was able to give information as to the location of old fence rows, outbuildings, and the like. This prevented confusion and waste of time in determining the nature of subsurface disturbances attributable to farmhouse occupation.

Excavations

In order to ascertain the internal structure of the site, a series of meter-square pits was dug in an east-west line across the presumed occupation area. While a few of the pits revealed nothing but sterile tan sand below the plow zone, others exposed a midden area some 130 meters across that lay along the edge of the bluff. A second series of test pits dug south of the first ones showed that the midden ran at least 130 meters back from the bluff. Since the area beyond was being prepared for planting by the landowner, no testing was done any further to the south, but gray ash and charcoal were noted in the plow furrows for a considerable distance in that direction.

By studying the profiles of the lines of test pits, the richest part of the midden zone was delimited. This area was explored intensively by digging meter-wide trenches of varying 
length and depth, but always carried down below the midden zone. The trenches were not always oriented with the cardinal direction, but rather were put where they crossed the most promising areas in the most direct way possible. Once a feature was located, the overlying soil was removed without regard to any particular dimensional units such as grid squares; instead, an area was cleared-usually eccentric of shape-othat was sufficiently large to encompass the feature being investigated. The feature was then dug in an appropriate manner: as a single unit, by natural strata, by arbitrary levels, or by whatever means best suited each unique set of requirements (Fig。17)。

Fourteen features were recorded, comprising eleven cache pits, three hearths, and a small indeterminate disturbance. Soil definitely associated with a feature (for example, the fill inside cache pits) was troweled out, the feature outline being preserved as accurately as possible in the process. This soil was then passed through screens of quarter-inch mesh. Soil was also washed through window screen at the field laboratory to obtain samples of objects too small for collecting on the regular screens. Flotation samples, pollen samples, and carbon samples were obtained whenever practicable.

In order to procure a sample of artifacts from the body of the midden outside the features, several pits were excavated. by 15-centimeter levels, the soil passed through quarter-inch screens, and the material from each level bagged separately. All the artifacts were sent to the field laboratory for washing, repairing, and cataloging.

For vertical control, a small quartzite pebble embedded in the northwest corner of the concrete storm cellar was designated as the datum and assigned an arbitrary elevation of 100 meters. A contour map was constructed showing the ground surface at all points over the site in relation to the vertical datum. Horizontal control was maintained by a standard system of north south and east-west coordinates. 
Internal Structure

As revealed by the test pits and trenches within the midden area, three distinct soil zones were present. The topmost was a regular, clearly discernible plow zone averaging about $32 \mathrm{~cm}$. in thickness. Below that, varying in thickness, was the undistur'jed midden zone--dark, organically stained sand containing cultural refuse. The midden zone reaches a maximum depth of $72 \mathrm{~cm}$. on the east side of the excavated area, thinning out to $40 \mathrm{~cm}$. and less in other parts of the site. The lower limits of this zone, always poorly defined, graded into a light tan sand that comprised the lowest zone. The latter, essentially sterile of cultural material, seemed to be the undisturbed body of the alluvial terrace; it extended to an undetermined depth. Although rodent and root disturbances were numerous, they posed no serious problems in defining occupational features.

As will be seen in the following section, most of these features consisted of cache pits dug into and below the midden zone (Fig. 19). These disturbances were noticed only after the overlying midden zone was stripped away, leaving the dark fill in the pit limned against the light tan sterile sand matrix of the lowest zone. The original mouth of these pits probably lay somewhere in the midden zone, but were effectively disguised by it. Consequently all measurements involving depths are given as below the present ground surface. Since there was no evidence of severe soil erosion or accretion at the site, however, these measurements are felt to approximate the original dimensions.

\section{Features}

As at the Upper Tucker Site, archeologically significant anomalies in the soil were designated features. Only one (Feature 12) was divided into smaller components.

The cache pits at the coyote site share at least two characteristics. All are straight-walled (or nearly so) (Fig. 19), contrasting in this respect to the bell-shaped pits of the historic components. Also the cache pits seemed to occur in clusters (Fig. 18), unlike the relatively isolated pits at Upper Tucker. 
Feature 1

Type: Round, straight-sided cache pit

Maximum dimensions: Diameter $2.0 \mathrm{~m} . \mathrm{N}-\mathrm{S}, 2.12 \mathrm{~m} . \mathrm{E}-\mathrm{W}$. The level floor was reached 1.24 meters below the surface,

Description: The upper portion of this pit extended into the dark midden zone, and, therefore, its exact original depth is not known. Below the midden zone the pit was composed of dark organic-stained sand, charcoal flecks, and the cultural detritus listed in Table 2.

\section{Feature 2}

Type: Round, straight-sided cache pit

Maximum dimensions: Diameter $1.18 \mathrm{~m} . \mathrm{N}-\mathrm{S}, 1.29 \mathrm{~m} . \mathrm{E}-\mathrm{W}$. Pit floor was 1.05 meters below the surface.

Description: The outline of Feature 2 did not become apparent until 60 centimeters of overlying midden soil had been removed. As in all other cache pits at the site, the fill was noticeably darker than the light sand matrix.

\section{Feature 3}

Type: Oval or round cache pit

Maximum dimensions: Diameter $1.8 \mathrm{~m} . \mathrm{N}-\mathrm{S}, 1.5 \mathrm{~m} . \mathrm{E}-\mathrm{W}$ 。

Description: Feature 3 appeared at 75 centimeters below surface as a dark stain in the bottom of a test trench. Subsequent troweling showed that it extended only a few centimeters below this trench floor. The feature was only partially exposed, the eastern half being left unexcavated. While it appears to have been the bottom of a cache pit, its exact nature remains uncertain.

\section{Feature 4}

Type: Round, straight-sided cache pit

Maximum dimensions: Diameter $1.62 \mathrm{~m} . \mathrm{N}-\mathrm{S}, 1.70 \mathrm{~m}, \mathrm{E}-\mathrm{W}$. The level pit floor was 1.24 meters below surface.

Description: The 53 centimeters of midden fill removed from this pit contained an inordinate amount of trash (see Table 2)。 
Feature 5

Type: Round, straight-sided cache pit

Maximum dimensions: Diameter $1.21 \mathrm{~m} . \mathrm{N}-\mathrm{S}, 1.31 \mathrm{~m} . \mathrm{E}-\mathrm{W}$. The pit floor was 1.34 meters below surface.

\section{Feature 6}

Type: Round, straight-sided cache pit

Maximum Dimensions: Diameter $1.55 \mathrm{~m}$. (estimated) $\mathrm{N}-\mathrm{S}$, $1.94 \mathrm{~m}$. F. W. The pit floor was 1.20 meters below surface.

Description: Feature 6 was one of the most clearly defined pit outlines in the site. A balk retained through the disturbed area revealed that the original depth was at least $80 \mathrm{~cm} .--t h e$ midden zone obliterated the profile above this level.

Feature 7

Type: Round, straight-sided cache pit

Maximum dimensions: Diameter $1.21 \mathrm{~m}$. (estimated) $\mathrm{N}-\mathrm{S}$, $1.10 \mathrm{~m}$. F-W. The pit floor occurred at $60 \mathrm{~cm}$. below surface.

Description: The west and southwest portions of Feature 7 were damaged while exposing the surrounding cache pits, thus making it necessary to estimate these dimensions.

Feature 8

Type: Round, straight-walled cache pit

Maximum dimensions: Diameter $2.25 \mathrm{~m}$. The level pit floor was $50 \mathrm{~cm}$. below the present surface.

Description: This feature, located on the western fringe of the site, was typical of the excavated pits. Had it not been for the thin midden deposit in this area such a shallow feature would have gone undetected. The eastern one-third of Feature 8 was not excavated. 


\section{Feature 9}

Type: Prepared stone hearth

Dimensions: Diameter $65 \mathrm{~cm} . \mathrm{N}-\mathrm{S}, 73 \mathrm{~cm}$. E-W. Top of the stones lay $91 \mathrm{~cm}$. below the present surface.

Description: Feature 9 was a carefully constructed hearth composed of eight small hearthstones closely grouped about a single large stone. Although somewhat disturbed by rodent burrowing, the original dished appearance was evident. The nature of the feature was revealed not only by the hard, bright orange burned sand around the stones but also by the ash debris among and around the stone. There were no associated artifacts.

\section{Feature 10}

Type: Round cache pit

Maximum dimensions: Diameter $1.77 \mathrm{~m}$. The floor was found $78 \mathrm{~cm}$. below surface.

Description: This pit was not completely excavated, but it clearly was circular with walls that sloped inward to a level floor. The interior was filled with midden soil.

\section{Feature 11}

Type: Round, straight-walled cache pit

Maximum dimensions: Diameter $1.39 \mathrm{~m} . \mathrm{N}-\mathrm{S}, 1.30 \mathrm{~m} . \mathrm{E}-\mathrm{W}$. The pit floor was 1.02 meters below surface.

Description: Feature 11 is a circular pit similar to the others found at the Cojote Site. Small lenses of gray-blue ash was present at various depths in the fill and appeared--as did all the material recovered--to represent trash dumped into the pit, The south wall of this pit was slightly undercut-not enough to suggest the bell-shaped pits previously reported, however.

Feature $12 \mathrm{a}$

Type: Cache pit (?)

Maximum dimensions: Diameter $2.8 \mathrm{~m} . \mathrm{N}-\mathrm{S}$ (estimated), 2.0 m。 F-W. The floor was 1.30 meters below surface. 
Description: Because of the unusually large size of this feature its exact nature is in doubt, but it appeared to be a very big cache pit with inward-sloping walls. Only the southeastern quadrant was excavated.

\section{Feature $12 b$}

Type: Hearth area

Maximum dimensions: Diameter $47 \mathrm{~cm} . \mathrm{N}-\mathrm{S}, 60 \mathrm{~cm} . \mathrm{E}-\mathrm{W}$. The bottom of the hearth was 1.10 meters below surface.

Description: Feature $12 \mathrm{~b}$ was a 20 centimeter-deep oval depression apparently used as a hearth. The surrounding sand was burned to a bright orange, and ash was found in the shallow pit. It was contiguous to the eastern edge of Feature 12a.

\section{Feature 13}

Type: Small trash pit (?)

Maximum dimensions: Diameter $45 \mathrm{~cm}$. Floor of the pit lay 1.00 meters below surface.

Description: This small pit, 35 centimeters deep and shaped like an inverted cone, contained the major portion of a deer skull. Present was a portion of the frontal bone, both parietals, part of the occipital, and both horn cores cut close to the base. The pit fill was flecked with charcosl, otherwise sterile.

\section{Feature 14}

Type: Hearth (?)

Maximum dimensions: Width $38 \mathrm{~cm} . \mathrm{N}-\mathrm{S}$, length $66 \mathrm{~cm} \cdot \mathrm{E}-\mathrm{W}$. The depression floor was $95 \mathrm{~cm}$. below surface.

Description: Feature 14 was a roughly rectangular pit 15 centimeters deep with a flat bottom and near-vertical sides. Ash was abundant in the pit fill. 
TABLE 2. Provenience of artifacts from the Coyote site.

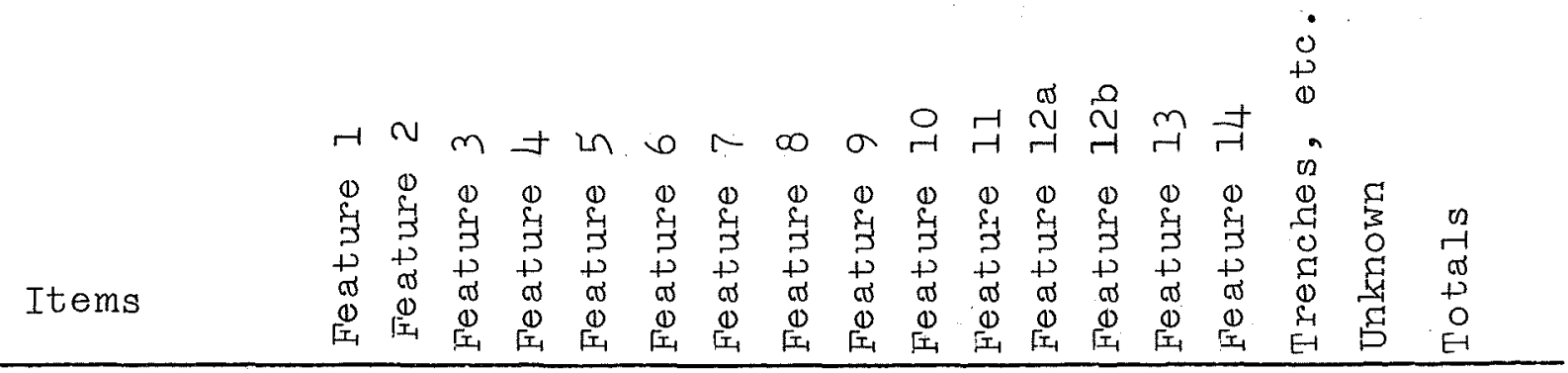

Ceramics

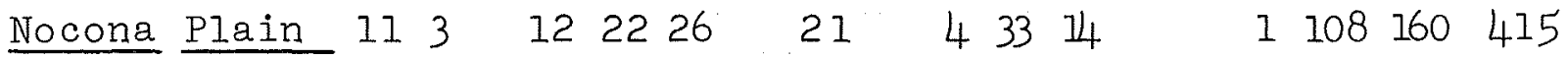

redware

6

$5 \quad 1.1$

Lithics

Scrapers

End

Thumbnail

Side

Denticulates

1.

Gouges

Notched filakes 1

Notched blades $I$

Retouched flakes

Retouched blades

Drills

Gravers

Arrow points

Fresno

Harre $1 \perp$

Scallorn

A.tha

1

Indeterminate 1

Dart points

I

11

\begin{abstract}
23
\end{abstract}
12

1
1.

1

$\begin{array}{rrr}2 & & 3 \\ 3 & 3 & 9 \\ 1 & 1 & 3 \\ 2 & & 4 \\ & 1 & 1 \\ 1 & 2 & 4 \\ & & 1 \\ 4 & 8 & 21 \\ 2 & & 2 \\ & 1 & 1 \\ & 1 & 3\end{array}$

1

1

2

$\begin{array}{lll}7 & 6 & 22\end{array}$

7314

$2 \quad 1 \quad 3$

1

214

2 
TABLE 2 (continued).

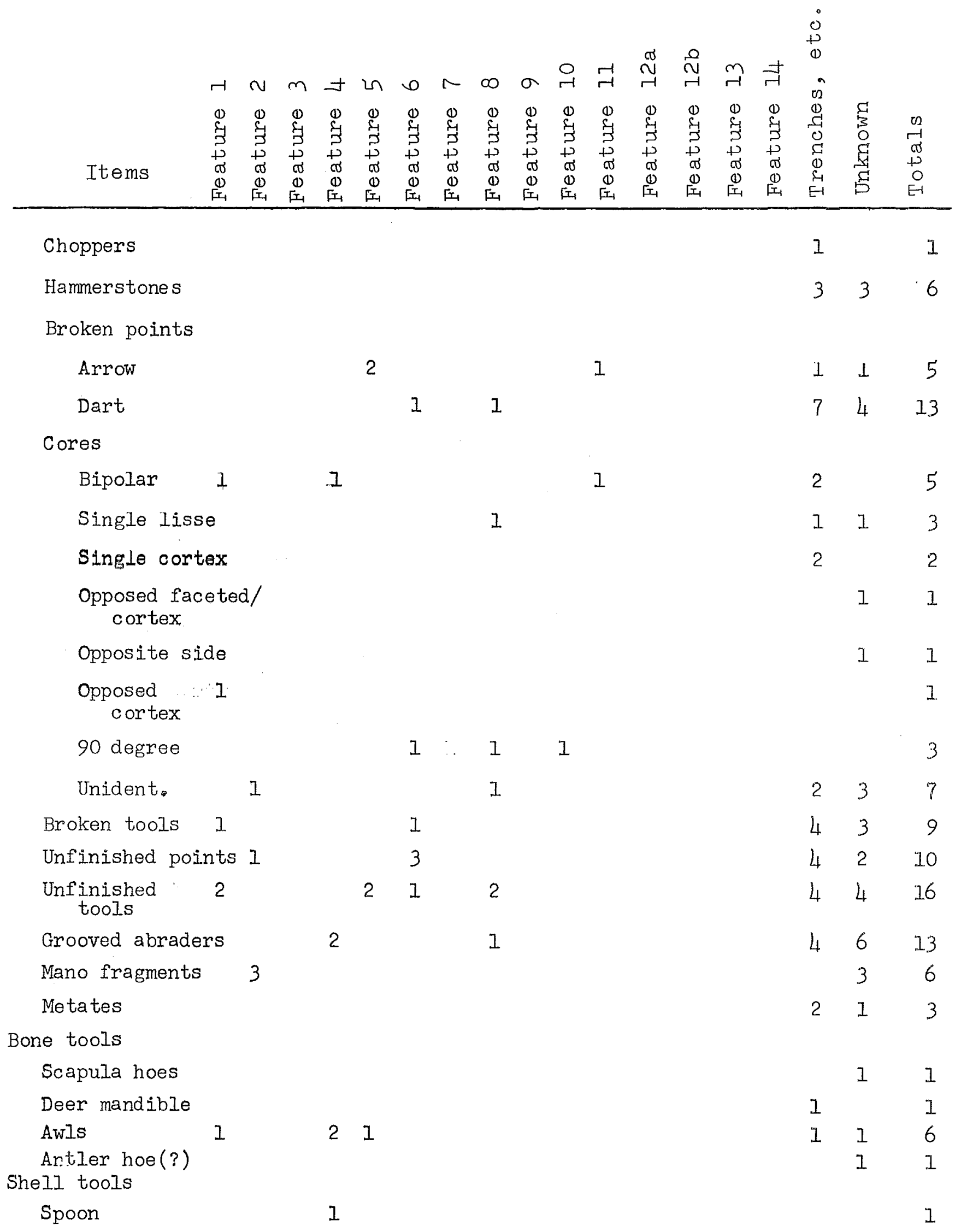




\title{
THE GLASS SITE
}

\author{
by Dessamae Lorrain
}

While excavations at the Upper Tucker and Coyote Sites were in progress in the fall of 1965, the field crew recorded several previously unknown archeological sites in the vicinity, including the Glass Site (x41 MU24)。 This late prehistoric site of apparent Henrietta. Focus affiliation promised to hold information relevant to the origins of the Norteño Focus; consequently, when the landowner, Hack Glass, offered the following March to let Southern Methodist University dig there before he began his spring planting, a field crew was dispatched forthwith.

Nine days of excavation were completed before Mr. Glass began planting. The principal work was done under the supervision of the writer with a crew of four local men: Weldon Crow, Clyde Sewell, David Glass, and Charles Haney.

\section{Appearance}

The Glass Site is situated between the Upper Tucker and coyote sites, on the same alluvial terrace. About 0.4 miles from the former and 0.6 miles from the latter, it lies at the edge of the terrace, overlooking the Red River flood plain to the north. The main part of the site is in a 20 by 7 meter field bordered on the west by the landowner's house, on the south by a dirt road, and on the north and east by fences.

Pottery, lithic artifacts, and other cultural materials were exposed on the surface in the spring of 1966. The landowner and his sons, who had dug several large holes in search. of relics, reported that they had found artifacts as deep as seven feet under the ground. The field had been in cultivation for years and had been plowed to a depth of 12 to 18 inches.

Excavation

The excavation was initiated by digging exploratory trenches in three different part of the site. The profiles and floors were scraped and examined for features, and, when found, additional areas were uncovered as required. The shape and size of the excavation units were regulated by the shape and size of the features encountered.

Nine cache pits and a house were located, but only the house and five of the cache pits were fully explored. 
A site map was made showing the horizontal relationships of the various excavations (Fig. 20). Vertical control was maintained by establishing a datum in a nearby tree and assigning it an arbitrary elevation of 100 meters. The elevations of the excavations were related to this datum by using transit and leveling rod. Measured drawings and photographs were made of the features to supplement the written descriptions.

Most of the dirt, excluding the plow zone, was screened through $\frac{1}{4}$-inch mesh hardware cloth. The artifacts were put into labeled bags and taken to Southern Methodist University for cleaning, repairing, and cataloging.

\section{Internal site structure}

Three soil zones could be distinguished at the Glass Site, comparable to those at the Upper Tucker and Coyote Sites. Zone 1 was a red sand forming the subsoil of the terrace. Its total depth was not determined, but it extended down to at least 1.6 meters below the base of Zone 2. Zone 2, the midden zone, was a dark gray sand containing charcoal flecks and cultural debris. Zone 3, the plow zone, was lighter and more friable than Zone 2 but otherwise was identifical to it. The mechanics of how Zones 1 and 2 were formed is imperfectly known.

Features

The house and the five cache pits that were completely excavated will be described. Four other cache pits were located but could not be excavated in the available time.

Feature 1

Feature 1 was first observed as a dark stain in the floor and profile of Trench 2. The trench floor was 55 centimeters below surface. Excavation was expanded to the east and west revealing a wasp-waisted stain in the floor. The stain measured about 2.5 meters east-west and 1.5 meters north-south. It appeared probably that the dark area represented one or more cacke pits.

Excavation was started in the east half of the feature after an initial 40 bj 40 centimeter test pit in the west part showed that the disturbed soil had a depth of about one meter below the trench floor. It was very difficult to follow the walls in the midden soil of Zone 2, but once the sterile subsoil of Zone 1 was reached, the pit became clearly visible. The elongated shape of the stained area was explained when the bottom of one cache pit (Feature IA) was reached in the eastern end. A second pit (Feature IB) was then discernible as a 
deeper, intrusive pit cutting the western edge of pit A. They were independent of a third pit (Feature lC) in the western end of the feature.

\section{Feature 1A}

Type: Bell-shaped cache pit

Dimensions: $0.65 \mathrm{~m}$. E-W by $1.10 \mathrm{~m}$. N-S at bottom of pit, depth greater than $1.05 \mathrm{~m}$.

Illustrations: Figure 21

Associations: see Table 3

Description: The level from which this cache pit was dug (and therefore the total original depth) could not be determined as the upper part blended with the midden soil of Zone 2. The fill was dark gray sand containing charcoal, ashes, bone scraps, broken mussel shells, flint flakes, and artifacts. The fill of Feature IA could not be distinguished from the upper part of Feature 1B. The floor of this pit was flat.

\section{Feature 1B}

Type: Bell-shaped cache pit

Dimensions: $1.30 \mathrm{~m}$. E-W by $1.50 \mathrm{~N}-\mathrm{S}$ at bottom of pit, depth greater than $1.53 \mathrm{~m}$.

\section{Illustrations: Figure 21}

Description: The fill in the upper part of this cache pit was the same as that described above for. Feature 1A. Just above the floor of the pit were thin lenses of sterile wash or blow sand, indicating that the pit had stood open for a while before trash was thrown in. Very few specimens were found in the bottom part of this pit where it could be dug separately from Feature 1A.

Feature 1C

Type: Bell-shaped cache pit

Dimensions: $1.45 \mathrm{~m}$. E-W by $1.20 \mathrm{~m}$. N-S at bottom of pit, depth more than 85 centimeters.

Illustrations: Figure 21 
Description: The walls of this pit sloped outward above the floor, then turned back inward to virtually the same. diameter as at floor level. As the upper part of the pit could not be seen, its shape is uncertain. The fill was dark gray sand with bits of charcoal, ashes, bone scraps, broken mus sel shells, flint flakes, and artifacts. Just above the floor were sterile sand lenses like those in Feature 1B. As with the other cache pits at Feature 1, this pit obviously was used for trash disposal.

\section{Feature 2}

Type: Oval pit house below $\operatorname{surface}$.

Dimensions: $6.6 \mathrm{~m} . \mathrm{N}-\mathrm{S}, 4.8 \mathrm{~m} . \mathrm{E}-\mathrm{W}$, floor at $1.02 \mathrm{~m}$,

\section{Illustrations: Figure 22}

\section{Associations: See Table 3}

Description: The house pit was dug into the subsoil to a depth of 27 centimeters or more. The unprepared floor was basin shaped with an uneven surface which sloped gently upward from a small level area in the center. There were four post molds near the margins of the pit, one each on the north, south, east, and west sides. The north post mold was 49 centimeters deep, the east one 22 centimeters, the south one 61 centimeters, and the west one 32 centimeters. There was no hearth, prepared or otherwise. If one was present originally, it could only have been subsequently destroyed by one of the intrusive cache pits described below.

The fill inside the house pit was clearly visible at the level of Zone 1 , but in Zone 2 it blended indistinguishably into the midden soil. Artifacts and bone scraps, however, were noticeably more frequent within the limits of the house than in the midden surrounding it. Apparently the abandoned house depression had been used as a trash pit after lying open long enough for lenses of sterile, washed sand to accumilate in the bottom. Above the sterile sand in the bottom, the fill consisted of dark gray sand containing charcoal, garbage bones, mussel shells, flint flakes, and artifacts. The artifacts found in the house fill s.re listed in Table 3. None were found directly on the floor, and therefore none can be considered contemporaneous with the occupation of the house. 
Five cache pits were encountered in excavating Feature 2, three within and two outside of the house limits. All appeared to postdate the house, only Nos. 2 and 3 (see Fig. 22) were completely excavated, and then only from the floor level of the house downward. Their limits above the house floor could not be determined Pit No. 3 had a flat floor and straight walls. As excavated, No. 2 had a basin-shaped floor and was so shallow that the shape of its walls could not be ascertained. Time ran out before excavation of cache pits 1, 4, and 5 could be completed.

\section{Discussion}

The Glass Site is a prehistoric site of the Henrietta Focus (Krieger, 1946). It was a village of typical plains agriculturalists with an economy divided between agriculture and buffalo hunting. Peoples with a similar economy were living throughout the Great Plains prehistorically and historically wherever the habitat was suitable: i.e., whereever the soils, rainfall, and temperature permitted successfull crop growth. As is known from historic records, the peoples practicing this way of life were not at all a homogeneous group. There were marked differences in language, social structure, and ceremonialism. Unfortunately, archeological evidence for such things is well nigh impossible to find. Archeologically we have little choice but to lump all sites exhibiting remains of an agriculturalbuffalo hunting economy into one large group with smaller divisions based on minor, sometimes subtle, differences in pottery types, house types, or tool type percentages.

Before 1965 the only excavated Henrietta Focus site was the Harrel site in Young County, Texas, at the junction of Clear Fork and Salt Fork of the Brazos. The Harrell Site was dug by the W. P. A. in 1938-39 as part of the salvage program at Possum Kingdom Reservoir。Alex D。Krieger analyzed the material from the site, and by combining the information so gained with information obtained from local amateurs, he defined a culture complex called the Henrietta Focus which embraced the Plains agriculturalist sites in north-central Texas. The Glass Site fulfills in all respects the criteria for a Henrietta Focus site. The minor differences may be attributed to sampling error since they are mainly the absence at the Glass site of artifacts reported rarely from Henrietta Focus sites. A comparison of the Glass site material with the trait list for the Henrietta Focus (Krieger, 1946: 138-141) reveals the following differences.

Architecture: No architectural data were known in 1946 , a.I though witte (1936) had reported possible house floors at a site at the mouth of the Little wichita River. The house 
at the Glass Site was oval, 6.6 meters long by 4.8 meters wide with its long axis running north and south. It was a semisubterranean house, had four interior support posts, and the floor was unprepared. No hearth was found, but it may have been destroyed by intrusive cache pits. Although no molds of wall posts were found, it is probable that the house did have wall posts. Perhaps they were set directly on the floor and left no molds. The house was very probably grass thatched rather than mud plastered.

Agricultural Implements: No hoe blades made from bison skulls or mussel shell hoes were found at the Glass site。

Food Storage: Undercut cache pits, present at the Glass Site, were not known in 1946.

Food Preparation: No metates, milling stones, edged manos, or two-handed manos were found at the Glass site.

Cutting, Scraping, Skin Preparation, etc.: No stemmed end scrapers or serrated mussel shells were found at the GIass Site。

Sewing, Punching Implements: No flint awls were found at the Glass Site.

Woven Artifacts: None of the basal sherds from the Glass Site have basketry impressions.

Ornaments: No whole mussel shell beads, bone beads, Olivella shell beads, pottery beads, or fossil crinoid stem beads were found at the Glass site.

Ceremonial Objects: No pipes or long bird-bone tubes were found at the GIass Site.

Burials: No burials were found at the Glass site。

Miscellaneous Artifacts: No celts, hematite blocks, sandstone balls, clay figurine fragments, bone fishhooks, obsidian, or trade pottery were found at the Glass site with the excepm tion of the one brown bone-tempered sherd which looks Caddoan.

As the above list shows, the absences are mostly in the ornamental, ceremonial, and miscellaneous categories. The principal kinds of Henrietta Focus artifacts concerned most vitally with day-to-day living--hunting and agricultural tools, tools for preparing food and making clothing, etc.-are all present at the Glass Site with the exceptions of a few rare forms such as long, two-handed manos. 
After excavation of the Harre11 Site in 1938-39, no major excavation was attempted in a Henrietta Focus site until the fall of 1965 when the Fish Creek sites near Gainesville and the Coyote Site at Spanish Fort were dugo Analysis of the material from Fish Creek Reservoir is not completed so it is not possible at this time to compare those sites with the Glass Site in any detail. There were certain noticeable dife ferences, however, in the number of bone tools, which were very scarce at Fish Creek but common at the Glass Site, in the types of arrow points, and in the relative proportion of deer and bison scrap bone. At Fish Creek deer bone prodominates; at the Glass Site bison bone is more frequent. It is not known whether these differences are due to factors of time or space.

The Glass and Coyote sites are very similar, as might be expected from their spatial proximity. At the Coyote Site 12 cache pits, 3 hearths, and 1 possible post mold were dug. At the Glass Site 5 cache pits and I house were dug. Roughly equal numbers of artifacts were recovered. In briefly com paring the material from the two sites, however, several differences were noted. There is somewhat more pottery from the Coyote site than from Glass。 Although Nocona Plain is the principal type at both sites, there are minor differences: for example, both round - and flat-bottomed vessels were found at Coyote but only flat bottoms were recovered at Glass; strap handles occurred at coyote but not at Glass; the nodes on Coyote pottery are larger than the ones on Glass pottery; there are two sherds from coyote site with nodes or Iugs at the roim rather than at the neck-body juncture, and the rim has a scallop above the node; some of the coyote sherds are much thicker than any of the Glass sherds: as a whole the surfaces of the Coyote vessels have a smoother finish than the Glass ones: the sherds from Coyote are consistently larger than the one from Glass. There is one undecorated pottery elbow pipe from the coyote site but none from Glass.

But the most striking discrepancy between the two sites is in the bone artifacts. There are 45 from the Glass site but only 15 from Coyote. There are 21 bison scapula hoes from the Glass Site and only 2 from Coyote. There are 9 bison tibia digging stick points from Glass, only 2 possible fragments of sueh tools from coyote. There are 6 bone rasp fragments from Glass, none from Coyote. Possibly more excavation at the two sites would prove that these discrepancies are a result of sampling error. Perhaps bone artifacts were discarded in groups and are only found by chance in limited excavations such as those.

In central and western Oklahoma are a number of sites very much like Henrietta Focus. They have been grouped into two fooi: the Washita River Focus and the Custer Focus (Bell. 
and Baerreis, 1951)。 Pillaert (1963) presents a detailed com parison of the two foci and points out that there are so many similarities that

...the comparative analysis of trait lists for western Oklahoma sites reveals a degree of homogeneity consistent with the hypothesis that peoples of the same cultural background occupied these sites. It would seem, therefore, that the focal distinctions which have been made do not appear to be valid, and it is here proposed that these sites comprise a single cultural unit. (Pillaert, 1963: 45)

This still leaves a completely arbitrary taxonomic division between like sites in Oklahoma and in Texas based upon the state boundaries: Washita River Focus for the Oklahoma sites, Henrietta Focus for the Texas sites. It is suggested that they all be combined into one focus which should be called the Henrietta Focus since that name has priority in the literature (Krieger, 1946). The earliest reference to either the Washita River Focus or the Custer Focus is Bell and Baerreis (1951)。

The really critical question to be considered in the present study is: Is the Henrietta Focus ancestral to the Norteño Focus? Either the Wichita people are descended from prehis toric people in the Texas-oklahoma area where they were Iiving after 1750, or they migrated into that area during historic times. If the former alternative is correct, there should be an observable continuity in the archeological remains. The Henrietta Focus occupies roughly the same geographic area that the Wichita tribes did in the early 19th century, and both the Henrietta Focus and the Wichita Indians were plains agricul= turalist-buffalo hunting peoples. The Henrietta Focus, there. fore, is a logical candidate for the local precursors of the historic Wichita, if, indeed, they had any local precursors.

Is there an observable continuity from the prehistoric to the historic period in the archeological remains in the Spanish Fort locality? There is not, or at least not much. There is a difference in size of the lithic tools during the historic and prehistoric periods. Those from the historic sites are consistently larger than the prehistoric ones. This can be seen by comparing the endscrapers. Of the 24 endscrapers from the Glass and Coyote sites, 22 are of the small thumbnail variety; yet none of the 11 endscrapers from the Longest Site fall into that category。

The materials used for the lithic artifacts differ. The prehistoric occupants used local materials such as chert and quartzite cobbles from the river and the silicified sandstone from bedrock formations. Very little of the prehistoric lithic material was imported. On the other hand a large percentage 
of the historic lithic material was non-local. By far the greatest amount was from Central Texas but there is enough Kay County, Oklahoma, flint to be significant. Lesser amounts of raw material were obtained from the west: Alibates siliceous dolomite from the Texas panhandle and obsidian from New Mexico.

The grooved sandstone abraders and the grinding stones, both manos and metates, are of the same form and material in all of the historic and prehistoric sites, but the ground and polished stone artifacts are different. In the historic sites are found grooved mauls and elbow pipes with straight or flaring arms, often engraved. Neither artifact was found at Glass or at Coyote.

The bone tool assemblages of the prehistoric and historic sites are strikingly dissimilar. The most common prehistoric bone tool is the bison scapula hoe. There are only three modified bison scapulae in the historic sites and none of them appear to be hoes although what they are has not been deter. mined. There are no bison tibia digging stick points from the two historic sites. There are bison metapodial tools which are similar in shape to the digging stick points, but they are serrated on the working edge.

The most common kinds of bone awls in the prehistoric sites are splinter awls and split deer metapodial awls while the most common awl form from the historic sites is made from the edge of a bison rib or dorsal spine.

The worn deer mandibles of the Henrietta Focus were not found in the Norteño Focus sites. There was only one fragment from the Upper Tucker Site. on the other hand, there were bone whistles and perforated animal teeth in the historic sites but none in the prehistoric sites. Virtually the only similarities in bone tools of the two time periods are spatulate doer ulna implements and modified deer antlers.

The Nocona Plain pottery from the Glass and Coyote sites is in the Plains tradition. Vessel forms are fairly large jars with globular to elongate bodies, rounded to flat bases, and straight or outturned rims。 Decorative techniques are confined to nodes, strap or loop handles, and occasional. punctations. Norteno Focus pottery, on the other hand, is in the Caddoas Area tradition. The characteristic Norteño Focus pottery type is Womack Engraved (Duffield and Jolks, 1961: 36-39) which incorporates a bowl form with an incurved rim, engraved decoration within a bordered zone on the rim, burnished or red-silpped exteriors, and variable temper cono sisting of sand alone or sand in combination with shell, clay, or bone. Several sherds of Womack Engraved pottery were found at the Upper Tucker and Longest Sites. Other potsherds from 
these two sites were from vessels of Caddoan pottery types such as Patton Engraved, Natchitoches Engraved, and Simms Engraved or were undecorated but with caddoan-iike paste and temper. In addition, at the Longest site were found sherds of a vessel with a shape similar to the Nocona Plain vessels but with completely different surface finish, surface color, and temper. Only two possible Nocona Plain sherds were found at the Upper Tucker sites: none at Longest.

In view of the marked differences in the artifacts from the prehistoric and historic sites in the Spanish Fort area, it is impossible to consider those Henrietta Focus sites to be immediately ancestral to the historic spanish Fort sites. There is a hiatus in time and/or in kind.

The hiatus may be the result of a time lapse during which the Spanish Fort area was unoccupied. Farther east, along the western part of the Caddoan Area, some prehistoric and historic sites are closer together in time. There are several seemingly protohistoric sites (Culpepper, Hunt, Clements, Sam Coffman, the late component at Sanders) with little or no trade material but with native-made artifacts of types which are found with abundant European trade items at other sites. Some of these sites have the appearance of Caddoan sites with a large ado mixture of Plains traits. Unfortunately, none of them have been adequately investigated. It is in this western Caddo fringe area that the earlier Norteño Focus sites such as Womack and Gilbert are located; the historic sites near Spanish Fort date largely or entirely from later times. If a transition from Henrietta Focus to Norteno Focus took place, the sites which could demonstrate it are likely to lie to the east of the spanish Fort area.

Robert E. Bell (1960: 55-56) has suggested that the Henrietta and Washita River foci represent prehistoric Wichita and that

...in late prehistoric times there was a movement of peoples westward out of the Caddoan area, follow ing the main river valleys, such as Red, Washita, Canadian, and Arkansas...

Bell postulated that this movement took place during the GibsonFulton transitional period between A.D. 1100 and 1300 .

There now appears to be a conflict in those dates, however. Radiocarbon dates from Washita River sites indicate a time span from A.D. 1000-1400 which is much earlier than the previous estimates of A.D. 1400-1600 for the Henrietta Focus. The radiocarbon dates from Gibson and Fulton Aspect sites are somewhat inconsistent, but now that a large number have been 
obtained there seem to be significant clusters between A.D. 1300-1400 for late Gibson Aspect and from A.D. 1450 to 1600 for prehistoric Fulton Aspect: so the transitional Gibson-Fulton period appears to be A.D. 1400-1500. This would mean that the Henrietta, Washita River, and Custer Foci are coeval with the Gibson Aspect. There seems to have been relatively little contact between the two areas, and their respective artifact assemblages are very unlike. It would seem that we must look elsewhere than to Gibson Aspect for the progenitors of the Plains groups.

I would suggest that there was an eastward movement by these same Plains groups from central Oklahoma and northcentral Texas eastward to the Caddoan Area between A.D. 1400 and 1500. There are no known sites in the plains area of Texas and oklahoma. which look even remotely protohistoric. There is apparently a cessation of Henrietta Focus sites in this area just after A.D. 1400, an interval of abandonment between A.D. 1400-1500 and 1700, and resettlement by Norteño Focus peoples after A.D. 1700 .

Wedel (1961: 14-17) reviews the evidence for an extended drought on the Great Plains which started around A.D。 1439 and lasted for a little over a hundred years. Archeologically there is evidence for a widespread abandonment by Plains agriculturalists of the regions west of the 96th meridian after A.D. 1400.

The appearance of Plains traits in the artifact assemblages of Fulton Aspect sites after their almost complete absence in Gibson Aspect sites has been noted by workers in the Caddoan Area. These traits have customarily been attributed to increased trade between the two areas. I suggest that it is because of an actual eastward movement of people from the drought-stricken plains into the better watered woodlands of the Caddoan Area.

Triangular arrow points, diamond beveled (Harahey) knives, bison bone tools, and the presence of many scrap bison bones in the midden debris have been cited as examples of Plains traits in Fulton Aspect sites. Utilized deer jaws and shell tempering in the pottery may be added. The latter is usually considered to have spread from the central Mississippi Valley southwestward into the Caddo Area. The Henrietta Focus area, which was inhabited by some of the most confirmed shelltemper-using people known, has been ignored because of former late guess-dates for Henrietta Focus relative to the Caddo, in spite of occasional trade vessels of Nocona Plain pottery found in Caddoan sites. 
The movement of Henrietta Focus peoples into the Caddoan Area was probably peaceful since there is no concentration of the Caddoan population into large fortified villages but rather a dispersal from the large Gibson Aspect ceremonial centers to smaller, more numerous, Fulton Aspect villages。

Perhaps more important than providing an explanation for Plains traits in Caddo sites, the hypothesis of an eastward movement of Henrietta Focus peoples may explain the Caddoan traits in the Norteño Focus sites. This involves the assumption that the Wichita people are in fact descendents of the Henrietta Focus people or some similar plains agriculturalist group. Most archeologists would agree that this assumption is reasonable. It is the basis for the identification of the Little River Focus in Kansas with the Wichita viliages visited by Coronado.

Previous hypotheses to explain the presence of the Wichita in north Texas in the historic period have fallen into one of two groups. Krieger (1946: 159), Wedel (1959: 65-66), and Harper (1953: 270) held that all of the Wichita peoples moved southward from Kansas and northern oklahoma into north central Texas after A.D. 1700。 They based this opinion on (1) documentary evidence for southward movement of at least some Wichita villages during the eighteenth century as a result of pressure from the Osage, (2) identification of early historic period villages in Kansas with Coronado's Quivira villages which are considered to be Wichita, and (3) dissimilarities between the material traits found at Henrietta Focus sites and at later sites identified as Wichita villages of the historic period (e.go, Upper Tucker, Longest, and other Norteño Focus sites)。

Duffield and Jelks (1961: 73-75), on the other hand, considered it likely that the Henrietta Focus was ancestral to at least some of the later Wichita. The Waco and Tawakoni subgroups of the Wichita were always, in the documented his. torical period, south of the Taovayas and Wichita subgroups. It seems probable that the movement of Waco and Tawakoni into central Texas in the latter half of the eighteenth century was a result of the movement of Taovayas and Wichita from southern Kansas to Red River, and, conversely, that when the Taovayas and Wichita were still in Kansas the Waco and Tawakoni were on, and slightly south of, Red River in north Texas。 As far as is known at present, they were not in north-central Texas where Henrietta Focus sites abound but were on the western fringes of the Caddoan area in the vicinity of present day Lamar County, Texas (Garrett's Bluff and Sanders Sites)。

As Pillaert pointed out (1963: 45) and Wedel recently affirmed (talk given at 1967 annual meeting of the society for 
American Archeology), the Little River Focus of Kansas, the Washita River Focus of Oklahoma, and the Henrietta Focus of Texas are so similar that they could be attributed to a single ethnic group. Wedel reported recent finds of several artifact types in Kansas which had been found in Washita River Focus sites but had not previously been found in Little River Focus sites. I suggest that these foci represent prehistoric Wichita who were living in a great strip of land in the Redbed Plains (Fenneman, 1938: Plate VI) between the hilly forested country to the east and the short-grass plains to the west from north-central Texas, through Oklahoma, to central Kansas. This country is rolling prairie grasslands with wooded river valleys. It provided all. of the natural resources necessary for the maintenance of the Wichita way of life.

It is further suggested that the prehistoric Wichita were pressured by drought or by some unknown factor into moving out of the more western parts of this region between A.D. 1400-1500 and that they settled on the western fringe of the Caddoan Area where an exchange of ideas and material traits took place be tween them and the Caddo. Triangular arrow points, shell temper, utilized deer mandibles, Harahey knives, and bison hunting were adopted by the Fulton Aspect Caddo, particularly by those of the more western foci: Titus, Mccurtain, Fort Coffee, and Turkey Bluff. The Wichita adopted Caddoan pottery designs and forms, bear-tooth pendants, bi-conical elbow pipes, and the practice of extended burial in place of their previous custom of flexed burial position. When the wichita can again. be recognized archeologically, independently of the caddo, they differ markedly in material traits from their Henrietta Focus precursors as a result of these adaptations and their increased mobility after acquisition of horses about A.D. 1700 . They were then making Caddo-like pottery and were no longer dependent on local stone for artifacts but could travel the distances necessary to obtain more desirable non-local raw material. Ease of transportation may have also alleviated the necessity for making their lithic tools as small as possible. In addition, French trade goods replaced native-made artifacts so rapidly that few sites of the Norteño Focus show a complete inventory of the latter.

With the horse and possibly improved weather conditions, the Wichita could move back westward after 1700 . Osage pressure caused the movement to be southwestward, however. The whole body of Wichita peoples from Kansas to Texas apparently wheeled first south from A.D. 1700 to 1775, then west between 1775 and 1800, and finally consolidated in old Henrietta Focus country after 1800. There was a northwest movement of the southern subgroups and a southwest movement of the northern subgroups as a result of pressure from white settlers and other Indians pushing westward ahead of the Whites. 
It is informative to note that with very minor exceptions the movement, at least in Texas, followed timbered country. To the extent they can be traced in Texas, the Wichita followed the western edge of the East Texas Timber Belt southward from Red River to the latitude of Waco where the prairie between the Timber Belt and the Cross Timbers is narrowest. They then crossed westward over the open prairie to the Cross Timbers and subsequently followed the Cross Timbers northwestward to and beyond the Red River. By, following this path, they were always able "to obtain the poles and thatch needed for their houses and the sandy, well-watered, river-bottom soils needed for their crops.

A determined search for protohistoric sites should be made in the western Caddoan area. Those already known and any newly discovered ones should be carefully and thoroughly excavated in order to discover whether people of Henrietta Focus affiliation were living side by side with Caddo villagers. Small scale excavation of one or two houses would not settle the problem. The total village pattern should be determined to see if house types differ and if there are consistent correlations between artifact types and house types of the protohistoric and historic cultures. 


\section{Lithic Artifacts}

The following description modifies and adds to Lubell's analysis of the Glass Site lithic industry which appears in a later section of this report. only categories in which a change has been made are included.

Because Table 3 is based on these revised category assignments, some discrepancies exist between it and Lubell's distributional data.

\section{Endscrapers}

No. of Specimens: 2

A convex endscraper formed by weak semi-steep retouch on the proximal end of a broken flake was found in addition to the one already described.

\section{Thumbnail Scrapers}

No. of Specimens: 14

One specimen has been added.

These little endscrapers differ from the endscrapers above in being steeply beveled on the working end and having a consistent shape with convex bit and tapered base. The large endscrapers, however, have only one edge of the flake retouched and no modification of the other edges or surfaces.

The thumbnail scrapers range from 14 to $32 \mathrm{~mm}$. in length and from 10 to $20 \mathrm{~mm}$. in width. The typical ones are about $18 \mathrm{~mm}$. thick; the others are thinner, down to a minimum of $2 \mathrm{~mm}$.

\section{Side Scrapers}

No. of Specimens: 8

Five specimens, one previously classified as an unfinished point, have been added:

4. Straight unilateral side scraper on a markedly curved cortex flake with steep retouch.

5. Straight unilateral side scraper on a basally broken cortex blade.

6. Convex unilateral side scraper with steep retouch. 
7. Convex unilateral side scraper formed by steep retouch on a small quartzite flake.

8. Recurved unilateral side scraper on a large silicified sandstone flake with semi-steep retouch.

All of these scrapers are 20 to $40 \mathrm{~mm}$. long with the exception of No. 8 which is $105 \mathrm{~mm}$. long.

This recurved scraper (No. 8) is the only side scraper made of silicified sandstone; however, all of the large tools from the site are made of this material. Either this sandstone was too coarse for small tools or it was deliberately chosen when a large tool was desired.

\section{Scraper-Graver}

\section{No. of Specimens: 1}

This specimen is reassigned from the unidentified broken tool category. It is a convex unilateral side scraper on a flake with stout broken graver point at the distal end formed by steep bilateral obverse retouch with minor inverse retouch. It is inversely retouched at the proximal end to thin the bulb of percussion.

\section{Denticulate}

\section{No. of Specimens: 1}

This is a straight unilateral denticulate scraper formed by steep retouch to the proximal end of a broken flake.

\section{Arrow Points}

No. of Specimens: 27

\section{Fresno}

8 Washita

Six points have been added, four Fresno points and two Washita points. The 4 points typed as Harrell points have been reclassified as Washita points.

The Fresno points are small, thin triangles. They range from 15 to $30 \mathrm{~mm}$. in length, from 8.5 to $17.5 \mathrm{~mm}$. in width at the base, and from 2 to $6.5 \mathrm{~mm}$. in thickness. 
The Washita points are side-notched triangular arrow points. They range from 18 to $23 \mathrm{~mm}$. in length, from 9 to $14 \mathrm{~mm}$. in width, and from 3 to $4 \mathrm{~mm}$. in thickness.

Suhm, et al. (1954) included all small triangular arrow points with side notches, both with and without a basal notch, in the Harrell type. Bell (1958) separated them into two types, Harrell for specimens with a basal notch and Washita for points without a basal notch. Recent evidence (Parsons, 1967; Pillaert, 1963 ) indicates that, although the two forms are usually found together, the percentage of basal notching increases in the later sites.

Dart Points

No. of Specimens: 1

This Edgewood point which is a common dart point type at Archaic sites in the North-Central Texas area, measures $33 \mathrm{~mm}$. in length (tip broken), $25 \mathrm{~mm}$. in width, and is $7 \mathrm{~mm}$. thick.

This point is almost certainly intrusive. It had probably been picked up from an Archaic site and carried home by one of the Glass Site villagers.

\section{Knives}

No. of Specimens: $\quad 10$

Four new specimens have been added and four transferred from the broken dart point category. Description follow:

3. Bifacially flaked and retouched knife with pointed distal end and convex base.

4. Bifacially flaked and retouched triangular knife.

5. \& 6. Two halves of a large silicified sandstone flake with a bifacial edge retouch. The distal end has been additionally retouched after the break occurred.

7. Broken proximal end of a knife similar to the proximal end of specimen Nos, 5 and 6 . Both have diagonal breaks.

8. Broken half of a bifacially flaked and retouched knife.

9. Medial fragment of a knife. This fragment is similar in size and shape to the corresponding segment of specimens No. 5 and 6 . 
10. Broken, large oval shaped knife with bifacial flaking and retouch and a lisse striking platform at proximal end.

All of the specimens except No. 4 are made from silicified sandstone and are larger than No. 4. Measurements of three complete specimens are:

$\begin{array}{llll}\text { Specimen } & \text { Length } & \text { Width } & \text { Thickness } \\ \text { No. } 2 & 68 \mathrm{~mm} & 25 \mathrm{~mm} & 7 \mathrm{~mm} . \\ \text { No. } & 75 \mathrm{~mm} & 38 \mathrm{~mm} & 9 \mathrm{~mm} . \\ \text { No. } 4 & 40 \mathrm{~mm} . & 33 \mathrm{~mm} & 5.5 \mathrm{~mm} .\end{array}$

Broken Dart Points

No. of Specimens: 0

The four broken dart points have been reclassified as knives.

\section{Varia}

No. of Specimens: 0

This specimen has been eliminated from the tool inventory. It has no more significance as a tool than an ordinary river cobble. It had surely been brought into the site by human agency but had not been modified after it was removed from the river. The flaking and battering occurred before it was river worn。

Small Bifacial Tools

No. of Specimens: $\quad 3$

These three artifacts are transferred from the unfinished point category. They are all small asymmetrically triangular tools with bifacial retouch.

Length varies from 26 to $33 \mathrm{~mm}$, width from 16 to $21 \mathrm{~mm}$, and thickness from 8 to $10 \mathrm{~mm}$. 
42

\section{Unidentifiable Broken Tools}

No. of Specimens: 9

One has been transferred to the scraper-graver category.

\section{Unfinished Points}

No. of Specimens: 0

One of these has been classed as a side scraper and three as small bifacial tools. 
TABLE 3. Provenience of artifacts at the Glass Site Item Surface Item Feature 1 Feature 2 \& Misc. Totals

End scrapers, large

End scrapers, thumbnail

Side scrapers

Scraper-gravers

Denticulates

Notched flakes

Retouched flakes

Retouched blades

Gravers

Truncations

Fresno arrow pts.

Washita " "

Unident. " , "

Edgewood dart pts.

Knives

Small bifacial tools

Choppers

Hammerstones

Misc. chipped stone

Cores

Abraders

Manos
1

1

5

5

1

21

2

1

1

11

6

9

1

3

2

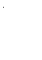

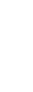

5

2

7

1

8

1

$I$

8

1
8

1

1

2

2

1

30

2

1

2

19

8

14

1

10

3

1

1

.13

10

14

9 
44

TABLE 3 (continued).

Item Feature I Feature 2 $\begin{gathered}\text { Surface } \\ \text { \&isc. Totals }\end{gathered}$

Bone

$\begin{array}{lrrr}\text { hoes } & 5 & 16 & 21 \\ \text { digging stick points } & 9 & 9 \\ \text { humerus heads } & 1 & 1 \\ \text { deer mandibles } & 1 & 1 & 1 \\ \text { spatulates } & 1 & 2 & \\ \text { awls } & 1 & & 1 \\ \text { scrapers } & 1 & & 1 \\ \text { worked antler } & 1 & 6 & 6 \\ \text { rasp fragments } & & & \end{array}$

Shell disks

1

Pottery sherds

$\begin{array}{lrrrr}\text { Nocona Plain } & 95 & 163 & 48 & 306 \\ \text { thin black } & 3 & & 3 \\ \text { light brown } & 9 & 11 & 5 & 25 \\ \text { redware } & & 1 & & 1 \\ \text { Clay "pendant" } & -3 & -4 & \frac{11}{559} \\ \text { Clay daub fragments } & -205 & 287 & 67 & 55\end{array}$


THE GAS PLANT SITE

by Harald P. Jensen, Jr.

On the east bank of the Brazos River, about two miles below the center of Waco's business district, is the Gas Plant Site ( $\times 41$ ML 1$)$. Several people are known to have been collecting surface material at this site for some years and a number of glass beads and other European trade items have been found there. It is probably the location of one of the Tawakoni or Waco villages reported to have been in the vicinity of Waco between the $1770^{\prime} \mathrm{s}$ and $1830^{\prime} \mathrm{s}$. So far as is known, there had been no archeological excavations at the Gas Plant Site before those reported here.

In the late summer of 1966 it came to our attention that rerouting of State Highway No. 6 was about to encroach on the site. Because of the impending danger to whatever cultural remains might be there, it was decided to make exploratory excavations before the highway was completed. Accordingly, the areas to be affected by the highway project were investigated, as was a portion of the site lying between the highway and the river on the property of Edward Hicks of Waco.

\section{Appearance}

The Gas Plant Site is located on and in an alluvial terrace bordering the Brazos. River at an elevation of 161 meters above sea level and some 12 meters above the river itself. Just south of the site, the ground drops off at the edge of the terrace and slopes steeply down to the active flood plain of the Brazos some five or six meters below. The site, as it appeared in the fall of 1966 when excavated, lay primarily in a field which had not been cultivated in several years and was heavily overgrown with weeds. A spur of the Texas and New Orleans Railroad ran along the south edge of the site; at its north edge was an earthen ramp of a highway overpass, then under construction; on the west the site was bordered by a small drainage ditch, running north and south, which was to be widened during the highway construction. A dirt access road paralleled the overpass ramp on the south. 
While archeological exploration was concentrated in the areas most threatened by construction, widely spaced test trenches were also dug across other parts of the site (Fig. 23). Most of the testing was done by scraping off the plow zone with a front-end loader. By that means, five long trenches were dug, each about two meters wide. The trenches were from 24 to 158 meters long. The trench walls and floors were shovel scraped wherever anomalies were noted that might be of archeological significance. Also, the walls of the drainage ditch at the west edge of the site were cleaned and studied at several places, and a few test pits were dug by hand. Only one feature of consequence was found: a bell-shaped cache pit.

\section{Internal site structure}

The physical evidence of Indian occupation at the Gas Plant Site was in the upper part of an alluvial terrace of the Brazos River. The top 25 to 75 centimeters of the alluvium was a loamy silt of dark brown to buff color, the upper 15 centimeters or so disrupted by plowing. Localized banding and lensing suggested that part of the silts had been deposited in small ponds.

At observed exposures, the brown to buff silts gave way to reddish silts at depths below surface of 25 to 75 centimeters. Total thickness of the reddish silts was not determined, but at one of the test pits it was followed down for a meter before the test was terminated.

Although there had been some disturbance by burrowing rodents and by tree roots below the plow zone, the silts were homogeneous enough that house pits, cache pits, graves, post molds, and other such man-produced disturbances should have been detectable if present.

\section{Features}

Despite the fact that a fairly large surface area of the site was trenched, only one feature--a cache pit--was found. It seems certain, however, that other features worthy of excavation must be present somewhere on the site. Probably, more thorough testing would locate them. 


\section{Feature 1}

Type: Bell-shaped cache pit

Dimensions: $1.05 \mathrm{~m}$. diameter where truncated by test trench, $1.17 \mathrm{~m}$. diameter at bottom.

\section{Illustrations: Figure 23}

Associations: 1 gunflint, 24 flint flakes, 1 piece of red ocher, I sherd of porcelain, 29 glass beads, 1 glass mirror sherd, 1 tinkler blank of kettle brass, 3 scraps of kettle brass, numerous bones (including deer, bison, turtle, bird, and fish), several mussel shell fragments, several pieces of egg shell (probably duck), charred seeds and nuts (including pecan and hackberry)

Description: This was a typical Norteño Focus bell-shaped cache pit that was obviously used for trash disposal. The fill consisted of dark midden soil containing a. lot of refuse; it was homogeneous and unstratified. Five burlap bags of fill were taken to the laboratory in Dallas and washed through window screen. The glass beads and most of the other tiny objects were found on the fine screen.

\section{Artifacts}

The artifact yield at Gas Plant was disappointingly meager. The artifacts found, however, were of forms and styles characteristic of the Norteño Focus. The absence of Indian pottery and the virtual absence of stone arrow points (only one fragment was found) may be indicative of a very late date for the site, perhaps well after 1800. This absence, on the other hand, may simply be a result of sampling error. 
48

TABLE 4. Provenience of artifacts, debitage, and biological specimens at the Gas Plant Site.

Item $\quad \begin{aligned} & \text { Feature } \\ & 1\end{aligned} \underline{1} \underline{2} \underline{3} \underline{4}$ Ditch face Totals

Dart points

(unident.)

$2 \quad 2$

Arrow points

(unident.)

$1 \quad 1$

Flint flakes

$24 \quad 1$

6

$10 \quad 25$

66

Flint cores

2

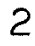

Maul fragments

1

1

Red ocher

1

1

Perforated deer phalanx

1

1

Porcelain sherds 1

12

Glass beads

29

29

Mirror glass

sherds

1

Bottle glass

sherds

11

Tinkler blanks

1

Brass scraps 3

3

Bones :

turtle

(Trionyx spinifer)

4

4

land tortoise (T'errepene sp. ) 3

3

whitetail deer

(odocoileus virginianus) $\quad 87$

$1 \quad 88$ 


\begin{tabular}{|c|c|c|c|c|c|c|c|}
\hline Item & $\begin{array}{c}\text { Feature } \\
\underline{I}\end{array}$ & $\underline{1}$ & $\begin{array}{l}\text { Trench } \\
2 \stackrel{3}{ }\end{array}$ & $\begin{array}{l}\text { No. } \\
4 \quad 5\end{array}$ & Ditch & $\begin{array}{l}\text { Sure } \\
\text { face } \\
\end{array}$ & Totals \\
\hline $\begin{array}{l}\text { bison (Bison } \\
\text { bison) }\end{array}$ & 39 & & & & & & 39 \\
\hline bird & 3 & & & & & & 3 \\
\hline $\begin{array}{l}\text { small mammal } \\
\text { (unident:) }\end{array}$ & & & & & & & 5 \\
\hline $\begin{array}{l}\text { fish } \\
\text { (unident.) }\end{array}$ & 5 & & & & & & 5 \\
\hline $\begin{array}{l}\text { miscellaneou } \\
\text { (unident.) }\end{array}$ & s 448 & 10 & & 1 & & & 459 \\
\hline $\begin{array}{l}\text { Mussel sheli } \\
\text { (Unionidae }\end{array}$ & $\left(\operatorname{spo}^{10}\right.$ & & & 2 & & & 12 \\
\hline Egg shell & 25 & & & & & & 25 \\
\hline Seeds \& nuts & 39 & - & - & - & $\square$ & $-\dot{s}$ & 39 \\
\hline Totals & 729 & 12 & $=-$ & $9-$ & 10 & 33. & 793 \\
\hline
\end{tabular}


One of the objectives of the Wichita Project is to locate as many archeological sites as possible in the southern plains-both historic and prehistoric--that bear on Wichita origins, culture, and ethnohistory. While excavations were in progress at Upper Tucker in the fall of 1965, intensive reconnaissance on the Texas side of the Red River in the Spanish Fort Bend area was carried out. A number of previously unrecorded sites were discovered, including the Coyote and Glass Sites, all of them prehistoric. At the same time, several reports were received of crevice burials in north-central Texas containing glass beads and other objects of European provenience. Following up those reports, several collection of artifacts from historic crevice burials were examined and some of the sites were visited that fall and the following spring.

Two other major reconnaissance projects in Texas were also undertaken: (1) a search for a Tawakoni village and a nearby Kichai village reported on the Trinity River in the 1770 's and (2) a search along the Brazos River between Possum Kingdom and Whitney Reservoirs for several Indian villages documented during the late 1840 's and early 1850's. A report on the Trinity and Brazos surveys follows. 


\author{
Archeological Reconnaissance \\ on the Trinity and Brazos Rivers \\ by C。A。Smith, Jr。
}

The field reconnaissance reported here was conducted by Jay C. Blaine and the writer with the objective of establishing, through archeological evidence, the specific geographic locations of sites known to have been occupied by Wichita Indians. In preparation for the field surveys, many hours were spent in libraries, in the state Archives, and in county courthouses searching for relevent documents and maps. After these had been assembled and evaluated, topographic maps and aerial photographs of the areas to be investigated were studied, and plans for systematic reconnaissance were formulated. Once the surveys began, reports of sites were received from local informants, and the more promising of them were investigated。 The basic approach, however, was to mark off a section of river within which--according to contemporary documentation--a particular site should be expected to lie, then to explore that section as thoroughly as possible in the field.

\title{
The Brazos Survey
}

In 1851 Colonel $S$. Cooper of the United States Army made an inspection tour of several Indian villages on the Brazos River above Fort Graham. His report to the secretary of the Interior (Cooper, ms。) describes and shows on an accompanying map the location of Barnard's Trading Post, Fort Graham, and villages of Waco, Tawakoni, Caddo, Anadarko, Hainai, and Kichai Indians. In addition, his narrative supplied detailed ethnic information useful to the wichita Project:s overall objectives.

Before beginning reconnaissance in the field, Cooper's map was correlated with modern topographical maps of the area, and his probable line of travel was laid out from Fort Graham northwest up the Brazos to present-day Possum Kingdom Reservoir and back to Fort Graham。As an additional aid, all presently known archeological sites along that stretch of the Brazos were plotted. Once this was accomplished, field trips were made in an attempt to locate and identify cooperis reported sites.

When archological sites were located and collections made from them, the artifacts were studied in the laboratory and compared to materials from 19th century sites of known Wichita 
affiliation (or mid-19th century Anglo-American affiliation in the case of Barnard's Trading Post). This method helped validate site identification.

An effort was made to locate all the sites reported by Cooper except the Hainai village, which he reported but did not visit.

The major landmark was Fort Graham, the exact location of which was already known. Starting from there, the survey party followed out Cooper's reconstructed route. The location of Barnard's Trading Post was established, and an archeological site that is probably the Kichai village described by Cooper was found. The latter was designated the Colonel Cooper Site. It was also determined that Cooper's reported caddo site is now under 40 feet of water in Possum Kingdom Reservoir. A small historic site in the area of Cooper's reported Anadarko village was found; but data obtained by surface search was too meager for any firm identification to be made.

\section{The Trinity Survey}

The survey team shifted its efforts to the Trinity River in hopes of locating Tawakoni, Kichai, and other Indian villages of the 18th and 19th centuries. A major effort was made to locate the site of the Spanish settlement of Pilar de Bucareli, 1774-1779, because several documented villages of Wichita and. other tribes along the Trinity in the 1770's were oriented relative to their direction and distance from Bucareli. Unfortunately, secondary sources of historical information on Bucareli (Bolton, 1914; Bolton, 1915; Castan̂eda, 1939) left much to be desired as far as our particular problem was concerned. Despite an intensive search of a 25-mile stretch of river, from the mouth of Bedias Creek north to the State Highway 7 crossing, the site of Bucareli remains undiscovered.

With the approach through Bucareli abandoned, an attempt was made to locate the reported Wichita sites on the Trinity by measuring from known historic sites such as the Vinson Site in Limestone County and Waco in McLennan County. A number of promising locations were examined, but none of the village sites were found.

A historically documented Kichai site (Wood, 1900) in Leon County was checked, but results were negative. The location of a Kickapoo village in Leon County is shown precisely on excellent maps dating 1849-1853, on file in the county Courthouse, Centerville, Texas; the same site is referred to by wood (1900). The spot indicated on the maps was visited by the 
Trinity River survey party, but careful surface search failed to demonstrate historic Indian occupation.

\section{Recommendations}

The Colonel Cooper Site on the Brazos is probably the site of a Kichai village of the mid-19th century, and it should be thoroughly tested. Surface evidence indicates that the site will almost certainly produce abundant archeological data on that little-known time period. Furthermore, the site is in danger of serious damage by construction activities.

Barnard's Trading Post in Hood County should be preserved as a unique historic site. It undoubtedly holds a large store of archeological material of importance not only to studies of Wichita and other Indian culture, but to pioneer history of the south plains as well. 
54

PRELIMINARY REPORT UPON EXCAVATIONS AT THE LONGEST SITE, OKLAHOMA

by Robert F. Bell and Tyler Bastian

INTRODUCTION

The Oklahoma phase of the Wichita Indian Research Project was conducted by a joint effort of the Museum of the Great Plains and the University of Oklahoma. Marvin E。Tong, Jr。, Director of the Museum of the Great Plains functioned as Chairman of the Planning Board, handled the financial and administrative paperwork, and helped to coordinate the activities of the project. The Museum of the Great Plains also functions as a repository for the records and accumulated specimens recovered by the Oklahoma project. Tyler Bastian, of the Museum of the Great Plains staff, was in immediate charge of the field work, supervision of the Oklahoma field laboratory, and a preliminary analysis of the Longest Site materials, Robert E。 Bell, of the University of Oklahoma, functioned in the capacity of consultant and advisor, chiefly with reference to planning and directing the field excavations.

The actual field excavations were done in two major sessions, with the addition of a third exploratory test. The first season's work was carried out from November 15, 1965, through February 23, 1966. Cold weather and snows caused some temporary halts in the excavations after January 19th, but intermittent work continued after that date through February. Tyler Bastian was in immediate charge of the excavations with assistance from two supervisors, David C. Brown of Southern Methodist University and Franklin L。 Chappabitty of the University of Oklahoma, A field laboratory was established near Nocona, Texas, where excavated materials from both Texas and Oklahoma excavations were processed for analysis. 'R. Ko Harris of Southern Methodist University was in charge of this field laboratory where the specimens were washed, cataloged, sorted and prepared for preliminary study。

The second season's work was done between June 6 and August 11, 1966. Tyler Bastian was again in charge of the excavations which were directed toward obtaining new, data or answering questions arising from the first season's work. A field 'laboratory was established at a farmhouse, located near the site, where Linda Brown supervised the cleaning and cataloging of excavated materials.

A final test was conducted on March 28 and 29, 1,967, to' examine the nature of a feature which was discovered by $R_{0} K_{0}$." Harris and later defined by an aerial photograph of the site. The test revealed the existence of a fortification 
ditch which had remained unidentified up to that time. Most of the materials recovered from these different excavations have been examined, however, so that a preliminary report on the findings can be offered. The preliminary data furnished herein, nonetheless, are subject to revision or modification resulting from further analysis and additional excavation.

\section{Acknowledgements}

Many individuals have contributed to the success of the investigations on Wichita archaeology in Oklahoma. The owners and farmers of the Longest site permitted us to conduct extensive excavations in their cultivated fields, and they extended other courtesies. These persons are Mr. Sexon Longest, Mrs. Onie Longest and other representatives of the Herman Longest estate, $\mathrm{Mr}$. and Mrs. Henry Austin, and Mr. and Mrs. C. J. Longest. "CJ" and his wife, Gladys, who live near the site, were especially helpful while we were in the field. Dave Brown and Franklin Chappabitty served as field assistants during the first season. Backfilling was aided by a road grader supplied through the courtesy of County Commissioner Dick Dillon. During the second season Linda Brown served as camp cook and supervised the field laboratory in which she was assisted by Gaye Baxley and Weldon Crow. Full time crew members during the first season were Malcolm Baxley, Pete Carroll, Virgil Davis, and Georgie Thurman; working part of the season were Cartex Allen, Ronnie Carroll, Virgil D。 Davis, Ken Hopkins, Gharles Mooney, and Jim Irwin. Returning veterans for the second season were Baxley, Davis, and Thurman; new members were Gordon Artherholt, Marion Davis, Don Garrett, Ken Longest, and Ed McGee. Sustained interest and occasional field assistance was provided by the following amateur archaeologists from Oklahoma and Texas: Jay Blaine, Marjorie Derrick, Ralph Elliot and sons, Walter and Marie Jones, King and Inus Marie Harris, Sherman Lawton, Jim and Helen Marler, Jim Martin, Buford Morgan, Joe Opala, Larry Parkhill, C。A。 Smith, Bill Southerland, Jack Williamson, and Stan Young and daughter. Professional archaeologists who visited the site during the excavations were Tom Barr, James Brown, R. K. Harris, Edward Jelks, Dessamae Lorrain, Dee Ann Story, Curtis Tunnell, Ned Woodall, and Don Wyckoff. Test of the fortification ditch was conducted with Oklahoma River Basin Surveys personnel and equipment and with the assistance of student volunteers Tim Baugh, Charles Rohrbaugh, and Fred Schneider. A number of people allowed us to conduct surveys on their land. Paul Payne, Wilbur weil, and the family of the late Jay winters permitted us to test sites on their property. Volunteer assistants for the tests were Elmer Craft and Terry Nowka and sons. Louis McGee assisted in the laboratory at the Museum of the Great Plains. Among those who examined part of the recovered material while it was being studied in Lawton are Tom Barr, John Ewers, Marvin Tong, and 
and Waldo Wedel. The skeletal material was studied by William Bass and Douglas Ubelaker at the University of Kansas. Chemical tests of selected specimens were conducted by Bobby Vowell of Cameron college, Lawton. Information on related collections was supplied by Mrs. Joe Benton, Jim Dickerman, King Harris, Ed Hemming, John McAlister, Gregory Perino, and Jay Winters. Pertinent ethnohistoric information has been contributed by Lathel Duffield, William Field, Gillett Griswold, Jack Haley, Dan McPike, Max Moorehead, William Newcomb, and Mildred Wedel. The facilities of the Oklahoma River Basin Surveys were used in preparing some portions of this preliminary report, and the final draft was edited by Virginia Bell.

\section{THE SITE}

The Longest Site $(\mathrm{Jf}-1)$ is located on the Oklahoma side of the Red River valley about 15 miles south of Ringling in the southeastern part of Jefferson County. Specifically it is located on the farm owned by Mr. C. J. Longest and the Herman C. Longest estate. The site has been the property of the Longest family for many years, and they have maintained a continued interest in the history of the locality. The Longests granted permission to conduct the excavations and followed our progress with keen interest even though the work often handicapped the routine farming of Mr. C. J. Longest and Mr. Henry Austin who leases a portion of the Herman Longest estate on which the site is located. The Longests and others were also able to supply useful information regarding accidental discoveries, previous cultivation, and early history of the farm. In appreciation for these courtesies, the site has been designated as the Longest Site in honor of the Longest family.

The Longest Site is situated on the west side of a broad terrace of Illinoian age locally known as Courtney Flats, 60 ft. above the Red River channel immediately to the west (Figs. 24 and 25). At this locality the Red River flows from north to south altering the general west to east trend. The site is not subject to flooding for the lower bottom lands across the river to the west can easily absorb all overflows. occupational debris is to be found scattered over an area of perhaps 35 to 40 acres, and almost all of this area has been cultivated. The cultivation has been more or less continuous for at least the past 75 years as the land survey records indicate that it was under cultivation in 1892. A small area of about six acres was abandoned in the $1920^{\prime} \mathrm{s}$ and has since become overgrown with dense brush and scattered trees. Mr. C. Jo Longest reports 
that when the land was first plowed, it was necessary to carry away quantities of bones from the field, and these were piled up and burned.

The site area is divided into two approximately equal sections by a small wooded canyon containing a spring-fed stream. This wooded canyon empties into the Red River to the west and serves to divide the site into two areas designated. as the south and north sections of the site (Fig. 24). An abandoned farmhouse and outbuildings are still present on the south area of the site, and surface debris indicates the former existence of other farm structures in the north area. As a consequence of previous or existing farmsteads upon parts of the site, debris from recent occupation can be found intermingled with the aboriginal materials upon the surface.

The site area has been hunted by collectors for many years, and there is some evidence of random digging for relics or treasure. With some exceptions, the identity of previously collected material remains questionable, although it is clear that a considerable quantity of specimens has been recovered over the years.

The occupational area is generally unmarked by any specific features such as mounds or evidence of a fortification. The long period of cultivation has apparently leveled most irregularities which might have provided clues regarding the former village and associated features. Two low mounds can be seen in the uncultivated area on the terrace crest, and two low mounds can be seen in the overgrown area which has not been plowed in recent years. Throughout most of the site, however, there are surface concentrations of occupational debris; these are believed to represent previously existing refuse mounds which have been leveled by cultivation although some such areas may represent the locations of former house structures.

\section{THE EXCAVATIONS}

Since no previous archaeological excavations had been carried out at the Longest site, the field work was directed towards obtaining as much information as possible by selected sampling of the occupied area. Several objectives were cono sidered as goals or directives in guiding the field activities:

1. To recover a sampling of the artifact and debris materials which would provide information about the life and culture of the inhabitants, who were identified as Wichita Indians 
of the late 18th century.

2. To establish, if possible, whether or not the site represented only a single occupation, or if it contained evidence of additional occupations, possibly prehistoric in time.

3. To obtain materials from different sections of the site which might suggest differences in time, utilization, or tribal identity.

4. To obtain information about house structures or constructions that were associated with the Wichita occupation.

5. To obtain information about the low mounds, refuse areas, storage pits, or other features that might be associated with the occupation.

6. To locate and obtain information regarding burial customs and grave associations of the Wichita Indians.

7. To locate and find evidence of any fortifications such as palisades, ditches, or embankments to aid in the positive historical identification of the site.

8. To obtain information which would be helpful in evaluating the potential value of the site for Wichita Indian research and in formulating recommendations for future research.

It is satisfying to note that all of these goals were achieved during this pilot project.

The first season's excavations include three major test areas, each with a network of trenches; two are located in the northern section of the site, and one is in the south. The trenches were primarily exploratory to locate features or concentrations of cultural debris. When such areas were found, the trench was expanded to explore the surrounding area. A grid system based upon l-meter squares and arbitrary levels of $20 \mathrm{~cm}$. in thickness were employed in areas where it appeared as desirable. All earth from features such as storage pits, houses, or refuse areas was screened through $\frac{1}{4}$-inch mesh hardware cloth. When glass beads were suspected to be present, samples of earth were passed through a finer fly-screen or were washed after transporting it to the Nocona laboratory.

During this season, five house structures were located, 16 storage or refuse pits were excavated, and two refuse concentrations thought to have been the site of refuse mounds were investigated. No burials or evidence of fortification were 
discovered at this time. This work provided information about the house patterns, the storage or refuse pits, the nature of the low mounds, and a reasonable sample of artifacts from different parts of the site. Moreover, a preliminary examination of the artifacts recovered suggested some minor differences, which might reflect a time difference, between items found in the northern and southern sections of the site. The artifact sample from the northern sector, however, was more limited, and the second season's work was partly directed to increasing this sample.

The second season's work was directed toward gathering more specific data. The northern section of the site was trenched to locate possible house structures and burials, and to increase the artifact yield from this section of the site. In order to establish the nature of the low mounds four of these were partly excavated. Trenches were placed to the south and east of the previous trench areas in an effort to locate house patterns, but only a short section of an unidentified structure was found. Some 13 additional storage or refuse pits were located and excavated, but no burials or suggestions of a fortification were found. Consequently, efforts were shifted again to the southern section of the site, and a series of trenches were dug in an effort to locate some burials. This effort was successful, and a total of 7 burials were recovered. With the removal of the burials and the refilling of the various excavations, the work came to a close on August 11, 1966. By this time most of the objectives had been achieved satisfactorily except for establishing the existence of a fortification.

In February, 1967, R. K. Harris revisited the site and observed that Mr. Longest had plowed a portion of the north section deeper than usual and that surface debris suggested an oval or circular pattern-possibly representing the fortification. Bell subsequently took several aerial photographs of the site, and these revealed the existence of a large oval= shaped ring, measuring approximately 80 by $120 \mathrm{~m}$. in diameter (Fig, 26). This feature appeared to the north of previous field work and had not been exposed by the exploratory trenches. Consequently, an exploratory trench was dug on March 28 and 29, 1967, to determine what was indicated by the photograph. The test trench exposed the existence of a buried ditch, measuring about $3.8 \mathrm{~m}$. across and $1.2 \mathrm{~m}$. in depth. The upper fill that had been placed in the ditch contained numerous bison bones, and these had been turned up by the deep plowing to mark the oval outline of the ditch upon an otherwise flat surface. Although the test trench was extended beyond the sides of the ditch cross section, no evidence of posts or an adjacent palisade was located. It is not believed, however, that this brief test was adequate to establish either the presence or absence of an associated palisade. The exploration of this fortification ditch and the enclosed area remains for future work at the site.

A checklist of Tests, Features, and Structures recorded during the Longest Site excavations follows: 
60

Checklist on Longest Site Tests

\begin{tabular}{|c|c|c|c|}
\hline Test No. & Location & Dimensions in meters & Nature of Deposits \\
\hline 1 & Northwest & $\begin{array}{l}\text { Trench } 2 \times 26 \\
\text { Test } 2 \times 2 \\
56 \mathrm{sq} \cdot \mathrm{m}\end{array}$ & $\begin{array}{l}\text { Heavy midden in plowed zone } \\
\text { (Feature 1), sterile beneath; } \\
\text { spurious postmolds (Feature 2)。 }\end{array}$ \\
\hline 2 & $\begin{array}{l}\text { Northwest } \\
\text { - }\end{array}$ & $\begin{array}{l}\text { Trenches } 2 \times 16,2 \times 6 \\
2 \times 2,0.4 \times 38 \text { plus } \\
\text { expansions; } 69 \mathrm{sq} \cdot \mathrm{m} .\end{array}$ & $\begin{array}{l}\text { Shallow midden pocket below the } \\
\text { plow zone (Feature 3), a fire } \\
\text { place (Feature 9), and a } \\
\text { storage pit (Feature 5). }\end{array}$ \\
\hline 3 & Northwest & $\begin{array}{l}\text { Trench } 0.5 \times 33 ; 2 \text { tests } \\
2 \times 2 ; 24.5 \mathrm{sq} \cdot \mathrm{m} .\end{array}$ & $\begin{array}{l}\text { Late 19th century cellar } \\
\text { (Feature } 15) \text {. }\end{array}$ \\
\hline 4 & Northwest & $\begin{array}{l}\text { Trench } 0.4 \times 44 \text { with } \\
\text { expansions; } 27.5 \mathrm{sq} . \mathrm{m} .\end{array}$ & Storage pit (Feature 7). \\
\hline 5 & Northeast & $\begin{array}{l}\text { Trenches } 2 \times 6,0.4 \times 24 ; \\
\text { two tests } 2 \times 2 ; 29.5 \\
\text { sq. m. }\end{array}$ & $\begin{array}{l}\text { Pit (Feature 18); light midden } \\
\text { in plow zone (Feature } 4 \text { ). }\end{array}$ \\
\hline 6 & Northwest & $\begin{array}{l}\text { Trench } 0.4 \times 18 \text { with } \\
\text { expansion; } 36 \mathrm{sq} . \mathrm{m}\end{array}$ & $\begin{array}{l}\text { Relic hunters pits (Feature } \\
\text { 6; Features } 10 \text { to } \Psi_{4} \text { ). }\end{array}$ \\
\hline 7 & Northeast & $\begin{array}{l}\text { Trench } 0.4 \times 10 \text { with } \\
\text { expansions; } 10 \mathrm{sq} \cdot \mathrm{m}\end{array}$ & $\begin{array}{l}\text { Two shallow pits (Features } \\
16 \text { and } 17 \text { ). }\end{array}$ \\
\hline 8 & Northeast & $\begin{array}{l}\text { Trench } 0.4 \times 37 \text { with } \\
\text { expansions; } 23 \mathrm{sq} \cdot \mathrm{m}_{0}\end{array}$ & Pits (Features 8 and 46 ). \\
\hline 9 & Northwest & Trench $0.4 \times 18 ; 7 \mathrm{sq} \cdot \mathrm{m}$ & Sterile below plow zone. \\
\hline 10 & South & $\begin{array}{l}\text { Trenches } 2 \times 15,0.4 \times \\
35 \text {; test } 2 \times 2 ; 48 \mathrm{sq} \cdot \mathrm{m} .\end{array}$ & $\begin{array}{l}\text { House (Structure 1); } \\
\text { Pit (Feature } 74 \text { ). }\end{array}$ \\
\hline 11 & South & $\begin{array}{l}\text { Trench } 0.4 \times 101 \\
44.5 \mathrm{sq} \cdot \mathrm{m} .\end{array}$ & $\begin{array}{l}\text { Midden relatively sparse in plow } \\
\text { zone; } 3 \text { pits (Features } 20 \mathrm{~A} \text {, } \\
20 B \text {, and } 31 \text { ). }\end{array}$ \\
\hline 12 & South & $\begin{array}{l}\text { Trench } 0.4 \times 70 ; 28 \mathrm{sq} \text {. } \\
\text { m. }\end{array}$ & $\begin{array}{l}\text { House and pit (Structure } 3 \text {, } \\
\text { Feature } 43 \text { ). }\end{array}$ \\
\hline 13 & South & $\begin{array}{l}\text { Trench } 0.4 \times 8 \text { with } \\
\text { expansion; } 18 \mathrm{sq} \cdot \mathrm{m} .\end{array}$ & $\begin{array}{l}\text { Three pits overlain with area } \\
\text { of subplow-zone midden (Feature 19). }\end{array}$ \\
\hline 14 & Northeast & $\begin{array}{l}\text { Trench } 0.3 \times 11 \text { plus } \\
\text { test } 2 \times 2.5 ; 8.5 \mathrm{sq} . \mathrm{m} .\end{array}$ & $\begin{array}{l}\text { Midden below plow zone; rodent } \\
\text { activity? }\end{array}$ \\
\hline
\end{tabular}




\begin{tabular}{|c|c|c|c|}
\hline Test No. & Location & Dimensions in meters & Nature of Deposits \\
\hline 15 & South & Trench $0.4 \times 12 ; 5 \mathrm{sg}_{4} \mathrm{~m}$. & House (Structure 2) \\
\hline 16 & South & $\begin{array}{l}\text { Trench } 0.14 \times 37 \text { with } \\
\text { expansions; } 20 \mathrm{sq} \cdot \mathrm{m} .\end{array}$ & $\begin{array}{l}\text { House and two pits (Structure } \\
4 \text {, Features } 20 \text { and } 44 \text { ). }\end{array}$ \\
\hline 17 & South & Trench $0.4 \times 12 ; 5 \mathrm{sq} . \mathrm{m}$. & House (Structure 4 ) \\
\hline 18 & South & $\begin{array}{l}\text { Trench } 0.4 \times 56 \text { with } \\
\text { expansions; } 27.5 \mathrm{sq} . \mathrm{m} .\end{array}$ & $\begin{array}{l}\text { Pit (Features } 19,28,75 \text {, and } \\
76) \text {. }\end{array}$ \\
\hline 19 & South & Trench $1 \times 4 ; 4 \mathrm{sq} \cdot \mathrm{m}$. & Pits (Features 22 and 23) \\
\hline 20 & South & Trench $0.4 \times 8 ; 3 \mathrm{sq} . \mathrm{m}$ & $\begin{array}{l}\text { House (Structure 2); thin lens } \\
\text { of aboriginal refuse (Feature 27)。 }\end{array}$ \\
\hline 21 & South & Trench $0.4 \times 22 ; 13 \mathrm{sq} . \mathrm{m}$ & $\begin{array}{l}\text { Unidentified structure (house } \\
\text { or moat? Structure 5). }\end{array}$ \\
\hline 22 & South & $\begin{array}{l}\text { Stripped area about } 6 \\
\mathrm{x} 15 ; \text { ca. } 100 \mathrm{sq} \cdot \mathrm{m} .\end{array}$ & $\begin{array}{l}\text { Storage pits (Features } 32 \text { to } \\
40) \text {; recent refuse (Feature } 41 \text { ) }\end{array}$ \\
\hline 23 & South & $\begin{array}{l}\text { Trench } 0.4 \times 38 \\
15 \mathrm{sq} \text {. m. }\end{array}$ & $\begin{array}{l}\text { House, midden area, and hearth } \\
\text { (Structure 2, Features } 45 \\
\text { and } 73 \text { ). }\end{array}$ \\
\hline 24 & Northwest & $\begin{array}{l}\text { Trench } 1 \times 19 ; 4 \text { tests } \\
1 \times 2 ; 1 \text { test } 1 \times 1 \text {; } \\
28 \mathrm{sq} . \mathrm{m} .\end{array}$ & $\begin{array}{l}\text { Aboriginal refuse mound (Feature } \\
52) ; 2 \text { early } 20 \text { th-century } \\
\text { cellars (Features } 50 \text { and } 51 \text { ) } \\
\text { fireplace (Feature } 48 \text { ); and } \\
\text { relic hunters pit (Feature } 49 \text { ). }\end{array}$ \\
\hline 25 & Northwest & $\begin{array}{l}\text { Trench } 1 \times 7 \text { with short } \\
\text { laterals; } 13 \mathrm{sg} . \mathrm{m} .\end{array}$ & $\begin{array}{l}\text { Aboriginal refuse mound } \\
\text { (Feature } 53 \text { ). }\end{array}$ \\
\hline 26 & Northwest & Trench $1 \times 8 ; 8 \mathrm{sq} . \mathrm{m}$. & $\begin{array}{l}\text { Aboriginal refuse mound } \\
\text { (Feature } 4)\end{array}$ \\
\hline 27 & Northwest & $\begin{array}{l}\text { Trench } 1 \times 8 \text { with lateral } \\
1 \times 4 ; 12 \mathrm{sq} . \mathrm{m} .\end{array}$ & $\begin{array}{l}\text { Aboriginal refuse mound } \\
\text { (Feature } 55) \text {. }\end{array}$ \\
\hline 28 & Northwest & Trench $0.4 \times 21 ; 8.5 \mathrm{sq} \cdot \mathrm{m}$. & Sterile \\
\hline 29 & Northwest & Trench $0.5 \times 22 ; 11 \mathrm{sq} . \mathrm{m}$ & One grinding slab. \\
\hline 30 & Northwest & Trench $0.4 \times 22 ; 9 \mathrm{sq} \cdot \mathrm{m}$. & Sterile \\
\hline 3.1 & Northwest & Trench $0.4 \times 10 ; 4 \mathrm{sq} . \mathrm{m}$. & Archaic point. \\
\hline
\end{tabular}




\begin{tabular}{|c|c|c|c|}
\hline Test No. & Location & Dimensions in meters & Nature of Deposits \\
\hline 32 & Northwest & Trench $0.4 \times 17 ; 7 \mathrm{sq} . \mathrm{m}$. & Scattered aboriginal refuse. \\
\hline 33 & Northwest & $\begin{array}{l}\text { Trench } 0.4 \times 9 ; 3.5 \\
\text { sq. m. }\end{array}$ & $\begin{array}{l}\text { Concentration of debris at } \\
\text { northwest end of trench } \\
\text { (Feature 56) }\end{array}$ \\
\hline 34 & South & $\begin{array}{l}\text { Trench } 0.5 \times 31 ; 15.5 \\
\text { sq. m. }\end{array}$ & Storage pit (Feature 57). \\
\hline 35 & South & $\begin{array}{l}\text { Trench } 0.4 \times 34 ; 13.5 \mathrm{sq} \text {. } \\
\mathrm{m}_{0}\end{array}$ & $\begin{array}{l}\text { 20th-century pits } \\
\text { (Feature 58)。 }\end{array}$ \\
\hline 36 & South & $\begin{array}{l}\text { Trench } 0.4 \times 32 ; 13 \\
\text { sq. m. }\end{array}$ & Burials 1 and 2 . \\
\hline 37 & South & $\begin{array}{l}\text { Trench } 1 \times 53 \text { with } 4 \text { cross } \\
\text { trenches and irregular } \\
\text { extensions; } 136 \mathrm{sq} . \mathrm{m} .\end{array}$ & $\begin{array}{l}\text { Burials } 3 \text { and } 4 \text {; late } 19 \text { th } \\
\text { and } 20 \text { th-century refuse. }\end{array}$ \\
\hline 38 & South & $\begin{array}{l}\text { Trench } 1 \text { x } 22 \text { with irregular } \\
\text { extensions; } 33 \mathrm{sq} . \mathrm{m} .\end{array}$ & $\begin{array}{l}r \text { Burials } 5,6 \text {, and } 7 ; \\
\text { aboriginal pit (Feature 60); } \\
\text { refuse. }\end{array}$ \\
\hline 39 & South & Trench $1 \times 17 ; 17 \mathrm{sq} \cdot \mathrm{m}$ & $\begin{array}{l}\text { Aboriginal and late } 19 \text { th- } \\
\text { and } 20 \text { th-century refuse. }\end{array}$ \\
\hline 40 & South & $\begin{array}{l}\text { Irregular test ca. } 1.5 \\
\mathrm{x} 2.5 ; 4 \mathrm{sq} \cdot \mathrm{m} .\end{array}$ & Storage pit (Feature 59). \\
\hline 41 & South & Trench $1 \times 16 ; 16 \mathrm{sq} \cdot \mathrm{m}$ & $\begin{array}{l}\text { Sparse aboriginal and } \\
\text { 20th-century refuse. }\end{array}$ \\
\hline 42 & Northeast & $\begin{array}{l}\text { Trench } 1 \times 3 I ; 23 \text { tests } \\
1 \times 1 \text { plus irregular } \\
\text { stripped area; ca. } 231 \\
\text { sq. m. }\end{array}$ & $\begin{array}{l}\text { Aboriginal storage pits and } \\
\text { postmold patterns (Features } \\
61 \text { to } 64,68 \text { to } 71 \text {, and } \\
\text { Structure 6). }\end{array}$ \\
\hline 43 & Northeast & $\begin{array}{l}\text { Trench } 1 \times 21 \text {; trench } \\
2 \times 11 \text { and } 5 \text { tests } 1 \times 1 \text {; } \\
48 \mathrm{sq} \cdot \mathrm{m}_{0}\end{array}$ & $\begin{array}{l}\text { Aboriginal storage pits and } \\
\text { refuse (Features } 65 \text { to } 67 \text { ). }\end{array}$ \\
\hline 44 & North & Strip $0.3 \times 4$. & $\begin{array}{l}\text { Fortification ditch area } \\
\text { (Structure } 7 \text { ). }\end{array}$ \\
\hline 45 & North & Trench $2 \times 10$ & $\begin{array}{l}\text { Test section in ditch area } \\
\text { (Structure 7); pit (Feature } \\
\text { 72). }\end{array}$ \\
\hline
\end{tabular}


Checklist of Numbered Features

\begin{tabular}{|c|c|c|}
\hline Feature No. & Location & Type of Feature \\
\hline 1 & Northwest & Aboriginal refuse concentration in plow zone. \\
\hline 2 & Northost & Spurious postmolds. \\
\hline 3 & Northwest & Small pocket of aboriginal refuse. \\
\hline 4 & Northeast & Area of aboriginal refuse in plow zone. \\
\hline 5 & Northwest & Aboriginal storage pit. \\
\hline 6 & Northwest & $\begin{array}{l}\text { Aboriginal refuse concentration in plow zone overlying } \\
\text { recent pits dug by relic hunters (Features } 10 \text { to } 14 \text { )。 }\end{array}$ \\
\hline 7 & Northwest & Aboriginal storage pit. \\
\hline 8 & Nor theast & Aboriginal storage pit. \\
\hline 9 & Northwest & Aboriginal fire place. \\
\hline 10 & Northwest & Recent pit dug by relic hunters. \\
\hline 11 & Northwest & Recent pit dug by relic hunters. \\
\hline 12 & Northwest & Recent pit dug by relic hunters. \\
\hline 13 & Northwest & $\begin{array}{l}\text { Shallow pocket of aboriginal refuse; may have been dug } \\
\text { by relic hunters. }\end{array}$ \\
\hline$\amalg_{4}$ & Northwest & $\begin{array}{l}\text { Shallow pocket of aboriginal refuse; may have been dug } \\
\text { by relic hunters. }\end{array}$ \\
\hline 15 & Northwest & Cellar containing late 19th-century refuse. \\
\hline 16 & Northeast & Shallow pit, may be recent. \\
\hline 17 & Northeast & Shallow pit, may be recent. \\
\hline 18 & Northeast & Aboriginal storage pit. \\
\hline 19 & South & $\begin{array}{l}\text { Aboriginal refuse concentration underlain by storage pit } \\
\text { and } 4 \text { other pits which may be recent. }\end{array}$ \\
\hline 20 & South & Aboriginal storage pit. \\
\hline 21 & South & Aboriginal storage pit. \\
\hline
\end{tabular}




\begin{tabular}{|c|c|c|}
\hline Feature No. & Location & Type of Feature \\
\hline 22 & South & Pit, may be recent. \\
\hline 23 & South & Pit, may be recent. \\
\hline 24 & South & Aboriginal storage pit. \\
\hline 25 & South & Small recent pit. \\
\hline 26 & South & Fire place in Structure 3. \\
\hline 27 & South & Thin lens of aboriginal refuse. \\
\hline 28 & South & Aboriginal storage pit. \\
\hline 29 & South & Aboriginal storage pit. \\
\hline 30 & South & Pit, may be recent. \\
\hline 31 & South & Probably a storage pit--not excavated. \\
\hline 32 & South & Shallow pit, may be recent. \\
\hline 33 & South & Aboriginal storage pit. \\
\hline 34 & South & Shallow, rock-filled basin of refuse, may be recent. \\
\hline 35 & South & Probably a storage pit, not excavated. \\
\hline 36 & South & Aboriginal storage pit. \\
\hline 37 & South & Aboriginal storage pit. \\
\hline 38 & South & Aboriginal storage pit. \\
\hline 39 & South & Aboriginal storage pit. \\
\hline 40 & South & Probably a storage pit--not excavated. \\
\hline 41 & South & Lens of contemporary refuse. \\
\hline 42 & South & Pit, may be recent. \\
\hline 43 & South & Probably a storage pit, not excavated. \\
\hline 44 & South & Probably a storage pit, not excavated. \\
\hline 45 & South & Small midden concentration, not excavated. \\
\hline 46 & Northeast & Small pit of recent origin. \\
\hline
\end{tabular}




\begin{tabular}{|c|c|c|}
\hline Feature No. & Location & Type of Feature \\
\hline 47 & South & Fire place, Structure 1 . \\
\hline 48 & Northwest & $\begin{array}{l}\text { Pire place; probably recent; could be a burned-out } \\
\text { stump. }\end{array}$ \\
\hline 49 & Northwest & Recent pit dug by relic hunters. \\
\hline 50 & Northwest & Cellar containing early 20 th-century refuse. \\
\hline 51 & Northwest & Cellar containing early 20th-century refuse. \\
\hline 52 & Northwest & Aboriginal refuse mound. \\
\hline 53 & Northwest & Aboriginal refuse mound. \\
\hline 54 & Northwest & Aboriginal refuse mound. \\
\hline 55 & Northwest & Aboriginal refuse mound. \\
\hline 56 & Northwest & $\begin{array}{l}\text { Aboriginal refuse mound; probably an extension of } \\
\text { Feature } 55 \text { into Test No. } 33 \text {. }\end{array}$ \\
\hline 57 & South & Aboriginal storage pit. \\
\hline 58 & South & Group of shallow 20th-century pits. \\
\hline 59 & South & Aboriginal storage pit. \\
\hline 60 & South & Pit, may be recent. \\
\hline 61 & Northeast & Aboriginal storage pit. \\
\hline 62 & Northeast & Aboriginal storage pit. \\
\hline 63 & Northeast & Aboriginal storage pit. \\
\hline 64 & Northeast & Aboriginal storage pjt. \\
\hline 65 & Northeast & Aboriginal storage pit. \\
\hline 66 & Northeast & Aboriginal storage pit. \\
\hline 67 & Northeast & Aboriginal storage pit and midden pockets. \\
\hline 68 & Northeast & Aboriginal storage pit. \\
\hline 69 & Northeast & Aboriginal storage pit. \\
\hline 70 & Northeast & Aboriginal storage pit. \\
\hline
\end{tabular}


66

$\begin{array}{lll}\text { Feature No. Location } & \text { Type of Feature } \\ 71 & \text { Northeast } & \text { Aboriginal storage pit. } \\ 72 & \text { North central } & \text { Probably a storage pit-not excavated. } \\ 73 & \text { South } & \text { Fire place in Structure } 3 . \\ 74 & \text { South } & \text { Midden; probably a storage pit--not excavated. } \\ 75 & \text { South } & \text { Midden; probably a storage pit-not excavated. } \\ 76 & \text { South } & \text { Midden; probably a storage pit-not excavated. }\end{array}$

Checklist of Numbered Structures

\begin{tabular}{|c|c|c|c|}
\hline Structure No. & Location & Type of Structure & Included Features \\
\hline 1 & South & Circular house & $\begin{array}{l}\text { Pits (Features 21, 24, and } \\
\text { 30); fireplace (Feature } 47 \text { ) }\end{array}$ \\
\hline 2 & South & $\begin{array}{l}\text { Oblong house (not } \\
\text { completely excavated) }\end{array}$ & $\begin{array}{l}\text { Fireplace (not numbered); } \\
\text { Pits nearby (Features } 29 \\
\text { and } 72 \text { ) }\end{array}$ \\
\hline 3 & South & Circular house & $\begin{array}{l}\text { Pits, probably recent } \\
\text { (Features } 25,26 \text {, and } 42 \text { ) } \\
\text { fireplace. }\end{array}$ \\
\hline 4 & South & $\begin{array}{l}\text { Circular house } \\
\text { (not excavated) }\end{array}$ & None \\
\hline 5 & South & $\begin{array}{l}\text { Probably a house } \\
\text { (not excavated) }\end{array}$ & None \\
\hline 6 & Northeast & Post alignment & None \\
\hline 7 & North & Fortification ditch & Pit (Feature 72). \\
\hline
\end{tabular}


STRUCT URES

Six structures were encountered during the excavations, three of these were completely excavated, and three were trenched or partially exposed. The largest and most clearly defined structure (Structure 1) is described in detail and will serve as a frame of reference for the brief descriptions of the others. A seventh structure, the fortification ditch, is described elsewhere in this report.

Structure 1 was a circular depression, 9.5 to $10 \mathrm{~m}$. in diameter, which contained three concentric rings of postmolds and a contral fireplace (Fig. 31). The presence of the structure was first suspected during preliminary testing of the site when a small test hole, dug in a concentration of surface refuse on a slight rise, revealed refuse and wash lines extending $0.5 \mathrm{~m}$. below the plow zone. When the major excavations began, a trench $2 \mathrm{~m}$. wide (Test No. 10) was placed to expose this promising area. Removal of the plow zone from the first square exposed the southwestern edge of a large refuse deposit. Scattered charcoal increased markedly in quantity toward the edge of the refuse where it formed a nearly continuous band about $2 \mathrm{~cm}$. in thickness. The surrounding undisturbed orange-brown soil was burned at the point of contact with the refuse deposit. Subsequent excavation prodedure assumed that the feature was the remains of a semisubterranean house which had burned and was eventually filled with refuse.

In order to determine the size, shape, and location of the structure, the plow zone was removed from the initial trench. In addition, another trench $0.5 \mathrm{~m}$. wide (Test No. 1I) was placed at a right angle to expose a larger area. When the cross trenches indicated the approximate position of the structure, the plow zone was removed from the entire area and beyond the periphery for about $1 \mathrm{~m}$., except for two balks or control strips $0.5 \mathrm{~m}$. in width which crossed the approximate center at right angles to each other. A small section along the western edge was also temporarily left in place until the cotton crop was harvested. Except for the initial trench (Test No. 10), the removed plow-zone soil was not screened for artifacts.

Removal of the plow zone revealed a dark circular deposit 9.5 to $10 \mathrm{~m}$. in diameter. The edge was well defined in most places, but nowhere as clearly as on the southwest edge where it was first discovered. There were four notable irregularities along the edge of the otherwise circular refuse deposit. A rounded expansion of refuse, $0.8 \mathrm{~m}$ wide, extended along the northwest edge for $1.5 \mathrm{~m}$; this later proved to represent a 
storage pit (Feat. 21). The curved outline of the refuse area was also flattened for a distance of $1.5 \mathrm{~m}$. along the western edge. Both the north and south edges of the circular area were interrupted for about $2 \mathrm{~m}$. by an inward projection of light-colored, nearly sterile soil resembling the surrounding deposit. These light-colored projections extended toward the center of the structure for a distance of $0.5 \mathrm{~m}$. Where it became blended with the darker midden.

In continuing excavation of the house, several small tests were dug through the exposed midden deposit adjacent to the control balks. These tests exposed three different layers: (A) a dark midden with soil lenses; (B) a zone of charcoal, ashes, and burned soil; (C) a light-colored soil with a burned surface. Each of these layers was removed separately from the four quadrants formed by the control balks. During this removal of the fill, stratum A was further subdivided into $10 \mathrm{~cm}$. horizontal levels. All of the fill was screened as it was removed from the structure.

Stratum A was a deposit of mixed refuse and soils filling a basin-shaped depression. The layer was marked by its dark color and contained bone fragments, ash, charcoal, and artifacts. This debris tended to occur in concentrations, especially near the center of the house and in the upper levels of the stratum. Light-colored soil, nearly sterile and appearing in lenses as if it had resulted from washing or wind action, was more prominent around the edges and at the base of the fill. From the profile evident upon the control balks, four subdivisions within stratum A could be observed. These were:

(1) The upper central lens of dark midden material about $4 \mathrm{~m}$. in diameter and up to $0.2 \mathrm{~m}$. in thickness.

(2) A second concavo-convex lens of lighter-colored midden material about $6 \mathrm{~m}$. in diameter and from 0.1 to $0.2 \mathrm{~m}$. in thickness.

(3) A third concavo-convex lens of dark-colored midden material from 8 to $9 \mathrm{~m}$. in diameter and about $0.2 \mathrm{~m}$. in thickness. In the central area this rested directly upon a burned layer, but in other places it was underlain by the fourth lajer.

(4) A fourth layer which consisted of a series of thin lenses of light-colored midden and sandy soils.

The only features encountered during the removal of stratum A were the irregularities around the edges of the midden as the different lenses of soil were removed. The significance of the rounded extension on the northwest edge was not then apparent. 
On the west side, the refuse outline expanded inward toward the center in a broad curve. This edge was sharply defined by the charcoal-bearing layer adjoining the burned soil; the northern side of this sector was obscured by the east-west control balk. The inward projection noted for the north side became less and less distinct and finally disappeared as stratum A was removed. The projection located on the south side persisted, however, and before much of stratum $A$ was removed, the area was left in place because it was suspected that it might be associated with a doorway or entrance. This resulted in an unburned arc-shaped area extending a distance of about $2 \mathrm{~m}$. toward the center of the depression.

Stratum B was a scattered irregular deposit less than $0.1 \mathrm{~m}$. in thickness containing charcoal-laden refuse and some ashy areas. The charcoal fragments were small and scattered except near the edges along the southern third of the structure where over a dozen fragments of small logs were preserved. The logs lay in no definite pattern although several were parallel with the radii of the structure. Perhaps the limited. area in which the logs were preserved can be attributed to their position along the windward side of the depression where they may have been buried more quickly from wind-blown soil. The ash lenses were small and thin, often being a light green in color and containing tiny greenish-gray bubbly particles resembling melted. glass. A hand-stone and milling-basin, both extensively fratured by heat, were found lying in place on the top of stratum $\mathrm{C}$. A charred corncob lay against the south end of the grinding basin. The soil beneath the grinding -basin was not burned, indicating that the basin had lain in that position during the fire. Discs of wood, charred on the top and sides but rotted on the bottom, lay over several hollow postmolds. The charred wood had apparently prevented soil from filling the post holes after the unburned portions of the posts had decayed. A heavy concentration of white ash in the center of the house at the base of stratum B proved to be a basin-shaped fireplace (Feat 47). The fireplace was $90 \mathrm{~cm}$. in diameter, nearly $20 \mathrm{~cm}$. deep, and had broadly sloping sides. Some of the ash was scattered on the floor north of the fireplace. The irregular ities in the edge of the refuse area, which were noted when the structure was first cleared, showed little change during the removal of stratum $B$.

Stratum $C$ includes the floor of the house and the overlying light-colored soil which was deposited during and after occupation of the structure, but before it was burned. The top of the stratum was a variegated orange, brown, black, and green color over most of the area, as a result of the fire and heat, but otherwise it was light colored. The actual floor surface was not discernible within stratum $C$, which graded imperceptibly 
into the underlying undisturbed sandy loam subsoil. The refuse contained in stratum $C$ extended 5 or $10 \mathrm{~cm}$ below the top of the layer, and its presence may be largely attributed to trampling by the occupants or subsequent rodent disturbances. The refuse found consisted mostly of small bone fragments or artifacts. Small scraps of metal, mostly iron amounting to several hundred fragments in a.ll, were found concentrated in three areas from 1 to $2 \mathrm{~m}$. in diameter. Larger artifacts including clay pipes, a paint palette, and a stone slab of unidentified function, were found near the edge of the house and do not appear to have been burned. Apparently they had been covered with soil which had accumulated in the structure before it burned. Possibly they had been stored or were hidden under benches or beds which probably appeared along the wall of the structure.

The outline of a refuse-filled storage pit (Feat。2l) was exposed near the top of stratum $C$ on the northwest edge of the structure. Additional stripping of stratum $\mathrm{C}$ exposed a second storage pit (Feat.24) on the western edge. Neither of the pits was detected in the fill above the floor of the house, although their presence may account for the irregularities of the midden outline mentioned earlier. It is possible that the dark fill of Feat. 21 obstructed its detection in the house fill, but the relatively light-colored fill of Feat. 24 would certainly have been noted if it had been dug through the darker debris. There was no debris such as greenish ash or clinkers similar to that found in the house fill in either of these pits, suggesting that they had been filled by the time the house burned. If the use of the storage pits and the structure was contemporary, their position on the edge of the house appears awkward. It would appear that the pits predate the house and that their position along the edge of the structure is coincidental. Ten additional pits were found in the immediate area of the structure, but it is not known if any of these were used at the same time as the house. In view of the fact that structure 3 and similar houses uncovered at the Upper Tucker Site, across the river in Texas, lacked pits, it is believed that Feats. 21 and 24 were not directly associated with the house.

The inward curvature on the west edge of the refuse filling the structure disappeared with the removal of the burned top of stratum $G$. The interruption on the north side had dis appeared during the removal of stratum $A$ and did not reappear. The arch-shaped projection of relatively light-colored soil on the south edge had been left in place after removing only part of stratum A. This was removed during the excavation of stratum $C$ in a series of cross sections which revealed occasional lensing and artifacts but no burning. A stone grinding basin lay near the floor level at one edge of the projection. The west side of this projection was included in the north-south. control balk and appears in the cross-sectional drawing (Fig. 32 ). 
A similar, although shallower and more widely dispersed, deposit was revealed beneath the burned top of stratum $C$ on the east side of the structure. Unlike the projection on the south, it was not apparent in the higher strata. The absence of burning on these soil projections may be a consequence of plowing which destroyed the evidence. The possibility is suggested that these light-colored soil projections indicate the locations of former doorways which were open and thus permitted the accumulation of windand water-born sediments at these locations within the abandoned house prior to burning. This idea is further supported by the finding of paired post holes on the four cardinal sides of the house in conjunction with these deposits, and, also, by the fact that ethnographic data indicate that Wichita houses had four doorways.

Several bits of evidence suggest the presence of a grass-covered superstructure. The fill in the depression is marked by wash lines and lenses indicating that it accumulated gradually over a period of time. If an earthcovered superstructure had been present, a more massive or mottled fill would probably have been associated with the burned stratum B. No burned clay with stick impressions suggesting wattle and daub construction was found. The greenish-gray bubbly particles or clinkers resembling glass found in burned stratum $B$ are characteristic of the remains of burned haystacks or hay-filled barns and have been found on the floors of burned structures identified as Wichita houses near Larned, Kansas.

Many post holes were revealed while clearing stratum $c$, but they were not recorded in detail until after the control balks were photographed, recorded, and removed. The entire floor of the structure was carefully scraped several times in an attempt to locate all of the posts. A strip of flagging tape was pinned with nails to each postmold, but it does not show clearly in the photographs (Fig. 3I)。 Each postmold was sectioned and recorded in detail, and the floor was subjected to overall and localized study in an effort to locate additional posts, especially where there appeared to be gaps in the pattern. When excavation was completed, the entire structure had been excavated 10 to $20 \mathrm{~cm}$. below the top of the original floor.

In order to determine if there were nearby structural features, the plow zone was cleared beyond the edges of the house for a distance of $1 \mathrm{~m}$. A larger area was cleared along the western side where a number of storage pits were found, but it is not clear if they were associated with the structure or not. 
The postmold pattern of structure 1 consists of three concentric rings. The outer ring of posts was placed close to the outside rim of the basin-shaped depression forming the house. The second ring of posts was inside the house at a distance of $1 \mathrm{~m}$. from the outer ring. The second ring had two sets of paired posts on each of the four cardinal sides of the house. In the outer ring, paired posts were present only on the east side of the house. The paired posts, occurring in conjunction with the light-colored soil areas, described above, suggest the presence of four entryways. The central ring of posts, located $2.8 \mathrm{~m}$. from the outside ring, was arranged to provide a clear passage from the central fireplace toward each of the suggested doorways. No postmold was found underneath the central fireplace as is the case at some Gaddoan sites.

The nature of the fill in the post holes varied considerably. As previously mentioned, some of the molds were nearly empty for the tops had been plugged by discs of charred wood. Only a small amount of rotted wood or a white powdery substance remained in the bottoms of these molds. Other postmolds were completely and compactly filled with a relatively light-colored soil difficult to distinguish from the surrounding soil. More commonly, however, the fill consisted of a darker-colored area which was less compacted than the surrounding soil. A distinctive characteristic of the post molds, which served as an important identifying feature to distinguish them from other disturbances, was a surrounding zone of fill of about the same color as the undisturbed soil, often outlined by a thin, relatively dark line. The larger outline represents the excavation made to receive the post, and the lighter-colored soil is the earth packed around the post after it was set in place.

The number and size of the posts and post holes in each ring is summarized in the following table:

\section{Dimensions (in $\mathrm{cm}$. ) of Postmolds in Structure 1}

\begin{tabular}{|c|c|c|c|c|c|c|c|}
\hline & Nog of & Diameter & of post & Diameter & of hole & Depth below & floor \\
\hline Ring & Posts & range & mean & range & mean & range & mean \\
\hline Outer & 15 & $6-13$ & 8 & $12-20$ & 15 & $38-77$ & 57 \\
\hline Middle & 20 & $5-16$ & 11 & $10-22$ & 18 & $31-97$ & 65 \\
\hline Central & 6 & $11-15$ & 13 & $17-21$ & 18 & $62-79$ & 72 \\
\hline
\end{tabular}


The method of construction and the appearance of struc ture 1 can be briefly summarized. A circular basin or bowlshaped area 9.5 to $10 \mathrm{~m}$. in diameter and $.5 \mathrm{~m}$. deep was $\theta \mathrm{x}-$ cavated. Two abandoned trash-filled storage pits were bisected by this excavation along the west edge. A shallow basin was excavated at the center to serve as a fireplace. Three concentric rings of posts for support of a grass-covered superstructure were set into the floor of the depression. Entryways placed at the north, south, east, and west sides of the house were reinforced by the use of paired-post construction. Artifacts preserved on the house floor included two milling basins, a grinding stone, a paint palette, pipes, and a few other smaller items. A number of specimens were found around. the edge of the house as if they had been stored or misplaced underneath an encircling bench or bed platform. The house floor was relatively clean except for many small scraps of iron, suggesting that metal had been worked by the occupants. After the structure was abandoned, winds and rain deposited. soil around the doorways forming ramp-like deposits of relatively sterile soil near the south and west entrances. The structure finally burned with intense heat which scorched most of the basin area. Subsequently, deposits moved by winds or rain, and trash dumped by Indians living elsewhere in the village, eventually filled the house depression.

Structure 2 was only partly excavated ated, but it appears to be oblong in shape, measuring about 4 by $15 \mathrm{~m}$. It was located initially by a narrow trench (Test 11) and then further defined by a narrow cross trench (Test 12), both of which were excavated through the floor of the structure. Several other trenches exposed this feature below the base of the plow zone. The house was filled with a light-and medium-colored soil showing lensing and scattered refuse to a depth 0.5 to $0.7 \mathrm{~m}$. below the plow zone. There was no evidence found to indicate that the structure had burned. Four postmolds were found, and a fireplace was situatednear the intersection of the cross trenches, but it was situated above the house floor and may not belong with the structure. Only a few artifacts were recovered from this structure area as most of the material from the exploratory trenches was not screened.

Structure 3 (Fig. 33 and 34) was circular and measured about $6 \mathrm{~m}$. in diameter. This house was completely excavated after it was discovered by means of a narrow trench (Test 12) which had cut through the house floor. Subsequent excavation procedure was similar to that used in uncovering structure 1 , although the overlying strata and the edge of the refuse fill were less clearly defined. Obscurity of certain house features is attributed to the shallowness of the overlying deposit and its damage by plowing, extensive rodent disturbances, and the nature 
of the fill. Stratum A was composed of from 10 to $20 \mathrm{~cm}$. of a greenish-gray ashy soil overlying from 5 to $10 \mathrm{~cm}$. of midden material. Stratum B was composed of thin lenses of a darkcolored midden containing refuse and finely-divided charcoal. Stratum $C$ had a burned surface, and in some areas it was baked hard and often broke away in chunks resembling a crude black pottery with one rough surface. Beneath this burned surface were from 5 to $10 \mathrm{~cm}$. of sandy soil lenses containing sparse refuse. The base of stratum $C$ was quite distinct in crosssection, suggesting a second floor.

The postmold pattern of structure 3 is less well preserved. than that of structure 1; however, it is clear that there were two rings of posts rather than three. One was about 0.5 inside the outer edge of the basin, and the second was $1.2 \mathrm{~m}$. inside the first. In several instances there were sets of paired posts suggesting that there were entryways in at least some of the cardinal directions as was found in structure 1 . A shallow hearth in the center of the structure was badly disturbed.

Structure 4 is represented by an area of refuse $10 \mathrm{~m}$. in diameter which was exposed under the plow zone by several narrow exploratory trenches (Tests 15 to 17). A small test into the floor of one of these trenches revealed a midden deposit showing lenses of wash such as was found in the fill of previous structures. No additional excavation was done at structure 4 .

Structure 5 is represented by an area, containing refuse of an unknown size and shape, that was observed underneath the plowed zone in Test 21. From a small test made in the floor of the trench, a laminated midden deposit could be observed. Since this deposit resembled that found in other structures, it was assumed that another house was present in this area.

Structure 6 is represented only by an alignment composed of 18 postmolds. The postmolds were about $5 \mathrm{~cm}$. in diameter, extended to a depth of $60 \mathrm{~cm}$. below the present surface, and were arranged in a broad arc with a chord across the ends measuring about $8 \mathrm{~m}$. Although a considerable area was cleared on all sides of this arc, no additional post holes or features were located. These post holes clearly indicate a different kind of structure than that represented by structures 1 and 3 since there was no evidence of special surface preparation or a circular depression. Possibly it represents a section from a corral or other surface feature of the site. 
REFUSE MOUNDS

Four low mounds (Feats. 52-55) in the north portion of the site were trenched, and all proved to be composed of aboriginal refuse. AII are located in areas which, for various reasons, have escaped intensive cultivation. It is possible that addi= tional mounds may be obscured by the dense brush which covers areas of the site not presently under cultivation. The most prominent mound (Feat. 52), situated in an uncultivated area, measures $10 \mathrm{~m}$. in diameter and about $0.4 \mathrm{~m}$. in height. The surface was pitted from random excavations by relic hunters. The test trench (Test 24) extended through the mound and $5 \mathrm{~m}$. beyond either edge. The mound consisted of a midden mixture of bone, ash, charcoal, and artifacts deposited in broad bands of dark soil or ash where they had not been disturbed by the previous digging. The base of the refuse was irregular and lay somewhat below the level of the present surface of the ground surrounding the mound, suggesting some soil accumulation since the mound was used. Very little refuse was found beyond the limits of the mound, and the debris below the mound base can probably be attributed to natural and recent disturbances. No postmolds or other aboriginal features were discerned in or beneath the mound. One notable recent feature was a deep cylindrical pit (Feat. 49), near the center of the mound, which extended $2 \mathrm{~m}$. into sterile soil beneath the base of the mound. The lower part of the pit contained loose clods of dirt and almost no debris. The floor of the pit was irregular, and short prospect holes ran from it at various angles. Similar prospecting pits, attributable to treasure hunters, were found in another part of the site and are described at the end of the section on storage pits.

Three other refuse mounds (Feats. 53-55) are about the same diameter as Feature 52 , but they have been reduced in height by cultivation. None appears to have been disturbed by relic hunters, and test trenches revealed that each mound consisted of a concentration of aboriginal refuse in dark soil or thick ashy lenses. In every instance the base of the refuse was slightly irregular and extended a short distance beLow the level of the surrounding ground surface. No features were found within or below the refuse mounds.

Other refuse mounds which may have been located in the intensively cultivated portions of the site have been leveled, but several refuse concentrations suggest their former exis tence. One such area (Feat. I) was trenched in the northwest portion of the site. The dense refuse in the plow zone occupied two fairly distinct areas and did not extend into the subsoil. A storage pit (Feat. 5) was found a short distance outside the concentrations of refuse, but no features were found beneath the concentrations. Thers is another reason 
for suggesting that the refuse concentrations may have been the site of mounds, for there seems to be a direct relation between the size of the existing mounds and the extent to which they have been subjected to cultivation. The most prominent mound is in the uncultivated area, one moderately prominent mound is in an area only recently subjected to cultivation, another mound of medium prominence is partly under a fence in a field not cultivated since the $1920^{\prime} \mathrm{s}$, and an almost undiscernible mound is near the center of the same abandoned field. Since all of the known major refuse areas on the south section of the site have been intensively plowed, all of the mounds on that portion of the site may be leveled. Several notable concentrations of refuse near the northeast edge of the south portion of the site may be the remains of former refuse mounds.

\section{STORAGE PITS}

The storage pits at the Longest Site are typically round and expand toward the bottom forming a bell-shaped pit (Fig. 36). A few are basin-shaped, one of which has a marked oval outline. The pits were normaliy filled with refuse, but the soil color was seldom much darker than the sterile orange-brown matrix into which they were dug. The precise outlines of the pits were often difficult to trace, especially near the top of the pit or when extensively disturbed by rodent burrows. Pertinent data about the excavated storage pits are tabulated in the attached tables.

Two excavation procedures were applied to the pits. Most of them were cross sectioned by removing a vertical half of the pit and some of the adjacent sterile matrix. A few were excavated, however, by clearing only the contents of the pit. The latter method was satisfactory for the relatively few pits with distinct walls, but this often resulted in more uncertainty about the shape of indistinct pits than might have been the case if they had been cross sectioned. Since all of the pits became indistinct near their tops, and there was no way to predict how distinct the pit outline would be before it was dug well below the base of the plow zone, the cross section technique seemed to be most successful.

The pit fill varied from a light to a very dark color, and from nearly sterile to rich in refuse. The light-colored pits tended to be relatively sterile, and vice versa. When the fill was nearly the same color as the surrounding matrix, the limits of the pit was determined by a difference in soil texture, the presence of refuse, or a fine slightly dark line which sometimes marked the edges. In every case the pits were less distinct near the top, and in many instances the outline could not be traced upward to the plowed zone. Lacking evidence to the contrary, it is assumed that all of the pits originated 
at or near the present ground surface, and that they have been truncated by plowing or other disturbances. In addition to possible leaching and disturbance by rodents or man, soil slump appears to have contributed to the obliteration of some pit outlines. Soil slump seems the most likely explanation for effects seen in two bell-shaped pits (Features 61 and 64) where cross sections revealed wedges of: light soil bounded by thin black wash lines near the top and edges of the pit. Such slumping could be noted during the field work when excavated pits were allowed to remain open for a period of time, and this must have happened in the past.

Classification of the pits by shape and whether or not they were used for storage is somewhat arbitrary because there is an apparent gradation of forms from distinctly bellshaped to shallow basin- or lens-shaped depressions. Even with the bell-shaped pits there is considerable variation in details of shape and size. The gradation may be due, at least in part, to the frequent obscurity of the pit outlines and to uncertainties as to whether some pits are aboriginal or of recent origin. Most of the bell-shaped and bowl-shaped pits are clearly aboriginal; however, none of the basinshaped pits are clearly of Indian origin. Even if further analysis should prove that some of the basin-shaped pits are aboriginal, their function remains unclear.

The designation of the bell-shaped and bowl-shaped pits as storage pits is an assumption based on ethnographic and archaeological parallels since no direct evidence for their function was revealed at the Longest site. One bowl-shaped pit (Feature 29) had a thin layer $(0.25 \mathrm{~cm}$ ) of charred grass covering part of the floor. There was no evidence that it was burned in place, but such a small amount of grass might not have baked the earth. Perhaps the pit had been lined with grass, or it may have been part of a cover that had fallen into the pit. It should be noted that a bellshaped pit was found at the Upper Tucker site, across the river in Texas, which contained a thick mat of charred grass on the floor.

Possible evidence suggesting the method of covering the pits was found during the excavation of two bell-shaped storage pits (Features 57 and 64). In attempting to follow the outline of the pits, neither of which were clear, there seemed to be an inset or shelf about $15 \mathrm{~cm}$. wide and $70 \mathrm{~cm}$. below the ground surface. The shelf was $15 \mathrm{~cm}$. above the mouth of the pit but could not be traced all around the pit opening. The possible shelf was carefully examined, however, and a short section of a charred log was found lying upon the shelf and imbedded a short distance into the wall. When the other half of the pit was excavated, a second charred 
log was found upon the shelf opposite the first one. Apparent ly the shelf supported a cover over the pit which was held in position by the small log, which was represented by the two ends. The log was charred and represented the only evidence of burning around the edges of the pit. Unfortunately, the possible shelf could not be traced clearly around the pit and was not evident in the cross section. Future work at the site should attempt to clarify the existence of similar features elsewhere。

Several pits of recent origin were also found, and some of the larger ones should be described since they can be confused with the aboriginal storage pits. Three large pits and two smaller ones were found below a heavy concentration of refuse thought to be the scattered remains of a refuse mound located in the cultivated northwest section of the site. Two of the large pits were irregularly shaped, up to $1.9 \mathrm{~m}$. in diameter and $1.5 \mathrm{~m}$. in depth. The third pit was cylindrical shaped, $1.3 \mathrm{~m}$. in diameter and $1.5 \mathrm{~m}$. in depth. A round shaft $0.2 \mathrm{~m}$. in diameter and $1.1 \mathrm{~m}$. deep, evidently an exploratory hole dug with a posthole digger, extended below the rounded bottom of the pit. Another similar pit was found in connection with the test of a refuse mound (Feature 52). The fill of the pits contained some refuse, but the cross section was characterized by thin sloping lenses very unlike the fill in the aboriginal pits. A few relatively recent historic items were found in some of the recent pits. The irregular or cylindrical shape of the pit, the nature of the fill, and the presence of recent artifacts attest to the non-Indian origin of these features. It is possible that they were dug into aboriginal pits, but this seems unlikely since no storage pits were encountered in the tests of refuse mounds. The depth to which the pits were dug can probably be attributed to efforts to prove the tales of buried treasure commonly associated with the Longest Site。 
Attributes of Storage Pits at the Longest Site

\begin{tabular}{|c|c|c|c|c|}
\hline $\begin{array}{l}\text { Feature } \\
\text { number }\end{array}$ & $\begin{array}{l}\text { Diameter: } \\
\text { in } \mathrm{cme} \\
\end{array}$ & $\begin{array}{l}\text { Depth*** } \\
\text { in } \mathrm{cm} .\end{array}$ & Shape & Nature of fill \\
\hline 5 & $90 / 11_{1} 0$ & 105 & be11 & $\begin{array}{l}\text { Light soil with refuse; rodent } \\
\text { disturbances. }\end{array}$ \\
\hline 7 & 105 & 90 & bow1 & Dark soil with sparse refuse. \\
\hline 8 & $55 / 100$ & 100 & bell & Loose ash with refuse. \\
\hline 18 & $77 / 122$ & 107 & bell & Dark soil with refuse. \\
\hline $19 \mathrm{E}$ & $130 / 152$ & 110 & bell & Light soil; nearly sterile. \\
\hline $20 A$ & $150 / 155$ & 72 & bell. & Dark soil; abundant refuse. \\
\hline $20 B$ & $145 / 160$ & 95 & bell & Dark soil; abundant refuse. \\
\hline 21 & $140 / 160$ & $\Psi_{7}$ & bell & $\begin{array}{l}\text { Light soil with abundant refuse; } \\
\text { outline indistinct. }\end{array}$ \\
\hline 24 & $115 / 135$ & 100 & bell & Light soil with sparse refuse. \\
\hline 28 & .110 & 86 & bowl & $\begin{array}{l}\text { Light soil with abundant refuse; } \\
\text { rodent disturbances. }\end{array}$ \\
\hline 29 & $175^{\circ}$ & 73 & bowl. & $\begin{array}{l}\text { Dark soil with refuse; rodent } \\
\text { disturbances. }\end{array}$ \\
\hline 33 & $150 / 167$ & 80 & be11 & Dark, soil with refuse. \\
\hline 36 & $80 / 112$ & 63 & bell & Dark soil with refuse. \\
\hline 37 & $110 / 122$ & 52 & beil & Dark soil with refuse \\
\hline 38 & $130 / 170$ & $45+$ & bell. & $\begin{array}{l}\text { Dark soil containing baked-clay } \\
\text { fragments; not completely excavated. }\end{array}$ \\
\hline 39 & 130 & 55 & bowl. & Dark soil with refuse. \\
\hline 57 & $150 / 180$ & 127 & bel1 & Light soil; almost sterile. \\
\hline 59 & $105 / 135$ & 137 & bell & $\begin{array}{l}\text { Dark soil; abundant refuse; } \\
\text { recent intrusion. }\end{array}$ \\
\hline 61 & $130 / 170$ & 148 & be11 & Dark soil with refuse。 \\
\hline 62 & 130 & 75 & bowl & Dark soil; abundant refuse. \\
\hline
\end{tabular}




\begin{tabular}{|c|c|c|c|c|}
\hline $\begin{array}{l}\text { Feature } \\
\text { number }\end{array}$ & $\begin{array}{l}\text { Diameter* } \\
\text { in } \mathrm{cm} \text {. }\end{array}$ & $\begin{array}{l}\text { Depth**: } \\
\text { in } \mathrm{cm} \text {. }\end{array}$ & Shape & Nature of fill \\
\hline 63 & $\mathbb{1}_{1} 0 / 155$ & 1.18 & bell & Light soil with refuse。 \\
\hline 64 & $90 / 160$ & 155 & bel1 & Dark soil; abundant refuse。 \\
\hline 65 & $100 / 190$ & 115 & bell & Light soil with sparse refuse. \\
\hline 66 & $105 / 150$ & 155 & bel1 & $\begin{array}{l}\text { Dark soil with sparse refuse; } \\
\text { fill loose from pit walls. }\end{array}$ \\
\hline $67 \mathrm{~B}$ & $120 / 1_{4} 0$ & 135 & bell & Dark soil; abundant refuse. \\
\hline 68 & $135 / 165$ & 120 & bell & Dark soil; abundant refuse. \\
\hline 69 & $115 \times 170$ & 80 & bowl & Ashy soil; abundant refuse。 \\
\hline 70 & $150 / 175$ & 142 & bell & $\begin{array}{l}\text { Light soil with sparse refuse; } \\
\text { outline indistinct. }\end{array}$ \\
\hline 71 & $115 / 164$ & 1.15 & be11 & Dark soil with sparse refuse. \\
\hline
\end{tabular}

*First number is the average of minimum and maximum dimensions at the top of the pit (a.l truncated by plowing) unless the pit is notably asymmetrical, when both dimensions are given separated by an $x$. Diameters of the bottoms of bell-shaped pits follow slash marks L.

*: Depth to bottom of the pit below the present surface of the ground; includes plow zone averaging about $30 \mathrm{~cm}$. in thickness.

Summarized Dimensions in $\mathrm{cm}$ o of Storage Pits at Longest Site

\begin{tabular}{|c|c|c|c|c|c|c|}
\hline \multirow[b]{2}{*}{ Shape } & \multicolumn{2}{|c|}{ Diameter at top } & \multicolumn{2}{|c|}{ Maximum Diameter } & \multicolumn{2}{|c|}{ Depth } \\
\hline & Range & Mean & Range & Mean & Range & Mean \\
\hline bel1 & $55-150$ & 1.18 & $100-190$ & 151 & $52-155$ & 114 \\
\hline bowl & $105-175$ & 132 & $105-175$ & 132 & $55-90$ & 77 \\
\hline
\end{tabular}

Note: the dimensions of the bell-shaped pits are skewed toward the larger sizes. 
Shape and Probable Origin of the Pits at the Longest Site

\begin{tabular}{lcccc} 
Shape & Aboriginal & Uncertain & Recent & Totals \\
\cline { 2 - 3 } & 23 & 1 & 0 & 24 \\
bell & 6 & 8 & 2 & 16 \\
bowl & 0 & 7 & 3 & 10 \\
basin or lens & 0 & 2 & 2 & 4 \\
irregular & 0 & 0 & 2 & 2 \\
cylindrical & 0 & 11 & 0 & $1]$ \\
$\begin{array}{l}\text { unknown (not } \\
\text { completely excavated) }\end{array}$ & 29 & 29 & 9 & 67 \\
Totals & & & &
\end{tabular}




\section{BURIALS}

Seven Wichita Indian burials were found on the southern portion of the site. They are the first wichita graves to be found during controlled excavations and merit relatively detailed descriptions. Mr. Longest reported that other burials had been found by plowing in past years, on both sides of the ravine dividing the site and along the bluff of the south part of the site, but no precise information is now available, Our search for graves necessitated an extensive amount of trenching before any were found, and those recovered came from scattered areas along the south edge of the ravine and along the bluff on the south part of the site. This suggests that the graves are widely distributed at the site in different localities along the edge of the main occupational area. All of the excavated graves contained single, primary, extended burials oriented with the head in a general east direction. The bodies had been placed on their back or left side, and in a few cases the legs were slightly flexed with the knees toward the south. The shallowest graves were only a few inches below the surface and had been damaged by cultivation, while the deepest and best preserved burials were in an uncultivated area. Although the latter burials were $30 \mathrm{~cm}$. below the present ground surface, the top foot of overburden consisted of recont sheet wash containing relatively recent historic debris from farming or homestead activity。

Burial 1 (Fig. 37) was so extensively damaged by plow ing that only the area between the abdomen and the knees was partly preserved. The grave was that of an adult male, who was turned slightly toward the left side with the legs slightly flexed. The outline of the burial pit, about $30 \mathrm{~cm}$. in width, was visible near the bottom of the grave. Located in a tight cluster near the knees, perhaps originally contained in a perishable bag or other container, was a triangular knife of Alibates flint, a diamond-shaped, alternately-beveled $\mathrm{knife}$ (Harahay) of Kay County flint, 2 native-made gunflints, 2 concave scrapers or spokeshaves, 18 moderately large flakes of Edwards flint, 2 fragments of sheet brass, and 13 iron fragments including parts of a heavily rusted gun barrel and knife blade. A few traces of red ochre were scattered through the cluster of artifacts, and a large stain of similar material occurred nearby. A crushed, native-made pottery vessel lay on its side in the abdominal area. The shelltempered vessel is about $13 \mathrm{~cm}$. high and $15 \mathrm{~cm}$. in diameter. It has a globular body with a small flat area at the base and a slightly flaring S-shaped rim. The lip and rim are not decorated, but the upper part of the body has groups of irregular parallel incisions arranged in a band of opposed triangles. The vessel has general affiliations with late 
Caddoan pottery, but it does not fit into any already established type. At the left of the pelvis lay a lump of ochre, an unfired ball of clay, a mussel shell, a lump of native asphalt, a small blue gilas bead, and a smooth pebble coated with red ochre. The burial also contained a fragmentary elbow pipe of soft red-colored siltstone. The plowed dirt surrounding the grave yielded 2 small brass rings (possibly from chain mail), a lead ball, 2 flint flakes, 8 metal fragments, and a small blue glass bead.

Burial 2 consisted of the legs and lower part of the left arm of an adult female (?) buried in an extended position. The rest of the burial had been destroyed by cultivation. Two large mussel shell halves lay near the feet.

Burial 3 (Fig. 38) was a 30 - to 40-year-old female lying extended, but with the legs slightly flexed. The grave was undisturbed, and the skeleton was in fair condition; the stature estimate is $170 \mathrm{~cm}$. Most of the 33 small blue glass beads found with the burial were in a small area around the middle of the lower right leg. Some red ochre was found scattered in the soil near the skull.

Burial 4 (Fig. 39), a female over 40 years of age, was buried in an extended position, on the back. A large disk-shaped knife or chopper of tabular sandstone and a smoothed, elongated stone of siliceous gneiss lay in the upper abdominal area. The elongated stone has a subrec= tangular cross sect ion measuring 5 by $8 \mathrm{~cm}$. and is $30 \mathrm{~cm}$. long. It has a high polish on one broad surface and red ochre stains on one end. Although the function of the diskshaped stone and the elongated specimen remains uncertain, these may have been hidewworking tools. A ball of soft, sandy carbonate (ash?) lay near one side of the neck, two fragments from an iron kettle were found above the left hip, and fragments of a heavily rusted iron knife were found $20 \mathrm{~cm}$. from the left elbow. No glass beads were found with Burial 4 .

Burial 5 is represented by a 20 to 25 year-old male that lay on the left side with the legs slightiy flexed. Small pieces of cloth on the upper part of the body were preserved by copper salts from small copper wires that had been woven into the fabric. An ornament composed of glass beads and a small perforated shell disk was found in the ear area on both sides of the skull (Fig.40). A small triangular-shaped silver alloy ornament, perforated in two corners, was located near the temple area. The ear ornaments on the left side of the skull, including about 40 glass beads, were removed with the skull in situ for potential exhibit. Other objects found with the burial were a handwrought iron nail from near the skull, a $13 \mathrm{~cm}$. section 
of cane from underneath the skull, 3 sandstone shaft abraders and a lump of ochre from under the back, a handstone found underneath the feet, and 43 glass beads from various places in the grave.

Burial 6 (Fig. 4I) consisted of a poorly-preserved female, probably between 20 and 25 years of age, who was buried on her back in an extended position. A diamond-shaped knife of Edwards flint and a rectangular glass mirror lay on the upper arm. Another rectangular glass mirror lay near the right hip. At the left elbow was a catlinite elbow pipe having an inlaid metal ferrule on the stem. The ferrule is continuous with four $V$-shaped inlays around the stem of the pipe. Three iron arrow points with traces of wood adhering to the stems and several unidentified scraps of iron lay near the upper left leg. Within the grave were 97 small blue or white glass beads.

Burial 7 contained no human bones or teeth. The feature is interpreted as a burial because of the regular placement of artifacts within an elongated faintly stained area $30 \mathrm{~cm}$. across (Fig. 42) and because of its proximity to the other graves. Most of the artifacts were recovered near the eastern end of the stained area where, judging from the other burials found, the upper part of the body was located. In the prem sumed head area was a concentration of glass beads, some of which were still in short alignments. Among the 636 glass beads recovered were 2 unusual disk-shaped, faceted, purple beads with two parallel perforations running through the maximum diameter. A variety of other bead types are represented in the sample. A tight cluster of four elbow pipes lay in the left shoulder area. Three of the pipes are made of clay and are not decorated. The fourth pipe is a small catininte elbow pipe decorated with parallel oblique incisions on the bowl. Also found in the grave were 4 metal hawk bells, a small brass pendant having a gilass set, and a turtle carapace.

\section{FORT IFICATION}

Structure 7. The north portion of the Longest site was subjected to unusually deep plowing in the spring of 1967 , and a large oval-shaped ring could be observed from the air and on aerial photographs (Fig. 26). On the ground this feature was not so obvious although its approximate location could be traced by bone refuse. Tentative measurements indicate an oval ring about 80 by $120 \mathrm{~m}$. (Fig。 30). A test trench placed across one side of the ring revealed a ditch nearly $120 \mathrm{~cm}$. deep, with sloping sides, and filled with soll and refuse (Fig. 43). The ditch is certainly to be associated with a fortification although no postmolds indicative of a palisade were found. The 
exploratory test, however, was not extensive enough to confirm either the presence or absence of a palisade. The excavation of this ditch and associated features remains as a major project for further work at the site.

It should be mentioned that this newly discovered feature coincides with the position of the fortification attacked by a Spanish army under Parrilla in 1759, according to the recon struction based upon historical documents made by Duffield (1965.

\section{ARTIFACTS RECOVERED FROM THE LONGEST SITE}

The following notes are devoted chiefly to artifacts that were found at the Longest Site during the second season's work of 1966. It does not include certain artifacts such as tabular scrapers, some ground stone items, or bone artifacts. These items are described elsewhere along with similar objects from the first season's work at both the Longest Site and the Upper Tucker site in Texas. This preliminary information arises from the fact that it was the original intention to integrate all artifact data from both the Longest site and related sites in Texas (Upper Tucker) into a single account。 While this has been done for certain specific artifacts, the final collation of data for all materials recovered has not been completed at the time of presenting this preliminary report. Consequentiy, the following descriptive accounts are subject to additions or modifications as further research continues.

\section{Chipped Stone Artifacts}

\section{Small Projectile Points}

Seven small unnotched points (Fig. 44, $A-F$ ) were recovered at the Longest site during the 1966 excavations. Four specimens are triangular-shaped with excurvate edges and a straight to slightly concave base. The materials from which the points have been made are Alibates flint, Kay County flint, quarisite and unidentified filint. The dimensions of these four points are as follows:

Range in $\mathrm{mm}$. Mean in $\mathrm{mm}$.

$\begin{array}{lrr}\text { Length } & \text { ca. } 11-27 & \text { ca. } 20 \\ \text { Width } & 9-16 & 12 \\ \text { Thickness } & 2-3 & 3\end{array}$


The above four points would be included in the Fresno type which is characteristic of late prehistoric and early historic cultures throughout much of North America (Bell, 1960: 44).

Three of the unnotched points (Fig. 44, E-F) are pentagonal-shaped with nearly straight edges and a straight or concave base. All appear to be made from Alibates or Tecovas flint. Their measurements are:

\begin{tabular}{|c|c|c|}
\hline & Range in mm. & Iean in $\mathrm{mm}$ \\
\hline Length & ca. $18-28$ & ca. 24 \\
\hline Width & $10-14$ & 12 \\
\hline Thickness & $2-4$ & 3 \\
\hline
\end{tabular}

The elongated shape, moderately fine workmanship, and recurved edges with a slight constriction displayed by one of the specimens are suggestive of the Talco type which occurs in late prehistoric contexts (Suhm and Jelks, 1962: 289). The other two specimens do not suggest the Talco type nor any other named type. All three of them, however, may be variants of the Fresno type, such as those found at the historic Pearson Site, Rains County, Texas, which have "a definite angle in the outline of the blade edges ..." (Duffield and Jelks, 1961: 19-20).

A small, carefully flaked, corner-notched point (Fig. 44, G) was found in Test 37 in the vicinity of Burials 2 and 4 on the south portion of the site. The blade is triangular with finely serrated slightly excurvate edges. The shoulders are barbed, and the stem is slightly expanding. The tip of the base appears to have been broken so that, originally, it may have been pointed rather than straight. The point is made of tan-colored flint and measures $23 \mathrm{~mm}$. in length, $15 \mathrm{~mm}$. in width, and $2 \mathrm{~mm}$. in thickness. The point has characteristics of both the Bonham and Perdiz types, but identification remains questionable.

\section{Large Projectile Points}

One complete point and three fragments were found during the 1966 excavations. The complete specimen (Fig。 44, H) is side-notched with a triangular blade having straight edges. The shoulders are subangular, and the stem is fan-shaped. The specimen is made of a mottled gray flint and measures $45 \mathrm{~mm}$. in length, $16 \mathrm{~mm}$. in width, and $17 \mathrm{~mm}$. in thickness. The point was found with early 20th-century debris in the fill of an abandoned cellar (Feature 50), and its relationship to the 
site is questionable. The point can probably be assigned to the Palmillas type, which is usually associated with late Archaic complexes (Suhm and Jelks, 1962: 229).

A broken large point (Fig. 44, I) was found in Test 34. $2 \mathrm{~m}$. from a storage pit (Feature 57) on the south portion of the site. The point appears to have had a deep side notch or basal notches, perhaps a triangular blade with convex edges, barbed shoulders, and a slightly expanding stem with a concave base. It is made of a mottled gray fossiliferous fint measuring $7 \mathrm{~mm}$, in thickness. The specimen when complete may have been up to $60 \mathrm{~mm}$. in length. It is probably an example of the Marshall type which is associated with middle Archaic cultures in OkIahoma and Texas (Be11, 1958: 44)。

A fragment of a large point (Fig。 44, J) was the only artifact found in Test 30 located in the north section of the site. It has an angular shoulder with a straight stem and base. The base of the stem has been ground smooth. Perhaps it could be assigned to the Yarbrough type. which is a late Archaic form in Oklahoma and Texas (Suhm and Jelks, 1962: 261).

Another fragment (Fig. 44, K) appears to be from a con= tracting - stemmed point having a triangular-shaped blade: It was recovered from a cellar filled with early 20th-century debris (Feature 51). The specimen is made of brown Ogallala chert and measures $6 \mathrm{~mm}$. in thickness. It is probably a Gary point associated with late Archaic or later cuItures (Suhm. and Jelks, 1962: 197).

\section{Point Fragments}

There are four tip fragments, two of which appear to be from large projectile points. One is of a tan filint, $8 \mathrm{~mm}$. in thickness, and was found in a refuse mound (Feature 54). The other is made of a gray silicified sandstone, $8 \mathrm{~mm}$. in thickness, and was found in a cellar filled with 20 th-century refuse (Feature 51)。

The other two tip fragments may be from projectile points or some other artifact. They are made of a dark gray flint and are from 2 to $4 \mathrm{~mm}$. in thickness. One is from a pit (Feature 62), and the other was found within the plow zone (Test 42) in the northeast section of the site.

Knives

Al1 three knives were found with burials, The only broken specimen (Fig. $44, L$ ) is a diamond-shaped, alternatelyo 
beveled Harahay knife from Burial 1. It measures $90 \mathrm{~mm}$. in

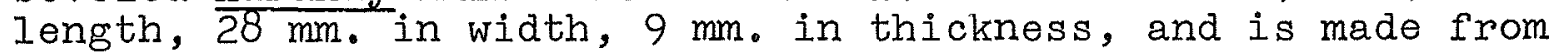
Kay county flint.

A second knife from Burial 1 (Fig. 44, M) is triangular in shape with a bevel along the long edge. It is $85 \mathrm{~mm}$. in length, $39 \mathrm{~mm}$. in width, $8 \mathrm{~mm}$, in thickness, and is made from Alibates flint.

The third specimen (Fig. 44, N) was found in Burial 6. It has broadly-convex edges and rounded ends. The knife measures $76 \mathrm{~mm}$. in length, $27 \mathrm{~mm}$. in width, and $10 \mathrm{~mm}$. in thickness. The material is a dark gray flint covered with a heavy tan patination. It should be noted that the knife was resharpened after the patination had formed, indicating that it was made long before the Wichita obtained the specimen.

\section{End Scrapers}

The eight end scrapers (Fig. 44, $0-S$ ) were made from large flakes which usually retain some of the cortex of the original nodule. They are unifacially chipped and most have a large striking platform at one end opposite the steeply retouched and often polished scraping edge. The specimens have varying amounts of steep retouch along one side, and one shows crushing and use-polish in this area. Five of the specimens are made of Kay county flint, one is made of Edwards flint, and two are made of an unidentified gray-colored flint. Their measurements are:

\begin{tabular}{lcc} 
& Range in mm. & Mean in mm. \\
\cline { 2 - 3 } Length & $38-63$ & 50 \\
Width & $36-42$ & 38 \\
Thickness & $9-18$ & 14
\end{tabular}

Flake Scrapers

Six flake scrapers made of Edwards flint (Fig. 44, T-Y) were included in the cache of flakes and gun flints found with Burial 1. All of them have iron stains on them. Three have fine unifacial flaking along one or more convex or concave edges. The other three specimens have been extensively worn by crushing on one or more concave edges. One of these also has a projection on one end, which is also crushed and battered. It appears that the latter three examples were used as strikea-lights. 
Waste Material or Debris

The chipped stone debris has not been completely studied at this time. The waste material found in one refuse mound (Feature 52) has been tabulated according to the kind of material, but no significant trends within the mound were noted. Since there are some distributional differences in artifacts, however, further work with waste materials should be undertaken. 
90

Chipped Stone Artifacts

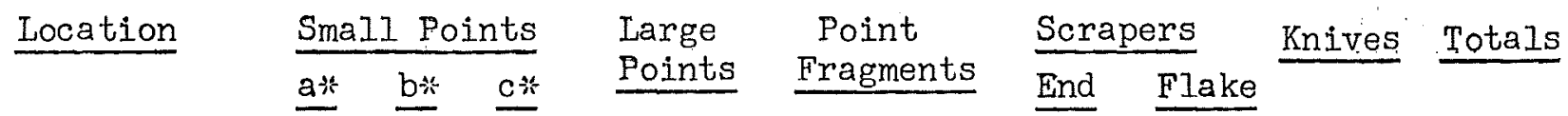

South

Burial I

$\begin{array}{lll}6 & 2 & 8\end{array}$

Burial 6

11

Test 34

1

Test 37

1

Northwest

Feature 12

1

Feature 50

I

1

Feature 511

1

1

3

Feature $52 \quad 1$

1

Feature 53

1

Feature 54

1

1

Feature $55 \quad 12$

$\operatorname{Surf}_{c} C$

1

1

Test 30

1

1

Northeast

Test 42

1

1

Surf。D

1

1

Feature 62

11

2

Feature 64

1

1

Feature 68

1

1

Test 43

1

1

Feature 67B I

1

Totals

$\begin{array}{llll}4 & 3 & 1 & 4\end{array}$

4

$\begin{array}{lll}8 & 6 & 3\end{array}$

33

* a, small triangular points; b, small pentagonal points; c, small cornernotched points. 


\section{Pottery}

Aboriginal pottery is not plentiful at the Longest site. In the 1966 excavations, 173 pottery sherds and I nearly complete vessel were recovered. Included in this study of the pottery are two large decorated sherds found on the site in 1963 by Mr. James A. Marler. Pending further analysis of the Longest Site pottery, the above sample has been handled as if it represents but a single pottery ware.

In general, the Longest Site pottery (Figs. 45, 46) has smoothed to polished surfaces, a compact paste, and is of moderate thickness of 7 to $8 \mathrm{~mm}$. Three small sherds with a bone-and-sand temper have a brushed surface. The tempering material includes bone, shell, sand, or various combinations of these; some clay grit or grog temper may be present. Most of the 20 rim sherds are small in size, but the rim form can be noted to vary from slightly outflaring to slightly inflaring profiles. The lip is turned outward on 11 of the examples. The only specimen that is sufficiently complete to indicate the vessel form was found in association with Burial I (Fig。 46). This vessel has a squat globular-shaped body resting on a small flat disk base. There are two other sherds indicating a flat disk base, and one sherd is from a slightly concave disk base.

The paste and form characteristics of the Longest Site pottery contrast with a small sample (16 sherds) from the prehistoric Orchard Site located immediately to the north. The Orchard pottery is relatively thick ( $9 \mathrm{~mm}$, average), moderately coarse-textured, exclusively shell-tempered, straight rimmed, and with flat lips.

The only decorative techniques found on the Longest Site pottery are engraving and incising. Engraving occurs on 26 sherds or 15 per cent, and incising is confined to the single vessel from Burial 1. The decorated sherds tend to be more highly polished than the others; four of the decorated sherds are rims.

Rim form, tempering, and the presence or absence of decoration do not appear to have any distributional or assom ciational significance within the site. There is a tendency for decorated sherds to have sand tempering, and only one sherd having a decoration lacks sand temper. The following table indicates the decoration and tempering correlations: 
Decorated Undecorated Total

Sand temper only

Other temper including combinations with sand
19

8

27
29

119

148
48

127

175

Design elements include parallel lines, hachuring, cross hatching, ticking, triangles, and scrolls. The engraved lines contain white pigment on several sherds, and in two instances there are traces of a red wash.

With the exception of the nearly complete vessel from Burial 1, the decorative motifs can not be satisfactorily reconstructed. The engraved motifs are: zones of hachuring bounded by one or more incised lines ( 4 sherds of 2 vessels), a zone of crosshatching enclosed by a single line (10 sherds of 5 to 7 vessels), and scrolls (2 sherds). Six distinctive sherds and the vessel merit separate description.

One small rim sherd (Fig. $45, N$ ) is $7 \mathrm{~mm}$ 。 in thickness and has a compact paste tempered with sparse sand, bone, and shell. There is a broad horizontal engraved line $5 \mathrm{~mm}$. below the lip, and a zone of crosshatching below the line. The sherd can probably be assigned to Womack Engraved because it has a dark, highly polished surface with an engraved line encircling the rim, with attached crosshatched areas. The lip is rounded, however, rather than flat, and the rim profile is nearly straight rather than incurved. In these latter two traits, this sherd varies from known Womack Engraved character-

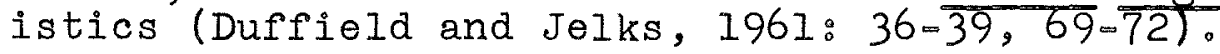

Another small rim sherd (Fig。 45, 0) is $6 \mathrm{~mm}$. in thickness with a compact paste containing fine sand, bone, and shell temper. The decoration consists of a horizontal engraved line from which a small plain triangle is suspended. Both surfaces are well polished, and there are traces of a red film. The rim flares outward, and the lip is rounded and slightly turned outward. The sherd suggests Avery Engraved and Natchitoches Engraved types although the tempering is not characteristic (Suhm and Jelks, 1962: 1, 113)。

The two largest sherds available are those collected by Marler as mentioned above. One sherd ( $F i g$ 45, R) was collected from a relic-hunter's pit in the refuse mound designated Feature 54。 It is $7 \mathrm{~mm}$ 。 ir thickness with a compact paste containing fine sand, bone, and shell tempering. Both surfaces are polished; the rim flares slightly inward, and the lip is rounded. There are two horizontal engraved lines at the top edge of the rim, tick marks occur along the top of the lower line, and a series of oblique parallel slightly curved lines extend downward from the lower line. Two of these oblique lines are connected near one edge of the sherd. 
The sherd does not seem to closely resemble any known type, but varieties having tick marks and broadly curved lines truncated by one or two horizontal lines at the top of the decorated area include Haley Engraved, Patton Engraved, and Taylor En= graved (Suhm and JeIks, 1962:61, 117, 149-152). Both the Haley Engraved and Taylor Engraved types were fairly widely distributed during late prehistoric times in the western part of the Caddoan area. Patton Engraved is considered as a marker type for historic Hasinai in northeastern Texas, and it is most similar to the sherd concerned.

The other large sherd (Fig. 45, S) was collected by Marler to the south of Feature 54 on the slope adjacent to spring Branch, which divides the site. The sherd consists of a basal disk and the lower part of the body wall. The disk base mea sures $65 \mathrm{~mm}$. in diameter and $12 \mathrm{~mm}$. in thickness with the body walls being considerably thinner and measuring from 6 to $7 \mathrm{~mm}$. in thickness. The paste is compact and tempered with sand. The sherd is decorated with heavy engraving that still contains a white pigment. Four arcs with exterior tick marks are evenIy spaced around the base. The sherd is broken along the en graved line in all but one area, where the edge of a second smaller arc with exterior tick marks is visible. In the spaces between each arc, with one exception where the sherd is broken close to the base, are pendant fingeralike areas filled with crosshatching. The sherd appears to be from a vessel of Patton Engraved, a marker type for the historic Hasinai (Suhm and Jelks, 1962: 117)。

One distinctive body sherd (Fig, 45, T) has three rows of pendant triangles, all pointing in the same direction. Two rows of triangles are hachured, and one row is crosshatched. A.1 of the lines contain a white pigment, and there are traces of red pigment in the outer row of triangles. The sherd meaw sures $5 \mathrm{~mm}$. in thickness and has a smooth polish and a como pact paste tempered with sparse sand and bone. The design of rows of hachured triangles is a common motif on several pottery types including Hempstead Engraved, Ripley Engraved, Sanders Engraved, and Womack Engraved TSuhm and Jelks, 1962: 69, 127-130, 137; Duffield and Jelks, 1961: 37). The examples described, however, have triangles confined to one row or two opposing rows rather than three. The above types, with the exception of Womack Engraved are prehistoric: Womack Engraved is found at protohistoric and historic sites.

A nearly complete vessel (Fig. 46) was found in association with Burial 1. It is a squat globular jar measuring 120 $\mathrm{mm}$. in height and $155 \mathrm{~mm}$. in maximum diameter. The wall thick = ness ranges from 5 to $8 \mathrm{~mm}$. with an average of about $6 \mathrm{~mm}$. The base is a small flat disk $38 \mathrm{~mm}$. in diameter; the rim has an S-shaped flaring profile, and the lip is turned outward. 
A rather carelessly incised decoration extends from the lower part of the rim across the shoulder to the sides of the vessel. The motif is a series of irregular opposed triangular areas composed of straight or slightly curving parallel lines. The design most closely resembles examples of Maydelle Incised, a late prehistoric ware widely found in northeastern and northern Texas (Suhm and Jelks, 1962: 103).

The total amount of pottery found at the Longest site is rather limited, and further studies are required. It is somewhat surprising that the type Womack Engraved is not better represented, as it is considered to be the characteristic ware associated with the Norteño Focus. Resemblances are also to be noted to Natchitoches Engraved and Patton Engraved, both of which occur late and extend into historic times. obviously, considerable work must be done with the various ceramic wares which were still in use at the time of White contact. From the small amount of pottery found at the Longest site, it would appear that trade goods (metal containers, for example) were already replacing native-made containers. 


\section{Clay Figurines}

Several fragments (14) of crude unfired clay figurines (Fig. 47, A-J) were found in the excavations. No doubt others were overlooked or mutilated beyond recognition during the digging as they are soft and fragile when in the ground. After removal from the soil, however, if they are dried slowly the clay will harden with little or no crumbling. The figurines are typically made of a brown or dark magenta-colored clay which is readily recognizable when scraped or cut during the excavation. Many of the specimens contain fine flecks of charcoal which produce a dark-colored smear across a scraped or cut surface.

The most distinctive figurines found during the 1966 exw cavations appear to represent birds, perhaps owls. These are represented by subrectangular tablets with slight constrictions at the neck (Fig. 47, A-C). The eyes and mouth are represented by incisions and gouging, and one example has an upturned nose or beak. There are four specimens of this kind of clay figurine; they range in size from 22 to $32 \mathrm{~mm}$. in width and from 12 to $17 \mathrm{~mm}$. in thickness. The length cannot be determined as all four examples are broken or damaged. Two specimens are broken across the body, but the heads are complete except for minor damage caused during recovery. A third specimen appears to be the head and upper portion of the body, but the face is obliterated. The fourth example may represent the neck and upper section of another bird.

A fragment representing part of the body of a quadruped is suggested by a short oval section having two penetrating holes at one end where sticks had been inserted to serve as legs. The body is $23 \mathrm{~mm}$. high and $18 \mathrm{~mm}$. in thickness; the irregular holes are $2 \mathrm{~mm}$. in diameter and $14 \mathrm{~mm}$. deep.

A cylindrical fragment having small crushed bone inclusions has a rough-sided hole $23 \mathrm{~mm}$. deep in one end suggesting that it may be a fragment from another figurine. It measures $11 \mathrm{~mm}$. in diameter. There are four other fragments which contain one or more irregular holes as if for the insertion of sticks, but they do not have a recognizable form. 
There are four conical-shaped objects (Fig. 47, F-1), the largest of which resembles the end of a bison horn with a maximum diameter of $46 \mathrm{~mm}$. The other three specimens are straight; two of them are broken on the ends opposite the tip, and the third is subconical. These latter examples range from 8 to $14 \mathrm{~mm}$. in diameter.

A number of small and/or irregular lumps (60) of the distinctive-colored, unfired clay used for figurines were collected. Some of these are most certainly parts or whole examples of former figurines. Such specimens, when found in a localized spot, were counted as a single object since specimens often crumbled or were crushed during excavation.

Unbaked clay figurines are a characteristic artifact at the Longest site and other protohistoric sites in the vicinity of Spanish Fort, Texas. They also occur at a number of late prehistoric and historic sites in the southern and central Plains (Newell and Krieger, 1949: 150-1; Pillaert, 1963: 32; Steen, 1955). Both steen and John C. Ewers (personal communication) suggest that the figurines were toys, but Marvin F. Kivett (personal communication) points out that they are frequently associated with ash deposits at Pawnee sites and may have some ceremonial significance. Although a number of the figurine fragments, including the two most complete specimens, recovered during the 1966 season were found in heavy ash concentrations, this association may be related to preservation factors or to vagaries of sampling.

\section{Unfired Clay}

In addition to the untempered, magenta-colored clay used for the figurines, occasional pieces of gray or magentacolored clay containing crushed bone were found. These pieces (10) tended to be relatively large and may represent the raw material from which other clay items were made. Two specimens have been rolled into long loaf-shaped forms, the largest measuring about $70 \mathrm{~mm}$. in diameter and $200 \mathrm{~mm}$. in length. An irregular ball of gray clay about $35 \mathrm{~mm}$. in diameter and containing some sand was associated with Burial 1.

\section{Mud Dauber Nests}

Numerous fragments of clay mud dauber's nests (46) were found in the excavations. These can be confused with pieces of fired clay from a wattle-and-daub construction or with a figurine fragment. No actual daub has yet been recovered from the Longest site, but mud dauber's nests are rather common. Specimens have been recovered from storage pits, the fill of structure 1 , and in the refuse mounds, especially Feature 52. The nests found on or close to the floor in structure 1 may have been attached to the superstructure of the house. The significance of these items elsewhere remains speculative. 


\section{Pipes}

The available sample of pipes, complete and fragmentary, includes 116 of native clay or stone, plus one kaolin pipe of Euro-American origin. All of the specimens recovered dur. ing the 1966 season and a few found during the first season are included. This does not include any specimens from the Upper Tucker site in Texas.

\section{Native Clay Pipes}

Ceramic pipes (Fig. 47, K-Q) are represented by 3 complete specimens (Burjal 7) and 90 fragments. The complete specimens and four large bowl fragments are elbow pipes in which the angle of the bowl with the stem varies from a right angle to a slightly obtuse angle. The outside angle rhere the bowl joins the siem varies; some are gently rounded here, and some have a slight spur. The pipe bowls vary from slight Iy bulbous to flaring, with a height measuring from 30 to 61 $\mathrm{mm}$. and averaging around $50 \mathrm{~mm}$. The maximum diameter of the bowls ranges from 20 to $43 \mathrm{~mm}$; the thickness of the bowl ranges from 4 to $9 \mathrm{~mm}$., averaging about $7 \mathrm{~mm}$. The stems tend to have a flaring exterior, and in contrast to the bowls they are relatively short and thick walled. The stem length varies from 24 to $44 \mathrm{~mm}$. and averages about $40 \mathrm{~mm}$. The outside stem diameter ranges from 20 to $36 \mathrm{~mm}$. While the inside diameter varies from 10 to $11 \mathrm{~mm}$. The stem holes are straight and slightly tapering, and their fairly uniform diameter would facilitate interchanging wooden or cane stems. The thick stem walls would also serve to strengthen the stem section against splitting when inserting the mouthpiece。

All of the specimens have a compact paste which has a fine but sparse tempering. The tempering material includes shell, sand, bone, and various combinations of these. The paste tends to be gray or black in color, but buff and reddishbrown are common. The exterior surface color is usually black or gray, but buff colored examples are present. Both the exterior and interior surfaces are carefully smoothed, and the exterior surfaces are often highly polished. Several bowl fragments still have a thin layer of carbonized material clinging to the interior wall, but this residue has not been analyzed.

One small sherd, believed to be part of a pipe, has some facets from 3 to $4 \mathrm{~mm}$. across upon the surface; otherwise none of the specimens is decorated.

\section{Stone Pipes}

The sample of stone pipes (Fig. 47, s - CC) includes 2 
complete pipes, 3 large fragments, and 18 small fragments. All of the larger specimens are elbow pipes with flaring bowls and a relatively long, straight stem. A bulbous-shaped bowl and a "micmac"-type bowl are suggested by two small fragments. Materials used for making the pipes include gray siltstone (18 specimens), red "pipestone" or Catlinite (?) (2 specimens), pale-red siltstone ( 1 specimen), limonite ( 1 specimen), and hematite ( 1 specimen). In addition, there are 10 small fragments of red "pipestone" which may be residue from pipe manufacturing. Several of the fragments have cutting or saw marks, and all were recovered in or near Feature 64.

The largest specimen (Fig. 47, T) is a complete elbow pipe of red pipestone with a metal ferrule (Burial 6). The moderately flaring bowl is $57 \mathrm{~mm}$. high, $14 \mathrm{~mm}$. in maximum diameter, and has a bore diameter of $18 \mathrm{~mm}$. at the top. The slightly expanding stem is $80 \mathrm{~mm}$. in length $165 \mathrm{~mm}$. without the metal ferrule), $25 \mathrm{~mm}$. in diameter, and has a 9-mm. bore stem-hole. The stem is encircled with a series of four pairs of converging grooves originating at the end of the stem. The grooves are 2 to $3 \mathrm{~mm}$. wide and about $2 \mathrm{~mm}$. deep, and were filled with metal extending from the ferrule. Chemical analysis indicates that the metal is primarily composed of lead and zinc, a "white metal" alloy. Some organic material was preserved in the bore of the ferrule; this may be the remains of a wooden stem, but it has not been analyzed.

Another whole elbow pipe made of red "pipestone" (Fig. 47, U) is remarkable small (Burial 7)。 The bowl and stem are straight-sided and measure about the same length (16 mm. and $18 \mathrm{~mm}$ e respectively). The bowl is 13 by $14 \mathrm{~mm}$. in diameter, and the stem is 12 by $13 \mathrm{~mm}$. in diameter. All wall thicknesses are about $2 \mathrm{~mm}$. The left side of the stem section is decorated with three parallel engraved lines running obliquely from the end of the stem toward the bottom of the pipe; there are four similar lines on the right side. A short line near the end of the stem connects the upper ends of the top oblique lines, and there is a short gash at the juncture of the stem and bowl on the right side above the oblique lines.

A complete pipe bowl (Fig. 47, W), is shattered by a direct hit during excavation, is made of gray siltstone. The bowl is 43 by $45 \mathrm{~mm}$. in maximum diameter, tapering to $27 \mathrm{~mm}$. in diameter at the top of the stem. The walls of the bowl are between 8 and $9 \mathrm{~mm}$. in thickness. The bowl has been decorated by two bands or rows of carelessly executed crosshatched triangles which encircle the bowl. There are six triangles in the top band, including a large one on the side facing the smoker. The bases of the triangles in the top row extend to the lip of the bowl, and an encircling line $2 \mathrm{~mm}$, below the lip cuts across them. The lower band consists of four triangles 
with their bases placed between the apexes of the upper row except on the side facing the smoker, where they are absent.

A tiny bowl fragment of a gray siltstone pipe is engraved with a straight line having closely spaced tick marks on one side and saw-tooth lines on the other.

A fragmentary elbow pipe made of a pale-red siltstone has a subangular stem cross section, and the bore for the bowl appears to extend through the base of the pipe (Burial 1)。 The specimen, however, is so badly weathered that it is not clear to what extent the details of form reflect workmanship or natural erosion.

One small fragment from the lower part of a pipe bowl is made of a mottled light- and dark-brown limonite. In cross section, the bowl fragment is a flattened oval $15 \mathrm{~mm}$. in thickness; it is elongated in a direction parallel to the stem. It has a complex engraved design including rows of $X^{\prime}$ 's between parallel lines, long rectangular blank areas, and a central rectangular design element which includes a central excised area and diagonal lines across the corners.

There appears to be no significant distribution differences in form or material for the stone pipes found at the site on the basis of this sample.

\section{Euro-American Clay Pipe}

A bowl fragment of a white kaolin trade pipe (Fig. 47, R) was found in Feature 5, a storage or trash pit. The bowl ap pears to have been decorated with three or four vertical pairs of converging flutes. There is a comb-like ridge (notched) between the flutes on the distal side of the bowl. The bowl is $8 \mathrm{~mm}$. in thickness near the base, and from 2 to $3 \mathrm{~mm}$. in thickness near the lip.

Metal Artifacts

\section{Axes}

A complete metal axe with a blunt, slightly splayed cutting edge (Fig. 48, A) was recovered from a storage pit (Feature 69). The blade is moderately long, narrow, and swept back in outline. The overall length of the specimen measures $129 \mathrm{~mm}$. The eye socket is oval-shaped with the long diameter oriented laterally. The socket has a maximum outside diameter of $57 \mathrm{~mm}$, a thickness of $9 \mathrm{~mm}$, and a length of $46 \mathrm{~mm}$. The axe blade measures $20 \mathrm{~mm}$. in thickness near 
the socket and $62 \mathrm{~mm}$. across the bit or cutting edge.

A second specimen represented by a fragment consisting of the lateral half of the socket and a short section of the blade was found in a refuse mound (Feature 53). The shape and measurements are nearly identical to the axe mentioned above.

A small curved strip of iron $35 \mathrm{~mm}$. wide and $6 \mathrm{~mm}$. in thickness appears to be part of the socket and blade of a small axe or other similar socketed implement.

\section{Hoes}

One socketed hoe with most of the blade missing (Fig. 48, B) was recovered from close to the surface adjacent to one refuse mound (Feature 53). The specimen was found by William Sutherland during experimental use of his metal detector. The distal end of the blade section is slightly splayed, and one edge appears to have been cut by deep scoring. The outside diameter of the round socket tapers from $55 \mathrm{~mm}$. near the blade to $48 \mathrm{~mm}$. at the proximal end. The socket is $56 \mathrm{~mm}$. in length and tapers from $7 \mathrm{~mm}$. in thickness at the distal edge to $5 \mathrm{~mm}$. at the proximal edge. The minimum blade thickness measures 6 mm. Sutherland also found a small battered fragment, apparentIy a section from the socket and adjoined blade from a similar type of hoe, from the same refuse mound area.

\section{Hammer}

An elongated object with a central socket (Fig. 48, D) appears to be a hammer, apparently an engineer's hammer, al though the ball end is missing. The unbroken end has a curved, wedge-shaped edge parallel to the axis of the handle. The effective length of the socket is increased by ears or tabs which extend from either side at one end of the socket. The specimen measures $16 \mathrm{~mm}$. in thickness and was recovered from a pit (Feature 63). Marvin Tong suggested that it may have been a metal-worker's hammer.

\section{Unidentified Heavy Iron Fragments}

Part of a unifacially beveled, curved bit resembling the toothed fleshers made of bone was found on the surface near the north burial area (Fig. 48, C). The specimen is so badly rusted that any teeth which may have been present are not evident. The specimen measures $6 \mathrm{~mm}$. in thickness and was probably at least $70 \mathrm{~mm}$. in width.

Five additional fragments of heavy iron are present but have not been identified. One specimen, recovered from a refuse mound (Feature 52), is severely battered and may be the 
butt of a wedge. One highly corroded rectangular piece of iron was found in the bottom of a postmold in structure 3 . It tapers from about $8 \mathrm{~mm}$. at one corner to less than $3 \mathrm{~mm}$. along one edge, and it has been folded across its narrow dimension. The other iron specimens were found in a refuse mound (Feature 55), a refuse pit (Feature 61), and the plow zone of Test 42; all were located on the north section of the site.

\section{$\underline{\text { Knives }}$}

Al1 of the knife specimens are very fragmentary and heavily corroded. One piece (Fig. 48, E) represents the proximal end of the blade and has a pin near one end. Since the blade is tapered along its full length and only one pin is present, it is probably from a clasp knife. The specimen was found in a pit (Feature 36).

The tang and a small portion of the proximal end of the blade of a case knife (Fig. 48, F) were recovered near, probabIy in association with, Burial 6. Some wood still adheres to the tang, which has a lead disk where it articulates with the handle. Part of another knife blade was also found in association with Burial 1.

Some strips of metal found near Burial 4 appear to be part of a knife blade, and other knife fragments were found elsewhere. The tip of a knife blade and two fragments were found in one of the refuse mounds (Feature 52). Three other knife fragments were found in refuse mounds (Features 54 and 55) or in the plow zone (Feature 42), all located on the north portion of the site.

\section{Arrow Points}

Most of the metal points are made of iron, but a few are of sheet brass. Without cleaning, the iron points are estimated to be from 0.5 to $2 \mathrm{~mm}$. in thickness, averaging about 1 $\mathrm{mm}$. The brass points are $0.5 \mathrm{~mm}$ or less in thickness. There are two basic point shapes: (1) those being diamond shaped in outline (Fig. $48, G-N)$, and (2) those having a distinctive stem section ( $F i g, 48,0=W$ ).

The diamond-shaped points vary from forms which are symmetrical, with the maximum width near the midpoint so that it is not clearly evident as to which end is the point and which is the base, to others in which one section is shorter than the other, producing an assymmetrical form. Three specimens have truncated bases. The edges tend to be straight but vary from slightly concave to slightly convex. One of the brass diamond-shaped specimens is distinctive, for it has. 
crude serrations along both edges of what is certainly the base. The serrations would serve to secure the point to the haft in mounting. A second brass specimen is of special interest as it suggests the process of point manufacture. The outline of the point has been cut out except near the tip which remains unfinished; scored lines, however, indicate the portions remaining to be trimmed. The dimensions of the diamond-shaped metal points are as follows:

$\begin{array}{lcc} & \text { Range }\left(\mathrm{mm}_{0}\right) & \text { Mean }\left(\mathrm{mm}_{0}\right) \\ \text { Length } & 22-34 & 29 \\ \text { Width } & 10-17 & 13\end{array}$

Most of the stemmed points resemble the diamond-shaped points except that one end is modified to form a stem. The shoulders are usually sloping while the stems are straight or tapered, and all examples are made of iron. One specimen (from a refuse mound, Feature 54), however, has an expanding stem, while a second specimen has both angular shoulders and an expanding stem. This latter specimen is one of five poorly preserved points associated with Burial 6, of which at least two have the more common sloping shoulders and straight or tapered stem. All of the specimens found with Burial 6 have traces of wood adhering to both sides of the stem. The dimensions of the Burial 6 specimens are:

$\begin{array}{lcc} & \text { Range }\left(\mathrm{mm}_{\bullet}\right) & \text { Mean }(\mathrm{mm}) \\ \text { Length } & 36-50 & 42 \\ \text { Width } & 19-23 & 21\end{array}$

The dimensions of the remaining stemmed metal points are as follows:

$\begin{array}{lcc} & \text { Range }\left(\mathrm{mm}_{\bullet}\right) & \text { Mean }\left(\mathrm{mm}_{\circ}\right) \\ \text { Length } & 16-40 & 25 \\ \text { Width } & 7-17 & 12\end{array}$

There are four additional metal fragments which appear to be parts of arrow points.

\section{Horse Trappings}

There are a few metal items (Fig. 48, X - EE) that may be pieces from horse trappings or equipment. A round cast iron 
pendant ( $F i g .48, X$ ) may be an ornament or jingler. It consists of a $10-\mathrm{mm}$. wide ring attached to a solid cone. The cone measures $5 \mathrm{~mm}$. across at the ring end but expands to $7 \mathrm{~mm}$. at the other end where it is attached to a drop shaped ball of metal. The total length of the object measures $34 \mathrm{~mm}$. It was found in the fireplace located in structure 1 .

Three tapering strips of iron having an eye at the narrow end may be jinglers or ornaments. They measure from 42 to 44 $\mathrm{mm}$. in length, 10 to $11 \mathrm{~mm}$. in width, and from 2 to $3 \mathrm{~mm}$. in thickness. One specimen (Test 42) has a sharp, double-beveled edge on one end and an eye, made by bending or roliing the strip back to form a loop, at the other. A second artifact (Test 38 near Burial 7) has irregular, crudely cut edges and a forged or cast eye whose axis is perpendicular to the width of the strip. The third specimen (Feature 61) has a forged or cast eye with an axis parallel to the width of the strip; it could be part of a gun spring.

One iron specimen rather similar to the one above was found in a refuse mound (Feature 53). It has a large hole at one end, through which an overlapping iron ring or rivet has been placed. The hole measures about $2 \mathrm{~mm}$. in diameter. The specimen remains unidentified.

Another strip of iron tapering from 12 to $15 \mathrm{~mm}$. in width has a perforation measuring $5 \mathrm{~mm}$. at one end and a right-angle curve at the other. It was found in a pit, Feature 67B。

One metal strip found in a refuse mound (Feature 53) measures $31 \mathrm{~mm}$. in length, $16 \mathrm{~mm}$. in width, and $3 \mathrm{~mm}$. in thickness. One end has two perforations.

There is also an $\mathrm{S}-$ shaped section of chain-link measuring $30 \mathrm{~mm}$. in length and $5 \mathrm{~mm}$. in thickness (Fig. 45, EE)。 This specimen was recovered from Feature 52, a refuse mound.

Kettle Fragments

A slightly curved copper lug (Fig. 49, B) has a straight top edge and a concave lower edge. The two mounting perforations, $5 \mathrm{~mm}$. in diameter and $29 \mathrm{~mm}$. apart, are chamfered on the concave side of the lug. The round bail attachment is 9 $\mathrm{mm}$. in diameter and appears to have broken after it was nearly worn through. The surface of the break is smooth and polished, suggesting that the kettle was used after the Iug broke. The overall dimensions of the specimen are $52 \mathrm{~mm}$. in length, 23 $\mathrm{mm}$. in width, and 2 to $4 \mathrm{~mm}$. in thickness. It was found on the surface on the south portion of the site. 
A bent piece of iron, $6 \mathrm{~mm}$. in diameter, pointed at one end and broken at the other, is probably a section from a bail or handle (Fig. 49, A). It is not noticeably worn, and was found in a pit (Feature 66).

What is probably a kettle patch is represented by a bent rectangular piece of sheet brass having several punched, elongated perforations. It is less than $0.5 \mathrm{~mm}$. in thickness and was recovered from the surface on the north section of the site.

Iron kettles are probably represented by two curved pieces of iron about $3 \mathrm{~mm}$. in thickness. One (Fig. 49, G) is a plain rim fragment; both pieces are found with Burial 4.

\section{Sheet Metal Rivets}

Rivets of native manufacture (Fig. 49, C - F) are made of sheet brass ( 8 specimens) and copper (2 specimens). They were made by bending an elongated, diamond-shaped strip of metal so that the wide center served as the head and the ends served as prongs. One specimen is attached to a small piece of sheet brass, but the o thers are separate items. Rivets of this type are known, from examples in private collections, to have been used in patching kettles. Rivet dimensions are:

$\begin{array}{lcc} & \text { Range }\left(\mathrm{mm}_{\bullet}\right) & \text { Mean }\left(\mathrm{mm}_{0}\right) \\ \text { Width of strip } & 7-26 & 13 \\ \begin{array}{l}\text { Width of head } \\ \text { across folds }\end{array} & 8-17 & 12\end{array}$

Iron Rivets

Two iron rivets were recovered from the plow zone in Test 42 and Feature 53. One has a plano-convex head $17 \mathrm{~mm}$. in diameter and a shank $6 \mathrm{~mm}$ 。 in diameter. The other has a head $13 \mathrm{~mm}$ 。 in diameter and a shank $6 \mathrm{~mm}$ 。 in diameter. Both may be of recent origin as they are only moderately corroded.

\section{Tinklers}

There are seven conical-shaped tinklers rolled from sheet metal (Fig. 49, H - L). Five are of brass, one of copper, and one of iron. The iron specimen is evenly cut, and the rolled ends abutt together in a straight splice rather than overlapping as in the other examples. The advanced workmanship suggests that this specimen was manufactured for trade to the Indians and that it was not locally made。 It is $22 \mathrm{~mm}$. in length, tapers from 4 to $6 \mathrm{~mm}$, in diameter, and is less 
than $1 \mathrm{~mm}$. in thickness. The iron specimen was found in a refuse mount (Feature 52). The dimensions of the other specimens follow (all are less than $0.5 \mathrm{~mm}$, in thickness):

$\begin{array}{lcc} & \left.\text { Range ( } m m_{\circ}\right) & \text { Mean }\left(\mathrm{mm}_{\circ}\right) \\ \text { Length (6 specimens) } & 21-36 & 26 \\ \text { Minimum diameter (5 specimens) } & 2-5 & 3 \\ \text { Maximum diameter (4 specimens) } & 6-10 & 8\end{array}$

One brass specimen is a flat rectangular strip tightly rolled at one end and flat at the other, suggesting that it is unfinished.

\section{Beads}

Four tubular beads (Fig. 49, M - 0) are rolled from rectangular pieces of sheet metal. Two are copper, one brass, and one lead. Their measurements, all less than $0.5 \mathrm{~mm}$. in thickness, follow:

$\begin{array}{lcc} & \text { Range }\left(\mathrm{mm}_{\circ}\right) & \text { Mean }\left(\mathrm{mm}_{\circ}\right) \\ \text { Length } & 7-37 & 19 \\ \text { Diameter } & 5-7 & 6\end{array}$

Rings

Four small strips of metal are bent into bands or rings (Fig. 49, P, Q, S). Two were recovered from the same pit (Feature 68). One of these is a 3 -mm.-wide strip of sheet brass cut to a long tapered point at either end and then rolled into an overlapping ring $8 \mathrm{~mm}$. in diameter. The other is a broken strip of lead, $4 \mathrm{~mm}$. wide, with a plano-convex cross section $1.5 \mathrm{~mm}$. in thickness and rolled into a partial. ring $16 \mathrm{~mm}$. in diameter.

The other two rings are nearly identical in shape and size. They were found with Burial 1 and are made of $1-\mathrm{mm}$.square pins of brass which have been bent to form a ring 14 $\mathrm{mm}$. in diameter. $R$. K. Harris states that these items resemble links from chain mail.

\section{Button}

A plain brass button (Fig, 49, R), $22 \mathrm{~mm}$. in diameter, was found on the surface on the south portion of the site. 
The brass is $1 \mathrm{~mm}$. thick and is formed into a small basin $6 \mathrm{~mm}$. in height. The eye is broken off near the point of attachment.

\section{Hawk Bells}

Five specimens representing two types of hawk bells made of thin sheet brass (Fig. 49, T, U, W) were recovered in the excavations. Four identical belis, found with Burial 7, were made by welding two basin-shaped halves into a round smooth-surfaced bell $15 \mathrm{~mm}$. in diameter and $11 \mathrm{~mm}$. in height. The eye is formed by a brass strip $1.5 \mathrm{~mm}$. in width which has been bent into a ring $5 \mathrm{~mm}$. in diameter. The ends of the strip protrude from the loop and were inserted in a hole at the top of the bell where they were bent apart and then lightly soldered in place. The bottom half of the bell contains two perforations $2 \mathrm{~mm}$. in diameter connected by a slit $8 \mathrm{~mm}$. long. The enclosed iron rattles are very corroded, but one measures about $5 \mathrm{~mm}$ 。 in diameter.

The fifth bell is also made of two basin-shaped halves, but the joined edges are soldered. The bell is $15 \mathrm{~mm}$. in diameter and $10 \mathrm{~mm}$. in height. Two engraved or embossed lines encircle the top half of the bell near the splice, and two pairs of faint lines encircle the bottom half near the splice. The eye is missing, but there is an enlarged hole at the top of the bell suggesting that the eye or loop had pulled out. It is obvious from the solder present that the eye was previously present and that it was attached as in the other bells. The two perforations on the bottom are $3 \mathrm{~mm}$. in diameter and separated by a slit $7 \mathrm{~mm}$. long. The rattle is missing. This specimen was found in one of the refuse mounds (Feature 55). The latter bell is very similar to some of the bells found at the Watson site, Fisher County, Texas, which seems to date during the first half of the 19th century (Ray and Jelks 1964: 133-4, 141, Fig。3B)。 It also resembles bells from the early 18 th-century Womack site in Lamar County, Texas (Harris and others, 1965: 354, Fig。22E)。

\section{Pendants}

A drop-shaped copper pendant with a glass set (Fig. 49, $\mathrm{X}$ ) was associated with Burial 7. It measures $11 \mathrm{~mm}$. in width and $13 \mathrm{~mm}$. in length. The perforation for suspension at the apex is $1 \mathrm{~mm}$. in diameter and has a raised rim $0.4 \mathrm{~mm}$. high on the front face. A small ring about $3 \mathrm{~mm}$. in diameter was looped through the perforation when discovered, but the ring has subsequently been broken and lost. Two encircling bands of small nodes are on the face of the l-mm.-thick pendant. The faceted, light translucent blue glass set is held in place by a flange I mm. in height. In the center of the reverse 
face is a conical-shaped node $3 \mathrm{~mm}$. in diameter and $1 \mathrm{~mm}$. in height.

A perforated and decorated triangular piece of white metal (silver?) (Fig. 49, Y) was associated with Burial 5. The edges are convex, and two perforations, $1 \mathrm{~mm}$. in diameter, are located at the apex and one basal corner of the triangle. The holes were punched through from the reverse side, but the resulting burr has been smoothed. The design of the decoration is not readily apparent as it clearly extends beyond the edge of the artifact indicating that it was cut from some larger object. The specimen measures $23 \mathrm{~mm}$. in width, $13 \mathrm{~mm}$. in height, and $0.4 \mathrm{~mm}$. in thickness. A preliminary chemical analysis indicates a low silver content.

\section{Lead Seal?}

A lead disk $33 \mathrm{~mm}$. in diameter and about $1 \mathrm{~mm}$. in thickness (Fig. 49, Z) appears to be a seal. The edges are slightIy turned toward what appears to be the lower surface. The latter surface is covered with an unidentified white, stoneytextured substance which reacts to acid; possibly it is an adhesive. Small bits of fibrous material, probably paper, adhere to parts of the white area. A thin coating of asphalt covers about one third of the opposite face. There are depressions in the asphalt which may represent parts of lettering or a design. The specimen was recovered from a pit (Feature 35).

\section{Wire}

A curved section of brass wire $0.7 \mathrm{~mm}$. in diameter and about $120 \mathrm{~mm}$. in length (Fig. 49, AA) was found in a refuse mound (Feature 52). One end of the wire is bent backward to form a narrow eye.

\section{Nails}

Two iron nails (Fig. 49, BB - CC) were found in aboriginal contexts, one with Burial 5 and the other in a refuse mound (Feature 53). Although they are heavily corroded, both appear to be nearly the same size. The heads are $8 \mathrm{~mm}$. in diameter; the shanks are nearly square, between 4 and $5 \mathrm{~mm}$. across and $39 \mathrm{~mm}$. in length.

\section{Pins}

A flat tapered iron strip with a short section bent over at the wide end (Fig. 49, DD) was found in the plow zone of Test 42. The specimen is $58 \mathrm{~mm}$ in length, tapers from 10 to $14 \mathrm{~mm}$. in width, and is from 3 to $4.5 \mathrm{~mm}$. in thickness, Three similar specimens were found at the Three 
Forks Trading Post Site, Wagoner County, Oklahoma, which was occupied during the first half of the 19th century (Thomas $P$. Barr, personal communication). Marvin Tong suggests that the Longest specimen may be a large barrel lock pin from a gun.

Another pin-like iron object (Fig. 49, EE) is composed of two pieces. One is a bent rod $36 \mathrm{~mm}$. in length having an ovalshaped cross section measuring 1.5 by $2 \mathrm{~mm}$. One end of the rod has a flat head 3 by $4 \mathrm{~mm}$ o in diameter while the opposite end appears to be broken. Wrapped around the top end of the rod and flush with the top of the head is a band of iron $6 \mathrm{~mm}$. wide and $1.5 \mathrm{~mm}$. thick. The specimen was found in a refuse mound (Feature 52).

\section{Perforated and Embossed Sheet Brass}

A twisted and folded fragment of sheet brass (Fig. 49, FF) has a central perforation about $18 \mathrm{~mm}$. in diameter. The edges of the perforation are loosely rolled and, in places, show evidence of having been attached to another piece of metal. Two concentric embossed bands surround the hole. The outer edge is irregular and broken; it apparently has not been cut. Marvin Tong suggested that the specimen may be the base of a candlestick holder. The item was found in the surface on the north section of the site.

\section{Miscellaneous Metal Fragments}

The great majority of metal fragments have not been identified as to the object represented; these include 2 fragments of lead, 82 fragments of brass or copper and 480 fragments of iron. Many of the pieces show intentional folding or cutting, but none of them has decorations. several of the brass or copper specimens appear to be parts of gun plates. This total number of metal fragments does not include items believed to be of more recent origin, but only those believed to be associated with the Wichita occupation. Apart from the provenience data, the aboriginal metal specimens can usually be distinguished by the scoring marks present from cutting, although this is not always evident. The specimens have not been cleaned, and some cutting marks are certainly obscured by rust. The amount of corrosion or rust present can be used in general in distinguishing the wichita metal items from modern items, but it may be unreliable. For example, the degree of preservation of iron scraps associated with Burial 1 ranges from only slightly corroded to severely corroded. Without doubt, after the miscellaneous metal fragments are carefully cleaned and subjected to examination by various specialists, some identifications will be made. 
Perforated shell disks

A perforated shell disk was associated with an ornament of glass beads found on each side of the skull in Burial 5 (Fig。 50, I)。 One disk is very fragmentary, and the other is covered with sand and dirt which has been cemented in place with copper salts. They are approximately $11 \mathrm{~mm}$ 。 in diameter with a $2 \mathrm{~mm}$. perforation.

One other shell disk (Fig. 50, H) was found in a pit (Feature 67). It measures 14 by $15 \mathrm{~mm}$. in diameter, $1.5 \mathrm{~mm}$. in thickness, and has a biconical central perforation $1 \mathrm{~mm}$. in diameter.

\section{Perforated Pendant}

One ornament (Fig. 50, G) has been cut from shell into a roughly triangular shape. The edges have been smoothed, and a perforation measuring $1.5 \mathrm{~mm}$. in diameter has been drilled through one corner for suspension. The specimen is $60 \mathrm{~mm}$. Iong, $50 \mathrm{~mm}$. wide, and has a thickness ranging from 1 to $2 \mathrm{~mm}$. The ornament was found in a refuse mound (Feature 52)。

All of the shell objects appear to have been made from mussel shells.

\section{Glass Beads}

The 445 glass beads recovered from the excavations during the summer of 1966 will not be described in detail as they are included in a more comprehensive report by $R$. $K$. Harris in another section of this report. Some brief observations, however, will be noted.

Most of the types of beads occur in such small quantities in the available sample that their distribution at the site can be attributed to sampling error. The two most common bead types, however, may have some significant differences reflected by their distribution. These are the small blue or white beads ranging from 2 to $4 \mathrm{~mm}$. in diameter. The sample of 79 common: blue or white beads from the north section of the site was obtained from several different proveniences scattered over a wide area and would, therefore, seem to be a fairly representative sample. The 323 common blue or white beads recovered from the south sector, however, is chiefly from burials, and only 14 beads were found in other contexts. The beads from the burials tend to be slightly elongated or tubular in shape, 
and they are not pitted by erosion. The blue beads are often a greenish-blue. The blue or white beads found elsewhere at the site are more nearly round, blue rather than a greenishblue, and are always pitted from erosion. While the differences in bead color and corrosion may be due to factors of preservation, the difference in bead shape cannot be accounted for in this manner. At least three explanations may account for this difference: (1) a selective preference of one type for burial purposes and another for ordinary usage, (2) a difference in tribal preference for certain bead styles, or (3) a temporal change in the source of supply.

\section{Sheet Glass Artifacts}

Two broken glass mirrors and 9 other glass specimens were recovered in aboriginal contexts and appear to be associated with the Wichita occupation. A large sample of glass was obtained in mixed or recent deposits, but this is not included in the present analysis.

Two glass mirrors (Fig. 50, A-B) were found in association with Burial 6. Both of them are made of clear, bubble efree glass which has a greenish tinge and a slight patina. There are traces of red ochre on one edge of the smaller mirror. The smaller specimen measures 60 by 55 by $1.4 \mathrm{~mm}$, and the larger specimen measures 90 by 61 by $1.8 \mathrm{~mm}$. Traces of a coating are present on one surface of each specimen. This coating, analyzed by Bobby Vowell, Instructor of Geology at Cameron College, is a silver coating of the type used on modern high-quality mirrors.

A small piece of glass in the form of a tall trapezoid (Fig. 50, E) appears to be unbroken. Although identification is uncertain, it appears to be an inlay from some larger object. Al1 surfaces are covered with a polished white substance which appears to be an applied coating rather than a corrosive prow duct. Where exposed, the surface of the glass is frosted, and a small broken corner reveals a clear, bubble-free interior. The specimen is $15.4 \mathrm{~mm}$ 。 in length, tapers from $6.7 \mathrm{~mm}$. to $7.8 \mathrm{~mm}$. in width, and is $1.7 \mathrm{~mm}$. in thickness. It was. recovered from a pit (Feature 68).

Two fragments of irridescent, corrosion-pitted glass (Fig. 50, $C-D)$ are decoreated with narrow line inlays. The motif consists of slowly converging, slightly curved, long lines with a series of fine, short lines eminating at acute angles from both sides of each main line. Microscopic examination of the lines reveals thin alternating bands of gray-and browncolored material, usually with a thicker central gray core. The filling is powdery and is easily removed by running a fine point along the grooves. The major lines are nearly $2 \mathrm{~mm}$. deep 
in the glass which is $2.6 \mathrm{~mm}$. in thickness。 One fragment has a straight, unbroken edge which is beveled on both sides. A fresh break reveals a clear, bubble-free glass. Both of these specimens were found in the plow zone within $5 \mathrm{~m}$ of a pit (Feature 62), and were possibly plowed out of this pit area.

Two undecorated, relatively thin glass fragments were also found in the plow zone near this same pit. They are heavily altered on the surface by pitting and a white patina, but a broken edge indicates a clear, bubble-free glass. They measure $1.4 \mathrm{~mm}$. in thickness and are possibly from mirrors.

Another piece of patinated greenish-colored glass, $2 \mathrm{~mm}$. in thickness, was recovered in the plow zone above structure 1. One edge is curved, but identification is uncertain.

Two fragments of highly irridescent dark-colored glass were found in two pits (Features 22 and 38 ) on the south section of the site. They are $3 \mathrm{~mm}$. and $5 \mathrm{~mm}$. in thickness.

A fragment of dark olive-green wine-bottle glass, slightly irridescent on the broken edges, was recovered from a pit (Feature 67). This glass fragment may be intrusive since this type of glass is characteristic of the late 19th century, according to A. R。 Pilling of Wayne State University。 Surface collections made in the area immediately to the south of this feature have produced similar pieces of glass from a late 19th-century occupation, supporting the view that the fragment is intrusive。

\section{Miscellaneous Specimens}

A few miscellaneous items were recovered which do not fall into any of the categories listed above, and these will be itemized separately, except for a few seeds and large quantities of bone refuse which has not been analyzed.

\section{Asphalt}

An ovoid chunk of asphalt measuring 95 by 70 by $33 \mathrm{~mm}$. (Fig. 50, M) was found in association with Burial l. small pits, coarse folds, and inclusions of red and yellow pigment are evident upon the surface. A small fresh break reveals a small stone inclusion. Asphalt seeps are well-known features in several areas not far from the Longest Site. A major seep occurred near Saint Jo, Texas; seeps are presert in several localities in Carter County, Oklahoma, and several seeps are known near the west end of the Wichita Mountains in Comanche County, Oklahoma (Shannon, 19.17: 74, 128-132, 311)。 


\section{$\underline{\text { Cane }}$}

A section of cane $117 \mathrm{~mm}$, in length and $16 \mathrm{~mm}$, in diameter (Fig. 50, F) lay alongside the neck and left cheek of Burial 5. Copper salts from the wires in the fabric included with this burial probably aided in the preservation of the cane, although no copper stains are evident on the cane itself. The specimen does not appear to be modified in any way, although both ends were damaged during excavation through mistaking it for a tree root. It seems probable that the specimen was included with the burial as an individual section of cane rather than part of a mat, since no additional pieces were found.

\section{$\underline{\text { ochre }}$}

Lumps of red, orange, and yellow pigment (Fig. 50, J-L) were widely distributed at the site. Powdered red ochre was found with three burials and on stones that apparently had been used for pulverizing lumps of ochre. Several lumps are not uniformly of one color but range from a red through orange to yellow. The largest lump of ochre found measures $30 \mathrm{~mm}$. across but most of them are smaller in size. Several specimens, selected for their range in color, were chemically analyzed and were found to have a high iron content. None of the specimens; however, was identified as representing vermillion, which was an important early trade item. Bobby Vowell, who made the assays, commented that the ochre should have been available from the local Pleistocene gravels which have a high iron content. One specimen has a sandstone matrix attached, which suggests a local origin。

Fabric

A number of small fragments of fabric, presumably all part of the same garment, were associated with Burial 5. Preservation is attributed to thin wires of copper or brass which were woven into the fabric. The preserved portions of fabric as well as many areas of the skeleton were stained green by the copper salts. The specimens have not been sub jected to a careful analysis, but the weave pattern appears to be rather complex. John C. Ewers suggests that the fabric may be braiding from a military officer's coat.

\section{Clinkers}

A number of small pieces of greenishagray, frothy glass like irregular masses of unidentified material (Fig。 50, $\mathrm{N}-0$ ) were recovered at the site, especially from the burned layers 
(stratum B) overlying the floors of structures 1 and 3. Similar specimens have been recovered on the floors of burned structures at a site near Larned, Kansas (Monger, 1966). According to the excavators of that site, the specimens can be attributed to burned grass, because local informants rem port that similar material remains after a hay stack has been burned (Robert Button, personal communication)。 The ruins of a barn filled with baled hay which had recently burned near Lawton was examined by Bastian and the owner. They found much clinker-like material usually adhering to bàiling wires from the bales. Most of the hay was Sudan grass, and the clinkers were small in size and much more frothy and fragile than the specimens found at the Longest site. The remains of a few bails, however, identified as wheat stock, had produced large clinkers of a moderately frothy, hard, greenish-gray material closely resembling those from the excavations.

While occasional clinkers found at the Longest site can be attributed to miscellaneous trash and grass fires, the concentration of clinkers in the burned strata above the floors of structures 1 and 3 suggests that the houses had a grasscovered superstructure.

\section{Human Tooth}

One fragmentary human molar was recovered from a refuse mound (Feature 52) in the northwest portion of the site. Although the tooth is worn, the dentine is not exposed.

\section{Summary and Conclusions}

Although this report is preliminary in so far as the details of analysis are concerned, a number of conclusions may be drawn which relate to the early history of the wichita Indians. The results obtained in this pilot project concerned with the archaeology and history of the wichita on the Southern Plains provide new basic data with which to formulate additional research efforts.

The Longest Site, located on the north bank of the Red River in southern Oklahoma, is now known to represent an ime portant village site of the Wichita Indians. It has already provided information regarding village area, fortifications, architecture, burial customs, storage pits, and a cultural inventory of the inhabitants. The abundant amount of French trade goods found indicates that trade was well established; Spanish goods or materials were negligible. The dating of this historic material suggests that the village was flourishing 
between the period from approximately A.D. 1750 to 1800 . The beginnings and end of the occupation are not precisely established.

The discovery of a large excavated ditch or earthwork situated upon the site suggests that this is the location of the Taovayas village that was attacked by Colonel Don Diego Ortiz Parrilla in October, 1759 (Duffield, 1965). Excavations of the fortification area and the identification of in terior subterranean structures would establish this identification beyond question, and this should be one goal included in future planning.

The village extent is fairly well known, but details concerning house arrangements or the village plan are not evident from the work already done. A number of small refuse mounds are to be found in the village area. These are low circular mounds of varying dimensions containing village debris, which appears to be characteristic of Wichita villages. Prior to excavation, however, the purpose of these low mounds remained unclear, and the possibility that the mounds represented house locations appeared reasonable. All of the Longest Site examples examined, however, were merely accumulations of midden refuse。 No doubt many others were formerly present at the site, but they have been leveled by years of cultivation and are evident only by concentrations of village refuse.

other features of the village area include numerous storage pits, houses, and an arc of post holes possibly being a corral. The storage pits appear at random throughout the village and vary considerably in their dimensions. A typical example would range between 1 to $1.5 \mathrm{~m}$ o across and 1 to $1.5 \mathrm{~m}$. in depth. Many of them had been refilled with midden material, but others were relatively sterile。

Two houses were excavated, and some others were located as to their position. All indications are that the house structures were typical beehive-shaped grass-covered houses such as have been associated with the wichita Indians from the time of Coronado up until the late 19th century. The house was erected over a shallow basin-shaped circular depression. The superstructure was held up by one or two interior rings of posts supporting rafters against which the exterior wall stringers could be placed to form the beehiveshaped structure. A fireplace was present at the center of the house, and doorways occurred in the outside wall at the cardinal directions. Grass thatch rather than wattle and daub was used to enclose the structure. Details of interior features remain obscure as only two houses were excavated, and these differed somewhat, primarily in size. Additional houses should be excavated, not only to provide details of the village plan but to detect variations in architectural style。 
Burial information has been obtained from seven graves. The burials appear to be scattered in various areas of the village and are not concentrated within a cemetery area. The graves are shallow; in each case, the skeleton was oriented in a generally east-west direction with the head toward the east. The body was placed in an extended position. sometimes with the legs slightly flexed, usually on the back or side, and accompanied by some grave offerings. The burial associations are varied but include both trade goods and aboriginal items.

The artifacts found during the excavations can be divided into two broad groups: the native-made aboriginal objects, and items that were obtained through European trade.

Native artifacts include flint projectile points, commonIy small triangular types such as the Fresno point, filint scrapers of various kinds, tabular sandstone scrapers, fint knives including the diamond-shaped alternate-beveled form or Harahay knife, flint drills, stone celts, sandstone arrowshaft abraders, hammerstones, and grinding basins including both metates and manos. Pipes are well represented, both in stone and clay. Additional artifacts include a small amount of pottery, clay figurines, shell beads and perforated disks, shell ornaments, bone rib-edge awls, bone beads, bone fleshers, bison scapula cutting tools, decorated bone disks, bird bone whistles, drilled deer and bear teeth, bone flaking tools, various pigments, and one specimen of asphalt. Widespread trade contacts are reflected in the presence of fint from the Alibates quarries in the Texas panhandle, flint from the Kay County quarries in northern Oklahoma, flint from the Edwards Plateau area of central Texas, and pipestone or catinite from Minnesota.

White contact materials are more varied and include many items associated with firearms. Gun parts represented include gun flints, both European and native made, gun barrels, lock side plates, side plate screws, gun cocks, frizzens, flashpans, breech plugs, triggers, trigger springs, trigger guards, pin loops, sears, front sight, gun worm, butt plates, and bullets. Other metal objects include axes, hoes, hammers, wedges, scrapers, knives, arrowpoints, horse trappings, kettle fragments of various kinds, rivets, tinklers, rolled tubular beads, rings, buttons, hawk bells, pendants, wire nails, pins, and numerous unidentified objects. Nonmetal trade materials include glass beads of many different types, glass mirrors, glass ornaments, fragments of fabric, and a kaolin trade pipe. The vast majority of this trade material is French in origin and was being brought into the area by way of Red River from Louisiana. 
The Longest site inhabitants were obviously obtaining varied trade materials in quantity, and the impact upon the native-made cultural inventory is clear. Metal arrowpoints were replacing flint points, and both were being replaced by the gun; iron and copper kettles were replacing pottery, items of metal and glass were replacing objects formerly made of stone, sheli, or bone. The culttural consequences of this situation remain for additional study and interpretation.

At this point it is perhaps worthwhile to ask if the original goals, as stated earlier in this paper, have been achieved. The answer is "yes," but new questions and new goals now arise which can guide future research; consequently, it is believed necessary to examine the original objectives and to offer comments which would be helpful in guiding additional research.

Objective 1: To recover a sampling of the artifact and debris materials which would provide information about the life and culture of the inhabitants, who were identified as Wichita Indians of the late 18th century.

A considerable quantity of excavated materials has been recovered which will supply this information. An analysis of all the material, however, has not been completed at this time. It is believed, nonetheless, that the sampling has been relatively complete, and that future work should be directed to wards specific problems arising from the currently available data.

Objective 2: To establish, if possible, whether or not the site represented only a single occupation, or if it contained evidence of additional occupations, possibly prehis. toric in time。

The materials recovered from the Longest Site suggest a single occupation associated with the historic babitation of the site. Very rarely, an older object was found, but it was apparently picked up by the wichita themselves or represent transient occupation as no stratigraphic evidence of an older occupation has been noted. Some late prehistoric materials are found in the area to the north of the main site, but this apparently has no relationship to the Wichita occupation. Modern refuse or debris from frontier days or farming activity is present on many sections of the site, but this can usually be detected and is generally limited to disturbed areas.

Objective 3: To obtain materials from different sections of the site which might suggest differences in time, utilization, or tribal. identity. 
Various sections of the site were examined, and sample materials are available. Final conclusions regarding site differences can only become apparent after the artifact analysis is completed. Differences in artifacts, however, are minimal, and those differences which have been noted may be a result of small or biased, samples. The fortification occupies the northern sector of the site, and, thus far, no houses have been located in this area. Refuse mounds and storage pits, however, are represented, so that houses are to be expected. All burials have been found on the south section of the site; houses and village refuse are also more abundant. Consequently, some areal differences in village plan are suggested, but further excavation work is necessary to confirm these suspicions.

Objective 4: To obtain information about house structures or constructions that were associated with the wichita occupation.

Two house patterns were excavated on the south portion of the site, and the locations of others are known from test trenches. Both structures represent circular grass houses such as have been attributed to the Wichita in documentary accounts. Both houses are from the same general portion of the village, however, and it is not known how typical they might be for all of the site. One of the houses encountered in testing was sufficiently exposed to determine that it was oblong in outline. Additional structures should be located and excavated to detect variations in house construction, and to identify other types of structures. Additional details regarding interior features, specialized usage, or associated external features may be availo able in other portions of the site.

Objective 5: To obtain information about the low mounds, refuse areas, storage pits, or other features that might be associated with the occupation.

The low mounds proved to be refuse mounds rather than the locations of houses or other features. Numerous storage pits were located and excavated, and some surface refuse areas were examired. Evidence of pot-hunting activity, modern cellars or foundations, fireplaces, and scattered postmolds was found and contributes to our overall knowledge of the site。

Objective 6: To locate and obtain information regarding burial customs and grave associations of the Wichita Indians.

Seven burials with associated grave goods were found on the southern sector of the site. Although this provides data not previously available, additional burials should be obtained. 
Objective 7: To locate and find evidence of any fortification such as palisades, ditches, or embankments to aid in the positive historical identification of the site.

A large oval-shaped earthwork represented by a ditch was located after the major field work was completed. This clearly represents an extensive fortification which is probably that referred to in various historical documents. This fortification should be carefully excavated to trace it size, nature, and interior associated structures. The possible entryway leading toward the river should also be carefully examined for construction data. Although a major task, this represents a primary focus for additional work at the site.

Objective 8: To obtain information which would be helpful in evaluating the potential value of the site for Wichita Indian research in formulating recommendations for future research。

From information presently available, the Longest site appears as the primary and most significant. site in Oklahoma representing the period from approximately A.D. 1750 to 1800 . Investigations indicate that the site contains a rich storehouse of information awaiting recovery. Some of the sugges tions regarding the direction of future research at the site have already been recommended. 
SURVEY OF POTENTIAL WICH ITA ARCHAEOLOGICAL REMAINS IN OKLAHOMA

\author{
by Robert E. Bell and Tyler Bastian
}

An integral portion of the present study is a recommendation for future research on Wichita archaeology in Oklahoma. The present section summarizes our surveys and investigations of known or suspected Wichita sites in the state.

In the vicinity of the Longest Site on the Oklahoma side of Red River, no additional Wichita sites have been found. Adjoining the Longest Site on the north is the prehistoric, apparently multicomponent, Orchard Site. North of the orchard site the river terrace is gullied and eroded with sloping irregular land. South of the Longest Site the terrace continues for perhaps one-half mile before it merges with lower, heavily forested land. A few scattered flakes, a handstone, and a late Archaic point were found a short distance south of the Longest site on this terrace. A survey for approximately $4 \mathrm{mi}$. up Red River from the Longest Site revealed a series of Archaic and late prehistoric sites, but nothing later. All of the sites are situated on the points of high bluffs or along tributary canyons. There are no broad terraces above the flood plain in the area surveyed. It is suggested that future surveys concentrate on broad terraces of intermediate height such as are occupied by the known Wichita sites on both sides of the river in the vicinity of Spanish Fort, Texas. Search should extend some distance back from the edge of the terrace in flat, featureless areas, as well as near tributary streams, as suggested by the known locations of sites on the Texas bank of the river. Although additional survey along Red River may not be of primary concern for future Wichita research in Oklahoma, the Spanish accounts of their attack on the Taovayas village in 1759 state that two villages existed on what is now the Oklahoma side of the river (Duffield, 1965)。

\title{
DEER CREEK AND VIC IN ITY
}

The only known archaeological remains in Oklahoma which are comparable in extent to the Longest Site are a series of sites along the Arkansas River near the Kansas border. One site, the Deer Creek or Miller Site, is unique among known Oklahoma Wichita sites because the greater portion of the site has not been subjected to cultivation, nor, so far as known, much indiscriminate digging by relic hunters. Apparent on the surface are several. dozen refuse mounds, some possible house depressions, and an interrupted ditch enclosure of unknown function. Available information suggests that the major period of occupation at Deer Greek was during the first half of the l8th century or prior to the assumed beginning of the major Wichita occupation of the Longest Site. No special investigations of the Deer Creek and 
nearby sites have been made in connection with the present study because the general importance and significance of the sites are already apparent, and plans for excavation are already underway in connection with salvage work in the proposed Kaw Reservoir (Wyckoff, 1965: 10-21).

\section{DEVILS CANYON}

The only other known site in Oklahoma which can be identified, with reasonable certainty, as Wichita is situated on a sandy terrace of the North Fork of Red River at the mouth of Devils Canyon near the west end of the Wichita Mountains in southwestern Oklahoma. The site is probably the location of the Wichita village visited by the U. S. Army in 1834 and depicted in a drawing by an assistant to George Catlin. Most of the site has been intensively cultivated for about 65 years, and only a few faint concentrations of refuse are visible on the surface. An elderly resident in the vicinity states, however, that the site was covered with depressions about 1902 , before it was cultivated. At the present time no depressions or other unnatural irregularities are apparent on the surface. The east portion is presently not under cultivation, but refuse can be found in a road crossing the site and elsewhere amongst the sparse vegetation. Although the west part of the site had been plowed and rained upon shortly before our visit to the site, refuse was sparse. There were a few large concentrations of ash and bone, but even these were sparse and barely discernible. Mr. Elmer Craft, Jr。, made a thorough surface collection of all materials except bone while the site was being tested. $\mathrm{He}$ recovered two brass fragments, a glass bead, and about 100 flakes of Ogallala chert. The scarcity of surface debris can be attributed to intensive cultivation and sustained surface collecting at the site by the owners and other individuals. The prevalence of Ogallala chert is consistent with the Archic points seen in private collections from the site. If the Wichita occupied the site as recently as the ethnohistoric data suggest, the native stone-working industry must have been very minimal.

Permission was obtained to test only in the cultivated field on the west part of the site. A series of small test holes, in two rows at right angles to each other, were dug across the site. Some shallow, sparse refuse was encountered below the plow zone in one or two tests, and a fireplace was found in a third test. The refuse found in the plow zone was scarce. A few years prior to our testing of the site, Mr. James A. Marler and Mr. Jack Williamson, of the Southwest Chapter of the Oklahoma Anthropological Society, excavated a test trench about $5 \mathrm{ft}$. wide and $12 \mathrm{ft}$. long near the fence dividing the site and in the vicinity of our tests. They recovered a variety of trade items and refuse including animal bones. Evidently their trench had encountered a refusefilled depression or storage pit. 
A detailed study, made by R. Ko Harris, of glass beads from the Devils Canyon Site, which are in private collections, and preliminary study of other artifacts from the site suggest that the Wichita component dates from early in the 19 th century and perhaps late in the 18 th century.

Despite extensive destruction of the site by cultivation, and perhaps to some extent by relic hunters, it is apparent that some subsurface features are preserved. No doubt careful excavation would produce considerable data from the site. The site should be important in documenting changes in architecture, village features, or the cultural inventory from that represented elsewhere.

Subsequent to the investigation of the Devils Canyon site, another site with early historic materials has been reported to exist about $2 \mathrm{mi}$. to the southeast. At this time, however, the reported site has not been investigated.

\section{FORT SILL AND VICINTIY}

Historical documents indicate that several Wichita villages were located on and near East cache Creek at the eastern end of the Wichita Mountains in the $1840^{\prime} \mathrm{s}$ and perhaps slightly earlier. The villages were visited by several persons who left brief accounts (Winfrey 1959; Richardson 1933). In 1852 a U。S.Army expedition observed the remains of three abandoned Wichita villages along Medicine Creek between Mount Scott and East Cache Creek; several lodges were still standing, and old com fields were nearby (March 1852: 71-2). The location of one village is so specifically described that there is only one, or possibly two, areas of about 25 acres each in which it could have been located. Visitors to the same site 18 years after its abandonment observed that the remains of their "... fortifications are easily traced" (Foreman, 1927: 386) and that ".. circular fireplace depressions, heaps of trash, burned stubs of cedar frameworks $=$ all covered with a scattered growth of vines" were present (Nye, 1942: 77). Recent investigations, however, have been unable to find any surface evidence which may be associated with the village (Bastian, 1965; Shaeffer, 1966), nor have any other mid-19th century sites been identified as Wichita in the vicinity of Fort Sill or along East Cache Creek。

New survey work has not been conducted in the area, but it is recommended that a systematic survey be made of East Cache Creek and its tributaries on and above the Fort sill Military Reservation, including a re-examination of those areas previously surveyed (Bastian, 1965; Shaeffer, 1966). The survey should emphasize a thorough search for the site of the large village whose remains were observed by several travelers before the founding of Fort sill 
in 1869. The location and testing of sites in the vicinity of Fort Sill would determine the suitability of the sites for further documentation of the rapid changes taking place in Wichita culture during the 19th century •

\section{RUSH SPRINGS}

In the 1850's several Wichita villages were located on Rush Creek southeast of Rush Springs, Oklahoma. Like the villages near Fort Sill, they are briefly mentioned by several travelers (Marcy, 1853: 76-80; Rector, 1859; Foreman, 1927; Nye, 1942: 18-24). The most exact description of their location is again that of the 1852 U. S。 Army expedition (Marcy, 1953: 76-80); however, this still leaves an area of several miles along the creek, which is in need of examination. A survey was made for about $2 \mathrm{mi}$. along both sides of Rush Creek, including areas on the south side seemingly described by the Army expedition report and the area on the north side designated by local historians (Ragland, 1952: 11-7, 63-4, 69-78). Only a few flint flakes from various places and some late 19th-century debris from the site of a stage depot and early post office were found. A few large bone fragments, apparently bison or cow, were found near the top of a deep ravine on the west side of the area designated by local historians as the site of a Wichita village in 1859. A few flint flakes were found on the surface, and one resident has a medium-sized, contracting-stemmed point (Gary) said to be from the "site." Most of the designated area was scheduled to be contour-plowed within a few weeks after our visit late in 1966, but the area has not been revisited. The potential of the above area seems poor, and an extended survey of collections and possible sites along other parts of Rush Creek is recommended.

The Wichita abandoned the Rush Springs locality in 1859 and were assigned a reservation on the washita by the U. S. government. During the Civil War they fled to Kansas; later, they returned to Oklahoma and settled around Anadarko. No attempt has been made to locate these sites, although they might be useful in completing a study of Wichita culture change in the 19th century.

THE VILLAGE VISITED BY LA HARPE IN 1719

In 1719 La Harpe traveled from his Nassonite Post near present-day Texarkana into what is now Oklahoma, where he visited a large Wichita (Tawakoni) village. The general location of the village is in considerable doubt, although most authorities place it on the South Canadian or Arkansas rivers in eastern Oklahoma (Bastian, 1966). Historians at the Oklahoma Historical Society have long held the view that the village was located on the Arkansas River in the vicinity of Haskell. Recent study of original maps 
and diaries of various early l8th-century explorers in eastern Oklahoma and adjacent areas has led Mildred Wedel (personal communication) to a similar conclusion. Thoburn (Lewis, 1924: 343) is very specific in describing the location of the village near Haskell, but our survey of the place he suggests revealed no aboriginal or early historic remains, nor could we recognize any early 18th-century artifacts in local collections. Additional survey and examination of collections over a wider area in the Haskell vicinity would be desirable. Perhaps most historians have placed the village on the lower South Canadian River; Smith (1959: 526) has been very specific about its location, but he is reluctant to defend his placement of the village near Rosedale (personal communication). Pending our independent examination of the original materials used by wedel, we feel that a general survey of collections and potential sites along the Canadian River from Rosedale to the Arkansas River and then up the Arkansas to Haskell would be consistent with the available evidence for the location of the village. Such a survey should begin, however, in the Haskell and Rosedale areas.

\section{THE WHEELER COMPLEX}

Three closely related, unexcavated sites in the Hydro-Hinton area of westcentral oklahoma may be protohistoric Wichita sites. Two of the sites, Little Deer ( $\mathrm{Cu}-10)$ and Scott $(\mathrm{Cn}-2)$, are situated on small tributaries of the South Canadian River, and one, Wilson Springs (Cd-6), is near the head of Sugar Creek, which begins near the Canadian but flows south to the Washita. The sites were reported to the University of Oklahoma in the early $1950^{\prime} \mathrm{s}$ by Fenton Wheeler, who recognized their close resemblance to each other. A brief listing and description of some artifacts from one site has been published (Robertson 1955a, 1955b); otherwise the sites have remained largely unknown and unstudied.

\section{The Little Deer Site $(\mathrm{Cu}-10)$}

The site covers less than five acres of a sandy terrace at the confluence of a tributary with Deer Creek, Custer County. At the time of our visits to the site, only a diffuse concentration of debris was apparent on the surface, but Mr. Terry Nowka states that when the site was first plowed, in the early $1950^{\prime} \mathrm{s}$, several distinct concentrations of heavy refuse were apparent. With the assistance of Mr. Nowka and his three sons, a surface collection was gathered, and three lines of small test pits were dug across the site. The tests revealed a moderate amount of refuse, including bones, in the plow zone, but only a few suggestions of sparse subplow zone deposits were found. The following characterization of the artifact complex at the Little Deer Site is based on this survey collection, collections made by Wheeler and Nowka and now stored at the University of Oklahoma Stovall Museum, 
Wheeler's descriptions on file at the Stovall Museum, and the C. B. Robertson collection which Mr. Gregory Perino of the Gilcrease Institute has kindly examined and briefly described in correspondence.

Little Deer Site artifacts (Fig. 5l, A-J):

Small triangular points, unnotched; a few small side-notched triangular points; over half of all the points are made of Kay County flint, but Alibates, Edwards, obsidian, and unidentified flints are also present.

Large scrapers, mostly of Kay County flint, characteristic of the early 18th-century Deer Creek sites on the Arkansas River.

Expanding-base flake drills; a few large drills.

Alternate beveled knives - rare.

Sandstone shaft abraders.

Handstones and grinding basins.

Hammerstones.

rounded

Smooth surfaced, thin, dark-colored, sand-tempered pottery with lips and occasional punctate (usually fingernail) or pinched decoration on the rim or lip. one rim has engraved lines filled with a white pigment, evidently a historic Caddoan sherd such as Natchitoches or Womack Engraved. Small number of various western oklahoma pottery types suggested by caliche and shell tempering and cord marking. One sherd of Glaze 6 from Pecos or northern New Mexico. Also tubular clay pipes with a flared bit and decorations (arrow, serpent) in relief. These latter specimens closely resemble illustrated examples of class IIB2 pipes found at Pecos (Kidder, 1932: 164).

Toothed metapodial flesher.

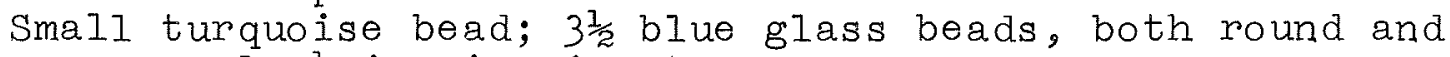
oval, $\frac{1}{4}$ in in diameter.

Several possible native-made gun flints.

Two burials (exposed after creek overflow)

The Scott site $(\mathrm{Cn}-2)$

The Scott Site extends over an irregular area on three different levels or terraces totaling about 40 acres. Judging from a road cut and other small exposures, the highest part of the site is the most productive, but it lay fallow at the times of our several visits. Plowing of the site, subsequent to our visit, is said to have turned up many bones. Debris is moderately abundant in other areas, and a few light bone concentrations may be noted. We were permitted to test in the latter areas, and 
our long series of small tests revealed no debris below the plow zone. Sandy bedrock was encountered at a relatively shallow depth. The following listing of cultural remains found at the scott site is based on the collections of Edward Weil, John B. McAlister, and those made by the survey。

Scott Site artifacts (Fig. 51, K-P):

Unnotched triangular small points; a few side-notched triangular points; mostly made of Kay County flint but some of Alibates, obsidian and unidentified flints. There are a few large points, none of which is made of Kay county flint, and evidently belonging to an earlier component at the site.

Large scrapers, mostly made of Kay County flint. Expanding-base flake drills. Handstones and milling basins.

Smooth surface, thin, dark-colored, sand-tempered pottery with rounded lips; some rims punctated with fingernail or stick impressions; a few small loop handles and lugs occur. A small number of caliche and bone-tempered sherds are present.

One asymetrical, decorated shell button (?) with two central perforations; the relationships remain unknown, but it does not appear to be of recent type.

One native-made gun flint.

One blue glass bead, round, $\frac{1}{4}$ in. in diameter。

\section{The Wilson Springs site (cd-5)}

The site covers several acres and lies at different elevations in the vicinity of a spring. At the time of our visit to the site it was covered with grass. Permission was obtained to conduct tests, but we did not have an opportunity to do so. When Charles Bareis visited the site in $1955^{\circ}$ the surface was exposed, and he found aboriginal materials mixed with a wide range of historic material over a large area. Bareis recovered four unnotched triangular small points; hard, smooth-surfaced, finely-tempered pottery including one rim with a fingernail punctated lip; Kay County and Alibates flint chips; and animal bone. He notes that the pottery is distinct from that known from other sites in the area.

\section{Discussion of the Wheeler Complex}

The artifacts from the Little Deer, Scott, and Wilson Springs Sites seem sufficiently distinctive to warrant a designating term, for which we propose "Wheeler complex" because Fenton Wheeler first recognized the relationship of the sites to each other and their distinction from other nearby sites. Distinctive attributes 
site was excavated by Edward B. Jelks and Lathel F。 Duffield, with the assistance of several members of the Dallas Archeological Society including the authors. A report on the excavation has been published (Duffield and Jelks, 1961).

The Pearson Site was probably abandoned around 1765 as Solís reported that the Tawakoni and related tribes lived between the Trinity and Navasota Rivers in 1767 (Forrestal, 1931: 27). A total of 1,860 beads from Pearson were analyzed.

Gilbert Site (Period 2). The Gilbert site is located on the west side of Lake Fork Creek in Rains County, Texas. It was partially excavated in 1962 as the first excavation project sponsored by the Texas Archeological Society. A report is now in press. Before the society dig, a short preliminary report of tests at the site was published by the authors of the present paper (Harris and Harris, 1962). To date, no historical documents have been found that mention an Indian village in this location; but a large sample of artifacts has been collected from the site, and they clearly indicate a mid-18th century date, probably the third quarter of the century specifically. Evidence of French trade is very heavy. A total of 3,453 beads from Gilbert were analyzed.

Vinson Site (Period 3). The Vinson Site was investigated by the summer field school of the Texas Archeological society in 1964. A report is being prepared by the Tarrant County Archeological Society, who co-sponsored the dig. Located on Tehuacana creek in Limestone County, Texas, this site has been identified with the Norteño Focus by Duffield and Jelks (1961: 70)。 Present evidence suggest that the Vinson site was occupied during the last quarter of the 18 th century and possibly somewhat earlier and/or somewhat later. A total of 1,564 beads from there were analyzed.

Stone Site (Period 3). This site is located on the west bank of the Brazos River above the city of Waco in McLennan County, Texas. Nothing but surface collections have been made at the site, but it appears to belong to the Norteño Focus (Duffield and Jelks, 1961: 70; Harris et al., 1965: 296, $314,352-353)$. Surface collections ma de by Frank H. Watt of Waco and by the authors were used in our study. A total of 139 beads were analyzed.

Gas Plant Site (Period 3). Located on the east side of the Brazos below the city of Waco in McLennan County, Texas, the Gas Plant Site was partially excavated by Harald P. Jensen, Jr., as part of the Wichita Project (see Jensen's description of the site elsewhere in this publication). The artifacts from Jensen's excavations were used in the present analysis, as well as a surface collection made by the authors. The site appears to be of Norteño Focus affiliation and probably dates largely or entirely within Period 3. A total of 161 beads from the Gas Plant Site were analyzed. 
Spanish Fort Sites (Late Period 2 and Period 3). Several major sites located on opposite sides of Red River in Montague County, Texas, and Jefferson County, oklahoma, are included under this heading. For several years, the authors, together with Jay C. and Jerrylee Blaine, have made surface collections from both sides of the river. Materials have been cataloged by three separate sites on the Texas side, and by three separate sites on the Oklahoma side, On the Texas side, the three sites are Lower Tucker, Upper Tucker, and Ayres Farm. The Oklahoma sites are Longest (Northwest Portion), Longest (Northeast Portion), and Longest (South Portion). During the fall of 1965 and the early winter of 1966, excavations were carried out at the Upper Tucker Site as part of the Wichita Project. Jo Ned Woodall's report on the excavations appears elsewhere in this report. Between the fall of 1965 and the spring of 1967, excavations were conducted at the different areas of the Longest site. A report by Tyler Bastian on this field work also appears elsewhere in this report. Krieger (1947: 163) mentions glass beads from the Spanish Fort sites including a description of one type.

The earliest known mention of sites in the Spanish Fort area was in 1759, when a Spanish military expedition attacked a large Taovayas village on the bank of Red River somewhere near the present community of Spanish Fort (castañeda, 1939: 130; Bolton, 1914: Vol。 I, 141; Harper, 1953: 271). Two Taovayas villages on Red River were visited by De Mézières in 1778

(Harper, 1953: 18), and the same or nearby sites were visited by Vial and Fernandez in 1787 and by Marés in 1789 (Harper, 1953: 8). Taovayas sites in the vicinity were also visited in 1808 by a Captain Glass and a Mr. Alexander from Natchitoches (ibid。: 17). The decline of the Taovayas seems to have reached a crisis in 1811, and by 1820 they had abandoned their Red River home and thereafter roamed restlessly between the Wichita Mountains and the Brazos River (ibid。: 18-19).

Bead totals used in the analysis from the Spanish Fort Sites are as follows: Lower Tucker 1,018, Ayers Farm 1,088, Upper Tucker 460, Longest (Northwest Portion) 211, Longest (Northeast Portion) 446, and Longest (South Portion) 3,694: a total of 6,917 for all six sites combined.

Colfax Ferry Site (Late Period 3 and Period 4 ). This site of the Pascagoula and Biloxi Indians, occupied from about 1787 to about 1825, is located about 30 miles below Natchitoches, Louisiana, on the Red River (Gregory and Webb, 1964: 33-39)。 The Colfax Ferry Site is used in this paper as some of the bead. types there also appear at the stansbury site, a Period 3-Period 4 site on the Brazos River in Texas. A total of 38,392 beads from Colfax Ferry were used in this analysis. 
Stansbury (or Towash) Site (Periods 3 and 4). This site, which was located on the east side of the Brazos River in Hill County, Texas, is now covered by the waters of Lake Whitney (Stephenson, 1947). It has been identified with a late 18th century village of the Tawakoni (Jelks, ms) but may be also related to the Towash--or possibly to the Hainai--Indians of the $1830^{\prime} \mathrm{s}$ and $1840^{\prime} \mathrm{s}$. The total bead sample analyzed is 3,419 .

Devils Canyon Site (Period 4). This site is located in the mouth of Devils Canyon, on the north side of the North Fork of Red River in Kiowa County, Oklahoma. The Taovayas Indians were roaming into the wichita Mountain country as early as 1820 (Harper, 1953: 19), and their occupation of Devils Canyon probably started about that time. The site appears certain to be the location of a Wichita village visited by Col. Henry Dodge on July 21, 1834 (Harper, 1953: 23). Shortly after 1836, the Wichita moved east to the present site of Fort Sill (Hodge, 1910: 949). A total of 43,542 beads were analyzed from this site.

Sheridan Lodge Site (Period 5). This site is located near Ft. Sill in Comanche County, Oklahoma, and dates around 1850 according to a personal communication from Tyler Bastian. It is not known whether the site was occupied by the Wichita or by the Kiowa. No count was made on the number of beads, but only on the number of types.

Colonel Cooper Site (Period 5). This site, located on the Brazos River in Palo Pinto County, Texas, was found during the reconnaissance phase of the Wichita project (see Smith's report elsewhere in this publication). A small surface collection has been made from the site. According to Neighbors (1847: 903-906) and Cooper (ms。) there was a Kichai village at the approximate location of the Colonel Cooper site between 1847 and 1851. A small collection of glass beads found by the survey party belongs to Period 5.

\section{Methods of Manufacturing Glass Beads*}

The major technical problem in the mass production of glass beads is that of finding some simple and practical means of forming the perforations by which the beads are strung.

苗he following sections on glass bead manufacture and structure were written by Edward B. Jelks several years ago when he began, but never completed, a treatise on glass beads. With Jelks' permission, these passages from his manuscript have been slightly revised and inserted in the present paper. 
Three basic methods of accomplishing this end have been devised, and all three have been in use for centuries. In this paper we are concerned with only two of the methods, but all three will be described.

One of the methods is to draw out a hollow glass tube and then to break the tube into bead-length sections. A second method is to apply viscous glass around a mandrel or wire by any of several techniques so as to form a bead, after which the mandrel or wire is removed. The third method is to blow a hollow glass sphere, then to puncture its thin walls at two opposite points.

In reference to trade beads, it is suggested that the terms hollow-cane, mandrel-wound, and hollow-sphere be employed respectively as standard names for these three manufacturing methods. Each method is described briefly below, and criteria are given to aid in the recognition of manufacturing methods through examination of the beads themselves.

\section{The Hollow-cane Method}

To make hollow-cane beads, the glass blower gathers a mass of molten glass at the end of his blowpipe (this mass is called a paraison by glass workers), blows a bubble into its center, and shapes it into a small cylinder a few inches long. An assistant attaches an iron rod to the end of the cylinder opposite the blowpipe, and he and the glass blower then move at a fast walk in opposite directions, a procedure which draws out the ductile glass into a long, hollow tube termed a cane. The bubble blown into the paraison at the beginning is e $\overline{l o n g}-$ ated, along with the viscous glass, so as to form a central hollow which runs the entire length of the cane. A cane produced in this manner may be more than 300 feet long. After the cane has been broken into sections about two feet long to facilitate handling, the breaking of the cane sections into bead-length pieces proceeds in the following manner, as described by Lardner (1832: 183):

- a sharp iron instrument is provided, shaped like a chisel, and securely fixed in a block of wood. Placing the glass tube upon the edge of this tool at the part to be separated; the workman then, with another sharp instrument in his hand, cuts, or rather chips, the cane into pieces of the requisite size; the skill of the man being shown by the uniformity of the size preserved between the different fragments. The minute pieces thus obtained are in the next process thrown into a bowl containing a mixture of sand and wood-ashes, in which they are continually 
stirred about until the perforations in the pieces are all filled by the sand and ashes. This provision is indispensable, in order to prevent the sides from falling together when softened by heat in the next operation.

A metallic vessel with a long handle is then provided, wherein the pieces of glass are placed, together with a further quantity of wood-ashes and sand; and the whole being subjected to heat over a charcoal fire, are continually stirred with a hatchetshaped spatula. By this simple means the beads acquire their globular form. This process is here called tumbling.7 When this has been imparted, and the beads are again cool, they are agitated in sieves, in order to separate the sand andashes; this done, they are transferred to other sieves of different degrees of fineness, in order to divide the beads according to their various sizes.

Structurally, hollow-cane beads may be either simple or compound, with layering being the standard technique for fashioning the compound varieties. In making layered beads by the hollow-cane method, the same procedure is followed as described above, except that the initial cylinder, which is shaped from the paraison, is dipped into molten glass of a second color just before the cane is drawn out. As a result, the cane emerges with a veneer of this second kind of glass superposed over the core component. Multiple layers can be formed by additional dippings. (In several archeological reports, each of the different layers in a bead has been called a cane. This, however, is not in accordance with standard usage among glass manufacturers; therefore it is suggested that the term cane be used in reference to the whole tube, whether simple or compound, and layer in reference to the individual concentric componentso)

Inlay, usually of stripes in the case of hollow-cane beads, is achieved by laying slender, solid canes of colored glass longitudinally along the surface of the initial cylinder and pressing them in firmly. Then, when the cane is drawn out, the slender inlaid canes are drawn along with it and appear on the finished beads as inlaid stripes. If the tube is twisted as it is drawn, the stripes will come out spiralled around the bead in the manner of stripes around a barber pole.

In cross section the shape of the cane may be round or polygonal. Some of the faceted beads are made from hexagonal canes by cutting or grinding facets on each end of the bead, 
leaving the original shape of the cane in the middle (Woodward, 1965:9)。

\section{The Mandrel-wound Method}

In making beads by this method, molten glass is formed around a mandrel and, after the glass has cooled, the mandrel is removed, leaving a perforation through the bead. We have been unable to locate any detailed description of the techniques by which the glass is actually formed around the mandrel, but probably the mandrel-wound beads were made by rolling a thread or ribbon of molten glass around a revolving mandrel so as to build up the body of the bead, in much the same manner as yarn is rolled onto a spindle. The exact procedure is not clear, but fortunately such knowledge is not requisite for an accurate bead typology.

Since the mandrel-wound method is inefficient-as compared to the hollow-cane method--for making seed beads, it was seldom if ever used for that purpose.

\section{The Hollow-sphere Method}

This method, which was possibly invented as early as the I5th century, has been used through the years for the production of imitation pearls and other beads. In this process small spheres are blown and perforated on opposite sides before cooling. Then their interior surfaces are coated with an opaque, iridescent substance. In the 19th century, according to Encyclopaedia Brittannica (9th edition, Vol。 3: 460), the iridescent substance was made from the scales of the bleak (Lenciscus alburnus).

Since hollow-sphere beads are quite fragile, they were probably bartered to Indians only rarely, To date, only two reports have been found by the authors that mention the hollowsphere variety of bead having been found archeologically in the United States。 Peter Po Pratt (1961: 15 \& No. 97 on color plates) is evidently describing hollow-sphere beads in the following passage (in reference to four beads from the Whitney Site, apparently somewhere in New York State): "。 。 like imitation pearls; they have outer layer about 1/64th inch thick The inner core has decomposed making these beads very fragile." The other reference is by Hiram Gregory and Clarence Webb (1964: 39) who describe five different types of hollow-sphere beads from the Colfax Ferry Site in Louisiana. 
Of the 184 types of glass beads recognized here, the following types were made from hollow canes: Noso 1 through 39; Nos. 44 through 51; Nos. 55 through 87; Nos. 90 through 92; Nos. 96 through 99; Nos。 113 through 123; Nos。 125 through 140; Nos. 146 through 153; Nos. 155 through 157; Nos. 159 through 168; Nos. 170 through 172; and Nos. 174 through 183. The others were made either by the mandrel-wound method or were molded. Based on these data, it appears, therefore, that the hollow-cane method of bead manufacture was the most popular method from 1700 to 1850 .

Many of the larger trade beads are mandrel-wound. Most, or possibly all, molded trade beads were also formed around mandrels; so molding may be considered a special technique of the mandrel method. The surfaces of many mandrel-wound beads are smoothed, polished, or faceted. This was probably done with small paddle-shaped tools while the mandrel was being rotated and the bead still plastic; for faceting, the mandrel would be stopped and facets pressed while the bead was plastic.

\section{Structure}

In spite of their small size, some glass beads are made up of numerous structural components. Most striped Cornaline d'Aleppo beads (Types 67 and 68 herein), for example, contain at least 38 distinct structural elements: three sets of stripes, each set consisting of three separate stripes, and each stripe made up of four or five tiny glass rods (minimum of 36 tiny rods); plus a core of green glass, a layer of opaque red glass, and sometimes a thin veneer of transparent glass on the surface.

In this study the beads were classified into three categories on the basis of structure: simple, compound, and complex.

Simple beads are those composed of a monolithic, structurally undifferentiated mass of glass. Both hollow-cane and mandrel-wound forms are common.

Compound beads are those consisting of two or more concentric layers of glass, one over the other. These are normally hollow-cane beads.

Complex beads are those having decorative designs made of tiny glass elements that are pressed into the bead. 
Glass Bead Type Descriptions

In the following descriptions, a standard color chart (Bustanoby, 1947: 28-29, Plate 8) has been used to indicate the hues of the beads. It should be noted that bead surfaces are frequently altered by age and weathering, and it is sometimes difficult to determine the original color. However, the color can often be restored by immersing the bead in a weak solution of muriatic acid for about two hours and then washing it in water. It is surprising how many beads that would have otherwise been classified as dirty white turn out to be red, green, yellow, or blue when cleaned.

General terms are used to describe the bead shapes: barrel shaped, donut shaped, round, and tube shaped (bugle). Some of the larger (necklace) beads are described as being olive shaped. This term was taken from an early 18 th century document (Thwaites, 1959: 143) and was apparently widely used by the French to describe certain of the trade beads.

There is documentary evidence that Indians used the larger beads mainly for necklaces and the small and mediumsized ones principally on skins, garters, and the like. The large beads will here be referred to as necklace beads, the medium and small ones as garter beads. The beads were sorted into size groups as follows:

$$
\begin{aligned}
& 0-2 \mathrm{~mm}=\text { extra small } \\
& 2-4 \mathrm{~mm}_{0}=\text { small } \\
& 4-6 \mathrm{~mm}_{0}=\text { medium } \\
& \text { over } 6 \mathrm{~mm}=\text { large }
\end{aligned}
$$

(The measurements are for bead diameter, perpendicular to the hole axis. The length is disregarded in this classification.)

At the end of each type description, it will be indicated whether the bead is tumbled (that is, in the manufacturing process as described above), untumbled (with ends left sharp), and/or twisted (while the hot canes were being stretched lengthwise)。The abbreviations T, UT, and TW Will be used to indicate the respective processes.

No. 1. Large, white, opaque, olive-shaped necklace bead of simple construction. The glass is porcelain-like in texture. T

No.2. Large, white, opaque, elongated, olive-shaped necklace bead of simple construction. The glass is porcelainlike in texture. $\mathrm{T}$

* Bead types illustrated in Figures 52 and 53. 
No. 3. Large, white, opaque, round necklace bead of simple construction. The glass is porcelain-like in texture. T。

No. 4. Large, white, opaque, barrel-shaped necklace bead of compound construction. The inner layer of glass has a porcelain-like texture, while the outer layer is clear glass but has a slightly frosted appearance, probably due to age. T.

No. 5. Medium, white, opaque, barrel-shaped garter bead, of compound construction. The inner layer of glass has a porcelain-like texture, while the outer layer is clear glass but has a slightly frosted appearance, probably due to age. T.

No. 6. Medium, white, opaque, olive-shaped garter bead of simple construction. The glass is porcelain-like in texture. T。

No. 7. Large, grayish-white, semitranslucent, oliveshape $\bar{d}$ necklace bead of simple construction. The glass has a frosted-like appearance. T.

No. 8. Large, light grayish-white, semitranslucent, donut-shaped necklace bead of simple construction. The glass has a frosted-like appearance similar to No。7. T.

No. 9. Large, Peacock Blue, opaque, elongated, oliveshape d necklace bead of simple construction. The glass has fine lines running lengthwise with the bead, giving it a texture reminiscent of stripped sugarcane. T.

No. 10. Large, Peacock Blue, opaque, barrel-shaped necklace bead of simple construction. The glass has fine lines running lengthwise with the bead, giving it a texture reminiscent of stripped sugarcane. T。

No. 11. Medium, Peacock Blue, opaque, barrel-shaped garter bead of simple construction. The glass has fine lines running lengthwise with the bead, giving it a texture reminiscent of stripped sugarcane. To

No. 12. Large, Turquoise Blue, opaque, olive-shaped necklace bead of simple construction. The glass is porcelain-like in texture. T。

No. 13. Large, dark Bluebird Blue, translucent, oliveshaped necklace bead of simple construction. The glass is often cane-like in appearance. T.

No. 14. Medium, dark Bluebird Blue, translucent, oliveshaped garter bead of simple construction. To 
No. 15. Medium, Gobelin Blue, opaque, barrel-shaped garter bead of simple construction. The glass is porcelainlike in texture. T.

No. 16. Large, clear, olive-shaped necklace bead of simple construction. The glass is clear but, due to age, sometimes appears frosted. T.

No. 17. Large, black, opaque, olive-shaped necklace bead of simple construction. The glass is somewhat cane-like in appearance. T.

No. 18. Large, black, opaque, round necklace bead of simple construction. The glass is porcelain-like in appearance. T。

No. 19. Large, Dandelion Yellow, opaque, barrel-shaped necklace bead of simple construction. The glass is porcelainlike in texture. T.

No. 20. Large, white, opaque, elongated, olive-shaped necklace bead of complex construction. The bead surface is covered with four dark blue stripes which are evenly spaced and parallel the long axis. The white glass is porcelain-like in texture. T.

No. 21. Large, white, opaque, olive-shaped necklace bead of complex construction. The bead surface is covered with three blue stripes which are evenly spaced and parallel to the long axis. The white glass is porcelain-like in texture. T.

No. 22. Large, white, opaque, olive-shaped necklace bead of complex construction. The bead surface is covered with two red and two blue alternating stripes. The white glass is porcelain-like in texture. T.

No. 23. Large, bluish-white, opaque, olive-shaped necklace bead of complex construction. The bead surface is covered with three longitudinal sets of three blue stripes spaced evenly around the bead. The bluish-white glass is porcelain-like in texture. T.

No. 24. Large, white, opaque, olive-shaped necklace bead of complex construction. Extending longitudinally across the surface of the bead are three sets of stripes, each of which is composed of two red stripes, and between these, a blue stripe. The white glass is porcelain-like in texture. T.

No. 25. Large, white, opaque, olive-shaped necklace bead of complex construction. The bead surface is covered with three sets of stripes, and between these, a blue stripe. The white glass is porcelain-like in texture. T. 
No. 26. Large, white, opaque, olive-shaped necklace bead of complex construction. The bead surface is covered with three sets of three blue stripes which are twisted in an S-shape around the bead. The white glass is porcelain-like in texture. The inner layer of glass is bluish-white. TW. T.

No. 27. Large, white, opaque, olive-shaped necklace bead of complex construction. The surface of the bead is covered with six more or less evenly spaced blue stripes which are twisted around the bead in an S-shape. The white glass is porcelain-like in texture. TW. T.

No. 28. Large, white, opaque, olive-shaped necklace bead of complex construction. The bead surface is covered with six rather evenly distributed red stripes which are twisted around the bead in an S-shape. The white glass is porcelain-like in texture. TW。 T.

No. 29. Large, Emerald Green, translucent, barrel-shaped necklace bead of complex construction. The bead surface is covered with eight white stripes, rather evenly spaced and parallel to the long axis. $T$.

No. 30. Large, Brittany Blue, opaque, elongated, oliveshaped necklace bead of complex construction. The surface of the bead is covered with three evenly spaced sets of stripes, each of which is composed of two white stripes, and between these, a red stripe. T.

No. 31. Large, dark Bluebird Blue, translucent, oliveshaped necklace bead of complex construction. The surface of the bead is covered with five white stripes, twisted S-like around the bead. TW. T.

No. 32. Large, dark Bluebird Blue, translucent, oliveshape d necklace bead of complex construction. Parallel to the long axis of the bead are more or less evenly spaced crescent-like white stripes. T.

No. 33. Large, dark Bluebird Blue, translucent, oliveshaped necklace bead of complex construction. The surface of the bead is covered with three sets of stripes, each of which is composed of two white stripes and, between these, a red stripe. T。

No. 34. Large, dark Bluebird Blue, translucent, barrelshape necklace bead of complex construction. The surface of the bead is covered with eight evenly spaced white stripes. T. 
No. 35. Large, clear, donut shaped necklace bead of complex construction. Eight twisted white stripes appear embedded in the body of the glass. In making this bead, a layer of clear glass was used for the core, then the white stripes were pressed into the surface of glass, and another layer of clear glass was added to finish the bead. The white stripes are twisted in S fashion. TW. T.

No. 36. Large, clear, barrel-shaped necklace bead of complex construction. The surface of the bead is covered with twelve white stripes running lengthwise with the bead. The surface of this bead type, like that of No. 35, sometimes appears frosted, probably due to age. This type is often called the "gooseberry bead." T.

No. 37. Large, black, opaque, barrel-shaped necklace bead of complex construction. The surface is covered with eight white longitudinal stripes, spaced more or less evenly. The black glass is porcelain-like in texture. T.

No. 38. Large, black, opaque, donut-shaped necklace bead of complex construction. The surface of the bead is covered with eight white stripes twisted around the bead in an $S$ pattern. The black glass is porcelain-like in texture. TW. T.

No. 39. Large, black, opaque, round necklace bead of complex construction. The surface of the bead is covered with six ivory-colored, crescent-shaped stripes which run perpendicular to the core. The black glass is porcelain-like in texture. T.

No. 40. Large, Bluebird Blue, translucent, eight-faceted necklace bead of mandrel-wound, pressed facet, simple construction. The surface of the glass sometimes appears to be frosted, probably due to age.

No. 4l. Large, milk-glass, eight-faceted necklace bead of mandrel-wound, pressed facet, simple construction. The surface sometimes appears frosted, probably due to age.

No. 42. Large, clear, barrel-shaped necklace bead of mandrel-wound, probably pressed facet, simple construction. The surface resembles that of hobnail glass. This type is often called the "mulberry bead."

No. 43. Large, clear, barrel-shaped necklace bead of mandrel-wound, probably pressed facet, simple construction. The surface is pressed into six spiral-shaped elements which give a corrugated effect. 
No. 44. Sma11, white, opaque, donut-shaped garter bead of simple construction. The glass has a porcelain-like texture. T.

No. 45. Small, white, opaque, donut-shaped garter bead of compound construction. The inner layer has a porcelainlike texture, and the outer layer is clear but has a slightly frosted appearance, probably due to age. T.

No. 46. Small, Peacock Blue, opaque, donut shaped garter bead of simple construction. The glass of this bead has a sugarcane-like texture. T.

No. 47. Small, Gobelin Blue, opaque, donut-shaped garter bead of simple construction. The glass has a porcelain-like texture. T.

No. 48. Small, dark Bluebird Blue, translucent, donut-

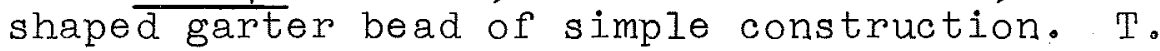

No. 49. Small, clear, donut-shaped garter bead of simple construction. T.

No. 50. Small, black, opaque, donut-shaped garter bead of simple construction. The glass is porcelain-like in texture. T.

No. 51. Sma11, red, opaque (outer layer), donut-shaped garter bead of compound construction. The outer layer of opaque glass is brick red, and the inner layer is a translucent light green. This bead is generally referred to as

"Cornaline d'Aleppo."T.

No. 52. Large, amber, translucent, barrel-shaped necklace bead of mandrel-wound simple construction.

No. 53. Large, milk-glass, translucent, round necklace bead of mandrel-wound construction.

No. 54. Large, milk-glass, translucent, olive-shaped necklace bead of mandrel-wound simple construction.

No. 55. Large, red, opaque (outer layer), tube-shaped (bugle) necklace bead of compound construction. The outer layer of opaque glass is brick red and the inner layer is a translucent light green. This bead is generally referred to as "Cornaline d'Aleppo," but in this case the bead stock was broken into tube-shaped beads. T.

No. 56. Small, Brittany Blue, opaque, tube-shaped (bugle) garter or necklace bead, of simple construction. The glass is porcelain-like in texture. T. 
No. 57. Small, red, opaque (outer layer), tube-shaped (bugle): garter or necklace bead of compound construction. The outer layer of opaque glass is brick red and the inner layer is translucent light green. This bead is the same as No. 55 except the diameter equals that of a small size bead. T。

No. 58. Extra small, red, opaque (outer layer) tube-

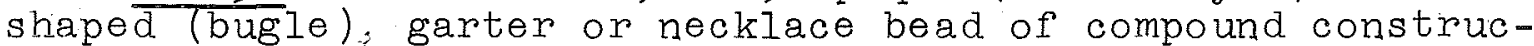
tion. The outer layer of opaque glass is brick red and the inner layer is translucent green. This bead is the same as No. 55, except the diameter is approximately one millimeter. T.

No. 59. Large, red, opaque (outer layer), tube-shaped (bugle) necklace bead of compound construction. The outer layer of opaque glass is brick red and the inner layer is a translucent light green. This bead is the same as No. 55, with the exception of the extra large diameter. Beads No. 57, 58, and 59 are generally referred to as "Cornaline d'Aleppo." T.

No. 60. Small, Gobelin Blue opaque tube-shaped (bugle) garter or necklace bead of simple construction. The glass is porcelain-like in texture. T.

No.61. Small, dark Bluebird Blue, translucent, tube-

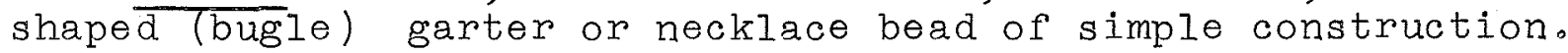
T.

No. 62. Small, Fern Green, opaque tube-shaped (bugle) garter or necklace bead of simple construction. The glass is porcelain-like in texture. T.

No. 63. Small, Colonial Yellow, translucent, tube-shaped (bugle) garter or necklace bead of simple construction. T.

No. 64. Sma11, white, opaque, tube-shaped (bugle) garter or necklace bead of simple construction. T.

No. 65. Small, white, opaque, tube-shaped (short bugle) garter or necklace bead of compound construction. The inner layer has a porcelain-like texture while the outer layer has a slightly frosted appearance. JT.

No. 66. Small, black, opaque, tube-shaped (bugle) garter or necklace bead of simple construction. The glass of this bead is porcelain-like in texture. UT.

No. 67. Small, red, opaque (outer layer), tube-shaped (bugle) garter or necklace bead of complex construction. The 
surface of the bead is covered with three evenly spaced sets of stripes, each of which is composed of two white stripes, and between these, a red stripe. The inner layer is translucent light green. This appears to be a variety of "Cornaline d'Aleppo" with addition of stripes. T.

No. 68. Small, red, opaque (outer layer), tube-shaped (bugle) garter or necklace bead of complex construction. The surface of the bead is covered with three evenly spaced sets of stripes, each of which is composed of two white stripes and, between these, a chocolate brown stripe. The inner layer is translucent light green. This appears to be a variety of "Cornaline d'Aleppo" with the addition of stripes. T.

No. 69. Small, dark amber, opaque, tube-shaped (bugle) garter or necklace bead of complex construction. The surface is covered with nine alternating red and white stripes which run parallel to the long axis of the bead. T.

No. 70. Small, dark Bluebird Blue, translucent, tubeshaped (bugle) garter or necklace bead of complex construction. The surface of the bead is covered with three evenly spaced sets of stripes, each of which is composed of two white stripes, and between these, a red stripe. T.

No. 71. Small, Peacock Blue, opaque, tube-shaped (bugle) garter or necklace bead of complex construction. The surface of the bead is covered with three evenly spaced white stripes. UT.

No. 72. Small, dark Bluebird Blue, translucent, tubeshaped (bugle) garter or necklace bead of complex construction. The surface of the bead is covered with four alternating red and white stripes which are evenly spaced. T.

No. 73. Small, bluish-white, opaque, tube-shaped (bugle) garter or necklace bead of complex construction. The surface is covered with three blue stripes evenly spaced around the bead. T.

No. 74. Small, white, opaque, tube-shaped (bugle) garter or necklace bead of complex construction. The bead surface is covered with three chocolate brown stripes, evenly spaced around the bead. UT.

No. 75. Large, Colonial Yellow, opaque, olive-shaped necklace bead of simple construction. The glass is somewhat cane-like in texture and has numerous bubbles throughout. T.

No. 76. Large, black, opaque, donut-shaped necklace bead of simple construction. The glass is porcelain-like in texture. T. 
No. 77. Large, dark Bluebird Blue, translucent, donutshape necklace bead of simple construction. T.

No. 78. Medium, pearly white, opaque, donut-shaped garter bead of simple construction. T.

No. 79. Small Sky Blue, opaque, donut-shaped garter bead of simple construction. T.

No. 80. Small, Peacock Blue, translucent donut to barrelshape garter bead of simple construction. T.

No. 81. Small, Colonial Yellow to Brass colored, opaque, donut-shaped garter bead of simple construction. The glass often has a cane-like texture. T.

No. 82. Small, Colonial Yellow to Brass colored, translucent donut-shaped garter bead of simple construction. T.

No. 83. Sma11, Emerald Green, translucent, donut-shaped garter bead of simple construction. T.

No. 84. Small, Emerald Green, opaque, donut-shaped garter bead of simple construction. The glass sometimes has a canelike texture. T.

No. 85. Large, Emerald Green, translucent, barrel-shaped necklace bead of simple construction. T.

No. 86. Large, brick red, opaque, donut-shaped necklace bead of compound construction. The outer layer of glass is brick red, and the inner layer is translucent light green. This bead is generally referred to as "Comaline d'Aleppo." T.

No. 87. Small, brick red, opaque, donut-shaped garter bead of compound construction. T.

No. 88. Large, Emerald Green, translucent, teardropshape d, faceted necklace bead of simple construction. The bead has a square hole and the surface has 6 pressed facets.

No. 89. Large, dark Bluebird Blue, translucent, teardrop-shaped, faceted necklace bead of simple construction. The bead has a square hole and the surface has 6 pressed facets.

No.90. Medium, bluish-white, opaque, donut-shaped garter bead of complex construction. On the surface of the bead are four rather evenly spaced blue stripes. T. 
No. 91. Small, black, opaque, donut-shaped garter bead of complex construction. The bead surface is covered with four rather evenly spaced white stripes. The black glass is porcelain-like in texture. T.

No. 92. Large, black, opaque, donut-shaped necklace bead of complex construction. On the surface are 5 pairs of rather evenly spaced white stripes. The black glass is porcelain-like in texture. T.

No. 93. Large, milk-glass, translucent, donut-shaped necklace bead. of mandrel-wound simple construction.

No. 94. Large, amber, translucent, donut-shaped, necklace bead. of mandrel-wound simple construction.

No. 95. Large, Olive Green, translucent, donut-shaped. necklace bead of mandrel-wound simple construction.

No. 96. Medium, black, opaque, donut-shaped garter bead of simple construction. The glass is porcelain-like in texture.T.

No. 97. Large, Colonial Yellow, semitranslucent, barrelshape d necklace bead of simple construction. T.

No.98. Medium, Colonial Yellow, semitranslucent, donut-

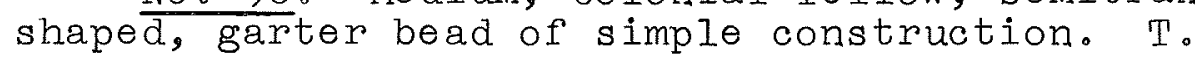

No. 99. Medium, Brick Red, opaque, donut-shaped garter bead of compound construction. The inner layer is translucent green. This type is generally referred to as "Cornaline d'Aleppo."T.

No. 100. Large, Harvard Crimson, semitranslucent, elongated or tube-shaped necklace bead of mandrel-wound simple construction.

No. 101. Medium, white, opaque, olive-shaped necklace or garter bead of mandrel-wound simple construction.

No. 102. Medium, white, opaque, olive-shaped necklace or garter bead of mandrel-wound simple construction. The surface has four pressed facets.

No. 103. Medium, Harvard Crimson, translucent, oliveshape d garter or necklace bead of mandrel-wound simple construction.

No. 104. Medium, Harvard Crimson, translucent, oliveshaped necklace or garter bead of mandrel-wound simple construction. The surface of the bead has four pressed facets. 
No. 105. Medium, pink and white, opaque necklace or garter bead of mandrel-wound construction. The surface of the bead has three pressed facets. It appears that two colors of hot glass threads (one pink and the other white) were wound on to the mandrel at the same time, giving the bead a marbled appearance.

No. 106. Medium, turquoise, opaque, olive-shaped necklace or garter bead of mandrel-wound compound construction. The outer layer of glass is turquoise and the inner layer is white. The surface of this type is nearly always badly pitted.

No. 107. Medium, dark Bluebird Blue, semitranslucent, olive-shaped necklace or garter bead of mandrel-wound simple construction.

No. 108. Medium, Black, olive-shaped, opaque necklace or garter bead of mandrel-wound simple construction.

No. 109. Medium, Turquoise, olive-shaped, opaque necklace or garter bead of mandrel-wound simple construction.

No.110. Medium, Pumpkin Yellow, olive-shaped, opaque necklace or garter bead of mandrel-wound simple construction.

No. 111. Large, Grape, donut-shaped, opaque necklace bead of mandrel-wound compound construction. The inner layer of glass is thin and Cornflower Blue in color.

No. 112. Large, Grape, opaque necklace bead of mandrelwound simple construction. The surface of the glass has five pressed facets.

No. 113. Large, Emerald Green, barrel-shaped necklace bead of complex construction. On the surface of the bead are five longitudinal sets of stripes, each of which is composed of two white stripes, and between these, a brick red stripe. Beneath the decorated surface is a thin layer of white opaque glass. The core is made of a thick layer of Delft Blue opaque glass. T.

No. 114. Large, dark Delft Blue, barrel-shaped necklace bead of complex construction. The surface of the bead is covered with five longitudinal sets of white stripes, and between these is a wider brick red stripe. The inner layer or core of the bead is a very light shade of Delft Blue semitranslucent glass. T.

No. 115. Medium, Bluebird Blue, donut-shaped, translucent necklace or garter bead of complex construction. On the surface are four rather evenly spaced white stripes which run parallel with the axis of the bead core. T. 
No. 116. Small, black, opaque donut-shaped garter bead of complex construction. The surface is decorated with six rather unevenly spaced brick-red stripes. The black glass is porcelain-like in texture. T。

No. 117. Sma11, white, opaque, donut-shaped garter bead of complex construction. The surface is decorated with four brick-red stripes which run parallel with the bead axis. T.

No, 118. Sma11, white, opaque, donut-shaped garter bead of complex construction. Two red stripes and two blue stripes alternate around the bead, the stripes running parallel with the bead axis. T.

No. 119. Medium, white, opaque, donut-shaped garter bead of complex construction. On the surface are two red, two green, and two blue alternating stripes that run parallel with the bead axis. T.

No. 120. Medium, brick red, opaque, barrel-shaped garter bead of complex construction. There are four rather evenly spaced white stripes running parallel to the bead axis. The inner layer of glass is translucent light green. This appears to be a variety of "Cornaline d'Aleppo" with white stripes. T。

No. 121. Large, white, opaque, barrel-shaped necklace bead of complex construction. There are two pair of red stripes and two pair of blue stripes alternating around the bead. The stripes run parallel to the bead axis. The white glass is porcelain-like in texture. T.

No. 122. Medium, white, opaque, barrel-shaped garter or necklace bead of complex construction. Two red and two green stripes alternate around the bead. The stripes run parallel to the bead axis. The white glass is porcelainlike in texture. T.

No. 123. Medium, black, opaque, donut-shaped garter bead of complex construction. There are two red and two white stripes alternating around the bead. The stripes run parallel to the bead axis. T.

No. 124. Large, white, opaque, olive-shaped necklace bead of complex mandrel-wound construction. On the bead surface is a blue floral pattern.

No. 125. Extra smal1, Mint Green, opaque, donut-shaped garter bead of simple construction. T。 
No. 126. Extra small, Bluebird Blue, opaque, donutshape garter bead of simple construction. T.

No. 127. Extra small, milk white, translucent, donutshaped garter bead of simple construction. T.

No. 128. Extra small, white, opaque, donut-shaped garter bead of simple construction.'T.

No. 129. Large, dark Bluebird Blue, barrel-shaped, translucent necklace bead of compound construction. The outer layer of glass has approximately 16 to 20 facets. The inner layer of glass is blue-white in color. The hollow cane used in this type of bead was hexagonal in cross section. After a piece was cut off the cane, approximately 6 facets were cut on each end of the bead. This would leave 6 facets around the center from the original shape of the cane.

No. 130. Large, dark Bluebird Blue, barrel-shaped, translucent faceted necklace bead of simple construction. There are 16 to 20 facets on the surface of the bead. This bead was made in the same way as Bead No. 129.

10. 131. Large, Fern Green, barrel-shaped, translucent necklace bead of faceted simple construction. The surface of the bead has six facets. The hollow cane used in this type of bead was hexagonal in cross section. The facets were not cut on each end as was done in making Bead No. 129. In fact, this bead is only a short section of the original cane.

No. 132. Large, milk.glass, translucent, barrel-shaped necklace bead of compound, faceted construction. The outer layer of glass has approximately 16 to 20 facets. The inner layer is milk-white in color. This bead was made in the same way as Bead No. 129.

No. 133. Large, Ruby Red, translucent, somewhat irregular round-shaped necklace bead of simple construction. The surface of the bead has approximately 16 facets. The facets were probably cut.

No. 134. Small, dark Amber, barrel-shaped, translucent, faceted garter bead of simple construction. The facets appear to be pressed and vary from four to eight in number.

No, 135. Small, Pimento, translucent, donut-shaped garter bead of faceted, simple construction. The hollow cane used to make this bead was hexagonal in cross section; therefore the bead has six facets.

No. 136. Large, clear, barrel-shaped necklace bead of simple construction. T. 
No. 137. Medium, white, opaque, barrel-shaped garter bead of simple construction. T.

No. 138. Medium, Peacock Blue, translucent, barrel-shaped garter bead of simple construction. T.

No. 139. Large, barrel-shaped, clear necklace bead of simple, faceted construction. There are approximately 16 to 20 facets on the surface of the bead. This bead was made in the same way as Bead No. 129.

No. 140. Smal1, Turquoise, opaque, donut-shaped garter bead of simple construction. T.

No. 14l. Medium, milk glass, semitranslucent, ovoid garter or necklace bead of mandrel-wound simple construction.

No. 142. Medium, dark Bluebird Blue, translucent, ovoid garter or necklace bead of mandrel-wound simple construction.

No. 143. Medium Emerald Green, translucent, ovoid garter or ne cklace bead of mandrel-wound simple construction.

No. 144. Medium, Harvard Crimson, translucent, ovoid garter or necklace bead of mandrel-wound simple construction.

No. 145. Large, Turquoise, opaque, round necklace bead of mandrel-wound simple construction.

No. 146. Large, Bottle Green, semitranslucent, oliveshape d necklace bead of simple construction. T.

No. 147. Large, Bluebird Blue, translucent, round, faceted necklace bead of simple construction. This bead has approximately 30 facets, and they appear to be cut facets.

No. 148. Medium, light pink, translucent, round, faceted necklace or garter bead of simple construction. This bead has approximately 16 facets which appear to be cut.

No. 149. Extra small, black, opaque, tube-shaped (bugle) garte $\frac{}{r}$ bead of faceted, simple construction. The hollow cane used to make this bead was hexagonal in cross section; therefore the bead has six facets. T.

No. 150. Extra small, clear, donut-shaped garter bead of faceted, simple construction. The hollow cane used to make this bead was hexagonal in cross section, producing six facets. T。

No. 151. Extra small, Fern Green, translucent, donutshape garter bead of faceted, simple construction. The hollow 
cane used to make this bead was hexagonal in cross section; therefore the bead has six facets. T.

No. 152. Extra smal1, Independence Blue, opaque, donutshape d garter bead of faceted, simple construction. The hollow cane used to make this bead was hexagonal in cross section; therefore the bead has six facets. T.

No. 153. Extra small, black opaque, donut-shaped garter bead of faceted, simple construction. The hollow cane used to make this bead was hexagonal in cross section; therefore the bead has six facets. T.

No. 154. Large, Harvard Crimson, translucent (outer layer), olive-shaped necklace bead of compound, mandrel-wound construction. The inner layer of glass is opaque white.

No. 155. Extra smal1, Peacock Blue, opaque, donut-shaped garter bead of simple construction. The glass has fine lines running lengthwise with the bead, giving it a texture reminiscent of stripped sugarcane. T.

No. 156. Large, barrel-shaped, Magenta, translucent necklace bead of simple, faceted construction. There are usually 16 to 20 facets on the surface of the bead. This bead was made in the same way as No. 129.

No. 157. Small, Magenta, opaque, tube-shaped (bugle) garter or necklace bead of simple construction. The glass is porcelain-like in texture. T.

No. 158. Medium, Emerald Green, translucent, olive= shaped necklace or garter bead of mandrel-wound simple construction.

No. 159. Large, Sky Blue, opaque, round necklace bead of simple construction. The bead usually has a ridge around the circumference as if it might be of pressed construction.

No. 160. Medium, Sunflower Yellow, translucent, round garter or necklace bead of simple construction.

No. 161. Sma11, Pimento, opaque, round garter bead of simple construction.

No. 162. Large, Black, olive-shaped necklace bead of complex construction. The surface of the bead is covered with a wavy spiral of cream-colored glass rod.

No. 163. Large, amber, semitranslucent, tube-shaped necklace bead of complex construction. The surface of the bead is covered with twisted copper-colored stripes.TW.UT. 
No. 164. Medium, Bluebird Blue, translucent, barrelshaped garter bead of simple construction. T.

No. 165. Medium, white, opaque, donut-shaped garter bead of compound construction. The outer layer of glass is white and is porcelain-like in texture. The inner layer is a very pale yellow in color and contains many small bubbles. T.

No. 166. Extra small, Mint Green, translucent, donutshaped garter bead of faceted, simple construction. The hollow cane used to make this bead was hexagonal in cross section; therefore the surface of the bead has six facets. T.

No. 167. Large, light pink, translucent, olive-shaped necklace bead of faceted, simple construction. The surface of the bead is covered with 20 facets.

No. 168. Small, Navy Blue, opaque, round garter bead of simple construction.

No. 169. Medium, dark Bluebird Blue, semitranslucent, "somewhat" olive-shaped necklace or garter bead of mandrelwound, pressed facet, simple construction. There are eight pressed facets.

No. 170. Large, black, barrel-shaped, opaque, faceted necklace bead of simple construction. There are generally from 16 to 20 facets. The hollow cane used in this type of bead was hexagonal in cross section. The facets were cut in the same manner as No. 129.

No. 171. Large, barrel-shaped, Emerald Green, translucent, faceted necklace bead of simple construction. There are usually 16 to 20 facets. This bead was made in the same way as No. 129.

No. 172. Large, round, clear, faceted necklace bead of simple construction. This bead has approximately 30 facets which appear to be cut. The surface is slightly frosted, probably from age.

No. 173. Large, clear, round, pressed facet over Harvard Crimson,mandrel-wound necklace bead of compound construction. The outer layer has a five-pointed star pressed in each end of the bead, and the surface is frosted due to age. The inner Harvard Crimson bead is olive-shaped, and translucent, and is listed as No. 103 on the Bead Chart. In reality, this is a bead built over another bead.

No. 174. Extra small, Harvard Crimson, translucent (outer layer), donut-shaped garter bead of compound construction. The inner layer of glass is opaque white. T. 
No. 175. Extra small, Colonial Yellow, opaque, donutshape d garter bead of simple construction. T.

No. 176. Extra small, Harvard Crimson, translucent donutshape d garter bead of simple construction. T.

No. 177. Extra small, Baby Pink, opaque, donut-shaped garter bead of simple construction. T.

No. 178. Extra small, Sky Blue, opaque, donut-shaped garter bead of simple construction. T.

No. 179. Extra small, Independence Blue, opaque, donutshaped garter bead of simple construction. T.

No. 180. Extra small, Yale Blue, translucent, donutshaped garter bead of simple construction. T.

No. 181. Extra smal1, Fern Green, opaque, donut-shaped garter bead of simple construction. T.

No. 182. Extra small, light pink, translucent, donutshape d garter bead of simple construction. T.

No. 183. Small, dark Bluebird Blue, translucent, tubeshape $\bar{d}$ (bugle) garter bead of simple construction. T。

No. 184. Large, dark Bluebird Blue, translucent, flattened oval necklace bead of simple, molded construction. The bead appears to have been made in a two piece mold, with facets in each side of the mold. There are 20 facets on each side, making a total of 40 facets on the completed bead. The bead has two holes for stringing, not on center but offset to one side.

\section{Type Descriptions for Shell Trade Beads}

No. 1. Smal1, white or purple banded, tube-shaped bead. The drilled hole is very uniform in size through the bead and probably was made with a metal drill as it does not appear hour-glass-shaped like typical Indian drilling. The bead is about 12 millimeters long.

No. 2. Small, white or purple banded, tube-shaped bead made from shell. The hole is of uniform diameter throughout. Length is about 6 millimeters.

Both of these shell beads have been identified by Arthur Woodward as shell wampum (personal communication). 
In this section, the utility of bead types as time markers will be discussed. Some bead types are not definitive of a certain time period, but extend through three or four of the periods recognized here. For example, some types of small garter beads may be present in about the same percentage from about 1700 to around 1836. In general, it can be said that the most definitive bead types are the medium- and large-size complex, striped ones and the medium- and large-size faceted forms. Sometimes a bead type may come into the trade in large numbers in a certain time period, and drop down to very small numbers in the following time periods. Where only one specimen of a type (Type No. 19, for example) is known from the area, it will not be discussed, due to lack of information.

\section{Period I ( 1700 to 1740 )}

Types 1-18, 20-43, and 52-54 appear to be characteristic of this period. These types match, almost type for type, between the Womack Site and the Angola Farm Site, and many of them match types from the Fish Hatchery, Roseborough Lake, Bryson, Sanders, and Nacogdoches sites. Most of the above types are found in large numbers during this period with the exception of some of the rarer stripes and facets which are present only in small numbers at any site. Types 16-22, 24 , $25,27-39,42,43$, and 52 do not occur at sites dating after Period 1 .

In the small garter beads, Types 44-46 and 48-51 are present beginning in Period 1 and extending through Period 4, or from around 1700 to 1836 .

During Period 1, the main source of the trade seems to have been the French settlements in Louisiana.

\section{Period 2 (1740 to 1767)}

Types $1-15,23,26,40,41,53$, and 54 are still in the trade from Period 1 but are found in reduced numbers. Small garter bead Types 44-46 and 48-51 are still present in large numbers. Types 2, 6-8, 12-15, 47, and 56 do not appear in the trade after 1767 (the end of Period 2)。

A few new bead types come into the trade during Period 2. Some of these are tube (or bugle) beads: Types 57, 59-62, and 66-69. Other new types are Nos.76-87, 90-92, 96, 97, 99, and 164 . 
Type 88 (green) is present in Period 2 at the Pearson Site in a single specimen. Type 89 (blue) is present at the Longest Site (south area) in a single specimen. The authors have seen this same form in black from the site of Presidio San Luis delas Amarillas. These beads have been examined by two Catholic priests, and both are of the opinion that this form is probably a rosary bead.

During Period 2 the source of the beads seems to be through the French trade from Louisiana.

\section{Period 3.(1767 to 1820)}

During this period a few of the earlier types from Period 1 are present, but usually in very small numbers. These are as follows: Nos. 1, 3-5, 9-11, 23, 26, 40, 41, and 53. Also, a few of the types from Period 2 are present in smaller numbers. These types are as follows: Nos. 57, 61, 67, $77,81,82,96,99$, and 164. A few types present in Period 2 appear in Period 3 in slightly larger numbers. These types are as follows: Nos. 66, 83, and 84.

Small garter bead Types $44-46$ and 48-51 are present during Period 3 in about the same numbers as during Periods 1 and 2. Small garter bead Types 81-84 seem to decrease in numbers in Period 3 sites except, at the Vinson site.

It is the opinion of the authors, based on historical research and on the types of artifacts present, that occupation of the Roseborough Lake Site ended around 1780. In the following discussion we will assume a cut-off date of 1780 for that site. New bead types appearing in the trade during Period 3 at the Roseborough Lake Site (that is, before 1780) are as follows: Nos.64, 65, 98, 101-104, 106-108, 115, 118, 137 and 138. New bead types appearing in the trade during Period 3, after 1780, are as follows: Nos. 95, 96, 100, 109, $111,112,113,114,116,117,119,120,122,124,129,132$, $134,136,146,147,170,183$, and 184, Nos. 116-118 are complex small garter beads and are found only in Period 3 sites.

During Period 3, several new types of small garter beads occur in the trade. These types are extra small garter beads (2 mm. or less in diameter). Two of the types (Nos. 128 and 155) come into the trade before the Roseborough Lake site is abandoned. The other types appear to enter the trade after the abandonment of the Roseborough Lake Site. These are Nos. $125,126,127$, and 179 。 
The source of trade during Period 3 seems to be mostly French; however, some English, Spanish, and possible AngloAmerican trade may enter the picture. This needs further research.

\section{Period 4(1820 to 1836)}

During this period some of the Period 1 types (nos. 4, 5, 10, 11, and 54) are present, but in very smal1 numbers. The small garter beads (Nos. 44-46 and 48-51) which have been in large numbers from Period 1 through Period 3 are in very large numbers in some sites of Period 4. By the end of Period 4, these small garter beads seem to have completely disappeared from the trade. Small garter bead Types 79,82 , and 84 from Periods 2 and 3 remain rather constant through Period 4 and then completely disappear. Small garter bead Types 80, 81, 83, and 84 increase in numbers during Period 4 , then completely disappear. Extra small garter bead Type 155 increases greatly during Period 4 and completely disappears at the end of the period. Small garter bead Type 128 increases strongly during Period 4.

Now bead types coming into the trade during Period 4 are as follows: Nos. $58,110,121,123,130,131,133,135,140-$ $145,148-154,156-163,166-168,171$, and 176.

During Period 4, the source of the trade is probably Anglo-American, English, or Spanish; however, more research is needed on this.

\section{Period 5 (1836 to 1850)}

During this period, only one site (Sheridan Lodge) has been analyzed in this study, and all the types are probably not complete. When the Wichita sites near Lawton and Rush Springs are located and excavated, the history of trade relations with the Wichita-speaking people will be more com= plete. However, a few remarks can be made at this time.

According to Tyler Bastian of the Museum of the Great Plains, extra small garter beads can be found at the Sheridan Lake Site in very large numbers-several thousand can be found from one six-inch level of a five-foot square. Types 128, 176, 177 , and 179 which appeared during Periods 3 and 4 are found in extremely large numbers in Period 5. New types of extra small garter beads appearing during Period 5 are as follows: Nos. 174, 175, 178, 180, 181, and 182. Nothing is known at present about the larger beads.

The source of trade during Period 5 is probably mostly Anglo-American. 
Discussion of Shell Wampum

The wampum beads found in some of the Norteño sites match in lengths and colors the shell wampum from the eastern part of the United States.

According to Hodge (1910: 906) a piece of white wampum $6 \mathrm{~mm}$. long was worth only half as much as a piece of dark (purple) wampum of the same length.

Shell wampum appears during Period 3 in our area at the Roseborough Lake Site (probably abandoned around 1780). It is present in all of the Spanish Fort sites on both sides of Red River, as well as in the Devils Canyon Site (Period 4). Wampum began to decline around 1830 (Arthur Woodward, personal communication, 1966); to date, shell wampum has been found in only one Period 5 site $(1836-1850)$ in our area--the Colonel Cooper Site, which appears to date around 1850 .

It is well known that attempts were made by the white traders to pass off glass beads to the Indians as shell wampum. Types 64, 65, 66, 157, and 183 which appear in Periods 3 and 4 were probably designed to imitate wampum.

\section{Wampum Pipes}

Although shell wampum hair pipes are not considered in this analysis, five specimens have been found at the Devils Canyon site (Period 4). These pipes were used as hair ornaments and in making breastplates. Wampum shell beads began to decline about 1830 and soon died out; however, wampum pipes continued on in large numbers until the end of the trade.

\section{Problems for Further Research}

Some of the unsolved problems of trade bead research will be mentioned before closing.

Intense research is needed on the history of bead manufacture and trade routes of such countries as Belgium, England, France, Italy, and Spain.

Research is needed concerning the preferred colors in the area involved. For example, it has been noticed that in the small number of Norteño Focus burials found to date there seems to be a preference for blue and white glass beads. And the scarcity of yellow beads in Norteño Focus sites is striking in comparison to their relative abundance in other sites of 
comparable date. Cultural selectivity on the part of the Wichita tribes was probably the major factor in determining what color beads were traded into the area.

The problems involved in trying to determine the countries where beads were manufactured between 1700 and 1850 are especially perplexing. Woodward (1965: 4) states, "In general, the bulk of the glass beads, traded on the North American continent from the 16th until around the first half of the 19th centuries, were made in the glass factories of Murano, Venice." This is undoubtedly an accurate statement with regard to the trade beads of the 16th, 17th, and early 18th centuries, but it evidently does not apply to the period of our particular concern: 17001850. For with the fall of the commercial Republic of Venice $1730^{\circ}$ in the $1830^{\circ} \mathrm{s}$, the glass production of Murano declined drastically, until by about 1735 what had once been a flourishing enterprise supporting 300 glass houses was quickly reduced to less than 20 (Rogers and Beard, 1937: 40). During that time many of the Italian bead makers fled to other European countries, including England, France, and Spain, where some of them were employed in glass factories. Because of the secrecy of the guilds that surrounded the manufacture of beads, it will be extremely difficult-perhaps impossible-mever to unravel the historical details concerning the places where l8th and 19th century trade beads were manufactured. Possibly the changes in bead types between Periods 1 and 2 reflect this shift in locus of manufacture.

\section{Metal Projectile Points}

Numerous specimens of native-made metal projectile points have been recovered from the various historic sites in the Spanish Fort area, on both sides of Red River. All of them are made of iron or brass obtained from Europeans. The iron points appear to have been made from flattened sections of gun barrels, from gun furniture (finials, butt plates, trigger guards, and the like), from knife blades, and from bridle parts. The brass points appear to have been made from kettle fragments and gun furniture.

In this preliminary description, only the metal projectile points found during the excavation of the Upper Tucker and Longest Sites will be considered. There are 12 specimens from Upper Tucker and 35 from Longest. One formal arrow point type is recognized in the sample: the Benton type, named in honor of the late Joe Bention, a pioneer cattle and oil man of Nocona, Texas, who with his wife and daughter for many years made extensive collections from the Spanish Fort sites in both Texas and Oklahoma. A detailed description of the type by the 
present authors will appear in the Gilbert site report, now in press (Bulletin of the Texas Archeological Society, Vol. 37)。

Bention Type A

This is a diamond-shaped projectile point with its maximum width approximately equidistant between base and tip. The lateral edges of both base and stem are essentially straight. The blade edges are honed sharp. Irregular, hacked notches along the stem edges evidently functioned to facilitate hafting. Of the 12 metal points found at Upper Tucker, three (one of brass and two of iron) are Benton Type A (Fig. 54, a). Seventeen of the 35 metal points from Longest TFig. 54, d-g) are Benton Type A. Three are brass, 14 iron.

Benton Type B

Type $B$ is similar to Type $A$ in all respects except that the stem edges are concave instead of straight. There are five Benton Type B points from Upper Tucker, all made of iron (Fig. 54, b), and eight (one of brass, seven of iron) from Longest (Fig. 54, h-i).

In addition to the Benton type, there are four metal projectile points from Upper Tucker (all of iron) and ten from Longest (five of iron and five of brass). These include both stemmed and nonstemmed triangular forms. Examples are illustrated in Figure 54,c, j-k。

Benton points have been found at most of the Norteño Focus sites, and they seem to have been a standard form used by the Wichita tribes. Iron appears to have been the preferred metal for projectile points in the southern plains, especially in the later part of the historic period.

\section{Metal Knives}

During excavation at the Upper Tucker and Longest Sites, several metal knives and knife fragments were found. Knife blades are important to typological studies of European trade goods because they are not only stylized, but also because they often bear makers' marks beneath their coating of rust which can sometimes be brought out by careful cleaning. 
Three small fragments of metal knives were found during excavation of the Upper Tucker Site. Two of them--both case knife fragments--came from the fill above the floor of Feature IA; the other, a blade tip, was a surface find. All three are too fragmentary for typological classification. One specimen (Fig. 54, 1) has had both its blade and handle cut away, leaving only the center boss. The blade and handle portions perhaps were made into metal projectile points. Points made from knife fragments are known from Norteño Focus sites.

Recovered from the Longest Site were one nearly complete clasp knife, one complete knife blade, one nearly complete blade, and three blade fragments. In the fill of House 1 was found an almost complete clasp knife with the blade folded into the handle (Fig. 54, $\mathrm{m}$ ). The maximum length is $94 \mathrm{~mm}$., the maximum width $27 \mathrm{~mm}$. It is impossible to clean the knife as it has almost completely oxidized. This knife is of a type very much like our present-day pocket knives. A few flecks of a bone handle can be seen in the rust. A clasp knife of much the same form was found in the excavation of Queen's Battery at Signal Hill, St. John's, Newfoundland, dating from the early 19th century ( $E$. B. Jelks, personal communication, 1965). Both of these knives are probably of English manufacture. They do not fit the typical French knife pattern.

A small clasp-knife fragment of the above type (Fig. 54,n) was found in the plow zone at the Longest site.

A complete knife blade (Fig. 54, o), found in Feature 19 at Longest, is $105 \mathrm{~mm}$. long, $12 \mathrm{~mm}$. wide, and from 1 to $2 \mathrm{~mm}$. thick. It is an example of French clasp knife Type 3 as defined by Harris, Harris, Blaine, and Blaine (1965: 348-350)。 When cleaned in an acid solution, letters and emblems were found stamped near the proximal end, on the left side of the blade. The top group of letters forms the name $H U$ U U $E S$, but only the first letter of the bottom name can be read, and it is a P. Turned at an angle of 90 degrees to the letters were parts of two emblems: a fleur-de-lis in front of the name and part of a heart-shaped element following the name. A fragment of knife blade stamped with the same name was found at the Ayres Site, on the Texas side of Spanish Fort Bend, by Jay C. Blaine (personal communication).

On the floor of House 1 at the Longest Site was found the blade of a case knife with part of the handle missing (Fig. 54, p). It is $110 \mathrm{~mm}$. long and $15 \mathrm{~mm}$. wide. It was cleaned with a weak acid solution, but no maker's mark was found, perhaps because of heavy oxidation.

Two small fragments of knife blades were found in the fill of House l, but both were too small for typological identification. 
Guns

by Jay C 。 Blaine

This brief preliminary report deals only with gun parts and related material found in the first season's excavations at the Longest and Upper Tucker Sites. Each specimen will be described individually in most instances. It should be noted that descriptions and measurements of some parts will need revising after major laboratory cleaning is completed.

\section{Barrels}

No. 1 (Longest site) is an iron gun barrel. It is an octagonal breech section. The back end of the barrel is evenly mushroomed apparently by being hammered, or possibly through use as a hammer. This end is closed and probably contains the threaded portion of the breech plug. The opposite end appears to have been hammered together from two opposite sides, and tapers down to the end which is broken or cut across. Length, 7.75 inches. Maximum diameter of breech across flats 0.75 inches below mushroomed end is 1.12 inches. No bore measurement can be made at this time because both ends are closed.

No. 2 (Longest site) is made of iron. This section appears to be octagonal, but this cannot be determined for certain without major cleaning. The barrel is broken across both ends and appears to have been hammered from two opposite sides since it tapers toward one end. Length, 3.87 inches. Maximum diameter, 0.97 inches. Bore, 0.53 inches plus。

No. 3 (Upper Tucker Site) is made of iron. Apparently this breech section is octagonal, although two of the flats are very indistinct. The back end is mushroomed evenly but the end of the bore is partially open. The opposite end is broken unevenly and hammering from two opposite sides has tapered the barrel toward the broken end. Length, 2.69 inches. Maximum diameter across flats 0.25 inches below mushroomed end, 1.13 inches. No bore measurement can be made。

Remarks: Octagonal barrel breech sections which measure in excess of one inch in diameter across the flats have been tentatively identified by Hamilton (1960d: 208; 1960b: 126) as representing 18 th century trade guns and military or colonial muskets and 19th century military muskets. Analyses of breech sections at the Gilbert site (report in press) and the Womack Site (Harris et al., 1965: 334) appear to substantiate Hamilton's findings concerning the 18 th century trade gun. It is also necessary to accurately determine the bore size before attempting to assign a breech section to a definite category。 
The bores of specimen No. 3 from Upper Tucker and of specimen No. I from Longest cannot be measured at this time; consequently it can only be said that neither is from a 19th century trade gun.

The bore of barrel section No. 2 cannot be measured accurately without major cleaning. It can only be stated that it is larger than 0.53 inches in caliber. We cannot determine what the maximum breech dimension was, for part of it is miss ing. The rough bore estimate seems to indicate a trade gun caliber, but the breech area could be of 18 th or 19 th century origin.

\section{Cocks}

No. I (Longest site; Fig. 55, a). This cock is made of iron. The comb is narrow and ungrooved. The cock base is flat faced with beveled edges. The form is goose-necked and the general curvature is sharp. The cock jaw is rounded on the end (plan view). Over-all length, 1.69 inches. Center of pivot hole to top of lower vise jaw, 3.13 inches. Width of comb, 0.34 inches.

No. 2 (Longest site).. This cock is of iron. The comb is wide and probably grooved, but this latter feature cannot be determined for certain until more cleaning has been done. The cock base is flat-faced with beveled edges. The form is goose-necked, the general curvature sharp."The cock jaw is rounded on the end (plan view). Over-all length, 1.47 inches. Center of pivot hole to top of lower vise jaw, 2.59 inches. Width of comb, 0.59 inches.

No. 3 (Longest Site; Fig. 55, b)。 This upper vise jaw from a cock is of typical spanish construction with the guide finger attached to the underside of the jaw. The jaw is spatula shaped, pierced for a jaw screw, and plano convex in cross section, with a single facet across the front end of the convex upper surface. The guide finger is thicker on the upper end and tapers down toward the lower end as viewed from the front. Length of upper jaw, 1.75 inches. Maximum width of jaw, 0.81 inches. Length of guide finger (measured from under surface of jaw), 0.88 inches. Thickness of guide finger, 0.19 to 0.10 inches.

No. 4 (Upper Tucker Site). The front end of this iron upper vise jaw is rounded (plan view) and has a single notch at the back. Immediately forward of the notch is a hole for the jaw screw. Length, 1.25 inches. Width, 1.06 inches.

No. 5 (Upper Tucker Site). Same description as for the preceding specimen. Length, 1.16 inches. Width, 0.94 inches. 
Remarks: Cock No. I from Longest closely matches those described by Kennard as typical of late 18 th century English cocks (Hamilton, 1960c: 154). But it would not appear to be typical of the Inglish trade gun as characterized by the Hudson's Bay Company offerings. S. James Gooding (1960:85) has stated that these weapons utilized locks with round or oval cross sections from the late 17 th century onward. Rounded locks would commonly use cocks with rounded faces as well as rounded or nonfaceted flash pans. This specimen may represent a minor mid-18th century gun used in the French trade.

Longest cock No. 2 is typical in size and form of those believed to represent the fusils used in the mid-l8th century French trade.

Longest Site cock jaw No. 3 is Spanish in design. The spatulata-shaped jaw had superseded the ovoid jaw by the mid17th century, and the location of the ring (cock jaw) screw had also been moved toward the rear as in this specimen (Lavin, 1965: 166). It is impossible to be more specific in dealing with this cock jaw than to say the design is spanish and the jaw could date anywhere between the mid-17th century and the first quarter of the 19th century (Lavin, 1965: Fig. 18).

Cock Jaws No. 4 and 5 from the Upper Tucker Site were intended for use with narrow comb cocks. As a general type they may date from around 1700 to the end of the flintlock era, about 1875 in North America, and cannot be assigned any specific origin.

\section{Frizzens}

All frizzens (batteries) described in this report have the steel and flashpan made together in one piece.

No. I (Longest Site). The top of the steel is rounded and the striking surface is curved. The front of the steel appears to be formed in three facets. The two major facets are parallel to the long axis of the steel and meet to form a central ridge. The smaller facet crosses these at the top of the steel. The outside edge of the pan cover is straight in the center with one straight cut angling across each end. The lower pivot body is broken out the rear of the pivot screw hole. There is no antifriction roller. Steel length, 1.63 inches. Steel width, 0.91 inches. Flashpan cover width, 0.98 inches. Thickness of pivot body, 0.31 inches.

No. 2 (Longest Site). The top of the steel is rounded and the sides are gently rounded also. The front of the steel is composed of two longitudinal facets which meet in a central ridge.

The outside edge of the pan cover is rounded. Starting at the 
inside edge of the pan cover the inner surface has been hollowed for about $1 / 3$ of the pan cover width. There is no antifriction roller in the pivot body. Steel length, 1.63 inches. Steel width, 0.94 inches. Flash pan cover width, 1.00 inches. Thickness of pivot body, 0.30 inches.

No. 3 (Longest Site). The steel is missing, having been broken off at the juncture with the pan cover. The outside edge of the pan cover is rounded. There is no antifriction roller in the lower pivot body. Width of flashpan cover, 0.91 inches. Thickness of pivot body, 0.30 inches.

No. 4 (Upper Tucker site)。The shape of the steel is the same as that of Longest frizzen No。 1 . The outside edge of the pan cover is straight. There is no antifriction roller in the lower pivot body. Steel length, 1.63 inches. Ste日l width, 1.00 inches. Flashpan cover width, 1.03 inches。 Thick ness of pivot body, 0.42 inches.

Remarks: The size of the frizzen parts indicates they would be suitable for use on fusils (light muskets) or on large pistols。 Frizzen steels with rounded tops and faceted fronts are common from about 1690 to about 1875 (Hayward, 1963: 295)。

The outer edge of the pan cover on the Upper Tucker frizzen and on Longest frizzen No。 1 would indicate use with a faceted flash pan and thereby infers use with a lock plate which is essentially flat in cross section. such a frizzen would be similar to those. which I believe are typical of the fusils used in the French trade around 1750. It may also be similar to post-1770 English guns in the fine grade, but I do not believe this kind of frizzen demonstrates high quality workmanship.

Longest frizzen No. 2 would be used with a rounded unfaceted pan, and if from a trade gun, by inference should normally be used on a gun lock with rounded surfaces on the cock base and lock plate. English trade gun locks exhibited such characteristics from the late 17 th century onward (Gooding, 1960: 85), and finer English guns from the late 17th century to about 1770 (Hayward, 1963: 200)。Guns of typical French design partially reverted to use of convex exterior lock surfaces in the mid-18th century (ibido: 49), but it has not been determined if this fashion was reflected by guns used in the late French trade。

Frizzen No. 3 from Longest, although broken, can probably be placed in the same category as No. 2 because it also should normally be used with a rounded surface lock plate. 


\section{Elashpans}

No. I (Longest Site). This Plashpan is iron and has been made separate (removable) from the lock plate. The under surface of the pan is formed in two major facets and would be termed shallow "V" in shape. A small facet angles across the outer edge of the pan, crossing the end of the "V". There is a low flash shield at the rear edge of the upper pan surface. The bottom of the pan is flanged where it would contact the lock plate. The inside edge of the pan extends rearward in a round-ended tang which contains a hole for a screw to help fasten the pan to the lock plate. The forward end of the pan or tang has an oblique surface which is intended to key into a matching cut in the lock plate. The pan is not waterproof, nor does it have a pan strap or bridle for the frizzen. The pan has been bent downward from the tang. Width, 0.98 inches. Length (front of oblique tang surface to rear of tang), 1.4 .7 inches.

No. 2 (Longest Site). This iron flashpan is made separate from the lock plate. Its under surface is rounded and thus the outer pan edge is also rounded. There is a high flash shield at the rear of the pan. The bottom of the pan is flanged and the tang is similar to that of pan No. I except that the rear tang end is cut at an angle instead of being round. The pan is not waterproof nor does it have a pan strap for the frizzen. Width, 1.06 inches. Length (as in No. 1), 1.28 inches.

Remarks: Flashpan No. I would be used with a frizzen pan cover such as that of Longest frizzen No. 1, and the general conclusion concerning that pan cover should apply here.

Flashpan No. I is generally similar to those that Harris, Harris, Blaine, and Blaine (1965: 323) believe are typical of the ilashpans used on guns in the French trade between approximately 1720 and 1750. Similar flashpans have been noted from the mid-18th century fine-grade English gun; but lack of a pan strap and any form of waterproof design makes this alternative extremely remote.

Flashpan No. 2 would be used with a rounded pan cover such as that on Longest frizzen No. 2, and the same conclusions should apply.

\section{Breech Plugs}

No. 1 (Longest Site; Fig.55, c). This iron breech plug is complete. The tang is bent upward at the tang screw hole. The tang screw hole is countersunk into the upper tang surface, 
and the end of the tang is rounded. The lower body of the breech plug contains a lateral hole. Length of tang (from rear of plug screw portion), 2.06 inches. Length of plug screw portion, 0.56 inches. Width of tang (maximum), 0.50 inches. Outside diameter of plug (bore screw), 0.64 inches. Maximum width (height) of rear body, l.13 inches.

No. 2 (Longest site). The tang of this iron breech plug is broken just behind the rear body of the breech plug. The lower portion of the rear body does not extend below the lower edge of the plug screw portion. The outside diameter of the plug screw portion is approximately 0.70 inches. The tang width is 0.50 inches. The maximum width of the rear body is 0.88 inches. The length of the plug (bore) screw portion is 0.44 inches.

No. 3 (Longest site)。 This breech plug is of the same description as No. 2 in all particulars. The outside diameter of the plug screw portion is 0.73 inches. The tang width is 0.50 inches. The maximum width of the rear body is 0.84 inches. The length of the plug screw portion is 0.41 inches.

No. 4 (Upper Tucker Site)。This probable tang section of an iron breech plug is broken or cut across both ends and a semicircular notch is centered in one of the ends. This may be a tang screw hole. Measurements: length, 0.75 inches; width, 0.53 inches; thickness, 0.25 inches.

Remarks: The maximum width (height) of the rear body of Longest specimen No。 1 would normally indicate use with a breech over one inch in diameter. As noted in the analysis of barrels, an 18th century trade or military gun may be inferred or a 19th century military gun. The 19th century trade gun can be eliminated. Since the tang screw hole is countersunk into the exterior surface we can assume the tang screw passed downward through the tang. The point can be verified after major cleaning by checking for the absence or presence of screw threads. The downward tang screw direction appears typical of the mid-18th century French trade gun。 Hanson (1955: 16, 18) has noted that all Northwest (English trade) guns he has examined have the tang screw coming up from below between about 1770 to 1830。 Even without major cleaning it seems evident the bore this plug was used with was approximately .60 caliber or smaller. The likeliest origin seems to be an 18 th century French trade gun.

Breech plug No. 2 from Longest appears to be from a pistol as judged by the lack of a lower portion of the rear body and the relatively short length of the plug screw.

Longest breech plug No. 3 can be placed in the same category as breech plug No.2。 


\section{Front Sights}

No. 1 (Longest Site). This front sight blade (and base) is made of brass. There is no evidence of solder on the under surface of the rectangular base. One end of the base is broken off, but the intact end is beveled on the exterior surface. The height is 0.13 inches. The length of the base is 0.34 . inches, and the width is 0.27 inches.

Remarks: This front sight is only the second example I have noted from Norteño Focus sites. The first example is on a barrel muzzle section from the Gilbert site, but its poor condition has prevented detailed examination and measurement.

\section{Pin Loops}

No. I (Longest Site). This iron pin loop or barrel mounting lug was probably dove-tailed into the lower barrel surface. A transverse pin which was passed through the stock and through the lateral hole in this loop helped secure the gun barrel to the stock. The height is 0.31 inches. The length is 0.50 inches, and the width is 0.44 inches.

Remarks: Similar pin loops have been noted from the Womack Site (Harris, et al., 1965). The time ranges and possible origins of such parts do not appear to furnish useful data at present. Of course they do indicate a pinned stock.

\section{Triggers}

No. 1 (Longest Site). This trigger is made of iron. Total length is 1.50 inches.

\section{$\underline{\text { Sears }}$}

No. 1 (Longest Site). This is an iron, vertical action sear for right hand lock. Length, 1.31 inches. Width (along trigger arm), 1.25 inches.

No. 2 (Upper Tucker Site). This is a vertical action sear of iron. The trigger arm tapers (plan view) to a point at the outer end. The sear is for the usual right hand gunlock. Length, 1.16 inches. Width (along trigger arm), 1.03 inches. Thickness (at sear screw hole), 0.25 inches. 


\section{Side or Lock Plate Screws}

No. I (Longest site) is made of iron. Diameter of screw head, 0.50 inches. Length of screw, 1.84 inches.

No. 2 (Upper Tucker Site) is of iron. Diameter of screw head, 0.50 inches; length of screw, 1.75 inches.

\section{Frizzen Springs}

No. I (Longest site). This is the upper leaf only of a frizzen spring that is broken in the bend. The outside edge of the spring has been notched or necked down at the end which would contact the lower frizzen body. Length of the upper leaf, 1.68 inches. Maximum width, 0.50 inches. Width of notched end, 0.34 inches. Length of notch, 0.44 inches.

Remarks: A notched upper leaf on the exterior edge of a frizzen spring generally indicates it was used with a frizzen bridle (or pan strap) or with a bridle link between the frizzen pivot screw and the frizzen spring screw. This feature apparently is not characteristic of the mid-18th century French trade gun. It appears more likely that either 18th or 19th century military origin is possible, or perhaps a lath century English trade gun. The two examples of the late 18th century Northwest gun illustrated by Hanson (1955: PI. IXA, IXB) show no pan bridle, and the same situation obtains with an early 19th century English trade gun (ibid: PI.XIB).

\section{Ornaments}

No. I (Longest Site; Fig。 55, d)。 This brass ornament is a representation of a maned lion. Detail has been engraved into the surface with both single and six-line gravers. The edges are slightly beveled toward the inner surface (undercut). Thirteen holes are strategically spaced about the lion and the ornament is slightly cupped or concavo-convex. Length, 2.78 inches, Width, 1.78 inches. Thickness, 0.024 to 0.041 inches.

Remarks: This ornament was found in the same cache pit as the miquelet flintlock cock jaw. The cock jaw is spanish in design and $I$ believe this ornament is also of Spanish origin。 Broad or coarse patterned metal openwork, either inlaid into the stock or placed upon its surface, seems to be more characteristic of the guns produced in the Spanish town of Ripoll than anywhere else.

Lavin illustrates a late 17 th century Ripoll miquelet arquebus having a stock inlaid with crudely engraved brass 
figures, one of them a lion (Lavin, 1965: PI. 116). Coarse openwork similar in nature but not in subject is iljustrated on a miquelet Ripoll pistol dated between 1690 and 1725 (ibid.: PI. 113B). Close inspection of this plate also reveals the use of pins to help hold the ornament in place. However, Lavin states that the use of animal (and human) elements ceases in Ripoll-style metal openwork decoration of the stock during the first quarter of the 17 th century (ibid.: 231). Since there were miquelets made in Mexico (ibjdo: PI. 60) there may possibly have been a later survival of the animal element in decoration produced abroad in this or other Spanish colonies.

Lavin states that a large part of Ripoll's external trade was with the Indies, primarily with Cuba and Mexico during the 18th century (ibid.: 237).

\section{Side Plates}

No. 1 (Longest Site; Fig. 55, e). This fragment of side plate contains a screw hole, probably for the upper side screw. The side plate is brass and appears to be cast in low relief and possibly retouched by engraving. The design was appar ently a foliate or leaf-scroll pattern. This plate has a recessed hole for the side screw head. Width, 0.78 inches. Height, 0.94 inches. Thickness, 0.05 inches to 0.07 inches. Side screw head recess diameter, 0.41 inches.

No.2 (Longest Site; Fig. 55, f). This side plate is of flat cast brass. Broken across both ends, it is the section between the areas of the front and upper side screw holes. The plate is beveled on the exterior surface along the upper edge. The upper edge is slightly undercut. The lower edge has been hammered and appears to have been bifacially sharp. ened. The upper and lower edges are bordered by single en graved lines with the upper one ending in a scroll at the widest part of the plate. The break at this point cuts across the beginning of a scalloped design. The plate has oxidized black. Length, 1.34 inches. Maximum width, 0.69 inches. Thickness, 0.05 to 0.06 inches.

No. 3 (Longest Site; Fig. 55, g)。 This is part of the front section of a zoomorphic side plate. The plate is flat cast brass and has oxidized black. The upper and lower edges are undercut and the plate is broken across both ends. The exterior surface is engraved and the mark XI has been cut or filed across the interior surface. Length, 1.06 inches. Maximum width, 0.55 inches. Thickness, 0.05 to 0.06 inches. 
No. 4 (Upper Tucker Site; Fig. 55, q). This cast-brass side plate is broken across both ends and across the center area. The upper and lower edges are beveled on the exterior surface. A single engraved line borders each of those edges. The central area is engraved with a design which, solely for descriptive purposes, may be said to resemble an inverted wicker basket from which two fern-like leaves or fronds extend. A small elliptical design is interrupted by the rear break. The upper side screw hole is present. Length, 2.34 inches. Width, 0.84 inches. Thickness, 0.06 inches. Upper screw hole diameter, 0.22 inches. Marks left on the plate surface suggest that a side screw with a head diameter of approximately 0.50 inches was used with this plate.

Remarks: The side plate represented by Longest specimen No. 1 was cast or embossed in low relief, fanciful in outine, and possibly fretted. Side plates combining these character istics are common to better or fine grade guns of varied origin during the major part of the 18 th century. They are not characteristic of side plates believed to be typical of French trade guns around 1720 (Harris et al., 1965: 330-332). This fragment probably is not from an English trade gun.

The side plate from Upper Tucker and specimen No. 2 from Longest are similar to ones from the Gilbert site which are believed to represent mid-18th century French trade guns. However, George (1947: 1.11) has described flat side plates of relatively simple outline and decorated by engraving as coming into use on English guns of "second" cuality during the third quarter of the 18 th century. There is not enough engraved detail on these two side plates to differentiate between French or English origin.

Side plate No. 3 from Longest is a section of Serpent or Dragon side plate, probably from an English gun dating before 1775. Flat Dragon side plates evidently appeared on minor English martial guns between about 1700 and 1775 . Flat, engraved serpent side plates seem to have been employed on English trade guns prior to regular use of the cast detail versions. Hamilton (1960b: 135) has assigned a tentative date of 1750 for the flat, engraved style.

\section{Butt Plates}

No. 1 (Longest site; Fig. 55, n). This cast-brass section of butt plate tang and finial is cut and broken across both ends. The right and left edges above and below the neck have been bifacially sharpened. The base of a tongue which once extended from the interior surface can be seen. Both edges 
Butt plate No. 3 from Longest, a finial section is practically identical to finials among a group of seven from fort Frederica, St. Simons Island, Georgia. These tang and finial sections are illustrated and described by Shiner (1958: 31 , Fig. V) who characterizes the butt plates as flat and secured by nails, and who notes that they do not appear standard for infantry muskets. Hamilton (1960b: 140, Fis. 52) illustrates another example of this tang design from a Little Osage site dated 1730-1775. Other examples from the Spanish Fort area and from the Vinson Site have been examined by the writer. Such finials are probably English in origin, should date between 1740 (or possibly somewhat earlier) and about 1770 , and most likely are from fusils or light muskets (suitable for Indian use) which seem to have shared some characteristics with the Northwest gun.

Remarks: Butt plate tang section No. 4 from Upper Tucker appears virtually identical to those employed on the typical Northwest gun. Similar examples are illustrated by Hanson (1955: PIs.XIXA, XIXB, XXA, XXB). Hanson (ibid: 18) indicates that the use of a screw in the tang is a characteristic of all trade guns made after 1830 .

Butt plate toe section No. 5 from Upper Tucker does correspond to similar sections of Northwest guns as they are known at present. It is generally similar to butt plates from the Gilbert site observed by the writer, but the incomplete specimen under consideration is too small for definite assignment。

\section{Trigger Guards}

No. 1 (Longest Site; Fig. 55, j)。 This castabrass tang and finial section of a trigger guard is probably part of the rear tang. A tongue protrudes from the inner surface and is drilled for a transverse pin. The tang is broken across at the front of the tongue. The tang and finial are plano-convex in cross section. Length, 2.69 inches.

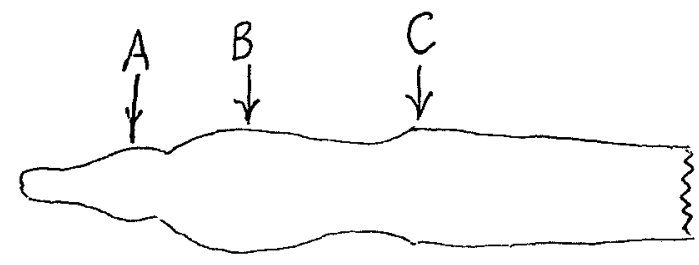

Width at "A", 0.25 inches. Thickness at "A", 0.07 inches. Width at "B", 0.48 inches. Thickness at "B", 0.09 inches. Width at "C", 0.44 inches. Thickness at "C", 0.08 inches. 
below the neck are bordered with a pair of parallel engraved lines. The center of the lower area is engraved with an inverted flower bud. The edges of the neck portion are each engraved with a single line, and the center shows the remnant of an elliptical design. Length, 1.35 inches. Width of neck, 0.33 inches. Thickness, 0.07 to 0.09 inches.

No. 2 (Longest site; Fig。 55, h) 。 This castobrass fragment is probably a butt plate tang. Single engraved lines parallel each border and converge to a point as the tang narrows. Both exterior and interior surfaces show marks of hammering. Length, 1.31 inches。 Maximum width, 0.75 inches。 Thickness, 0.10 inches (in area least thinned by pounding)。

No. 3 (Longest site; Fig. 55, il. This finial of cast brass is from a butt plate tang. Trere is a rectangular hole lateraliy centered in the widest section. A series of divergent lines are engraved on the finial, and it is broken across one end at the neck. The finial edges are undercut。 The cross section is slightly concavomconvex. Length, 0.72 inches. Maximum width, 0.45 inches。Thickness, 0.06 to 0.08 inches。

No. 4 (Upper Tucker Site; Fig。 55, o)。 Brass, probably cast. This butt plate tang section appears to be partially cut and broken across one end. A screw hole is countersunk. into the external (smoothed) surface. The tang edges are undercut or beveled toward the interior surface. Some irregular markings on both interior and exterior surfaces appear to be the results of hammering。 Length, 1.31 inches. Width, 0.75 inches. Thickness, 0.05 to 0.06 inches.

No. 5 (Upper Tucker Site; Fig。 55, k)。 This is the toe section of a cast-brass butt plate that is broken across a screw hole. The screw hole is countersunk into the external surface. The section is convex externally and concave in ternally. The edges of the plate are slightly rounded or beveled toward the exterior surface. Length, 1.03 inches. Width, 1.36 inches. Maximum thickness, 0.09 inches.

Remarks: Butt plate No. I from Longest was secured to the stock in the finial area by a tongue through which a securing pin was passed. According to Harris, Harris, Blaine, and Blaine (1965: 341, Fig. 16-G), this system was used on French trade guns about 1720. The presence of this method of attachment at the Gilbert Site indicates use on French trade guns of about 1750. The same system was employed on the better grade English fowling piece by around 1700 according to George (1947: 104). It also was apparently used on better grade French fowling pieces or fusils by the same time。

Longest butt plate No. 2 does not offer enough detail for any assignment concerning origin or date. 
No. 2 (Longest Site; Fig. 55, m). This front tang and finial section of a trigger guard is of cast brass and is plano-convex in cross section. The tang is broken across a screw hole countersunk into the exterior surface. The edges of the bulbous finial are undercut. The piece is oxidized to a dark green hue. Length, 1.19 inches. Width at tang shoulder, 0.56 inches; thickness at same point; 0.11 inches. Maximum width of sinial, 0.64 inches; thickness at same point, 0.13 inches.

No. 3 (Longest site; Fig. 55, p). This fragment of cast brass, broken across both ends, appears to be a front tang section of trigger guard. A drilled hole (presumably a screw hole) is centered laterally and the tang is plano-convex in cross section. Length, 0.81 inches. Maximum width, 0.58 inches; thickness at same point, 0.09 inches.

Remarks: Trigger guard No. I does not resemble the trigger guards believed typical of those used on guns in the French trade in the 1720 to 1750 period. I believe it dates within the l8th century, but the design origin is uncertain at present.

Trigger guard No. 2 bears a very strong resemblance to the corresponding trigger guard area on an early Northwest. gun illustrated by Hanson (1955: PI. XXIA) and dated about 1770. It appears quite probable that trigger guard No. 2 is from an early Northwest gun of this period.

The identification of trigger guard No. 3 is uncertain. It does not resemble guards from guns used in the French trade between 1720 and 1750 .

\section{Ramrod Guides}

No. 1 (Upper Tucker Site; Fig。 55, 1)。 This sheet brass upper or intermediate rampipe is flattened and broken. Four parallel sets of triple grooves have been pressed into what would be the lower (cylindrical) part of the rampipe. A hole is present in the upper or flange area presumably for a trans verse pin to fasten the rampipe into a gun stock. Length, 1.22 inches. Thickness, 0.017 inches.

Remarks: Rampipes with annular ribs were used not only on Northwest guns but also on a wide variety of other guns over a considerable range in time. Apparently, however, they were not used on French trade guns. 


\section{Rear Sights}

No. I (Upper Tucker Site; Fig. 55, r). This rear sight made of brass is deeply grooved fore and aft in the sighting notch. Part of the lower surface of the sight is formed into a transverse dovetail tenon, presumably to fit a corresponding mortise in an upper gun barrel surface. A short tang projecting forward from the base of the sight appears to be broken across the end. Length at base, 0.69 inches. Width at base, 0.50 inches. Height, 0.35 inches.

Remarks: Rear sights like this one (that is, made of brass and dovetailed into the barrel) do not appear to be characteristic of most guns from Norteño Focus sites.

\section{Bullets}

No. I (Longest site). This lead bullet is spherical and unfired. The diameter is approximately $17 / 32^{\prime \prime}$ and the caliber would be about .53 .

No. 2 (Longest site). This lead bullet has been fired. Originally spherical, it has been partially flattened by impact. Additional marring also appears to have taken place.

No. 3 (Upper Tucker Site). This bullet is scarred and distorted but may be unfired.

No. 4 (Upper Tucker site). This specimen has been fired and shows impact distortion.

No. 5 (Upper Tucker Site). This bullet has been fired and shows impact distortion.

No. 6 (Upper Tucker Site). This specimen may be a lead bullet but has been hammered into a roughly spatulate form.

Remarks: The fired lead bullets could be assigned a tentative caliber based upon weight. While there are several reasons that argue against the accuracy of this method, it probably should be employed in the final analysis. Such weighing can establish, at least, the probable minimum caliber of a distorted buliet.

\section{Gun Worms}

No. I (Longest Site). This partial corkscrew of round iron wire has a sharpened point at one end and is broken in 
the third coil at the other end. Maximum diameter, 0.47 inches.

Remarks: Gun worms (or wad pullers) are mentioned in lists of trade goods but have rarely been recovered or recognized in material from historic Indian sites in Texas.

\section{Gunflints}

Spall Gunflints

Five plano-convex spall gunflints can be recognized.

No. I (Longest Site) is made from tan-gray chert and is "D" shaped. The striking edge has been straightened and/or sharpened by bifacial retouching. The sides and heel have been partially shaped by unifacial secondary flaking. This spall gunflint was produced from a prepared core.

Width measurements are made across the presumed striking edge. Width, 1.23 inches. Length, 0.81 inches.

No. 2 (Longest Site) is " $D$ " shaped and made from tangray chert. The striking edge has been retouched mainly in a unifacial manner, and the side and heel have been partially shaped in the same way. This spall gunflint was produced from a prepared core and shows a faceted striking platform. Width, 1.38 inches. Length, 0.86 inches.

No. 3 (Longest Site) is subrectangular and made from dark tan chert. The striking edge bears two short, shallow, concave areas, and the sides and heel exhibit retouch that is primarily unifacial. This spall gunflint was produced from a prepared core and the striking platform is a large single facet. Width, 1.03 inches. Length, 0.86 inches.

No. 4 (Longest Site) is essentially $D$-shaped and made from light gray chert or low quality flint. The plane surface exhibits patination on part of its surface. The striking edge is battered, apparently from frizzen contact. The other edges and surfaces show secondary flaking. Width, 1.09 inches. Length, 0.75 inches.

No. 5 (Longest Site) was probably D-shaped but exhibits lateral edges apparently broken in a random fashion. Width, 1.13 inches: Length, 0.95 inches. 
Conventional Gunflints

No. I (Upper Tucker Site) is made of French blond flint and has been worked to such a degree that its original form cannot be determined with complete accuracy. Width, 0.67 inches. Length, 0.69 inches.

No. 2 (Longest site) is battered and basically planoconvex. There is a short, and shallow, concave area in the remnant of the long bevel. The edge of this area would have been the striking edge. The material is dark blond flint. Width, 0.81 inches. Length, 0.59 inches.

No. 3 (Longest site) is a double-edged gunflint, planoconvex, with the convex side formed in two major facets which meet in a central ridge. The sides were originally squared up with unifacial secondary flaking. The gunflint apparently was originally rectangular, but both striking edges now have double concave areas in them. The color of this flint is now whitish but fine checking and the pattern of some of the breakage indicate that the gunflint was in a fire. Width, 0.97 inches. Length, 0.77 inches.

No. 4 (Longest Site) has been resharpened bifacially along part of the striking edge. The material is dark gray flint; the shape is square and plano-convex in profile. The striking edge is at the area of a long bevel, and the opposite heel and each side show secondary unifacial retouch. There is a remnant of a reaction bulb of percussion at the top of each of the two sides. Width, 0.81 inches, Length, 0.78 inches.

Native-Made Gunfilints

Twelve native (Indian) gunflints can be recognized, Nos。 1-9 from Longest Site and Nos。 10-12 from Upper Tucker Site。 On well-made specimens the longest side was probably the striking edge. The material from which these gunflints are made would be called chert in comparison with European gunflints of good quality. With the exception of No. 4 all are bifacially worked to a greater or lesser degree. 


\begin{tabular}{cccl} 
Specimen No. & Width* & Length* & Shape (Plan View) \\
\cline { 1 - 1 } 1 & 1.09 & 0.81 & Rectangular \\
2 & 1.06 & 0.94 & D-shaped \\
3 & 1.09 & 0.84 & Rectangular \\
4 & 0.98 & 0.75 & Rectangular \\
5 & 1.13 & 1.03 & Subrectangular \\
6 & 0.91 & 0.83 & Square \\
7 & 0.81 & 0.80 & Square \\
8 & 0.73 & 0.63 & Rectangular \\
9 & 1.09 & 0.91 & Subrectangular \\
10 & 0.98 & 1.02 & D-shaped \\
11 & 1.06 & 1.07 & Rectangular \\
12 & 0.88 & 0.67 & Rectangular
\end{tabular}

*Measurements in inches.

Three additional specimens, Nos. 13-15, from Longest Site were probably in process of manufacture as native gunflints.

Remarks: The spall gunflint, as a general type, was the major form used between 1700 and 1750 in the Northeastern United States according to Witthoft (Hamilton, 1960a: 74). According to the same source the conventional gunflint completely dominated by 1775. The vast majority of both forms were French in origin until the early 19th century; the English conventional gunflints did not appear until about 1750 (ibid.: 74). However, there is evidence that the French conventional gunflint appeared as early as 1680 (Hamilton, 1964: 52-57). Harris, Harris, Blaine, and Blaine (1965: 343) note one specimen from about 1720 . 
Miscellaneous European Trade Goods

by J。 Ned Woodall

The descriptions in this section are based not only on specimens from the Upper Tucker and Longest Sites, but from other Norteño Focus sites as well, especially Gilbert, Womack, and Pearson.

\section{Iron Wedges}

Wedges are characterized by a convex cutting bit and laterial edges that taper back to a thick, heavy butt. Vigorous pounding has usually expanded the butt laterally, resulting in edges that are broken and curled downward toward the bit. (Fig. 56, d). Overall dimensions vary greatly, but an idea of the size range can be seen in the illustrations (Fig.56, c-e)。

\section{Iron Axes}

The axes all have a single bit on a swept-back blade--e.e. the upper blade edge is perpendicular (or nearly so) to the bit and handle, while the lower edge angles sharply inward to a constricted neck. Three types may be distinguished on the basis of hafting techniques.

Type 1 (Fig. 56, a-b). This is by far the most common style trade ax, usually referred to as a camp or belt ax. It was manufactured by bending the shaped metal around a form back on itself and forging the laminated bit and blade together, leaving an eye for the insertion of a handle.

Type 2 This type has a sleeve paralleling the long axis of the blade, necessitating a handle bent or forked at a $70^{\circ}-75^{\circ}$ angle. This type was probably forged at local trading posts (Harris et al, 1965: 346).

Type 3 Characterized by the absence of any kind of hafting eye, this type has only a long narrow proximal end. It presumably was inserted and bound in a split handle (Harris et al, 1965: Fig. 19D)。

\section{Iron Awls}

These are generally slender, straight tools sharpened at one or both ends (Fig. 56, g). A few specimens show a gentle S-shaped curvature in the manner of modern sailmaker's and upholsterer's needles (Fig.56, f). Awls manufactured in Europe 
are distinguished by a squared or diamond-shaped shaft, while those of native manufacture are of various shapes and sizes. Some awls bear names impressed on their shank.

\section{Scissors}

The few scissor fragments recovered from Norteño Focus sites have oval finger openings bent outward at varying degrees from the closed blades. The blades are beveled on their outer edges and pivot on a screw set near the handles.

\section{Chisels}

Chisels are made from small iron rods rectangular in cross section. One end is hammered round and a narrow chisel point fashioned at its extremity. Proximal ends usually show signs of battering. All chisels recovered are rather delicate tools, and were probably used to cut thin brass, sheet iron, or wood.

\section{Iron Scrapers}

These artifacts, often difficult to identify because of rust damage, were manufactured from thin rectangular metal fragments. One end, a side or both were honed to a sharp edge. A slight curvature noticed on several specimens may indicate barrel hoops were a favorite source of metal.

\section{Metal Ornaments}

Rings

The Wichitas used brass and iron wire or narrow strips to manufacture finger rings, bending the metal around a form of the desired diameter (Fig. 57, b-c). Known but rare are specimens showing no closure seam or gap; these are probably of European manufacture (Fig. 57, a). A ring of a type previously worn by Jesuit priests was found at the Gilbert site.

Bracelets

All known examples of bracelets are oval and made of heavy guage brass wire. Decoration (if present) consists of closely spaced notches filed into the outer surface (Fig. 58, $a, b)$.

Hawk Bells

These small, round, ornamental bells are scarce in most Norteno Focus sites. There are two types. In one the brass hemispheres forming the round bell are soldered together with 
flush edges, while in the other they are crimped together by means of a flange present on each half. The flush-edge variety is the prevalent type in excavated Wichita sites.

Tinklers

Small cones of brass or iron ( $F i g .57, d-f$ ), made by rolling thin rectangular or trapezoidal fragments of sheet metal, presumably were used as ornaments attached to clothing. A thrum was passed: through the small end of the cone and knotted, thus serving as an attachment device.

Pendants

This category includes both those artifacts traded to the Indians as pendants and objects altered by Indian handicraft into pendants. Examples of the former include religious pendants and presentation medals. Native-made examples are perforated coins and triangular bits of sheet brass or silver pierced near the apex and notched along the base (Fig. 57, g, h).

Buttons

Both simple and compound buttons are known from Norteño Focus sites. The one-piece specimens typically have a convex or flat, plain exterior, with attachments made possible by either a soldered brass wire loop (Fig. 57, i, j) or a wedge-shaped, drilled cast shank. Compound buttons are sometimes decorated on their obverse side with various patterns, including a frequent floral motif.

Sheet-Metal Cylinders

Several sites have produced scrap pieces of kettle brass or copper rolled into short, narrow cylinders. These are often referred to in print as tubular metal beads.

Lead Beads

There are two known examples of lead beads from historic Wichita sites. Both are of native manufacture, made by perforating musket balls.

Kettle Fragments

Recognizable kettle fragments from Norteño Focus components include bails, bail ears, and pieces of sheet brass from kettle walls. Wall fragments of cast-iron kettles occur in some sites. Bail ears (Fig。 58, c-e) show considerable variation in size and form. The bottom portion, which may be lobed or straight, was attached to the vessel by one or more rivets. The upper part of the ear is perforated to receive the bail. Bail ears of native manufacture are known, as well as rather ingenious methods of patching (including the use of leather gaskets). 
Pipe Tomahawk Bowl

Found in the fill of Feature $1 B$ at the Upper Tucker site, this specimen is of iron with an inflaring bowl. The base of the bowl is constricted to a narrow neck where it joins the tomahawk (Fig. 58, f).

Horse Trappings

Occurring frequently in most Norteño Focus sites are horse trappings, many of distinctively Spanish design (Di Peso, 1953: 194). Included in the collections are headstall and cheekplate fragments (Fig. 58, h, i), bridal bits, higos or decorative jinglers (Fig. 58, j), conchos, buckles $\overline{(F i g .} 58, g$ ), and numerous $\mathrm{S}$-shaped fastening devices. Most of these are of iron, although at least one heavy brass buckle, a brass concho, and several pieces of sheet brass covering for leather strips are known.

Chain-Mail Links

Small circles of brass or iron wire probably represent chain-mail links. In one case three such links were found interlocking, intact.

Metal Scrap

Scattered about most historic Wichita sites are miscellaneous pieces of metal, unidentifiable as artifacts and often showing evidence of native alteration. The frequency of metal scrap at a site has been suggested as an index to the amount of Indian blacksmithing activity (Harris, et. al, 1965: 352)。 Probably it reflects the availability of metal as well.

Glass

Fragments of bottle glass (usually amber or dark green) and pieces of flat, clear glass are recovered from some Norteño Focus sites. At least some of the clear glass represents mirrors traded to the Indians; spots of silvering still adhere to some of the pieces. In the manufacture of such tools as projectile points, knives, and scrapers glass occasionally was used as a substitute for stone. Glass beads are described elsewhere in this report.

European Ceramics

Although European ceramics are often found in Norteño Focus sites, most of them are of uncertain cultural affiliation, and some probably belong to a post-aboriginal habitation. Specimens believed to date from a Wichita occupation include a wheel-turned olla from the Womack site (Harris, et al, 1965: 357), and an occasional clay pipe fragment. 


\section{NATIVE-MADE ARTIFACTS FROM HISTORIC SITES}

by Tyler Bastian

Here are described those artifacts made by the Indians from native materials. Except for the pottery and pipes, the descriptions are based solely on the specimens found at the Longest and Upper Tucker Sites in 1965 and 1966.

\section{Pottery}

Complete vessels found at Norteño Focus sites (usually in burials) are of the types Womack Engraved (Duffield and Jelks, 1961: 36-39), Simms Engraved (Suhm, Krieger, and Jelks, 1954: 354), Natchitoches Engraved (Suhm, Krieger, and Jelks, 1954: 334), Emory Punctated and Hudson Engraved (Suhm, Krieger, and Jelks, 1954: 304) In the more westerly sites, particularly those near Spanish Fort, sherds of Nocona Plain (Suhm and. JeIks, 1962: 115) occur in the midden depositso Affiliated primarily with the prehistoric Henrietta Focus, this type may have Iingered into the contact period. In addition to Nocona Plain, other undecorated pottery includes a crude gritutempered ware with a dark interior and bright red exterior, found mainly in Oklahoman sites, and a few fragments of a buff to dark brows pottery, highly polished and tempered with bone, grit and (rarely) shell, found at Upper Tucker.

\section{Figurines}

Figurines and figurine fragments have been found at the Spanish Fort and Womack Sites (Steen, 1955; Harris, et alo, 1965: 303). Identifiable specimens, all from Spanish Fort, include several complete and fragmentary human effigies (Fig. $57, n-p)$, models of a quadruped (probably horse) (FIg. $57, q$ ), and several small fragments of unknown identity.

\section{Pipes}

Several characteristic features are shared by the clay and stone pipes found in Norteño Focus components. AII are elbow pipes with a conical bowl and a silghtly flaring stem of length equal to, or slightly greater than, the bow l height (Fig. 58, $k-0)$. The stem often projects slightly beyond the bowl to produce a small spur at the heel. The thickness of the stem is nearly always markedly greater than the bow thick ness. Most specimens are undecorated, although some-oboth clay 
and stone ones-have been found with engraved designs, often with motifs similar to those on Womack Engraved vessels.

\section{Shell Artifacts}

A total of three pieces of worked shell were recovered at the Upper Tucker site. Included in this group is a single completed pendant (Fig. 57, $k$ ). The remaining two specimens are pieces of river mussel shell showing evidence of notching or cutting.

The Longest site produced a plethora of worked and unworked shell. Over 200 pieces of mussel shell show evidence of modification, usually one or two cut edges. In addition five distinct artifacts were found, including four small per. forated disks (Fig。 $57, \mathrm{~m}$ ) and one subtriangular pendant (Fig. 57, 1).

Tabular scrapers

One of the characteristic artifacts of the protohistoric sites in the vicinity of spanish Fort is a large, thin, ovate, bifacially chipped scraper or flesher made of tabular sandstone (Fig。62). The chipping extends at least three quarters of the way around the perimeter. These tools are usually made of the gray tabular sandstone which outcrops along bluffs in the vicinity of the sites. The sandstone is soft and weathers rapidly so that the edges of the scrapers are usually not well preserved. Those specimens which are not weathered have working edges smoothed from use. Some of the specimens have streamworn surfaces, and at least three are made on large spalls from sandstone cobbles. A few specimens are made of quartzite and silicified sandstone. Complete specimens range from elongate ( $2 \frac{1}{2}$ times longer than wide) to nearly round. The specimens made from waterworn cobble spalls tend to be relatively thick and short. The largest example, associated with burial 4, is $163 \mathrm{~mm}$. long, $112 \mathrm{~mm}$. wide, and $19 \mathrm{~mm}$. thick. Several fragments appear to be from equally large specimens. The dimensions of the 18 complete and nearly com-. plete tabular scrapers are:

$\begin{array}{lll} & \text { Range } & \text { Mean } \\ \text { length (9 specimens) } & 88-163 \mathrm{~mm} & 121 \mathrm{~mm} . \\ \text { width (18 specimens) } & 43-112 \mathrm{~mm} & 68 \cdot \mathrm{mm} . \\ \text { thickness (18 specimens) } & 8-40 \mathrm{~mm} & 16 \mathrm{~mm} .\end{array}$


In addition to the above specimens there are 55 small fragments of tabular scrapers and 13 other fragments which may be from tabular scrapers.

Tabular scrapers are significantly more frequent on the south portion of the Longest Site in comparison to the north portion where the large end scrapers of Kay County filint are most frequent. Perhaps the availability of a new local resource contributed to a change in seraper type.

\section{Grooved Abraders}

Al1 29 grooved abraders are made of sandstone and tend to be rectangular shaped (Fig。63)。Cross sections are usually rectangular or plano-convex with the groove on a flat surface. The grooves parallel the long axis of the specimen and are usually on the broadest surface of the specimen. Multiple grooves are present on at least six specimens including those which are most irregular in shape. Sometimes a broad, flat area will be entirely covered with grooves and abrasion marks. The grooves tend to be straight and of uniform depth along the length of the abrader, although a few are curved and several are either deeper or shallower at the ends than near the center. In cross section the bottoms of the grooves are $U$-shaped on 20 specimens, $V-$ shaped on nine. The U-shaped grooves tend to have nearly flat rather than rounded bottoms, and about half of the V-shaped grooves are slanted so that they are, in effect, L-shaped. The sandstone used for all of the abraders tends to be composed of relatively coarse, pure quartz. The locally plentiful, relatively fine and impure sandstone was seldom used for grooved abraders. Dimensions of the grooved abraders are:

$\begin{array}{lll} & \text { Range } & \text { Mean } \\ \text { length (4 specimens) } & 71-135 \mathrm{~mm} . & 91 \mathrm{~mm} \text {. } \\ \text { width (29 specimens) } & 29-72 \mathrm{~mm} . & 38 \mathrm{~mm} \text {. } \\ \text { thickness (29 specimens) } & 15-37 \mathrm{~mm} . & 25 \mathrm{~mm} \text {. }\end{array}$

Grooved abraders are relatively more abundant on the north part of the Longest Site than on the south part. The various forms of abraders do not appear to have any distributional significance.

A pair of similar abraders were found in close proximity to Burial 5. They are plano-convex in cross section, and the grooves are straight and uniform in depth. In outine, one 
specimen is rectangular and the other is subrectangular. The groove is noticeably off-center at one end of the former, but nearly centered on the latter so that the edges of the two halves are not parallel when the grooves are aligned. The dimensions are:

Length Width Thickness

rectangular specimen

subrectangular specimen
$74 \mathrm{~mm}$. $30 \mathrm{~mm}$. $15 \mathrm{~mm}$.

$82 \mathrm{~mm}$ 。 $31 \mathrm{~mm}$ 。 $18 \mathrm{~mm}$ 。

A third complete abrader is oblong in outline, planoconvex in cross section, and has two irregular grooves on the convex surface. It is the only abrader grooved on a convex surface。 It is $135 \mathrm{~mm}$ 。 long, $41 \mathrm{~mm}$ 。 wide, and $20 \mathrm{~mm}$ 。 thick。

A distinctive specimen is made of relatively fine, hard sandstone shaped in a rectangular block with angular corners. The groove has a pronounced L-shaped cross section。

Another abrader is subrectangular in outline and in cross section and has a shallow groove which is hardly perceptible in the center where it crosses a wide band of different-colored sandstone. The different depths to which the groove is worn suggests that the item being abraded was small and/or resilient. There is a small depression $3 \mathrm{~mm}$ 。 deep and $11 \mathrm{~mm}$ 。 in diameter in the center of one end of the abrader.

In addition to grooved abraders, there are 16 fragments which may be parts of grooved abraders.

\section{Possible Abraders}

A large number of tabular pieces of local sandstone or very similar material may be abraders or fragments of abraders and grinding implements. Some of them may have been used as whetstones; however, the surfaces tend to be slightly undulating rather than flat or symmetrically concave or convex as is usually the case with artificially abraded surfaces. Smooth, almost polished, slightly undulating surfaces are a natural characteristic of some outcrops of tabular sandstone.

\section{Grinding Basins and Slabs}

Specimens which can be definitely identified as grinding slabs or basins (Fig. 64) are not common at either Upper Tucker or Longest Sites. Perhaps their scarcity can be partly attributed to the frequent use of the locally available, relatively soft sandstone which erodes and fractures rapidly. However, grinding stones (or manos) are made of the same material and 
they are more common. Moreover, grinding basins of similar material are plentiful on several late prehistoric sites furo ther up Red River. Only the first specimen described below is from the Upper Tucker Site。

\section{Grinding Basins}

A large fragment from the Upper Tucker Site appears to be from the edge of a larger grinding basin $9 \mathrm{~cm}$. thick. There are two similar edge fragments, each $6 \mathrm{~cm}$. thick, from a pit (Feature I9D) at the Longest site。

The largest complete grinding basin recovered was found on the floor of structure 1 at the Longest site. Its black clouding and highly fragmented condition indicates that it was subjected to the fire which destroyed the structure. The ovalshaped rock is $88 \mathrm{~cm}$. Iong, $45 \mathrm{~cm}$. wide and up to $12 \mathrm{~cm}$. thick. The basin is 32 by $50 \mathrm{~cm}$. in diameter and $3.5 \mathrm{~cm}$. deep, and it is offset toward one end. A smoothed flat area about 13 by 18 $\mathrm{cm}$. in diameter is on the other end.

A large, moderately coarse, compact sandstone specimen appears to be the end of a huge grinding basin $16 \mathrm{~cm}$ thick and $40 \mathrm{~cm}$. wide. The smoothed area is $30 \mathrm{~cm}$. wide. Several broad grooves near the end of the smoothed surface may be the result of abraiding, but the irregularity of the individual grooves seems to indicate some other origin. It was recovered from a pit (Feature 61).

Another specimen appears to be the end of a medium-sized grinding basin at least $12 \mathrm{~cm}$. thick and $19 \mathrm{~cm}$. wide. The maximum width of the basin is $12 \mathrm{~cm}$. and it has a contral pitted area. It is made of local sandstone and was recovered from the fill of structure 4 。

The bestopreserved grinding basin was also found on the floor of structure 1, but it was shielded from the intense heat of the fire by the ramp-like fill on the south side of the structure. It is made of lightwcolored quartzite with iron inclusions and appears to be much more resistant than the loca 1 sandstone. It is roughly wedge-shaped with three broadly concave grinding facets-one on each side and one on the largest edge. Each of the two opposite facets is 19 by $28 \mathrm{~cm}$ across and 2 to $3.5 \mathrm{~cm}$. deep. The facets are generally smooth and regular, but their surfaces are uniformiy pitted over a large area as if they had been used as anvils. The edge facet is 10 by $20 \mathrm{~cm}$. across and about $1 \mathrm{~cm}$. deep; its surface is broadly undulating and pitted near one end. 
Another complete specimen is a dubious artifact. It is a relatively thin slab of poor-grade fossiliferous limestone measuring 23 by 35 by $4 \mathrm{~cm}$. with very rough surfaces on the bottom and sides. It has a smooth, oval grinding area with a central concavity $12 \mathrm{~cm}$. in diameter and $1.5 \mathrm{~cm}$. deep. There is a series of deeply eroded, meandering grooves on the floor of the basin. The specimen was found face up $50 \mathrm{~cm}$. beneath the surface in the wall of an otherwise sterile exploratory trench (test 29) near spring Branch.

There are nine fragments 4 to $7 \mathrm{~cm}$. thick with broadly concave, smooth surfaces suggesting that they may be parts of grinding basins.

\section{Grinding Slabs}

Fragments of a large, flat grinding slab were included in a shallow rock-filled depression (Feature 34) near structure I at Longest site. The slab is made of the local sandstone and has been subjected to a fire. It is $32 \mathrm{~cm}$. wide and $7 \mathrm{~cm}$. thick with a flat grinding surface extending across the full width of one face. Judging from the shape and size of the fragments, the specimen may have been over $75 \mathrm{~cm}$. long.

Four edge fragments 4 to $7 \mathrm{~cm}$. thick represent other grinding slabs.

Ten other rocks 3 to $5 \mathrm{~cm}$. thick with flat, smooth surfaces may be from grinding slabs.

\section{Grinding Stones or Manos}

The grinding stones or manos (Fig. 65) tend to have an oblong outline, shaped edges, flat or slightly convex surfaces, and the usage surface confined to one face. Two specimens have subrectangular outlines, two are irregular in outline, and one fragment is wedge-shaped in cross section. The grinding sur faces are about equally divided between being flat and sightly convex. Only on two specimens are both surfaces flat. One complete specimen, lying under the feet of burial 5, is unusual in that the grinding surface is convex along the longitudinal axis rather than along the lateral axis as is the case with the other specimens. One specimen has red ochre stains on the dor sal surface and on one end. All of the grinding stones are made of sandstone, usually the soft, locally available variety. Dimensions of the 22 complete and nearly complete oblong grinding stones are as follows: 


$\begin{array}{lcl} & \text { Range } & \text { Mean } \\ \text { length (6 specimens) } & 116-280 \mathrm{~mm} .160 \mathrm{~mm} . \\ \text { width (22 specimens) } & 80-129 \mathrm{~mm} .100 \mathrm{~mm} . \\ \text { thickness (23 specimens) } & 22-65 \mathrm{~mm} .39 \mathrm{~mm} . \\ \begin{array}{c}\text { length/width ratio } \\ \text { (6 specimens) }\end{array} & 1.3-2.2 \mathrm{~mm} .1 .5 \mathrm{~mm} .\end{array}$

The two complete, irregularly shaped grinding stones tend to be relatively small and short in comparison with the oblong specimens.

\section{Grooved Mauls}

One complete grooved maul and two fragments were recovered from the Upper Tucker site. None were found at the Longest Site. The complete specimen (Fig。66, B) is made on a smooth quartzite cobble, is three -quarters grooved, and is moderately battered on both ends. It is $91 \mathrm{~mm}$. long, $74 \mathrm{~mm}$. wide, $81 \mathrm{~mm}$. from front to back ( perpendicular to the ungrooved side, and weighs 771 grams. The pecked groove is $21 \mathrm{~mm}$. wide and $2 \mathrm{~mm}$. deep.

The largest fragmentary maul (Fig。66, A) is made on a smooth cobble of high quartz content and the remaining end is heavily battered and spalled. The specimen is broken along the groove which appears to extend nearly all the way around. The maul is $63 \mathrm{~mm}$. wide and $89 \mathrm{~mm}$. from front to back. If the maul was symmetrical, it would have been about $150 \mathrm{~mm}$. long and weighed over 1500 grams.

The third specimen is a small fragment of a smoothed quartzite cobble which appears to have the edge of a groove on one corner.

\section{Hammerstones}

Three principal forms of battered surfaces, described below, are evident on 74 cobbles and fragments. The hammer. stones range from 70 to $195 \mathrm{~mm}$ 。 in length, and from 46 to 125 mm. in width. The weights of complete specimens vary from 185 to 1800 grams and average 540 grams. Most of the specimens are made of natural pebbles and cobbles of dense, heavy quartzite or quartz; five are Ogallala chert。 
End Battered Hammerstones

Flattened, circular battered areas on both ends are typical of the 44 specimens of this variety (Fig.66, C $\backsim$ G)。 If the cobble is irregular or broken the battering tends to follow the resulting ridges. A few specimens exhibit battering in one or two places on the sides of the cobbles. Impact spalls of various sizes have been removed from several specimens, and 20 large spalls were recovered which can be attrib uted to that source. One specimen has an area of red ochre impacted near one edge of a battered surface suggesting that it was used to pulverize a lump of ochre. The hammer is 82 mm. long, $80 \mathrm{~mm}$. in diameter, and weighs 490 grams. It was found in a pit (Feature 19D).

\section{Bitted Hammerstones}

A bifacially flaked, elongated, battered edge characterizes five hammerstones (Fig. 66, I-J). Two of them may be the result of impact spalling along fracture planes, but at least one appears to have been intentionally flaked prior to its use as a hammerstone. The latter specimen is made on a cobble of Ogallala chert and has a long curved edge; it closely resembles an artifact type common on Archaic sites in western oklahoma.

\section{Edge Battered Hammerstones}

Four hammerstones (Fig. 66, K) have a narrow battered area along all broken edges. Three appear to be broken and battered hammerstones, and one may be part of a grinding stone.

\section{Pitted Hammerstones}

A flattened, round cobble (Fig。66, I) is battered around the periphery and in the center of each side. The degree of pitting on the sides is slight. The specimen is about $70 \mathrm{~mm}$. in diameter and $42 \mathrm{~mm}$. thick.

\section{Rubbing stones}

Five smooth cobbles and fragments have one highly polished surface such as would result from rubbing on soft, fine-grained material (Fig。67, A-B)。All are composed of hard, dense rock of high quartz content. 
The largest complete specimen is an elongate cobble of quartz mica schist associated with burial 4 at the Longest Site. The object is $304 \mathrm{~mm}$. long, $85 \mathrm{~mm}$. wide, and 52 to $60 \mathrm{~mm}$. thick. The polished area extends the full width along the central half of the length of the flattened face. Traces of red ochre are present near one end on the oppo site surface.

The other complete specimen is the midsection of an elongated quartzite cobble. The edges, where the broken and natural surfaces intersect, have been battered and ground smooth. The polished area is located in the center and toward one end of the flattest side and applied, at least in part, after the cobble was broken. The specimen is $82 \mathrm{~mm}$. Iong, $93 \mathrm{~mm}$. wide, and $57 \mathrm{~mm}$ 。 thick; it was found in a pit (Feature 19D)。

The largest fragment is the midsection of a flattened, elongated cobble of quartz mica schist. The polish is cen= trally located on the flattest surface and is poorly developed. The specimen is $75 \mathrm{~mm}$. wide, $44 \mathrm{~mm}$. thick, and is from the Upper Tucker Site。

Another fragment of a quartz mica schist cobble includes a portion of a moderately polished surface. The cobble is $61 \mathrm{~mm}$. thick and was found in a rodent hole beneath structure $I$ at the Longest Site。

A quartzite pebble fragment from the Upper Tucker Site may have served as a rubbing stone. It is $58 \mathrm{~mm}$. wide and $26 \mathrm{~mm}$ 。 thick。

\section{Paint Palettes}

Five tabular fragments of sandstone (Fig。67, C-F) have red ochre adhering to one surface. None of them is cleariy modified, although two could be included in the "double abrader" category。 The largest specimen, measuring 230 by 185 by $30 \mathrm{~mm}$. was found on the floor of structure 1 and has only a silight ochre stain near one end. It is the largest unmodified tabular piece of sandstone recovered from the Longest Site. The other specimens range from 14 to $36 \mathrm{~mm}$. in thickness. Three are from the Longest site and two are from the Upper Tucker site. 


\section{Anvil Stones}

Five irregularly shaped sandstone slabs and chunks (Fig. 67, G-I) have central battered areas on one or more faces, and on two of the specimens faint grooves extend through and beyond the battered area. They range from 145 to $175 \mathrm{~mm}$. in maximum diameter and from 30 to $93 \mathrm{~mm}$. in thickness.

\section{Miscellaneous Ground Stone Artifacts}

Three small, shaped pieces of well cemented sandstone (Fig. 69, E-G) were recovered from a pit (Feature 64) at the Longest site. One is nearly cylindrical, 9 by $10 \mathrm{~mm}$. in diameter and $16 \mathrm{~mm}$. long. Another is rhomboidal, 18 by 11 by $8 \mathrm{~mm}$. in maximum dimensions. The third specimen resembles a short armed, broad $V$. Its maximum dimensions are 31 by 18 by $12 \mathrm{~mm}$.

A section of smooth-surfaced, elongated, rectangular quartzite appears to have been abraded near the edge of one surface. It measures 15 by 24 by $37 \mathrm{~mm}$. and was found near a pit (Feature 62) at Longest.

\section{Crinoid Stem Disks}

Nineteen fossil crinoid stem disks (or beads) and two crinoid stem sections were found at the Longest site (Fig. 69, $K-Q$ ). None were recovered from the Upper Tucker Site。 Most of the disks are made of a single segment, show some polish, and have a natural hole. The holes of two disks may have been drilled. The dimensions are:

$\begin{array}{lll} & \text { Range } & \text { Mean } \\ \text { outside diameter } & 6-13 \mathrm{~mm}, & 8.8 \mathrm{~mm} . \\ \text { thickness } & 1-4 & 2.5 \\ \text { hole diameter } & 1-4 & 2.8\end{array}$

Fossil crinoids do not occur locally at the Longest site where only Permian and Quaternary deposits are exposed. They are plentiful, however, in the limestones of the Criner Hills and Arbuckle Mountains to the north and northeast. 
Toothed Fleshers of Bone

Five specimens comprising two varieties are present (Fig. 68, B $-F$ ). Both varieties are made from large split long bones and have a flat bevel on the ventral or inside surface and a series of narrow slits 1 to $3 \mathrm{~mm}$. apart cut into the sharp working edge。 One variety is represented by a single specimen from the Upper Tucker Site. It is made from the distal end of a left bison tibia, the outside or dorsal surface is flat, and the working edge is slightly curved. The other variety is represented by four specimens from structures 1 and 3 at the Longest site. At least two are made from bison metatarsals, the outside or ventral surface is arched, and the working edge is markedly curved. The notches on the complete specimen are nearly obliterated by use. The only other example of a toothed flesher made of bone known in Oklahoma is from the little Deer Site of the proposed Wheeler complex, discussed elsewhere in this report。

Worked Bison Scapulas

Three modified bison scapulas (Fig。 68, $G-H$ ) were recovered from structure 1 and immediate vicinity at the Longest site. The anterior border including half of the glenoid cavity is removed. The acromion is also removed. The posterior border is beveled to a sharp edge. The angle of the bevel intersects the base of the acromion. There are slight undulations perpendicular to the edge together with striations on both of the beveled surfaces. The function of this kind of tool is uncertain.

\section{Rib Edge Awls}

This awl (Fig. 68, J) is made from a long; tapering

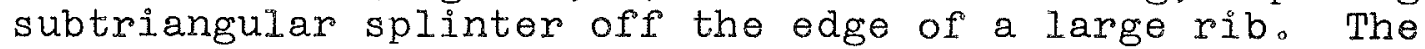
split side has been carefully smoothed. The cross section is flattened at the small end, but the extreme tip is missing. The larger end was broken and lost during excavation of Feature 53 at the Longest Site. The remaining fragment is $169 \mathrm{~mm}$. long.

\section{Bird Bone Whistles}

A broken section ( $100 \mathrm{~mm}$. long) of a large bird bone (Fig。68, A) has a triangular hole $(5 \times 8 \mathrm{~mm}$ ) cut near the center. The triangle is isosceles with slightly curved 
sides. Blowing through the end of the bone opposite the apex of the triangle produces a loud, shrill whistle. A second bird bone has a notch at one broken end suggesting that it may be part of a whistle. Both objects were found in pits on the south portion of the Longest site.

\section{Drilled Teeth}

A large bear canine (Fig. 69, A) and an artiodactyle incisor (Fig. 69, B) are perforated laterally near their proximal ends. The holes are countersunk on both sides and show little or no sign of wear. The bear canine is $72 \mathrm{~mm}$. long. Both specimens are from the Longest $\$$ ite.

\section{Decorated Bones}

Two fragmentary objects of unknown function were recovered from the south portion of the Longest site. One (Fig. 69, C) is a flat piece of dense bone with a rounded edge. It appears to be part of a disk $42 \mathrm{~mm}$. in diameter. It is 2 to $3.5 \mathrm{~mm}$. thick and has three small, shallow depressions aligned in an arc near the broken edge. The second specimen (Fig. 69, D) has a smoothed decorated surface and an irregular back of cancellous material. It is $8 \mathrm{~mm}$. thick. A very broadly curving edge is decorated with a series of notches $2 \mathrm{~mm}$. wide, $3 \mathrm{~mm}$. deep, and spaced 2 to $3 \mathrm{~mm}$. apart. Two rows of closely spaced conical depressions $4 \mathrm{~mm}$. In diameter parallel the edge. Traces of red pigment occur in the bottoms of some of the depressions and notches.

\section{Miscellaneous Bone Objects}

A burned, rounded, smoothed deer bone (Fig.69, J), encircled with columns of shatter marks and with one end cut off and smoothed, was recovered in the fill of structure 1 at the Longest site. There is a shallow, conical depression in the cancellous tissue of the cut end. The opposite end was broken in excavation and may be part of a burned deer metatarsal recovered from the same structure.

Two specimens (Fig.69, H-I) seem to be end waste from the manufacturing of cylindrical objects. One is a splinter of thick bone which has been rounded at one end and cut by an encircling groove. It was excavated at the south portion of the Longest Site. The other is a rounded fragment of dense bone that has been roughly shaped at one end and 
carefully rounded at the other where it has been cut by an encircling groove. The later specimen was found at the Upper Tucker Site.

A fragment of long bone, probably a bison tibia, showing heavy use polish along one edge was recovered from the plow zone in the northwest portion of the Longest site. It could be part of a toothed flesher.

Along bone with both ends broken (Fig. 68, I) came from a refuse mound (Feature 55) in the northwest portion of the Longest site. It is probably a bear bacula. It has several long series of small, closely spaced striations perpendicular to the bone, but no major modifications are apparent.

Although a number of complete and fragmentary deer ulnas were recovered, there are no complete deer ulna awls. Four ulnas with distal ends broken have some marks and polishing suggesting possible use but their status as artifacts is doubtful. Three are from the plow zone in the northwest portion, and one is from the fill of structure 1 at the Longest site.

One of the several antler tines recovered has a blunt, rounded end suggesting that it may have been used as a flaker. It was recovered from the plow zone above structure 3 in the south portion of the Longest site. 
ART IFACTS FROM PREHISTORIC SITES

by Dessamae Lorrain

Abraders

No. of Specimens: Glass, 14; Coyote, 13

Illustrations: Fig. 60, a-b

These are shaped sandstone blocks with U-shaped or Vshaped grooves on one or more faces. The typical specimen has a square or rectangular cross section with one flat side, two very slightly convex sides, and one strongly convex side. The flat side has a deep longitudinal U-shaped groove from one end to the other. The two slightly convex sides have very shallow grooves extending only part way along the long axis; the strongly convex side is ungrooved. Fifteen abraders fit this general description. The remaining 12 specimens show various combination of grooved and ungrooved surfaces. of these, eight have U-shaped and four have V-shaped grooves.

The abraders with long U-shaped grooves were presumably used to smooth arrow shafts. If so, the arrow shafts had diameters between 6 and $9 \mathrm{~mm}$. The abraders with V-shaped grooves may have been used as awl sharpeners.

\section{Manos}

No. of Specimens: Glass, 9; Coyote, 6

All the manos are made from friable, ferruginous sandstone. Each has been used on one surface only. The dorsal surfaces are convex to almost flat. The largest complete mano measures $120 \times 100 \times 18 \mathrm{~mm}$., the smallest $80 \times 50 \times 20 \mathrm{~mm}$.

A few manos have one or more short grooves, apparently from incidental use as abraders. One fragmentary specimen has a shallow pit pecked into one face.

\section{Metates}

No. of Specimens: Coyote, 3

Illustrations: Fig. 60, h

One complete metate and fragments of two others were recovered at the coyote site. The intact specimen has a trough- 
shaped grinding area indicative of a back-and-forth motion. The trough measures $18 \mathrm{~cm}$. wide and $31 \mathrm{~cm}$. long: the entire metate is $49 \mathrm{~cm}$. long and $31 \mathrm{~cm}$. wide. Both the complete and the fragmentary metates are made of soft red sandstone, the same material used for abraders.

\section{Pottery}

Nocona Plain

No. of Specimens: Glass, 306; Coyote, 415

Illustrations: Fig. $60, \mathrm{cg}$

This plain, heavily shell-tempered pottery is the most common type at this and other Henrietta Focus sites. The vessels were built up by coiling, then shaped and smoothed with paddle and anvil. Surface color varies from gray to light brown to reddish brown. Core color is usually dark gray. Fire clouds are rare. The paste is compact to crumbly, tempering particles are commonly visible on the surface. Surface finish varies from rough to well-smoothed but is never burnished. The most common vessel shape is a large jar with small circular. flat, or rounded bottom, globular body, constricted neck, straight outflaring rim, and simple flat or round lip. There are no vessels complete enough to measure at Glass Site but the one reconstructed vessel from Coyote Site (Fig. 59, g) is $170 \mathrm{~mm}$. high and $190 \mathrm{~mm}$. across the orifice.

Vessels of Nocona Plain are usually without decoration, but occasionally there is a row of nodes or vertical handles (either strap or loop) at the juncture of rim and body. Thickness of the sherds varies from 4 to $8 \mathrm{~mm}$. for body sherds and from 11 to 15 for base sherds. At the Glass Site only flat bases were found. There were sherds with nodes at Glass, but none with strap or loop handles.

Nocona Plain is the usual pottery type found on the southern plains buffalo-hunter-agriculturalist sites. The temper varies considerably from one area to the next. Surfaces are almost always plain in the north-central Texas area, but farther north into oklahoma cordmarking becomes common. This pottery has been called Stafford Plain, Stafford Cordmarked, Lindsey Plain, Lindsey Cordmarked, Stamper, Borger, Nocona, etc. (Krieger, 1946; Bel1 and Baerreis, 1951; Buck, 1959; Sharrock, 1961; Pillaert, 1963). 
$\underline{\text { Redware }}$

No. of Specimens: Glass, 25

Illustrations: Fig. 60, d-f

This unusual pottery has been found at numerous sites of the Henrietta and Washita River Foci (Kreiger, 1946: P1. 6, e-h; Pillaert, 1962: Pl. 34, No. 2; Pillaert, 1963: P1. 19, Nos. 8-10; Shaeffer, 1965: Fig. 50).

The redware pottery is untempered. All but one of the sherds from the Glass and Coyote Sites are hand molded; the one exception shows a coil mark on the break. Fracture is usually very irregular. The sherds frequently come apart in plate-like layers (Fig. 60, d). Thickness is quite variable within a single vessel, ranging from 10 to $20 \mathrm{~mm}$., but as a group these sherds are characterized by their great thickness in comparison with other pottery types.

Surface color of the outside is red-brown or brown; the inner surface is usually bright red. Core color blends gradually from a bright orange-red into various shades of red and brown from inner surface to outer and from one area of a vessel to another. The surfaces are quite rough and frequently show the imprints of the potter's fingers. The exterior is impressed in a pattern which resembles corn cobs but whether actual corn cobs, some other implement, or fingernails were used is an unresolved problem. Both surfaces show random brush marks. Vessel shape is unvarying--only small cylindrical mugs, about 40 to $80 \mathrm{~mm}$. in diameter, with flat circular bases, straight sides, and simple rounded or slightly flattened rims have ever been reported (Fig. 60, e-f), and $I$ know of only one complete example (in a private collection). The uniformity of size, shape, and color of these little vessels and their striking contrast with the common utility ware at the same sites indicates that they were made for some quite specific use. Frequently they seem to be burned on the inside far more than would result from firing a pots during manufacture. Possibly they were for ceremonial fire or fire storage.

\section{Thin Black Pottery}

\section{No. of Specimens: Glass, 3 sherds}

This may be a variant of Nocona Plain. Sherds are quite thin (2.7 to $3.5 \mathrm{~mm}$.); surface color is black; paste color is black; temper is abundant crushed shell (burned). Interior surface finish is rough; exterior surface finish is smooth. Vessel shapes are unknown. 
Brown Pottery

No. of Specimens: Glass, I

Surface color is medium brown; surfaces are rough. The paste is gray-brown, soft, and fairly compact. Temper appears to be burned and unburned crushed bone. There are a few sand and grit particles which were probably natural inclusions in the clay. The sherd is very reminiscent of some Caddoan sherds from East Texas. Material from several Caddoan sites was being processed in the laboratory at the same time as the Glass Site material. Possibly this one sherd was inadvertently mixed.

Baked, Untempered Clay Objects

No. of Specimens: Glass, I

This lump of unbaked clay has apparently been intentionally shaped but was never fired. It is $78 \mathrm{~mm}$. long, 32 and $45 \mathrm{~mm}$. wide at the two ends, and $19.6 \mathrm{~mm}$. thick. There is a hole $19 \mathrm{~mm}$. from the smaller end. The hole has a uniform diameter from front to back of $9.8 \mathrm{~mm}$. It appears to have been formed by molding the wet clay around a stick. The purpose of this object is unknown.

Clay Daub

No. of Specimens: Glass, 11

These pieces of burned clay have grass impressions and were probably plaster for a house. The small amount indicates that the houses were not plastered all over but only in small areas, most likely around the smoke hole in the roof or in a band around the outside lower walls.

\section{Bison Scapula Hoes}

No. of Specimens: Glass, 21; Coyote, 1

Illustrations: Fig. 61, a-c

Five of these hoes are complete or nearly so; 17 are

fragmentary. The fragments may represent fewer than 17 tools, but it is impossible to be certain. The scapulae have been modified by removing the acromion and anterior ridges on the dorsal face and smoothing the cut surfaces, by cutting a hafting groove into the dorsal face, and by cutting away the articular surface of the glenoid fossa in some cases. The hafting groove extends from the proximal end of the hoe to a point which varies from 90 to $130 \mathrm{~mm}$. from the proximal end. The groove curves to- 
ward the anterior border to take advantage of the thickest portion of the scapula. This particular type of long curved groove is unusual although hafting notches or grooves are common on such tools. These specimens all appear to be worn out or broken. By far the largest number of hoes were found in the house fill of Feature 2 at the Glass site.

\section{Bison Tibia Digging Sticks}

No. of Specimens: Glass, 9 (2 complete)

Illustrations: Fig. 61, d

These are all made from the distal end of bison tibae. The anterior surface has been cut away to within 55 to $95 \mathrm{~mm}$. of the end of the bone. The posterior side has been left longer ( 126 and $116 \mathrm{~mm}$. in two unbroken tools) and ground down to a sharp edge. A hole for insertion of the digging stick was made by burning through the articular surface and cutting away the cancellous tissue within. The holes are around $32 \mathrm{~mm}$. in diameter in all cases. On the shorter complete specimen, wear is confined mainly to the outside of the bone, but both sides of the longer complete tool are worn smooth.

Worked Bison Humerus Heads

No. of Specimens: Glass, 1

This bone had been modified by removal of a considerable amount of cancellous tissue from the interior, leaving a cavity about $75 \mathrm{~mm}$. long, $50 \mathrm{~mm}$. wide, and $60 \mathrm{~mm}$. deep. In addition, the outer surface of the bone has been chopped away in several places. The purpose of these modifications is unknown.

Utilized Deer Mandibles

No. of Specimens: Glass, 1; Coyote, 1

Illustrations: Fig. 6.1, k, I

On the Glass Site specimen there is a worn groove, between the second cusp of the third molar and the ascending ramus, which extends downward on the inner surface of the jaw. The third cusp and part of the second cusp of the third molar are worn away. The last premolar has a.lso been worn down even with the bone, and there is a shallow groove on the inner surface of bone below this tooth. The first molar is worn down at an angle, but not so severly as the last premolar and the back of the third molar. The wear has left the buccal surface of the first molar higher than the lingual surface which is the reverse of the natural slope of a deer tooth. 
The Coyote site mandible shows less wear than the above specimen. Use polish is present on both the buccal and lingual surfaces of the mandible body. A hole $50 \mathrm{~mm}$. in diameter has penetrated the ascending ramus, possibly a hafting aid. Teeth show little abrasion.

Deer madible tools similar to these have been found at the Lee II and McLemore Sites in Oklahoma (Pillaert, 1962: PI. 30, Nos. 5-7; Pillaert, 1963: P1s. 23, 24, and 34). Three of the specimens from the McLemore Site were in the graves of females. A hafted deer mandible said to be a sickle is illustrated in Swanton (1942: P1. 16-1), but it does not appear to have worn teeth or grooves.

\section{Spatulate Bone Tools}

No. of Specimens: Glass, 1

This spatulate tool is made from a deer ulna. Similar tools have frequently been called flaking tools, but they were more likely used in basket making or weaving.

Bone Awls

No. of Specimens: Glass, 4; Coyote, 6

Illustrations: Fig. 61, e-g

Four of the awls are made from the proximal ends of split deer metapodials, five are splinter awls, and one is the distal end of a fish-fin spine used as slender awl or needle.

\section{Bone Scrapers}

No. of Specimens: Glass, 1

This object is a segment cut from a rib or dorsal spine of a large animal, probably bison. It is shaped like an orange segment and is $58 \mathrm{~mm}$. long by $21 \mathrm{~mm}$. wide. The straight edge is rough, the convex one smoothed. This artifact's use is not known, but in shape it resembles the ula or woman's knife of the Eskimo which is used to scrape the blubber and hair from seal skins (Mason, 1889: 562-563).

Modified Deer Antler

No. of Specimens: Glass, 1

This segment of deer antler has been cut smoothly at the distal end and the inner tissue of the bone removed to form a 
hole $28 \mathrm{~mm}$. deep. Possibly it was used as a haft for some kind of implement.

\section{Bone Rasps}

No. of Specimens: Glass, 6

Illustrations: Fig. 61, i-j

These small, notched rib fragments evidently are pieces of bone rasps. The largest is $38 \mathrm{~mm}$. long and has eight. transverse grooves.

$$
\text { Antler Hoes (?) }
$$

No. of Specimens: , Coyote, 1

Illustrations: Fig. 6I, h

This is a large, flat piece of antler with one end sharpened by abrasion from opposing surfaces. Possibly it was a hoe. The entire piece is twisted and displays one smooth surface and one pitted, convoluted surface. Atypical for area sites of any age or culture, the antler appears much too large for deer.

\section{Shell Disks}

No. of Specimens: Glass, 1

This specimen is a small, thin, oval piece of shell with a possible drilled hole at one end. The shell is unfortunately broken at that end.

\section{She11 Spoons}

No. of Specimens: Coyote, 1

A valve from a fresh-water mussel exhibits wear along one edge, possibly from use as a spoon. 
THE CHIPPED LITHIC INDUSTRIES FROM THE GLASS,

COYOTE, AND LONGEST SITES*

by David Lubell

The following is a description of the chipped stone artifacts recovered from the Longest, Glass, and coyote sites in the fall and winter of 1965-1966. Chipped stone material from the Upper Tucker Site would have been included also had there been a large enough sample for statistical viability.

Only four flint specimens were found at Upper Tucker. One of these is a dart point similar to type Marshall (Suhm, Krieger, and Jelks, 1954: 444)--the shoulders and tip are broken and missing. The other projectile point is a straight-based unnotched triangular point, identified as type Fresno (Suhm, Krieger, and Jelks, 1954: 498). The remaining two artifacts, both crude blade scrapers, display unifacial semi-steep retouch along one lateral edge and, in one instance, along the distal end.

The Longest Site

\section{Endscrapers}

No. of Specimens: 10

1. On a flake with a cortex butt. The scraper edge is formed by steep retouch on the distal end and partial steep retouch on one lateral edge with opposed semi-steep retouch.

2. Same as No, 2 with the exception that the semi-steep lateral edge has had three inverse flakes removed and the distal end has been broken on the ventral surface through crushing.

3. Endscraper on a small flake with inverse retouch on

* This paper was written in a slightly different form as a term paper at Southern Methodist University in the spring of 1966. The author, who served as assistant archeologist during excavation of the Upper Tucker and Coyote Sites, has had extensive training and experience in European methods of lithic artifact classification and analysis. This study constitutes an effort to classify and analyze samples of artifacts from the Spanish Fort area by a system currently in vogue in Europe. (Ed。) 
one lateral edge and the butt.

4. Endscraper on a small flake with very light discontinuous marginal retouch.

5.-10. The distal portions of broken endscrapers. These are all similar. The scraping edge is formed by steep retouch on the distal end of a flake.

\section{Double Endscrapers}

No. of Specimens: 1

1. On a large flake. A broad convex endscraper is formed on the distal end by steep retouch with an opposed smaller convex endscraper on the proximal end. "The lateral edges are marginally retouched.

\section{Sidescrapers}

No. of Specimens: $\quad 5$

1. Denticulate side scraper with opposed inverse retouch on an endscraper.

2. A smooth convex side scraper merging into a denticulated scraper at the distal end of the scraper edge and then into a convex endscraper on the distal end of the flake.

3. A convex denticulated side scraper with an opposed inverse concave side scraper.

4. Concave side scraper formed by marginal retouch on a flake with opposed inverse marginal retouch.

5. Broken side scraper on a flake.

\section{Oval Scrapers}

No. of Specimens: 4

1. Very large, thick cortex flake with well formed steep continuous retouch around the entire edge of the flake with the exception of the proximal end which has been broken irregularly along internal fracture planes in the stone created by veins of impurities.

2. Large flake with continuous retouch on the edge with the exception of the lisse platform. The small amount of inverse retouch on the lateral edges appears due to battering. 
One lateral edge is foliated with opposed semi-steep retouch. and with steep retouch on the distal end.

3. Medium-sized flake with continuous steep retouch grading into semi-steep retouch on one lateral edge.

4. Medium-sized flake with continuous steep retouch.

\section{Denticulates}

No. of Specimens: 3

1. Rectangular denticulate scraper on a basally truncated flake. Both lateral edges and the distal end are denticulated. The basal truncation is formed by abrupt obverse retouch with a small area of inverse retouch at one proximal corner.

2. Distal end of a denticulate scraper on a flake. Retouch is steep and well-formed. The flake was broken at the proximal end by a blow perpendicular to the long axis of the flake.

3. Denticulate side scraper on a large thick blade. Retouch is well formed and steep, but discontinuous, occurring only on the proximal half of one lateral edge.

\section{Gouge}

No. of Specimens: 1

1. An atypical example of the Clear Fork Gouge. This piece is on a quartzite pebble which has been unifacially worked to form the dorsal surface of the tool, while the ventral surface is cortex.

Notched Flakes

No. of Specimens: 8

1. Distal notch on a broad flake with discontinuous marginal retouch.

2. Two opposed lateral notches on an unretouched trianguloid flake.

3. Double laterally notched flake with opposed bifacial retouch and inverse distal retouch. All retouch is marginal.

4. Well formed inverse distal notch on an irregular flake with discontinuous marginal retouch. 
5. Small flake, broken at both ends, with two opposed lateral notches formed by steep retouch.

6. Small flake with unilateral marginal retouch and an opposed notch at one distal corner which has been bisected by a transverse distal break.

7. Inverse notch bisected by a basal break with bilateral marginal inverse retouch.

8. Notch on one distal corner of a flake bisected by a break.

\section{Notched: Blades}

No. of Specimens: 1

1. Inverse lateral notch on a blade with opposed marginal inverse retouch and obverse marginal retouch on the distal end.

\section{Retouched Flakes}

No. of Specimens: $\quad 32$

$\begin{array}{cc}\text { Number } & \frac{\text { Type }}{23} \\ 9 & \begin{array}{l}\text { Obverse } \\ \text { Inverse }\end{array}\end{array}$

\section{Retouched Blades}

No. of Specimens: 4

All four have very weak bilateral marginal retouch.

\section{Arrow Points}

No. of Specimens: 8

$\frac{\text { Number }}{6} \frac{\text { Type }}{1} \frac{\text { Fresno }}{\text { Broken }}$

Dart Points

No. of Specimens: 7 


\begin{tabular}{cl} 
Number & Type \\
\cline { 1 - 1 } 1 & Paleo-Indian \\
1 & Lange \\
1 & Indeterminate \\
4 & Broken
\end{tabular}

\section{Choppers}

No. of Specimens: 1

1. On a very large flake $(87 \times 60 \mathrm{~mm}$.) with a cortex platform. Bilateral retouch is heavy and semi-steep, and both lateral edges and the distal end are heavily battered and bifacially foliated. The retouch is not steep enough to be considered scraper retouch, and the battering and foliation indicates use as a chopping/cutting tool.

\section{Battered Edge Pieces}

No. of Specimens: $\quad 10$

These pieces can be considered fabricators used as retouching or flaking tools in the production of other tools. All are distinguished by bifacial battering on one or more edges, but are too small and irregular to be considered chopping tools.

\section{Varia}

No. of Specimens: 1

A bifacially flaked point (probably Archaic) with a concave basal truncation.

\section{Cores}

No. of Specimens: 7

Single Lisse

Single Cortex

Opposed Lisse

Bipolar

Unidentifiable

\begin{tabular}{ccc} 
& Number & Percent \\
& 1 & $14.3 \%$ \\
2 & $28.5 \%$ \\
2 & $28.5 \%$ \\
& 1 & $14.3 \%$ \\
Total & 1 & $14.3 \%$ \\
\cline { 2 - 3 } & 7 & $99.9 \%$
\end{tabular}


Unidentifiable Broken Tools

No. of Specimens: $\quad 30$

Unfinished Tools

No. of Specimens: 7

Debitage

No. of Specimens: $\quad 609$

Cortex Flakes

Number

Secondary Flakes

37

118

Chips and Fragments

454

Coyote Site

Endscrapers

No. of Specimens: 3

Illustrations: Figure 59, a,b

All three are formed by steep retouch on the distal ends of bilaterally retouched flakes. Two are broken at the proximal end and one is basally thinned.

\section{Thumbnail Scrapers}

No. of Specimens: 9

Illustrations: Figure 59, e-g

Five are convex. Two of these have dorsal retouch and are typical. The third is on a very small flake with bilateral marginal retouch and steep retouch on the distal end. The fourth is the distal end of a broken specimen which was apparently only retouched on the distal end of the flake. The fifth is an atypical specimen which has been bifacially worked by very flat retouch.

Three are atypical in that the distal end (the scraping edge) is straight and oblique to the long axis of the flake. 
Steep retouch is confined to the distal end with steep to semi-steep marginal retouch on the lateral edges. These pieces lack the dorsal thinning common of the typical thumbnail scraper.

One is a concave thumbnail scraper on a cortex flake with a very weak opposed convex scraper and one lateral notch.

\section{Side Scrapers}

No. of Specimens: 4

Illustrations: Figure 59, c-d

1. Unilateral side scraper formed by well-executed semisteep retouch. The distal end of the flake is marginally retouched forming a possible graver at the right angle formed by the intersection of the scraper edge and the distal edge at one distal corner.

2. An atypical example of a de jete scraper (the scraping edge is at an oblique angle to the long axis and intersects that axis approximately in the middle of the distal end) formed by unilateral marginal semi-steep retouch.

3. An atypical convex side scraper formed by partial semisteep retouch on one edge of a cortex flake.

4. A double convex side scraper on a blade, formed by bilateral semi-steep retouch on a dorsally thinned blade with a distal hinge fracture.

\section{Denticulates}

No. of Specimens: 4

1. Straight denticulate scraper on a high keeled bifacially worked quartzite core fragment:.

2. Concave denticulate scraper on one lateral edge of the distal end of a large thick quartzite flake with some bifacial flaking.

3. Convex denticulate scraper on one lateral edge and the distal edge of a small thick flake.

4. Denticulate scraper on the basal portion of one lateral edge of an irregular cortex flake. 


\section{Gouge}

No. of Specimens: 1

A very atypical example of the Clear Fork Gouge, on a thick, high keeled flake with a lateral notch. Flaking is rough.

Notched Flakes

No. of Specimens: 4

1. Bilaterally notched flake with steep well formed bilateral retouch.

2. Lateral notch on a cortex flake formed by steep retouch grading into weak marginal retouch on the notched edge.

3. Double notch on the distal end of a flake formed by steep retouch on a cortex edge.

4. Inverse notch on the distal end of a broad, thick irregular flake.

\section{Notched Blades}

No. of Specimens: 1

Lateral notch on a blade with partial bilateral marginal retouch.

$\underline{\text { Retouched. Flakes }}$

No. of Specimens: 21

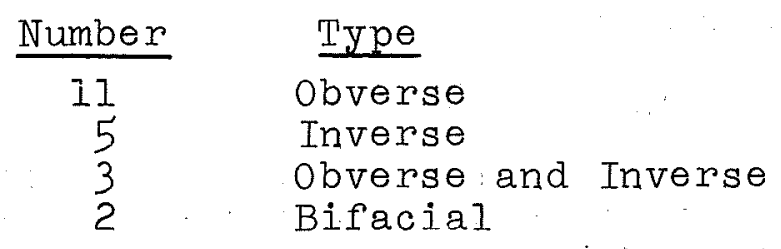

Retouched Blades

\section{No. of Specimens: 2}

1. Extensive flat to semi-steep retouch along one edge.

2. Bilaterally retouched blade. Retouch is steep and foliated. 
$\underline{\text { Drills }}$

No. of Specimens: 1

"T-shaped" base drill with a diamond cross-section drill bit and a bifacially worked base. The basal edge of the base is cortex.

\section{Gravers}

No. of Specimens: 3

1. Very weak graver on a retouched core fragment.

2. Well formed graver on the distal end of a core trimming flake with discontinuous unilateral steep retouch and flat dorsal thinning.

3. Stubby graver on a lateral edge of a thick irreg-

ular flake with a cortex butt. Retouch is steep and well formed.

\section{Arrow Points}

No. of Specimens: 41

\begin{tabular}{c} 
Number \\
\hline 22 \\
14 \\
3 \\
2 \\
4
\end{tabular}

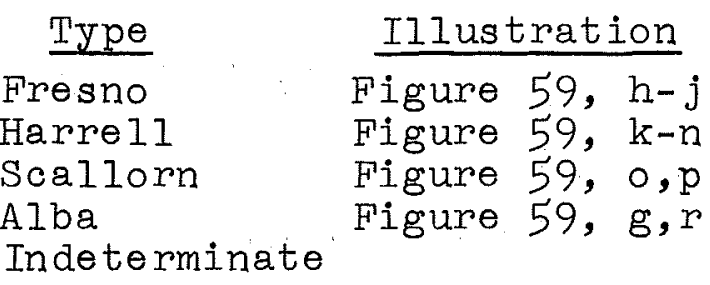

Dart Points

No. of Specimens: $\quad 3$

Illustrations: Fig. 59, t

All indeterminate. Two are trianguloid (one rounded base and one straight base) and could be large Fresno points. However, they fall outside the size range of Fresno points for this site. The third is a large $(85 \mathrm{~mm}$. long) point with a rounded base and completely bifacially worked.

\section{Choppers}

No. of Specimens: 1

Irregular bifacially flaked chopping tool with one sinuous chopping edge. Flaking is crude and atypical of the rest of this industry. 


\section{Hammerstones}

No. of Specimens: 6

Large quartzite pebbles with battered edges and occasional random flakes removed; evidently through use, as no prepared platforms are visible.

\section{Broken Points}

No. of Specimens: $\quad 18$

5 Arrow points

13 Dart Points

Cores

No. of Specimens: 23

$\begin{array}{lc}\frac{\text { Type }}{\text { Bipolar }} & \frac{\text { Number }}{5} \\ \text { Single Lisse } & 3 \\ \text { Single Cortex } & 2 \\ \text { Opposed Faceted/Cortex } & 1 \\ \text { Opposed Cortex } & 1 \\ \text { Opposite Side } & 1 \\ \text { 90 Degree } & 3 \\ \text { Unidentifiable } & \frac{7}{23} \\ & \text { Total } \\ & \text { Unidentifiable Broken Tools } \\ \end{array}$

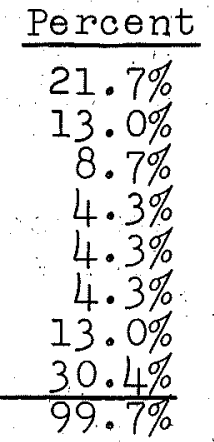

No. of Specimens: 9

Unfinished Points

No. of Specimens: $\quad 10$

Unfinished Tools

No. of Specimens: $\quad 16$

Debitage

No. of Specimens: 769

Cortex flakes

Number

Secondary flakes

100

208

Blades

21

Chips

Core fragments

411

29 


\section{Glass Site}

\section{Endscrapers}

No. of Specimens: 1

This convex endscraper is formed by weak semi-steep retouch on the distal end of a basally broken flake.

\section{Thumbnail Scrapers}

No. of Specimens: 13

Five are typical of this type. They have high keeled profile, extensive or complete dorsal thinning, convex scraping edge and tapering base. Two of these are basally thinned.

One piece is atypical. It is made on the side of a small core rather than on a flake. The dorsal surface is retouched to form the typical high-keeled thumbnail scraper, but the piece is circular and the ventral surface is a flake scar with the butt at the working end of the scraper.

Two are convex, formed by weak retouch on thin cortex flakes. Four are convex on flakes which have not been dorsally retouched.

One is oval and extensively worked on the dorsal surface. However, there is no steep scraper retouch on the piece, and this might be considered an unfinished thumbnail scraper. Such a conclusion implies that the piece was struck from an extensively prepared core and then the scraper bit and the characteristically tapered base produced.

\section{Side Scrapers}

No. of Specimens: 3

1. Straight bilateral side scraper on a small thin flake with steep retouch and dorsal thinning.

2. Opposed alternate straight double side scraper on a blade.

3. Unilateral convex side scraper on a flake with a nosed scraper at the distal corner of the side scraper edge. 
Notched Flakes

No. of Specimens: 2

1. Two opposed alternate notches at both distal corners of a large irregular flake.

2. Weak notch at one distal corner of a small flake.

Retouched Flakes

No. of Specimens: 31

Number Type

19 obverse

$9 \ldots$ Inverse

3 Both obverse and inverse

Retouched Blades

No. of Specimens: 2

1. Unilateral inverse retouch.

2. Bilateral retouch

Gravers

No. of Specimens: 1

1. On the distal end of a bilaterally retouched\%, this graver is dorsally thinned triangular flake with a straight broken base. Retouch is marginal, and dorsal thinning is the result of core preparation.

\section{Truncations}

No. of Specimens: 2

1. Straight oblique distal truncation on a small cortex flake.

2. Straight transverse distal truncation on an inversely retouched cortex flake.

Arrow Points

No. of Specimens: $\quad 21$

$\begin{array}{cl}\frac{\text { Number }}{15} & \frac{\text { Type }}{\text { Fresno }} \\ 6 & \text { Harreli }\end{array}$ 
Dart Points

No. of Specimens: $\quad 1$

$1 \quad$ Edgewood (Archaic)

Knives

No. of Specimens: 2

1. On the distal end of a large trapezoidal flake. The knife edge is parallel to the base and formed by the removal of a blade transverse to the long axis of the flake and by inverse retouch.

2. Atypical four-bevel knife. The alternating beveled edges are poorly (or incompletely) formed and may well be unfinished. The poor quality of the stone (macrocrystalline quartzite) and the rough flaking: make any final classification inadvisable.

\section{Chopper}

No. of Specimens: 1

on the distal end of a large flake.

Hammerstone

No. of Specimens: 1

Battered quartzite cobble with random flakes removed and no striking platforms.

Broken Points

No. of Specimens: $\quad 18$

$\begin{aligned} 14 & \text { Arrow } \\ 4 & \text { Dart }\end{aligned}$

$\underline{\text { Varia }}$

No. of Specimens: 1

Split, heavily weathered flint cobble which appears to have been flaked and battered. It may possibly be a core from an older period. 
Unidentifiable Broken Tools

No. of Specimens: 10

$$
\text { Unfinished Points }
$$

No. of Specimens: $\cdots$

Unfinished Tools

No. of Specimens: $\quad 4$

\section{$\underline{\text { Cores }}$}

No. of Specimens: 10

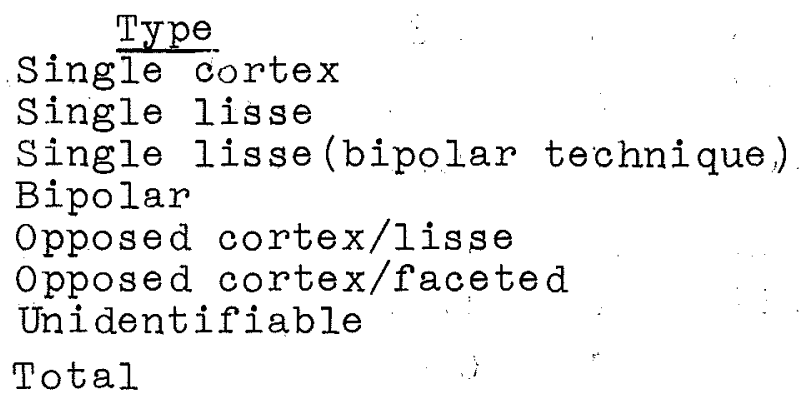

Debitage

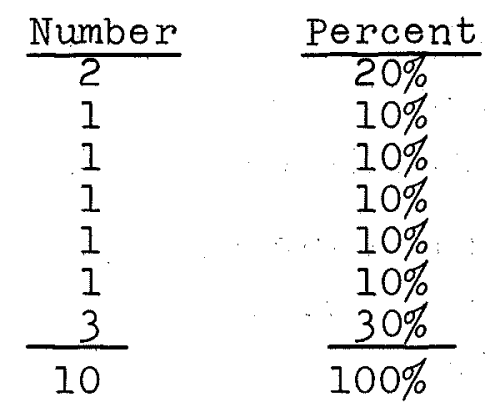

No. of Specimens: 440

Cortex flakes

Secondary flakes

Blades

Chips

Core Fragments

\begin{tabular}{c} 
Number \\
\hline 23 \\
74 \\
2 \\
339 \\
2
\end{tabular}

\section{Technology and Interpretation}

The Glass and Coyote Sites are both prehistoric while Longest is an historic site. The emphasis in this study has been placed on trying to indicate the similarity of the two prehistoric sites, rather than the difference between the historic and prehistoric materials.

The two prehistoric sites are considered to be microlithic industries. The microlithic tool index for the three sites (including all measurable tools but excluding retouched flakes) is as follows: 
Tool Type

No.

1 Endscrapers

2 Double Endscraper

3 Thumbnail Scrapers

4 Side Scrapers

5 Oval Scrapers

6 Denticulates

7 Gouges

8 Notched Flakes

9 Notched Blades

10 Retouched Flakes

II Retouched Blades

12 Drills

13 Gravers

14 Truncations

15 Arrow Points

16 Dart Points

17 Knives

18 Choppers

19 Hammerstones

20 Broken Points

21 Battered edge pieces

22 Varia

Totals
Longest Coyote

Glass

No. Percent No. Percent No. Percent

$10 \quad 10.4 \%$

$3 \quad 2.5 \%$

1

$1.0 \%$

$1 \quad 1.0 \%$

$\begin{array}{lllll}9 & 7.4 \% & 13 & 13.0 \%\end{array}$

$5 \quad 5.2 \%$

$43.3 \%$

$3.0 \%$

$4 \quad 4.2 \%$

$33.1 \%$

$4 \quad 3.3 \%$

$11.0 \%$

$1 \quad 0.8 \%$

$8 \quad 8.3 \%$

4

$3.3 \%$

$2 \quad 2.0 \%$

$1 \quad 1.0 \%$

1

$0.8 \%$

32

$33.3 \%$

$21 \quad 17.2 \%$

31

$31.0 \%$

$4 \quad 4.2 \%$

$2 \quad 1.7 \%$

2

$2.0 \%$

$1 \quad 0.8 \%$

$3 \quad 2.5 \%$

$1 \quad 1.0 \%$

$2 \quad 2.0 \%$

$8 \quad 8.3 \%$

$41 \quad 33.6 \%$

21

$21.0 \%$

$7 \quad 7.3 \%$

$3 \quad 2.5 \%$

1

$1.0 \%$

$2 \quad 2.0 \%$

$1 \quad 1.0 \%$

$1 \quad 0.8 \%$

1

$1.0 \%$

$\begin{array}{llll}6 & 4.9 \% & 1 & 1.0 \%\end{array}$

$18 \quad 14.7 \% \quad 18 \quad 18.0 \%$

$10 \quad 10.4 \%$

$1 \quad 1.0 \%$

1

$1.0 \%$

$\begin{array}{llllll}96 & 99.7 \% & 122 & 100.1 \% & 100 & 100.0 \%\end{array}$ 
Microlithic Tool Index

Site
Glass
Coyote
Longest

\begin{tabular}{cc} 
Number & Percent \\
\hline 34 & $80.1 \%$ \\
61 & $75.3 \%$ \\
17 & $34.7 \%$
\end{tabular}

There is an obvious similarity between the two prehistoric sites, and this is illustrated graphically in Graph 1 .

An index of blade tools was computed, but it has not proved particularly instructive. The historic site has a higher index of blades than the other two. The blade tool index follows:

\section{Biade Tool Index}

$\begin{array}{lr}\frac{\text { Site }}{\text { Glass }} & \therefore \frac{\text { Percent }}{3.0 \%} \\ \text { Coyote } & 1.6 \% \\ \text { Longest } & 6.3 \%\end{array}$

In an attempt to show the similarity of the prehistoric sites, four frequency distributions were plotted (Graphs 2, 3, 4, 5). Graphs 2 and 3 indicate the frequency distributions of the three sites, including arrow points and broken points. Graphs 4 and 5 indicate the frequency distributions of the two prehistoric sites excluding arrow points and broken points. It was felt that the points were distorting the distribution graphs, and that a less extreme plotting of the distribution might be obtained by eliminating them. In addition, we were attempting to see exactly what the significance of the arrow points was. In the two prehistoric sites, it is possible to show contemporaneity without referring to the arrow points, and this indicates a further use of this kind of study.

There is no pattern observable for the cores in these sites, and it is felt that the core sample is inadequate. This may be the result of a number of factors, but most likely is that most cores were worked away from the site or in specialized areas that were not reached in the excavations. Debitage is also limited in these sites and tends to support this conclusion. Stone for tools would have to be acquired away from the site (probably in the river bottom of the Red River), and most cores may well have been worked where the cobbles occurred and the finished tools brought back to the sites.

of the three sites, Longest contains the greatest quantity 
of identifiable nonlocal stone. It is the only site producing obsidian and Kay County flint. The breakdown for the three sites is as follows:

Stone Type for Tools

Longest $\quad$ Glass $\quad \underline{\text { Coyote }}$

Flint

Quartzite

Alibates

104

75

72

5

23

22

3

1

Kay County

Obsidian

10

1

Stone Type for Cores

Longest Glass Goyote

Flint

Quartzite

4

6

28

Alibates

3

4

6

1 


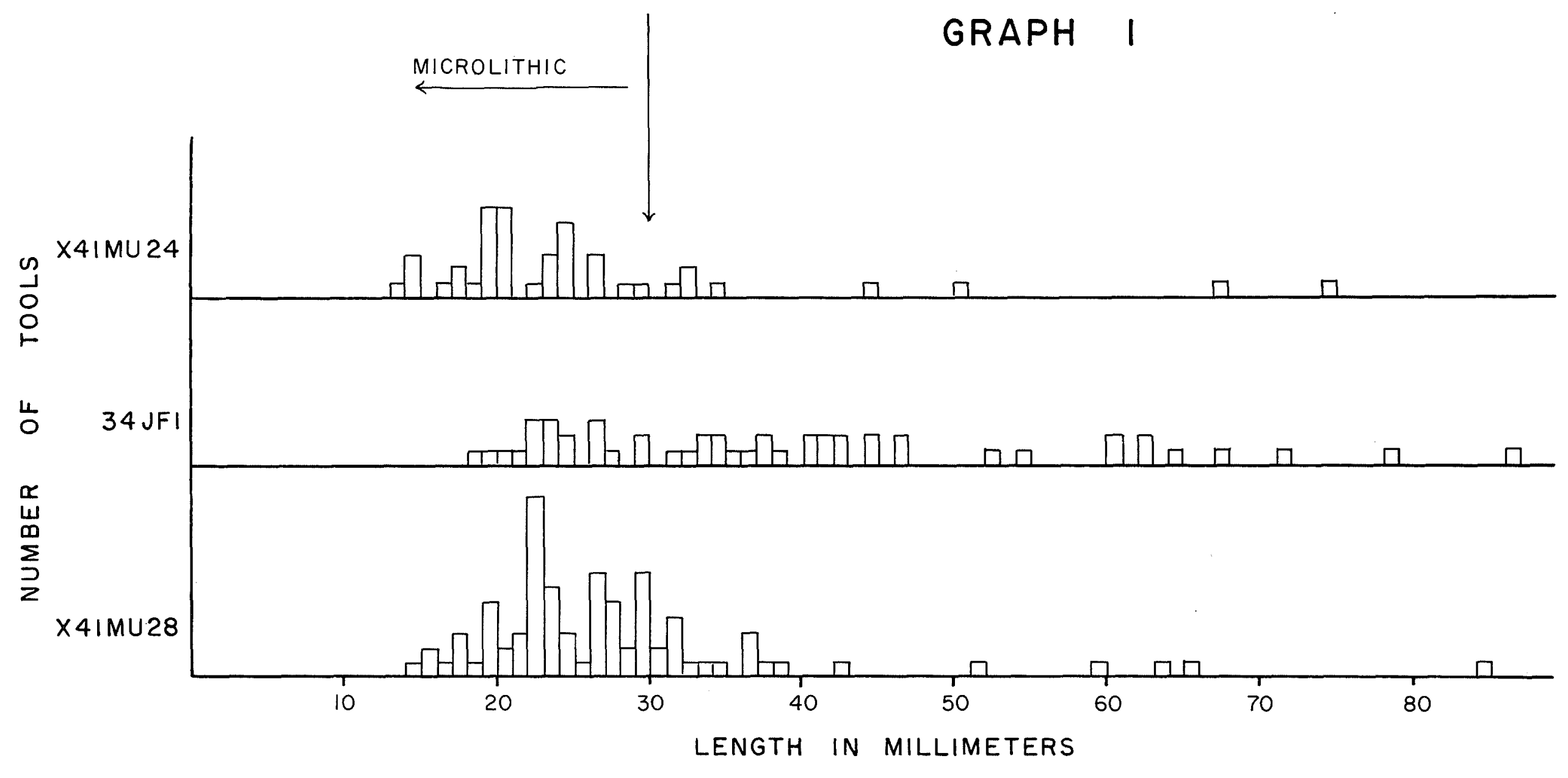


. 


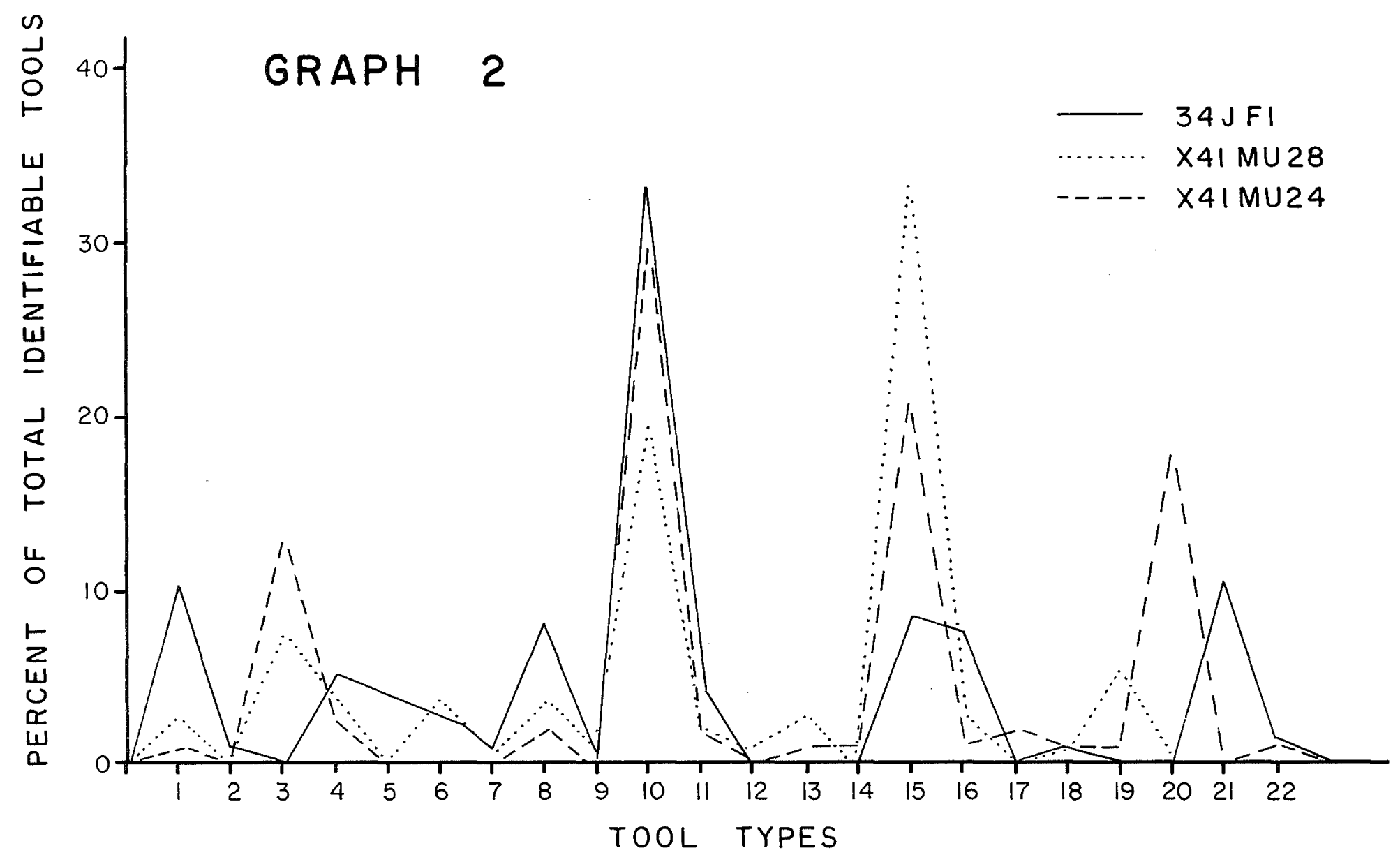





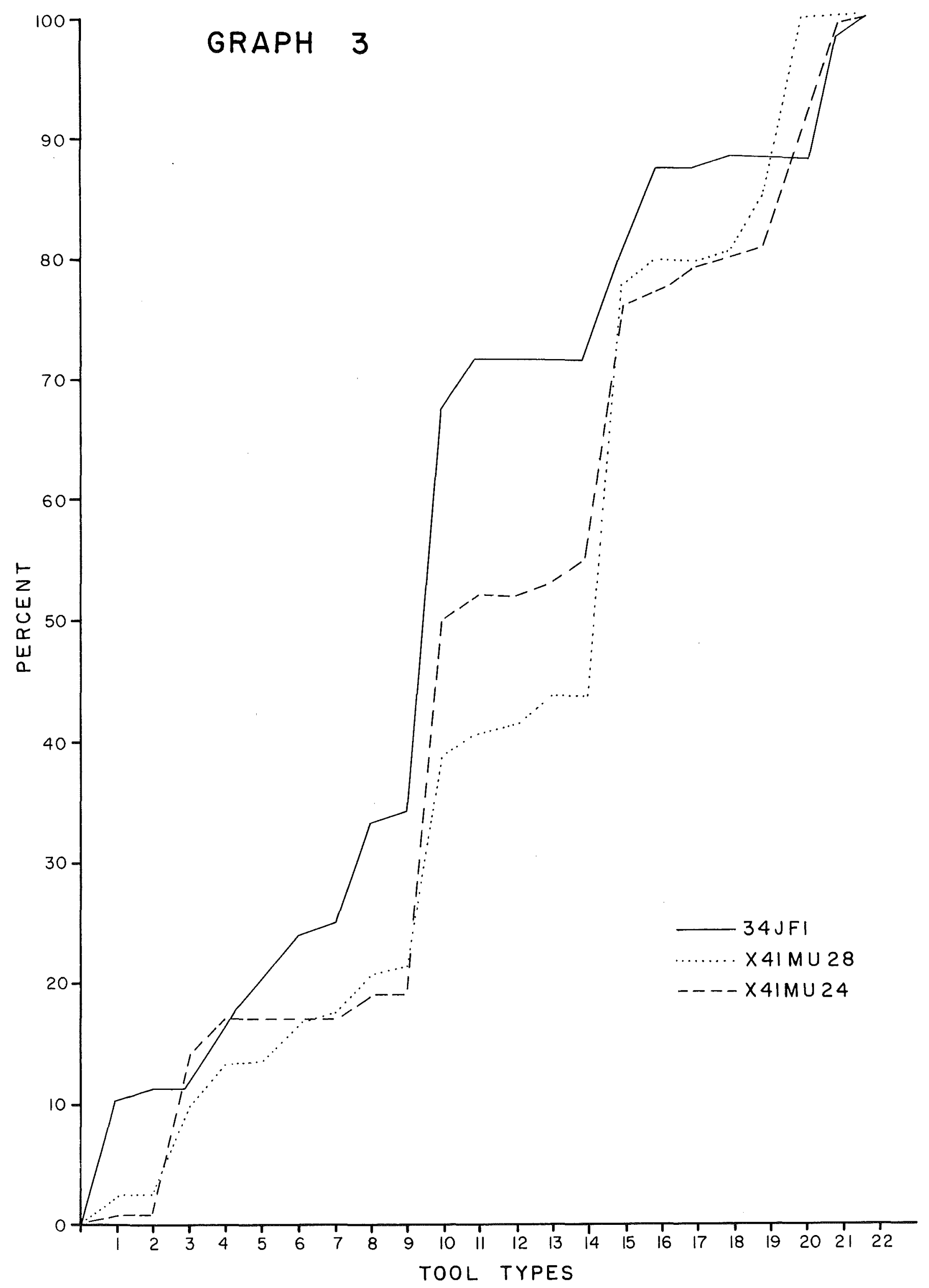





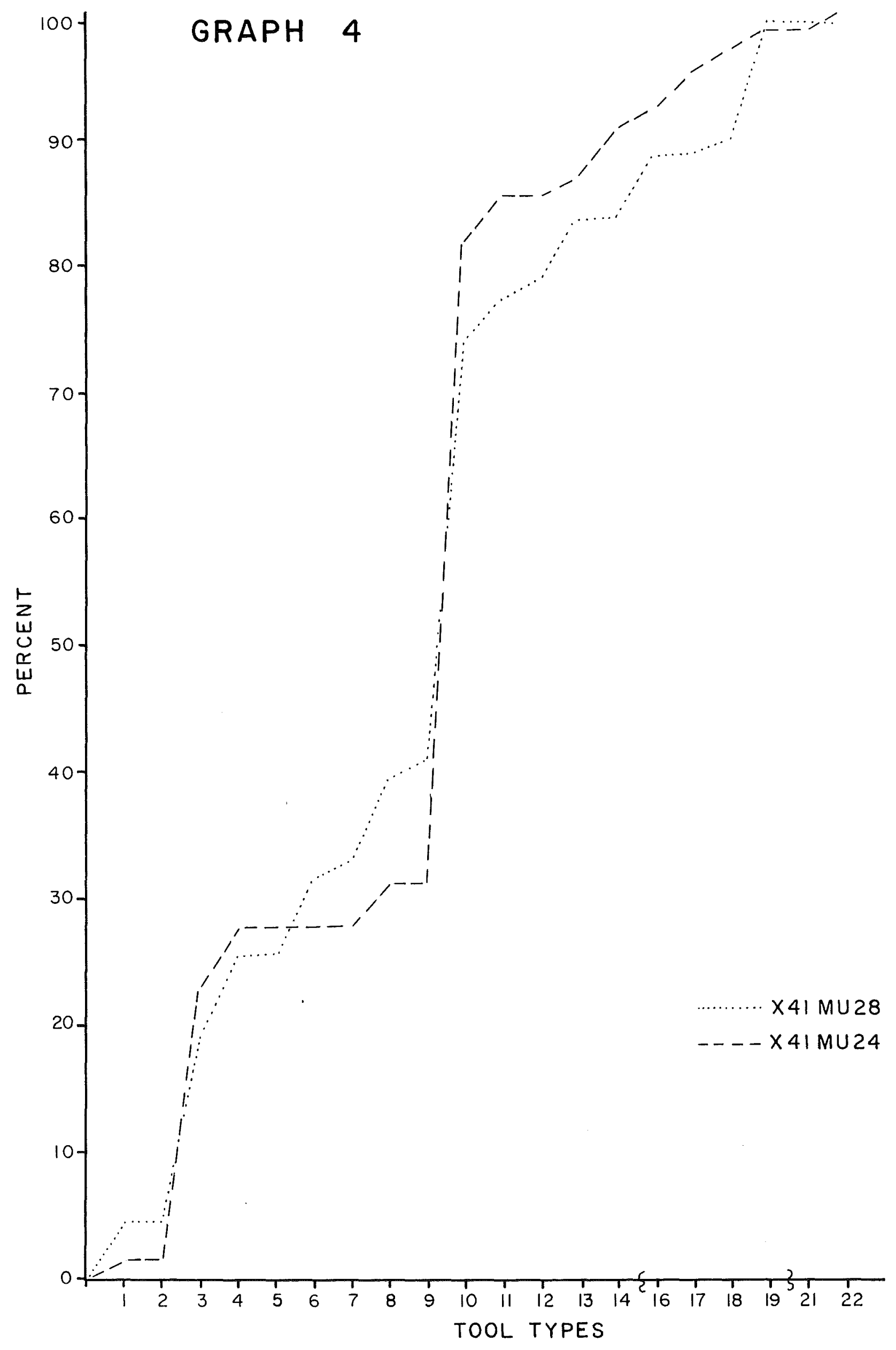





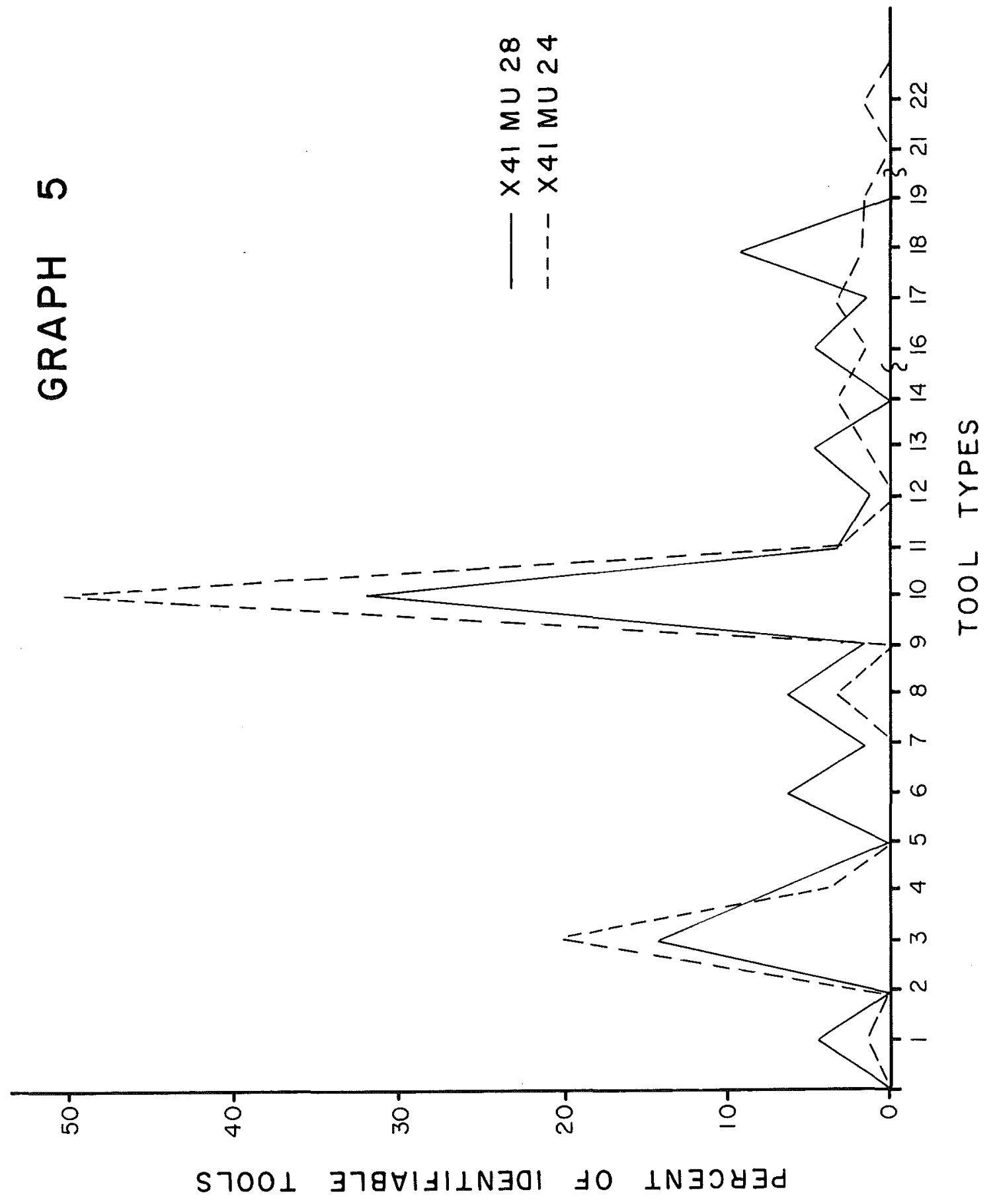





\title{
A. MICROSCOPIC STUDY OF CERTAIN POTTERY TYPES
}

\author{
AND CLAYS IN THE SOUTHERN PLAINS*
}

by Kathleen Gilmore

In connection with the archeological and ethnohistorical investigation of the Wichita Indians, a microscopic study of pottery and clays was undertaken in an attempt to help solve problems regarding the movements of Indian groups in the southern plains during protohistoric and historic times.

Thin section analysis of pottery and clays can add much to the knowledge of traditions, movements, and diffusion of aboriginal people. In many instances instrusive pottery may be identified through petrographic analysis, and a particular type may be more clearly defined. Cross sectional and longitudinal studies of a large sample of pottery types in comparison with a wide variety of clays located near the sites where the pottery is found can be invaluable in determining changes and diffusion of traditions in pottery making. Thus a library of thin sections can be compiled of control samples of clay with a variety of tempering agents, and of pottery sherds of known distribution in time and space. At present, pottery within broad categories can be recognized on a geographic basis, as for instance the difference between caddoan pottery and Puebloan pottery. However, the source of styIistic and traditional change is difficult to recognize within a group. Here technological analysis is helpful. in being able to recognize intrusive material with local integrated designs, or foreign design elements on pottery of local manufacture.

Clay studies in connection with aboriginal ceramics in Texas are lacking, and this study serves as a small beginning. Studies of this sort are never complete and could continue indefinitely.

Seventy-five sherds of pots, pipes, and figurines were provided for the study by $R$. Ko Harris from his collection from the surface: of the Ayres and Upper Tucker Sites in Montague County, Texas; from the Longest Site in Jefferson County, Oklahoma; and from the Womack and Sanders Sites in Lamar County, Texas.

* I wish to express my thanks to E. B. Jelks, M. Holdaway, T. Williams, and R. K. Harris of Southern Methodist University, and to C.M. McNulty of Arlington state College for encouragement and aid. 
The sherds were selected as being typical of the Norteño Focus, this focus being associated with the southern wichita people (Duffield and Jelks, 1961).

\section{Me tho dology}

An analysis of the sherds was made with the binocular microscrope, and the thin sections were analyzed with a petrographic microscrope. The Geological Society of America's Rock Color Chart was used for designating colors of the pottery and the clay samples. Categories of the National Research Council (Truesdell and Vames, 1950) were used in classifying grain sizes. These categories are as follows:

$\begin{array}{llll}2.000 \mathrm{~mm} . & \text { very coarse sand } & .0625 \mathrm{~mm} . & \text { coarse silt } \\ 1.000 & \text { coarse sand } & .0313 & \text { medium silt } \\ .5 & \text { medium sand } & .0156 & \text { fine silt } \\ .25 & \text { fine sand } & .0078 & \text { very fine silt } \\ .125 & \text { very fine sand } & .0039 & \text { clay }\end{array}$

The term paste as used in this report refers to the material inferred to be gathered by the potter to which was added other material or tempering agents to make the clay more workable and durable. The term temper refers to the tempering agents. The paste, then, as well as tempering agents should be useful in identifying the source of the material. Material added to the paste may be culturally as well as functionally determined, making it difficult to ascertain the nature of the tempering agent where additive material is culturally determined. The potter, for example, may have used a sandy clay and perhaps added more sand to the paste for one reason or another. Again if grog (crushed potsherds) were added to the paste to make it more workable, then any tempering agent in the grog would become mixed with the paste of the new pot.

Eleven sherds and seven baked clay samples were thinsectioned. Eleven more sherds and samples are in the process of being thin-sectioned but have not yet been analyzed. A few sherds were selected for sectioning for their uniqueness, but most were selected from a type group. Each thin section was given a series and a number. The $\bar{X}$ series is the experimental series which includes clay from known sources and experiments with tempering agents and firing temperatures. The thin sections of pottery are in series according to state: for example all sherds sectioned from Texas have a T series, Oklahoma, O series. This number appears on the slide, on an analysis sheet, and on two sets of cards, one set of which if filed by state, site name, and site number, the other set filed numerically。 It is hoped that eventually thin-section analyses will be put on punch cards whereby particular characteristics may be sorted from the group. 
All three sites from which the pottery samples were taken are located on the Red River. The headwaters of the Red River have cut into the ogallala Formation of Pliocene age on the High Plains, and after crossing a narrow belt of Triassic rocks, the river flows about 300 miles over Permian rocks, and thence over Cretaceous rocks to the Arkansas border (Frye and Leonard, 1963: 7), then onward to the Mississippi River. The Permian rocks consist of formations which include limestones, dolomites, gypsum, sandstone, and red, blue and gray shales (Sellards et al, 1958: 166). The cretaceous rocks include shales, limestones and marls. Tributaries of the Red River drain areas of the Wichita and Arbuckle mountains where igneous rocks are exposed. Throughout the Red River basin are Pleistocene deposits as well as those of Recent age. Thus pottery made of local material by people living on the Red River quite probably would show some of the constituents of these formations.

Because some of the sherds seem to have pastes which may have been of alluvial derivation, samples of clay were collected from a Wisconsian terrace deposit near the Gainesville River Bridge crossing of the Red River on U. S. Highway 77. This terrace deposit is present in the Spanish Fort area (Frye and Leonard, 1963: 34)。A sandy clay of Trinity age (Cretaceous) was collected from a quarry in Cooke County, Texas, and clay samples were obtained from the Spanish Fort site during excavation. Permian shales and Eagle Ford (Cretaceous) marls within the vicinity of the sites studied should be tested. The location and collection of clay samples is hampered by the fact that clays are soft and are generally covered by vegetation or slumping (Fisher, 1965)。

In treating the clay samples the methods of the potter were simulated as nearly as possible in the laboratory (Shepard, 1961). The samples were soaked in water overnight. The next day they were worked or kneaded, and then put in plastic sacks to cure. The following day they were again worked and then rolled and cut into test tiles.

These tiles were dried at room temperature for two days, then placed in a furnace with 90 per cent input heat. In one hour the temperature had reached 750 degrees $C$. and the furnace was turned off and the door was opened. The tiles were drawn when the temperature reached 200 degrees $C$. two hours later. It was discovered on previous firings that a slower input rate produced too much oxidation and would not approximate the rapid rise in temperature of an outdoor firing. With the more rapid input of heat the tiles became red on the outside only. (This would also vary with the clay; experiments with different clays would establish more of these firing properties.) Thin sections were made of the clay tiles。 
To make a thin section, a piece about $\frac{1}{4}$-inch long was cut from the sherd or tile with a diamond saw, using a water lubricant. The fragment was then ground on a flat lap with a coarse grit about size 100, until it could no longer be held with the fingers. It was then washed well to remove all grit and fine material. The sherd, a glass slide and a stick of Lakeside 70c were then heated to about 140 degrees $C$. The Lakeside was lightly brushed over the slide and the sherd, and the slide was placed on the sherd with slight pressure to remove all air bubbles from the contact. After the slide had cooled, it was ground on the flat lap with size 400 grit. For the finishing process a glass plate was used with progressively finer abrasives, from size 600 to 1000, to grind the sherd to.03 mm. thickness. Extreme care had to be taken to get the sherd to a uniform thickness without breaking. Permount brushed lightly over the section was used to set the cover slip.

\section{Pottery Analysis}

Because the Sanders Site, the Womack site and the Spanish Fort sites are of Norter̃o Focus affiliation and date from the same general time period (Duffield and Jelks, 1961; Harris et a.1. 1965), the pottery from all three sites was grouped according to type and compared with the thin sections available. $\mathrm{R}$. Ko Harris kindly made the type identifications.

\section{Womack Engraved}

Womack Engraved pottery has been recognized as diagnostic of the Norteño Focus (Duffield and Jelks, 1961). Within this type are three varieties labeled A, B, and $C$.

Womack A Analysis (5 sherds: 3 from Womack Site, 2 from Ayres)

Thin Section T-103 (Ayres; Fig. 70)

Paste: Light moderate brown; silt, including some feldspars, ranges from fine to very coarse; scattered carbon and shell fragments. The shell fragments appear to be alike and may represent a thin-walled creature such as a snail.

Temper: Grog, similar to the paste of the sherd; one grog has a shell fragment. 


\section{Thin Section T-105 (Ayres)}

Paste: Dark brown; fine quartz sand grains; smaller silt includes quartz, microcline, plagioclase, hornblende; carbon; fine shell。

Temper: Probably grog; some grog fragments look like the paste of the sherd, while others are lighter and may be inclusions of another sort.

The Womack A sherds all have generally the same paste, and all have grog save one. The design elements on the sherd. without grog vary somewhat from the others of the group. This sherd represents either a sloppy Womack pattern or possibly a different tradition.

Womack B Analysis. $(6$ sherds: 5 from Sanders, 1 from Ayres)

No thin sections were made of sherds of the Womack $B$ group, but from microscopic examination all have grog in varying amounts and color. The paste is similar to the paste of the Womack A group。

Womack $\underline{C}$ Analysis. (3 sherds: I from Spanish Fort area, 2 from Womack Site)

No thin sections were made of the Womack $\mathrm{C}$ group. From microscopic examination all have what appears to be grog, and one sherd has fragments of bone. The paste is similar to that of Womack $A$ and $B$ with somewhat coarser sand grains being present in this variety.

Remarks. Present in the thin sections made from Pleistocene terrace material are small, light tan lumps which do not have the appearance of grog. Similar lumps are present in almost all the Womack sherds. When the Pleistocene material was collected it was noticed that several varieties of small snail shells and some carbonaceous material were present in the clay. In thin sections of the tiles made of this clay the shells look very much like the particles of shell material in the Womack sherds. The grit in thin sections of the terrace material is similar in size and variety to that in the Womack sherds. The cores of the test tiles are a moderate gray in color as are the cores of the Womack sherds.

On the basis of these similarities between the Womack sherds and the fired samples of Pleistocene clay, it can be hypothesized that paste for Womack pottery came from the local Pleistocene clay, with sand and sherds of other Womack pots added for tempering agents. The design motifs are related to pottery occurring to the east and the south (Duffield and Jelks, 1961)。 
Emory Punctated

This ware has been recognized as resident pottery at the Womack Site and as trade ware along the Red River (Harris et al. 1965)。

Emory Analysis. (11 sherds: 6 from Womack, 5 from Sanders)

Thin Section T-101: (Sanders Site)

Paste: Fine to very fine sand grains most of which are quartz with some chert and a little feldspar; some mica; large pieces of carbonized material.

Temper: Grog, both light and dark, some seem to be grog-in-grog.

Thin Section T-102 (Sanders; Fig。71)

Paste: Moderate to dark gray in reflected light; fine sand.

Temper: Abundant shell, possibly 1/3 by volume, several species seem to be represented.

Probably all the shell is fossil shell, as some may be a fenestillid type bryozoan and some shell has a structure similar to the shell of brachiopods; one fragment may be an opthalmid foraminifer, This is a fossil assemblage of the Carboniferous or Permian. Whether fossils were used deliberately as tempering agents or whether a clay with these as inclusions was used is unknown, but it is reasonable to assume that the fossils were not collected without the clay.

Source: Permo-Carboniferous formations do not crop out in the Sanders Site area, but they do crop out about 100 miles to the west near Spanish Fort Site and continue northward through central oklahoma and eastern Kansas.

of the remainder of the Emory sherds, two are similar to T-101; four sherds are similar to T-102 with varying amounts of shell and sand; three sherds contain grog and shell. The grit particles vary in size from coarse silt to coarse sand. Most of the sand grains are rounded, and some appear to be frosted, which may indicate that their source is from a deposit susceptible to wind action or water action. The decorative technique differs on the individual sherds, but all have a smoothed interior and a roughened exterior. 
Remarks. At least two traditions of pottery making may be represented by the foregoing sherds. However, comparisons with other attributes in a larger sample would be necessary to confirm this. Pottery sherds and fossiliferous Permian clays from near the Deer Creek Site, Kay County, Oklahoma, are being analyzed for the possibility of characteristics in common with Thin Section $\mathrm{T}-102$ 。

Nocona Plain

Nocona Plain Analysis ( 7 sherds, 2 from Upper Tucker, 3 from Longest, 2 from Sanders)

Thin Section T-107 (Longest; Fig. 72)

Paste: Moderate gray; some quartz grains and scattered silt; high in carbon content; this may represent an alluvial type clay。

Temper: High carbonate shells aligned mainly with vessel walls; some of these may be fossils.

Thin Section T-108 (Longest; Fig. 73)

Paste: Brown to medium dark gray with some silt, very little sand; minute particles of mica.

Temper: Soft white isotropic inclusions with no particular alignment. These particles do not have the morphology of either shell or bone, nor do they have the properties of a carbonate petrographically. They may be bone which has been altered with treatment, firing and use. Some scattered lumps appear to be grog.

of the remainder of the Nocona sherds, one has few white particles and is grog tempered; the others contain shell tempering material which is not aligned in any particular direction.

Remarks. Nocona pottery is not a clearly defined type. It is a plain ware with no design motifs to aid in delineation. If copious shell tempering material is a definitive attribute for this type, the vessel from which Thin section T-108 was made should not be included. 


\section{Miscellaneous Thin Sections}

Thin Section T-106 (plain sherd from Upper Tucker)

Paste: Moderately silty, with scattered siltstone fragments; possibly made of local material.

Temper: Large coarse to fine quartz sand and chert.

Thin Section T-109 (pipe fragment from Longest Site)

Paste: Silty with fine sand grains; one well rounded hornblende grain.

Temper: Small white particles that originally may have been bone.

Thin Section 0-100 (plain sherd from Longest)

Paste: Silty, with muscovite; some material may be gypsum, but this cannot be demonstrated at this time; local clays containing gypsum should be tested.

Thin Section T-110 (sherd with one incised line containing red pigment, from Sanders Site; Figs. 74, 75)

Paste: Little sand, contains microfossils (foramifera); lumps of clayey marl. The foraminifera, Robulus, Globogerina, are probably from an Upper Cretaceous formation.

Temper: Dark gray to black grog.

Source: The Eagle Ford formation, Upper cretaceous in age, contains shales and marls and crops out near the Sanders and Womack sites.

This is the only sherd in which these fossils were observed. The presence of microfossils should be a useful criterion in placing the origin of the clay, as many are diagnostic of particular formations. They should be watched for and noted. 
Miscellaneous Microscopic Analys is

Natchitoches Engraved ( 6 sherds: 1 from Womack, 3 from Ayres, 2 from Sanders)

All sherds contain shell and/or bone in varying amounts; most have burned fibrous material in the paste as well as hematite or claystone nodules.

Black-on-cream painted sherd from Longest

Black on cream, slipped ware with carbon paint and geometric design.

Paste contains micas and tuff.

Remarks. This ware is probably from the southwestern archeological area.

Dark sherd from Upper Tucker

Paste: Dark gray to black micaceous paste, contains muscovite and biotite, with muscovite predominating.

Temper: Large rock fragments as large as $4 \mathrm{~mm}$ 。 in diameter.

Remarks: This sherd is probably from the southwestern archeological area.

Figurine fragments from the Spanish Fort area

Paste: Fine-grained, light tan.

Source: The figurine fragments are similar in paste qualities and color, and probably were made of local material although a comparable clay has not been

located.

Conclusions

From analysis of pottery collected at the sites Sanders, Womack, Longest, Upper Tucker, and Ayres on the Red River, it was found that:

1. Womack Engraved pottery may have been made of material that was found near the sites in Pleistocene terraces; 
2. some of the Emory Punctated pottery found at the Sanders site may have been made of material that occurs near Spanish Fort in Permo-Carboniferous formations;

3. one sherd from the Sanders site was made of material which occurs near that site and near the Womack Site in Cretaceous formations;

4. sherds from the southwestern archeological area were found at the Spanish Fort sites.

These findings support the conclusion that there was communication among sites along the Red River during the Historic stage, as well as with the southwestern archeological area, and indicate that much of the pottery was made locally although the ceramic traditions may have originated. elsewhere.

From this beginning it is hopeful that further microscopic studies of pottery will materialize. They should produce fruitful results. 
REFERENCES C TTED

IN ARCHEOLOGICAL REPORTS

Bastian, Tyler

1965 An Archaeological Survey of the. East Cache Creek

Local Flood Protection Project, Comanche County, Oklahoma. Manuscript on file at the Museum of the Great Plains, Lawton, Oklahoma。

1966 Early Eighteenth Century Wichita occupation in the Area of Haskell, Muskogee Co。, Oklahoma. Manuscript on file at the Museum of the Great Plains, Lawton, Oklahoma.

Bel1, Robert $\mathrm{E}$

1958 . Guide to the Identification of Certain American Indian Projectile Points. Special Bulletin No. 1 of the Oklahoma Anthropological Society。

1960a Guide to the Identification of Certain American Indian Projectile Points. Special Bulletin No. 2 of the Oklahoma Anthropological Society.

1960b Relationships Between the Caddoan Area and the Plains. Texas Archeological Society Bulletin, Vol. 31, pp. 53-59.

Bell, Robert E., and David A Baerreis

1951 A Survey of Oklahoma Archaeology. Texas Archeological and Paleontological Society Bulletin, Vol. 22, pp. 7-100。

Bolton, Herbert $E$.

1914 Athanase de Mézières and the Louisiana-Texas Frontier, 1768-1780. 2 volumes.

1915 Texas in the Middle Eighteenth Century。

Boudriot, J.

1963 Armes a Feu Francaises-Modeles Reglementaires。

Buck, Arthur D。, Jr。

1959 The Custer Focus of the Southern Plains Oklahoma Anthropological Society Bulletin, Vol。 7, pp.1-31.

Bustanoby, J。H。

1947 Principles of Colore and Color Mixing.

Cast $\tilde{a}$ eda

1939 Passing of the Missions, 1762-1786. Our Catholic Heritage in Texas, 1519-1936, Vol.4。 
Conger, R。N

1952 George Barnard。 In Handbook of Texas, Vol A-K.

Cooper, Samuel

ms. Report to the Secretary of the Interior, dated July 23. 1851. On file in the Records of the Bureau of Indian Affairs, Letters Received, 1851, Texas I-752, The National Archives, Washington.

Cushman, J。A 。

1933 An Illustrated Key to the Genera of the Foraminifera. Cushman Laboratory for Foraminiferal Research Special Publication No. 5 .

Duffield, Lathel F。

1965 The Taovayas Village of 1759: In Texas or Oklahoma? Great Plains Journal, Vol. 4, No. 2, pp. 39-48.

Duffield, Lathel, and Edward B。 Jelks

1961 The Pearson Site: A Historic Indian Site in Iron Bridge Reservoir, Rains County, Texas, The University of Texas, Department of Anthropology, Archaeology Series No. 4 。

Di Peso, Charles Co, A。 Woodward, R。 E。 Gerald, and M。V. Gerald. 1953 The Sobaipuri Indians of the Upper San Pedro Valley, Southeastern Arizona, The Amerind Foundation, Inc. No.6.

Enclyclopaedia Britannica

1878 Ninth edition, Vol. III.

1879 Ninth edition, Vol. X。

Fenneman, Nevin M.

1938 Physiography of Eastern United States. McGraw-Hill Book Co., Ine.

Fisher, W。 L.

$1965^{2}$ Rock and Mineral Resources of East Texas. Report of Investigations, No. 54, Bureau of Economic Geology, The University of Texas,

Ford, James A。

1936 Analysis of Indian Village Site Collections from Louisiana and Mississippi. Department of Conservation, Louisiana Geological Survey.

Foreman, Grant

1927 A Journal Kept by Douglas Cooper of an Expedition by a Company of Chickasaw in Quest of Comanche Indians. Chronicles of Oklahoma, Vol, 5, No. 4, pp, 381-90。 
Forrestal, Rey. Peter Po, Co S。 Co, A。 Mo, Litt。 D。

1931 Solis Diary of 1767. Texas Catholic Historical Society, Vol。I, No.VI。

Frye, J。 Co, and A. B. Leonard

1963 Pleistocene Geology of the Red River Basin in Texas. Report of Investigations, No. 49, Bureau of Economic Geology, The University of Texas.

Geological Society of America

1963 Rock-Color Chart. Geological Society of America.

George, J。N.

1947 English Guns and Rifles, The Stackpole Company.

Gooding, James $\mathrm{S}$.

1960 A Preliminary Study of the Trade Guns Sold by Hudson's Bay Company。 In Indian Trade Guns (compiled and arranged by T.M. Hamilton)。 Missouri Archaeologist, Vol. 22, pp. 81-95.

Gregory, Hiram A。, and Clarence $\mathrm{H}$ 。 Webb

1965 European Trade Beads from Six Sites in Natchitoches Parish, Louisiana. The Florida Anthropologist, Vol。XVIII, No. 3, part 2。

Hamilton, T。M。

1960a Additional Comments on Gunflints。 In Indian Trade Guns (compiled and arranged by T. Mo Hamilton)。 Missouri Archaeologist, Vol。22, pp. 207-209.

$1960 b$ Some Gun Parts from 18th Century osage Sites. Ibid。, pp。120-149.

1960c The Gunsmith's Cache Discovered at Malta Bend, Missouri. Ibid. pp.150-171。

l960d Concluding Comments and observations. In Indian Trade Guns (compiled and arranged by T.M. Hamilton)。 Ibid。, Vol. 22, pp. 207-209.

1964 Recent Developments in the Use of Gunflints for Dating and Identification. In Diving into the Past (edited by June Drenning. Holmquist and Ardis Hillman Wheeler)。 The Minnesota Historical Society and the Council of Underwater Archaeology, pp. 52-57.

Hanson, Charles E。, Jr.

1955 The Northwest Gun. Nebraska State Historical Society。 Publications in Anthropology No. 2 . 
Harper, Elizabeth Ann

1953a The Taovayas Indians in Frontier Trade and Diplomacy 1719-1768.

The Chronicles of Oklahoma, Vol。XXXI, No.3, pp. 268-289.

1953b The Taovayas Indians in Frontier Trade and Diplomacy, 1769-1779. The Southwestern Historical Quarterly,

Vol. LVII, No. 2, pp, 181-201.

19530 The Taovayas Indians in Frontier Trade and Diplomacy, 1779-1835. Panhandle-Plains Historical Review, pp. I-32.

Harris, R。 Ko, Inus Marie Harris, Jay $C$ o Blaine and Jerrylee Blaine

1965 A Preliminary Archological and Documentary Study of the Womack Site, Lamar County, Texas. Bulletin of the Texas Archeological Society, Vol. 36, pp. 287-364.

ms. The Spanish Fort Site in Texas and Oklahoma. Unpublished manuscript.

Harris, $R_{0} K_{0}$, and Inus Marie Harris

1961 Spanish Fort, A Historic Trade Site, The Record, Vol. 16. No.1. The Dallas Archeological Society.

1962 Another Marker on the Trail of the Norteño: A Preliminary Report on the Gilbert Site. The Dallas Archeological Society. Vol. 17, No. I.

Harris, Ro Ko, Mo Po Miroir, Jo L, McVay, and Jay Co Blaine。 ms. Fort St. Louis de Kadohadecho. Unpublished manuscript.

Hayward, J。F.

1963 The Art of the Gunmaker。Vol。II. St, Martins Press.

Hodge, Frederick Webb, (ed).

1910 Handbook of the American Indians North of Mexico. Jelks, Edward B.

ms. Documentary Evidence of Indian Occupation at the Stansbury Site。 Texas Archological Salvage Project, Austin. Unpublished manuscript。

Johnson, LeRoy, Jro, and Edward B, Jelks。 1958 The Tawakoni-Iscani Village, 1760: Archeological Site Identification. The Texas Journal of Science, Vol. X, No. 4 . 
Kidder, Alfred

1932 The Artifacts of Pecos。 Yale University Press, New Haven。

Krieger, Alex C.

1946 Culture Complexes and Chronology in Northern Texas。 The University of Texas Publication, No. 4640.

Lardner, Rev。 Dionysius ( $\left.e d_{0}\right)$

1832 The Cabinet Encyclopedia.

Lavin, James D。

1965 A History of Spanish Firearms A Arco Publishing Co.

Lewis, Anna

1924 La Harpe's First Expedition in Oklahoma, 1718-1719. Chronicles of Oklahoma, Vol.2, No. 4, pp。33l-349。

Marcy, Randolph B.

1853. Exploration of the Red River of Louisiana in the Year 1852. U. S. 32nd Congress, 2nd Session, Senate Executive Document 54. Robert Armstrong.

Mason, otis $T$.

1889 Aboriginal Skin Dressing--A Study Based on Material in the U. So National Museum. United States National Museum Report for 1889: 553-590。

Monger, Earl W。

1966 Preliminary Report on Site 14PA307 (abstract)。 Plains Anthropologist, Vol。1l, No. 32 pp。169-170。 Lincoln。

Neighbors, Robert $\mathrm{S}$ 。

1847 Report to Commissioner of Indian Affairs 0ct. 12, 1847, Senate Executive Document No。1, 30th Congress First Session。

Newell, $\mathrm{H}$ 。 Perry and Alex D。 Krieger

1949 The George Co Davis Site, Cherokee County, Texas。 American Antiquity, Vol。14, No。 4, Pt。2。

Nye, Wilbur S。

1942 Carbine \& Lance, The Story of 0ld Fort Sill. The University of Oklahoma Press. Second Edition.

Parsons, Mark

1967 Archological Investigations in Crostby and Dickens, Counties, Texas, during the Winter 1966-1967。 State Building Commission Archeological Program, Report No. 7. 
Pillaert, Elizabeth

1962 Test Excavations at the Lee II Site, GV-4, Garvin County, Oklahoma. Oklahoma Anthropological Society Bulletin, Vol. 10, pp. 79-101.

1963 The McLemore Site of the Washita River Focus. Oklahoma Anthropological Society Bulletin, Vol. Il, pp. 1-123.

Pratt, Peter P.

1961 Oneida Iroquois Glass Trade Bead Sequence 1585-1745. Onondaga Printing Company.

Ragland, Hobort D.

1952 The History of Rush Springs. Gazette Publishing Co.

Ray, Cyrus No and Edward B. Jelks

1964 The $W . H$. Watson Site: A Historic Indian Burial in Fisher County, Texas. Bulletin of the Texas Archeological Society, Vol. 35, pp. 127-142.

Rector, Elias

1859 Report of Superintendent Rector upon the Country Assigned to the Wichitas and Texas Indians, of July 2, 1859. Report of the Commissioner of Indian Affairs, for the year 1859, pp. 673-682. U.S. Government Printing office.

Richardson, Rupert $\mathbb{N}$.

1933 The Comanche Barrier to South Plains Settlement. The Arthur H. Clark Company。

Robertson, C。B。

$1955 \mathrm{a}$ Some New Archaeological Sites in Western Oklahoma. Newsletter of the Oklahoma Anthropological Society, Vol. 4, No. 4, pp. 5-6.

$1955 \mathrm{~b}$ Some New Archaeological Sites and Discoveries in Oklahoma. Newsletter of the Oklahoma Anthropological Society, Vol。 4, No. 6, pp, 7-9.

Rodgers, Frances and Alice Beard

19375000 Years of Glass. Frederick A. Stokes Co.

Schroeder, Albert $\mathrm{H}$.

$1962 \mathrm{~A} R e$-Analysis of the Route of Coronado and Oñate into the Plains in 1541 and 1601. Plains Anthropologist, Vol. 7, No. 15, pp. 2-23.

Sellards, E. Ho, W. S. Adkins, and F。 B. Plummer

1958 The Geology of Texas, Vol. 1, Stratigraphy. The University of Texas Bulletin No. 3232. 
Shaeffer, James B.

1965 The Heerwald Site, Cu-27, Custer County, Oklahoma. Paper No. 10 of the Oklahoma Archaeological Salvage Project, Oklahoma Anthropological Society Bulletin, Vol.13, pp。108-128。

1966 An Archaeological Survey of the Ft。 Sill Military Reservation, Oklahoma. Oklahoma Archaeological Salvage Project, Paper No。18. In Bulletin of the Oklahoma Anthropological Society, Vol. 14, pp.5-40。

Shannon, E。 Wo, et al.

1917 Petrole $\overline{\text { and }}$ Natural Gas in Oklahoma, Part II. A Discussion of the Oil and Gas Fields, and Undeveloped Areas of the State, by Counties. Oklahoma Geological Survey, Bulletin No, 19.

Sharrock, Floyd W。

1961 The Grant Site of the Washita River Focus. Oklahoma Anthropological Society Bulletin, Vol。9, pp.1-66.

Shepard, Anna 0 .

1961 Ceramics for the Archaeologist. Publication 609, Carnegie Institute of Washington.

Shiner, Joel L。

ms. The Excavation of Fort Frederica. Unpublished manuscript.

Smith, Ralph A。

1858- Account of the Journey of Benard de la Harpe: Dis-

1959 covery Made by Him of Several Nations Situated in the West. The Southwestern Historical Quarterly, Vol. 62 .

Steen, Charlie R。

1955 Baked Clay Figurines from the Spanish Fort Site。 Panhandle-Plains Historical Review, Vol。28, pp。 $107=109$.

Stephenson, Robert I.

1947 Archeological Survey of Whitney Basin: A Preliminary Report. Bulletin of the Texas Archeological Society, Vol. 18, pp. 115-128.

Strecker, J。K.

1928 Chronicles of George Barnard. Baylor University Bulletin.

Suhm, Dee Ann and Edward B. Jelks

1962 Handbook of Texas Archeology: Type Descriptions. Texas Archeological Society Special Publication No. 1. 
Suhm, Dee Ann, Alex D。 Krieger, and Edward B。 Jelks

1954 An Introductory Handbook of Texas Archeology. Texas Archeological Society Bulletin, Vol. 25.

Swanton, John R.

1911 Indian Tribes of the Lower Mississippi Valley and Adjacent Coast of the Gulf of Mexico. Bureau of American Ethnology. Bulletin No. 43.

1942 Source Material on the History and Ethnology of the Caddo Indians. Bureau of American Ethnology Bulletin No. 132 .

Thwaites, Reuben Gold

1959 The Jesuit Relations and Allied Documents, Vol. LXVI. Pageant Book Company.

Truesdell, P.E., and D。 Jo Varnes (compilers)

1950 Chart Correlating Various Grain-size Definitions of Sedimentary Materials. U. S. Geological Survey.

Walker, Winslow M.

1935 A Caddo Burial Site at Natchitoches, Louisiana. Smithsonian Miscellaneous Collections, Vol. 94, No. It.

We del, Waldo $\mathrm{R}$.

1959 An Introduction to Kansas Archeology. Bureau of American Ethnology Bulletin No. 174.

1961 Prehistoric Man on the Great Plains. University of Oklahoma Press。

Winfrey, Dorman $\mathrm{H}$.

1959 Texas Indian Papers 1825-1843.

Witte, Adolph $\mathrm{H}$.

1936 Kitchen Middens of the Upper Red River Drainage. Texas Archeological and Paleontological Society Bulletin, Vol. 8, pp. 71-86.

1938 Spanish Fort An Historic Site. Bulletin of the Texas Archeological Society, Vol. 10, pp. $234-244$.

Wood, W. D.

1900 Sketch of the Farly Settlement of Leon County, its Organization and Some of the Early Settlers. Texas Historical Quarterly, Vol. IV, pp. 203-206.

Woodward, Arthur

1965 Indian Trade Goods. Publication of the Oregon Archaeological Society, No. 2 . 
Wyckoff, Don G.

1965 The Archaeological Survey of the Kaw Reservoir, Kay and Osage Counties, Oklahoma. Oklahoma River Basin Survey Project, General Survey Report No.6. 
AN ETHNOHISTORIC INVESTIGATION OF THE WICHITA INDIANS IN THE SOUTHERN PLATNS

by

W. W. Newcomb and W. T. Field

INTRODUCT ION

This ethnohistoric investigation of the Wichita Indians has had two broad, overall purposes:

(1) To make an exhaustive survey and study of the Spanish, French, and English documents which deal with the wichita peoples in order to reconstruct wichita culture before it was heavily influenced by Western civilization, as well as to describe the changes it underwent after contact. An important and related $\mathrm{aim}$ is to investigate the relationships wichita peoples had with other Indians, particularly the Comanches, Plains Apaches, and Osages.

(2) To collect data relative to specific village locations, village migrations, and tribal and subtribal ethnography in order to aid in the identification, interpretation, and analysis of archeological sites and remains.

This report contains three parts, two appendices, and a bibliography. Part I, A Calendrical Summary of Wichita Ethnohistory, started out as an annotated bibliography. It has become much more, and whether or not its title is apt, it has served as a useful and ever-growing guide. It has been carried up to 1867 when the shattered wichitas returned to Indian Territory from their temporary wartime home in Kansas. A considerable body of data has been accumulated for the years following 1867. Much of it is pertinent to acculturation and assimilation and has not been used here. Ethnographic data from this period has been incorporated in Part II.

Part II, New Light on Wichita Culture, adds to and amends what was previously known about wichita culture. It takes as a base point the exposition of wichita culture as found in Newcomb (1961), rather than re-describing the entire cultural system. It also assumes that the reader is acquainted with Dorsey (1904) and Schmitt (n.d.).

This report does not deal specifically with wichita acculturation, although a large amount of material relating to it has been incorporated in these pages. The story of Wichita acculturation can probably best be summed up as one 
of long-term deterioration. The Wichitas did not undergo a period of "nativistic reaction" during the latter part of the l8th century when it might be guessed it should have occurred. The Wichitas were, however, active in the Ghost Dance craze in 1874. These and many other aspects of Wichita acculturation invite future study.

This report does not deal separately with the relationships between the Wichitas and other Indian groups, but some data on this subject are included in PART I. These relationships are important to the understanding of the history of the southern plains and also to the understanding of the development of native cultures. They could be pursued with profit. The bulk of our data relates to the Comanches and Apaches (primarily Lipan but also Mescalero), some is concerned with the Tonkawas, and relatively little with the osages. One would think that osage materials would be most plentiful since they are credited as the major force causing the southward movement of the wichitas, but this is not the case. This may be a function of the documents we have examined; it may also mean that the osages were less important to the southern migration than had been thought.

The Wichita-Comanche relationship extending through many years was an intimate and complex one, and although we have not yet pursued all of its ramifications, it is clear that in the earlier period the two peoples were hostile and the wichitas dominant. The wichitas continued their dominant role after the alliance was concluded in the 1740's, but the Comanches were in the ascendancy. By the nineteenth century their positions were reversed. The Lipan Apache-Wichita relationship was constant: they were enemies of one another in the sixteenth century, a state of affairs which continued into the reservation period. As a result of this study some new material concerning the Lipans has been uncovered. Some data on Apache-TonkawaWichita relations have also emerged; the Tonkawa data are particularly welcome since they have not been employed so far as we can discern by the few interested in this little known people.

In this report the term "Wichita" has been used in two senses, first to refer to a specific sub-tribal group, second as the collective term for all the sub-tribes. We have done this because of common usage, mindful that it can lead to confusion. We believe, however, that the intended meaning is clear in every instance of its use in this report.

Finally, we do not pretend to have examined every published, much less every documentary item dealing with the Wichitas. We have not been able to go back to primary 
sources in many instances, but have had to rely on the interpretations and translations of others. The likelihood that documents bearing on Wichita culture or history lie undiscovered--or at least unknown to us--in France, Spain, Mexico, or elsewhere, is good. In short, this investigation is primarily a survey of Wichita ethnohistory. It is in no sense a definitive, final study. A tremendous amount of work remains to be done--of discovery, translation, and interpretation. 
PART I

A Calendrical Summary of Wichita Ethnohistory

1541

Coronado Expedition

Historical background: The Wichita peoples were first contacted by members of the coronado Expedition in 1541.

Sources: Translations of the accounts of members of this expedition are found in Winship, 1896; Hodge, 1907; Hammond and Rey, 1940. Much has been written concerning the location of Quivira (the land of the wichitas), for which see: Jones, 1929, 1937; Bolton, 1949; Wedel, 1942, 1959; Schroeder, 1962. Donoghue, 1929, argued that Coronado never got farther than the Texas Panhandle. Pichardo (Hackett, 1941) also had. some curious ideas about the location of Quivira. Winship brought together the most important documents of the expedition and has also written an informative introduction. Many of the documents were reprinted in Hodge, 1933. Hodge, 1937, examined the route of Coronado. The obregón narrative, unknown to winship, does not deal with Quivira. For a detailed discussion of the documents relating to this expedition see Wagner, 1937. Wedel, 1959: 20-21, contains a summary of the pertinent parts of the expedition. Schroeder's re-analysis (1962) of Coronado's route is persuasive.

Ethnography: The Coronado and Jaramillo accounts of the Wichita are those of eyewitnesses, the Relacion del suceso may be (Bolton, 1949: 283); Castañeda's is secondhand. The accounts are conflicting on some points, particularly concerning the number of settlements, population size, and the like. They are unanimous in describing the people of Quivira as village-dwelling agriculturalists, who also hunted bison. In general, the accounts contain only the sketchiest descriptions of the wichitas.

Other natives mentioned in these documents are: Querechos, Teyas, Tareque, Araes (Relacion del Suceso), and Arahey (Jaramillo). Lesser and Weltfish, 1932, identify Arahey (Arae) with the Pawnee, perhaps the Arikara. Schroeder (1962) argues that the Teyas were a Caddoan-speaking tribe, i.e., one of the Wichita tribes. His argument rests on Alvarado's statement that the Teyas had houses of straw and raised maize, Castañeda's description of their "pueblos of rancherias," and the fact that they had beans. Castañeda also said that the people of Quivira "are almost of the same type and dress as the Teyas" (Hammond 
and Rey, 1940: 239, 263). And the Teyas painted themselves. Schroeder also uses the enmity of the querechos for the Teyas as evidence for the Teyas being non-Athapascan.

Most investigators have considered the Teyas to be Athapascan. Schroeder has not taken into account that the eastern Apaches also raised corn, squash, and beans, lived in semi-permanent rancherias, and in a Spaniard's eyes also might be "almost of the same type and dress as the Teyas." The Coronado expedition encountered Teyas in May, an unlikely time for a Wichita tribe to be hunting. The identity of the Teyas is not crucial to the purposes of this investigation, and the details of the arguments are not given further space.

Remarks: It has not seemed profitable to make a more thorough study of the Coronado documents or to go beyond the readily available published accounts and translations. The debate about the location of Quivira is for reasonable men concluded; it lay within the great bend of the Arkansas River in what is now south-central Kansas. And it is extremely unlikely that additional ethnographic data will be dredged up from the accounts of the members of the expedition. The extent of territory inhabited by wichita peoples in the midsixteenth century is not necessarily coterminous with what is usually thought of as Coronado's Quivira. Unfortunately no documentary evidence bears on the matter. The solution may lie within the purlieus of archeology (see Krieger, 1946: Part II; Stephenson, 1952, and others).

$$
1593 \text { or } 1594
$$

Bonilla-Humana Expedition

Historical background: Francisco Leyva de Bonilla and Antonio Gutierrez de Humana, led an expedition from San Ildefonso northeast to the plains. On a stream Bolton (1916: 201) identifies as the Arkansas, the Spanish encountered a Iarge rancheria of grass houses whose inhabitants grew bountiful crops. From this place they went north for 12 days to another stream. Bolton (1916: 201) identifies it as the Platte, Wedel (1959: $21)$, the Smoky Hill of Kansas. Quarrels led to the murder of Bonilla, and all except the Indian guide were ultimately killed by the natives of the region.

Sources: Bolton, 1916. 
Oñate Expedition

Historical background and location: Don Juan de Oñate led a large expedition into the plains and encountered wichitas although he did not give them a name. He left the Rio Grande (San Gabriel between Santa Clara pueblo and the mouth of the Chama), June $23 \mathrm{rd}$, crossed the Pecos, Gallinas, and descended the Canadian, where they met Vaquero Apaches. He left the river because of sand dunes 110 leagues from San Gabriel, and turned north and east. About 200 leagues from San Gabriel Escanjaques were encountered. Bolton (1916) contains a translation of this "True Account of the Expedition of Oñate Toward the East, 1601." He (1916: 260) locates the "gran poblacion" on either Cow Creek or the Little Arkansas within the great bend of the Arkansas River. Wedel (1942: 18-20) has suggested a location at the junction of the walnut River with the Arkansas (Cowley County, Kansas), toward the southeast, but now (1959: 22) regards this location less favorably. Schroeder (1962) has retraced Onate's route and suggests (1962: 21) that "Oñate's Quivira extended slightly farther south to the Chicaskia River near Ponca City in Oklahoma . . ."

According to Scholes and Mera (1940: 274), in testimony given in Mexico City in 1602 by members of the expedition, the Indians were called Jumanes because they were painted or tattooed. This is the first reference to the wichitas by this term.

Ethnography: Oñate's account contains a good description of some aspects of Wichita culture; there can be no doubt as to their identity. The ways the Spaniards and Escanjaques were greeted by the wichitas is unique. A powerful chief, Catarax, is mentioned, the grass houses are described at considerable length, and the spaniards were amazed at the productive fields of corn, beans, and gourds. Oñate positively states that irrigation was not practiced. Catarax told Spaniards that upriver were more people similar to themselves.

The identity of the Escanjaques, who were enemies of the Wichitas, is not certain. Newcomb (1961: 106) identified them as Apache. But perhaps they did not speak an Athapascan language. It has been suggested that they were Kansa or Osage (Hammond and Rey, 1953, II: 752), or Tonkawas (Forbes, 1960: 101, see also 145). In any case, they were nomadic bisonhunters who used skin tipis, tattooed themselves, and leaders had little control over their followers.

Remarks: The original document should probably be studied and translated by someone who is anthropologically oriented. But little would likely be gained so far as additional ethnographic data is concerned. The identity of the 
Escanjaques is the most challenging and perplexing problem of this account.

Fray Alonso de Benavides' Memorial (Ayer, 1916) states that the Xumana nation was 112 leagues east of Santa Fe, beyond the Vaquero Apache nation (p. 58), and that 30 to 40 leagues to the east of the Xumana was the Kingdom of Quivira and that of the Aixaos (p. 63). This is secondhand information at best, but it may suggest that even at this date the Spaniards were aware that the wichitas were composed of a number of independent tribes.

$$
1639-1680
$$

In this period some Taos Indians fled eastward into the plains and established a fortified structure afterward known as El Cuartelejo. This hegira may have taken place in 1639-41, since Taos had revolted and a priest was slain in this period (Hodge, Hammond, and Rey, 1945: 284). Wedel (1959: 64) places the date between 1664-1680. Archuleta was sent to bring back these apostates, and he discovered that they had kettles and other pieces of metal. They said they had gotten them from the Quivira pueblos to which they had journeyed, and that Quivira lay on the route to the Pawnees who were then trading with the French.

Valverde visited El Cuartelejo in this year at which place were Calchufines (Apaches), as well as a band of newly arrived Paloma Apaches. The Paloma chief had a gunshot wound. According to him, the Paloma Apaches had lived "on the most remote borderlands of the Apaches," which Thomas (1935: 132) suggests was in northeastern Colorado, probably along the South Platte. The Pawnees and (or?) Wichitas had ambushed the chief's people while they were planting corn, and only nightfall permitted their escape. Whether any Frenchmen were with the Pawnees or wichitas is not clear, but the gunshot wound of the Paloma chief suggests one reason why they had become more aggressive in their war against the Apaches.

Bénard de la Harpe

Historical background: Throughout the second half of the seventeenth century the French were pushing westward and probing into the plains country. Unfortunately, many of the men who were doing the probing were unlettered, private entrepreneurs who did not leave diaries or journals of their activities. 
LaHarpe was given a grant on the Red River, and in 1718 took possession of it. The Council of Louisiana made him commandant of the Nassonites, Cadodaquious, Nadacos, and Natchitoches. He was instructed to explore the Red River and to establish commerce with the Spaniards in Texas and New Mexico. The site La Harpe chose for his post or settlement was two leagues above the Nassonites. Lewis (1924: 331-332), basing her argument on a description by Sibley (1832: 729) locates the Nassonite post in what is today Bowie County, Texas, north of Texarkana. Harris et al. (1965: 359) have tentatively identified the Nassonite Post of 1719 and Fort St. Louis de Kadohadacho as the Roseborough Lake Site, also known as the Rochelle Place, near Texarkana.

La Harpe, with Quidehais (Kichai) guides, soon made an expedition to the northwest into what is now Oklahoma, reaching a thriving village complex of Wichita Indians.

Sources: La Harpe's journal of his expedition into Oklahoma to meet the wichitas may be found in Margry, 1886, pt. 6: "Projets De Bénard La Harpe," pp. 241-306. It appears to be inaccurate in some details (Mrs. Waldo Wedel, personal communication). Lewis, 1924, and Smith, 1958-59, have translated the Margry account.

Location of the villages complex: Mooney (1910: 947), Wendels (1914), Bolton (1914, I, map, 46), Wedel (1959: 65), Schroeder (1962: 18) place the villages La Harpe visited on the lower South Canadian River near its juncture with the North Canadian in what is now east-central Oklahoma (probably McIntosh County). Smith's map (1959: 526, 532) places it farther upstream in McClain County.

Joseph B. Thoburn studied La Harpe's journal, and Anna Lewis utilized this study (1924: 343, footnote), locating the villages on the north side of a small tributary of Concharty Creek northeast of Haskell. Harper (1953: 274) favors this location. Bastian (1966, ms), during the course of the present investigation, spent two days in the Haskell area searching for the site with negative results. He comments:

The results of the investigation were not particularly encouraging with respect to discovering the location of a Wichita village site in the Haskell vicinity. The only specimens seen which may date from the early eighteenth century are some beads of uncertain provenience in a private collection. No field evidence for an eighteenth century site was found.

Foreman (1946: 305) places the site on the Cimarron River near its junction with the Arkansas, west of Tulsa. Pratt (n.d.: 2, 5, 7) places it in the Antelope Hills on the western border of Oklahoma. 
Ethnography: La Harpe's journal contains a fuller account of wichita culture than any earlier document. Unfortunately, it is not very clear on a number of points. We relied on the Margry version of La Harpe's journal which may be defective; it also should be noted that the published translations of Margry should be used with caution. The nature of the villages La Harpe visited illustrates the difficulties involved in using Margry, as well as the manner in which he has been translated. The Margry version says (p. 289):

A une portée de fusil de leurs habitations, nous traversasmes un beau ruisseaù, enfermé d'un bois clair, au-dessus duquel sont les villages situes sur des costeaux, le long de la branche du $\overline{S .0}$. de la riviere des Alcansas. Ces villages n'en font qu'un, les maisons se joignant les unes aux autres, courant de l'Est a l'Ouest, une lieue dans la plus belle situation que l'on puisse voir. Les nations de ces establissements (sic) sont les Touacaras, Toayas, Caumuches, Aderos, Ousitas, Ascanis, Quataquois, Quacasquiris, Honechas; ils peuvent fournir six mille personnes de tout sexe.

We translate this passage as:

At a musket shot from their dwellings, we crossed a beautiful creek, enclosed by a light forest, above which are the villages placed on knolls along the southwest branch of the Alcansas River. These villages make only one village, the houses adjoining one another, running from east to west a league through the most beautiful location that one might possibly see. The nations of these settlements are the Touacaras, Toayas, Caumuches, Aderos, Ousitas, Ascanis, Quataquois, Quicasquiris, Honechas; they can supply 6,000 persons of both sexes.

Lewis (1924: 343$)$ translates this passage as:

Within easy musket range of their village, we crossed a beautiful brook, enclosed in woods, on the other side of which were the villages. They were situated upon some hills which extended the length of the southwest branch of the river of Alcansas. This village is very compact; the houses are joined together one to the other running east and west. The location is one of the most beautiful that I ever saw. The nations of this location are the Touacaras, Toayas, Caurnuches (sic), Aderos, Wusitas, Ascania, Quata- 
quois, Ouicaspueris, Honechas; they are able to provide for six thousand people of both sexes.

Smith (1959: 526-528) translates this passage as follows:

At a musket shot from their habitation we crossed a beautiful stream, surrounded by a clear forest, above which are the villages situated upon hillocks, along the southwest branch of the Alcansas (Arkansas)River. These villages make only one village, the houses adjoining one another, running from east to west a league through the most beautiful location that one might possibly see. The nations of these establishments are the Touacaras (Tawakoni), Toayas (Tawehash), Caumuche (Comanche), Aderos (Ardeco), Ousitas (Wichita), Ascanis (Yscanis), Quataquois (Kiowa-Apaches), Quicasquiris (Wichita), Honechas (Waco); they can furnish 6,000 persons of all sexes.

The custom of Wichita sub-tribes locating their villages side by side was common in subsequent years, and it is obvious that La Harpe visited such a village complex. Other passages in La Harpe's journal suggest that one of them was Touacara (Tawakoni). That all of the "nations" enumerated occupied this village is extremely unlikely. The number present at the villages is given as 6,000. The Calumet is celebrated with La Harpe, for which event the presence of nomadic tribes brings the native's number to 7,000. Cannibalism of slaves (Cancy) is mentioned, also quite a bit concerning trade, subsistence, political organization, and social habits in general. One paragraph is devoted to religion. La Harpe says these Indians raise horses and "prize them highly."

Many other natives are mentioned by La Harpe: Cancy, who are enemies of the Wichitas, as they are of the Padoucas. They are undoubtedly Lipan Apache. The Padoucas lived far. to the west; they "were a numerous nation, whose villages extended very far to the northward and north-northwestward; that the spaniards were not allied with all this nation; and that, when they went to trade at some distant village in the direction of the Aricaras, they were frequently attacked by the Panis nation, enemies of the Padoucas." The Wichitas did not go to the Spanish villages by ascending the Arkansas because the Padoucas blocked the way. The Padoucas were, of course, the Comanches. The Wichitas were also enemies of the Anahous and Missoury. Two Ascani (Iscani) and Ousita (Wichita) 
villages were situated 60 leagues north-northwest of the Contiquous villages. This is the first usage of the term Wichita.

The tribes or tribal representatives who came to see La Harpe at the Tawakoni village are a confusing lot. The Touacaras are Tawakoni; the Toayas, Taovaya; the Ousitas, Wichita; and the Ascanis, Iscani. The Caumuche are not Comanche as Smith (1959: 527) has it, who follows Mooney in the Handbook (Hodge, 1907, I: 328). As noted, the Comanches were enemies of the Wichitas at this date, and the two peoples did not make peace until three decades later. And they are referred to by La Harpe as Padoucas. We have not encountered any other mention of the Caumuche. But one may suspect that the cau is the phoneme which appears in many wichita names and designations (i.e., Ki or Kui, as in Quivira). The Aderos are equally puzzling. Smith (1959: 527), following the Handbook (Hodge, 1907, pt. I:82), terms them "a small Caddoan band." Mooney (Hodge, 1907, I:702) equates the Quatoquois with the Kiowa Apaches. It seems extremely unlikely that they were so far east in 1719, and even less likely that they would have been on amicable terms with wichitas. Again, the initial phoneme seems relatable to Ki, Kui, Hui. Mooney (Hodge, 1907, I: 950) believes that Quicasquiris, Quirasquiris, Ouicaspueris is a variation of the Wichita term for themselves, corrupted in Spanish to Quivira. Bolton (Hodge, 1907, II: 888) equates the Honechas with the Wacos. And they may well have been a wichita sub-group, but since the term Waco does not appear until more than a century later, such ascription should be regarded as tenuous at best.

Remarks: It is obvious that a new translation of La Harpe 's diary is in order. Mrs. Waldo Wedel is engaged in doing so (personal communication), and it is hoped that the discrepancies in the Margry version, and the defects in the current translations will be corrected.

La Harpe's route should be completely restudied, using the original diary and retracing the expedition's route on the ground. Actually, La Harpe was quite specific about the number of leagues he traveled each day and the landmarks that were encountered. The setting of the Tawakoni village is also clearly described, so that it should be locatable. 
M. $\underline{\text { Du }} \underline{\text { Rivage }}$

Historical background: While La Harpe was establishing the Nassonite Post, he sent M. du Rivage up the Red River with four soldiers, six of his men, and eight "Nadsoos" warriors as guides. They carried 1500 livres of merchandise to give to the nomadic tribes with whom they hoped to make an alliance. La Harpe was specifically attempting to gain information about the "nearby" Spanish settlements.

Du Rivage departed on June 4 and returned July 29. Two Quidehais (Kichai) guides returned with him. According to La Harpe (Margry, 277) Du Rivage met part of the "nomadic" tribes, the Quidehais, Naouydiches, Joyvan, Huanchané, Huané, and Tancaoye, 70 leagues by land to the westward and from the west a quarter northwest. According to Harris, et al. (1965: 359-360):

Du Rivage states that he traveled 70 leagues by land which, using the 1.59 conversion, is 111.3 miles. Today, if one will start at the Roseborough Lake Site, come out of the Red River bottoms (it is doubtful that Du Rivage went through the dense thickets of the river bottom land), and follow present Hwy. 82 to Paris, Texas, then turn northwest to the Womack Site, one would have gone about 108 miles -- only 3.3 miles less than the distance covered by Du Rivage. The age and nature of the Womack Site, coupled with its distance and direction from the Roseborough site, argue for its identification as the village where Du Rivage obtained the two Kichais who guided La Harpe north to the Toucaras on the great river (Arkansas River) in September 1719.

Sources: La Harpe reported on Du Rivage's expedition so at best the account is second-hand. It may be found in Margry, 1888: 273, 277-279. Smith, 1959: 371-379 contains a translation of Margry. See also Harris, et al., 1965.

Ethnography: The tribes or parts of tribes encountered by Du Rivage are difficult, probably impossible to equate confidently with their descendants of later times. The Quidehais are by all investigators equated with the Kichais. The Naouydiches are probably the Caddoan Nabedache (Bolton, in Hodge, 1907, II: 1-4). The Joyvan are the Tonkawan Yojaune, and the Tancaoye the Tonkawa proper. The identity of the Huanchane and Huané is less clear. Bolton (ibid., 888) assumed, but without giving any supporting evidence or reason, that both 
were Waco. That they were Tonkawan would be as good, perhaps a better assumption.

All of these tribes are lumped together by La Harpe and described as nomadic bison hunters. At this season the horticultural Nabedache and Kichai would not ordinarily be hunting. Apparently these tribes, or representatives of these tribes, heard of Du Rivage and met him on the Red River at what is now known as the Womack Site. But there is no hint in Du Rivage's or rather La Harpe's journal about the nature of the place where they met. It would appear that these tribes were active allies since La Harpe reported that they had just had a battle with some of the Cancy (Lipan), who then had a populous vil= lage sixty leagues up the Red River. It was while hunting that they were apt to encounter these and presumably other enemies, it was reported. The allied tribes numbered 2,500 men, but La Harpe noted, they were scattered out so that they could more easily secure their food.

La Harpe also mentioned that these tribes were allied with the Quichuan, a people who lived two leagues south of the Red River somewhere between where he met the allied tribes and the Nassonite Post. Mooney (Hodge, 1907, I: 701) identifies them as Kiowa, but this is almost surely in error. They were in all probability a wichita tribe, if not in fact Kichai. The initial Ki phoneme suggests this interpretation.

The presence of Quidehais (Kichai) and Quichuan (Kichai ?) peoples south of the Red River at this early date is tantalizing. Were they old occupants of this part of Texas? Were the Kichai really a nomadic hunting people? But the scant evidence is too poor to answer these or the other questions that come to mind. (See Delisle map, PART II, p. $1-4$, and following)

\section{Claude Du Tisné}

Historical background: Claude Du Tisné coming from the Illinois country visited two "Panis" (wichita) villages in the fall of this year. An account of this expedition is in Margry, pt. 6: Voyage fait par M. Du Tisné in 1719, Chez les Missouris pour aller aux Panioussas. Extrait de la Relation de Bénard de La Harpe, pp. 309-310, Autre extrait de la Relation de Bénard de La Harpe, II, pp. 310-312; Lettre de Du Tisné a M. de Bienville, Datée des Kascakias, le 22 Novembre, 1719, pp. 312-315. See also: Harper, 1953a: 275-276; Nasatir, 1952, Vol. I: 18 . 
Location: Du Tisné says the first village was 40 leagues southwest of the Osages on the banks of a stream which was 12 leagues west of the Atcansas (Arkansas?) river. The village was surrounded by a prairie; on the southwest was a forest which was useful to the Indians. One league to the northwest on the banks of the same stream was another village comparable to the first. There were several other villages to the west and northwest, Du Tisné was told, but they were not visited.

Where the villages were that Du Tisné visited is subject to some dispute. Wedel (1959: 65) says:

It has been customary to identify Du Tisné's Panis villages with some locality near present Vinita, Okla.; but there is a growing feeling among archeologists that two early, and manifestly important contact village sites situated on the Arkansas just south of the Kansas (p. 66) line in Kay County, okla., may actually be the correct location (Bell and Baerreis, 1951, p. 91; see also Steen, 1953, pp. $177-178)$.

Wedel, himself, favors another location (1959: 533):

The Neodesha locale is about 85 miles airline southwest of the Osage sites in Vernon County, Mo. To reach it in 4 days, Du Tisné would have had to travel about 20 to 22 miles daily; he would have crossed creeks tributary to the osage and finally the largest stream, the Neosho, about 20 to 25 miles east or northeast of present Neodesha. To reach the Vinita locality, he would have had to travel mostly south from the osage villages, and the daily marches would have been at least 25 to 30 miles. To reach the Kay County sites, which are probably chronologically acceptable, he would have had to travel not less than 150 miles, or a highly improbable average of 40 miles or more per day; and he would have crossed the Neosho, the Verdigris, probably Fall River and Caney creeks, and perhaps other south-flowing streams that he could hardly have mistaken for tributaries of the osage. In short, the Neodesha sites seem to fit the geography and also the distances and directions supposedly traveled, provided it can be assumed that the French mistook the Neosho for the 'Atcansas'; and a shell-tempered pottery complex would be a probable one for a Wichita community of this period. The Kay County sites seem much too far away; and the Vinita locality, aside from the 
254

difficulties raised by distance and direction, has not yet produced White contact Indian sites that might be of the period demanded.

For reasons that must be obvious, I do not press the correlation here suggested; but I am inclined to think that further archeological ethnohistorical studies might profitably be pursued in connection (p. 534) with the problem.

Ethnography: The first village had 130 houses and 200 warriors, and the second village was equal in size and strength to the first. The Panis already had six guns (fusils), and were eager to get more. Du Tisne traded them three guns, powder, picks or mattocks (pioches), and some knives for two horses and a mule which bore a Spanish brand. He also traded for an ancient silver cup. In the two villages Du Tisne estimated there was a total of 300 horses which were highly valued by the natives. Du Tisné planted a white flag in the middle of their villages and the natives received them with pleasure.

These Wichitas were engaged in a harsh war with the Padoucas (Comanches), even to the extent of eating each other, presumably meaning that this was the fate of captives. In war they used a tanned leather cuirass to protect their horses. They were very skillful with the bow and arrow; they also made use of lances which had wooden(?) sword tips hafted to the shafts. Whenever they fed strangers, the cook cut the meat in pieces and put it into the mouth of those whom they were enter taining. The Panis were at first fierce, really meaning unfriendly, but were easy to pacify with guns.

Relations with other tribes: The Padoucas (Comanches) were mortal enemies, barring the way westward to the spaniards. Osage were also enemies. The Osages did not want Du Tisne to visit the Panis, and in turn the Panis did not want him to visit the Comanches. The Panis, through Osage connivance, thought the French had come for slaves, but Du Tisne finally convinced them of his peaceful intentions.

Remarks: The original document should be used. We relied on the account in Margry. 
Expedition of Colonel Pedro de Villasur

Historical background: Spanish were disturbed by French activity, and in June, 1920 sent Villasur from Santa $\mathrm{Fe}$ with about 60 soldiers and traders, 70 Indians, and two priests. Went northeast from Santa $\mathrm{Fe}$, but nearly all of them were massacred August 11 .

Source: Thomas, A. B., "The Massacre of the Villasur Expedition at the Forks of the Platte River, August 12, 1720." Nebraska State Historical Society Publications, Vol. VII, No. 3.

Wichitas were not encountered.

1739

Mallet Brothers

Historical background: The Mallet (Malic) brothers, Pierre and Paul and a party of 8 , explored a route from a point on the Platte River near the mouth of the Loup, on a southwesterly course across Nebraska and Kansas, to Santa Fe. They did not encounter wichitas. The significance of their journey is that they were the first such traders to reach New Mexico from the northeast. Somewhere in the upper Arkansas Valley they encountered Laitanes (Laytanes), and spelled several ways in the document, apparently meaning the Comanches. It seems, then, that by this date the Apaches had been driven out. Padokas (2 men, 3 women) (Margry, 1886: 461) were encountered on the return trip; they seem to have been Apache. For a summary of the Padouca problem with pertinent references, see Wedel, 1959: 77-78.

Source: An incomplete account of their journey is found in Margry, 1886, pt. 6: 455-462. Thomas, 1940: 15, comments on this expedition, as do many other students.

1741

André Fabry de la Bruyère

Historical background: Fabry de la Bruyère was sent by Jean-Baptiste Bienville, Governor of Louisiana, to follow up the explorations of the Mallet brothers. He was to explore the Arkansas and make alliances with the natives. He was also instructed to attempt to get the Osages, Panis, and Comanches 
to stop attacking New Mexico. His expedition was abandoned because of difficulties and dissension.

Sources: Margry, 1886, pt. 6: 472-492, "Extrait des lettres du sieur Fabry, a l'occasion du voyage projeté a Santa Fé." Harper, 1953a; 276-277 refers to this source.

Ethnography: A party of 35 Osages came into the French camp; they were on a war expedition against the "Mentos", their name for the "Panis." They distinguished between them and the "Panis noirs." There is a clear suggestion that the Wichitas are moving south under Osage pressure. The Mentos (Panis) used to be on the Arkansa River, about the forks, and about 25 leagues above the Panis noirs, from which they had withdrawn to the Saint Andrew River, "where one still can see their old village." For the preceding four or five years they had been near the Cadodacho, where they were in 1741.

Remarks: It would be worthwhile to look at the original document. Which subdivision of the wichita the Mentos were, if in fact they were such, is conjectural.

$$
1747-1749
$$

Wichita-Comanche alliance

Historical background: The important event taking place during this period was the peace made between the Wichitas and the Comanches. It opened the way to French trade with the Spanish settlements in New Mexico, it allowed the Comanches a way to obtain firearms, and it made possible a lucrative trade for the Wichitas, as well as giving them an ally instead of an enemy on their western flank.

It has been generally held that the French persuaded the Wichitas and Comanches to make peace, and of course the French desired it because they wanted to breach the comanche barrier and establish trading connections with Santa Fe. But the view that the French were responsible for this alliance is wholly conjectural and apparently based on a naive and erroneous conception of Indian cultures. The assumption seems to have been that these Indian tribes--notorious cannibals on one hand, famous horse thieves on the other-were too primitive, backward, savage, or just plain dumb to conclude alliances, even when to their mutual advantage. Hence, they must have been pushed and cajoled into such an arrangement by the clever, wise, and politically sophisticated French. Bolton (1917: 391), for example, alleged that "the Arkansas route (to Santa Fe) was made safe by 
effecting in 1746 or 1747 a treaty between the Comanche and the Jumano (Wichita)." Thomas (1940: 17) has said that "between 1746 and 1748 the French succeeded in effecting a treaty of peace between the Comanches and the Jumanos (Wichitas) along the Arkansas." Harper (1953a: 278) stated that "the Panipiquets (Wichitas) were very well disposed toward the French and since 1747 had been allies of the Comanches, an arrangement accomplished by French mediation." Wedel (1959: 76) alleged that "the French engineered a treaty between the Comanche and Jumano (Wichita) along the Arkansas," and Newcomb (1961: 268) added to the myth by claiming ". . the French negotiated a mutually advantageous treaty between wichitas and Comanches." Hollon (1961: 82) has also averred that the French" . . . succeeded in making friends with the Comanches and Wichitas and establishing peace between them and their neighbors." A careful search has failed to reveal any evidence which would support the thesis that the French were responsible for the alliance. (See Newcomb, n.d. "Scholarly Distortion and the Southern Plains Indians.) The fact of the alliance was first deduced by Bolton from accounts of Frenchmen interrogated at Santa Fe, for which see below.

1749

Luis Febre (Luis del Fierro), Pedro Satren (Pedro Sartre),

Historical background: These three Frenchmen arrived at Taos in company with and guided by Comanches. They had come from "Los Zarca" on the Arkansas. A series of questions were put to them by the Governor of New Mexico, Don Tomas Velez Cachupín. Their answers are so much alike, one wonders how the questions were put.

Sources: Archivo General de Mexico, Provincias Internas, Vol. 37. $1749 \mathrm{Wm}$. E. Dunn Transcripts, Archives, U. T. Proceedings to investigate the visit of three Frenchmen who arrived in Taos, New Mexico, accompanying the Comanche Indians. Copy of transcript and translations, TMM library. Hackett, 1941: 298-319, contains a translation of these documents.

Ethnography: Febre said the Panipiquets or Jumanos painted their faces, were very warlike; lived upon the flesh of other Indians of various nations, whom they killed. He also said they had firearms but lacked powder and bullets. He had visited two Jumano rancherias with 300 warriors. The 
Comanche and Jumano were about 150 leagues apart, and had made peace two years previously. He also said the Comanches did not harm them because of their fear of the Panipiques, who were guiding them. The Comanches wanted the Frenchmen to stay with them and lead them in war against the A nation.

Satren also mentioned painted faces, cannibalism, use of furearms, and lack of powder and balls. He said there were more than 300 warriors in two rancherias, and agreed that the Comanches were afraid of the Wichitas. He too remarked that "a little over two years ago these two nations made peace. . ."

Jose Miguel parrots the other two, saying, for example, that the Panipiquetes number probably 300, "all warriors, in two rancherias, and the nation of cumanches, which is about 150 leagues from the first-named; that they told them a little more than two years ago they made peace with one another. . ."

Remarks: Cachupín tells us what he wants us to know; he does not let the three men speak for themselves unfortunately. 
$1749-1750$

Felipe de Sandoval

Historical background: This Spaniard, who had escaped the English and been with the French some years, ascended the Arkansas, or possibly one of its branches such as the Canadian, and visited two Wichita towns on its banks. Ultimately, after a sojourn with the Comanches, he reached Taos. He was interrogated at Santa Fe, the report carrying the date of March, 1750. Sandoval learned that some Frenchmen had visited New Mexico in 1740, the Mallet brothers, one would assume.

Sources: Archivo General de Mexico, Provincias Internas, Volume 37, 1749. A typed transcript is in the UT archives; a photostat and a translation are in the TMM lib'y. A translation may also be found in Hackett, 1941: 320-324.

Ethnography: From near the mouth of the Arkansas, Sandoval traveled with French traders by boat for 50 days, arriving at two Wichita towns at the banks of the river. He says the French term for these people is Panipiquees; the Spanish Jumanes. The document contains some ethnographic information on houses, subsistence, numbers, cannibalism, etc., and information on trade. They owned some horses given and traded to them by Comanches. Indians mentioned are Comanche (friendly), a Quituche captive of a Comanche, and Pananas (who are enemies).

Remarks: From the information contained in this deposition it is impossible to locate the wichita villages, or to positively associate them with the one (s) visited by La Harpe or others.

\section{2}

Juan Chapuis and Luis Foissy

Historical background: August 6, 1752, Chapuis and Foissy arrived at Pecos Pueblo led by an Indian woman. They carried a white flag, and had nine horses loaded with seven bales of clothing and two small sealed bales. They were arrested and their goods confiscated. Eight others had come 
from the Illinois country with them but had turned back.

Sources: Thomas, 1940: 82-89, "Council of the Indies to his Majesty, Madrid, November 27, 1754." This is followed by a series of affadavits pertinent to this affair, pp. 90-110. The Frenchman said they were ignorant of the four who preceded them. Chapuis had less of interest to say (about the wichitas) than Foissy.

Ethnography: Foissy, in answer to Governor Cachupín, said that the Comanche and Jumanos were friendly with one another ". . . so much so that together they campaign against the Canceres (Kansa) and Osage tribes, and that the Comanches have recently established friendship with the Pawnees through the Jumanos.". (Thomas, 1940: 107, "Declaration of Luis Fuesi, Frenchman.").

The Indian woman who guided the Frenchmen was of the Ae or A tribe.

Remarks: Historically the material is interesting and pertinent to the wichita, but otherwise it is of little value. There is no ethnographic information other than mentioned above.

$$
1757-1758
$$

San Sabá Mission

Historical background: In 1757 a mission and presidio were built by the Spaniards on the San Sabá River, near present Menard, Texas, for the Lipan Apaches. Parrilla commanded the presidio. In March, 1758, a combined force of Wichita, Comanches, and apparently Tonkawas attacked the mission. Fathers Terreros and Santiesteban plus eight other persons were killed and the mission pillaged and burned. The presidic was not assaulted, but its soldiers were unable to come to the aid of the missionaries. The Indians appear to have been led by a Comanche chief; how active the Wichitas were, and just which subdivisions were involved should be further investigated.

Parrilla proposed a retaliatory campaign and that San sabá be abandoned. These proposals were considered by a junta in Mexico in June, 1758. The campaign was approved, but the other proposal was rejected. Parrilla then held a conference in San Antonio in January, 1758, with Barrios, governor of Coahuila, Martos, governor of Texas, and Lt. Eca y Muzquiz, commander of San Antonio, Bolton (1915: 89). When finally gathered together there were about 380 militiamen and presidials, 90 mission Indians, 30 Tlascaltexos 


\section{$1757-1758$}

from Saltillo apparently, and 134 Lipan Apaches. There appear to have been over 600 men in the army.

Sources: Dunn, 1914, Weddle, 1964, Castañeda, 1939.

1759

Parrilla's Campaign Against the Wichitas

Historical background: (August departure), Parrilla led the expedition from San Antonio to the San Saba presidio, thence to a fortified Wichita village on the Red River, presumably in the vicinity of modern Spanish Fort, Montague County, but on the Oklahoma side of the river. Parrilla's attack on the village was unsuccessful. He lost his two cannon, a number of killed and wounded, and made a hasty retreat.

Sources: The basic documents which recount this campaign are a Testimony of Don Diego Artiz Parrilla and a Consulta del Cornel Ortiz Parrilla both in the Archivas General de las Indias, Audiencia de Mexico. Both are in the Dunn Transcripts, UT archives, and copies of them and a translation are deposited in the TMM library. These documents have been much cited by historians: Bolton, 1915: 89; Allen, 1939; Castañeda, 1939; Harper, 1953a: 282-283; Weddle, 1964; and others.

Location of the fortified Wichita village: The fortified Taovaya village cannot be located with any exactness from the documents, despite what some accounts would have you believe. Parrilla said in his Consulta:

We traveled north two hundred and twenty leagues from the settlements at San Antonio River and one hundred and fifty from those at the San Zava, in search for the enemies...

Bolton (1915: 90) and others (Thoburn and Wright, 1929: 43-44; Allen, 1939) place the village near Ringgold, Texas, west of Spanish Fort. Castañeda (1939, IV: 127) said it was in "the vicinity of present Spanish Fort, some twelve miles northeast of Ringgold." Parrilla does not unequivocally state which side of the river the village was on, instead he seems to assume that the reader knows it is on the north side. Duffield (1965), from the Parrilla documents, has concluded that the village was on the north side of the river. Pertinent passages are as follows in Parrilla:

It was noticed by all, that the huts which formed the village occupied a large area and that there 
was a great number of them. They were situated at the edge of the river and the populated land ran from east to west. And one could see that one part of this village was the part which was fortified and that the other part was uninhabited; all the inhabitants having run to the site of the fort. One could clearly see the enemy's remuda which was protected by some corrals of palisade and that behind these the Comanches, allies of this town, had set up their camp, as one could see the tall tents in which they lived.

In giving the reasons for the decision to retreat to San Sabá, Parrilla mentioned that the Apaches

had withdrawn from the main body and had searched up and down the river for great distances for a road that would lead them to the side of the river where the villages were located, but they had seen only the fields and crops of corn (because to have the fields on this side was easier for irrigation).

Also see below, 1759, emphasized section. The Treviño document makes it perfectly clear that the fortified village was on the north side of the river (see below). Preliminary investigation has established, then, that the palisaded village Parrilla attacked was on the north side of the Red River. It may or may not be opposite Spanish Fort in Jefferson County. Oklahoma。

Parrilla's massacre of a Tonkawa village: On October 2, somewhere north of the Brazos River according to Allen (1939: 66), Parrilla surprised an Indian racheria. He attacked it and in one hour "fifty-five Indians were killed and one hundred and forty-nine were taken prisoner." None of Parrilla's force was killed. He did not say what the tribal affiliations of this rancheria were, though other evidence indicates that the people were Yujuan (a Tonkawan tribe). Domingo Cabello, Bexar, to Jacobo de Ugarte y Loyolo, Chihuahua, in "Statement concerning the visit of six. Indians of the Tabaoyozes who re= ported the defense made by the Taguacanes against the Lipanes, 7-3-1786. Bexar Archives, UT. Photostat and translation, TMM Iibrary. A number of Indians had come to Cabello to report on an attack a combined force of Wichitas and Tonkawas had made on the Lipans. One of the Indians was Miguel Peres, a Yujuan Indian. As a boy of eight he had been captured by the Lipans "who went along as auxiliaries in the expedition of 1759 against the Tabaoyazes led by Colonel Don Diego ortis Parrilla." The boy was ransomed by Balthazar Peres, raised by him, and after baptism took the name of Miguel Peres. The evidence is very good, then, that the rancheria Parrilla attacked was 
Tonkawan. Castañedo (1939, IV: 126, 131) has identified the village first as Tonkawan, then as Tawakoni. Cabello also said that the "Yujanes had established a rancheria on the Rio del Fierro which flows between the above mentioned Presidio de San Saba' and the Taboayazes town." What river this may have been is not clear, although one of the branches of the Trinity would seem probable.

Attack on and nature of the Taovaya village: Yujuan prisoners le d the way northward toward the fortified village, arriving in the vicinity, october 7. With no warning the Spanish vanguard was attacked. Parrilla in the Testimony said:

Although we saw no more than sixty or seventy of them, and some of our men confronted them while the others mounted fresh horses, in this lapse of time the enemies were joined by more men (who were also) on the road. They flung themselves confidently into combat and appeared capable of holding their ground. But because of our resistance and our well-ordered attack, they desisted, leaving three of their dead on the road, and began to escape by a road which led into a forest, and with our troops in pursuit. This road has (apparently) been cleared by hand, and was extremely even, meas uring in length one-eighth of a league and running through a thick forest overgrown with the branches of many tall, thickly foliaged trees. The road ends on the sandy shores of the deepest and $\overline{\text { most }}$ turbuIent river we had yet encountered, and in front of the Tahuaya town (emphasis ours). our troops pursued the fugitives to that point, but they managed to escape our efforts with aid from their people who were waiting in an advantageous position. We found the way into the town thus obstructed with the enemies, who had led us to that point, immediately before us. Therefore, our troops retreated a short distance to establish formation before the enemy and to study the situation and our surroundings. At a distance of a short shot from any mediumsized gun, we clearly discerned a town of tal1, ovalshaped huts encircled by a stockade and a ditch. The road of its entrance was enclosed in the same manner and in addition it zigzagged intricately with its gate at the aforementioned river, whose waters flowed by with a depth of more than a yard and a third.

Relations with other tribes: The palisaded town was Taovaya (Tahuaya), and "at a very short distance in an eastward direction" was a "Yascale" (IScani) village similar to it. Help was received from the Iscani town, and Parrilla adds: 
Through the Indian prisoners and through many of the Apaches who were acquainted with the people in this country, we learned the enemy forces included Indians from the Tahuayan nations, as well as leaders from the Comanche, Yascales, Tehuacanes, and many other northern nations, who were probably near the Tahuayas' town as a preventive gesture and as friends and allies as they had been when they joined in making their forays upon the San Zava River.

The 134 Lipans, who accompanied Parrilla, are referred to as "Ipande." The families of these warriors sought refuge during the campaign with the "Nattagees, Mescaleros, and Faraones" all of whom became the Mescalero in later years, Parrilla applauded this, even though this meant that San Sabá was bereft of Lipans, since the Mescaleros would not be attacking the Spanish or inciting the remaining Lipans to do so while the Lipans remained with them.

The position of the Tonkawas (Yujuan) is not entirely clear. Parrilla was able to justify his attack on their village after the fact since they had horses and mules taken from San Saba' as well as a fragment of one of the slain priest's habits. On the other hand, the only natives Parrilla could surprise were Tonkawas, a non-wichita group. And Tonkawa prisoners led the Spaniards directly to the fortified village, though perhaps with malice aforethought. One can only conclude that the Tonkawas were not intimately associated with the wichitas; their usually friendly relations with Lipans in the next few years would argue for this point of view too.

Population: Some of Parrilla's soldiers thought there were 6,000 armed enemy, 500 of them mounted. Others felt that they numbered, both foot and mounted, 2,000 more or less. Parrilla said that he was outnumbered, meaning that there were more than 500 of the enemy.

Ethnography: Parrilla's account contains some interesting and varied ethnographic data. There are comments on the crops, houses, dress of a paramount chief, nature and situation of the palisaded village, methods of fighting, and the like。

Trade: That the wichita (Taovayas) had extensive trade relationships with the French is clear from Parrilla's account. In one place he even claimed that ". . . there were fourteen European Frenchmen inside the heathen town when I tried to get inside." A French flag was flown from the center of the palisaded area and Indians played the drum and fife during the battle; the Indians were well supplied with guns (muskets) and ammunition, and Parrilla claimed that none of the natives used 
bows and arrows during the fighting. The Spanish also saw white clothing hung over the house, implying European fabrics were in use. His most succinct statement is (Consulta, p. 31):

- . the French have not ceased to supply our heathen enemies with firearms, powder, and shot; nor have they ceased to instruct them (i.e., the Indians) in their most skillful use and in the best (military) discipline. Nor have they (the French) taken back their flags . .

Calahorra's visit to Tawakoni-Iscani village on the Sabine

Historical background: After Parrilla's defeat Spanish policies with respect to the Indians were confused and conflicting. At San Saba', the attempt by the military and the missionaries to persuade Apaches to adopt mission life was continued. This meant, so far as the Wichitas were concerned, that the Spanish were still hostile and enemies. In East Texas, Governor Martos $y$ Navarrete and Father Calahorra, the missionary at Nacogdoches, attempted to restore peace, and the Tawakonis, for their part came to Father Calahorra to ask forgiveness for having participated in the attaok on San Sabá. The Hasinai Caddo, who seem to have been quite friendly to the Tawakonis, acted as intermediaries. As a result, Calahorra agreed to go to the Tawakoni village for a conference, and did so in september, 1760. An escort was provided by the Governor.

Sources: Calahorra to Navarrete, 5/27/1760. A.G.I. (Dunn Transcripts), translation in TMM files; also translation may be found in Johnson and Jelks, 1958: 409-410.

Calahorra, Diario del Viaje, 9/16 - 10/24, 1760. A.G.I., Audiencia de Mexico (Dunn Transcripts), photostat and translation in TMM library. Johnson and Jelks, 1958 also contains translation. See also Bolton, 1915: 90-93; Harper, 1953: 285.

Location: Bolton (1915: 92, footnote) located the village complex "north of the north or Lake Fork of the Sabine, near the edge of the great prairies. . " Johnson and Jelks (1958) and Duffield and Jelks (1961) have argued persuasively that the village was on the main stream of the Sabine in what is now southwestern Rains County, Texas. They have excavated a site, designated the Pearson Site, in this locality which apparently represents this village complex.

Ethnography: The Taguacana (Tawakoni) and Yscani (Iscani) towns were separated only by a street, and four chiefs who were "brothers", governed them. The towns were situated in a beauti- 
ful meadow on the other side of the other arm of the sabine, and their streets and garden were beautifully arranged. There were 47 large dwellings each housing twelve families in them. They could muster 250 warriors. They were building an underground fort to defend themselves against the spaniards and other enemies.

Calahorra and his party were met by the entire populace and "all joined joyously in extending warm greetings to us. They fed us sumptuously (that day) and the eight days I was obliged to stay there.. ." Each of the chiefs took turns in feeding Calahorra and he reciprocated with gifts; they also provided corn, pinole, and meat for the return trip. The visitors were housed in tipis, especially erected for them one would gather.

Calahorra noted their fine horses, and stated that maize, beans, and squash were grown in a single communal field a league's distance from "the town." Crops were distributed equally at harvest time and there was enough surplus to give to other nations.

Calahorra credited the Taovayas with having 600 men, and being located about five days' travel time from New Mexico. A Taovaya chief, 20 men and six women came to talk peace. The two cannon lost by Parrilla were discussed among other things, and Calahorra agreed to a second visit the following summer in order to establish closer bonds and good relations.

The only other Indians mentioned were "los Seautos or Apaches Pelones," whose land bordered New Mexico.

\section{1}

Calahorra's second visit to the Tawakoni-Iscani villages on the Sabine.

Historical background: Bolton, 1915: 91, says:

In the following year he repeated the journey, taking presents and conferring titles of honor upon the chiefs. The Taovayas were not present at this council, but Father Calahorra was told that a short distance above their village there were five French houses, established with the pretext of hunting for the Arkansas post.

Intertribal Relations: The relationship of the wichita tribes to the Tonkawa tribes, and the original range of the latter is puzzling. Calahorra in a letter to Navarrette (5/6/ 
1761, A.G.I. Seville) provides some information on this point. In this letter Calahorra reported that Chief Canos of the Tawakonis (actually chief of "Texas" Indians) had arrived, presumably from the twin village on the Sabine, accompanied by Taovaya and Texas (Caddo) Indians. They said they knew that the Tancagues (Tonkawa), Llojuanes (Yojaunes), and Mayeyes had stolen a great number of horses and mules from San Antonio and from a person on his way to "Los Adayes." They were spreading the rumor that the Tawakonis were the culprits. The Tawakonis had "sent representatives to request the stolen articles, and since the thiefs refused to give them up they have decided to fight them to the end."

The Tawakonis had also captured three Spanish women "from the Santos or Apaches Pelones" who had taken them in New Mexico. Calahorra said he would secure them and Parrilla's cannon in July when he again visited their town.

In September, 1761 Calahorra again visited the TawakoniIscani village on the sabine, staying with them eight days. Calahorra's subsequent letter to Navarrete (10/18/1761, Bexar Archives, translation in TMM lib'y) says in part:

On the day following my arrival (in the combined village) I named the Indian 'Flechado en la cara' captain of the Taguacanas with the members approval. And the Indian called 'Llaso' which in our language means Zurdo (lefty), I named Captain for the Yscanis. Through the interpreter I stated the duties implicit in this honor and they, as well as other prominent members of the nation, promised to observe and comply with these duties. I then gave them their staffs and flags which they received with signs of veneration in keeping with the entire ceremony which was solemnly and joyously celebrated by them all.

Is it possible that this marks the origin of the name of the Flechazo division? As is pointed out in the following pages, the Tawakonis are composed of at least two villages in the next two decades, that of Quiscat receiving more attention than Flechazo.

After distributing the presents he had brought, including gifts for the Taovayas who were not there, the captives, two women and a boy, were turned over to him. Calahorra said that the Tawakonis had "negotiated with the Seauttos (Pelones Apaches) Indians" for these captives, but Calahorra's previous statement leaves no doubt that they were captured from the Apaches. Because of ill health Calahorra could not or at least did not go on to the Taovaya's village. The Tawakonis 
told him, however, that beyond the Taovaya village were five dwellings of Frenchmen from the Arkansas Post. Before returning to Nacogdoches Calahorra witnessed the destruction of the ditch which the Indians had been digging when he first visited them.

The presents Calahorra gave the Indians were as follows: for the chiefs of each of the three tribes a loincloth, shirt, staff, musket, and hat. For their people, three arrobas of gunpowder, four arrobas of bullets, 130 bundles of tobacco, six loincloths, nine pounds of beads, three dozen combs, three dozen eslabones (strike-a-lights), three dozen awls, a roll of woolen thread, three hundred piedras (gun flints?), three dozen wormers, a dozen scissors, $2-\frac{1}{2}$ pounds of vermiliton, two pounds of Azarcon, twenty knives, yellow ribbon, and a blanket. (10/18/1761, Certification by Fray Joseph de Calahorra y Saenz. Bexar Archives. Translation in TMM lib'y.)

Sources: Also see Bolton, 1915: 91.

1763

Calahorra's third visit to Tawakoni-Iscani villages

Historical background: Louisiana was transferred to Spain

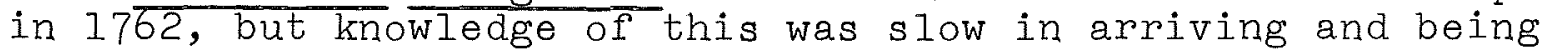
acted upon in the New World. The transaction took place when it became plain to France that England was going to win the Seven Years' War, so she made the transfer to her ally. As a result of Calahorra's previous visit, he and Martos proposed that missions be established for the northern tribes, moving the San Saba' presidio to the twin village. The Viceroy was in doubt and Calahorra made a third visit.

Bolton (1915: 91-92) said of the third visit: "He found the Indians still desirous of missions, but noted the ominous (p. 92) presence of a French flag planted there since his last visit by a trader from Cadodachos."

Letter from Commander Monsieur de Macarti to Governor Martos, sept. 10, 1763, in which he explains why the Tawakonis have a French flag, and why it cannot be taken from them. It was incidentally, being flown on the same pole but below the Spanish flag.

Photostat of transl. in TMM Iib'y. Bexar Archives.

Macarti had obviously not learned of transfer of Louisiana to Spain. Letter indicates that Calahorra went all out to obtain peace with the wichitas, and that in consequence they responded favorably. Macarti did not agree that the Wichitas were 
1763

included in the "Dominion of Spain" by choice or otherwise. Importance of letter is that it contradicts some historians in the sense that the Spanish were eager in attempts for peace, the Wichitas were receptive but hardly as acquiescent as is generally as sumed.

\section{5}

Antonio Treviño

Historical background: Nothing came of Calahorra's and Navarrete's attempts to pacify and missionize the wichitas. But the Wichitas continued friendly to Spaniards in East Texas, though not with those at San Saba. More precisely, the Tawakonis and Iscanis on the Sabine remained friendly with Calahorra and the Spanish while the Taovayas of the Red River continued to raid San Saba. The Taovayas could not maintain peaceful relations with the Spaniards so long as they escorted Apaches on their bison hunts and in other ways shielded and protected them at San Sabá. The Apaches continued to attack the Taovayas.

Treviño, a soldier from Nacogdoches, was captured not far from San Sabá amidst "the wild lettuce" while escorting a prisoner there, Santiago Garcia. The prisoner, his wife, and another person were killed. One soldier escaped to report this attack by 47 Taovayas. Treviño himself had four bullet and two lance wounds, but was spared from death because of his valor. Eyasiquiche, head chief of the Taovayas, delivered Treviño up to Calahorra at Nacogdoches in July after a captivity of some six months. Father Morfi (1932: 11-12) wrote rather inaccurately of this incident.

Sources: Proceedings Concerning the Restoration of Antonio Treviño to his Presidio by the Chief of the Taguais (Taovayas) Indians, March 20 - August 26, 1765. Bexar Archives (translations), Archives, University of Texas Library. Photostats in Texas Memorial Museum library. The following documents (translations) are included:

Letter from Pedro de Sierra to Governor Martos y Navarrete, advising of his impending arrival with the detachment which has been at San Sabá and reporting the situation there, pp. $81-83$.

Letter from Fray Joseph de Calahorra y Saenz to Governor Martos $y$ Navarrete informing him that the chief of the Taguais Indians has brought Antonio Treviño to the Mission of Nacogdoches, pp. 84-86. 
Reply made by Governor Martos y Navarrete, pp. 87-90.

Letter from Fray Joseph de Calahorra y Saenz to Governor Martos y Navarrete remitting results of conference held with Indian chief, pp. 91-93.

Certified statement of the results of the conference, pp. 94-98.

Order providing that those present during said conference make statements concerning it, pp. 99-100.

Statement made by Pedro de Sierra, pp. 101-102.

Statement made by Antonio Treviño, pp. 103-104.

Order providing that Treviño make a statement concerning the Tawciais Indians, p. 105.

Statement made by Antonio Treviño, pp. 106-109.

Location: Treviño said ( $p$. 106) that the Taguais (Taovaya) lived about 140 leagues (363 miles) from San Sabá. In a direct line the distance from Menard to Spanish Fort is 240 miles, but the route followed by his captors was undoubtedly considerably farther. located

Palisaded village: Treviño said that the village was

- . on the other side of the river which flows through this surrounding territory and empties into the Mizisipi. In the middle of (this settlement) is the fortress they built to resist Colonel don Diego Ortiz Parrilla's campaign. It is made of split logs, which the Indians have placed separate one from the other in order to make use of muskets, the weapons they use, through them. (p. 106)

(p. 107) Said fortress is completely surrounded on the outside by an earthen rampart, close to more than a vara and a third in height, which serves them as an intrenchment, and, about four paces to the east and west, a very deep trench made so that no one can come close to (the fortress) on horseback. Inside there are four subterranean apartments occupying all of its circumference, into which all of the people who cannot help with the defense of the said settlement retreat in time of invasion. 


\section{5}

Population: Treviño believed that the Taovaya, Wichita, and Iscani could count more than 500 warriors (pp. 107-108).

Trade: Navarrete sent Calahorra a number of presents for the Taovaya chief Eyasiquiche and the other Indians who had brought Treviño to Nacogdoches. Included was clothing, a cane, mirrors, hoes, ax, powder, shot, beads, vermillion, strike-a-lights, worms, knives, awls, wire, tobacco, 2 muskets, ribbon and cloth, a bridle, and 3 horses (pp. 87-88).

Treviño ( $p$. 106) stated that the Taovayas acquired from the French muskets, powder, shot, cloth, shirts, and "everything else they use as apparel" (106-107). In exchange, they traded to the French buffalo and deer skins, Apache women and children whom they had captured, horses, mules, "and everything else they steal from the Spanish." (p. 107) Treviño continued:

The one who goes to said village and trades with them most frequently is a man, already middleaged, whom they call Antonio, who has been established on the bank of the above mentioned river about forty leagues from them for a long time. They like and love him very much, not only because of the above mentioned, but also because he is the first one they have come to know. (p. 107)

Relations with other tribes: Treviño was queried about the surrounding peoples. He said that adjacent to the Taovaya village on the north "is the nation of the Guichitas, (Wichitas) which is not large, and on the south at the same distance is part of the Yscania (Iscani) tribe" (p. 107). The Tehuacanas lived to the south about 50 leagues and were also allies of the Taovayas.

The "Guazas, Cuitaranches, Huitaguiras and other nations" lived to the northeast. Treviño said that because of the serious losses the Taovayas were sustaining at the hands of these people, who were more skillful in handling muskets, the Taovayas had been forced to move, in about 1757, to this Red River location. The Taovayas, in turn, supplanted the Apaches in this region because they were better armed. The Comanches lived to the north, were allied with the Taovayas, were nomadic, and were beginning to use muskets which they acquired from the French.

Ethnography: There is very little straight ethnographic description in the Treviño documents. 
Rubi's inspection of Texas

Historical background: This was part of a general survey the spanish government was making in order to reorganize military forces in New Spain. Marques de Rubi's report was the basis for the policies begun by Teodoro de Croix in 1776, when he organized the Provinces Internas, the northern provinces of New Spain. Rubi recommended a war of extermination against the Apaches, and applauded the "Norteños" for their good disposition.

December, 1767. A group of Taovayas and Comanches appeared at San Sabá. Wanted a peace parley, though they were also looking for a fight with the Apaches. Not let inside but given gifts, and they let supply train into the presidio unmolested.

vol. 94 .

Source: Felipe de Rabago y Teran, A.G.M., Historia,

$1769-1771$

Historical background: In dealing with the Indians on the borders and in former French territory, the Spanish used French personnel and more or less perpetuated the French commercial system. Licensed traders replaced the free French traders. Firearms were to be traded only for hunting purposes. Also in 1769, Governor Alejandro O'Reilly abolished Indian slavery in Louisiana, and traders were to stop buying horses and mules from the Indians. Both were a blow to the Wichitas, and seems to mark the beginning of the decline of the wichitas as important traders and middlemen.

Athanase de Mézières prevented total collapse of the Spanish Indian policy. He entered Spanish service with the transfer of Louisiana in 1769. He made an alliance with the Caddo, and used the Cadodacho chief, Tinhiouen, particularly, to deal with the wichita. In the fall of 1770 he went to Cadodacho village where Tinhiouen had invited chiefs of the Taovayas, Tawakonis, Yscanis, and Kichais. De Mézières promised to restore trade in exchange for peace.

By the summer of 1771 the Wichitas and Tonkawas were ready to play ball with De Mézières, even if it meant war with the Comanches, so desperate were they for trade. In the fall of 1771 peace treaties concluded with Taovayas, Tawakonis, Yscanis, Kichai, and by proxy with Tonkawas. Bonded traders were sent, and discontent among the Indians disappeared for a time. 
$1769-1771$

Sources: Bolton, 1914a; Harper, 1953b. used.

Remarks: Should look at original documents that Bolton

1772

De Mézières expedition from Natchitoches

to the nations of the Upper Trinity and Brazos Rivers

Historical background: Apaches now seeking peace with Spain. De Mézières feared Apache-Norteño alliance and early in 1772 made a trip to Wichitas to strengthen the alliance. De Mézières also feared the English. Osage also a menace, attacking both the Wichita and the Spanish. He encouraged war with the Osage. Proposed presidio at Wichita village on the Brazos, and withdrawal of Taovaya from Red River to it. But the project never was approved and the Taovayas forgot to move.

\section{Source: Bolton, 1914e, I: 283-351.}

(De Mézières to Baron de Ripperda, July 4, 1772) visited Kichai village "situated on a pleasant and fertile little meadow crossed by a permanent arroyo" ( $\mathrm{p}$. 285). Had 30 houses and 80 men. 100 leagues from Natchitoches and 30 from San Pedro. Maintained close ties with Cadodachos and Texas (Hasinai), and were close allies of Iscanis, Tuacanas, Taouaiazes, and Oedsitas. Brief ethnography, De Mézières emphasizing that they were like the other wichita tribes. Considerable trade with Natchitoches, buffalo and deerskins traded for guns, powder, balls, and "other merchandise."

Eight leagues west of the Kichai village, though scattered, were Iscanis. De Mézières wanted them to unite in a single village which they agreed to do (p. 286). There were 60 warriors and many more women and children.

Seven leagues west of the Iscani, and across the Trinity, was a Tuacana (Tawakoni) village. When the river was high it formed a peninsula where the village was located. With 30 houses, there were 120 warriors. Described as like the others. Brief ethnography with divergence on burial customs (abandonment of bodies in fields).

Another Tawakoni village located 30 leagues away on the Brazos. There were 30 families in this village. A Ouedsitas 
(Wichita) village was located 110 leagues up (?) the Brazos. Another village of Taouaiaz (Taovaya) was located 60 leagues toward the northeast, "on the banks of the Natchitoches River, at the foot of a ridge which furnishes this river its chief supply of water." De Mézières summoned the Taovayas to the Wichita village, not visiting it. The two peoples are described together with data on houses, subsistence, and quite a bit concerning religion.

Remarks: Original documents should be consulted. This period was slighted, though obviously much of importance might be turned up.

$$
1773-74
$$

\section{Expedition of $\mathrm{J}$ : Gaignard up Red River}

Historical background: De Mézières was in Europe in 1773 and Wichita-Spanish relations were disintegrating. Balthazarde Villiers, post commander, sent the trader, J. Gaignard, up Red River to make peace with the Comanches. Gaignard stayed at the Taovaya village six months. They would not let him go to the Comanches. The Taovayas engaged in considerable illicit trade. At this time they were joined by Panis Mahas, who had fled from sioux.

Source: In Bolton, 1914b, II. "Journal of an Expedition up the Red River, 1773-1774; by J. Gaignard。"

Location and Population: Gaignard had been at a village of the "Great Cados," which was 80 leagues west of Natchitoches. The "Panis" village was "situated in a prairie on the bank of the Red River, west of the cados one hundred leagues." They still had Parrilla's cannon.

(p. 85) "The name of the nation is Panis. It contains four villages, namely, the Tavoyache, the Ouatchita, the Nescaniche, and the Toyacane. There are in all one thousand warriors."

Ethnography: A few notes: women charged with agriculture, men hunted and went to war. They are brave, steal horses and capture slaves. "When they take a slave capable of returning, they broil him and eat him. They are very cruel, and are liars and thieves, the women as well as the men." 
Nuestra Señora del Pilar de Bucareli

Historical background: Spanish colonists as a result of Rubi's report had to leave their East Texas homes. They lived in San Antonio briefly, then Ripperda gave them permission to settle at the site where the old San Antonio road crossed the Trinity. It had a plaza, church, guard house, twenty wooden houses, and many huts. The epidemic of 1777 and Comanche raids in 1778 caused its abandonment. Led by Gil Ibarvo, they moved back to East Texas, and in 1779 established present Nacogcoches.

Sources: Bolton (1915), Castañeda, IV (1939), Handbook of Texas, 1952: I, 235. Some documents in Bexar Archives deal with.

Location: It is presumed by historians that Bucareli was probably near the Robbins Ferry crossing of the Trinity in Madison County, north of Midway. (Handbook: I, 235)

Cabello to Croix, March 31, 1779 (transl. in TMM lib'y) remarked: the place Bucareli located was called "Paso de Tomas." Its location was poor, since the river could not provide adequate water for crops; implication is that it was not right on river. In 1777 the town had 125 males, 53 of whom were in the military establishmənt; 89 women, 64 boys, 64 girls, 2 male slaves, 3 female slaves.

Remarks: Though there is no direct connection between this town and the wichitas, it was a listening post and near the Wichita villages.

Athanase de Mézières, expedition from Bexar to the Nations of the Upper Trinity, Brazos, and Red Rivers.

Source: Bolton, 1914c, II: 187-238.

Locations: (De Mézières to Croix, March 23, 1778) visited a Kichai (Quitseis) rancheria of 20 warriors "separated from the main body of their nation." They were situated in a broad, fertile valley Bolton identified as near Grand Saline in Van Zandt County.

Fifteen leagues to the west of the Kichai village was La Tortuga. (De Mézières to Croix, March 28, 1778) Tonkawas lived in this vicinity. 16 leagues farther west (De Mézières to Croix, April 5, 1778) took him to the Brazos. The "Tuacanas" (Tawakonis) ferried him across the swollen stream.

(p. 195) This village contains about one hundred fifty warriors. It is located in a fertile plain 
protected from the overflows of the river that bathes it by a high, thick wall, at whose base rises a spring from which the inhabitants drink, and from which they could draw the water necessary to irrigate the broad plains where they have planted their crops, but they are ignorant of this advantage.

(De Mézières to Croix, April 7, 1778) p. 1968 leagues westward from former village and up-river, was another settlement of Tuacanas. De Mézières then goes along western side of Cross Timbers to the Red River.

(De Mézières to Croix, April 18, 1778) at the Red River villages.

(p. 201) The nation of the Taovayazes is divided into two villages, one situated on the northern bank of the Vermejo, or Natchitoches, River, the other (p. 202) opposite the first on the other bank. The former is composed of thirty-seven houses, the latter of one hundred twenty-three. Each dwelling contains from ten to twelve beds, considering which fact a conservative estimate places the number of men, including youths, at more than eight hundred, while that of the women and the children of both sexes is very large. (p.205) In the meantime I gave to their villages the names of San Theodoro and San Ber(p. 206 ) nardo...

Whether the two Taovaya villages De Mézieres visited in 1778 on the Red River were at the same location as the palisaded village attacked by Parrilla in 1759 is debatable. If it is the same location, the number of houses on the north bank had decreased, and the large village on the south bank had come into being. There were good springs in the vicinity of the villages in 1778, and were located just west of the Cross Timbers since "they have fire-wood right at hand, securing it from that Great Forest of which I have spoken." (De Mézieres to Croix, April 18, 1778, p. 202). He also noted that "the Bermejo River rises in the mountains of New Mexico four days' journey above the Taovayazes, forming there three branches, which unite near their village. The more northern branch has that salt deposit which I have just mentioned." (ibid., p. 204).

Ethnography: Very good information given concerning the Taovaya: subsistence, dress, division of labor, government, and religion.

Remarks: Original documents should be consulted. 
Historical background: De Mézières died and there was no one to take his place. July, 1780. Comanches attacked by settlers while coming to Bucareli on peaceful visit (Thomas, A.B. in Croix, Gen'l. Report of 1781, p. 75)

Relationship breaking down generally. Spain had few goods available and these at high prices. Wichitas suffering from lack of firearms.

De Mézières to Croix, Sept. 7, 1779 (Bolton, 1914f: II, 274) noted a bad epidemic among the Tuacanas, less among the Indians of San Theodoro and the Pani-mahas. It did not reach the Comanches. Quiscat and Flechazo pointed out as Tawakoni villages.

$$
1784-86
$$

The Taovaya-Wichita Division

Gran Sol was chief of the Taovayas in the 1780's and perhaps previously; on at least one occasion some of his warriors attacked the Spanish at San Antonio. Apparently for this reason, Cabello on at least one occasion referred to him as the "Notorious Gransot" (2). The identity of the Indians who were raiding San Antonio in this period is often difficult and sometimes impossible to discover. But one of the raids, on the night of July 16, 1784, was made by a party of Taovayas and Wichitas as a young Christian captive of theirs escaped and was subsequently questioned by Cabello (1). On this raid two of Cabello's best horses and two others belonging to his servants were taken. "Tremendous" damage was also done to their "orchard" of watermelons, cantaloupes, squash; and corn. Earlier, on the eighth of July, fifteen Indians had surprised two settlers plowing at sunset and had beaten them to death and scalped the bodies. The Indians were immediately pursued, but they escaped, traveling so rapidly that two of their horses and a mule died during the flight. But this party was believed to be Comanche.

When Gran Sol died in 1785 or late 1784, he had had a change of heart about the Spaniards. Four Indians were sent to tell Cabello that on his deathbed the chief had named a minor chief, "Guersec," to be his successor. But Gran Sol did this conditionally, in that Guersec was to get Cabello's approval, and he stipulated that Guersec was to remain friendly with the Spaniards. "He turned over to Guersec the merit badge and the staff, but asked to be buried in the Chief's headdress and coat with the Spanish Royal flag." The Taovaya messengers told Cabello that they had elected Guersec because "he is a person endowed with such virtues as courage, and affection toward Spaniards." Cabello on February 14, 1785 appointed Guersec chief of the Taovaya nation (3). 


$$
1784-86
$$

On May 16, just after sun-up, two Taovayas and two wichitas appeared in San Antonio (5). These messengers notified Cabello that a "captain" and 23 other Indians were on their way to visit him, and Cabello sent an escort with them to bring the delegation to the presidio. They arrived at ten o'clock, the leader coming forward and displaying the "Great Pipe" which Guersec had given him as his credentials "to prove he was sent as an official representative." After they had smoked, Cabello asked the purpose of their visit. Their leader replied that they came to thank Cabello on their leader's behalf for naming him chief of the Taovayas and Wichitas, and because Cabello "had offered him and his people a gift to be made on the moon of June at Nacogdoches." Then the real purpose of the visit came to light: the Osages had surprised the Taovayas and wichitas "during the middle part of the past moon," taking most of their horses, killing two people, and threatening to return at the summer's end and kill them all. The Taovaya-Wichitas had come to Cabello for powder, bullets, and horses. They also wanted him "to send Captain Siscat Gainor, leader of the Taguacanes, Flechazos, and Yzcanis to aid them as much as possible and to free them from the great harm they might suffer if the Huaes (Osages) attack again."

Since Cabello did not have enough horses for his own men, and claimed that he needed his powder and bullets to fight the Comanches, the Taovaya-Wichitas did not get the assistance they requested. He did promise to tell siscat Gainor to help them. Cabello even reprimanded them for coming so often to san Antonio and staying so long, since an annual meeting had been arranged at Nacogdoches. They replied that they had come because they had an important event to report, and Geursec had told them to stay no more than seven nights, since this was the minimum time needed to rest up from the long walk from their towns.

\section{Sources:}

(1) Letter from Don Domingo Cabello to Commander Don Phelipe de Neba, July 20, 1784. Bexar Archives; photostat and translation in TMM lib'y.

(2) Letter from Domingo Cabello to Commander General Don Phelipe de Neba, August 19, 1784. Bexar Archives, photostat and translation in TMM Iib'y.

(3) Don Domingo Cabello, appointment, dated February 14, 1785, Bexar Archives; transcript and translation, TMM lib'y. (4) Joseph Antonio Rengel to Cabello approves appointment of Guersec in place of Gran Sot, April 1, 1785, Bexar Archives; photostat and translation, TMM lib'y.

(5) Letter from Domingo Cabello to Don Jose Antonio Rengel, May 20, 1785. Bexar Archives; transcript and translation, TMM Iib'y。 


$$
1784-86
$$

Remarks: The Taovayas and Wichitas are obviously coalescing into a single entity during this period. Although Guersec was in Spanish eyes chief of the Taovayas, it would appear that the Indians viewed him as chief of both people. There is also during this period a marked division between the Taovaya-Wichita, and the Tawakoni-Iscani-Flechazos, as subsequent pages reveal.

\section{$1784-1795$}

\section{Tawakoni-Iscani-Flechazo Division}

Ciscat Gainor (Quiscat) was paramount chief of the Iscanis, Flechazos, and Tawakonis in this period. He seems to have been more friendly to the spaniards and more amenable to their control than the more northerly Taovayas. (1) In 1794 , "Quiscat," principal chief of the Taguacanas (Tawakonis) was unhappy with the Spaniards in Texas because gifts and presents were too few. (2) on May 11, 1795, Chief Quiscat, 22 men, 3 women of Taguacan (Tawakoni), 14 men and 4 women from the "Quichas" (Kichai), and one minor chief, El Defensor, and two "gandules" of the Guichitas (Wichitas) were given a long list of presents of San Antonio. (3)

Sources: (1) Letter From Domingo Cabello to Commander General Don Phelipe de Neba, August 19, 1784, Bexar Archives, UT. Photostat and translation in TMM Iib'y.

(2) Pedro de Nava, in Chihuahua, May 21, 1794 , to the Governor of Texas. Bexar Archives, UT. Photostat and translation in TMM 1 ib'y.

(3) List, untitled, dated May 11, 1795. Bexar Archives, UT. Photostat and translation in TMM Iib'y.

Tawakoni-Iscani-Flechazos and the Tonkawas and Lipans

In the spring of 1786 a party of 49 Tawakoni-IscaniFlechazos, who were visiting La Bahia (at present Goliad) were attacked by Lipans. Two of the wichitas were wounded, but not seriously. One of the Lipans was killed and Chief Cuernitos and another warrior were gravely wounded. Cabello was fearful the Iipans would attack again since attempted revenge was sure to follow. He ordered Captain Don Luis Cazorla of the Presidio of La Bahia to escort the wichitas to San Antonio. They left April 13, by which time ten more hichitas had joined them. 
These ten seem to have been members of a scouting party which was out looking for Lipans when the Lipans attacked at La Bahia. Cabello, after the wichitas reached San Antonio, lectured them about their dangerous habit of roaming in disorganized parties. He wanted them to cooperate with the Comanches so that they could have more success in their struggle with the Lipans. The Wichitas indicated they would do so, returning to their villages together to report to their chiefs and to the Comanches about what had befalien them.

The Lipan threat was real enough, as they were stealing horses from the settlers at San Antonio. This was made easier by the fact that the settlers had relaxed their vigilance following the recent peace with the Comanches.

(Cabello to Rengel, April 18, 1786, Number 203. Bexar Archives, photostat and translation, TMM lib'y.)

The Wichitas acted quickly: they recruited 190 Tonkawas, and the combined force of Tawakonis, Iscanis, and Plechazos attacked the Lipans on May 22. The leader of the Wichitas was the son of "Siscat Gaynor," the Tawakoni chief. His strategy was "to attack the enemy from the woods of the Colorado River and an arroyo, which is the site of Captain cuernitos' rancheria." (Cabello to Ugarte, July 3, 1786). But the Tonkawas botched the campaign by being more interested in stealing horses than in exterminating Lipans. They captured 600 horses, which alerted the Lipans, so that the strategy could not be carried out. The combined wichita-Tonkawa force returned to their villages, highly gratified at their success. Although Taovayas reported this attack to Cabello, they had no part in the campaign. Nor is there any indication that the comanches participated.

At this time the Tonkawa chief, El Gordo, brother of Miguel Peres (see entry under 1759, page 4), reported that 150 Lipans were with the Vidais (Bidais). The $W$ ichitas and Tonkawas next planned to attack them. But Cabello thought an attack on the Lipans at the mouth of the Rio Frio would be more practical since most of them were there.

Source: Cabello to Ugarte, July 3, 1786, numbered 232. Bexar Archives. Photostat and translation in TMM lib'y,

1786

Taovaya-Wichita Division

On January 23, 1786, Cabello wrote Rengel that 37 men and one woman from the Taovaya-Wichita tribes, including some Tawakonis who joined them when they passed through their town, 
had arrived in San Antonio. They had been sent by the principal chiefs, the two leaders said, to find out whether the Comanches had complied with the promises they had made to the spaniards. A party of Comanche "chieftains" was already at the presidio, so Cabello held a joint meeting. In it he called "for their union in order to wage effective warfare against the Lipanes." The Wichitas promised to discuss the matter with their chiefs and also with the Tawakonis, Iscanis, and Flechazos when they passed through there on the return journey.

Cabello asked the Taovayas if they could be reconciled with the Huaes (Osages), the Indians replying that they were tired of the hostilities but that the osages lived so far away that it would be difficult to do anything.

Cabello admonished the Taovayas for not bringing their captives with them as they had promised. The Taovayas replied that they had been unable to do so because they did not have enough horses. The truth of this was demonstrated by the fact that they had only six horses with them. Cabello then asked them to bring the captives when they came to the presidio in August for their gift. (I)

Source:

(1) Cabello to Rengel, January 23, 1786, Bexar Archives, photostat and translation in TMM lib'y.

(2) Cabello to Rengel, April 16, 1786

(3) Jacobo Ugarte y Loyolo to Domingo Cabello, May 5,

24, 1786. Bexar Archives, translation in TMM lib'y.

Sometime between their January visit to Cabello and April, the Taovaya-Wichita under Guersec abandoned their village on the Red River. Cabello reported that:

The aforesaid Taboayazes (Taovayas) and Guachitas (Wichitas) have moved in closer to the Taguacanes, Yzcanis, and Flechazos and are now in a more direct location in relation to the Cumanches ${ }^{\prime}$ rancherias. According to them the motivation was the fact that they were very isolated at their previous location on the river called the Colorado by some and the (Rio) de la Palizada by others, which flows by Natchitos and into the Misisipi. (2)

They moved to the "Rio de los Pedernales," not to be confused with the modern stream, with the active assistance of Comanches under "Camisa de Fierro." According to Ugarte:

- . they hoped to escape the attacks of the Guazas, their enemies, from whom they had recentIy suffered injuries in December. With this 
neighborly move, the friendship and the union among these tribes had been strengthened. The Taguayaces and Guachitas found that the other tribes were willing to help them build their houses, and they were already finished. Then and there, amidst all the rejoicing, the great expedition of the United (Indians) that was to be made against the Lipanes, was discussed. The chief of the Comanches, especially, showed great spirit and desire to please the spaniards, their newly acquired friends. (3)

Pedro Vial - From San Antonio to Santa Fé

Juan Bautista de Anza, Governor of New Mexico, achieved peace with the comanches in 1786 (Thomas, 1932: 294-321, 329332). This breached the barrier between east and west. Pedro Vial, a Frenchman who had a good knowledge of the Comanches and other Indians, was sent by Governor Cabello of Texas to pioneer a route from San Antonio to Santa Fe. He c.nd a companion, Cristobal de los Santos, left San Antonio october 4, 1786 and. rode northward, striking the Tawakoni village on the Brazos (?), october 24, but no one was there. They found the Tawakonis on the 29th, Vial going to "the house of the Quiscot chief" (i.e., Quiscat, see above). The village of Quiscat was presumably on the Brazos River in the vicinity of Waco; he seems to have found them at a temporary camp. Vial had been at Quiscat's village before, but apparently at a different location. It was not at the place where De Mézières visited it in 1772, 1778, and 1779 (Bolton, I: 144ff.) Vial's diary is difficult to follow so far as his itinerary is concerned. He was sick during most of the journey to the Tawakoni village, perhaps delirious, and probably could not accurately say where he was. His companion seemed only fearful that he would be held accountable for Vial's death in case he expired.

A Taovaya-Wichita party had gone to San Antonio to steal horses, despite their ostensible peace with the Spaniards, shortly before Vial had departed. The Indians had succeeded in stealing many horses, but one of the Taovayas, a minor chief, had been killed. Vial, who was there, identified him for what he was, a Taovaya, not an Apache as had been suspected. Quiscat now told Vial that the Taovaya-Wichita party had stopped in their village on the way home from the raid, and that he had reprimanded them and taken some of their horses from them. He was obviously concerned lest the spaniards implicate his people, perhaps too much so. Quiscat said that from the time De Mézières had brought about the peace between the spaniards and his people, 


\section{$1786-1787$}

he had sought to maintain it. At that time De Mézières had taken Quiscat to San Antonio

then Governor, and he (the Indian) had given him
his word that he would do no harm or have any more
wars, and had been gratified with a full dress, a
horse, a medal, and a flag. Thus, his people al-
ways maintained peace (Vial, Diary, p. 6).

Vial told Quiscat that he was sick and asked if there was someone who could cure him. Quiscat said he would call somebody to treat him. Vial stayed in the chief's house until December 15, when he left, cured.

Vial followed the Brazos northward, making between 5 and 8 leagues a day. On December 21, some 90 miles up the Brazos from Waco (probably in Hood or Parker County; Castañeda says the town of Dennis in Parker County) he saw smoke and answered it. Vial crossed the river and waited, and two men came up, a wichita and a Spaniard named Juan de la Cruz. The pair said they were returning from a horse stealing expedition to San Antonio. Castañeda (1942: 153) calls Juan de la Cruz a "captive," which Vial does not do. In any case, they camp together and continue on the next day, the 22nd, leaving the Brazos. They traveled four leagues, camped at a stream, and the next day continued on six more leagues reaching another stream. On the $24 \mathrm{th}$, going in the same direction which is presumably northerly, they went through some hills, crossing them near a Taovaya village. They slept near another group of hills where there was water. On the 25th they crossed the river and continued on to a stream where there was good water. On the 26 th they turned west and apparently continued in this direction until they reached the Taovaya-Wichita village on the 28 th.

It is obvious that it is again difficult to follow Vial's route with accuracy. Loomis and Nasatir (1967: 274) say that Vial "continues to speak of traveling west, but that must be discounted." To suggest that an experienced explorer did not know in what direction he was going is incredible, but it is typical of how Vial's travels have been interpreted. Vial must have struck the Red River below the villages, and altered course to the westward or upstream. Just where the Taovaya-Wichita village(s) was is in doubt. The village cannot be located by using Vial's diary, although the route should be followed out much more carefully, preferably by using a photostat of the original document and actually going over the ground with it. As has been shown (Taovaya-Wichita Division, p. 2), the Taovaya-Wichitas had moved earlier in the year, presumably from the old "Spanish Fort" site. But Vial gives the impression that the village he visited was not temporary or recently 
established. Perhaps the Taovaya-Wichitas had abandoned their village complex in the spring but moved back in the fall; perhaps there were still multiple villages.

As soon as Vial arrived at the Taovaya-Wichita village (and he so referred to it), the chiefs gathered together in "Chief Concho's house" (Loomis and Nasatir, 1967: 274, spell it "Corichi," Castañeda, 1942: 153, "Corichin"). Chief Guersec is not mentioned. The discussion again was the Taovaya-Wichita raid on San Antonio and the slain warrior. Vial quite bluntly told them of the man's death and the Spanish feelings about the Taovayas. The Taovayas replied that it was "four fools who had gone to do wrong, leaving at night, saying they were going to the Apaches to campaign . . . " They agreed that Vial's harsh words about them were true, and they promised to wait for vial in order to go to San Antonio with him to make amends. They were afraid to go alone. A group of Taovaya-Wichitas were planning on a trip to the Comanches and were waiting for the return of a chief who had gone to the Comanches to inform them that they were coming "to dance the Pipe." It would appear, then, that the Taovaya-Wichitas were going to establish or secure peace with the Comanches. Loomis and Nasatir (1967: 277) assume they were going to trade with the comanches. But the fact that a Comanche chief subsequently endeavors to return some stolen horses from the Taovaya-Wichitas would seem to argue for the former point of view.

The chief arrived January 6, 1787, with six Comanches. Vial left January 8 with some of these Comanches for the Comanche camp. Vial wintered, according to Castaneda (1942: 154) near Clara or Burkburnett, then went on to Santa Fe with a Comanche escort in the spring.

Sources: Our information concerning Vial's initial trip to santa $F$ is drawn from a translation by Margarita costero of Vial's diary which is in A.G.M., Historia, Vol. 43, a photostat of which is in the U. T. archives. Castâneda (1942: Vol. V: 150-155) and Bolton (1915: 127-133) summarize the diary using the same document. Loomis and Nasatir (1967: 262-287) translate the diary from a copy in the A.G.M. Historia, leg.62, no.2. Castañeda goes over the route in detail, but as Loomis and Nasatir note (p. 269) "with unexplained discrepancies." H. Bailey Carroll also worked on the route of Vial, but this material is unpublished.

Remarks: Vial wrote his diary in French which was translated into Spanish, and the Spanish versions obviously leave much to be desired, as it appears, do translations of it to English. There is not very much in Vial's diary which adds to knowledge of Wichita ethnography, and it is difficult as has been observed to locate with exactness the route he followed. 
Jose Marés (Jose Marés Gorbo)

Historical background: Vial had reached Santa $F e$ in the latter part of May, and his diary had been translated by early in July. Governor Anza had replaced Fernando de la Concha as Governor of New Mexico. Jose Marés, a retired soldier, left Santa Fe July 31 to find a more direct route to San Antonio. With him was Cristobal de los Santos, Vial's companion, and an interpreter, Alejandro Martin. It would appear that the expedition had been planned before Vial's arrival.

Marés reached the "Spanish Fort" village complex on September 5, 1787, and his diary leaves little doubt about its location. He went through the villages saying ". . the first one has 23 houses, the second 40, and the third, which is on the other bank of the river, has 27."(1) Mares was accompanied by Comanches on their way to the village complex to trade, and in fact a retinue accompanied him all the way to San Antonio. Their presence may account for the fact that he did not pioneer a short cut. Near the wichita villages was a place, "Comercio de los Franceses," where French traders customarily traded with Comanches. When Marés passed through there, however, the traders were absent, being in the Wichita villages. Heading southward, Marés missed the Wichita villages on the Brazos, and reached San Antonio october 8, 1787.

Sources:

(1) Dizry of a Trip Made by Jose Marés from Santa Fe to San Antonio de Bexar, July 31, 1787, to october 8, 1787 A.G.M. Historia 43, Microfilm copy, Bexar Archives, also translation by Margarita Costero. Loomis and Nasatir, 1967, pp. 288-302, contains a translation of this document. Castañeda, 1942, V: 155-158 summarizes this trip.

In January Marés began his return trip to Santa Fe, cutting northwestward and so missing Wichita settlements. Accompanied by Comanches, no Lipans were encountered. He arrived in Santa Fe, April 27, 1787.

Sources: Diary of a trip made by Jose Marés from San Antonio de Bexar to Santa Fe, Jan. 18, 1788, to April 27, 1788. A.G.M. Historia 43, Microfilm copy, Bexar Archives; translation by Margarita Costero. Loomis and Nasatir, 1967: 306-315 contains translation. Castañeda, 1942, V: 158-159, summmarizes the journey. 
Pedro Vial, Santiago Fernandez, and Francis Xavier Fragoso

Historical background: Less than a month after Marés arrived in Santa Fe, Pedro Vial began a journey with the objective of opening up the road to Natchitoches, at the order of the Governor, Fernando de la Concha. Santiago Fernandez, commanding three cavalrymen, was sent along as far as Taovaya country. He was then to return and he was to keep a diary. Also included in the party were Jose Maria Romero, Gregorio Leiva, and Juan Lucero. Francisco Xavier Fragoso was to keep a diary of the entire trip from Santa Fe to Natchitoches, to San Antonio, and thence to Santa $\mathrm{Fe}$.

Fernandez diary. This diary contains very little about the "Jumanes." Spaniards were given a cordial welcome at the "Spanish Fort" villages and were questioned about why they came to their village. Fernandez answered them that they had come to get acquainted with them and to escort Pedro Vial. Fernandez reported 17 huts of "zacate" (straw), and that "they have their fields of corn, beans, watermelon, and pumpkins." He only visited this one village, but said there were "two other pueblos near this one in the short distance of one half league, and both have approximately the same number of huts."

Sources: Diary of a trip made by Santiago Fernandez from Santa Fe to the Jumanes village and return, June 24, 1788 to August 17, 1788. Translated from microfilm by Margarita Costero, 1952. From A.G.M., Vol. 43, Bexar Archives. Copy of translation in TMM lib'y. Loomis and Nasatir, 1967: 318-326 is a translation of the Fernandez diary, based on a certified copy in Historia, Vol. 62, no. 5. See also, Castañeda, 1942, Vol. 5: $162-165$.

Fragoso diary: contains remarkably little about the wichitas. It notes only that they were "well received and treated" by the Wichitas in the Red River villages.

Sources: Diary of a trip made by Francis Xavier Fragoso from Santa $\mathrm{Fe}$ to San Antonio de Bexar and return; June 24, 1788 to August 20, 1789. Translated from microfilm by Margarita Costero, 1952. From A.G.M., Vol. 43, Bexar Archives. Copy of translation in TMM Iib'y. According to Loomis and Nasatir (1967: 327)

- . there are four known copies of Fragoso's rather extensive journal of the Santa Fe-Natchitoches portion: one in the Archivo General de Indias in Seville; one in Volume 43, Seccion de Historia, Archivo General $\mathrm{y}$ Publico de la Nacion, Mexico City; one in volume 62 
of the same Historia; and one in abbreviated form but signed by Fragoso and apparently in his handwriting, in the General Land office at Austin, Texas and they are quite different at times.

See also Castañeda, 1942, Vol. 5: 165-170.

\section{0 's}

Historical background: Spain, hardpressed, and trying to contain U.S.A. Plans for trade went down the drain in these years, and so in consequence the favorable position of the Wichitas on the Red River. Also dispute between Texas and Louisiana over trade jurisdiction. Finally, Louisiana traders forbidden to trade with Texas Indians.

Colonel Juan de Ugalde, January 9, 1790 led Taovayas, Comanches, Wichitas, Tawakonis against Apaches. 44 soldiers, 52 civilians from San Antonio won decisive battle in the Arroyo de la Soledad, w. of San Antonio (Bolton, 1915: 127).

In 1791 Antonio Treviño led a joint campaign of Comanches and wichitas. But this time not successful.

Source: Antonio Treviño, Diario:. . de lo ocurrido en la expedicion de los Lipanes con todo lo demas que hace presente, San Antonio, June 20, 1791. A.G.M., Provincias Internas, Tomo CLXII. UT Archives.

Wichitas felt let down by Spaniards, and as they had come to depend upon European guns and other things, were soon in difficult circumstances, Suffered from Osage hostilities as did spaniards. In this period spain invited southeastern Indians hopefully as a buffer against Osage. Choctaw and Chickasaw came.

But in 1789 wichitas and Comanches sent 700 warriors on a fairly successful expedition against Osage.

1794 Franco-Spanish war and fear that America would take over Louisiana.

1790 Kiowas became allied with Comanches and subsequently with Wichitas (Mooney, 1898: 162-65). 
Taovaya-Spanish, Tawakoni-Spanish relationships

The Taovayas were reported to be living peacefully in their town of "xacales" and raising crops. It was reported also that two traders, either French or English, lived in the town, one of whom, "Equix," had a forge and repaired weapons and made knives and lances for the Indians. Pedro de Nava asked the governor of Texas to have these Europeans removed since "it is not to our advantage to have such men living among our Indian allies, since with their habits and erroneous ideas they are capable of alienating their affection and inclinations from us, converting them from our allies to our enemies." (Pedro de Nava to Governor of Texas, March 27, 1794, No. 162, Bexar Archives). The governor replied that there were no foreign traders among the Taovayas (Pedro de Nava to Governor of Texas, May 21, 1794, Bexar Archives). But in February, 1795, it appears that there was in fact an English "silversmith" (platero) among the Taovayas (Bernardo Femandex to the Governor, Don Manuel Munoz, February 2, 1795, Bexar Archives).

Pedro de Nava also reported that the Tawakonis had killed a settler who had in his possession a horse which one of the Tawakonis recognized as his own. The settler claimed he had gotten it in trade from a Lipan. Pedro de Nava believed the governor could get the "Senior Chief, Quiscate" to give up the murderer or to punish him in the presence of Spaniards.

\section{5}

\section{Gifts to Quiscat}

The Spaniards appear to be making an effort to maintain good relations with the Tawakonis and other wichita tribes. In May, Thief Quiscat with 22 men and three women of his tribe (Tawakonis), 14 Kichais and four of thejr women, a minor chief, El Defensor, and two gandules of the Wichitas, came to San Antonio. One of the Kichais also appears to have been a minor chief, vaslon.

The list of presents given the Indians is extensive and included clothing, cloth, beads, bells, mirrors, and other items of attire and ornamentation, tobacco, gunpowder, bullets, guns, and various firearms tools, hoes, hatchets, wire, and other things.

Source: Unsigned, May 11, 1795, Bexar Archives. 
Historical background: On October 1,1800 Spain secretly ceded Louisiana back to France, and the United States was indignant at France, and it led to the purchase in 1803. The Wichitas were again astride a disputed international border.

Dr. John Sibley, an American who had lived in Natchitoches, became an Indian agent. He was supposed to win the Red River Indians to the U.S. side. Sibley did not visit the Wichitas but obtained material concerning them from French traders. Sibley was interested in accuracy, and he seems to have checked when possible the information his chief informant gave him.

Wichitas.

Sources: Sibley left two documents that deal with the

1) "Historical Sketches of the Several Indian Tribes in Louisiana, South of the Arkansas River, and between the Mississippi and River Grande." in American State Papers, Indian Affairs, I, pp. 721-725. Washington, 1832. It contains a very good ethnography of the wichita, though it is secondhand. Gives divisions, subsistence, dress, trade, etc. Mentions that four years previously, in 1801, a great many Taovaya "were swept off by the small pox." (p. 723)

2) "A Report from Natchitoches in 1807." ed. by Annie Heloise Abel, 1922, Indian Notes and Monographs, Heye Foundation. This contains considerable on trade with wichitas, but virtually no ethnography. It does contain an excellent Comanche ethnography.

Chiefs Iras Coques and Qucháeta

Governor Cordero appointed Qucháeta as chief of the Tahuayas (Taovayas) to fill the vacancy left by the death of Iras Coques, on July 5, 1808.

Source: Note by Cordero. Bexar Archives, photostat and translation also in TMM lib'y.

1809

Location of Wichitas

Tawakonis settled on both banks of the Brazos. "There are three towns at a distance of about thirty leagues from the camino real whose population numbers three hundred men and their families. They grow maiz, frixol and other crops, and their harvests are usually good. 
"The Tahuayas, Huichita and Aquichi Nations are settled in three towns on the Colorado River, about one hundred leagues northeast of Natchitoches. The combined population of these three towns is four hundred men with their families. They grow maiz, frixol, etc., for their sustenance and almost every year their harvest is plentiful.

"The Quichain Nation is established at about six leagues east of la Trinidad river and ten leagues from the camino real. Its settlement is permanent and maiz and other crops are grown for the settler's sustenance. Its population is composed of fifty to sixty men and their families."

Source: "Information on the Texas Province Indian Nations submitted to me by Don Samuel Davinport at Nacogdoches to be used as a basis in establishing their circumstances and (geographic) location." Nacogdoches Archives, typescripts, Vol. II, Archives, UT lib'y. p. 255. Typescript also in TMM Iib'y. This was written by Manu de Salcedo, April 24, 1809.

Awakakei, Taovaya chief, died on way home after visiting Sibley at Natchitoches. No leader to take his place. According to Harper (19530: 58):

Part of them joined a wandering Comanche group and the remainder, fearing that they were too weak to fend off osage raids, joined the Tawakoni village about two hundred miles further down the Red River. The dispersal of 1811 is an epoch in Taovayas history, for in abandoning their strategically important location the Taovayas lost the principal advantage which had made them so much more significant than the similar village bands of the Red River region.

1813

Battle of Medina. Taovayas, Tawakonis, Tonkawas, and Lipan Apaches fought on side of filibusters.

Source: Hatcher, Mattie Austin (ed.), 1908, Joaquin de Arredondo, "Report of the Battle of Medina," Southwestern Historical Quarterly, Vol. II: 230 .

\section{$1818-1819$}

1819 Juan de Padilla

Source: Hatcher, Mattie Austin (ed.), 1919, "Report on the Barbarous Indians of the State of Texas," Southwestern 
Historical Quarterly, Vol. 23

Said they traded at San Antonio, population over 1,000. Noted mixed bloods.

1818 Jedidiah Morse

Source: A Report to the Secretary of War of the United States on Indian Affairs, 1822: p. 529.

400 Taovayas (malke?) located 1200 miles above mouth of Red River. mark.

1820 Stephen H. Long. Red River villages still a land-

Source: James, Edwin, 1905, Account of S. H. Long's Expedition, 1819-1820, III in Early Western Travels, ed. by Reuben Gold Thwaites, Vol. 16: 106.

1824 Wacos and Tawakonis near or at present Waco. (Kuykenda11, 1903: 248).

Massacre by Osages (Mooney, 1896: 257)

1834

September 2, 1834 Fort Gibson Council

Source: Foreman, Grant, 1926, Pioneer Days in the Early Southwest.

August 24, 1835 Treaty of Camp Holmes

Source: Kappler (ed.) Indian Treaties. Provided perpetua peace and friendship between U. S. and Comanche and Wichitas and between eastern Indians. Also the Pawnee Picts (etc.) become officially the Wichita. Camp Holmes near Canadian, probably across river from Purcell. Representatives from Cherokee, Creek, Choctaw, Osage, Seneca, and Quapaw tribes met with those of Wichita and Comanche. Agreed to remain friendly with one another and with U.S. Prairie west of the cross Timbers to be made a common hunting ground and licensed traders to be admitted.

May 15, 1846 Treaty of Council Springs

Robinson Co., Texas. Butler and Lewis, acknowledged sole protection of U. S. 
Dragoon Expedition

Historical background: Aim was to bring Wichitas, Comanches, and other Plains Indians to terms and to Fort Gibson to dicker. Eastern Indians (Choctaws) had already been assigned Wichita lands. Colonel Henry Dodge led expedition.

Source: Wheelock, Thompson B., 1860, "Journal of Colonel Dodge's Expedition from Fort Gibson to the Pawnee Pict Village." American State Papers, Military Affairs, V (Washington) $377-385$.

Catlin, George, 1841, Letters and Notes on the Manners, Customs, and Condition of the North American Indians, vol. 2: $70-75$.

Location: Wichita village, in Devil's Canyon near modern Lugert, Oklahoma. Catlin sketched site.

Ethnography: Catlin put the village size at 500-600 grass lodges; mentions subsistence, describes very well the hassle Dodge had in council with the chiefs over the nineyear old captive they at first denied having. Dodge's ace was the two Wichita girls he had ransomed from the osages and was returning to the tribe. Good estimate of population, and other information.

\section{1}

Texan Santa Fe Expedition

Source: Kendall, George W., 1844, Narrative of the Texan Santa Fe Expedition, Vol. 1: 134-144.

Location: Northwestern section of present Wichita Falls according to Carroll, H. Bailey, 1951, The Texan Santa Fe Trail, Panhandle Plains Historical Society, p. 89.

Kendall, p. 134, said it was in "a large and delightful valley, through which a river coursed along... in a large bend of the stream the village was situated." It was on the north side of the stream.

Ethnography: A Waco village; the inhabitants deserted as the Texans approached and the Texans never parleyed with them. Kendall described quite completely the village, its layout, the houses, and much about material culture.

Population: Kendall thought probably 300 to 400 inhabitants occupied the village. They could see other villages up and down the river. 
Wacos, Wichitas, and Tawakonis reported to "have for the last year been committing depredations upon Texas." (1) Butler in a subsequent letter (2) said:

The other little bands viz: Witch-e-taws, Tow yash, To woc onies Ke chies and Wacos are inconsiderable in number and degenerate in character. They do not exceed one hundred and fifty souls each--they plant corn and pumpkins for their own use, and raise some for trade. They live in villages, and have temporary huts made of skins and straws.

The wich e taws and Tow yash live on the north side of the Red river in the Witchetaw Mountains. The other three tribes reside upon the Brazos, about one hundred miles above Camanche Peak. They informed us they had lost their numbers by the small pox and repeated wars with the Texans. They have the reputation of being the best horse thieves in the prairie.

\section{Source:}

(1) $\bar{P}$. M. Butler, Letter to William Medill, Commissioner of Indian Affairs, March 4, 1846, U. S. Office of Indian Affairs, Letters Received, 1838-1862 (Photostats), Archives, University of Texas Library.

(2) P. M. Butler, Letter to William Medill, Commissioner of Indian Affairs, August 8, 1846, remainder same as (1).

\section{7}

R. S. Neighbors reported from Texas that:

The only hostile Indians now on our borders are a part of Wacos, Wichetas, and Towaconies, numbering about 500 warriors, assisted by those small bands of Kickapoos, Delawares, and Shawnees. Their object appears to be plunder, as I cannot learn of their having committed any murders. The friendly portion of these tribes are anxious for the government to send a few troops into their country, when they will assist in reducing those refractory bands to subjection.

Source: R. S. Neighbors to W. Medill, Commissioner of Indian Affairs, Letter Dated January 6, 1847, Austin, Texas, House Executive Documents, 29 Congress, 2 Session, No. 100, U. S. 500, Ritchie and Heiss, Washington, 1847 . 
R. S. Neighbors reported that Wacos and Wichitas had joined the Comanches under Chief Santa Anna, along with Lipans, in a party of 500 warriors, to raid along the Mexican side of the Rio Grande about 40 miles below Presidio. They were joined by a few Mexicans and Americans, and they were said to have devastated many villages and returned with large quantities of captives, mules, and horses.

Source: Robert S. Neighbors, U. S. Special Agent, Letter to William Medill, Commissioner of Indian Affairs, June 18, 1849, U. S. Office of Indian Affairs, Letters Received 1838-1862.

In October I. H. Williams, who was at Barnard's trading house (Hood County, near present Weatherford) reported that "the Keechies, Wacos, Wichitas and Tonkawas are all quiet, and awaiting your arrival to hear what the President has to say to them." The Comanches and the Jaddos had been hard hit by a cholera epidemic, Williams wrote; apparently it did not affect the Wichitas.

Source: L. H. Williams to R. S. Neighbors, Letter dated October 9, 1849, U. S. Office of Indian Affairs, Letters Received 1838-1862 (photostats). Archives, U. of Tex. Iib'y., Austin.

\section{1}

Colonel Samuel Cooper, Assistant Adjutant General of the U. S. Report of inspection trip from Fort Graham to the Indian villages on the upper Brazos, dated June 14, 1851. Photostat of typed copy in TMM files.

Location: Kichai village in valley on left bank of the Brazos, about 15 miles below slear Fork of the Brazos. Wacos and Tawakonis on Brazos about six miles beyond the Kichai village (upstream).

Ethnography: "Ioni, Keechi, Caddo, and Anandaco" and the "Wacos and Tawaconis". . "are united in two separate bands, and each band is governed by a head chief, each tribe having its own particular chief who is subordinate to the head chief of the band. Thus, Jose Maria is chief of his own particular tribe, the Anandaco's, Towysh of the Inni tribe, and Haddebar of the Caddo tribe, and these three tribes are united under Jose Maria as head chief. So also Acaquash is the chief of his own particular tribe, the Waco's, Chacheruck of the Keechi tribe, and Ocherash of the Tawaconis tribe and these three again form a separate band under the head chief Acaquash."

Also some remarks on subsistence, broken promises of the Great White Papa, and population. All six tribes total about 1,000; with 240 warriors. 


\section{$1854-1859$}

The Brazos Reservation in Texas

Historical background: In hopes of settling the Indian problem, the Texas Legislature authorized the United States to select land for Indian reservations in Texas. General Randolph B. Marcy, under orders from the U. S. Department of War and Interior, selected for the remnant tribes four leagues (18,576 acres) on the Brazos near the mouth of the Clear Fork, about 12 miles south of Fort Belknap. The main building was three miles east of Graham. Major Robert $\mathrm{S}$. Neighbors was put in charge of all Texas Indians and Captain Shapley P. Ross was made agent of the Brazos Reservation.

\section{5}

About 2,000 Indians were settled on the Brazos reservation including Caddo, Anadarko, Tonkawa, Waco, and Tawakoni. They got some 600 acres in cultivation, American style houses started, and many men enlisted as scouts. In his report for the quarter ending December 13, 1855, Agent Ross reported that these Indians had

- Completed some fifteen comfortable log houses and have a number of grass houses allredy completed they have planted eight hundred peach trees presented them by late special agent G. W. Hill and are now busily engaged in fencing their farms and finding them disposed to work I have thought fit to isue one wagon and team to each tribe also ploughs and other farming tools as they have promised to make good use of them they have taken special care of the stock cattle isued to them and should the coming season be a favorable one for farming purposes I have no doubt but a surplus of corn will be raised by the Indians on the Reserve as the most perfect harmony exists a mong the different bands under my charge. I find very little trouble in controlling them. ( $S$. P. Ross to R. S. Neighbors, January 1, 1856, United States office of Indian Affairs, Letters Received 1838-1862 (photostats), Archives, U. T. Iib'y.)

The success of the Brazos Agency attracted non-reservation Wichitas. We learn, for example, that: 
- - we were visited by Ten Camps of Wichita Indians, who came in for the purpose of expressing their sincere friendship for the Indians of the Reserve. They show a strong desire to settle here and come under the rules and regulations of the Agency.

I deem it important that they should be settled, if only temporarily, as if they are allowed to remain south of Red River this winter it will be with great trouble that I can keep the Waco and Tahwaccarro young men from visiting their camps with or without permits as they are one and the same people. The Wichitas have been permitted to trade their buffalo robes at the Trading House of this Agency and have conducted themselves well both here and since they have been off this immediate frontier. I have given them a small amount of provisions with the understanding that they return to their villages near the wichita mountains to await the action of the government concerning them. (S. P. Ross to R. S. Neighbors, December 27, 1856, U. S. Office of Indian Affairs, Letters Received 1838-1862 (photostats), Archives, U. T. Lib'y.).

But nearby whites became increasingly hostile. In 1858 Governor Runnels and General Houston petitioned the government to remove the Indians, so bad had the situation become. In December, 1858, Choctaw Tom and 17 other Indians while on an authorized hunt in Palo Pinto County were ambushed while as leep. Eight were found dead in their blankets. The situation had become explosive. On March 28, Neighbors wrote to J. W. Denver:

I have the honor to report that on my arrival at this agency on the $23^{D}$ inst. I found all the Indians assembled at the agency with their families: and barricades and all other preparations that was practicable made for their defense, against the lawless bands, who it was known were assembling to attack the reserve. I also found Capt. King Ist Infty. U. S. A. with one piece of artillery of the agency, to prevent if possible the attack and to defend the Indians. Capt. Ross had arrested two of their spies on the reserve, and learned that the camp of the marauders was 15 miles from the agency. It appears now that the whole force assembled was about one hundred men: on the 24 th capt. J. R. Baylor arrived in their camp to assume the command; on the 26th we were fully informed that they had dispersed, as they failed to obtain the reinforcements they expected from the adjoining counties.

On the same day we had reliable information from Jamieson's Peak, Palo Pinto County, which was the point at which the main force were to assemble. The result was 


\section{6}

that only 35 men assembled. Thus reducing capt. A. Nelson's command to a force too weak to reinforce Baylor. They consequently 'Resolved' to suspend

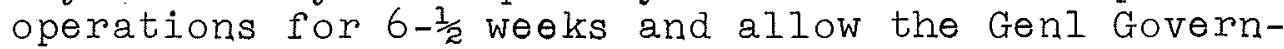
ment that time to 'peaceably' remove the Indians out of the state. I have little doubt that capt. King with his artillery was the strongest argument used to bring them to that conclusion. This is suggestive and it is hoped that before that period the Indians will be on the road to Red River, to occupy the new reserve.

on May 23, 1859, John R. Baylor, who was on the outs with Neighbors and had been stirring up trouble, appeared at reservation demanding some Indians. Agency prepared for battle; Baylor retreated for consultation and killed an Indian woman working in her garden and scalped an old man.

J. B. Plummer wrote of the clash with Baylor (Plummer, May 23, 1859):

I have the honor to inform you, that information was brought to me this morning, at about half past ten o'clock that capt. Baylor with about two hundred and fifty men, had marched upon the reservation to attack the Indians, and was then about a mile distant and approaching the agency, where my command and the Indians were encamped. I immediately dispatched Sapt. Gilbert with his company to meet fapt. Baylor and to demand of him, ifor what purpose he had come upon the reservation with an armed body of men?' To that demand he replied that, the had come to assail certain Indians of this reserve, but not to attack any whites: but should the troops fire upon his men during the fight, he would attack them also, or any other white who did the same thing, and treat all alike: ' he desired my reply and would wait for it three quarters of an hour.

As soon as I received the above message, I sent Lieut. Burnet (?) to Capt. Baylor with instructions to say to him, that my orders were to protect the Tndians on this reserve, from the attacks of bands of armed citizens, and that I would do so, to the best of my ability, and with the arms in my possession, and that I warned him in the name of the Government of the United States to leave this reservation.

Capt. Baylor rejoined that, "this message did not alter his determination of attacking the Indians on the reserve, and that he would attend to it himself: that he regretted the necessity of coming in collision with the Jnited states 
troops, but that he had determined to destroy the Indians on this and the upper reserve, if it cost the lift of every man of his command."

The Indians in the meantime as well as the troops had prepared for action, and some of the former who were mounted, were hovering near capt. Baylor and his men, watching their movements. By friendly signs, they induced a very old Indian to approach them, when they tied a rope around his neck, and then moved off in a westerly direction, but before going far killed and scalped their prisoner. They were followed by fifty or sixty Indians, constantly exchanging shots with them, and eight miles from the agency, and about one and a half miles from the limits of the reserve, they came to a stand, taking possession of a farmers house and out buildings. There the Indians fought them until dark, when they returned to the reservation. They killed, they state, five of capt. Baylor's men, and had one of their own killed, besides the one I have already mentioned, and several wounded.

The Indians attacked; two of Baylor's men were killed, others wounded. At least one Indian killed; as a consequence Neighbors ordered Indians removed. Reservation abandoned July $31,1859$.

Source: Noel, Virginia Pink, 1924, The United States Indian Reservations in Texas, 1854-1859. M. A. thesis, University of Texas.

$1854-1859$

Kock, Clara Lena, "The Federal Indian Policy in Texas, 1845-1860," Southwestern Historical Quarterly, Vol. 28.

Remarks: Further research will probably turn up much more information concerning the wichita part in the reservation and its difficulties. But since our quest is not primarily for historical information, this has not been pushed.

\section{$1855-$}

Indian Territory Wichitas

June, 1855: The "Leased District" was created by a treaty between the United States and the choctaws and Chickasaws. They leased the lands west of the 98th meridian to the United States 
for the use of the wichitas and other western tribes.

In October, 1857, A. H. McKisick reported to the Superintendant of Indian Affairs that:

Of the tribes of wichitas and Keechies I find in round numbers, twelve hundred souls, (nine hundred Wichitas, and three hundred Keechies). The two tribes having intermarried and are in the habit of living and hunting together. They are now located in a village on Rush creek about sixty miles west of Fort Arbuckle. . . E-sae-e-wah, the principal chief of the Wichitas in my interview with him stated that he and his people desired to be treated as the Government had treated other tribes, that is, they wished Farmers, Blacksmiths, Mills and schools - . Of Wacoes and Tahwacconos there are three hundred living on the Ganadian about fifty miles north west of Fort Arbuckle. (A. H. McKisick to Superintendant of Indian Affairs, Letter dated October 21, 1857, Letters Received by the office of Indian Affairs, Wichita Agency, 1857-1878. The National Archives, Washington, D. S. )

Möllhausen, Baldwin

Source: Möllhausen, Baldwin, 1858, Diary of a Journey from the Mississippi to the Coasts of the Pacific with a United States Government Expedition. (2 voIs.) Vol. i, pp. 114-117. Oklahoma.

Location: Vicinity of Wichita mountains, western

Ethnography: Two Waco Indians rode into camp; they were on their way to Canadian River to meet a trader. Contains fairly detailed description of attire and demeanor. He terms them "Wakos" or "Waekos" and p. 115 "who live to the east of the Wichita Mountains, in a village situated on the bank of a small river rising in that direction." Some description, apparently derivative, about wacos and wichitas, including material on houses and subsistence. Next day Kichai, he spells is "Kechie," appear. Said they also lived near wichita Mountains and had about 100 warriors. This Indian guided them--they were lost. 
Rush Creek Massacre

Comanches, on urging of Wichitas, coming to Fort Arbuckle for peace council. Reached wichita village on Rush Creek, but on October 1, were attacked by force under Major Van Dorn. Many killed; wichita crops destroyed. Somanches blamed Wichitas, Wichitas fled to Fort Arbuckle.

Source: Rep't. of the c. of I.A. 1859: 217.

$1859-60$

Consolidation in Indian Territory

S. A. Blain was appointed as the first Wichita Agent in the Leased District. In the winter of 1858, he found conditions less good than had McKisick. He visited the "Wichita Camps on Wild Horse Creek," and found that although the temperature was down to 12 degrees the 484 people in the wichita Camp has only five blankets worthy of the name. They were almost as poorly supplied with buffalo robes. Their condition was due to the fight Major Van Dorn had had with the Comanches in their village. The Comanches, urged by the wichitas, had been on their way to Fort Arbuckle for a peace council. They reached a wichita village on Rush Creek, but on october 1, 1858, were attacked by a force under Van Dorn. The Comanches blamed the Wichitas, and fled to Fort Arbuckle (Report, Commission of Indian Affairs, 1859: 217). Blain decided "to move them south of the mountains that 1 ie in the vicinity of Arbuckle and on caddo Greek to protect them from the bleak north winds and to get, at the same time, good bottom range for their ponies . ."

(S. A. Blain to Superintendent of Indian Affairs, Letter dated December 1, 1858, Southern Superintendency Field Records, Letters Received, Wichita Agency. The National Archives, Washington, D. O.)

Wichitas had a hand in selecting the site of their reservation--on the Washita on the site of the Old Kichai village. In July, 1859, the Wichitas left Fort Arbuckle for the reservation just about the time the Tawakonis and wacos were being escorted out of Texas.

By 1860 many grass houses had been built and 141 acres were under cultivation with hoes. This land was enclosed by a rail fence on one side and brush and stick fence on the others. 
1860 was a bad drought year and Blain was relieved september 10, 1860.

Sources: Gates, Gladys Esther, 1926, The Wichita Indians from 1859 to 1868. M. A. Thesis, Univ. of Oklahoma.

Report of the Commissioner of Indian Affairs, Records.

$$
1861-1865
$$

The Civil War Period

The Wichita and affiliated bands, partly because of the 1860 drought, were dependent upon the government for goods and clothing. But not long after the outbreak of the war the federal troops left for Fort Leavenworth, Emory reaching Fort Leavenworth May 31, 1861. Even though left without protection, the wichitas did not immediately follow the troops north.

August 12, 1861 some wichitas were forced to sign a treaty with the Confederacy. But they seem not to have been authorized to do so. Albert Pike, the Confederacy Commissioner, was unable to get the chiefs to sign any treaty. The confederacy and Texas were synonymous in the wichita mind, and Texas and Texans meant almost literally treacherous enemy.

On September 1, 1862, 70 Delawares, 26 Shawnees, left Kansas, under Ben Simon, a Delaware, and went first to Texas, then north to the Wichita agency. Reached the agency october 23, 1862, after sundown. They took Agent Leeper prisoner, but when Indians went into agency a fight broke out. A Delaware was killed and a Shawnee wounded. As a result the three white men inside the agency were killed as was Leeper. The bodies were placed in the agency and the building burned. The Indian force then trailed the agency Indians--or rather the Tonkawas who had fled, and killed 150 of them. The wichitas were not molested, but fled north.

E. H. Carruth was appointed United States agent for the wichitas on March 8, 1862. On December 7, 1862 large number of refugees arriving from Indian Territory. They wintered on the Verdigris and Fall rivers. 10-20 miles from the temporary Wichita agency at Belmont, Kansas. 
In 1863 with osage permission they moved to the mouth of Little River, across from what is now the Murdock Avenue Bridge, in wichita, Kansas. We learn from the agent appointed to supervise the Wichita Agency which included Caddos, Shawnees, Delawares, Creeks, and Cherokees as well as the wichita tribes that:

Upon assuming the duties of my office, I found the Indians attached to this agency in a deplorable condition; poorly fed, naked, sick, and in utter despondency as to their future prospects. Arrangements were immediately made for supplying them with flour, beef, and salt in sufficient quantities to prevent suffering, also proper medicines for the sick.

These Indians had made praiseworthy efforts in the spring to provide in part for themselves. A large amount of corn and vegetables had been planted, but the heavy rains in June caused the banks of the Little Arkansas and White water rivers to overflow and utterly destroy nearly the whole of the crop planted. ("Letter from Henry Shanklin, J.S. Indian Agent, to Colonel Elijah Sells, Superintendent of Indian Affairs, Lawrence, Kansas," Report of the Commissioner of Indian Affajrs for the Year I866, Government Printing office, Washington, $\overline{p p .} \overline{322-323 .) ~}$

In the fall of 1867 the Wichitas moved back to Indian Territory. The Acting Commissioner summed up their recent experiences and their prospects:

Wichitas, Caddoes, Wacoes, Keechies, Tawacapoes, Delawares-most of these tribes were formerly residents of Texas, and all before the late war were living on the leased lands west of the choctaw Country. During the war they were compelled to go into Kansas, where they received assistance from the government. Measures were taken during this year to have them removed back to the leased district. Infortunately serious obstacles interposed and delayed the movements until lately; the season was too far advanced for planting; streams were very high, and then appeared the cholera among several of the bands, causing a panic; besides, those who had lost friends wished to remain for a while to mourn over the graves of the dead. On the 3lst of August several of the bands not thus afflicted left for that country, but the disease broke out among them also and many died. To this cause is attributable the large decrease in the 
population of these bands, or tribes, as reported by agent Shanklin. I recommend that liberal provision be made to establish these Indians upon a suitable reserve in the district named, and to provide them with agricultural implements, cows, cattle, and the means of educating their people. With such assistance, and the assurance that the place is to be their permanent home, there is no question but that they will rapidly improve. It is suggested that efforts be made to induce any small parties or bands of these Indians who may be living about the settlements of Texas to remove to the same reservation. (Charles E. Mix, Acting commissioner, to O. H. Browning, Secretary of the Interior, November 15, 1867, Letter, in A.R.I.A. for Year 67.)

Sources: Reports of the Commissioner of Indian Affairs. Records of the Rebellion: Series I, Vols. 1, 3, 8, 13, $22,23,24,41,48$; Series II, Vols. 4, 5, 8.

Abel, Annie Heloise, 1915, The American Indians as Slaveholder and Secessionist.

Gates, Gladys E., 1926, The Wichita Indians From 1859 to 1868. M.A. Thesis, University of Oklahoma.

The Kiowa outbreak and Wichita relations

Source: Schmitt, Karl, 1950, "Wichita-Kiowa Relations and the 1874 Outbreak," The Chronicles of Oklahoma, Vol. 28 (2) : $154-160$.

An account received from old Wichita informants concerning the animosity which resulted from this outbreak. Kiowa went on rampage and Wichita helped gov't. pacify the Kiowas. 
304

\title{
PART II
}

\author{
Locations of Wichita Groups \\ on Maps and Charts
}

\begin{abstract}
Throughout the course of investigation concerning the Wichita, particular attention was devoted to a review of maps and charts reflecting particular locations of different Wichita groups. Research was conducted at The University of Texas Archives and the Texas State Archives in Austin, and in the Library of Congress and the National Archives in Washington, D. C. Except where otherwise indicated, the following information was taken from originals or copies of original maps in The University of Texas Archives.
\end{abstract}

Unsigned

1717 Mapa Geografico que Presento con su Informe al Virrey de la Na Espana, Dn Juan de Olivan Rebolledo Oydor de la Real Audiencia de Mexico en 18 de Diciembre de 1717 y a Consequencia de Reconocimto $q^{e}$ Hizo de Estas Provincias de Orden de So E. Original in AGI, Seville.

This map has a minimum of detail. Gran Quivira is situated in the approximate location of the southern portion of the present state of Kansas.

Delisle, Guillaume

1718? Carte de la Louisiane et du Cours du Mississippi Dresse sur Grand Nombre de Memoire Entr-Autres sur Ceux de Mr. Le Maine par Guillme De L'isle de L'Academie $R^{l e}$ des Scients. Amsterdam, Chez Jean Covens et Corneille Mortier Geongrapher.

Precise locations are extremely difficult to determine with any degree of accuracy because of obvious errors in river direco tions and lengths. Specific tribe locations are as follows: Quainco Indians on the Red River, and, proceeding from northwest to southeast on the Arkansas River, Ouatchitas, five villages of Paniassa, and Mentous.

Beauvilliers, Sr。de

1720a Carte Nouvelle de la Partie de l'ouest de la Province de la Louisiane sur les observations et decouvertes du sieur Benard de la Harpe--Commandant sur, Ia Riviere Rouge et ou paroissent ses Routes Colorés de jaune et establissement relatif á son journal dresse par le $\mathrm{Sr}$. de Beauviliiers Gentilhomme servant du Roy et son 
Inqenieur Ordinaire de l'Academie Royalle des Sciences a Paris en Nobre 1720 (Photostat). Library of Congress, Washington.

I720b Carte Nouvelle de la Partie de l'ouest de la Province de la Louisiane sur les observations et decouvertes du sieur Benard de la Harpe Commandant sur la Riviere Rouge et ou paroissent ses Routtes Colorées de Jaune et Etablissement relatifs a son Journal dresse par le Sr. de Beauvilliers Gentilhomme Servant du Roy et son Inqenieur ordinaire de l'Academie Royale des Sciences a Paris en Novembre 1720 (Photostat). Library of Congress, Washington.

Each of these maps is essentially the same as the other; the information below applies to both.

Both maps are particularly significant in a historical sense because they show, albeit in relatively crude form, the routes followed by La Harpe in 1719. The River of the Ouachitas is shown on both maps between the Red River and the Arkansas. It is apparently the Canadian.

The Quiohouan are shown south of Red River, perhaps in the vicinity of modern Spanish Fort, Texas, although this would be virtually impossible to determine. Extending from the River of the Ouachitas to the Red River are the nations with whom La Harpe made an alliance in 1719. Immediately to the north is the Iand where the unicorns (Iicornes) were seen. Again, immediately to the north on the Arkansas (Alcanka) River, are the nations of 8,000 people discovered in 1719 by La Harpe. Above these are the villages of the Padoukas Noirs, and, immediately to the north of them are villages of the Ascanis and Ousita.

Unsigned

1756? Carte de la Provincia de Texas. Undated.

This is a highly stylized map; rivers and boundaries are depicted by straight lines. In a generally north northeast direction from San Saba, the Fuerte de la Tahuallas is placed north of the Red River in the present state of Oklahoma.

Spain Dirreccion de Hidrografia

1800? Mapa que Comprende el Territorio Situado Entre $28 \times 48$ Grados de Latitud Norte y Entre 266 y 284 (265 y 289) Grados de Longitud Occidental. Unsigned, undated.

Taquayaces are represented on this map along Red River in the approximate location of present Spanish Fort, Texas.

Puelles, Jose Maria

1807 Mapa Geographica de la Provincias Septentrionales de Esta Nueva Espana. 
Again, precise locations are quite difficult to determine。 The Taguayases are placed on Red River in the approximate area of modern Spanish Fort, Texas. Taguacana Indians are shown to the south southeast and on the south side of the Brazos River. Guicha Indians are on the west bank of the Trinity River, a short distance north of the crosing of the Camino Real.

Pike, Zebulon M.

1810 A Map of the Internal Provinces of New Spain.

The Fort of Tuwayhays is placed north of the Red River in the present state of Oklahoma. Its exact location in relation to modern landmarks is difficult to ascertain.

Austin, Stephen F.

1829? Stephen F. Austin's Map of Texas.

A Waco village is depicted south of the juncture of the Bosque and Brazos rivers. Several miles to the north and on both sides of the Brazos River is shown an old Waco village. On the Big Wishita, ostensibly a few miles south of the present city of Wichita Falls, are drawn a Towyash village and an old Pawnee village. A Kechais village is situated on a tributary of the Trinity River at a point east of the Waco viliages.

Austin, Stephen F.

1829a Mapa Original de Texas por el Ciudadano Estevan F. Austin Presentado al Exmo sor Presidente por su Autor 1829. Original in the Archivo General y Publico de la Nacion, Mexico City.

A pueblo of Tahuases Indians is shown on the Huishita River, apparently a few miles south of modern Wichita Falls. Pueblos of the Huecos and Tahuacanos are on both sides of the Brazos River south of its juncture with the Bosque River. Kichais Indians are situated on the Tortuga, a tributary of the Trinity River.

Austin, Stephen F.

1829b Mapa Original de Texas por Ciudadano Estevan F. Austin.

This map is almost a duplicate of 1829a, and the information concerning Wichita groups is the same for both maps.

Austin, stephen F.

1822 Map Geografico de la Provincia Tehas por don Estevan Austin, 1822 .

On the east side of the Brazos River, on the approximate 
site of present Waco, Texas, are located the Waco, Tawacani, and Towcayses Indians. To the east of these groups, and on the east side of the Trinity River, are the Kichyes. Pawnee are shown on Red River in the vicinity of the modern town of Spanish Fort.

Young, J. H.

1835 New Map of Texas with the Contiguous American \& Mexican States. S. Augustine Mitchell, Philadelphia.

A Whaco village is situated between Cow Creek and the Bosque River on the Brazos, and Whaco Indians are shown slightly to the west on Cow Creek. A Toweeash village is located to the north of Red River on about the lolst meridian in the southeast portion of the Texas Panhandle. Pawnee Pict or Toweeash Indians are shown a short distance to the north of the village.

Groves, $\mathrm{H}$.

1837 Map of the Republic of Texas Showing its Division into Counties and Latest Improvements to 1837 . $\mathrm{H}$. Groves, N. 0 .

A Waco village is west of the Rio Brazos just south of its juncture with the Rio Bosque. A Touwiash village is on the Wishetaw River, south of present Wichita Falls.

Upshur, H. L。

1841 Sketch showing the Route of the Military Road from Red River to Austin. Col. Wm. G. Cooke, Commanding, Wm. H. Hunt, Engineer, 1840, Drawn by $\mathrm{H}$. L. Upshur.

A Waco village is on the west bank of the Brazos River just south of its juncture with the Rio Bosque. A Toweash village is on the Brazos River a short distance to the north and at the extreme southern portion of the Eastern Cross Timbers.

Burgvin, E.

1846 A Chart of the South Western Region Extending From the Arkansas to the Colorado From Actual Survey. Notes of Capt. Boone, USA and instructions Received From Other Authenticated Sources.

According to the scale included on this map, Tiwocknies and Wacoes are situated some seventy to eighty miles west of Bird's Fort on the upper Trinity River. A Wichetaw village is located on Cashe Creek in the Pilot Mountains in Oklahoma. A Toweash village is just west of the looth meridian and north of the Red River. The Keechies are on the Brazos River northwest of Comanche Peak. A Waco village is shown north of Bosky River and west of the Brazos. 
De Cordova, Jacob

$1850 \mathrm{~J}$. De Cordova's Map of the state of Texas Comm piled From the Records of the General Land Office of the state by Robert Creuzbaur, Houston, 1850. Engraved by J. M。Atwood, New York。

A village of Wichita Indians is situated at about the site of present Wichita Falls, Texas.

Kendall, George Wilkins

1850 Texas and Part of Mexico \& the United States, Showing the Route of the First Santa Fe Expedition. D. Boque, 86 Fleet street.

A Waco village is located on the Wichita River at the approximate site of present Wichita Falls, Texas.

United States Engineer Department, U. S. Army

1851 Map of the Route to the Indian Villages on the Upper Brasos, Made in June, 1851, by Col. Cooper and Major Sibley.

On the north side of the main Brazos River but below its junction with the Clear Fork are shown Waco and Tawaconi villages. A short distance to the east, and on the north side of the Brazos, is a Keechi village.

Marcy, Randolph B.

1840- Map of the Country Between the Frontier of Arkansas

1852 and New Mexico Embracing the Section Explored in 1849 , 50, 51, \& 52 by Capt。 R. B. Marcy, 5th U. S. Infy. Under Orders From the War Department. Ackerman Lith., New York.

On the Brazos River below Fort Belknap are Towockonies and Wacos. In what is now the state of Oklahoma, an old Wichita village is shown on Cashe Creek near Mount Scott. Due east on Rush Creok are Waco and Wichita villages.

United States Engineer Department, U. S. Army

1852? Map of the Country Upon Upper Red River Explored in 1852 by Capt. R. B. Marcy, 5th U. S. Inf. Assisted by Bvt. Capt. G. B. McClellan, U. S. Engineers Under Orders From the Head Quarters of the U. S. Army. Ackerman Lith., N. Y.

An old Keechi village and an old Wichita village are depicted on the East Fork of Cache Creek near Mount Scott in present Oklahoma. A Waco and a Wichita village are located due east of this area on Rush Creek. 
Marcy, Randolph $B$.

1854 Map of the Country Upon the Brazos and Big Wichita River, Explored in the Lands Appropriated by the State of Texas for the Use of the Indians. Published by the Brazos-Red River Historical Society, Museum of Midwestern University, Wichita Falls.

The following villages are shown in the area now comprised by the present state of Oklahoma: Witchita, Waco, and Towocoone $\theta$ villages at about 34 degrees 45 minutes north latitude and 98 degrees 5 minutes west longitude; and an old Witchita village at about 34 degrees 45 minutes north latitude and 99 degrees 10 minutes west longitude. 
PART III

Now Light on Wichita Culture

Subsistence

General remarks: The Wichitas had a mixed gardening and hunting subsistence. It is probably misleading to attempt to state which activity was the more "important." Garden produce was a more dependable source of food, and at least by the eighteenth century was an important item in trade. Hunting produced food, but also hides and other needed materials. Gardening activities were in the hands of women; bunting was done by men. Gardening was a spring and summer activity; hunting was mainly a fall and winter one. In short, these subsistence activities were in large part complementary. Even the addition of the horse to the system did not, so far as we can tell, adversely effect horticulture. The gardens remained large and the crops good right up to and into the reservation period. This may be because it was a womanly activity and because of 1 ts importance in trade. Gathering of wild plants was a supplementary activity.

Crops raised: The triumvirate of corn, beans, and squash were the principal crops. The documents are disappointing in that they do not reveal specific varieties.

The importance of tobacco has apparently been underestimated, La Harpe saying (Margry, 1888: Pt. 6, 294) that the natives cultivated a "prodiguous quantity of tobacco" which they pressed into flat loaves after pounding it. La Harpe was presented with some of these loaves. De Mézières (Bolton, 1914c: II, 201), Morfi (Chabot, 1932: 9) confirm that it was grown. Sibley (1832: 723) says: "Their tobacco they manufacture and cut as fine as tea, which is put into leather bags of a certain size, and is, likewise (i.e. like dried pumpkins), an article of trade." They received tobacco from Europeans as early as the mid-eighteenth century, but obviously the native grown product was not entirely displaced. Almost every list of items given or traded to the Wichitas includes tobacco.

None of the documents are clear concerning the gourdsquash-pumpkin-melon problem. Whether pumpkins (Cucurbita pepo) were the only squash grown is unknown. C. pepo is quite variable and we can only guess that their "icalabazas" and "calabashes" were too. That they possessed C. maxima

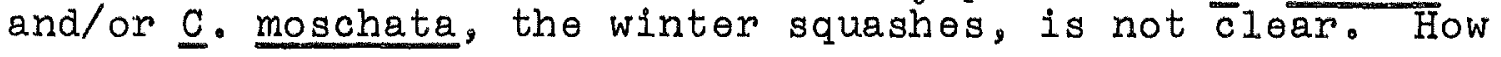


early they obtained the melons is difficult to decide because of the confusion of names, but it seems to have been after 1750. The musk melons (Cucumis melo), were originally Asiatic or at least not American, and watermelon (Citrullus vulgaris) is African, although some of the translations would lead you to believe the Wichitas had them from time immemorial. Parrilla in 1759, however, distinguished clearly between pumpkins and watermelons (see next section for quotation), the implication being that the French introduced this fruit. The next melon reference encountered is for 1772, De Mézières stating (Bolton, 1914e, I: 285) "Their crops are limited to maize, beans, cantaloupes, watermelons, and pumpkins." Morfi (Chabot, 1932: 9) a few years later says: "They also raise an abundance of water melons, melons and tobacco." Watermelons and/or melons are commonly mentioned as being grown in later years. See Sanchez, 1828 (1926: 266), Wheelock, 1834 (1834: 81), Catlin in 1834 (1841: 70), etc.

Size and Nature of Cultivated Land: Until the second half of the eighte日nth century, statements concerning the size and location of garden plots are distressingly meager even though it is clear that the women were skilled agriculturalists who produced bountiful crops. Parrilla in 1759, though vague, was the first European to remark about the extensiveness of agricultural operations. His account leaves the impression that a large acreage was under cultivation.

On the left flank of the position occupied by our troops were found some large areas of land with crops of corn that were in bloom and many crops of beans, pumpkins (or squash), and watermelons, all handsomely enclosed (by a palisade). (Testimony)

The Lipans, who Parrilla had sent out to scout for a convenient crossing place in the river, also reported corn fields up and down the river for a considerable distance. Could it be that fenced fields were the result of their acquisition of horses?

Even the frequent migrations and the general turmoil of the eighteenth and first part of the nineteenth centuries, and the more efficient hunting techniques made possible by the acquisition of horses and firearms, seem not to have caused any diminution in the agricultural productivity or the size of the fields. In 1834, for example, George Catlin (1841, II: 70) found them "cultivating quite extensive fields of corn (maize), pumpkins, melons, beans, and squashes; so, with these aids, and an abundant supply of buffalo meat, they may be said to be living very well." T. B. Wheelock (1834, I: 81), who was also a member of the Dragoon Expedition, was more specific than the 
artist, noting that approaching the Taovaya town (on the north fork of the Red River below the junction of Elm Fork) they,
- passed their cornfields on our way to their town; these fields are well cultivated, neatly en closed, and very extensive, reaching in some in- stances several miles. We saw also here, melons of different kinds, squashes, etc.

In 1841 George Wilkins Kendall visited a Waco village in what is now the northwestern part of Wichita Falls, Texas (Carroll, 1951: 89). Kendall said:

The viliage itself was situated at the western extremity of a large bend in the river, and although the bend must have been some five or six miles in length, by nearly two in breadth in the wider parts, every portion of it appeared to be under cultivation, and the land was extremely fertile. The purlieus of the village appeared to be kept clean, which can be said of few Indian towns (Kenda11, 1844, I: 137-138)。

Dorsey in 1882 (1904: 9) confirms the continuing importance of gardening, noting that

Even to-day their cornfields are not inconsiderable, and with encouragement would become a source of great profit to them; for apparently throughout their whole career they have been devoted to agriculture, raising large crops of corn, beans, melons, etc. The produce of their fields was, of course, supplemented by the flesh of the buffalo and other wild game, but unlike the more nomadic tribes of the north they were by no means dependent upon the buffalo. As among the Pawnee, many of their most important ceremonies were concerned with the cultivation of their fields.

Garden plots seem to have been located in valley bottoms, but information is not entirely clear on this point. If gardens were usually located in bottoms or on flood plains, and hence subject to annual flooding, their fertility may not have declined with long usage. In short, evidence is lacking which would indicate villages were moved because of declining ferm tility of the fields.

Irrigation: Oñate in 1601 (Bolton, 1916: 261) states categoricaliy that "The crops were not irrigated but dependent on the rains.." and Morfi (Chabot, 1932: 8) late in the eighteenth century also says the Wichitas were unaware of the advantages of irrigation. But two accounts suggest that crops were sometimes irrigated or could be. Parrilia in his attempt to defeat the Wichitas in their palisaded village on Red River in 1759, sent the Lipan up and down the river to 
find an easy crossing. But they saw only the fields and crops of corn located on the south side of the river because irrigation was easier on that side (como el mas facil para el riego)... Parrilla also stated that the corn was "in bloom," probably meaning that it was tasseled out. But that this should be the case in the latitude of Spanish Fort in October is an anomaly, unless irrigation was indeed practicod.

De Mézières visited this same site (?) in 1778, and left a rather puzzling statement about irrigation:

The abundance of the springs furnishes them fresh and crystalline, water to drink, moistens and fertilizes the broad plains where they plant their crops, and offers itself to anyone who may irrigate them. (Bolton, 1914c, II: 202)

Methods of cultivation: There is very little information concerning the tools used or the techniques involved in growing crops. The reason seems to be that they had only simple tools, and the women never shared their know-how with others. Marcy (1853: 77) in 1852 has one of the best statements:

These people have no ploughs, or other agricultural instruments, but a small hoe, with which they prepare the ground for the reception of the seed, and do all other necessary work in its cultivation; yet the prolific soil gives them bountiful returns.

Mollthausen in the following year (1858: 116) made much the same kind of comment:

These Indians practice agriculture; and beans, peas, maize, gourds, and melons are seen prospering very well round their villages, though their only agricultural implement is a small rake. With this, they manage to get a little seed into the ground, and the fruitful soil repays the trifling trouble with the most abundant harvests.

Hunting: Very little can be added. Bison were the chief game animal. No descriptions of hunting methods were encountered. Sibley (1832: 723): "their meat is principally buffalo; they seldom kill a deer, though they are so plenty they come into their villages, and about their houses, like a domestic animal." Bear hunting was mentioned by Sanchez in 1828 (1926: 265). Möllhausen, in 1853 (1858: 116): "They are skilful buffalo bunters, and, like most of the prairie tribes, shoot their game with arrows from their horses." 
Gathering: In 1601 Oñate remarked on the presence of plum trees between the cultivated fields (Bolton, 1916: 261), and this fruit is mentioned in later centuries (Wheelock, 1834: 81, for example). The inference in oñate is that the trees were being cared for, perhaps to be regarded as the first step toward domestication. De Mézieres in 1772 referring to Kichais (Bolton, 1914e, I: 285-286) mentioned that "they likewise provide themselves with various wild products, especially nuts and medlars (crab apples), from the latter of which they make a kind of bread that is very palatable; and they do not despise even acorns."

The Wichitas did not eat fish (Bolton, 1914c, II: 202).

Salt deposits in the Red River, and other places, were used. (Bolton, 1914c: 203, 191; Chabot, 1932: 9).

Preparation and Preservation of Food: Coronado (Winship, 1896: 852) said the wichitas ate "raw flesh" like the Apaches. Oñate (Bolton, 1916: 258) was presented with "round loaves of bread, as large as shields and three or four fingers thick, made of the same maize." A number of references to this unleavened corn-bread-tortilla type of preparation may be found, none of them very detalled. Green corn was roasted (Catlin, 1841: 72, for example), and corn was used in dishes with beans and buffalo marrow (Margry, 1888: VI, 295). Pumpkins and presumably other foods were boiled in earthen pots (Kendall, 1844, I: 137). This source, incidentally (ibid., p. 138), states that all cooking was done outdoors.

Meat was smoked and/or dried. Pumpkins were the most intriguing type of preserved food. De Mezieres in 1778 (Bolton, 1914c: II, 201): "They preserve the latter (calabashes) from year to year weaving them curiously like mats." Sibley (1832: 723) says:

- . the pumpkins they cut round in their shreds, and when it is in a state of dryness, that it is so tough it will not break, but bend, they plat and work it into large mats, in which state they sell it to the Hietans (Comanches), who, as they travel, cut off, and eat it, as they want it.

Butier (1928: 495) in 1870 said:

They (the Wichita women) were all very busy, drying pumpkins and squashes, cutting them to narrow strips and pounding them out thin and, when dry, weaving them up like splint bottom chairs. 
In the nineteenth century, but undoubtedly earlier as well, surplus produce was stored in cache pits. Jose Maria Sanchez, a member of the Berlandier Expedition, when at the modern site of Waco, Texas, remarked:

In winter the women hide the agricultural products in holes which they make in the ground, and the whole tribe sets out to hunt the buffalo and wild bison. (1926: 266)

De Mézières in 1778, stated: (Bolton, 1914c, II: 201)

Their foresight in supplying provisions shows them to be industrious, for there is no house in which at present there may not be seen four or five vessels full of maize, each one estimated at four and a half fanegas, besides a great quantity of beans and calabashes.

They also stored corn in deer, antelope, and wolf skins (Kendal1, 1844, I: 137).

Annual Round: La Harpe in 1719 is the earliest source to report the dual subsistence pattern of the Wichitas--a sedentary gardening existence from spring through harvest in the fall, a nomadic hunting life from late fall until spring. His statement ". . that these people were leaving all their villages after the month of october in order to go on the chase, from where they returned only in the month of March in order to sow their maize, beans, and pumpkins, from which they feed themselves in the summer" (Smith, 1959: 531) strongIy suggests that the villages were abandoned completely and not that hunting parties left them for longer or shorter periods of time. Considering the abundance of game in the early years, and the transportation difficulties which the then pedestrian Wichitas must have had, the possibility seems good that the nomadic hunting phase was less emphasized or perhaps shorter in pre-horse times. But when La Harpe visited them horses were still not plentiful, and there is no other evidence which would suggest that the dual subsistence pattern was a new one.

The horse complex: Sometime after Oñate's visit to the Wichitas in 1601 and before La Harpe's and Du Tisnés visits in 1719, the Wichitas obtained horses and became horse-using. According to Du Tisné (Margry, 1888, Pt. 6: 314), before the Comanches had blocked the way, the Wichitas had gone to the Spanish settlements, presumably acquiring horses there. It is thought that Comanches moved into the southern plains about the beginning of the century, hence this would have the 
Wichita visits to the Spanish settlements taking place in the seventeenth century. The two viliages Du Tisne visited had 300 horses which they valued highly, none of which they wanted to part with (ibid.: 312). But Du Tisné was able to trade for a mule with a Spanish brand, two horses, and an old silver cup. La Harpe was ceremoniously greeted by the principal Tawakoni chief and six other chiefs, and they were mounted on beautiful horses, saddled and bridled in the Spanish manner (ibid.: 288). When they entered the village they had La Harpe mount a fine horse; he later learned that

- . these natives raise very beautiful horses; they prize them highly, being unable to do without them elther for war or for the hunt; they have saddles and bridles which are very well made, and carry even leather breast plates as protection from arrows. (ibid.: 294, tr. WWN)

La Harpe also noted (ibid.: 279) that the Cancy (Lipan) had an advantage over their enemies, who included the Wichitas, in having good horses, while their enemies had few of them, and that horses came from or by way of the Lipans. (". et encore viennent-ils de la deroute de leur adversaires!)

It would seem, then, that by 1719 the Wichitas were entirely familiar with horses, and apparently the techniques of horsemanship and horse care. But horses were not so plentiful that they wanted to trade them. The probabilities would seem to favor the Wichitas first acquiring horses after 1650, perhaps after 1675, directly from the Spanish sources, but also at least in later years from the Lipans.

One of the advantages of alliance with the Comanches was that it gave the Wichitas better access to horses than they had had before. Sandoval in 1749 (Sandoval manuscript) noted that the Wichitas "own some horses given to them by the Comanches," and he met a Comanche coming to the wichita villages to trade a horse as well. Ten years later Parrilla made some pertinent comments on Wichita horsemanship:

- . the Indians who fought on horseback were accompanied by a foot soldier at both sides who carried extra firearms, so that when the horseman fired, one of the foot soldiers handed him a loaded musket; then after the horseman charged, and as he retreated, the foot soldier would cover any counter charges.

The paramount war chief demonstrated ". . great skill in horsemanship and the handling of his weapons which consisted 
of a lance and muskets which his foot soldiers provided .. . . His mount was the best found anywhere for the type of warfare (we have described)."

By the end of the eighteenth century the Wichitas were well supplied with horses, and they maintained large numbers up to 1850. By 1824 "A small plug of tobacco was the price of a horse and a plug and a half that of a mule" (Kuykendall, 1903: 248). Horses were used in hunting and war; no account of usage as food has been discovered.

\section{Dress and Ornament}

Nothing new was discovered about this aspect of Wichita culture. A few items are mentioned below simply because we found them interesting.

In a letter signed "De Gannes" and dated at Montreal, Canada, 10-20-1721 is found the following (Pease and Werner, 1934: 388):

These two nations (Pawnee and Wichita) have an abundance of turquoises, looking like our little glass beads. They make use of them as ornaments hung from their noses and ears, spinning out the beads to the length of a finger with buffalo sinew, afterwards joining the two ends together, at the bottom of which they hang a turquoise, triangular shaped, of the thickness of about two crowns and not quite as big as a half-franc piece. They call them their pendants and esteem them, according to their beauty, of the value of a slave, who in those regions is worth sometimes a hundred francs.

A quotation concerning tattooing we had not seen before (Gregg, 1844: 305-306):

They are chiefly remarkable for their profuse tattooing, whereby they have sometimes acquired the title of 'Pawnee Picts': the females particularly make a perfect calico of the whole under-jaw, breast and arms, and the mammae are fancifully ornamented with rings and rays. The tattoo, in fact, seems to constitute the chief female ornament of these tribes; for their only gown consists of about a yard and a half of strouding, or else a small dressed skin, suspended from the waist, and constituting a sort of primitive petticoat. The upper part of the body remains uncovered, except by a blanket or small skin, thrown loosely over the shoulders. 
The men are often without any other vesture than the flap, and sometimes a buffalo rug or blanket.

By nid-nineteenth century on the Texas reservation, the dress of the Wichitas reflected pretty well the state of their culture. W. B. Parker, no doubt a paragon of sartorial elegance himself, remarked:

A son of the old Chief (i.e., Ak-a-quash) made his appearance last, in full court costume, and a most laughable sight he was.

He had on a pair of moccasins, leggings made out of an old greasy, summer sackcoat, over which he wore an old fashioned full uniformed infantry coat minus one tail, the other, as Ak-a-Quash told us, having been cut of by one of his comrades to get at his bottle of whiskey, whilst he lay drunk and asleep at Fort Belknap. His face was painted half a dozen colours, his ears loaded down with large brass rings, and with a shock head of hair, to one of the side locks of which was attached an old red worsted comforter, he presented the most ludicrous figure imaginable, more particularly as he seemed so well pleased with himself, and strutted about like a young turkey cock. (p. 112)

A woman's attire (ibid., 114): "One of the squaws had not an article of clothing on her but an old filthy rag round her loins, and a gay calico sun bonnet on her head."

\section{Tools, Implements, and Weapons}

Only a few items were discovered which add to or supplement what is already known about these aspects of Wichita culture.

Stone metates and manos were reported in the 1780 's by Morfi, who also reported that clay was used for pipes. But no mention was made of pottery or other ceramic articles. Perhaps the Wichitas had already abandoned the potter's art. Kenda11 in 1841 found a musical instrument (1844, I: 134-144):

In one of the main buildings an instrument, evidently intended for musical purposes, was found. It was made of cane, and in some respects resembled a fife, although much longer. It had five holes for the fingers, besides a mouth-piece somewhat after the fashion of a clarionet. The notes of the instrument 
were nearly as soft as those of a flageolet, the workmanship extremely neat, and evincing not only ingenuity, but taste.. 。

The bow and arrows were the standard arm of warriors, but we have not run across a single detailed description. The bow and arrow continued in use, particularly for hunting, becaus $\theta$ of the scarcity of firearms and/or the need to conserve powder and shot. In addition, they used "the lance, the sword, the dagger," and they had "for defensive arms the leather shield and a kind of heavy cap which serves them for a helmet" (Bolton, 1914a, I: 174).

In 1823 a war party of some 700 Wichita warriors was described by an eyewitness:

Each Indian was armed with a short gun, a bow and arrows, and a lance; some had pistols, and each had two horses, one of which he rode for marching, and one, his war horse, which he led, for the battle. (James, 1916: 215).

Other useful references follow:

1805 (Sibley, 1832: 723) The Wichitas "... are good hunters, have guns, but hunt principally with the bow . . ."

1837 (Winfrey, 1959: 23) The Wichitas" . . travel altogether on horseback armed mostly with the bow and lance, what fire arms they have are smooth bores or traders guns of little value and seldom used."

\section{Houses and other Structures}

Grass lodges have been described more thoroughly than any other aspect of Wichita culture. Dorsey in 1882 (1904: 4-5) probably contains the best description. Little, if anything, can be added to what he says. Here, we will simply quote descriptions which add detail or are unique in some way.

Jaramil10 in 1541 (Winship, 1896: 591) after describing the round grass lodges added:

they have something like a chapel or sentry box outside and around these, with an entry, where the Indians appoar seated or roclining.

Castañeda in 1541 (Winship, 1896: 528-529): "The houses are round, without a wall, and they have one story like a loft, 
under the roof, where they sleep and keep their belongings. The roofs are of straw."

La Harpe in 1719 (Margry, 1888: Pt. 6, 294-295):

Their huts are raised, the majority of straw and reeds, plastered with earth, forming a dome; above their doorway, each tribal chief has his arms painted on a piece of round hide; some represent the sun, the moon, or the stars, others different animals.

De Mézières on the upper Trinity and Brazos in 1772 said of the Wichita village (Bolton, 19140, I: 294): "The present houses of the ouedsitas, through lack of wood, are made of earth, and are wretched and uncomfortable."

T. C. Battey in 1872 (1876: 53-54) carefully described Wichita dwellings. He remarked, perhaps significantly, that, "These grass houses are only used as summer residences, being too airy for winter use, and are from twenty to thirty feet in diameter."

If La Harpe was accurate, and wattle and daub houses were constructed in 1719, it would appear likely that they would have been adequate for winter use. Would they have abandoned daubing their houses? In the $1780^{\prime} \mathrm{s}$, at least on occasion, they remained throughout the winter in their twin villages on the Red River. Did they shiver or plaster over the grass lodges?

\section{House Furnishings}

Dorsey (1904: 4-5) has a detalled description of this aspect of Wichita culture. These references supplement his account. Sanchez (1926: 265):

The floor is covered with small bundles of grass, leaving a part uncovered in the center for the hearth or fireplace which is directly under an opening left in the top of the house.

Wheelock (1834: I, 8I): ". . in the centre of the floor a shallow excavation serves as a fireplace; around the sides are comfortable berths, large enough to accomodate two persons each."

Kendal1 (1844: I, 138):

Within many of the houses, at an elevation of four or five feet from the ground, was a row of berths 
extending nearly the whole circuit, and very neatly got up. The bottom of these berths appeared to be of rough basket work, the frame which supported them being of large poles. As all the cooking for the family was done out of doors, their lodges had neither fireplaces nor chimneys.

Marcy (1853: 77):

The interior arrangements are such, that every person has a bunk, raised from the ground and covered with buffalo-hides, forming a couch which is far from being uncomfortable. When seated around their fires in the centre of the lodges, they have an air of domestic happiness about them which I did not expect to find.

Möllhausen (1858: 115):

A place is hollowed out in the centre for a fireplace, and round this, and a little raised, are placed the beds of the inhabitants of the hut; which when covered with good buffalo skins, make tolerable resting-places. Each of these wigwams is generally occupied by two families.

\section{Special Structures}

Kuykendall in 1824 (1903: 248): "The largest of these lodges (their council-house), was fifty-nine paces in circumference."

Sanchez (1926: 265): The Tawakonis and Wacos, "have two kinds of houses, one of straw and grass, where they make their permanent quarters, the other of buffalo skins, which is moveable. Those of straw are conical in shape, about twenty-five feet in height and forty feet in diameter."

Kendal1 in 1841 (Kenda11, 1844: I, 138):

Attached to each residence, and immediately in the rear, was another building of smaller dimensions, the lower part of which was evidently used as a corn-crib and storehouse. In these buildings were found a quantity of corn and pumpkins, besides finely-cured venison, antelope and buffalo meat. Above the corn-crib was a species of balcony, although without a railing, and this led into a small room in the second story, if I may so call it. One of the company said that this room was the sleeping apartment of the young and marriageable squaws of the family, and that their mother kept a ladder by which they climbed up to it at night and were let down in the morning. 
Dorsey (1904: 6), it will be recalled, differentiated between the corn drying arbor and the platform on which the maidens slept, describing the latter as smaller. Dorsey also described another structure, saying (1904: 5):

At one side of the lodge, in well-to-do families, was a large summer arbor, built like the grasslodge, but of $\theta$ longated shape, and with open sides to a height of about four feet. These arbors were often of great size, and were provided with a platform raised a foot ( $p$. 6) above the ground. Here they worked and rested in the shade during the summer months. It was under such a 'ramada' or 'antichon,' as the French called it, that La Harpe and his men were entertained.

Curtis (1930: XIX, 38) a little more specifically, said of these arbors:

The frame was solidly constructed by first erecting a number of crotched poles in a rectangle, then laying timbers in the crotches. Next, long cedar poles were set vertically against the timbers, one end sunk in the ground and the tops tied together. Lashed to the cedar posts were many horizontal rows of saplings to support the thatch of grass on the roof and upper portions of the side walls. The thatched cover only formed a dome-shape roof, leaving a large open space between it and the ground. The arbors were generally much more roomy than the houses. Their shapes were usually twice as long as wide; but their size, like that of the regular dwellings, depended on the number in the family.

Kendall (1844: I, 138) also mentioned what seems to have been a chief's lodge:

Near the centre of the village was a house of larger dimensions, and more elaborate workmanship than any of the other dwellings. This may have been the general council-house, or the abode of the medicine man of the tribe, or it may have been the residence of their principal chief, who must neods, as is the custom in more civilized nations, live in better quarters and more costiy style than his subjects. 
Fortifications, Spanish Fort

Parrilla in 1759, who, of course, only saw the palisaded village from a distance said:

- . we clearly discerned a town of tall, ovalshaped huts oncircled by a stockade and a ditch. Its entrance road was enclosed in the same manner and in addition it zig-zagged intricately, with its gate at the aforementioned river, whose waters flowed by with a depth of more than a yard and a third. Crowning the front of the stockade were Indians armed with muskets....

All of our people saw and distinguished the French flag that was waving in the center of the fenced place... .

And one could see that one part of this village was the part which was fortified and that the other part was uninhabited; all the inhabitants having run to the site of the fort.

Treviño's description of the palisaded village is the most complete one we have. On questioning, he said

hundred and forty leagues away from san Sabá, live settled in a village situated on the other side of the river which flows through this surrounding territory and empties into the Mizisipi. In the middle of (this settlement) is the fortress they built to resist Colonel don Diego Ortiz Parrilla's campaign. It is made of split logs, which the Indians have placed separate one from the other in order to make use of muskets, the weapons they use, through them. The witness is certain, because he saw this during the six months he lived there... Said fortress is completely surrounded on the outside by an earthon rampart, close to more than a vara and a third in hoight, which serves them as an entrenchment, and, about four paces to the east and west, a very deep trench made so that no one can come close to (the fortress) on horseback. Inside there are four subterranean apartments occupying all of its circumference, into which all of the people who cannot help with the defense of the, said settlement 
retreat in time of invasion. (Letter from Fray Joseph de Calahorra y Sanz to Governor Navarrete, (translations); Bexar Archives 3-20-1765; UT Archives.

In later years, others alluded-often with questionable accuracy--to the palisaded village. In 1859. Captain W. A. (Bud) Morris, as quoted by McConnell (1933, I: 17) said:

After the West Texas frontier began to be settled, a number of citizens built their little log cabins not a great many miles from 'old Spanish Fort'. Captain W. A. (Bud) Morris who was numbered among these early settlers, stated that he visited these dilapidated old relics of a former civilization in 1859. At that time a part of the walls were stili standing. They were circular in form and punctured with portholes approximately four feot from the ground. These ruins consisted of about six circular fortifications. They were located ap proximately one hundred and fifty yards apart, and situated on an imaginary line running north and south.

An unsigned article in a high school paper ("The Signs of the White Man," The Eagle, Spanish Fort High School paper, Spanish Fort, Texas, Centennial Edition, May 10, 1935, p. 7):

Near the home of John Evans on the Boland estate, we find the evidence of the white occupancy. European pottery, knives, parts of swords, earthen walls, etc., may be found here. Uncle John Le日, who first cultivated this field reports that the walls of the old fort were very much in evidence in 1897. Logs were there, giving evidence that the inner walls were bulit of them. Their cooking ovens have been locatied by a large amount of ash and burned bones. Near this, burnt clay, or bricks, have been found.

Guy R. Donnel. (1940: 102) stated:

According to remains excavated at Spanish Fort, old Fort Theodoro was octagon in shape and $a$ bout seventy-five yards across, with an underground room in the center. Burried bricks and ashes were found at the northeast side of the fort, which shows that sections of the fort may 
still be seen on the farm now owned by Wash Ayers.

Apart from the precise location of the palisaded village on the Red River, the question of whether such fortified villages were aboriginal or were planned or fostered by French traders is unsolved. It should be noted, too, that the occupants of the twin Tawakoni Iscani village on the Sabine in 1760 were building a fort comparable to the one on the Red River (Calahorra, Diario, 10-24-1760). We believe that the weight of the evidence favors their being aboriginal. This does not mean that every Wichita village was fortified or that the French did not exert some influence on the construction of the Red River village. Palisaded villages were common in the Eastern Woodlands and to some Prairie tribes, so that it is not unreasonable to find the custom practiced, or at least known to the wichitas. After all, the Wichitas were severely challenged in the second half of the eighteenth century by both the Spaniards and Indian enemies. Unprotected grasshouse villages were easy marks for raiders, so that the compulsion to build some sort of defensive fortification must have been considerable. That the French had to show them how is not persuasive.

Other fortifications: Wilbarger in 1829 (1889: 174) reported that a Waco village at Waco," ".. had built a kind of fortification by scooping out the ground and raising a circular embankment around the depression thus formed, several feet high." He also reported that the Tawakonis built small stone enclosures in Limestone County for defense (ibid., 177-178). Paddock (1911, II: 772) said that fortifications "were said to exist in Waco as late as 1872, in the vicinity lying north of Austin street." Kenney (1898: I, 745) reported that there was a circular earthwork in Waco, which a few years ago was still visible."

\section{Social Organization}

This project has discovered nothing which materially alters, and surprisingly little, which adds to knowledge of Wichita social organization. This is partly because Dorsey (1904) and Schmitt (n.d.) have provided excellent descriptions of this aspect of culture, and partly because ethnohistoric sources seldom provide the kinds of data which reveal details of social organization. 
Captives and Cannibalism

The treatment of captives has been misinterpreted by modern investigators, more by sins of omission than commission. Newcomb (1961: 258) says only, for example, that captives were "sometimes eaten." The facts are that during much of the eighteenth century captives of both sexes and all ages were often and perhaps customarily eaten. Despite the lack of data from earlier centuries, anthropophagy would seem to be an old custom. The rationale for cannibalism is unknown.

La Harpe in 1719 was the earliest source to mention cannibalism. In this case he was given an eight year-old Lipan, a finger from each of the captive's hands having been eaten as a mark that he (or she) was to be eaten at a later date. The Tawakoni chief apologized for having only one slave to give La Harpe, saying that if he had come a moon sooner he would have presented him with seventeen Lipans, but these had been eaten in a public feast (Margry, 1888: PT。6, 292). Sandoval at midcentury was repulsed by the treatment accorded captives, stating that the Wichitas" ". eat all prisoners of war, since their favorite dish is human flesh. During my stay with them (20 days) I saw them eat a fifteen yearold girl and an infant whom they had captured from another nation." There are many other allusions to cannibalism not mentioned here.

Harper (1953, SWQ: 3) argues that cannibalism was abandoned because it was more profitable to sell captives to the French than to eat them. But during the years when this trade was at its liveliest cannibalism was still practiced, and the custom was continued after Indian slavery in Louisiana was abolished in 1769. The last reference to cannibalism we have found was in 1773: "When they take a slave capable of return ing they broil him and eat him" (Bolton, 1914, II: 853). The evidence would seem to indicate, then, that the economic value of captives may have played a part in the abandonment of can nibalism, but that it was not the only or perhaps even the major factor.

Ritual cannibalism, that is, the eating of human fiesh for magical or similar reasons, was practiced at least sporad ically by the neighboring Lipans, Tonkawas, and Caddoes

(Newcomb, 1961: 126, 150-152, 308). One would suppose that Wichita cannibalism would also be of this sort, but the docum ments do not reveal it. If cannibalism was practiced for non-gustatory reasons, it may have been for revenge. J.Gaignaird said in the $1770^{\prime} \mathrm{s}$, for example, that the wichitas were

- In general more revengeful for injury than grateful for benefits, as is proved by 
the atrocities which their prisoners experience at their hands, which are so great that even to relate them would cause horror and make the narrator a party to them. (Bolton, 1914 C, II, 204)

Political Organization

Our study alters to some degree the traditional conception of the Wichitas as being composed of four or five distinct tribes which were forced to consolidate as a result of European conquest. Our data suggest that it would be more accurate to view the Wichita peoples as being grouped into a variable number of autonomous villages. Europeans, probably following Wichita custom, applied designations to related villages, but with the southerly movement of the wichitas in the seventeenth and eighteenth centuries, their consolidation, extinction, and the confusing assortment of names applied to them by Europeans, the nature and relationships of all the subdivisions are difficult to discern. It seems highly probable that all of the Wichita villages, save those of the Kichai, were very similar culturally.

In 1719, La Harpe visited a Tawakoni (Touacaras) village at which were gathered representatives from other "Wichita" villages. Recognizable are the Taovayas (Toayas), Wichita proper (Ousita), and Iscani (Ascanis). We would guess that the Caumuche, Aderos, Quataquois, Quicasquiris, and Honechas are Wichita villages which either did not persist, or were known by other names in later years. La Harpe also learned that there were two Iscani and Ousita villages located to the north-northwest some sixty leagues. This may refer to the "Pani" villages visited by Du Tisne in the same year, perhaps in what is now Kay County, Oklahoma. Although it would be foolish to make much of this evidence, the southerIy or southeasterly location of the Tawakoni with respect to the other Wichita villages is already apparent.

Thirty years later Parilla, between San Saba' and the fortified Taovaya village on the Red River, ran across a num ber of abandoned "rancherias," some of which may have been Wichita. The fortified village on the Red River was Taovaya and it

- - received constant assistance from those (Indians) who in anticipation (of our arrival) lived close by; and (aid also came) from the Yascales who lived in a town similar to the one mentioned previously, and at a very short dis tance in an eastward direction from the Tahuayan town. . . we learned that the enemy forces included Indians from the Tahuayan nations, as well as leaders from the Comanche, Yascales, Tehuacanes, and many other northern nations. . 
In the last three decades of the eighteenth century, a tripartite division of the Wichita clearly emerges. Generalm Iy to the north was a Taovaya-Wichita division; to the south and southeast were the Tawakoni-Flechazos. The Iscanis were now affiliated with this division, but seem not to have been in earlier years. The Kichai were more easterly and continued to be distinct from other Wichitas. The consolidation con tinued in later years with population decline and continued migration. We have not pursued nor have we discovered what was the earlier designation for the Waco. Bolton (1910c, 2: 888) derived them from either the Flechazos or Quiscat villages. The Iscani, if they are not one of these two villages, would seem to be an equally good candidate.

Some of the references to Wichita divisions and the trend to fewer named units follows:

In 1786 (Ugarte to Cabello, 5-24-1786) Guersec was chief of the Taovayas and also apparently of the Wichitas in that he sent ten of his men and some Wichitas (Wichita proper) to see Ugarte. They were then moving to a site ". " near the Taguacanes, Yscanis, and Flechazos, their friends and kinsmen - . With this neighborly move, the friendship and the union among these tribes had been strengthened."

1805 of the Kichai (Sibley, 1832: 722): ". . have their peculiar native language . .".

1824 (Kuykenda11, 1903: 248) "The Wacoes and Tawacanies spoke the same language, and were essentially the same people."

1852 (Marcy, 1853: 78) Wacos: ". . the habits and customs are similar to the Wichitas, with whom they frequently intermarry, and are upon the best and most friendly terms."

1853 (Möllhausen, 1858: 115): "The Wakos and Witchitas differ only in name, and in some slight varieties of dialect. . .

1860 (Schoolcraft, 1-860, I: 518): "The Hitchies (Kichai), once a distinct and isolated tribe, have so inter. married with their neighbor bands, that they have lost their identity, and may be considered as merged into the common stock."

\section{Greetings}

La Harpe was greeted quite ceremoniously at the Tawakoni village in 1719.

Upon arriving at this village, the chiefs who 
had accompanied me, had me step to the ground a musket shot from the Tawakoni chief; then two important persons carried me on their shoulders, their faces turned toward the ground; they put me on a buffalo robe, spread upon a plank. Then, all the principal. Indians made a circle around me, and each one of them put his hand in mine as a mark of good will. When my packs were in the lodge, I made my present to the Tawakoni chief; it consisted of some muskets (fusils), powder and balls, hatchets, knives and aunes of cloth. Although he was surprised to see so much merchandise, nevertheless he showed no emotion, maintaining his air of gravity, although he was only about twenty-five jears old. In order to demonstrate his gratitude, he gave me a crown of eagle feathers, decorated with little birds of all colors, with two calumet feathers, one of war and one of peace, the most important gift these warriors may bestow.

Catlin more than a century later, recounted another manner of greeting strangers:

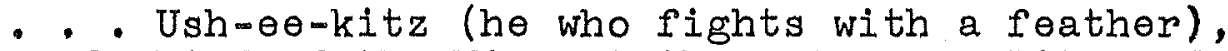
head chief of the Wi-co tribe, a very polite and polished Indian, in his manners, and remarkable for his mode of embracing the officers and others in council.

In the different talks and councils that we have had with these people, this man has been a conspicuous speaker; and always, at the end of his speeches, has been in the habit of stepping forward and embracing friends and foes, all that were about him, taking each one in turn, closely and affectionately in his arms, with his left che日k against theirs, and thus holding them tightly for several minutes.

\section{The Calumet}

La Harpe in 1719 mentions that this ceremony was held for him at the Tawakoni village. Over 7,000 people of eight "nations" plus some nomadic tribes were present. It included sperches by chiefs explaining the importance of alliance with the French, recitation of military prowess by warriors, dances, and chants. Duration of the ceremony was from eight in the morning until two the next morning. It was held under an arbor, but unfortunately, La Harpe did not leave other details. Calumet ceremonies were widespread in the Mississippi Valley, and it is not surprising that the Wichita possessed it. Cabello in 1785 mentions what is probably an 
abridgement of the calumet (Cabelio to Rengel, 5-20-1785, Bexar Archives):

- . the 27 Indians representing the Taboayazes and Guachitas tribes arrived. Their leader came forward, displaying the Great Pipe, which his chief had given him as credential to prove he was sent as an official representative. Before any discussion was held clarifying the meoting's purpose, they smoked on this pipe, all of which is part of the usual ceremony showing a delegation's official status.

After this ridiculous ceremony, in which I did not participate, because I have always abhorred smoking, I asked them why they were here. Their leader replied that they came to thank me on their Chief's behalf for naming him chief( $i_{0} \theta_{0}$, Guersec of the Taboayazes and Guachitas). (They also wanted to thank $m e$ ) because I had offered him and his people a gift to be made on the moon of June at Nacogdoches.

General Comments on Nature, Mores, Et Cetera

Comments about the "nature" of other people often reveal as much or more about those who are making the comments. In any case, some of those statements which seemed pertinent follow:

1541. Relacion del suceso, (Winship, 1896: 577): "Al1 that there is at Quivira is a very brutish people, without any decency whatever in their houses nor in anything."

1749. Sandobal (Sandoval manuscript): "The natives are pagan and practice no conventional social graces, but they are good natured."

1770. De Mézières (Bolton, 1914d, I: 217):

of the Quitseys (Kichais) I have nothing to say except that they are most docile and wellintentioned, and that, having taken part in the hostilities only once, this being when the mission of San Saba was sacked (an event in which they participated through accidentally being with the others), they have since steadfastly refused to have a hand in any of the disturbances which the hostile nations have been plotting. 
1772. De Mézières (Bolton, 1914e, I: 295) (concerning Wichitas and Taovayas):

Sad it is that the good seen in these Indians serves only as a counterweight for their evil inclinations, such as the barbarous treatment of their captives, their incestuous and base intercourse, and other abominations. But (p. 296) through association and familiarity with us they will desist from these and become reduced to civilized life, as their docility promises.

1778. J. Gaignard on expedition up Red River (Bolton, 1914c, II: 204):

They are cheerful, affable, and docile in their manner, compassionate toward the sick, orphans, and widows, respectful to their elders, generous toward strangers, kind to guests, but in general more revengeful for injury than grateful for benefits, as is proved by the atrocities which their prisoners experience at their hands, which are so great that even to relate them would cause horror and make the narrator a party to them.

1841. George Wilkins Kendall (1844: I, 140):

- . while the Wacoes did not exhibit any of those fruits of civilization which too often mar the virgin leaf of those other nations, I confess that I saw evidence of a more elevated kind of humanity than I had supposed was to be found anywhere among the original Americans.

\section{Ideological system}

No new information was uncovered which adds to or alters what was already known about this segment of Wichita culture. Dorsey (1904) has covered the subject thoroughly.

The first attempt to describe Wichita religious beliefs was by La Harpe (Margry, 1888), who ridiculed it to some extent, but he also noted their belief in a "great spirit," the importance of first fruits ceremonies, and their ideas of the afterworld.

See also De Mézières in Bolton, 1914e, I: 295; Fletcher and La Flesche, 1898. 


\section{APPENDIX I}

\section{Synonymy}

The following synonymy represents a selected listing of names attributed to separate Wichita groups from initial contact until the twentieth contury. Without exception, an attempt has been made to present each name as it appears in its original document. In those instances wherein primary sources were not available, secondary printed sources were utilized.

Specific names were taken only from those sources providing material for the present work. Different spellings for the same groups can be found in other sections of the works that were consulted. In the Bexar Archives, for example, two or more spellings for an identical group can be found in a single document. Since standardization of spellings of certain Wichita groups has not been completely accomplished even today, such a circumstance is not entirely unreasonable.

As a measure of utility as well as of clarity, a fourfold grouping has been established for the various Wichita designations: French, Spanish, United States, and Indian, This procedure has been followed even for those persons of one nationality working for a government of another nationality, with designations being made according to the nationality of the country involved rather than that of the person.

The primary purpose of this synonymy has been to provide a representative sample of the names most often utilized in referring to the Wichita. A comprehensive listing would have been virtualiy impossible as well as undesirable. It is felt that the following list contains the designations most likely to be encountered in conducting research concerning wichita Indians.

\section{France}

Iscani

Ascani (La Harpe in Margry, 1888: VI, 289, 290, 293). Mento (Beaurain in Margry, 1888: VI, 289n).

Taovayas

Jumanos (Febre et al., 1749; Thomas, 1940: 107). Mento (Beaurain in Margry, 1888: VI, 289n). Pana (Garraghan, 1927: 312)。 
Paniassa (Garraghan, 1927: 312; Delisle, 1718?).

Paniassey (Pease and Werner, 1934: 388 ).

Panipiques (Febre et al., 1749).

Panipiquees (Sandoval, i749).

Panipiquets (Febre et a.l., 1749).

Panipiquetes (Febre et al., 1749).

Panis (Garraghan, 1927: $\frac{1}{3} i 2$; Pease and Werner, 1934: 388; Sibley, 1832: I, 723).

Toajas (La Harpe in Margry, 1888: VI, 290).

Toayas (La Harpe in Margry, 1888: VI, 289).

Tawakoni

Mento (Beaurain in Margry, 1888: VI, 289n).

Touacara (La Harpe in Margry, 1888: VI, 288, 290).

Touacaras (La Harpe in Margry, 1888: VI, 289, 295, 297, 298).

Waco

Quainco (Delisle, 1718?).

Wichita

Jumanos (Febre et al., 1749; Thomas, 1940: 107).

Mento (Beaurain in Margry, 1888: VI, 289n).

Ouatchitas (Delisle, 1718?).

Ousita (La Harpe in Margry, 1888: VI, 293).

Ousitas (La Harpe in Margry, 1888: VI, 289).

Paniassey (Pease and Werner, 1934: 388).

Panipiques (Febre et al., 1749)

Panipiquees (Sandoval, 1749).

Panipiquets (Febre et al., 1749).

Panipiquetes (Febre et al., 1749).

Panis (Pease and Werner, 1934: 388).

\section{Spain}

Iscani

Hiscanes (Parrilla, 1749).

Isacanis (Bolton, 1914e: I, 286).

Iscanis (Bolton, 1914d: I, 214; 19140: I, 286, 289, 294).

Niscaniche (Bolton, 1914b: II, 85).

Panis (Bolton, 1914b: II, 85).

Yascalo (Parrilla, 1759).

Yscanes (Calahorra y Saenz, 1762: 54).

Yscania (Treviño et al., 1765).

Yscanis (Hackett, 1946: IV, 331; Kinnaird, 1958: 185;

Calahorra y Saenz, 1765; Bolton, 1914d: I, 211; Chabot,

1932: 7; Ugarte y Loyola, 1786a).

Yxcanis (Chabot, 1932: 8).

Yzcanis (Cabel1o, 1786a, 1786o, 1786c). 
Kichai

Aquichi (Salcedo, 1809).

Guicha (Puelles, 1807).

Kichais (Austin, 1829a, 1829b).

Kichyes (Auistin, 1822).

Queisseis (West, 1904: 52).

Quichain (Salcedo, 1809).

Quichas (Hatcher, 1919: 52; Cabel10, 1784c).

Quitseis (Bolton, 1914c: II, 1911).

Quitseys (Bolton, 1914d: I, 211, 217; 19140: I, 285, 286, 289;

1914b: II, 174; 1914a: II, 145).

Quitzeis (chabot, 1932: 7).

\section{Panis Mahas}

Ovaes (Chabot, 1932: 13, 14).

Panis Mahas (Bolton, 1914a: II, 145; 1914f: II, 274; Chabot, 1932: 13, 14).

\section{Trovayas}

Jumanes (Scholes and Mera, 1940: 274; Sandoval, 1749). Jumano (Croix, 1768, in Bexar Archives Translations, XLVI, 110). Panis (Bolton, 1914b: II, 85).

Tabayas (Hackett, 1931-1946: IV, 331).

Taboaya (Cabelio, 1786a).

Taboayases (Cabelio, 1786a).

Taboayazes (Cabelio, 1785e, 1786b).

Taguais (TreviKo et al., 1765).

Taguayaces (Ugarte y Loyolo, 1786a).

Taguayas (Kinnaird, 1958: 185; Ugalde, 1786).

Taguayases (Ugalde, 1786; Spain Dirreccion de Hidrografia 1800?; Puelies, 1807).

Taguayasses (Ugalde, 1786$)$.

Taguayaz (Ugarte y Loyolo, 1786a).

Tahuallas (Anonymous, 1756; Curbelo, 1805, in Bexar Archives Translations, March $1-20,1807,62)$.

Tahuases (Austin, 1829a, 1829b).

Tahuaya (Parrilla, 1759).

Tahuayas (Elguezabal, 1804a, in Bexar Archives Translations, IXVI, Pt. I, 35, 36, 37; Cordero, 1808; salcedo, 1809).

Tahuayases (Hatcher, 1919: 57).

Taouaiazes (Bolton, 1914e: I, 286, 289, 295).

Taouaizes (Bolton, 1914a: II, 145)。

Taouayazes (Bolton, 1.914c: II, 201).

Taovaiases (Chabot, 1932: 14).

Taovaya (Croix, 1771, in Bexar Archives Translations, IL, 38).

Taovayases (West, 1904: 52; Bolton, 1914c: II, 204; Chabot, 1932: 9, 10, 13).

Tauaiases (Bolton, 1914d: I, 211).

Tavaiases (Bolton, 1914d: $I, 215$ ).

Tavaiaz (Bolton, 1914d: I, 211).

Tavoyache (Bolton, 1914b: II, 85).

Tawciais (Treviño et al., 1765: 105). 
Toauyaas (Bolton, 1914b: II, 174). Towcayses (Austin, 1822).

Towiaches (Sibley, 1832: I, 723).

Towyash (Austin, 1829?).

Tawakoni

Flechasos (Cabello, 1786a, 1786b).

Flechazo (Bolton, 1914f: II, 277; Chabot, 1932: 8).

Flechazos (Ugarte y Loyolo, 1786a; Cabelio, 1786e).

Guancane (Hackett, 1931-1946: III, xi-xvii, 66-67).

Panis (Bolton, 1914b: II, 85).

Quiscat (Bolton, 19I4f:II, 277; Chabot, 1932: 8).

Tacuacan (Cabello, 1784c).

Taguacana (Puelies, 1807).

Taguacanas (Kinnaird, 1958: 185).

Taguacanes (Cabello, 1786a, 1786b, 1786e; Ugarte y Loyolo, 1786a).

Tahuacanos (Hatcher, 1919: 57; Sanchez, 1926: 265; Austin, $1829 a, 1829 b)$.

Tawacani (Austin, 1822).

Tawakoni (Croix, 1771, in Bexar Archives Translations, IL, 38).

Tehuacana (Curbelo, 1805, in Bexar Archives Translations, March $1-20,1807,62)$ 。

Tehuacanas (Calahorra y Saenz, 1762, in Bexar Archives Translations, XXXVII, 54; Treviño et aI., 1765).

Tehuacanes (Parrilla, 1759).

Tehuacanos (Hatcher, 1919, 52).

Teuacanas (Hackett, 1931-1946: IV, 3).

Touacana (Bolton, 19140: I, 294).

Touacanas (Bolton, 1914d: I, 211).

Tuacana (Chabot, 1932: 7, 8, 9; BoIton, 19140: II, 277;

Hackett, 1931-1946: III, xi-xvii, 66-67).

Tuacanas (Bolton, 1914d: I, 214, 292; 19140: I, 286; 289;

1914b: II, 174; 1914a: II, 145; 1914c: II, 193, 196, 201;

1914f: II, 274; Chabot, 1932: 7).

Tuacanes (West, 1904: 52).

Waco

Huecos (Austin, 1829a, 1829b).

Waco (Austin, 1822, 1829?).

Wacos (Sanchez, 1926: 265).

Wichita

Guachitas (Cabe110, 1786a, 1786b, 1786e; Ugarte y Loyolo, 1786a).

Guichitas (Treviño et al., 1765; Cabello, 1784c).

Huichita (Curbelo, 1805, in Bexar Archives Translations,

March 1-20, 1807, 62; Salcedo, 1809).

Jumanes (Sandoval, 1749).

Ouatchita (BoIton, 1914b: II, 85). 
Ouedeitas (Hackett, 1931-1946: IV, 331).

Ouedsitas (Bolton, 1914e: I, 286, 289, 294, 295; Chabot, 1932: 9).

Panis (Bolton, 1914b: II, 85).

Pawnes (Austin, 1822, 1829?).

\section{United states}

Kichai

Hitchies (Schoolcraft, 1860: I, 518).

Kechie (Mölihausen, 1858: I, 117).

Kechies (Butler and Lewis, 1846; Marcy, 1853: 93; Schoolcraft, 1860: V, 702; Leeper, 1862).

Keechi (Winfrey, 1959: 23, 53, 54, 284; March, 1853: 78; Battey, 1876: 53; United States Engineer Department, U. S. Army, $1851,1852 ?$ ).

Keechie (Richards, 1872: 252).

Kee-chies (Butler, 1846).

Ke日chies (Butler and Lewis, 1846; Catlett, 1849; Williams, 1849; U. S. Department of Interior, 1850?; Howard, 1852; Marcy, 1853: 93; Neighbors, 1853; McKisick, 1857; Le日per 1860; Schoolcraft, 1860: VI, 687, 705, 708; ShankIin, 1868; Burgiin, 1846).

Keechis (Stem, 1853b, 1853c; Marcy, 1853: 72; Butler, 1928: 495). Keychie (Sibley, 1922: 24; 1807: 43).

Keyes (Sibley, 1807: 43).

Ki-chis (Fletcher and LaFlesche, 1898).

Kitchies (Sibley, 1922: 95; Schoolcraft, 1860: I, 237).

Reechis (Hardie, 1851).

\section{Panis Mahas}

Pawnee Mohaws (Wheelock, 1834: I, 81).

Taovayas

Panie (Sibley, 1922: 69).

Panies (Sibley, 1922: 69).

Panis (Sibley, 1922: $11,24,34,40,42,43,44,70 ; 1807: 46$; Jamison, 1819: 46).

Panis Piques (Schoolcraft, 1860: III, 557, 559).

Pawnee (Wheolock, 1834: I, 81; Catlin, 1841: II, 71, 72; Winfrey, 1959: 23).

Pawnee Picts (Bonnel1, 1838: 47; Catlin, 1841: II, 71, 72, 73; Young, 1835).

Pawnee Piques (Schoolcraft, 1860: III, 595).

Tawehash (Winfrey, 1959: 23, 53, 54).

Tawiache (Sibley, 1922: $24,34,40$ ).

Toriush (Schoolcraft, 1860: II, 126).

Touwiash (Groves, 1837).

Towash (Catlett, 1849).

Towashes (James, 1916: 225)。

Towcashes (Bonne11, 1838: 47). 
Tow-e-ahge (Catlin, 184I: II, 73).

Toweash (Upshur, 1841; Burgvin, 1846).

Towe-ash (Sibley, 1922: 94).

Tow-e-ash (Schoolcraft, 1860: I, 518).

Toweeash (Young, 1835).

Towiach (Jamison, 1819: 46).

Towiaches (Sibley, 1807: 46).

Tow i-ash (Butler, 1846).

Towyash (Butler and Lewis, 1846).

Toyash (Wheelock, 1834: I, 81, 82).

Tuwayhays (Pike, 1810).

Tawakoni

Tahuacanos (Unsigned, 1875: 314).

Tahuacarros (Ross, 1857b).

Tahwaccaroe (Coombes, 1858).

Tahwaccarro (Ross, 1856c).

Tah-wac-car-roes (Ross, 1857a).

Tahwaccarroes (Leeper, 1862).

Tahwaccarros (U. S. Department of Interior, 1850?; Ross, 1858; Blain, 1859a; Leeper, 1860; Schoolcraft, 1860: II, 126, 708). Tah-wac-car-ros (Neighbors, 1853; Ross, 1857b).

Tahwacconos (McKisick, 1857).

Tawacanie (Kuykenda11, 1903: 248).

Tawacanies (Catlett, 1849; Schoolcraft, 1860: I, 518).

Tawacanoes (Hardie, 1851).

Tawaccanos (Howard, 1852).

Tawacarros (Schoolcraft, 1860: III, 635, and VI, 689).

Tawaccarro (Hill, 1854).

Tawaccarroes (Hill, 1855).

Tawaccarros (Stem, 1853c).

Tawaconi (United States Engineer Department, U. S. Army, 1851).

Ta-wa-ka-noo (Fletcher and La Flesche, 1898)。

Tawakeno (Sibley, 1922: 23).

Tawakenoes (Sibley, 1807: 46, 47).

Tawakoni (Winfrey, 1959: 23, 53, 54, 284).

Tawoccarroes (Hill, 1854).

Tehuacanas (Wilbarger, 1889: 177).

Three Canes (Sibley; 1807; 46).

Tiwocknies (Burgvin, 1846).

Tiwocknees (Butler, 1846).

Ti-wock-o-nies (Butler, 1846).

Touwackanies (Sibley, 1922: 94)。

Towacanies (Bonnell, 1838: 46).

Towacarros (\$choolcraft, 1860: VI, 705).

Towaconies (Neighbors, 1847: 4; Schoolcraft, 1860: V, 702).

Towacunu (Fletcher and La Flesche (1898).

Towecarros (Schoolcraft, 1860: VI, 687).

Towockonies (Marcy, 1849-1852).

Towoconies (Butler and Lewis, 1846).

Towocoonee (Marcy, 1854).

Towacaries (Shanklin, 1868: 322). 
Towoekonies (Schoolcraft, 1860: V, 712).

Toyacane (BoIton, 1914b: II, 85).

Yo-woc-o-nees (Schoolcraft, 1860: v, 712)。

Waco

Pawnee Picts (Gregg, 1844: II, 305).

Waco (Winfrey, 1959: 23, 53, 54, 284; stem, 1853a, 1853b; Ross, 1856c; Ford, 1889: 67; Groves, 1837; Upshur, 1841; Burgvin, 1846; United States Engineer Department, U. S. Army, 1851, 1852?; Marcy, 1849-1852, 1854).

Wacoes (Kuykendal1, 1903: 248; Bonnel1, 1838: 46, 47: Kendal1, 1844: 140, 141, 142; Gregg, 1841: II, 305; Neighbors, 1847: 4; Catlett, 1849; U。 S. Department of Interior, 1850?; Hardie, 1851; Howard, 1852; Stem, 1853c; McKisick, 1857; Ross, 1858; Leeper, 1860; Schoolcraft, 1860: III, 635, V, 7.12, and VI, 687, 705; Leeper, 1862; Shanklin, 1868: 322; Butler, 1928: 495; Burgvin, 1846). Wa $=$ coes (Butler, 1846; Ross, 1857a). Wacos (Butler and Lewis, 1846; Neighbors, 1849; Williams, 1849; Marcy, 1849-1852; 1853: 77, 78, 93; Neighbors, 1853; Hi.1, 1855; Ross, 1857b; Blain, 1859a; Schoolcraft, 1860: II, 126,708, V, 702 and VI, 689; Marcy, 1866: 161; Wilbarger, 1889: 174, 175).

Waekos (Môlihausen, 1858: I, 115). Wako (Mölihausen, 1858: I, 116).

Wakoe (Battey, 1876: 53).

Wakos (Moblithausen, 1858: I, 115, 116).

We he ko (Fletcher and La Flesche, 1898).

We-koo (Fletcher and La Flesche, 1898).

Whaco (Young, 1835).

Whacos (Sibley, 1922: 94; Schoolcraft, 1860: I, 518). Wico (Catiin, 184I: II, 75). Wicos (Catiin, 184I: II, 73).

Wichita

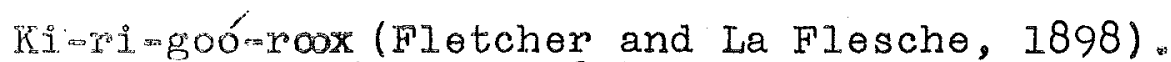

Pawneo Piots (Gregg, 1844: II, 305).

Tooc-a nie Kiowas--part Wichita and part Kiowa (Richards, 1875: 289).

Whitchetaws (Sibley, 1922: 94).

Wichetas (Neighbors, 1847: 4).

Wichetaw (Burgin, 1846).

Wichetaws (Butler, 1846; Butler and Lewis, 1846; Schoolcraft, 1860: VI, 689).

Wicheta (stem, 1853a; Butler, 1928: 495; Richards, 1873: 223; Fletcher and La Flesche, 1898; Kendal1, 1850; United

States Engineer Department, U. S. Army, 1852?). 
Wichetas (Catlett, 1849; Neighbors, 1849; Howard, 1852; Stem, $1853 \mathrm{~b}, 1853 \mathrm{c}$; Neighbors, 1853; Hill, 1854; Ross, 1856c; MoKisick, 1857; Leөper, 1860; Schoolcraft, 1860: III, 635, and VI, 708; Shanklin, 1868: 322).

Witcheta (Sibley, 1922: 34).

Witchetaws (Sibley, 1922: 94; Butler and Lewis, 1846; Schoolcraft, 1860: V, 702; Marcy, 1866: 157, 160, 161).

Witchita (Richardson, 1925: 66: Marcy, 1849-1852; 1853: 69, 77; 1854; Ross, 1856c; Möllhausen, 1858: I, 115; Ross, 1856a).

Witchitas (Gregg, 1844: II, 305; U. S. Department of Interior, 1850?; Marcy, 1853: 69, 72, 77, 78, 79, 93; Möllhausen, 1858: I, 115, 116; Schoolcraft, 1860: V, 172; Leeper, 1862).

Indian

Wichita

Ki-ri-goóroox (Fletcher and La Flesche, 1898) (Pawnee)

Kirikuruks (Lesser and Weltfish, 1932: 12) (Pawnee)

Kirikiris (Lesser and Weltfish, 1932: 1I) (Wichita)

Taovayas

Tow-ee-ahge (Catlin, 1834: II, 73) (Taovayas)

Waco

Weku (Lesser and Weltfish, 1932: 10) (Wichita) Wehiko (Lesser and Weltfish, 1932: 10 (Wichita)

Kichai

Tikítsias (Lesser and Weltfish, 1932: 10) (Kichai)

Kikiskitsu (Lesser and Weltfish, 1932: 10) (Wichita)

Kitsas (Lesser and Weltfish, 1932: 10) (Pawnee) 
An Estimation of Wichita Population

Knowledge of the size of cultural entities, whether tribes or nations, is crucial to adequate comprehension of them. The social structure of a unit of 100 people must be different than if their number is ten or a hundred times greater, a vi.l. terms of exploitation of natural resources, relationships to other villages, even of how man regards his world and the cosmos. It follows that if a reasonable estimate of Wichita population from the sixteenth through the nineteenth centuries is beyond our reach, understanding of most aspects of Wichita culture will be seriously impaired. Fortunately, statements which bear on Wichita population are plentiful and were made throughout their long association with white men. Consequently, the investigator can stand off, so to speak, and compare his population estimates of one year with those of the next year, and the next. If the resulting graph of such population estimates is studded with sharp peaks and valleys, they must be explicable in terms of epidemics, wars, or other factors. If, on the other hand, the graph is a relatively smooth curve broken only by known calamities at a few points, then confidence in the relative accuracy of year to year estimates is high.

Since Europeans were in no position to take censuses of Wichitas even if they had wanted to do so, and since they rarely visited every Wichita subdivision or even knew of them all, the estimates of population depend upon a number of deductions and a few basic assumptions. We have assumed, first of all, that when the number of warriors is given in the sources, they represent about one-fifth of the total population. This seemed a reasonable figure, and it is not in conflict with other data. The number of dwellings in various villages is often given, and this is a valuable clue to population size. We have assumed that each Wichita dwelling held ten to eleven persons, basing this figure primarily on a statement of De Mézières, but which tends to be confirmed by other sources. In 1778 at the twin villages on the Red River, De Mézières said:

The nation of the Taovayazes is divided into two villages, one situated on the northern bank of the Vermejo, or Natchitoches, River, the other opposite the first on the other bank. The former is composed of thirty-seven houses, the latter of one hundred 
twenty three. Each dwelling contains from ten to twelve beds, considering which fact a conservative estimate places the number of men, including youths, at more than eight hundred, while that of the women and children of both sexes is very large (Bolton, 1914, II: 201-202)。

It may be argued that the number of occupants in the grass lodges varied through time, and that with declining numbers the average number of persons per household also declined. But Randolph Marcy (1866: 136) in the midenineteenth century described a Wichita village of 42 lodges, each containing two families of some ten persons. A Waco village about one mile away had twenty lodges and about 200 people (ibid., 137). It would seem then, that ten or eleven occupants per grass lodge is a stable and accurate population index.

The following discussion is intended to be read in conjunction with Table 1 .

Members of the Coronado expedition gave conflicting testimony concerning the number and size of villages and their population. Jaramillo wrote (Winship, 1896: 590): "There were, if I recall correctly, six or seven settlements, at quite a distance from one another, among which we traveled for four or five days..." The Relacion del Suceso (Winship, 1896: 577) contains the following: ". . - in some villages there are as many as 200 houses." Coronado (Winship, 1896: 285), said ". " there are not more than 25 villages of straw houses there. ." Castaneda (Winship, 1896: 512) reported: "It is to be noted that in place of settlements great deserts were found, and instead of populous cities villages of 200 inhabitants and only 800 or 1,000 people in the largest."

It is unlikely that Jaramil10's "settlements" and Coronado"s "villages" refer to the same entity. The probabilities would seem to favor the existence of contiguous villages, which Jaramillo lumped together as settlements. If this is indeed the explanation, the village complexes of later years are not necessarily the result of new, European-induced factors, but were an old tradition. The maximum of 200 houses per village (2,000-2,200 persons) of the Relacion del. Suceso agrees tolerably well with what is known about maximum village size in later years. It does not agree with Castaneda's fron-eyewit= ness) estimate of 1,000 people in the largest viliages.

On the basis of the Coronado expedition figures, it seems reasonable to assume that there were less than 25 viliages, perhaps between 15 and 20 , grouped into settlements as described by Jarami110. If it is also assumed that most villages had between 100 and 150 houses (1,000-1,650 occupants), a population of 15,000 to 33,000 is suggested. This is 
properly termed a guess, nothing more.

La Harpe in 1719 (Margry, 1888, VI: 289) made reference to nine tribes, the Touacaras, Toayas, Ousitas, Ascanis, Caumuches, Aderos, Quataquois, Quicasquiris, and Honechas, numbering 6,000 persons. It is assumed that they were al1 Wichita. La Harpe mentioned two other villages, and assuming a population of 1,300 persons per village, all these groups would total 8,600 people. Du Tisné (Margry, 1886, VI 309-315), in the same year, noted that the Panis had two villages of 130 houses and 200 warriors each. Two hundred warriors would indicate a population of 1,000 persons for each village; 130 lodges would mean a total of 1,300-1,400 persons in each village. For two villages, therefore, the number would be from 2,000 to 2,860 persons. This would yield a total population in 1719 of 10,600 to 11,460 persons, assuming that La Harpe and Du Tisne' visited all the Wichita villages but none of the same ones. The probabilities would seem good that there were more villages than they visited or heard about so that total population would be somewhat higher than indicated. Our guess for 1541 does not seem so ridiculously high in the light of this estimate.

French traders in 1749 spoke of the Panipiquets, or Jumanos, as having two villages of three hundred warriors each (or 1,500 persons in each village, for a combined total of 3,000 persons). Sandoval's estimate in 1749 for the same Panipiquets, or Jumanes, was 500 warriors in all, or using a five to one ratio, 2,500 persons. If these villages were of average size and there were ten villages as there had been in La Harpe's day, Wichita population would have been between. 12,500 and 15,000 。

Estimates of the number of Taovaya, Iscani, and Comanche men involved in the parrilla debacle of 1759 ranges from 2,000 to 6,000, representing a combined total population of 10,000 to 30,000 persons. But Parrilla is vague about the number of enemy involved, perhaps intentionally so, suggesting that he was overestimating their number. It is also difficult to estimate to what extent Comanches, Iscanis, and other wichitas participated in the battle alongside the Taovayas.

Calahorra, in 1760, gave population figures for the Tawakonis and Iscanis on the Sabine River. He said:

The Taguacana's town is so close to the Yscani's that only a street separates them. The towns include forty-seven large dwellings each housing twelve families. Altogether there are two hundred fifty warriors and they are governed by four chiefs who are brothers. (Calahorra to Navarrete, 10/24/1760) 
What Calahorra meant by twelve families in each of 47 large dwellings is perplexing. If there were four to five persons to a "family" there would be 48-60 people per dwelling. But it does not seem possible that Wichita lodges were this commodious. The statement has been disregarded. On the basis of the number of warriors, the population of the villages was probably about 1,250 persons. The Taovayas on Red River, according to Calahorra, could muster 600 warriors, giving them a presumed population of some 3,000 persons in two villages. The combined total of Wichita peoples known to Calahorra in 1760 would, then, number 4,250. If there were still ten villages in all, this total represents 40 per cent of the population, a total population of 10,620 .

Treviño's 1765 estimate of Taovayas, Wichitas, and Iscanis on Red River was 500 warriors, or 2,500 persons. Since he was actually there and Calahorra was not, Calahorra's estimate of the population at the Red River villages five years earlier may have been high. It should also be noted that the Wichitas had also settled at the Red River site and perhaps should have been included in Calahorra's earlier estimate. The 1760 estimate is, then, probably a maximum figure.

In 1772, De Mézières listed 30 houses and 80 males for the Kichais on the upper Trinity River. Thirty houses would indicate a population of $300-330$ : 80 men (probably warriors) would mean a population of 400. The Iscanis, he wrote, had 60 warriors ( 300 persons). The Tawakonis on the upper Trinity had 36 houses ( $360-396$ persons) and 120 warriors (600 persons), while the Tawakonis on the upper Brazos had 30 families ( 300 persons), giving a combined total for the Kichais, Iscanis, and Tawakonis in 1772 of from 1,260 to 1,600 persons. De Mézières" estimate of the "Southern Wichitas" is, then, close to that of Calahorra's of 1760, though there is no assurance that exactly the same groups were counted by both men.

Two years later, Gaignard gave an estimate of the combined warrior strength of the Taovayas, Wichitas, Iscanis, and Tawakonis as 1,000, representing a total of 5,000 persons for the Red River country. But it is not entirely clear whether he was referring only to the Red River villages or to all the Wichitas. In 1772 De Mézières had estimated the Taovayas and Wichitas to number 600 warriors $(3,000$ persons) (Bolton, 1914, II: 294).

Although De Mézières provides considerable population data, it is not easy to use this material effectively. Some villages appear to be in the process of fragmentation in the $1770^{\circ}$ s, and it is difficult to follow village groups as they move about. In 1777, for example, De Mézières (Bolton, 1914, II: 145) gave the warrior strength of the Kichais as 25 (125 persons). Five years earlier they had been credited 
344

with 80 warriors (400 persons)。De Mézières explains that one group of 20 warriors (100 persons) had "separated from the main body of their nation" (ibid., 191) and were living on the upper Trinity. Unfortunately, the fate of the main body is unknown; they never reappear so far as we can tell. In 1777, De Mézières estimates the Taovayas and "PanisMahas" warrior strength at 300 each. These appear to be the Red River Taovaya-Wichitas whom he visited in 1778 and credited with 800 warriors and youths. There seems to have been two Tawakoni villages in 1777-1778 totaling about 1,000 persons. All these sub-groups would then total 2,750-2,935 persons.

De Mézières, in 1779 (1914f: II, 274), wrote that the Tawakonis had 250 men, having suffered heavily in the last epidemic. The Indians of San Theodoro and the Panis-Mahas, the Red River villages, had not experienced as great a loss in numbers.

Morfi (Chabot, 1932: 7-9) listed ninety families of Iscanis on the upper Brazos River (450 persons), twenty warriors among the Kichais in Limestone County (100 persons), thirty-seven houses and twenty-three houses respectively for the Taovayas and Wichitas for a total of 800 men (1,600 persons), and 150 warriors for the Tawakonis on the upper Brazos (750 persons). This makes an overall total of 2,900 persons for the various Wichita groups in 1780 .

Jose Marés, in his expedition of 1787, mentioned only the Taovayas on the Red River, in three villages of twenty three, forty, and twenty-seven houses each, a total of ninety houses, or, on the basis of the previously defined computations, 900-990 people. On a similar expedition in 1788, Fernandez also recorded three Jumanes villages, but with each containing only seventeen huts. A total of fiftyone huts would give a population of 510-561. In a decade, then, the decline of the Red River villages was drastic.

John Sibley gave population figures for male members of the Kichais, Taovayas, and Tawakonis as 60, about 400 , and 200, respectively. If he was including all men in the groups and not warriors only, this would give population of 120,800 , and 400 , or a total of 1,320 . If he was estimating warrior strength, the total would have been 3,300. Sibley (1832: I, 723), in referring to the Panis, or Towiaches, in 1805, emphasized that a great number of them were swept away by the smallpox epidemic of 1801.

An article in the Cincinnati Gazette, presumably by Sibley but containing no author's name and no date, was appended to material by Sibley that was later published 
(1922: 93-95). The date of the known Sibley material is 1807, and it is assumed that the date of the newspaper material is much later, although this is not known with certainty. The name Waco is used in the newspaper material, and, if this. data were contemporaneous with the other sibley information (1807), then it would represent, by far, the earliest use of the word Waco. The figures given are: Wacos on the Brazos River, 350400; Tawakonis on the Trinity River, 230-250; Kichais on the Trinity River, 130-150; and Taovayas and Wichitas on Red River, 500-600 in each village. This gives a combined population total of from 1,710 to 2,000。

Salcedo, in 1809, reported fifty to sixty men (250-300 persons) for the Kichais east of the Trinity River, and a combined total of 400 men (2,000 persons) for the Taovayas and Wichitas on the Red River.

Morse (1822: 529) recorded a Taovaya population of 400 in 1818. Padi1la (Hatcher, 1919: 47-60), in 1819, noted that the Tawakonis had three villages, totalling 800 persons; the Taovayas had 1,000 persons; and the Kichais about 800 people, for a combined total of 2,600 .

Kuykendall (1903: 248) in 1824 stated that the Wacos and Tawakonis living in the vicinity of modern Waco, Texas, had from 200 to 300 men, giving an assumed population of 400 to 600, if he was referring only to males, and a population of 1,000 to 1,500 if he was referring to warriors. Sanchez (1926: 265), four years later, listed 260 families for the same groups at the same general location, or a total of 1,300, which suggests that Kuykendall used "men" synonymously with warrior.

General Po B. Porter in Schoolcraft (1860: III: 595) gave an 1829 listing of Pawnee Piques in Texas of 4,000.

Several figures were given for the Pawnee Pict population by members of the 1834 Dragoon Expedition in Oklahoma. Whe lock (1834: I, 81) counted almost 200 grass lodges, indicating some 2,000-2,200 people. Catlin (184I, II; 70,73) estimated that there were 500-600 grass lodges in the village. The chief told him there were 3,000 warriors, which Catlin said "if true, estimating according to the usual rule, one warrior to four, would make the whole number about twelve thousand; and, allowing a fair percentage for boasting or bragging, of which they are generally a little guilty in such cases, there would be at a fair calculation from eight to ten thousand" (ibid,, 73). If Wheelock's count is used rather than Catlin's overgenerous estimate, to which are added 2,500 Wichitas in Texas, a tribal total of 4,500 to 4,700 is achieved. The Texas Wichita population is drawn from I. W. Burton, chairman of a standing Committee on Indian Affairs for the Republic of Texas (Winfrey, 1959: 24). 
According to him in this listing for 1837, the Taovayas, Wacos, Kichais, and Tawakonis numbered 500 warriors (2,500 persons).

In 1838, Bonnell (1838: 46,47) estimated 450 wacos on the upper Brazos. 300 Taovayas on Red River, and 500 Tawakonis on Pecan Bayou of the Colorado River, making a total of 1,250 persons in Texas. Perhaps, then, Burton's earlier estimate is too high. This is strengthened by looking back at the Texas estimates of Kuykendall and Sanchez in 1824 and 1828. On a basis of 1,000 - 1,500 Texas Wichitas a tribal total of 3,200 $-3,700$ is reached.

Kendall, in 1841 (1844: I, 134-144) encountered a Waco village in the vicinity of present Wichita Falls, Texas, containing from 300 to 400 persons; more villages could be seen in the distance.

Butler and Lewis (1846) wrote that the Wichitas and Taovayas, numbering 300, lived on the north side of the $\operatorname{Red}$ River in the Wichita Mountinas; the Wacos, Kichais, and. Tawakonis, numbering 450, resided on the Brazos River, some 100 miles above Comanche Peak. These groups advised that they had lost their numbers from smallpox and from repeated wars with the Texans. According to the above information, they numbered 750 persons at this time.

Schoolcraft (1860: VI, 708) included an 1849 listing of 1,000 for Wichitas, Wacos, and Tawakonis and 300 for the Kichais, making a total of 1,300 .

Catlett (1849) gave a total of 400 men for the Kichais, Wichitas, Wacos, and Tawakonis on Red River, which meant a population of 2,000.

In what was listed as a Conservative Estimate (Anonymous, 1850?), 300 Kichais are listed and 1,000 Wacos, Wichitas, and Tawakonis, for a grand total of 1,300 people.

Schoolcraft (1860: VI, 687) listed 300 Kichais, 400 Tawakonis, and 300 Wacos for 1850, giving a total of 1,000.

Cooper (1851) had the same number, but included in this amount Caddos, Ionis, and Anadarkos.

Hardie (1851) gave an 1851 estimate for groups on the upper Brazos based on a careful count "by their chiefs and principal men" as follows: Wacos, 114; Tawakonis, 141; and Kichais, 38, for a total of 293 in Texas.

Stem (Schoolcraft, 1860: III, 635) gave the identical figures that Hardie gave for 1851, adding 100 persons for the 
Wichitas in the Wichita Mountains beyond Red River, making a total of 393 .

In 1852, Howard (1852) gave the total number of Tawakonis, Wacos, Kichais, and Wichitas in Texas as 547.

March (1853: 69, 77, 78) gave the total number of Wichitas in 1852 on Rush Creek in Oklahoma as not over 500.

For 1853, Schoolcraft (1860: VI, 689, 705) had two sets of figures for wichita groups. One listed wichitas and Wacos as having 300 and 200 people, respectively, and the other listed on the upper Brazos 300 Kichais, Wacos, and Tawakonis. The same source (V, 702), gives 1854 figures for Wichita groups in "Southwestern" Texas which add up to almost 900 Wacos, Wichitas, Tawakonis, and Kichais, which is only slightly less than the total number of Kichais, Wacos, and Wichitas noted in central Oklahoma (100, 200, and 800, for a total of 1,100) by Möllhausen (1858: I, 116, 117) in 1853.

The population of Tawakonis and Wacos who settled on the Texas Reservation during its six years of existence was relatively constant, hovering between 340 and 383 people. They seem to have represented about a third of the total population, the Oklahoma Wichitas and Kichais numbering about 600 persons.

In 1867, the totals for Wichita groups on the Oklahoma Reservation were as follows (U. S. Department of Interior, 1868: 397): Kichais, 127; Tawakonis, 143, Wacos, 140; and Wichitas, 299, giving a total of 758 , but showing a drop in population for Wacos and Tawakonis of 80. This drop is explained by Shanklin (1867: 322) and Mead (1904: 175-177), who documented the appearance of cholera among the Wichita groups in Kansas in 1867. As the Wichitas traveled back to Oklahoma, so many of them died at skeleton Creek and remained on the ground unburied that their bones gave a name to the stream.

By 1891 , the overall Wichita population figure was 426 (Randlett, 1905: 293), only two less than the 1962 population (U. S. Department of Interior, 1963: 24)。

Summary and Conclusions

The study of Wichita population through time is a complex business fraught with uncertainty and frustration. And we are the first to admit that this study is a preliminary one, and that our judgment in some instances may have been clouded by a misreading of the data, or simple ignorance. But we have confidence that by carefully examining population data through a 
long period of time a realistic idea of that population can be achieved, and that our estimates of this study are probable and realistic. In brief, our data shows that up to the mideighteenth century Wichita population was in excess of 10,000 persons. Their decline was rapid for the next fifty years or more, slowing down in the nineteenth century.

These population estimates do not agree with traditional estimates of Wichita population. Kroeber (1947, Table 18), for example, lists the "Caddo, Hasinai, Wichita, etc., Quapaw (?)" with a total population of 16,000. Although there is no intention of examining here the myth, fabrication, and guesswork which has typified many studies of North American Indian populations, it is perfectlj clear to us that Kroeber's estimate, to single out one, is ridiculous. 
Table 1

An Estimation of Wichita Population

\begin{tabular}{|c|c|c|c|c|c|c|c|}
\hline Year & Group & $\begin{array}{ll} & \text { No } \\
\text { Source } & \text { Wa }\end{array}$ & $\begin{array}{l}\text { o. of } \\
\text { arriors }\end{array}$ & $\begin{array}{l}\text { No. of } \\
\text { Dwellings }\end{array}$ & $\begin{array}{l}\text { No. of } \\
\text { Vilizages }\end{array}$ & $\begin{array}{l}\text { Pop: } \\
\text { Sub-Total }\end{array}$ & $\begin{array}{l}\text { Estim, } \\
\text { Tribal } \\
\text { Population }\end{array}$ \\
\hline 1541 & $\begin{array}{l}\text { (at) Qui- } \\
\text { vira }\end{array}$ & Coronado & $\infty$ & $-\infty$ & 25 & $-\infty$ & \\
\hline .1541 & " " & Castañeda & $\cdots$ & - & $\begin{array}{r}200 \text { min. } \\
1000 \text { max. }\end{array}$ & $-\infty$ & $\begin{array}{l}15,000 \cdots \\
33,000\end{array}$ \\
\hline 1541 & $"$ & $R$. delSuce & eso =- & $200 \max$ & $-\infty$ & - & \\
\hline 1541 & " $"$ & Jaramillo & -- & & $\begin{array}{l}6-7 \text { set- } \\
\text { tlements }\end{array}$ & -- & \\
\hline 1719 & $\begin{array}{l}9 \text { tribes } \\
+2\end{array}$ & La Harpe & $=-$ & $-\infty$ & $\infty$ & $\left.\begin{array}{l}6,000+ \\
2,000\end{array}\right\}$ & \multirow{2}{*}{$\begin{array}{l}10,600- \\
11,460\end{array}$} \\
\hline 1719 & Panis & Du Tisné & 200 ea. & 130 & 2 & $\begin{array}{l}2,000= \\
2,860\end{array}$ & \\
\hline 1749 & Panipiquet & $\begin{array}{l}\text { Febre, } \\
\text { et al. }\end{array}$ & 300 ea. & $\infty$ & 2 & 3,000 & \multirow{2}{*}{$\begin{array}{l}12,500 \cdots \\
15,000\end{array}$} \\
\hline 1749 & Panipiquet & Sandoval & $500 \mathrm{ea}$. & $-\infty$ & 2 & 2,500 & \\
\hline .1759 & $\begin{array}{l}\text { Taovayas } \\
\text { Iscanis } \\
\text { Comanches }\end{array}$ & Parrilla & $\begin{array}{l}2,000= \\
6,000\end{array}$ & $-\infty$ & $\infty$ & $\infty$ & $\begin{array}{l}10,000= \\
30,000\end{array}$ \\
\hline 1760 & $\begin{array}{l}\text { Tawakoni } \\
\text { Isc oni }\end{array}$ & Calahorra & 250 & $\begin{array}{l}\text { 47-12 fam. } \\
\text { per house }\end{array}$ & 2 & 1,250 & \multirow{3}{*}{10,620} \\
\hline 1760 & Taovaya & Calahorra & 600 & $-\infty$ & 2 & 3,000 & \\
\hline 1765 & $\begin{array}{l}\text { Taovaya } \\
\text { Wichita } \\
\text { Iscani }\end{array}$ & Treviño & 500 & $\rightarrow \infty$ & 3 & 2,500 & \\
\hline
\end{tabular}




\begin{tabular}{|c|c|c|c|c|c|c|c|}
\hline Year & Group & Source & $\begin{array}{l}\text { No. of } \\
\text { Warriors }\end{array}$ & $\begin{array}{l}\text { No. of } \\
\text { Dwellings }\end{array}$ & $\begin{array}{l}\text { No, of } \\
\text { Villages }\end{array}$ & $\begin{array}{l}\text { Pop. } \\
\text { Sub-Total }\end{array}$ & $\begin{array}{l}\text { Estim. } \\
\text { Tribal } \\
\text { Population }\end{array}$ \\
\hline
\end{tabular}

\begin{tabular}{|c|c|c|c|c|c|c|c|c|}
\hline 1772 & Kichai & $\mathrm{De}$ & Mézières & 80 & 30 & 1 & $\begin{array}{l}300- \\
400\end{array}$ & \multirow{6}{*}{$\begin{array}{l}4,260- \\
6,600\end{array}$} \\
\hline 1772 & Iscani & $"$ & " & 60 & $-\infty$ & 1 & 300 & \\
\hline 1772 & $\begin{array}{l}\text { Tawakoni } \\
\text { Up. Trin. }\end{array}$ & 11 & $n$ & 120 & 36 & 1 & $\begin{array}{l}360- \\
600\end{array}$ & \\
\hline 1772 & $\begin{array}{l}\text { Tawakoni } \\
\text { Up. Brazos }\end{array}$ & $"$ & 11 & -- & 30 & 1 & 300 & \\
\hline 1772 & $\begin{array}{l}\text { Wichita } \\
\text { Taovaya }\end{array}$ & $" 1$ & 11 & 600 & -- & 2 & 3000 & \\
\hline $177 L_{4}$ & "Red River" & & ignard & 1000 & -- & 4 & 5000 & \\
\hline \multirow[t]{2}{*}{$\begin{array}{l}1777 \\
1777\end{array}$} & $\begin{array}{l}\text { Kichai } \\
\text { Up. Brazos }\end{array}$ & De & Mézières & 25 & -- & - & 125 & \multirow{7}{*}{$\begin{array}{l}2,750 \\
2,935\end{array}$} \\
\hline & Tawakoni & $"$ & " & 60 & -- & - & 300 & \\
\hline 1777 & $\begin{array}{l}\text { Taovayas } \\
\text { Red River }\end{array}$ & $" 1$ & $" 1$ & 300 & -- & -- & 1500 & \\
\hline 1778 & $\begin{array}{l}\text { Panis- } \\
\text { Mahas }\end{array}$ & $" 1$ & $" 1$ & 300 & -- & - & 1500 & \\
\hline 1778 & Kichai & 11 & $" 1$ & $\begin{array}{c}20 \\
\text { sep. vill.) }\end{array}$ & -- & -- & 100 & \\
\hline 1778 & $\begin{array}{l}\text { Up. Brazos } \\
\text { Tawakoní }\end{array}$ & $"$ & $"$ & 1.50 & -- & -- & 750 & \\
\hline 1778 & $\begin{array}{l}\text { Taovayas } \\
\text { Red River }\end{array}$ & 11 & $" 1$ & $\begin{array}{l}\quad 800 \\
\text { arrior } \\
\text { ouths }\end{array}$ & -160 & 2 & $\begin{array}{l}1600- \\
1760\end{array}$ & \\
\hline
\end{tabular}

1779 BAD EPIDEMIC AMONG TAWAKONIS

\begin{tabular}{|c|c|c|c|c|c|c|c|}
\hline 1780 & Kichai & Morfi & 20 & -- & - & 1.00 & \\
\hline 1780 & Iscani & Morfi & .90 & - & - & 4.50 & \\
\hline 1780 & Taovaya & 11 & men-800 & 37 & $-\infty$ & $660-$ & 2,900 \\
\hline \multirow{3}{*}{1780} & Wichita & & & 23 & & $1000 ?$ & \\
\hline & Tawakoni & & & & & & \\
\hline & Up. Brazos & 11 & 150 & -- & -- & 750 & \\
\hline 1787 & $\begin{array}{l}\text { Red River } \\
\text { Taovaya }\end{array}$ & Marés & $-\infty$ & 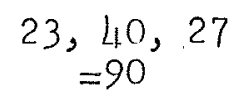 & 3 & 990 & \\
\hline 1788 & Red River & Fernandez & - & 51 total & 3 & 561 & \\
\hline
\end{tabular}


Estim. No of No, of No of Pop. Tribal

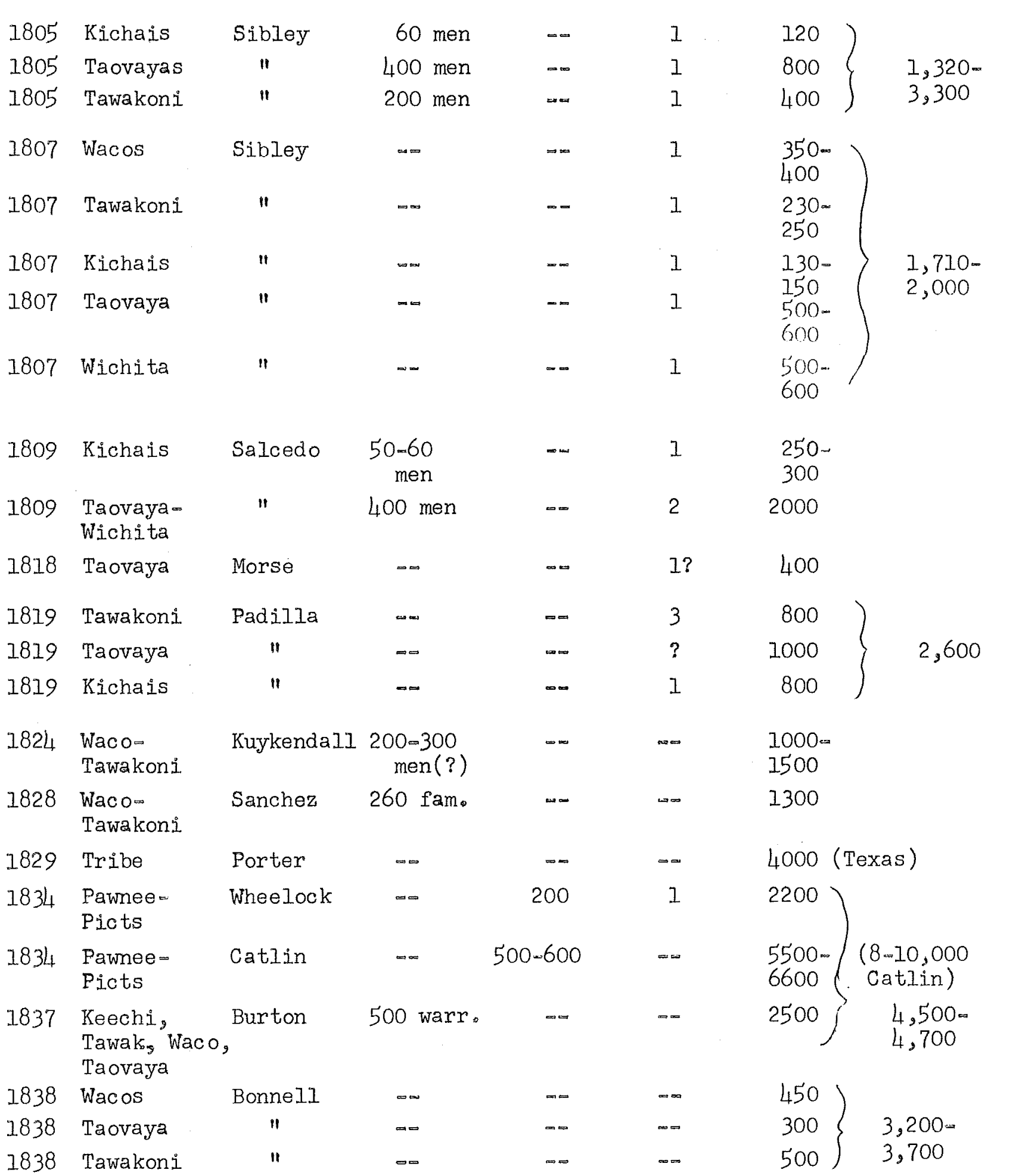




\begin{tabular}{|c|c|c|c|c|c|c|c|}
\hline Year & Group & Source & $\begin{array}{l}0 . \text { of } \\
\text { arriors }\end{array}$ & $\begin{array}{l}\text { No, of } \\
\text { Dwellings }\end{array}$ & $\begin{array}{l}\text { No, of } \\
\text { Villages }\end{array}$ & $\begin{array}{l}\text { Pop. } \\
\text { Sub-Total }\end{array}$ & $\begin{array}{l}\text { Estim. } \\
\text { Tribal } \\
\text { Population }\end{array}$ \\
\hline 184.1 & Waco & Kendall & - & - & 1. & $\begin{array}{l}300- \\
400\end{array}$ & \multirow{3}{*}{750} \\
\hline 1846 & $\begin{array}{l}\text { Wichita \& } \\
\text { Taovaya }\end{array}$ & $\begin{array}{l}\text { Butier \& } \\
\text { Jerjis }\end{array}$ & - & -- & 1 & 300 & \\
\hline 1846 & $\begin{array}{l}\text { Wacos, } \\
\text { Kichai } \\
\text { Tawakoni }\end{array}$ & $" 1$ & $-\infty$ & - & $7(?)$ & 450 & \\
\hline 1849 & $\begin{array}{l}\text { Wichita, } \\
\text { Waco, } \\
\text { Tawakoni }\end{array}$ & Schoolcraft & -- & - & - & $1000)$ & \multirow[t]{2}{*}{1,300} \\
\hline .1849 & Kichais & $" 1$ & -- & $\sim$ & -- & 300 & \\
\hline 1849 & $\begin{array}{l}\text { Kichais, Wac } \\
\text { T'awakoni, } \\
\text { Wichita }\end{array}$ & o, Catlett & 400 men & -- & -- & 2000 & 2,000 \\
\hline $1850(?$ & $\begin{array}{l}\text { ?) Kichais, } \\
\text { Wacos, Wichi } \\
\text { Tawakoni }\end{array}$ & $\begin{array}{l}\text { Anonymous } \\
\text { ita, " }\end{array}$ & -- & $\cdots$ & - & $\begin{array}{r}300 \\
1000\end{array}$ & 1,300 \\
\hline $185^{\circ}$ & Kichais & Schoolcraft & $-\infty$ & $-\infty$ & -- & 300 & \multirow{3}{*}{1,000} \\
\hline 1850 & Tawakoni & 11 & $-\infty$ & - & -- & 400 & \\
\hline 1850 & Waco & $"$ & -- & - & -- & 300 & \\
\hline .1851 & Waco & Hardie \& Stem & $m--$ & $-\infty$ & - & $1 \mu_{4}$ & \multirow{5}{*}{393} \\
\hline 1851 & Tawakoni & 11 & $\sim$ & $-\infty$ & -- & 141 & \\
\hline 185.1 & Kichais & $" 11$ & - & - & $-\infty$ & 38 & \\
\hline 1851 & Wichita & $\begin{array}{l}\text { Stem in } \\
\text { Schoolcraft }\end{array}$ & -- & -- & -- & 100 & \\
\hline 1852 & $\begin{array}{l}\text { Tawak, Waco, } \\
\text { Kichai, } \\
\text { Wichita }\end{array}$ & Howard & - & - & $-\infty$ & 547 & \\
\hline 1852 & Wichitas & Marcy & $-\cdots$ & $-\infty$ & $-\infty$ & \multicolumn{2}{|l|}{$500 \max }$. \\
\hline 1853 & Wichita & Schoolcraft & $\sim$ & -- & - & 300 & \\
\hline 1853 & Waco & "1 & $-\infty$ & -- & $-\infty$ & 200 & \\
\hline 1853 & $\begin{array}{l}\text { Tawakoni } \\
\text { Kichai } \\
\text { Waco }\end{array}$ & $" 1$ & $-\infty$ & $-\infty$ & $\sim$ & 300 & \\
\hline 1853 & $\begin{array}{l}\text { Kichai- } \\
\text { Oklahoma }\end{array}$ & Móllhausen & 100 men & $-\cdots$ & -- & 200 & \\
\hline
\end{tabular}




\begin{tabular}{|c|c|c|c|c|c|c|c|}
\hline Year & Group & Source & $\begin{array}{l}\text { No, of } \\
\text { Warriors }\end{array}$ & $\begin{array}{l}\text { No, of } \\
\text { Dwellings }\end{array}$ & $\begin{array}{l}\text { No. of } \\
\text { Villages }\end{array}$ & $\begin{array}{l}\text { Pop. } \\
\text { Sub-Total }\end{array}$ & $\begin{array}{l}\text { Estim. } \\
\text { Tribal } \\
\text { Population }\end{array}$ \\
\hline 1853 & Wacos & MölIhausen & $-\infty$ & $-\infty$ & $-\infty$ & 200 & \multirow{6}{*}{$\begin{array}{l}1,038- \\
1,070\end{array}$} \\
\hline 1853 & Wichita & $1 "$ & - & - & $-\infty$ & 800 & \\
\hline $\begin{array}{l}1854 \\
\& \\
1855\end{array}$ & Wacos & Schoolcraft & $\begin{array}{l}65 \text { men } \\
88 \text { fem. } \\
72 \text { juv. }\end{array}$ & - & - & $225>$ & \\
\hline $\begin{array}{l}1854 \\
\& \\
1855\end{array}$ & Tawakoni & $\begin{array}{l}5] \\
63 \\
55\end{array}$ & $\begin{array}{l}51 \text { men } \\
63 \text { fem。 } \\
55 \text { juv. }\end{array}$ & $-\infty$ & - & 169 & \\
\hline $\begin{array}{l}1854 \\
\& \\
1855\end{array}$ & Wichita & $\begin{array}{r}80 \\
112 \\
122\end{array}$ & $\begin{array}{l}80 \text { men } \\
12 \text { fem. } \\
22 \text { juv. }\end{array}$ & $-\infty$ & $-\infty$ & 3I) & \\
\hline $\begin{array}{l}1854 \\
1855\end{array} \&$ & \& Kichais & 100 & $.00 \mathrm{men}$ & $\infty$ & $\rightarrow$ & $\left.\begin{array}{l}330- \\
362\end{array}\right)$ & \\
\hline 1855 & $\begin{array}{l}\text { Tawakoni } \\
\text { (Texas Res。) }\end{array}$ & )$^{H i I I}$ & - & $-\infty$ & $-\infty$ & 136 & \multirow{2}{*}{230} \\
\hline 1855 & $\begin{array}{l}\text { Waco } \\
\text { (Texas Res。) }\end{array}$ & $"$ & $=$ & $-\infty$ & - & $94\}$ & \\
\hline 1857 & Kichai & $\begin{array}{l}\text { Schoolcraft } \\
1860: \mathrm{VI}, 687\end{array}$ & $87,-\infty 89$ & $-\infty$ & - & $\left.\begin{array}{r}300 \\
\text { (about) }\end{array}\right)$ & \multirow{8}{*}{1,280} \\
\hline 1857 & Tawakoni & $"$ & $-\infty$ & $-\infty$ & $-\infty$ & $380\}$ & \\
\hline 1857 & Wac os & $"$ & $-\infty$ & - & $-\infty$ & 300 & \\
\hline 1857 & Wichita & $"$ & - & $-\infty$ & $-\infty$ & $300)$ & \\
\hline 1857 & Tawakoni & $\begin{array}{l}\text { Ross, } 1857 \mathrm{a} \\
\& \mathrm{~b}, \mathrm{Tex} \text {. Res. }\end{array}$ & s. & $\infty$ & $-\infty$ & $\begin{array}{l}203- \\
224\end{array}$ & \\
\hline 1857 & Wacos & $"$ & $-\infty$ & $=$ & $-\infty$ & $\begin{array}{l}161 \\
171\end{array}$ & \\
\hline 1859 & Tawakoni & $\begin{array}{l}\text { Blain, 1859d } \\
\text { Tex.Res. }\end{array}$ & $d=\infty$ & $-\infty$ & - & 200 & \\
\hline 1859 & Waco & $"$ & - & $-\infty$ & $-\infty$ & 11,4 & \\
\hline 1866 & $\begin{array}{l}\text { All (Kansas } \\
\text { Reservation }\end{array}$ & $\begin{array}{l}\text { Shanklin- } \\
1866\end{array}$ & $-\infty$ & $\infty$ & $-\infty$ & & 822 \\
\hline 1867 & $\begin{array}{l}\text { A.ll (Okla. } \\
\text { Reservation }\end{array}$ & $\begin{array}{l}\text { U.S. Dept, } \\
\text { Inter., } 1868\end{array}$ & $-\infty$ & $-\infty$ & $\infty$ & & 758 \\
\hline 1872 & $\begin{array}{l}\text { All (Okla. } \\
\text { Reservation }\end{array}$ & Richards & $=-$ & $\infty$ & $-\infty$ & & 692 \\
\hline
\end{tabular}


354

\begin{tabular}{|c|c|c|c|c|c|c|c|}
\hline Year & Group & Source & $\begin{array}{l}\text { No, of } \\
\text { Warriors }\end{array}$ & $\begin{array}{l}\text { No. of } \\
\text { Dwellings }\end{array}$ & $\begin{array}{l}\text { No. of } \\
\text { Viliages }\end{array}$ & $\begin{array}{l}\text { Pop. } \\
\text { Sub-Total }\end{array}$ & $\begin{array}{l}\text { Estim. } \\
\text { Tribal } \\
\text { Population }\end{array}$ \\
\hline 1873 & $\begin{array}{l}\text { All (Okla. } \\
\text { Reservation) }\end{array}$ & Richards & -- & $\cdots$ & -- & & 671 \\
\hline 1874 & $\begin{array}{l}\text { All (Okla, } \\
\text { Reservation) }\end{array}$ & Richards & $-\infty$ & -- & -- & & 671 \\
\hline 1875 & $\begin{array}{l}\text { All (Okla. } \\
\text { Reservation) }\end{array}$ & Richards & - & - & -- & & 486 \\
\hline .1876 & $\begin{array}{l}\text { All (Okla. } \\
\text { Reservation) }\end{array}$ & Williams & - & -- & $\cdots$ & & 472 \\
\hline 1877 & $\begin{array}{l}\text { All (Okla. } \\
\text { Reservation) }\end{array}$ & Williams & -- & -- & -- & & 499 \\
\hline 1880 & $\begin{array}{l}\text { All (Okla. } \\
\text { Reservation) }\end{array}$ & Hunt & -- & -- & - & & 458 \\
\hline 1881 & $\begin{array}{l}\text { All (Okla. } \\
\text { Reservation) }\end{array}$ & Hunt & - & -- & -- & & 483 \\
\hline 1882 & $\begin{array}{l}\text { All (Okla. } \\
\text { Reservation) }\end{array}$ & Hunt & -- & - & - & & 491 \\
\hline 1883 & $\begin{array}{l}\text { All (Okla, } \\
\text { Reservation) }\end{array}$ & Hunt & - & -- & -- & & 506 \\
\hline 1884 & $\begin{array}{l}\text { All (Okla. } \\
\text { Reservation) }\end{array}$ & Hunt & - & -- & -- & & 491 \\
\hline 1885 & $\begin{array}{l}\text { All (Okla. } \\
\text { Reservation) }\end{array}$ & Hunt & -- & - & - & & 471 \\
\hline .1886 & $\begin{array}{l}\text { All (Okla. } \\
\text { Reservation) }\end{array}$ & Hunt & - & $-\infty$ & $\infty$ & & 432 \\
\hline .1887 & $\begin{array}{l}\text { All (Okla. } \\
\text { Reservation) }\end{array}$ & Hall & - & -- & $-\infty$ & & 458 \\
\hline 1889 & $\begin{array}{l}\text { All (Okla. } \\
\text { Reservation) }\end{array}$ & Myers & - & - & - & & 400 \\
\hline 1890 & $\begin{array}{l}\text { All (Okla. } \\
\text { Reservation) }\end{array}$ & Adams & $-\infty$ & $\infty$ & - & & 424 \\
\hline 1891 & $\begin{array}{l}\text { All (Okla. } \\
\text { Reservation) }\end{array}$ & Adams & $-\infty$ & $-\infty$ & $-\infty$ & & 426 \\
\hline
\end{tabular}




\author{
BIBL IOGRA PHY \\ Published Books and Articles
}

Abel, Annie Heloise

1915 The American Indian as Slaveholder and Secessionist; an Omitted Chapter in the Diplomatic History of the Southern Confederacy. Cleveland

Allen, Henry Easton

1939 The Parrilla Expedition to the Red River in 1759, Southwestern Historical Quarterly, XLIII, No. 1 , $53-71$.

Anonymous

1875 Reports of the Committee of Investigation sent in 1873 by the American Government to the Frontier of Texas. New York.

1935 The Signs of the White Man, The Eagle (Spanish Fort High School Paper, Spanish Fort, Texas, Centennial Edition), May 10, 1935.

Ayer, Mrs. Edward E. (trans.)

1916 The Memorial of Fray Alonso de Benavides, 1630. Chicago.

Battey, T. C.

1876 Life and Adventures of a Quaker Among the Indians. New York.

Bell, Robert E., and David A. Baerreis

1951:9 A Survey of Oklahoma Archeology, Bulletin of the Texas Archeological and Paleontological Society, XXII, 7-100.

Boas, Franz

1895 Zur Anthropologie der nordamerikanischen Indianer, Verhandlungen der Berliner Gesselschaft fur Anthropologie, Ethnologie and Urgeschichte. Berline, 367-411.

Bobb, Bernard E.

1962 The Viceregency of Antonio Maria Bucareli in New Spain, 1771-1779. Austin.

Bolton, Herbert E.

1910a Tawakoni, Bureau of American Ethnology, Bulletin 30

(2 vols.). Washington, II, 701-704. 
1910b Tawehash, Bureau of American Ethnology, Bulletin 30 (2 vols.). Washington, II, 705-707.

1910c Waco, Bureau of American Ethnology, Bulletin 30 (2 vols.). Washington, II, 887-888.

l9lod Yscanis, Bureau of American Ethnology, Bulletin 30 (2 vols.). Washington, II, 1002-1003.

1913 Guide to Materials for the History of the United States in the Principal Archives of Mexico, Carnegie Institution of Washington, Publication 163. Washington.

$1914 a$ Athanase de Mézières and the Louisiana-Texas Frontier 1768-1780 (2 vols.). Cleveland.

1914b Journal of an Expedition up the Red River, 1773-1774; by J. Gaignard, Athanase de Mézières and the Louisiana-Texas Frontier 1768-1780 (2 vols.). Cleveland, II, 83-100.

1914c The Expedition of 1778 from Bexar to the Nations of the Upper Trinity, Brazos, and Red Rivers, Athanase de Mézières and the Louisiana-Texas Frontier 17681780 (2 vol.s). Cleveland, II, 187-238.

19.14d Report by de Mézières of the Expedition to Cadodachos, October 29, 1770, Athanase de Mézieres and the Louisiana-Texas Frontier 1768-1780 (2 vols.). Cleveland, I, 206-220.

1914e The Expedition of 1772 from Natchitoches to the Nations of the Upper Trinity and Brazos Rivers, Athanase de Mézières and the Louisiana-Texas Frontier 1768-1780 (2 vols.). Cleveland, I, 283-351.

$1914 f$ The Expedition of 1779 to the Nations Between Natchitoches and the Middle Brazos, Athanase de Mézieres and the Louisiana-Texas Frontier 1768-1780 (2 vols.). Cleveland, II, 239-287.

1915 Texas in the Middle Eighteenth Century: Studies in Spanish Colonial History and Administration. Berkeley.

1916 Spanish Exploration in the Southwest, 1542-1706. New York.

1917 French Intrusions into New Mexico, 1749-1752, in H. Morse Stephens and Herbert E. Bolton (eds.), The Pacific Ocean in History. New York, 389-407. 
1949 Coronado, Knight of Pueblos and Plains. New York.

1964 The Mission as a Frontier Institution in the SpanishAmerican Colonies. El Paso.

Bonnell, George W。

1964 Topographical Description of Texas, to Which is Added, an Account of the Indian Tribes. Waco.

Bushell, D. I,

1922 Villages of the Algonquian, Siouan and Caddoan Tribes, Bureau of American Ethnology, Bulletin 77. Washington, $179-182$.

Butler, Josiah

1928 Pioneer School Teaching at the Comanche Kiowa Agency School 1870-3, Chronicles of Oklahoma, VI, No. 4, 483-528.

Caldwell, Warren W.

1964 Fortified Villages in the Northern Plains, Plains Anthropologist, Vol. 9 (23): $1-7$.

Carroll, H。Bailey

1951 The Texan Santa Fe Trail. Lubbock.

Castañeda, Carlos E.

1936- Our Catholic Heritage in Texas (7 vols.). Austin.

1958

Catiin, George

1841 Letters and Notes on the Manners, Customs, and Conditions of the North American Indians (2 vols.). London.

Chabot, Frederick C.

1932 Excerpts from the Memorias for the History of the Province of Texas. San Antonio.

Chapman, B. B.

1944 Dissolution of the Wichita Reservation, Chronicles of Oklahoma, XXII, 192-209, 300-314.

Connelley, W. E.

1918 Notes on the Early Indian Occupancy of the Great Plains, Kansas State Historical Society Collections, XIV, 438-470,

Cox, Isaac Joslin

1905 The Journeys of Rene Robert Cavelier Sieur de La Salle (2 vols.). New York. 
Curtis, Edward S.

1930 The North American Indian (20 vols.). Norwood, X.IX, 35-104.

Curtis, F. S.

1927 Spanish Arms and Armor in the Southwest, New Mexico Historical Review, II, No.2, 107-133.

Delanglez, Jean

1939 Tonti Letters, Mid-America, XXI, No. 3, 209-238.

1943 Fraquelin, Mapmaker, Mid-America, XXV, No. 1, $29-74$.

Dockstader, Frederick J.

1957 The American Indian in Graduate Studies, A Bibliography of Theses and Dissertations, Contributions from the Museum of the American Indian, Heye Foundation, XV. New York.

Donoghue, David

1929 The Route of the Coronado Expedition in Texas, Southwestern Historical quarterly, XXXII, No. 3, 181-192.

Dorsey, G. A.

1901 Hand or Guessing Game Among the Wichitas, American Antiquarian and Oriental Journal, XXIII, 363-370.

1902- Wichita Tales, Journal of American Folf Lore, XV, 1904 215-239; XVI, 160-179; XVII, 153-160.

1904 The Mythology of the Wichita, Carnegie Institution of Washington, Publication 21. Washington.

Douglas, F. H.

1932a The Wichita Indians and Allied Tribes Waco, Towakoni, and Kichai, Denver Art Museum Indian Leaflet Series, $\mathrm{XL}, 1-4$.

1932b The Grass House of the Wichita and Caddo, Denver Art Museum Indian Leaflet Series, XLII, 1-4.

Driver, Harold E. and William C. Massey

1957 Comparative Studies of North American Indians, Transactions of the American Philosophical Society, New Series, XLVII, Part 2.

Douglas, Frederic H. (comp.)

1934 A Guide to Articles on the American Indians in Serial Publications, Part I. Denver Art Museum, Denver, 1934. 
Duffield, Lathel F。 1965

The Taovayas Village of 1759: in Texas or Oklahoma? Great Plains Journal, IV, No. 2, 39-48.

Duffield, Lathel and Edward B. Jelks

1961 The Pearson Site, a Historic Site in Iron Bridge Reservoir, Rains County, Texas. Archaeology Series, No. 4, Department of Anthropology, The University of Texas at Austin.

Erath, George B.

1923 Memoirs of Major George Bernard Erath. Austin.

Ethridge, A。N,

1940 Indians of Grant Parish, Louisiana Historical Quarterly, XXIII, 1108-1131.

Fenton, William No, et al.

1957 American Indian and. White Relations to 1830: Needs and Opportunities for Study, University of North Carolina Press, Chapel Hill, 1957. (This contains a bibliography concerning Indian-White Relations).

Field, Thomas $W$.

1873 An Essay Towards an Indian Bibliography, Scribner, Armstrong, and Company, New York, 1873.

Fletcher, A. C.

1907 Kichai, Bureau of American Ethnology, Bulletin 30 (2 vols.). Washington, I, 682, 683.

Forbes, Jack D。

1960 Apache, Navaho and Spaniard. Norman.

Foreman, Grant

1926 Pioneer Days in the Early Southwest. Cleveland.

1936 Indians and Pioneers: The Story of the American Southwest Before 1830. Norman.

1941 A Pathfinder in the Southwest: The Itinerary of Lieutenant A. W. Whipple During his Explorations for a Railway Route from Fort Smith to Los Angeles in the Years 1853 and 1854. Norman.

1946 The Last Trek of the Indians. 


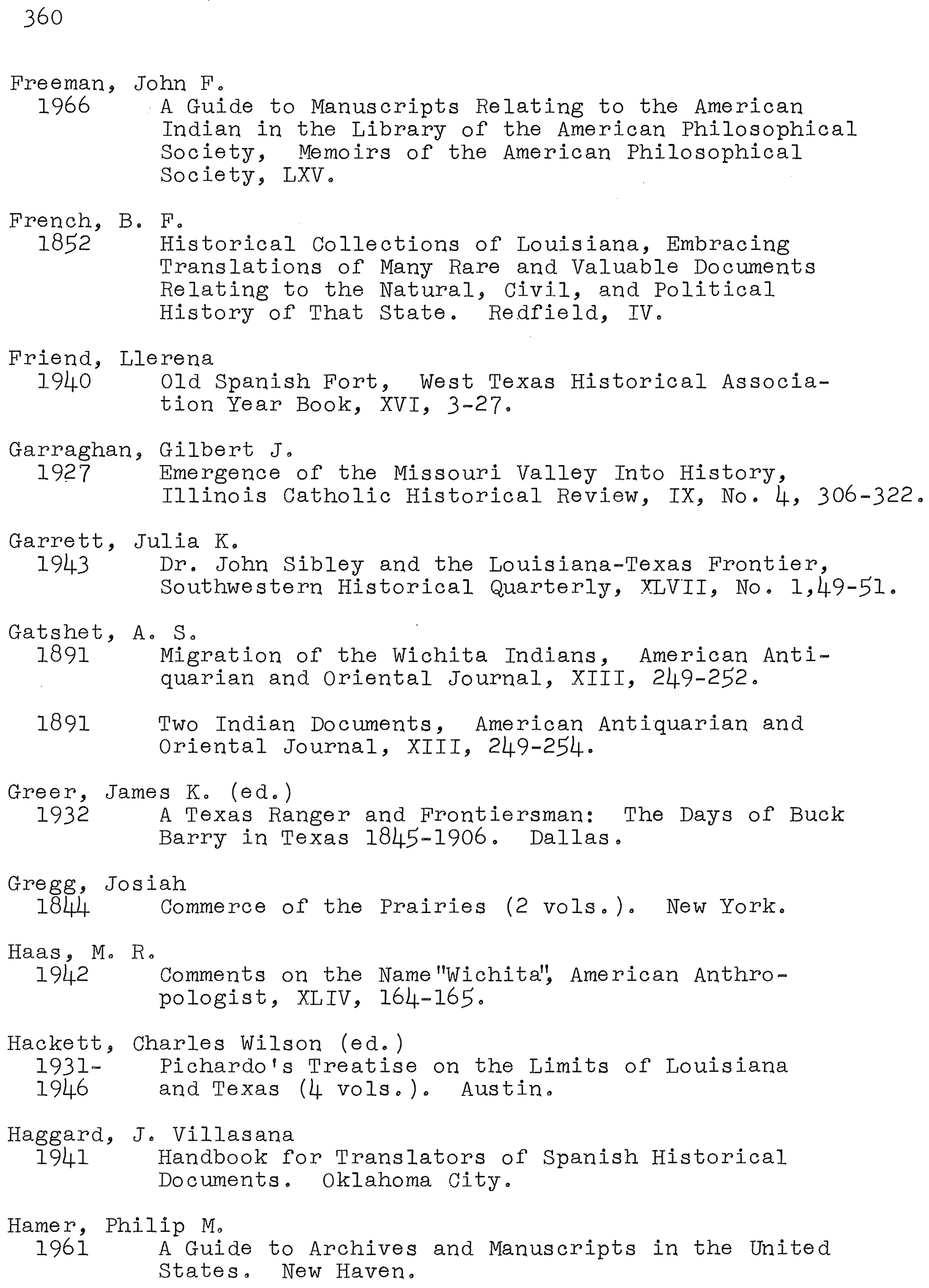

Hackett, Charles Wilson (ed.)

1931- Pichardo's Treatise on the Limits of Louisiana

1946 and Texas (4 vols.). Austin.

Haggard, J。 Villasana

1941 Handbook for Translators of Spanish Historical

Documents. Oklahoma City.

Hamer, Philip M。

1961 A Guide to Archives and Manuscripts in the United States. New Haven. 
Holley, Mary Austin

1836 Texas. Lexington.

Hollon, W. Eugene

1961 The Southwest: Old and New. New York.

Houck, Louis

1909 The Spanish Regime in Missouri (2 vols.). Chicago.

Howard, Edgar B.

$1935^{\circ}$ Evidence of Early Man in North America, Museum Journal, XXIV, Nos. 2-3, 61-175.

Hungate, M.

1938 Religious Beliefs of the Nebraska Indian. Nebraska History Magazine, XIV, No. 3, 207-236.

James, Edwin

1905 Account of $\mathrm{S}$. H. Long's Expedition, 1819-1820, in Early Western Travels (Reuben Gold Thwaites, Ed.), XVI。

James, Thomas

1916 Three Years Among the Indians and Mexicans. St. Louis.

Johnson, LeRoy, Jr., and Edward B. Jelks

1958 The Tawakoni-Yscani Village, 1760: A Study of Archeological Site Identification, Texas Journal of Science, $X$, No. 4, 405-422.

Jones, Paul A.

1929 Quivira. Wichita, Kansas.

1937 Coronado and Quivira. Lyons, Kansas.

Kenda11, George Wilkins

1844 Narrative of the Texan Santa Fe Expedition (2 vols.). London.

Kenney, M. M。

1898 The History of the Indian Tribes of Texas, in Dudley G. Wooten (ed.), A Comprehensive History of Texas (2 vols.), I, 717-783. Dallas.

Kinnaird, Lawrence

1945 Spain in the Mississippi Valley. Annual Report of the American Historical Association (3 vols.). Washington.

1958 The Frontiers of New Spain: Nicolas de Lafora's Description 1766-1768, Quivira Society Publications, XIII。 
Hamilton, Raphael N.

1934 Early Maps of the Missouri Valley, American Historical Review, XXXIX, No. 4, 645-662.

Hammond, G。 Po, and A. Rey

1940 Narratives of the Coronado Expedition. Albuquerque.

1953 Don Juan de Oñate, Colonizer of New Mexico, 1595-1628 (2 vols。). Albuquerque.

Harper, Elizabeth Ann

1953a The Taovayas Indians in Frontier Trade and Diplomacy, 1719-1768, Chronicles of Oklahoma, XXXI, No. 3, $268-289$.

1953b The Taovayas Indians in Frontier Trade and Diplomacy, 1769-1779, Southwestern Historical Quarterly, LVII, No. 2, 181-201.

19530 The Taovayas Indians in Frontier Trade and Diplomacy, 1779-1835, Panhandle-Plains Historical Review, XXIII, $1-32$.

Hatcher, Mattie Austin (trans.)

1908 Joaquin de Arredondo's Report of the Battle of the Medina, August 18, 1813, Quarterly of the Texas State Historical Association, XI, No. 3, 220-236.

1919 Texas in 1820, Southwestern Historical Quarterly, XXIII, No. 1, 47-68.

1927 Descriptions of the Tejas or Asinais Indians, 16911722, Southwestern Historical Quarterly, XXX, No. 3, 206-218; XXX, No。 4, 283-304; XXXI, No。1, 50-52; and XXXI, No.2, 150-180。

Hill, Roscoe R。

1916 Descriptive Catalogue of the Documents Relating to the History of the United States in the Archivo General de Indias at Seville. Carnegie Institution of Washington, Publication 234. Washington.

Hodge, Frederick Webb

1907 The Narrative of the Expedition of Coronado, by Pedro de Castañeda. Original Narratives of Early American History。

1933 The Journal of Francisco Vazquez de Coronado, 1540-1542.

1937 History of Hawikuh, New Mexico, one of the So-called Cities of Cibola. Los Angeles.

, G. P. Hammond, and A. Rey

1945 Fray Alonso de Benavides' Revised Memorial of 1634. Albuquerque. 
Koch, Clara Lena

1925 The Federal Indian Policy in Texas, 1845-1860, Southwestern Historical Quarterly, XXVIII, No. 3, 223-234; No. 4, 259-286; XXIX, No. 1, 19-35; and No. 2, 98-127.

Krieger, Alex D。

1946 Culture Complexes and Chronology in Northern Texas. The Univ, of Texas Publication, No. 4640 .

Kroeber, A。L。

1947 Cultural and Natural Areas of Native North America. Berkeley.

Kuykendall, J。H。

1903 Reminiscences of Early Texans, Quarterly of the Texas State Historical Association, VI, No. 3, 236-253.

Lanzas, Pedro Torres

1900 Relacion Descriptiva de los Mapas, Planos, \& de Mexico y Floridas Existentes en al Archivo General de Indios (2 vols。). Seville.

Lesser, A。 1930

Levirate and Fraternal Polyandry Among the Pawnees, Man, XXX, 98-101.

and $G$ 。 Weltfish

1932 Composition of the Caddoan Linguistic Stock, Smithsonian Miscelleneous Collections, LXXXVII, vi, $1-15$.

Lewis, Anna

1924 La Harpe's First Expedition in Oklahoma, 1718-1719, Chronicles of Oklahoma, II, No. 4, 331-349.

1925 Du Tisné's Expedition into Oklahoma, 1719, Chronicles of Oklahoma, III, No. 4, 319-323.

Loomis, Noel Mo and Abraham P. Nasatir

1967 Pedro Vial and the Roads to Santa Fe。 University of Oklahoma Press. Norman.

Lowie, Robert H.

1963 Indians of the Plains, American Museum Science Books Edition, Garden City.

Mc Connell, Joseph Carroll

1933 The West Texas Frontier, or a Descriptive History of Early Times in western Texas ( 3 vols。). Jacksboro. 
364

Marcy, R。 B。

1853 Exploration of the Red River of Louisiana in the Year 1852. Washington.

1866 Thirty Years of Army Life on the Border. New York.

Margry, Pierre

1875- Decouvertes et establissements des Francais dans

1888 l'ouest et dans le sud de l'Amerique Septentrionale (1614-1754) (6 pts.). Paris.

Mason, otis Tufton

1894 North American Bows, Arrows, and Quivers, Annual Report of the Board of Regents of the Smithsonian Institution Showing the operations, Expenditures, and Condition of the Institution to July, 1893, $631-680$.

Me ad, J.R.

1904 The Wichita Indians in Kansas, Transactions of the Kansas Historical Society, VIII, 171-177.

1908 The Little Arkansas, Transactions of the Kansas Historical Society, $\mathrm{x}, 7-14$.

Methvin, J。 J。

n.d. In the Limelight, or History of Anadarko (Caddo County) and Vicinity From the Earliest Days. n.p.

Mitchell, Sara Brown

1950- Early Days of Anardarko, Chronicles of Oklahoma,

1951 XXVIII, No 4, 390-398.

Mồllhausen, Baldwin

1858 Diary of a Journey From the Mississippi to the Coasts of the Pacific with a United States Government Expedition (2 vols.). London.

Mooney, J。

1893 The Ghost-Dance Religion, Annual Report, Bureau of American Ethnology, XIV. Washington, ii, 1078-1091.

1898 Calendar History of the Kiowa Indians, Annual Report, Bureau of American Ethnology, XVII. Washington, i, $14.1-447$.

1910a Population, Bureau of American Ethnology, Bulletin 30 (2 vols.). Washington, II, 286-287.

1910b Wichita, Bureau of American Ethnology, Bulletin 30 (2 vols.). Washington, II, 947-950. 


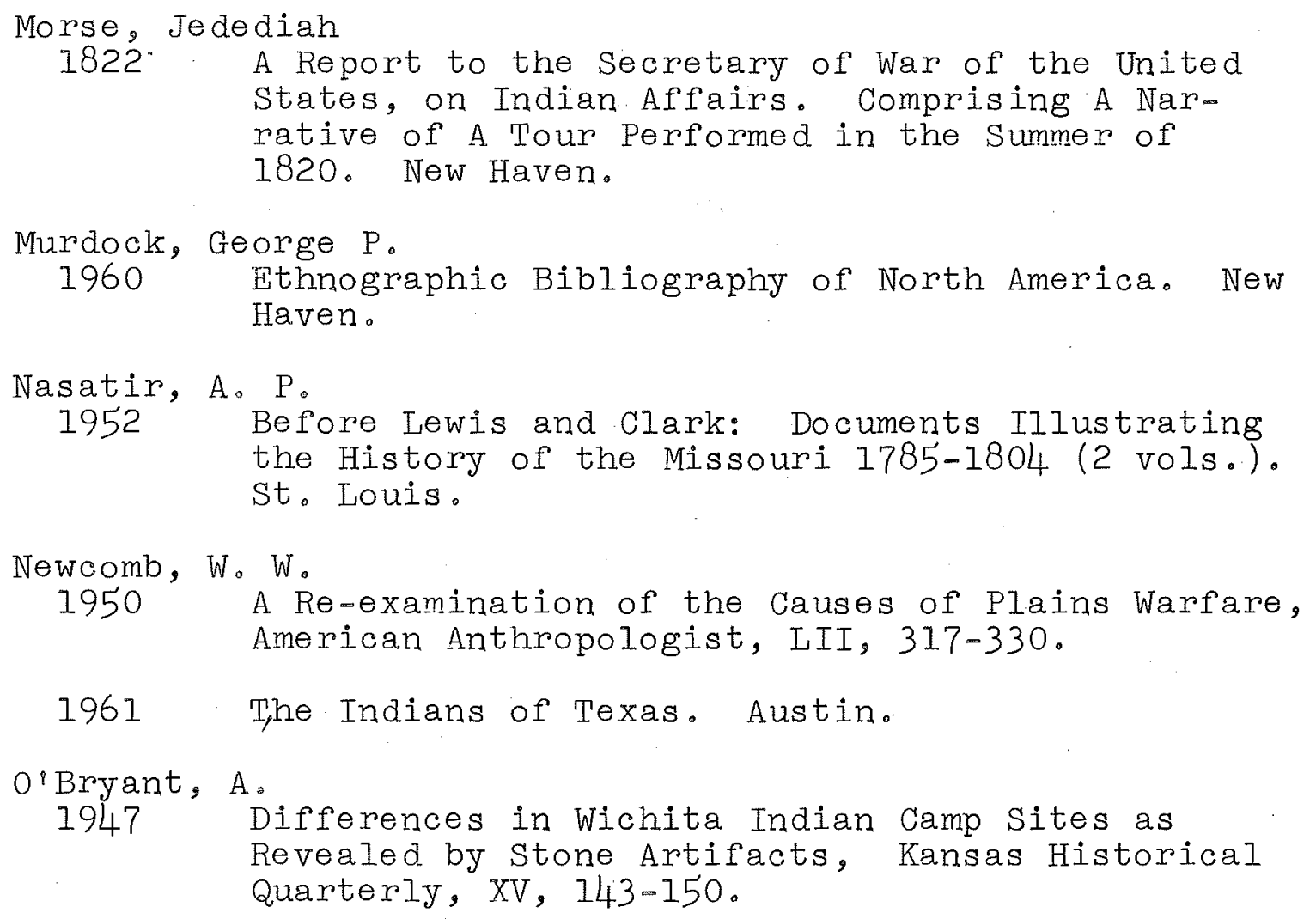

Nasatir, A。P.

1952 Before Lewis and Clark: Documents Illustrating the History of the Missouri 1785-1804 (2 vols.). st. Louis.

Newcomb, W。W。

1950 A Re-examination of the Causes of Plains Warfare, American Anthropologist, LII, 317-330.

1961 The Indians of Texas. Austin.

O'Bryant, A.

1947 Differences in Wichita Indian Camp Sites as Revealed by Stone Artifacts, Kansas Historical Quarterly, XV, 143-150。

Paddock, B。B.

1911 A History of Central and Western Texas (2 vols.)。 Chicago.

Parker, W. B.

1856 Notes Taken During the Expedition Commanded by Capt. R. B。 Marcy, U.S.A., Through Unexplored

Texas in the Summer and Fall of 1854. Philadelphia.

Pease, T. Co, and R。 Co Werner (eds.)

1934 Memoir of De Gannes Concerning the Illinois Country, Collections of the Illinois State Historical Library, XXIII, French Series, I, 302-395.

Pratt, $\mathrm{C} 。 \mathrm{H}$.

n. d. The Wichita Nation (mimeograph report), n.p.

Richardson, Rupert N. (ed。)

1925 Documents Relating to West Texas and Her Indian Troubles, West Texas Historical Association Year Book, I, 30-83.

Sanchez, Jose Maria

1926 A Trip to Texas in 1828 (Carlos E. Castañeda, trans.) Southwestern Historical Quarterly, XXIX, No.4, 250-288. 
Scarborough, Dorothy

1916 Traditions of the Waco Indians, Publications of the Folk-Lore Society of Texas, I, 50-54.

Schmitt, Karl

1952 Wichita Death Customs, The Chronicles of Oklahoma, XXX, No. 2, 200-206.

1950 Wichita-Kiowa Relations and the 1874 outbreak, The Chronicles of Oklahoma, XXVIII, No.2, 154-160.

, and Iva Osanai Schmitt

n.d. Wichita Kinship, Past and Present.

Scholes, France Vo, and H. P. Mera

1940 Some Aspects of the Jumano Problem. Carnegie Institution of Washington, Publ. 523, 265-299.

Schoolcraft, Henry R.

1860 Information Respecting the History Condition and Prospect of the Indian Tribes of the United States (6 vols.). Philadelphia.

Schroeder, Albert $\mathrm{H}$.

1962 A Re-analysis of Coronado and Oñate into the Plains in 1541 and 1601, Plains Anthropologist, Vol. 7 $(15): 2-23$.

Shepherd, William R.

1907 Guide to the Materials for the History of the United States in Spanish Archives, Carnegie Institution of Washington, Publication 91, Washington.

Sibley, George C.

1922 From a journal to the Pawnee and Kansas Villages, undertaken by an officer of the Factory on the Missouri. Louisiana Gazette, May 16, 1912; reprinted in Nebraska Hist. Publ., XX, 5-11。

1927 Extracts from the Diary of Major Sibley, Chronicles of Oklahoma, $\mathrm{V}, 196-218$.

Sibley, John

1807a Historical Sketches of the Several Indian Tribes in Louisiana, South of the Arkansas River and Between the Mississippi and River Grand, in Travels in the Interior Parts of America; Communicating Discoveries Made in Exploring the Missouri, Red River and Washita, by Captains Lewis and Clark, Doctor Sibley, and Mr. Dunbar; With a Statistical Account of the countries Adjacent. London. 
1807b Letter to General Henry Dearborn, in Travels in the Interior Parts of America; Communicating Discoveries Made in Exploring the Missouri, Red River and Washita, by Captins Lewis and Clark, Doctor Sibley, and Mr. Dunbar; With a Statistical Account of the Countries Adjacent. London.

1922 A Report From Natchitoches in 1807, (Annie Heloise Abel, ed.), Indian Notes and Monographs (F.W. Hodge, ed。), Museum of the American Indian, Heye Foundation, New York。

1832 Historical Sketches of the Several Indian Tribes in Louisiana, South of the Arkansas River, and Between the Mississippi and River Grande, in American State Papers, Indian Affairs. Washington, I, 721-728.

Simpson, Lesley Byrd (e,do)

1959 The San Saba Papers: A Documentary Account of the Founding and Destruction of San Sabá Mission, (Paul D. Nathan, trans.). San Francisco.

Smith, Ralph A。 (trans.)

1958- Account of the Journey of Bénard de la Harpe:

1959 Discovery Made by Him of Several Nations Situated in the West, Southwestern Historical Quarterly, LXII, No. 1, 75-86; No. 2, 246-259; No. 3, 371-385; and No. 4, 525-541.

1952 The Tawehash in French, Spanish, English, and American Imperial Affairs, West Texas Historical Association Year Book, XXVIII, 18-49.

Spier, Leslie

1924 Wichita and Caddo Relationship Terms., American Anthropologist, XXVI, No. 2, 258-263.

Steen, Charlie R。

1953 Two Early Historic Sites on the Southern Plains, Bulletin of the Texas Archeological Society, XXIV, 177-188.

Stephens, Ho Morse and Herbert E。 Bolton (eds。)

1917 The Pacific Ocean in History. New York.

Stephenson, Robert L。

1952 The Hogge Bridge Site and the Wylie Focus, American Antiquity, Vol。17 (4): 299-312。 
Surrey, No Mo Miller (ed.)

1928 Calender of Manuscripts in Paris Archives and Libraries Relating to the History of the Mississippi Valley to 1803 (2 vols.), Carnegie Institution of Washington, Department of Historical Research, 1928.

Swanton, John R.

1924 The Aboriginal Population of America North of Mexico, Smithsonian Miscellaneous Collections, LXXX, No. 7 .

Tallichet, $\mathrm{H}$.

1896 A Contribution Towards a Vocabular of Spanish and Mexican Words Used in Texas, Dialect: Notes, I, 185-196.

1896 Addenda to the Vocabulary of Spanish and Mexican Words Used in Texas, Dialect Notes, I, 243-253.

Thoburn, Joseph Fo, and Muriel H. Wright

1929 Oklahoma: A History of the state and Its People

(4 vols.). New York.

Thomas, A。B.

1924 The Massacre of the Villasur Expedition at the Forks of the Platte River, August 12, 1720, Nebraska History Magazine, VII, No. 3.

1928 Spanish Exploration of Oklahoma 1599-1792, Chronicles of Oklahoma, VI, 6, No. 2 .

1932 Forgotten Frontiers. A Study of the Spanish Indian Policy of Don Juan de Bautista de Anza, Governor of New Mexico, 1777-1787. Norman.

1935 After Coronado: Spanish Exploration Northeast of New Mexico 1696-1727. Norman.

1940 The Plains Indians and New Mexico, 1751-1778. Albuquerque.

1941 Teodoro de Croix and the Northern Frontier of New Spain 1776-1783. Norman.

Thomas, Bera V.

1929 Montague County Abounds in Wealth of Indian Lore Attached to Hill Ridge, Dallas Morning News, October 20, 1929, Montague County Scrapbook. Archives, University of Texas Library, Austin。

Thompson, B. Wheelock

1860 Journal of Colonel Dodge's Expedition from Ft. Gibson to the Pawnee Pict Village, in American State Papers, Military Affairs. Washington, $V, 377-385$. 
Tilghman, Z.A.

1941 Origin of the Name Wichita, American Anthropologist. XLIII, 488-9.

Tucker, Sara Jones

1942 Indian Villages of the Illinois Country, Scientific Papers, Illinois State Museum, II, Pt. I, Atlas.

Twitchell, Ralph Emerson

1914 The Spanish Archives of New Mexico (2 vols.). Cedar Rapids.

Villiers du Terrage, Marc de

1925 La decouverte du Missouri et l'histoire du Fort Orleans (1673-1728). Paris.

Wagner, Henry R。

1937 The Spanish Southwest, 1542-1794 (2 parts), Quivira Society Pulbications, XIII.

Webb, Walter Prescott and $\mathrm{H}$. Bailey Carroll (eds.)

1952 The Handbook of Texas (2 vols.). Austin.

Weddle, Robert S。

1964 The San Sabá Mission: Spanish Pivot in Texas. Austin.

Wedel, Waldo R.

1942 Archeological Remains in Central Kansas and Their Possible Bearing on the Location of Quivira, Smithsonian Miscellaneous Collections, CI, No. 7, 1-24.

1959, 65 An Introduction to Kansas Archeology, Bureau of American Ethnology, Bulletin 174. Washington.

West, Elizabeth Howard (trans.)

1904 Bonilla's Brief Compendium of the History of Texas, 1772, Quarterly of the Texas State Historical Association, VIII, No. 1, 2-78.

Wilbarger, J。W。

1889 Indian Depredrations in Texas. Austin.

Winfrey, Dorman H.

1949 Texas Indian Papers 1825-1843. Austin.

Winship, George Parker

1896 The Coronado Expedition, 1540-1542, Fourteenth

Annual Report, Bureau of American Ethnology. Washington.

Witte, Adolph Henry

1938 Spanish Fort, an Historic Wichita Site, Bulletin of the Texas Archeological and Paleontological Society, $x, 234-244$ 。 
Adams, Chas. E.

1890 Report of Kiowa, Comanche and Wichita Agency, Fiftyninth Annual Report of the Commissioner of Indian Affairs to the Secretary of the Interior. Washington.

1891 Report of Kiowa; , Comanche, and Wichita Agency, Sixtieth Annual Report of the Commissioner of Indian Affairs to the Secretary of the Interior. Washington. (2 vols.), I。

Anonymous

1897

Investigation of Affairs at the Kiowa, Comanche and Apache Indian Reservation, Senate Executive Documents, Fifty-fifth Congress, Session II, Document No. 34 , U. S. No. 3559. Washington, 1-388.

Bonnell, George W。

1838 Letter to Secretary of War of Republic of Texas, dated November 3, 1838, U. S. Senate Reports, 30 Congress, 1 Session, No. 171, U.S. 512. Washington

Calmes, W. T.

1881 Letter from W. T. Calmes, Superintendent to Colonel P. B. Hunt, United States Indian Agent, Annual Report of the Commissioner of Indian Affairs to the Secretary of the Interior for the Year 1881. Washington.

Day, George D.

1892 Letter to Commissioner of Indian Affairs, August 30, 1892, Sixty-first Annual Report of the Commissioner of Indian Affairs to the secretary of the Interior. Washington.

Ford, John S.

1889 Report of Texas Boundary Commission. House Executive Documents, 50th Congress 1 Session. U. S. No. 2550. Washington.

Hall, J。 Lee

1886 Letter to Commissioner of Indian Affairs, dated August 26, 1886. Annual Report of the Commissioner of Indian Affairs to the Secretary of the Interior for the Year 1886. Washington.

1887 Letter to Commissioner of Indian Affairs (undated). Annual Report of the Commissioner of Indian Affairs to the Secretary of the Interior for the Year 1887. Washington. 


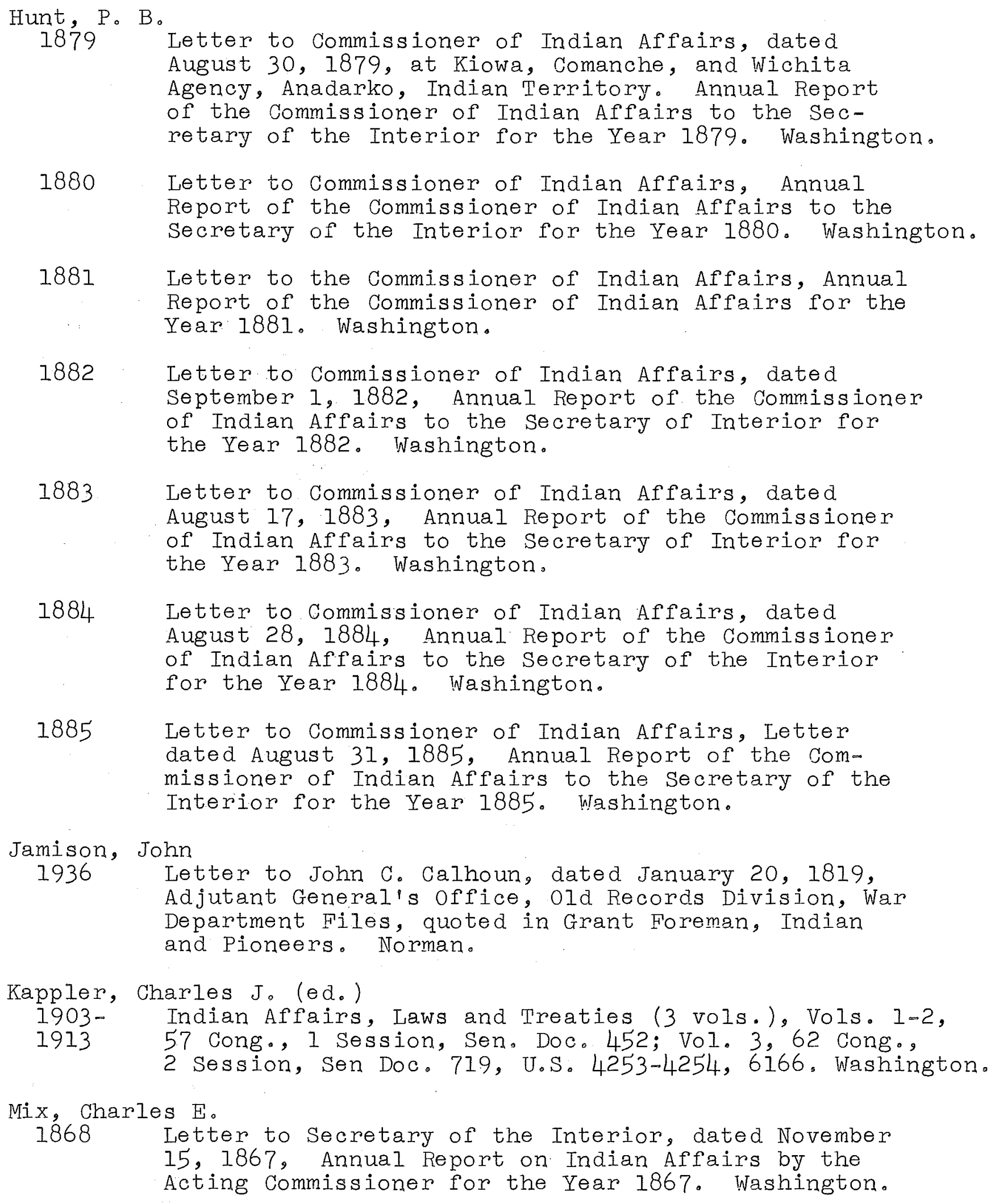

1883. Letter to Commissioner of Indian Affairs, dated August 17, 1883, Annual Report of the Commissioner of Indian Affairs to the Secretary of Interior for the Year 1883. Washington.

1884 Letter to Commissioner of Indian Affairs, dated August 28, 1884, Annual Report of the Commissioner of Indian Affairs to the Secretary of the Interior for the Year 1884. Washington.

1885 Letter to Commissioner of Indian Affairs, Letter dated August 31, 1885, Annual Report of the Commissioner of Indian Affairs to the Secretary of the Interior for the Year 1885. Washington.

Jamison, John

1936 Letter to John C. Calhoun, dated January 20, 1819, Adjutant General's office, Old Records Division, War Department Files, quoted in Grant Foreman, Indian and Pioneers. Norman.

Kappler, Charles Jo (ed.)

1903- Indian Affairs, Laws and Treaties (3 vols.), Vols. 1-2,

191357 Cong., 1 Session, Sen. Doc. 452; Vol. 3, 62 Cong., 2 Session, Sen Doc.719, U.S. 4253-4254, 6166. Washington.

Mix, Charles E。

1868 Letter to Secretary of the Interior, dated November 15, 1867, Annual Report on Indian Affairs by the Acting Commissioner for the Year 1867. Washington. 


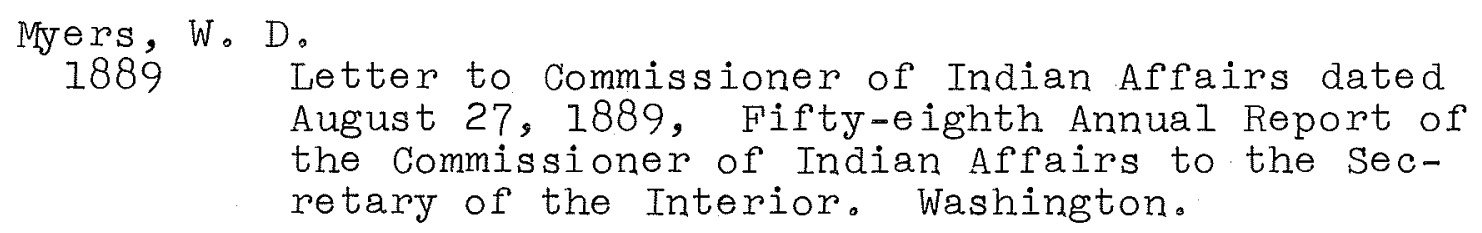

Neighbors, R。S。

1847 Letter to $W$. Medill, dated January 6, 1847, House Executive Documents, 29 Congress, 2 Session, No. 100, U. S. 500, Washington.

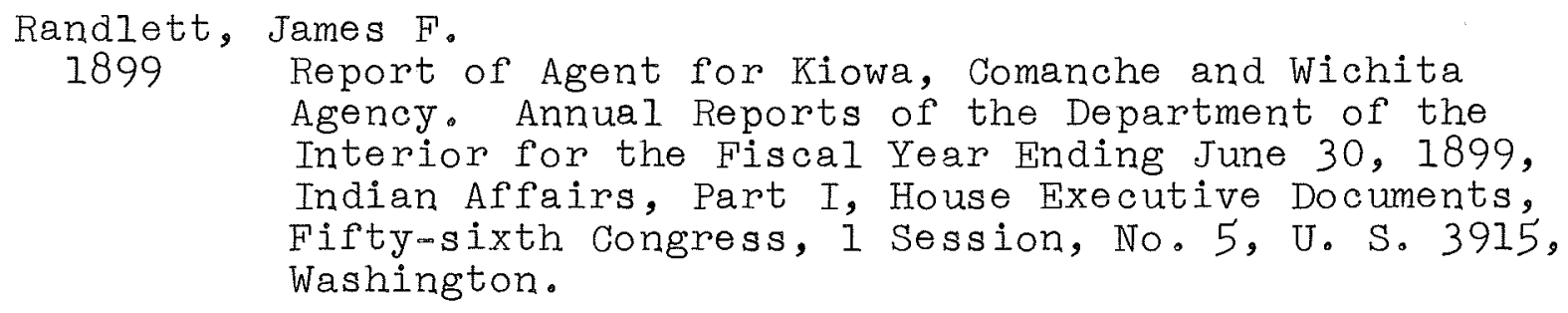

1902 Report of Agent for Kiowa Agency, Annual Reports of the Department of the Interior for the Fiscal Year Ending June 30, 1901, Indian Affairs, Part I, House Executive Documents 57 Congress, 1 Session, No. 5, U. S. 4290. Washington.

1903 Report of Agent for Kiowa Agency, Annual Reports of the Department of the Interior for the Fiscal Year Ended June 30, 1902, Indian Affairs, Part I, House Executive Documents, 57 Congress, 2 Session, No. 5. Washington.

1904 Report of Agent in Charge of Kiowa Agency, Annual Reports of the Department of the Interior for the Fiscal Year Ended June 30, 1903, Indian Affairs, Part I, House Executive Documents, 58th Congress, 2 Session, No. 5. Washington。

1905 Report of Agent for Kiowa Agency, Annual Reports of the Department of the Interior for the Fiscal Year Ending June 30, 1904, Indian Affairs, Part I, Report of the Commissioner and Appendixes. Washington.

1906 Report of Agent for Kiowa Agency, Annual Reports of the Department of the Interior for the Fiscal Year Ended June 30, 1905, Indian Affairs, Part I, Report of the Commissioner and Appendixes. Washington.

Richards, Jonathan

1872 Letter to Superintendent of Indian Affairs, dated Ninth Month 1, 1872, Annual Report of the Commissioner of Indian Affairs to the Secretary of the Interior for the Year 1872. Washington. 
1873 Letter to Superintendent of Indian Affairs, dated Ninth month 1, 1873, Annual Report of the Commissioner of Indian Affairs to the Secretary of the Interior for the Year 1873. Washington.

1874 Letter to Superintendent of Indian Affairs, Annual Report of the Commissioner of Indian Affairs to the Secretary of the Interior for the Year 1874. Washington

1875 Letter to Commissioner of Indian Affairs, dated Ninth-month 1, 1875, Annual Report of the Commissioner of Indian Affairs to the Secretary of the Interior for the Year 1875. Washington.

Shanklin, Henry

1866 Letter to Superintendent of Indian Affairs, Lawrence, Kansas, Report of the Commissioner of Indian Affairs for the Year 1866. Washington.

1868 Letter to Superintendent of Indian Affairs, Southern Superintendency, dated Sept. 1, 1867, Annual Report on Indian Affairs by the Acting Commissioner for the Year 1867. Washington.

U. S. Department of Interior

1868 Statement Showing the Population of the Various Tribes of Indians by Superintendencies, Annual Report on Indian Affairs by the Acting Commissioner for the Year 1867. Washington.

1872 Annual Report of the Commissioner of Indian Affairs to the Secretary of the Interior for the Year 1872. Washington.

1884 Message From the President of the United States Transmitting a Communication from the secretary of the Interior of the 4 th Instant Submitting Draft of Bill to Confirm the Title to Certain Land in the Indian Territory to the Cheyennes and Arapahoes, and the Wichitas and Affiliated Bands, to Provide for the Issuance of Patents Therefor, Senate Executive Documents, 48 Congress, 1 Session, No. 13, U. S. 2162. Washington.

1893 Report of the Secretary of the Interior; Being Part of the Message and Documents Communicated to the Two Houses of Congress at the Beginning of the second. Session of the Fifty-Third Congress, U.S. 3210 (5 vols.), II. Washington. 
1896 Population, Civilization, Religion, Vital, and Criminal statistics, Annual Report of the Coma missioner of Indian Affairs, Washington.

1897 Report of the Secretary of the Interior; Being Part of the Message and Documents Communicated to the Two Houses of Congress at the Beginning of the Second Session of the Fifty-fourth Congress. U. S. 3489 ( 5 vols。), II. Washington.

1907 Population of Indians, Report of the Commissioner of Indian Affairs to the Secretary of the Interior, 1907. Washington.

1963 U. So Indian Population (1962) and Land (1963). Washington。

U. S. War Department

1880 - The War of the Rebellion: A Compilation of the

1901 Official Records of the Union and Confederate Armies (70 vols.).Washington.

Walker, W。 T。

1898 Report of Kiowa Agency, Annual Reports of the Department of the Interior for the Fiscal Year Ended June 30, 1898. Indian Affairs. House Executive Documents, Fifty-Fifth Congress, 3rd. Session, No.5 U. S. 3757. Washington.

Wheelock, T。B.

1834 Report to Colonel Henry Dodge, August 27, 1834 , Public Documents Printed by Order of the Senate of the United States, Second Session of the Twenty-Third Congress Begun and Held at the City of Washington, December 1, 1834, and in the FiftyNinth Year of the Independence of the United States, U. S. 266 (4 vols。), I。 Washington。

1860 Journal of Colonel Dodge's Expedition from Fort Gibson to the Pawnee Pict Village, American State Papers, Military Affairs, V, 377-385. Washington.

Williams, A。C。

1876 Letter to Commissioner of Indian Affairs, dated Eighthmonth 21, 1876, Annual Report of the Commissioner of Indian Affairs to the secretary of the Interior for the Year 1876. Washington.

1877 Letter to the Commissioner of Indian Affairs, dated Eighthmonth 20, 1877, Annual Report of the Com- 
missioner of Indian Affairs to the Secretary of the Interior for the Year 1877. Washington.

1878 Letter to Commissioner of Indian Affairs, dated August 31, 1878. Annual Report of the Commissioner of Indian Affairs to the Secretary of the Interior for the Year 1878. Washington. 
Theses and: Dissertations

Donnell, Guy R.

1940 The History of Montague County, Texas.

M. A. Thesis, Jniversity of Texas, Austin.

Gates, Gladys Eisther

1926 The Wichita Indians from 1859 to 1868.

M. A. Thesis, University of Oklahoma, Norman.

John, Elizabeth Ann Harper

1957 Spanish Relations With the Indios Barbaros on the

Northernmost Frontier of New Spain in the Eighteenth

Century, Ph. D. Dissertation, University of Oklahoma, Norman.

Muckleroy, Anna

1919 The Indian Policy of the Republic of Texas. M. A. Thesis, University of Texas, Austin.

Murphy, William Hymen

1932 A History of the opening of the Wichita-Caddo-KiowaComanche Apache Reservations. M.A. Thesis, Oklahoma $A$ and $M$ College, Stillwater.

Neighbors, Alice Atkinson

1936 Life and Public Works of Robert S. Neighbors, M. A. Thesis, University of Texas, Austin.

Neighbours, Kenneth F.

1955 Robert $S$. Neighbors in Texas, 1836-1859, A Quarter Century of Frontier Problems (2 vols.). Ph. D. Dissertation, University of Texas, Austin.

Noel, Virginia Pink

1924 The United States Indian Reservations in Texas, 18541859, M. A. Thesis, University of Texas, Austin.

Reynolds-Coffey, Lois Marie

1931 A History of the Wichitas. MA Thesis, Oklahoma A\&M College, Stillwater.

Wendels, Maria Anna

1914 French Interest in and Activities on the Spanish Border of Louisiana, 1717-1753, M.A. Thesis, University of California, Berkeley. 
Unpublished Manuscripts

Amangual, Francisco

1808 Diary of the Incidents and Operations Which Took Place in the Expedition Made from the Province of Texas to the (Province) of New Mexico in Compliance with Superior Orders ( $J$. Villasana Haggard, trans.), Bexar Archives (translations), March 31-April 30, 1808 (including Amangual Diary March 30 to December 23, 1808). Archives, University of Texas, Austin.

Anonymous

1763 Testimonio de una Lipan escapada de los Texas sobre la convocacion de 14 naciones del norte convocadas para atacar San Saba, y San Antonio, Real Presidio de San Saba, 4-4-1763, Archivo San Francisco El Grande (Photostat). Archives, University of Texas Library, Austin.

1764 a Declaracion del cautivo indio comanche, San Saba, 10-91764, Archivo San Francisco El Grande (Photostat). Archives, University of Texas Library, Austin.

$1764 \mathrm{~b}$ Breve resumen y opinion del auditor sobre las diligencias contra los indios Northenos practicadas durante el ano proximo pasado y sobre el ataque de los susodichos indios sobre el presidio de San Saba el 19 de enero de 1764, Mexico, 2-16-1764. Archivo San Francisco El Grande (Photostat). Archives, University of Texas Library, Austin.

1764c Declaracion de los cinco indios sobre el fuerte de los Tahuayas, San Saba, 10-8-1764, Archivo San Francisco El Grande (Photostat). Archives, University of Texas Library, Austin.

1794 'List of Items Given to Indian Nations, 3-27-1794, Bexar Archives. Archives, University of Texas Library, Austin.

1850? Indian Population of Texas, 1846-1850, United States Office of Indian Affairs, Letters Received 1838-1862 (Photostats). Archives, University of Texas Library, Austin。

Araindain, Joaquin de, et al.

1763. Nuevas del intertado ataque de los indios del Norte sobre San Antonio de Bexar y declaraciones sobre este asunto de Joaquin de Araindain, Joseph de Pena, y Joseph Joaquin Sanchez, Rectificacion de estos Presidio de San Saba, 3-12-1763, Archivo San Francisco El Grande (Photostat). Archives, University of Texas Library, Austin. 
Babbitt, Major E. B。

1849 Extract from a letter from Bvt. Major $E$. B. Babbitt dated October 15, 1849, San Antonio, United States Office of Indian Affairs, Letters Received 1838-1862 (Photostat). Archives, University of Texas Library, Austin.

Bastian, Tyler

1966 Early Eighteenth Century Wichita Occupation in the Area of Haskell, Muskogee Co., Oklahoma. M.S. Carbon Copy on file, Texas Memorial Museum.

Blain, S。A。

1858 Letter to Superintendent of Indian Affairs, dated December 1, 1858, Southern Superintendency Field Records, Letters Received, Wichita Agency. National Archives, Washington, D.C.

1859a Letter to E. Rector, dated September 4, 1859, United States Office of Indian Affairs, Letters Received 18381862, (Photostat). Archives, University of Texas Library, Austin.

1859b Letter to E. Rector, dated September 15, 1859, United States Office of Indian Affairs, Letters Received 18381862, (Photostat). Archives, University of Texas Library, Austin.

$1859 \mathrm{c}$ Muster Roll of Texas Reserve Indians for the Month of October, 1859, United States office of Indian Affairs, Letters Received 1838-1862 (Photostats). Archives, University of Texas Library, Austin.

1859d Muster Roll of Texas Reserve Indians for the Month of October, 1859, United States office of Indian Affairs, Letters Received 1838-1862 (Photostats). Archives, University of Texas Library, Austin.

1860 Letter to Commissioner of Indian Affairs, dated March 31, 1860, Southern Superintendency Field Records, Letters Received. National Archives, Washington, D.C.

Butler, P。M。

1846 Letter to William Medill, dated March 4, 1846, United States Office of Indian Affairs, Letters Received 1838-1862 (Photostat). Archives, University of Texas Library, Austin。

, and Lewis, M. G.

I846 Letter to William Medill, dated August 8, 1846, United States Office of Indian Affairs, Letters Received 1838-1862 (Photostat). Archives, University of Texas Library, Austin。 
Cabello, Domingo

1779 Summary of Letter Discussing Settlement of Bucareli, dated 3-31-1779, Bexar Archives. Archives, University of Texas Library, Austin.

1784 a Letter to Neve, dated 3-29-1784, Bexar Archives, Archives, University of Texas Library, Austin.

$1784 \mathrm{~b}$ Letter to Nebe, dated 7-20-1784, Bexar Archives, Archives, University of Texas Library, Austin.

1784c Letter to Neba, dated 8-19-1784, Bexar Archives. Archives, University of Texas Library, Austin.

$1785 a$ Commission as Captain Grande Issued to Guersec, Toboayas Indian, as successor to his Father, Gran Sol, Bexar Archives. Archives, University of Texas Library, Austin.

$1785 \mathrm{~b}$ Letter to Jose Antonio Rengel, dated 2-18-1785, Bexar Archives. Archives, University of Texas Library, Austin.

1785 c Letter to Jose Antonio Rengel, dated 2-20-1785, Bexar Archives. Archives, University of Texas Library, Austin.

1785 d Letter to Jose Antonio Rengel, dated 5-19-1785, Bexar Archives. Archives, University of Texas Library, Austin.

1785 e Letter to Jose Antonio Rengel, dated 10-23-1785, Bexar Archives. Archives, University of Texas Library, Austin.

$1785 \mathrm{f}$ Letter to Jose Antonio Rengel, dated 12-10-1785, Bexar Archives. Archives, University of Texas Library, Austin.

1786a Letter to Jose Antonio Rengel, dated January 23, 1786, Bexar Archives. Archives, University of Texas Library, Austin.

1786b Letter to Jose Antonio Rengel, dated 4-16-1786, Bexar Archives, Archives, University of Texas Library, Austin.

1786c Letter to Jose Antonio Rengel, dated 4-18-1786, Bexar Archives. Archives, University of Texas Library, Austin.

1786d Letter to Jacobo de Ugarte y Loyolo, dated 7-3-1786, Bexar Archives. Archives, University of Texas Library, Austin。

1786e Letter to Jacobo de Ugarte y Loyolo, dated 9-10-1786, Bexar Archives. Archives, University of Texas Library, Austin。 
Calahorra y Saenz, Fray Joseph de

1760 Diario del Viaje, September 16-october 24, 1760, Archivo General de las Indias, Audiencia de Mexico (William E。 Dunn transcripts). Archives, Jniversity of Texas Library, Austin.

1762 List of gifts to be taken to Indian Leaders in 1763, dated 10-1-1762, Bexar Archives (translations). XXXVII, 54. Archives, University of Texas Library, Austin.

1765 Letter to Gov. Navarrete, dated 3-20-1765, Bexar Archives (translations). Archives, University of Texas Library, Austin, Texas

Catlett, H, G。

1849 Letter to W. Medill, dated May 12, 1849, Letters Received by Office of Indian Affairs, Texas Agency, 1849-1859. National Archives, Washington, D.C.

Coombes, Z.E。

1858 Letter to S.P. Ross, dated November 30, 1858, United States office of Indian Affairs, Letters Received 1838-1862 (Photostat). Archives, University of Texas Library, Austin.

1859 Letter to S. P. Ross, dated 3-30-59, United States Office of Indian Affairs, Letters Received 1838-1862 (Photostat). Archives, University of Texas Library, Austin.

Cooper, Samue 1

1851 Report of Inspection Trip from Fort Graham to the Indian Villages on the Upper Brazos Made in June, 1851 (typescript). Archives, University of Texas Library, Austin.

Cordero, Antonio

1808 Commission of Quichaeta as Tahuayas captain, dated 7-5-1808. Archives, University of Texas Library, Austin.

Croix, Marquis de

1768 Report to Hugo Oconor, dated September 3, 1768, Bexar Archives (translations), XLVI, 110。Archives, University of Texas Library, Austin.

Croix, Theodoro de

1780 Letter to Domingo Cabello, dated 9-10-1780, Bexar Archives. Archives, University of Texas Library, Austin.

Curbelo, Juan Jose

$1800 a$ List of presents given Comanchaces and Tahuayazes, dated 3-12-1800, Bexar Archives. Archives, University of Texas Library, Austin. 
$1800 \mathrm{~b}$ List of presents given to Comanches and Tahuacanas, dated 3-18-1800, Bexar Archives. Archives, University of Texas Library, Austin.

1800c List of presents given to Comanches and Tahuacanas, dated 3-21-1800, Bexar Archives. Archives, University of Texas Library, Austin.

1800d List of presents given to Tahuacanes, dated 3-28-1800, Bexar Archives. Archives, University of Texas Library, Austin.

1800 List of presents made to Tahuacano Captain, dated 4-3-1800, Bexar Archives. Archives, University of Texas Austin.

1800f List of presents given to Comanches, dated 4-16-1800, Bexar Archives. Archives, University of Texas Library, Austin.

$1800 \mathrm{~g}$ Letter to Jose Joaqn. Ugarte, dated November 30, 1800, Bexar Archives (translations), November 12-December, 1805, 62-63. Archives, University of Texas Library, Austin.

Elguezabal, Juan Bautista de

$1804 a$ Military Report of Presidial Company of Bexar, January 1, 1804. Bexar Archives (translations), LXVI, Pt. 1, 35-37. Archives, University of Texas Library, Austin.

$1804 \mathrm{~b}$ Letter to Nemesio Salcedo, Chihuahua, Draft No. 183, Quaderno, 1-4-1804-12-19-1804, Bexar Archives (translations) LXVI, Pt. 1, 80-82. Archives, University of Texas Library, Austin.

Febre, Luis, et al.

1749 Proceedings to Investigate the Visit of Thre Frenchmen Who Arrived in Taos, New Mexico, Accompanying the Comanche Indians, Provincias Internas, XXXVII, Archivo General de Mexico (William E. Dunn Transcripts). Archives, University of Texas Iibrary, Austin.

Fernandez, Santiago

1788 Diary of Trip Made from Santa Fe to the Jumanes Village and Return, June 24, 1788 to August 17, 1788 (Margarita Costero, trans.), Archivo General de Mexico, XIIII Bexar Archives. Archives, University of Texas Library, Austin.

Fernz., Nacogdoches

$1795^{\prime}$ List of presents for Taguacanos, dated 3-13-1795, Bexar Archives. Archives, University of Texas Library, Austin. 
Fletcher, Alice Cunningham and Francis La Flesche 1898 Manuscript 4558, Wichita Notes, To-wa-can-nu Jim, March 24, 1898, Personal Papers and Ethnographic Notes, office of Anthropology Archives, Smithsonian Institution, Washington.

Fragoso, Francis Xavier

1788- Diary of Trip Made from Santa Fe to San Antonio de Bexar

1789 and Return, June 24, 1788, to August 20, 1789 (Margarita Costero, trans.), Archivo General de Mexico, XLIII, Bexar Archives. Archives, Iniversity of Texas Library, Austin.

Garrett, CoF。

1868 Letter to J. B. Henderson, Chairman of Committee on Indian Affairs, dated 1868, Letters Received by office of Indian Affairs, Wochita Agency, 1857-1878. National Archives, Washington。

Hardie, W。 J。

1851 Letter to Major George Deas, dated August 29, 1851, United States Office of Indian Affairs, Letters Received 18381862 (Photostat). Archives, University of Texas Library, Austin.

Hill, G。W.

1854 Letter to Robert S. Neighbors, dated December 15, 1854, United States Office of Indian Affairs, Letters Received 1838-1862 (Photostat). Archives, University of Texas Library, Austin.

1855 Annual Census, United States office of Indian Affairs, Letters Received 1838-1862 (Photostats). Archives, University of Texas Library, Austin.

Howard, George T.

1852 Estimate of the Different Tribes of Indians in Texas, June 14, 1852, United States office of Indian Affairs, Letters Received 1838-1862 (Photostat). Archives, University of Texas Library, Austin.

Jones, Isaac (interpreter)

1877 Deposition of Indians of Wichita and Affiliated Tribes, September, 1877, Central Superintendency Field Records, Letters Received, Wichita Agency. The National Archives, Washington, D。C. 
La Concha, Fernando de

1792 Instructions to be Followed by Pedro Vial in Going from Santa. Fe to San Luis Yrinueces Given to him by Fernando de la Concha on May 21, 1792 (Margarita Costero, trans.), Archivo General de Mexico, XLIII, Bexar Archives. Archives, University of Texas Library, Austin.

Leeper, M。

1860 Letter to Superintendent of Indian Affairs, dated September 26, 1860, Southern Superintendency Field Records, Letters Received, Wichita Agency. National Archives, Washington.

1862 Letter to Superintendent of Indian Affairs, dated January 13, 1862, Confederate Materials, Arkansas Superintendency, Wichita Agency. National Archives, Washington.

Macarti, El Caballero

1763 Letter to Don Angel de Martos y Navarrete, dated 9-101763, Bexar Archives (translations), XXXVIII, 123-131. Archives, University of Texas Library, Austin.

McKisick, A。H.

1857 Letter dated October 21, 1857, to Superintendent of Indian Affairs, Letters Received by the office of Indian Affairs, Wichita Agency, 1857-1878. National Archives, Washington。

Marés, Jose

1787 Diary of Trip Made from Santa Fe to San Antonio de Bexar, July 31, 1787 to October 8, 1787 (Margarita Costero, trans.), Archivo General de Mexico, XLIII, Bexar Archives. Archives, University of Texas Library, Austin.

1788 Diary of Trip Made from San Antonio de Bexar to Santa Fe, January 18, 1788 to April 27, 1788 (Margarita Costero, trans.), Archivo General de Mexico, XLIII, Bexar Archives. Archives, University of Texas Library, Austin.

Martos y Navarrete, Angel

1762 Carta del gobernador de Texas Martos y Navarrete al capitan Rabago y Teran sobre la llegada de los naciones del Norte en Busca de los Apaches, San Antonio de Bexar, dated 9-12-1762, Archivo San Francisco el Grande (Photostat). Archives, University of Texas, Austin.

1764 a Communicaciones de Angel Martos y Navarrete sobre danos hecho por las naciones del norte y los Tahuacanos $\mathrm{y}$ Texas, Bahia del Espiritu Santo, dated Mayo 8, 1764 , Archivo San Francisco El Grande (Photostat). Archives, University of Texas Library, Austin. 
$1764 b$ Peticion de Martos y Navarrete para que se establezca una mision para los, Tehuacanos, R. Presidio de San Agustin de Ahumada, dated Julio 8, 1764, Archivo San Francisco, El Grande (Photostat). Archives, University of Texas Library, Austin.

Menchaca, Cap.

1765 Informe del Cap. Menchaca sobre incursiones de los indios del norte, $R$. Presidio de San Antonio, dated Septiembre 18, 1765, Archivo San Francisco El Grande (Photostat). Archives, University of Texas Library, Austin.

1769 Informe del Cap. Menchaca sobre danos causados por los indios, dated Junio 27, 1769, Archivo San Francisco, el Grande (Photostat). Archives, University of Texas Library, Austin.

Munoz, Manuel

1791 Letter to Exmo Senor Virrey, Conde de Revilla Gigedo, dated June 20, 1791, Provincias Internas, No. 162, Part III, Archivo General de Mexico. (c. W. Hackett Transcripts). Archives, University of Texas Library, Austin.

1795 Letter to Ayuntamiento, San Fernando, dated 10-5-1795, Bexar Archives. Archives, University of Texas Library, Austin.

Nava, Pedro de

1794a Letter to Governador, dated 3-27-1794, Bexar Archives. Archives, University of Texas Library, Austin.

1794b Letter to Governador, dated 5-21-1794, Bexar Archives. Archives, University of Texas Library, Austin.

1795 Letter to Govor. dated 3-13-1795, Bexar Archives. Archives, University of Texas Library, Austin.

Neighbors, Robert S.

1849 Letter to William Medill, dated June 18, 1849, United States office of Indian Affairs, Letters Received 1838-1862 (Photostat)。 Archives, University of Texas Library, Austin.

1853 Letter to Geo. W. Manypenny, dated August 12, 1853, United States office of Indian Affairs, Letters Received 1838-1862 (Photostat). Archives, University of Texas Library, Austin. 
1859a Letter to J. W. Denver, dated March 28, 1859, United States Office of Indian Affairs, Letters Received 1838-1862 (Photostat). Archives, University of Texas Library, Austin.

$1859 \mathrm{~b}$ Letter to Superintendent of Indian Affairs, dated May 28, 1859, Sothern Superintendency Field Records, Letters Received. National Archives, Washington, D.C.

1859 Letter to A. B. Greenwood, dated August 18, 1859, United States Office of Indian Affairs, Letters Received 1838-1862 (Photostat)。Archives, University of Texas Library, Austin.

Newcomb, W. W.

n.d. Scholarly Distortionand the Southern Plains Indians. MS.

Pacheco, Rafael Marz.

1787 Letter to Ugalde, dated 12-24-1787, Bexar Archives, Archives, University of Texas Library, Austin.

Paraxe de la Navidad, Bernado. Fernz.

1795 Letter to Manuel Munoz, dated 2-2-1795, Bexar Archives. Archives, University of Texas Library, Austin.

Parrilla, Don Diego Ortiz

1759 Testimony Dated October 7, 1759, Archivo General de las Indias, Audiencia de Mexico, 92-6-22 (William E. Dunn Transcripts, 1759-1761), 208-228. Archives, University of Texas Library, Austin。

Plummer, J. B.

1859 Letter to Asst. Adjt. General Headqr. Dept. Texas, dated May 23, 1859, United States office of Indian Affairs, Letters Received 1838-1862 (Photostat). Archives, University of Texas Library, Austin.

Rabago y Teran

1766 Informe que rinde el capitan Rabago y Teran al virrey sobre otro nuevo ataque de las naciones enemigas del Norte, Real Presidio de San Saba, dated 11-20-1766, Archivo San Francisco El Grande (Photostat). Archives, University of Texas Library, Austin.

Randlett, James F.

1901 Letter to Commissioner of Indian Affairs, dated December 11, 1901. National Archives, Washington, D.C.

Rebolledo, Don Juan de Olivan

1717 Don Juan de Olivan Rebolledo, Mexico, to Viceroy, Mexico, Recommending Establishment of Presidios, 
Settlements, and Missions in order to stop the Incursions of French Subjects into Spanish Territory, With Definite Suggestions as to Manner of Carrying out the Project, and the Location and Number of Missions, Berar Archives (translations), I, 17-38. Archives, University of Texas Library, Austin. December 24, 1717 .

Rengel, Jose Antonio

1784 Letter to Cabe11o, dated 8-24-1784, Bexar Archives. Archives, University of Texas Library, Austin.

1785 a Letter to Cabello, dated 4-1-1785, Bexar Archives. Archives, University of Texas Library, Austin.

$1785 \mathrm{~b}$ Letter to Cabe110, dated 10-11-1785, Bexar Archives. Archives, University of Texas Library, Austin.

1785 c Letter to Cabel10, dated 10-11-1785, Bexar Archives. Archives, University of Texas Library, Austin.

Richards, Jonathan

$1873 a$ Letter to Superintendent of Indian Affairs, dated 5 th Month 10th 1873, Central Superintendency Field Records, Letters Received, Wichita Agency. National Archives, Washington, D. C.

1873b Letter to Superintendent of Indian Affairs, dated 7-1-1873, Central Superintendency Field Records, Letters Received, Wichita Agency. The Nationa?. Archives, Washington. D. C.

$1873 \mathrm{c}$ Letter to Superintendent of Indian Affairs, dated 7-9-1873, Central Superintendency Field Records, Letters Received, Wichita Agency. National Archives, Washington, D, C.

$1873 d$ Letter to Superintendent of Indian Affairs, dated 8-13-1873, Central Superintendency Field Records, Letters Received, Wichita Agency, National Archives, Washington, D。C.

1875 Letter to Superintendent of Indian Affairs. dated 5th mo. 1st, 1875, Central Superintendency Field Records, Letters Received, Wichita Agency. National Archives, Washington, D. C.

Ross, S. P.

1856a Letter to Ro S. Neighbors, dated January 1, 1856, United States office of Indian Affairs, Letters Received 1838-1862. (Photostats). Archives, University of Texas Library, Austin. 
1856b Letter to R. S. Neighbors, dated October 1, 1856, United States Office of Indian Affairs, Letters Received 1838-1862, (Photostats). Archives, University of Texas Library, Austin.

1856 c Letter to R. S. Neighbors, dated December 27, 1856, United States Office of Indian Affairs, Letters Received 1838-1862 (Photostats). Archives, University of Texas Library, Austin.

$1857 \mathrm{a}$ Census Roll, Brazos Agency, dated April 30, 1857, United States Office of Indian Affairs, Letters Received 1838-1862. (Photostats). Archives, University of Texas Library, Austin.

$1857 \mathrm{~b}$ S. P. Ross, Census Roll, Brazos Agency, dated December 31, 1857, United States Office of Indian Affairs. Letters Received 1838-1862 (Photostats). Archives University of Texas Library, Austin.

1858 Statement of Provisions Issued to Indians from July 10 to July 17, 1858, United States office of Indian Affairs, Letters Received 1838-1862 (Photostats). Archives, University of Texas Library, Austin.

Salcedo, Manuel de

1809 Information of the Texas Province Indian Nations, dated April 24, 1809, Nacogdoches Archives (Typescript), II, 255. Archives, University of Texas Library, Austin.

Saucedo, Beramendi, etc.

1825 Saucedo, Beramendi, etc. Informacion Sumaria, Information concerning reunion of Comanches, Tahuacanas, Tahuayases, Huecos, and other Indians to attack Bexar, 8-31-1825, Bexar Archives. Archives, University of Texas Library, Austin.

Sandoval, Felipe

1749 Deposition, Archivo General de Mexico, Provincias Internas, XXXVII, 1749, William E。 Dunn Transcripts, Bexar Archives. Archives, University of Texas Library Austin.

Scott, Lt. H。G。

1891 Letter to Post Adjutant, Fort Sill, dated February 10, 1891. National Archives, Washington, D。C。

Soule, W. S. ca.1875 Album of photographs taken by W. S. Soule, photographer of Fort Sill, Caldwell Collection. Humanities Research Center, University of Texas, Austin. 
Stem, Jesse

1853 a Letter to $G$. Loomis, dated 1-9-1853, United States Office of Indian Affairs, Letters Received 18381862 (Photostats). Archives, University of Texas Library, Austin.

1853b Letter to G. Loomis, dated 3-30-1853, United States Office of Indian Affairs, Letters Received 1838 1862 (Photostats). Archives, University of Texas Library, Austin.

1853c Letter to L. Lea, dated 4-1-1853, United States office of Indian Affairs, Letters Received 1838-1862 (Photo stats). Archives, University of Texas Library, Austin.

Treviño, Antonio, et al.

1765 Proceedings concerning the restoration of Antonio Treviño to his Presidio by the chief of the Taguais (Taovayas) Indians, March 20-August 26, 1765, Bexar Archives, (Translations). Archives, University of Texas Library, Austin.

U. S. Department of Interior

1850 Indian Population of Texas, 1846-1850, United States Office of Indian Affairs, Letters Received 18351862 (Photostats). Archives, Jniversity of Texas Library, Austin.

1917 Narrative Report, Kiowa Agency. National Archives, Washington, D。C。

1931a Narrative Report, Kiowa Agency, National Archives, Washington.

1931b Annual Statistical Report, Office of Indian Affairs. National Archives, Washington.

1933 Annual statistical Report, office of Indian Affairs. National Archives, Washington.

1934 Annual Statistical Report, office of Indian Affairs. National Archives, Washington.

1935 Annual statistical Report, office of Indian Affairs. National Archives, Washington.

1936 Annual statistical Report, Office of Indian Affairs. National Archives, Washington.

1937 a Narrative Report, Kiowa Agency, National Archives. Washington. 
1937b Annual Statistical Report, Office of Indian Affairs. National Archives, Washington.

1938 Annual Statistical Report, Office of Indian Affairs, National Archives, Washington.

1939 Annual Statistical Report, Office of Indian Affairs. National Archives, Washington.

1940 Annual Statistical Report, Office of Indian Affairs. National Archives, Washington.

1941 Annual Statistical Report, Office of Indian Affairs. National Archives, Washington.

1942 Annual Statistical Report, office of Indian Affairs. National Archives, Washington.

1943. Annual Statistical Report, Office of Indian Affairs. National Archiv,s, Washington.

Ugaide, Juan de

1786 Letter to Raphael Martinez Pacheco, dated 12-30-1786, Bexar Archives. Archives, University of Texas Library, Austin.

Ugarte, Jose Joaquin

1805 a Report for Year 1865, Bexar Archives (translations), November 12-December, 1805. Archives, University of Texas Library, Austin.

$1805 \mathrm{~b}$ List of Articles Given to Indians on December 19, 1805, Bexar Archives (translations), November 17December, 1805. Archives, Jniversity of Texas Library, Austin.

1807a Report for Year of 1806, Bexar Archives (translations) March 1-20-1807. Archives, University of Texas Library, Austin.

1807b Estimate of Articles necessary for Indian Presents During Year of 1807, Bexar Archives (translations), March 1-20-1809. Archives, University of Texas Library, Austin.

Ugarte y Loyolo, Jacobo

1786 a Letter to Domingo Cabello, dated 5-24-1786, Bexar Archives, Archives, University of Texas Library, Austin.

1786b Letter to Domingo Cabello, dated 8-17-1786, Bexar Archives. Archives, University of Texas Library, Austin. 
Valero, Marquis de

1719 Statement dated 6-3-1719, that Rebolledo has been appointed Governor of New Philippines, Bexar Archives (translations), I, 64-66. Archives, Jniversity of Texas Library, Austin.

Varela, Mariano

1807 Year of 1807. Bexar Archives (translations), February 1-29, 1808. Archives, University of Texas Library, Austin.

1808 List of goods for Indians of the North -- Commanches, Tancaues, Lipans, Huichitas, Tahuacanas, Yascaris, Hatseis, and Orcoquisac, dated 12-30-1808, Bexar Archives. Archives, Jniversity of Texas Library, Austin.

Vial, Pedro

1786- Diary of Trip made from San Antonio de Bexar to Santa

$1787 \mathrm{Fe}$, October 4, 1786, to May 26, 1787 (Margarita Costero, trans.). Archivo General de Mexico, XLIII, Bexar Archives. Archives, Jniversity of Texas Library, Austin.

1792- Diary of Trip made from Santa Fe to San Luis Ylinueces

1793 and return, May 21, 1792 to November 15, 1793 (Margarita Costero, trans.). Archivo General de Mexico, xLIII, Bexar Archives. Archives, University of Texas Library, Austin.

Williams, A。C.

1877 Letter to Commissioner of Indian Affairs, dated May 1, 1877, Central Superintendency Field Records, Letters Received, Wichita Agency. National Archives, Washington.

Williams, L. M。

1849 Letter to R. S. Neighbors, dated october 9, 1849 , United States office of Indian Affairs, Letters Received 1838-1862 (Photostats). Archives, University of Texas Library, Austin.

Ximenez, Fr。Diego

1762 a Carta de Fr. Diego Ximenez al capitan Rabago y Teran sobre la llegada de los naciones del Norte en busca de Apaches, San Antonio de Bexar, 9-12-1762. Archivo San Francisco El Grande (Photostat). Archives, University of Texas Library, Austin.

1762b Letter to Don Felipe Rabago y Teran, dated 10-8-1762, Archivo San Francisco El Grande (Photostat)。Archives, University of Texas Library, Austin. 


\section{Maps}

Anonymous

1717 Mapa Geografico que presento con su informe Al Virrey de la $\mathrm{N}^{\mathrm{a}}$ España, $\mathrm{D}^{\mathrm{n}}$ Juan de Olivan Rebolledo oydor de la Real Audiencia de Mexico en 18 de Diciembre de 1717 y a consequencia de reconocimto genizo de estas $^{e}$ Provincias de Orden de S. E. Original in AGI, Seville.

1722 Carta de la Bahia del Spiritu Santo de la Provincia de las nuevas Philipinas que dejrn observada Del Marancho del Seno Mexicano en 10-de Abril de 1722.

1756? Carta de la Provincia de Texas. Undated.

1835? Map of Spanish Texas. Undated. From H. K. Yoakum, History of Texas, 1856

1722 Mapa de la Bahia del Spiritu Santo de la Provincia de la Nuevas Filipinas (Texas) que dexo observado el Marques de San Miguel de Aguayo en 10 de Abril de 1722. Original in AGI, Seville, No. 111 .

1757 Mapa de parte de la Provincia de Texas (Photograph). Original in AGI, Seville, No. 205.

1691 Map de la provincia donde habita la Nacion Casdudacho (Texas) Santa Maria de Galve. Executose este Nuevo discubrimiento de la Nacion Casdudacho en la?. . de Polo Boreo de $35 \mathrm{~g}^{\mathrm{s}} 30 \mathrm{~m}^{\mathrm{s}}$ Dentro del Seno Mexicano, Governando el exercitto que lo Hizo el General. Original in AGI, Seville.

n.d. Plan del Real Presidio de San Sabá. Undated. Archivo San Francisco El Grande (Photostat).

1722 Plano del Presidio de Nuestra Señora de Loreta en la Bahia del Spiritu Santo de la Provincia de Texas, Nuevo Reino de Filipinos que demarco y de jo abiertas las zanjas de toda la fortificacion el Marques de san Miguel de Aguayo (Photograph)。 Original in AGI, Seville No. 116 .

1722 Plano del Presidio de Nuestra Séñora del Pilar de los Adais en la frontera de los Texas, Nuevo Reino de Filipinas, cuya fortificacion delineo y de jo executada el Marques de San Miguel de Aguayo en 1.0 de Noviembre de 1721 (Photograph)。 Original in AGI, Seville, No. 113. 
1722 Plano del Presidio de Nuestra Señora del Pilar de los Adays, en la frontera de los Texas, Nuevo Reyno de Philipinas, cuya fortificacion demarco $\mathrm{J}$ dexo executada el Marques de San Miguel Aguayo en 1. de Noviembre de 1721 (Photograph)。Original in AGI, Seville, No. 114.

1690 Viage que el año de 1690 hizo el Gouernador Alonso de Leon desde Cuahuila hasta la Carolina Provincia habitada de Texas y otras naciones al Nordeste de la Nueva España.

Austin, Stephen $F$.

1822 Mapa Geografico de la Provincia Tehas por Don

Estevan Austin, 1822 .

1829? Stephen F. Austin's Map of Texas.

1829a Mapa Original de Texas Por el Cuidadano Estevan F, Austin Presentado al Exmo Sor Presidente Por su Autor 1829. Original in the Archivo General y Publico de la Nacion, Mexico City.

1829b Mapa Original de Texas Por el Cuidadano Estevan F. Austin.

Beauviliers, Sr。de

l720a Carte Nouvelle de la Partie de L'ouest de la Province

de la Louisiane sur les observations et de Couvertes

du Sieur Bénard de la Harpe. . . (Photostat). Library of Congress, Washington.

$1720 b$ Carte Nouvelle de la Partie de L'ouest de la Province de la Louisigna sur les observations et Decouvertes due sieur Bénard de la Harpe . . (Photostat). Library of Congress, Washington.

Bolton, Herbert $E$.

1535- Explorations on the Northern Frontier of New Spain

1706 1535-1706, compiled by Herbert Bolton, 1915. H. B. Foster, Del。

Burgvin, E。

1846 A Chart of the South Western Region Extending from the Arkansas to the Colorado from actual survey. Notes of Capt. Boone, USA and instructions received from other authentic sources.

Carter, W. T.

n.d. Map of Public road from Inez to Keeran's Ranch and from ranch the trail to site of old La Salle Fort. 
De Cordova, Jacob

$1850 \mathrm{~J}$. De Cordova's Map of the state of Texas Compiled from the Records of the General Land office of the state by Robert Creuzbaur, Houston 1850. Engraved by J。M. Atwood, New York.

Delisle, Guillaume

1718? Carte de la Louisiane et du Cours de Mississipi Dresse sur Grand Nombre de Memoire Entriautres sur Ceux de Mr。 le Maine Par Guill me de L'Isle de L'Academie Rle des Sciencts. Amsterdam, Chez Jean Covens et Corneille Mortier Geongrapher.

Dorchester, E。 D。

1927 Trails Made and Routes Used by the Fourth U. S. Cavalry under command of General $R$. So Mackenzie in its operations against hostile Indians in Texas, Indian-Territory (now Oklahoma), New Mexico and Old Mexico during the period of $1871-2-3-4$ and 5. E. D. Dorchester, Freeport, Texas.

Duran, M。

1744 Descripcion y Mapa de la Provincia Poblada de Barbaros que en la America Septentrional . Miguel Custodio Duran. Original in Archivo General de Mexico.

Freeman, J。D。

1936 Map of Texas in 1836 compiled and Published by J。D。 Freeman, Fort Worth, Texas. Compiled from old maps and records in the State Archives and General Land office of the state of Texas.

Groves, H。

1837 Map of theRepublic of Texas Showing its Division into Counties and Latest Improvements to 1837. Compiled and written on Stone by Go Groves Lith ${ }^{\mathrm{C}}$ Office 53 Magazine St $。, N o O$.

Ibarvo, Gil Antonio

1778 Govierno para besitar y saber la entrada del Rio de San Jph. trinidad Santa Rose San Jacinto Brazos de Dios y Rio Colorado.

Kendall, George Wilkins

1850 Texas and part of Mexico \& the United States. Showing the Route of the First Santa Fe Expedition. D, Bogue 86 Fleet street.

Lafora, Nicolás de

1767 Plano de el presidio de $\mathrm{S}^{\mathrm{n}}$ Saba, situado en 31.38 Latitud Borly 273, 27 de Long\& contada desde el Merid de el Pico de Thenerife. - Presidio de $\mathrm{S}^{\mathrm{n}}$ Ant ${ }^{\mathrm{O}}$ de Bejar a 12 de Agosto de 1767 Nocolas de Laffora. 
394

Marcy, Randolph B.

1852 Map of the Country Between the Frontiers of Arkansas and New Mexico embracing the section explored in $1849,50,51$ \& 52. by Capt. R. B. Marcy 5th U. S. Inf.y. under orders from the war Department. Ackerman Lith. 879 Broadway N.Y.

Minet, L'ingénieur

1685? Plan de la Cost De La Floride la plus occidentale; Carte dessinee par Minet. Undated.

Parrilla, Diego Ortiz

1766 Mapa de una parte del Seno Mexicano comprendido desde al Rio Grande del Norte, y la Bahia de $\mathrm{S}^{\mathrm{r}}$ Berbardo Reconocide por Diego Ortiz Parrilla por Comision $q^{e}$ obtubo del Ex ${ }^{m o}$ Sr. Virrey Marquis de Cruilles, en al Ano 1766 .

Pike, Zebulon M。

1810 A Map of the Internal Provinces of New Spain.

Puelles, Jose Maria

1807 Mapa Geographica de la Provincias Septentrionales de esta Nueva España.

Ronquillo, Pedro de, conde de Gramedo

1687 Planta de la entrade del lago donde dejaron a Mr. de la Salle, 20 Enero 1687, (Photograph). Original in Archivo General de Indias, Seville, No. 79.

Siguenza y Gongora, Carlos de

1693 Nueva Demarcacion de la Bahia de $\mathrm{S}^{\mathrm{a}}$ Maria de Galve (antes Pensacola) que por orden del EX. ${ }^{m o} \mathrm{~S}^{\circ{ }^{\circ}} \mathrm{y}$ Conde de Galve \&ca Virrey de la $n^{a}$ Espana Hizo el ano de 1693 D. Carlos de Siguenza y Gongora Cosmographo del Rey nro San y su Cathedratico Jubilado de Mathematica en la Academia Mexicana.

Spain Dirreccion de Hidrografia

1800? Mapa que comprende el territorio situado entre 28x48 grados de Latitud Norte y entre 266 y 284 (265 y 289) grados de Longitud Occidental. Unsigned, undated.

United States Engineer Department, U. S. Army

1851 Map of the route to the Indian Villages on the Upper Brasos, made in June, 1851 by Col. Cooper and Maj. Sibley.

1852? Map of the Country upon Upper Red River explored in 1852 by Capt. R。 B. Marcy 5th U. S. Inf. Assisted by 
Bvt. Capt. G. B. Mc Clellan, U. S. Engineers under orders from the Head Quarters of the U.S. Army. Ackerman Lith., N.Y.

1873 Survey of Trinity River Made Under the Direction of Capt. C. W. Howe 11, U.S. Engs. and Lieut. H. M. Adams, U.S. Engrs. By J. S. Bird U.S. Ass't. Eng. From Oct. 1872 to Jan. 1873, Cross section No. 10.

Upshur, H. L。

1841 Sketch showing the Route of the Military Road from Red River to Austin. Col. Wm. G. Cooke, Commanding. Wm. H. Hunt, Engineer. 1840. Drawn by H. L. Upshur.

Urrutia, Joseph de

1768? Plano del Presidio de Nra Señora de Pilar de los Adaes Capital de la Provincia de los Tejas situado

- en 32 grados y 15 minutas de Latitud Boreal y en 285 degrees, y 521 de Longitud respecto del Meridiano de Tenerife. Joseph de Urrutia. Unda.ted, Original In British Museum.

Young, J. H.

1835 New Map of Texas with the Contiguous American and Mexican States. S. Augustus Mitchell, Philadelphia. 


\section{CONCLUDING STATEMENT}

This report has been essentially a presentation of descriptive archeological and ethnohistorical material, with little attempt at interpretation of the data in general terms. The primary purpose has been to assess, through systematic sampling, the nature and scope of existing archeological and archival data relating to the wichita Indians. On the basis of that assessment, the feasibility of a long-range, comprehensive study of the Wichita was to be explored.

Data accumulated through the pilot study support the following conclusions regarding the proposed long=range study.

1. Archeological remains are abundant at historic and late prehistoric sites in the southern plains-even more so than the co-investigators, in their optimism, had expected. A long-term project of excavation and analysis of archeological. data would unquestionably lead to:

a) accurate knowledge of the origins of Wichita culture (see discussions by Lorrain and by Bell and Bastian above);

b) acquisition of detailed information about aspects of Wichita culture that are not recorded ethnographically.

c) establishment of a sound chronology for historic and prehistoric Wichita sites;

d) establishment of sound typologies for articles of local Indian manufacture and for trade materials of European origin (see papers under ARTIFACTS section above)。

2. A large body of ethnohistorical data on the wichita was assembled during the pilot study, but certainly there is a great deal more relevant archival material that was not examined. A comprehensive search for original documents would be a very large undertaking, but one that would probably be rewarding。

3. The potential results to be gained through a longterm archeological-ethnohistorical study of the wichita are promising. The archeologists and ethnohistorians were so busy collecting data during the pilot study that no attempt was made to combine their respective data in a synthetic cultural study. Such a study, however, would undoubtedly be rewarding.

4. The long-range study set forth in the original proposal to the National Science Foundation now appears -after completion of the pilot study--to be not only feasible but, in the opinion of the co-investigators, of great potential anthropological value. 


\section{EXPLANATION OF FIGURES}

Fig. 1. Map of Oklahoma and Texas showing site locations.

Fig. 2. Sketch map of Spanish Fort area showing sites excavated on both sides of the river.

Fig. 3. Aerial view of Spanish Fort Bend.

Fig. 4. Excavation plan and site amp of the Upper Tucker Site.

Fig. 5. Plan of Features 1 and 5, Upper Tucker Site.

Fig. 6. Profile of Feature IA, Upper Tucker Site.

Fig. 7. Feature IA after clearing, Upper Tucker Site.

Fig. 8. Profiles of Features 1 and 5, Upper Tucker site.

Fig.9. Profile of Feature IB, Upper Tucker Site.

Fig. 10. Aerial view of Features 1 and 5, Upper Tucker Site。

Fig. 11. Profile of Feature 2, Upper Tucker Site.

Fig. 12. Plan of Feature 5, Upper Tucker Site.

Fig. 13. Feature 5A partially excavated (showing bones in fill), Upper Tucker Site.

Fig. 14. Feature 5A after clearing, Upper Tucker Site.

Fig. 15. Feature 5B after clearing, Upper Tucker Site。

Fig. 16. Feature 8, Upper Tucker Site。

Fig. 17. Excavation plan and site map, Coyote Site.

Fig. 18. Cache pit cluster, Coyote site.

Fig. 19. Profile of Feature 4, Coyote Site.

Fig. 20. Excavation plan and site map, Glass Site。

Fig. 2l. Plans and profiles of cache pits at Feature 1, Glass Site.

Fig. 22. Feature 2, Glass Site. 
Fig. 23. Excavation plan and site map; plan and profile of Feature 1; Gas Plant Site.

Fig. 24. Map of Longest Site.

Fig. 25. Aerial view of Longest Site。

Fig. 26. Aerial view of Longest site taken in March, 1967, showing outline of fortification ditch.

Fig. 27. Excavation plan of Longest Site, northwest portion.

Fig. 28. Excavation plan of Longest Site, northeast portion.

Fig. 29. Excavation plan of Longest Site, south portion.

Fig. 30. Excavation plan of Longest Site, north-central portion.

Fig. 31. Structure 1, Longest Site, after removal of fill and 5 to $10 \mathrm{~cm}$. of the underlying soil. Post molds are marked by barely visible strips of flagging tape 。

Fig。32. Plan and profile of Structure 1, Longest Site。

Fig. 33. Plan and profile of structure 3, Longest Site.

Fig. 34. Structure 3, Longest Site, after removal of fill. Suspected post molds are marked with flagging tape. The mottled appearance of the floor is due largely to extensive rodent disturbance. The intersecting trench and pits are exploratory tests。

Fig. 35. Cross section of post mold in structure 3, Longest site. The central dark fill represents the post; the outer light fill is soil packed into the hole around the post.

Fig. 36. Cross sections of pits, Longest Site。

Fig. 37. Burial 1, Longest site。

Fig. 38. Burial 3, Longest site。

Fig. 39. Burial 4, Longest site。

Fig. 40. Burial 5, Longest site (close-up view of skull).

Fig. 4I. Burial 6, Longest site。

Fig. 42。 Burial 7, Longest site。

Fig. 43. Cross section of fortification ditch (Feature 7), Longest Site. 
Fig. 44。 Chipped stone artifacts. A-D, small, unnotched, triangular points; E-F, small, unnotched, pentagonal points; $G$, small, corner notched point; $H-K$, large points; L-N, knives; O-S, large end scrapers; T-Y, flake scrapers。All from Longest site。

Fig。 45. Pottery...A-C, undecorated, straight rim sherds; $\mathrm{D}-\mathrm{F}$, undecorated rim sherds with outturned lips; G-T, engraved rim and body sherds; U, basal sherd; V-W, brushed sherds。All from Longest Site。 $R$ and $S$ collected by $J$. A。 Marler in 1963.

Fig. 46. Incised pottery vessel. From Longest Site.

Fig. 47. Figurines and pipes. $A=J$, figurine fragments; $K-Q$, native-made clay pipes; $R$, Euro-American kaolin pipe; $\mathrm{S}-\mathrm{CC}$, native-made stone pipes. All from Longest Site。

Fig. 48. Metal artifacts。 A, ax; B, hoe; C, flesher?; D, hammer; $E-F$, knives; $G=N$, diamond-shaped points; $0-W$, stemmed points; $X-E E$, horse trappings. All from Longest Site。

Fig. 49. Metal artifacts. A, end of kettle bail; B, kettle lug; $C-F$, rivets of sheet metal; $G$, kettle rim; $H-L$, tinklers; $M=0$, beads; $P, Q$, $S$, rings; $R$, button; $T, U, W$, hawk bells; $V$, clapper from bell; $X-Y$, pendants; $Z$, lead seal?; $A A$, wire; $B B-C C$, nails; $D D-E E$, pins; $F F$, candlestick holder base? All from Longest Site。

Fig. 50. Glass, shell, and miscellaneous objects。A-B, glass mirrors; $C=D$, inlaid glass; $E$, coated glass; $F$, section of cane; $G$, pendant; $H-I$, shell disks; $J-L$, pigment; $M$, as phalt; $N=0$, clinkers from burned grass. All from Longest Site。

Fig. 51. Selected artifacts from two sites of the proposed Wheeler complex in westem Oklahoma. A, Womack Engraved rim sherd; $B-D, O-P$, plain rim sherds; $E-\bar{H}, J$, end scrapers; $I$, unnotched triangular point fragment; $K$, engraved body sherd; L. base of loop handle?; $M-N$, punctated rim sherds. $A-J$ from Little Deer Site; $K-P$ from Scott Site. $M$ and $P$ collected by John B. McAllister.

Fig. 52. Glass bead types. Key to symbols: $S=$ simple, $\mathrm{CP}=$ compound, $\mathrm{CX}=$ complex, $\mathrm{M}=$ mandrel-wound, $\mathrm{F}=$ faceted, $\mathrm{PF}=$ pressed faceted; Under size column: $\mathrm{L}=$ large, $\mathrm{M}=$ medium, $S=$ small, $E S=\operatorname{extrasmall.~}$

Fig. 53. Glass and shell bead types. Key same as for Figure 52 。 
Fig. 54. Metal arrow points and knife fragments. a, d-g, Benton A type; b, h-i, Benton B type; c, j-k, miscellaneous arrow points. $a-c, I$ from Upper Tucker Site; $d-k, m-p$ from Longest Site。

Fig. 55. Gun parts. a, cock; b, Spanish miquelet upper vise jaw; c, breech plug; d, stock ornament; e-g, q, side plate fragments; $h-i, k, n-0$, butt plate fragments; $j, m, p$, trigger guard fragments; 1 , ramrod guide; $r$, rear sight. $a-j, m-p$ from Longest Site; $k-1, r$ from Upper Tucker Site.

Fig. 56. Axes, wedges, and awls. a-b, trade ax Type 1; $c-e$, wedges; f-g, iron awls。 $a-b, d, f$, from Gilbert site; $c, e, f r o m$ Longest Site; $g$ from Upper Tucker Site.

Fig. 57. Ornaments and clay figurines. a-c, metal rings; $d-f$, tinklers; $g, h$, pendants; $i-j$, buttons; $k-m$, shell artifacts; $n-p$, human effigies; $q$, horse figurine? $a-b, d$, $f, k, n-o$ from Upper Tucker Site; $c, e, g-j, 1-m, p-q$ from Longest Site.

Fig. 58. Miscellaneous metal artifacts, native-made pipes. $\mathrm{a}-\mathrm{b}$, bracelets; $\mathrm{c}-\mathrm{e}$, kettle bail ears; $f$, pipe tomahawk bowl; $g-j$, bridle parts; $k, 1$, stone pipe fragments; $m-0$, clay pipes。 $a, c-d, n-0$ from Gilbert Site; $b, e, g, k-1$ from Longest Site; $f, h-j$ from Upper Tucker Site; $m$ from Lower Tucker site.

Fig. 59. Chipped stone artifacts. a-b, endscrapers; $c-d$, side scrapers; e-g, thumbnail scrapers; h-j, Fresno arrow points; $k-n$, Harrell arrow points; $0-p$, Scallorn arrow points; $q$, $r$, Alba arrow points; $s$, drill; $t$, unidentified dart point. All from Coyote Site.

Fig。 60. Ground stone and ceramic artifacts from prehistoric sites。 $a-b$, abraders; $c-g$, Nocona Plain pottery; $d-f$, redware; $h$, metate. $a-b, g-h$ from Coyote Site; c-f from Glass Site。

Fig. 61. Bone artifacts from prehistoric sites, a-c, bison scapula hoes; $d$, bison tibia digging stick tip; $e-g$, bone awls; $h$, antler hoe?; $i-j$, bone rasps; $k-1$, utilized deer mandibles, a, $c-d, i-j, 1$ from Glass site; $b, e-h, k$ from Coyote Site.

Fig. 62. Tabular scrapers. A, E-H from Longest Site; B-D from Upper Tucker Site.

Fig. 63. Grooved abraders. A-G, I regular U-shaped groove; $\mathrm{H}$, J-K, regular V-shaped groove; I-O, irregular U-shaped groove, A-H, $\mathrm{K}-\mathrm{O}$ from Longest Site; I-J from Upper Tucker Site. 
Fig. 64. Grinding basins and slabs. Specimen at right center from Upper Tucker Site; others from Longest Site。

Fig. 65. Grinding stones or manos. A, C-G from Longest Site; B from Upper Tucker Site.

Fig. 66. Grooved mauls and hammerstones. A-B, three-quarter grooved mauls; $C-G$, end battered hammerstones; $H$, spall from end battered hammerstone; I-J, bitted hammerstones; $\mathrm{K}$, edge battered hammerstone; L, pitted hammerstone. A-B from Upper Tucker Site; C-I from Longest Site.

Fig。67. Rubbing stones, paint palettes, and anvils. A-B, rubbing stones; $C-F$, palettes; $G-I$, anvils. $A-B, D-E, I$ from Longest Site; C, F-H from Upper Tucker Site.

Fig. 68. Bone artifacts. A, whistle; B-F, toothed fleshers; $G=I$, modified bones of unknown use; J, awl. A, C-J from Longest Site; B from Upper Tucker Site.

Fig. 69. Bone and ground stone artifacts. A-B, pendants; $\mathrm{C}-\mathrm{J}$, objects of unknown function; $\mathrm{K}-\mathrm{P}$, beads; $\mathrm{Q}$, bead stock.

Fig. 70. Photomicrograph of thin section T-103 (enlarged approximately 60X).

Fig. 71. Photomicrograph of thin section T-102 (enlarged approximately 60X).

Fig. 72. Photomicrograph of thin section T-107 (enlarged approximately 60X)。

Fig. 73. Photomicrograph of thin section T-108 (enlarged approximately 60X)。

Fig. 74. Photomicrograph of thin section T-llO (enlarged approximately 60X).

Fig. 75. Stylized drawings of some Cretaceous Foraminifera (after Cushman, 1933). 



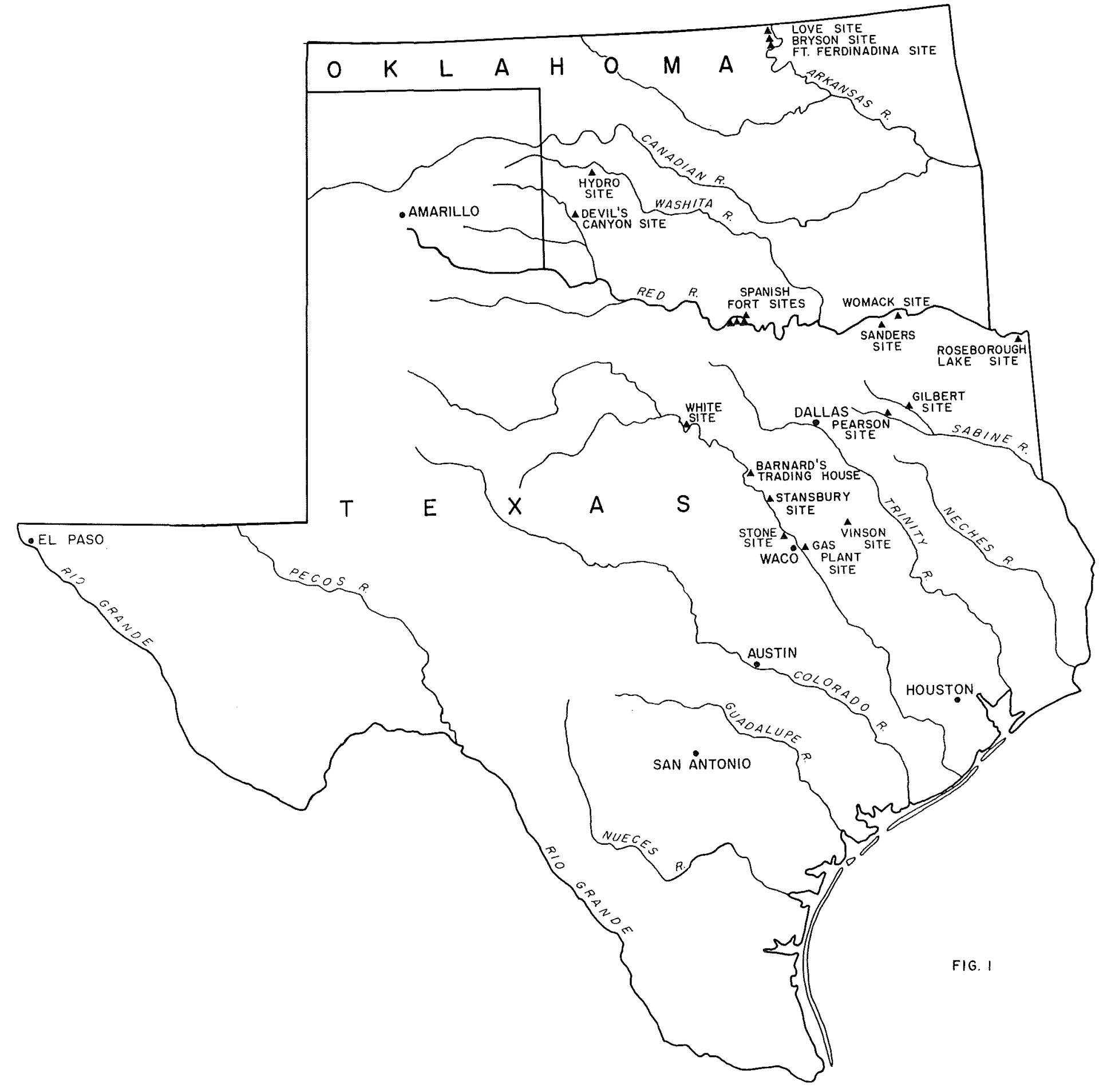





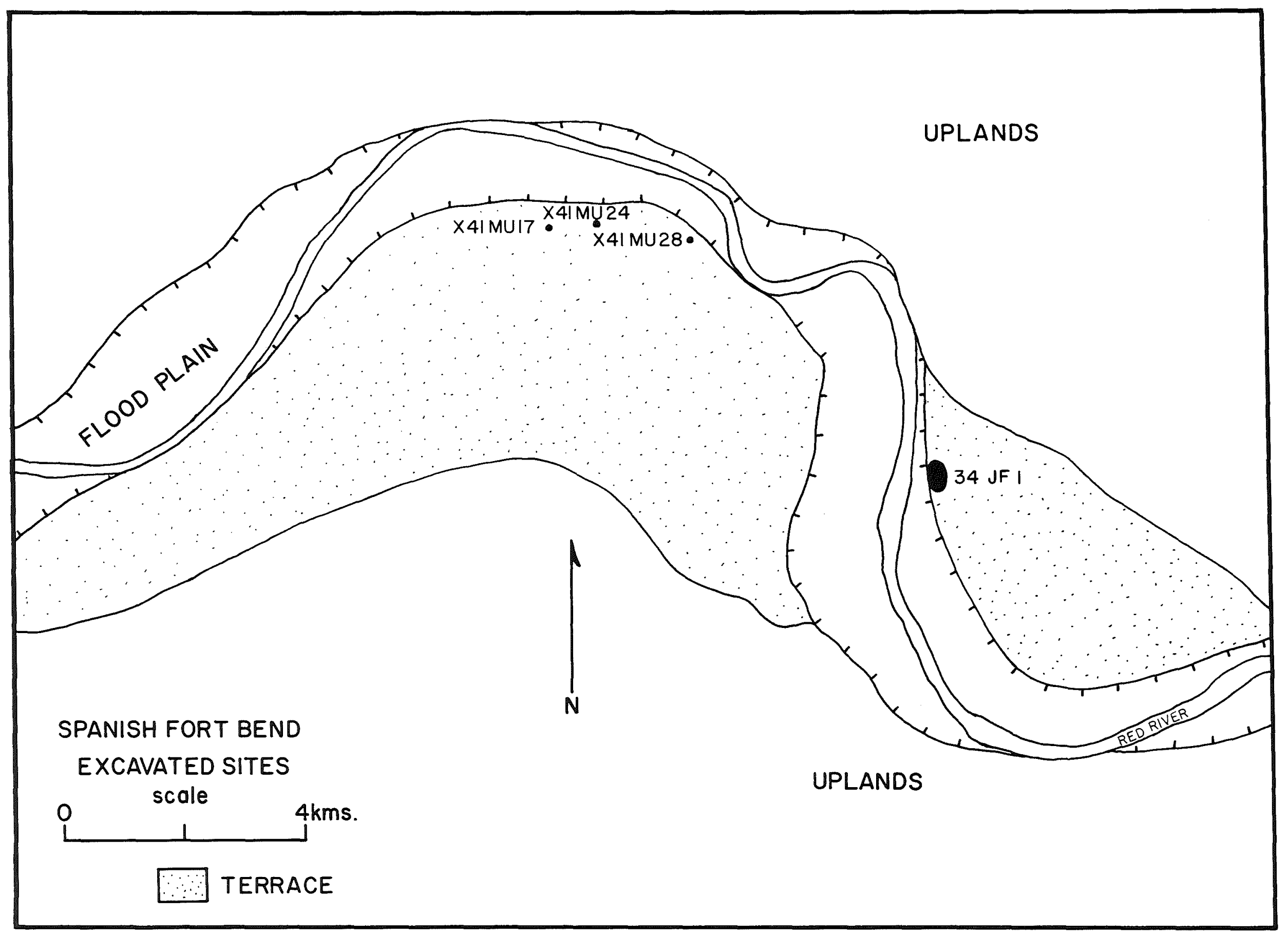

FIG. 2 



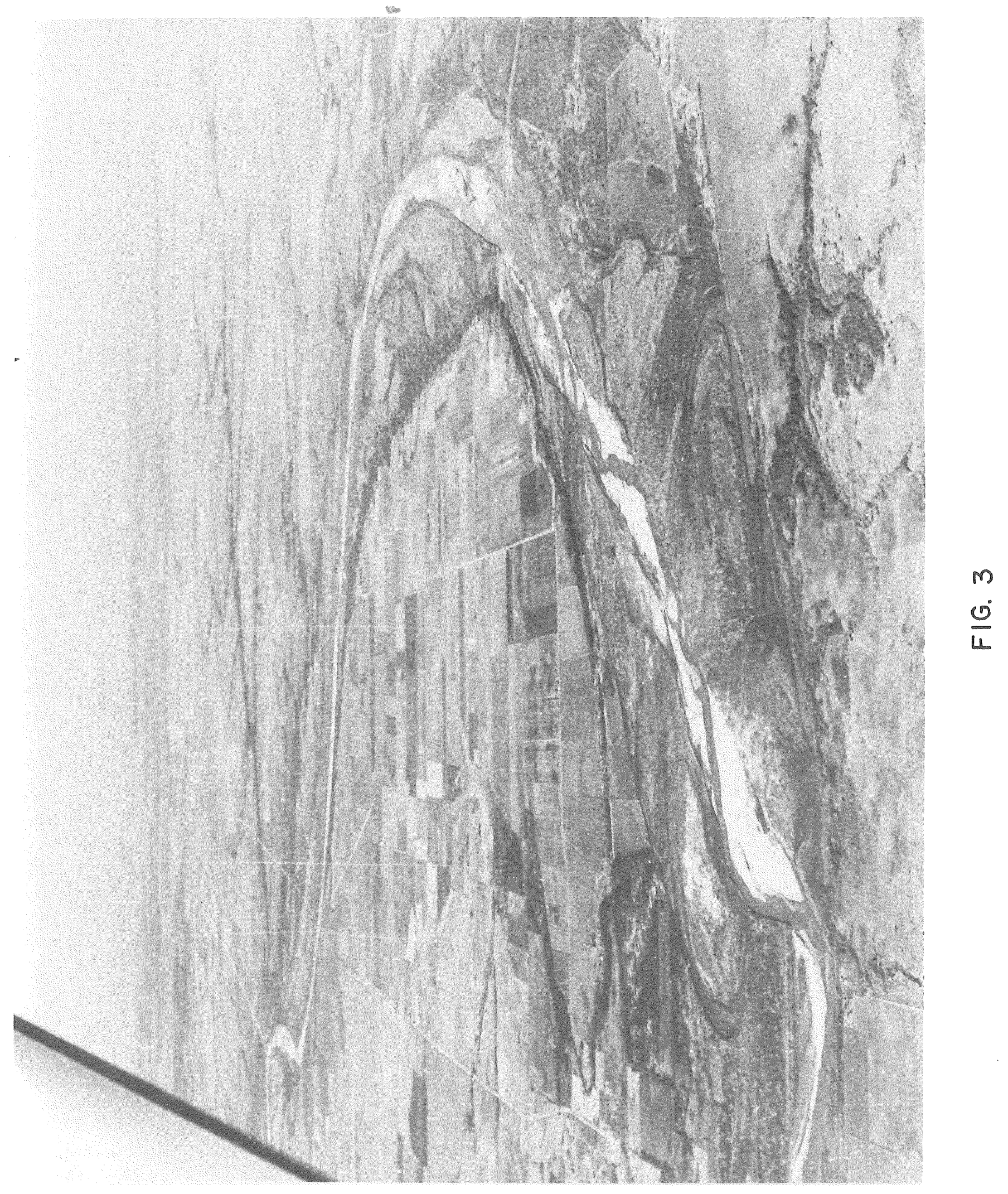





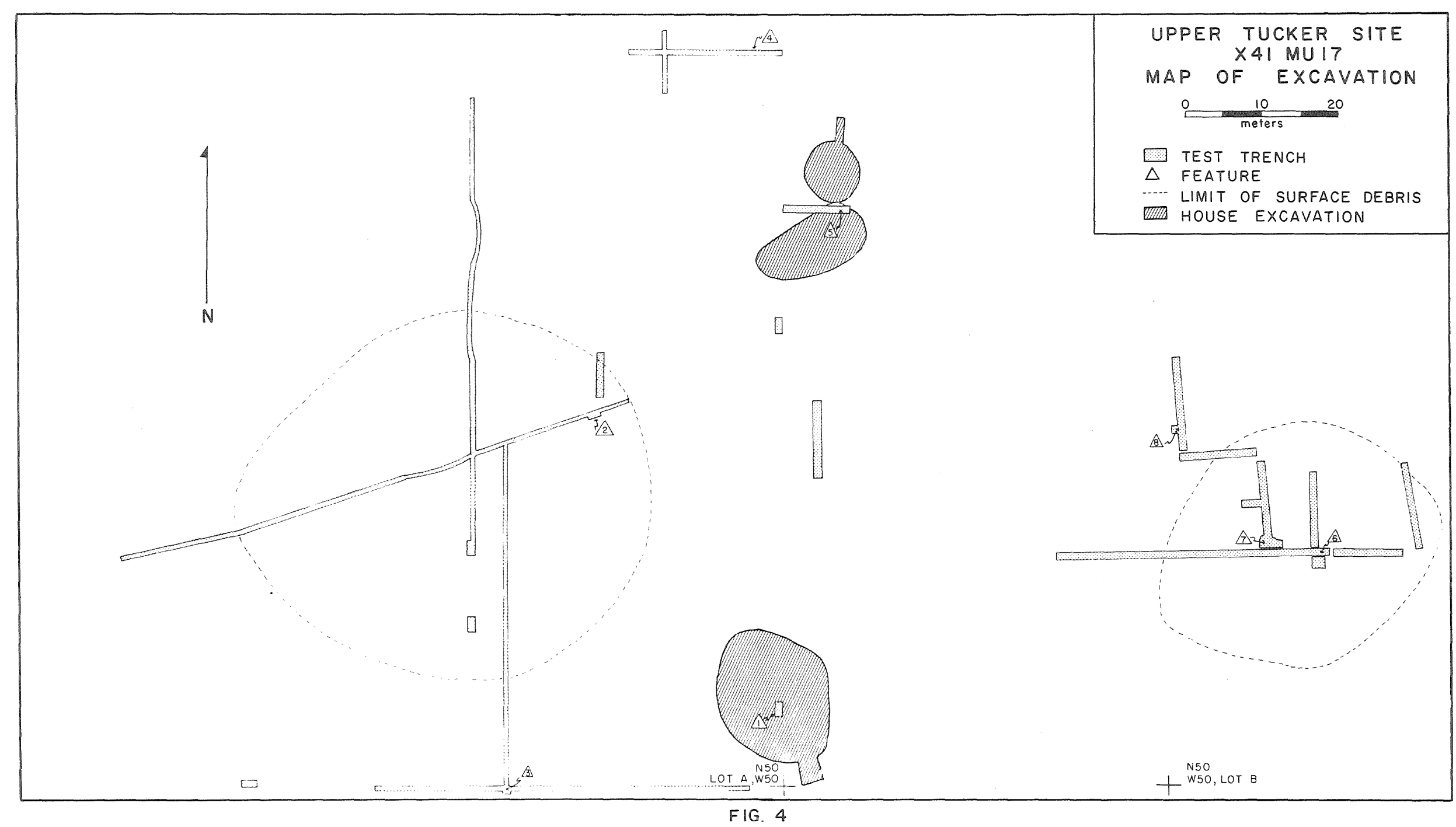





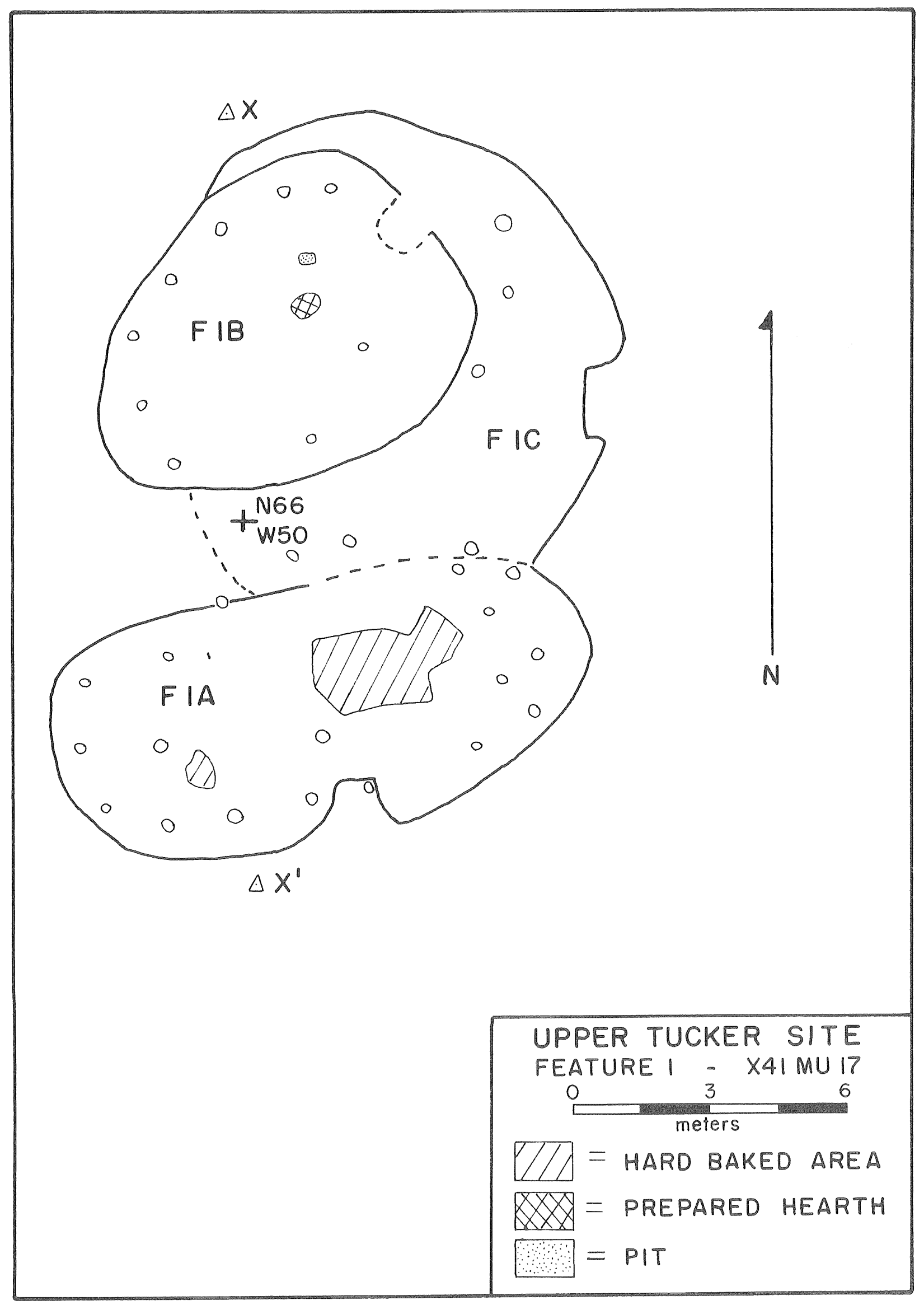

FIG. 5 


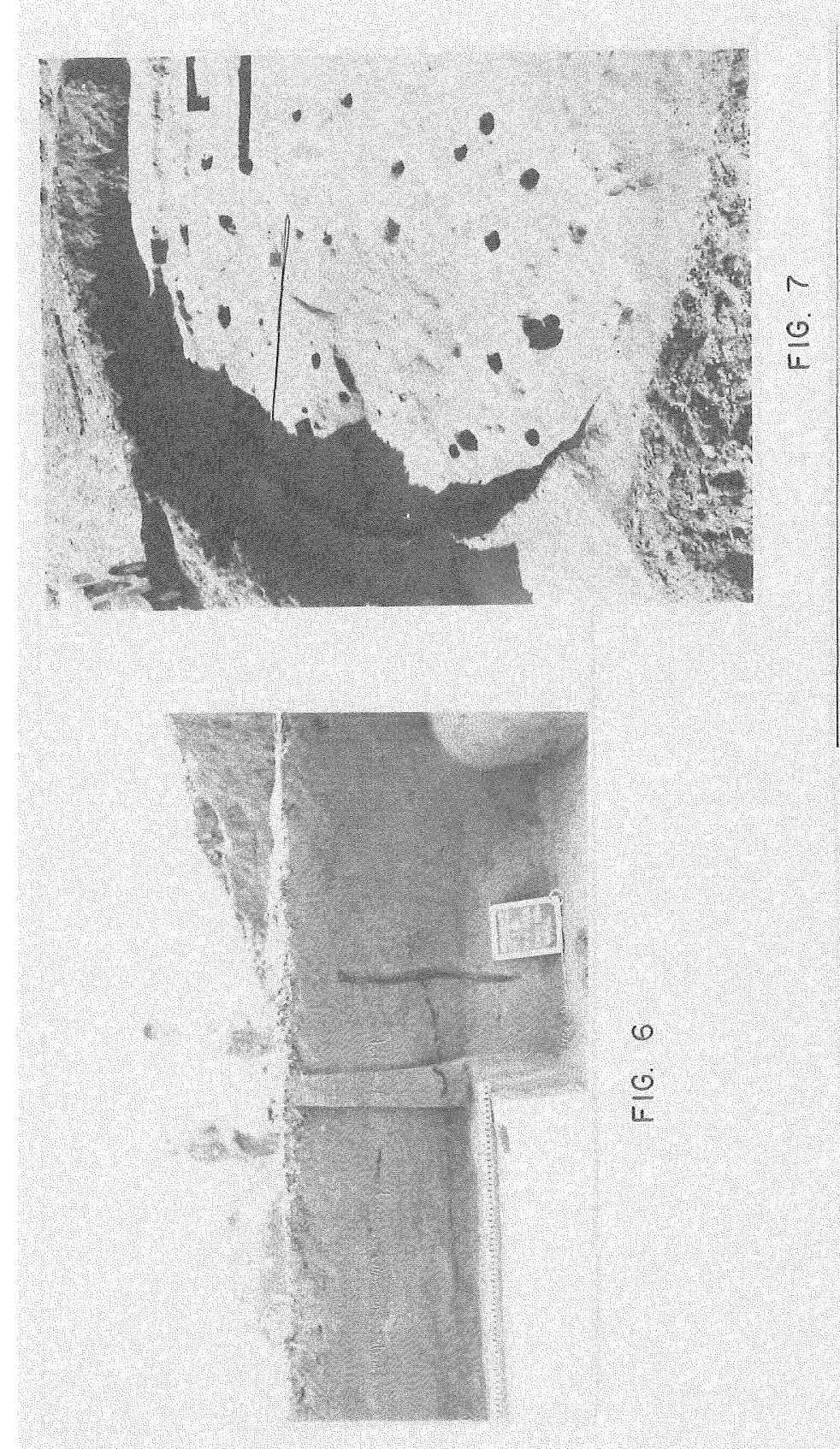

$\omega$
$\frac{0}{4}$
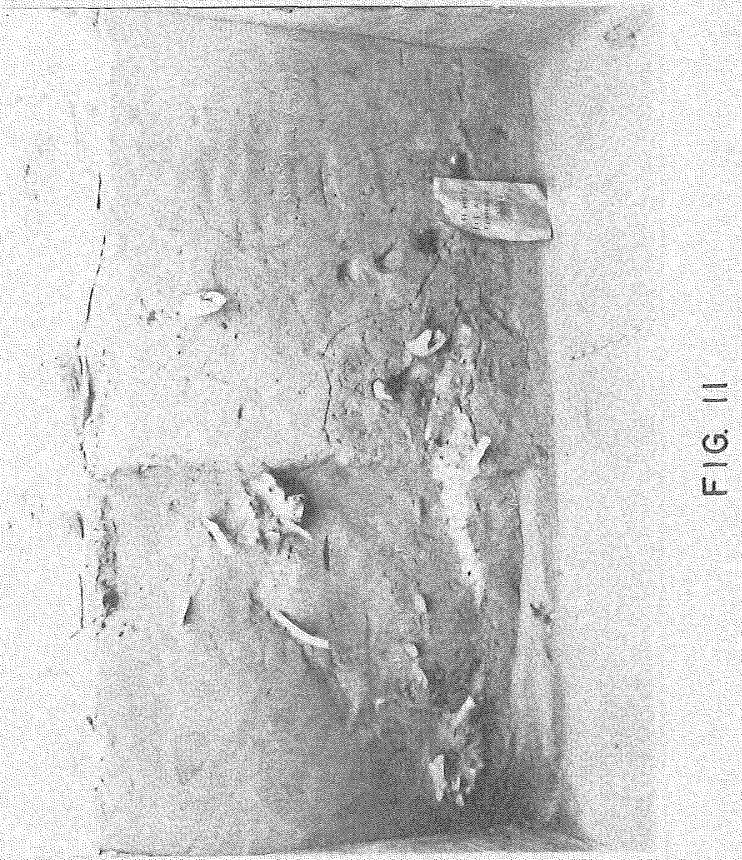

$\frac{0}{4}$

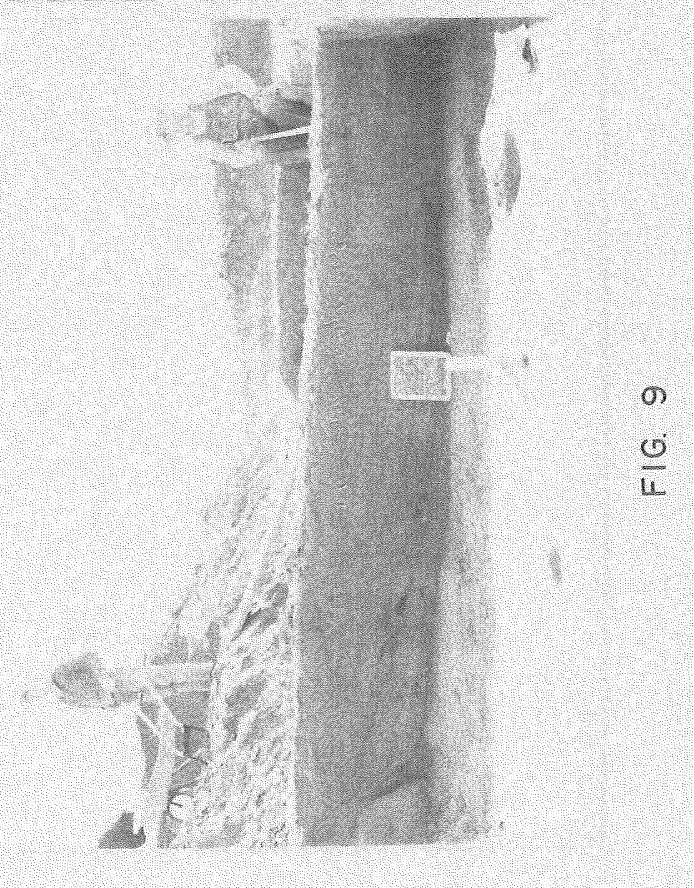





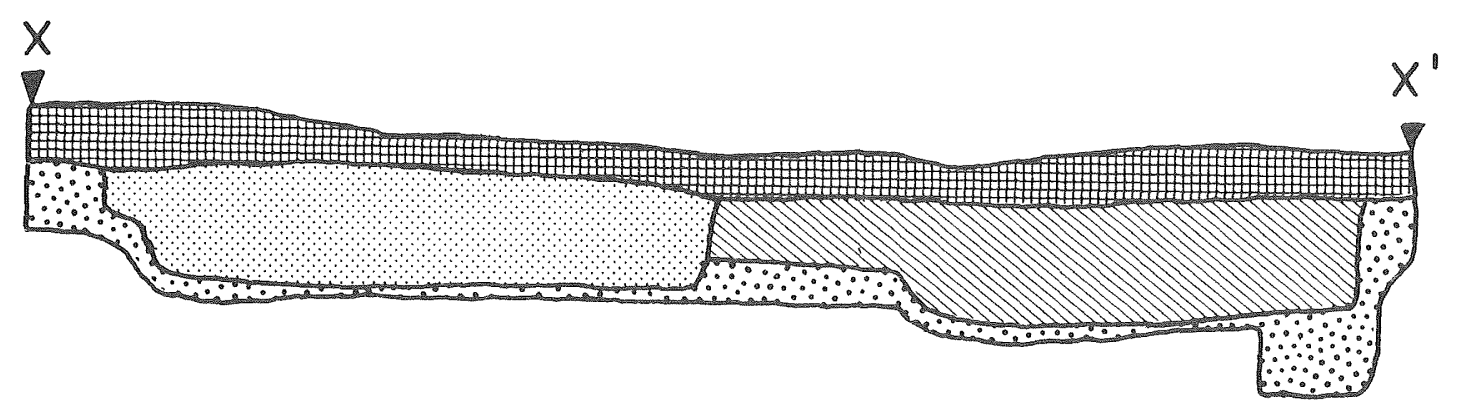

FEATURE ।

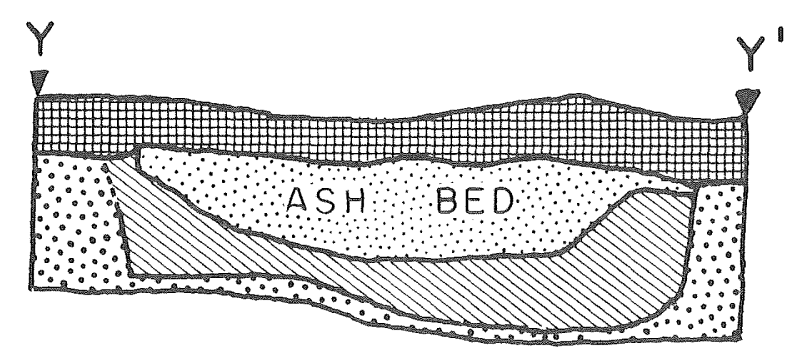

FEATURE 5B

UPPER TUCKER SITE, HOUSE PIT PROFILES HORIZONTAL: $\frac{0 \quad 1}{\text { meters }}$

$\because \because$ STERILE ORANGE SAND

HOUSE PIT, FEATURES IA,IC,5B

HOUSE PIT, FEATURE IB MODERN PLOW ZONE

FIG. 8 



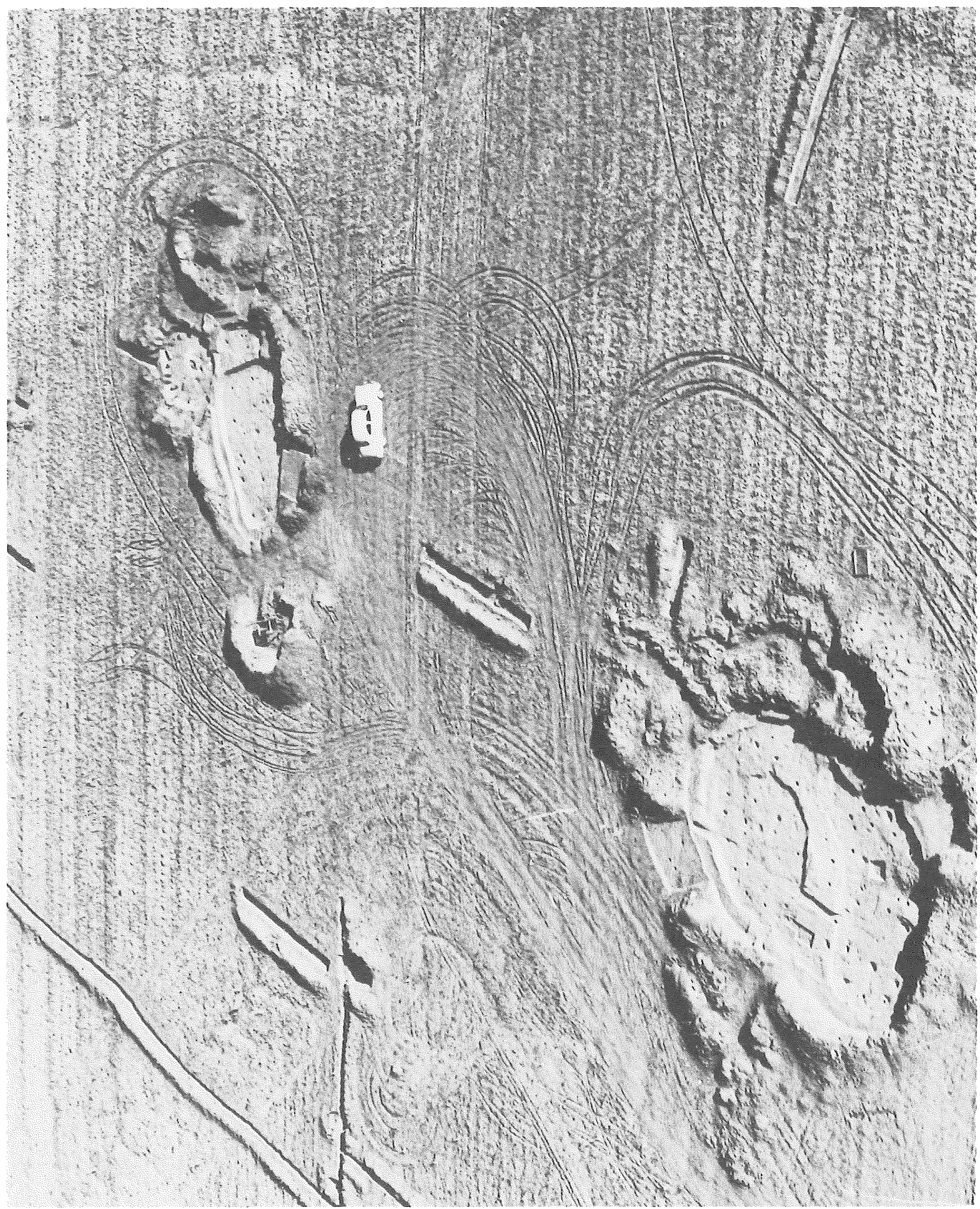





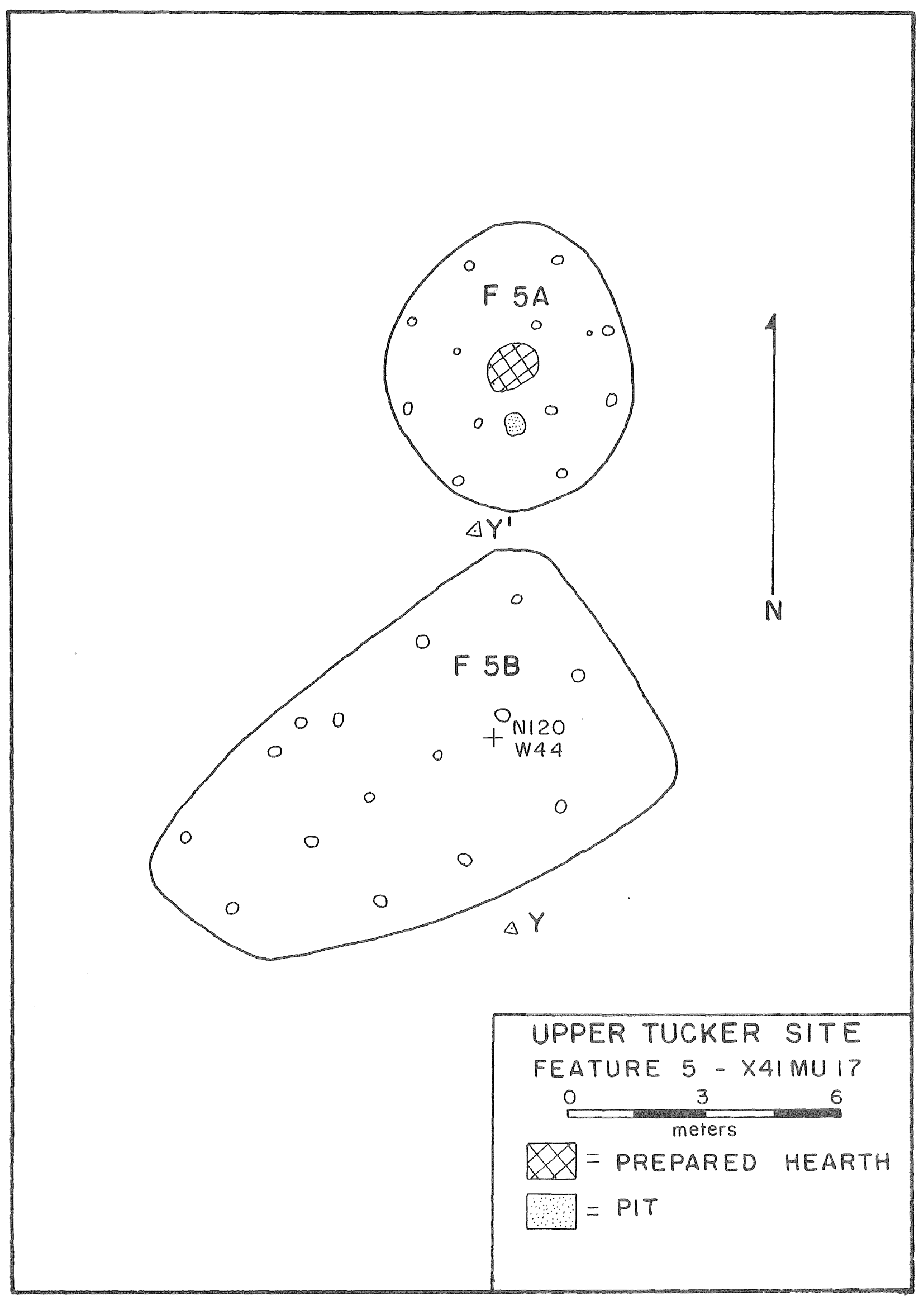

FIG. 12 



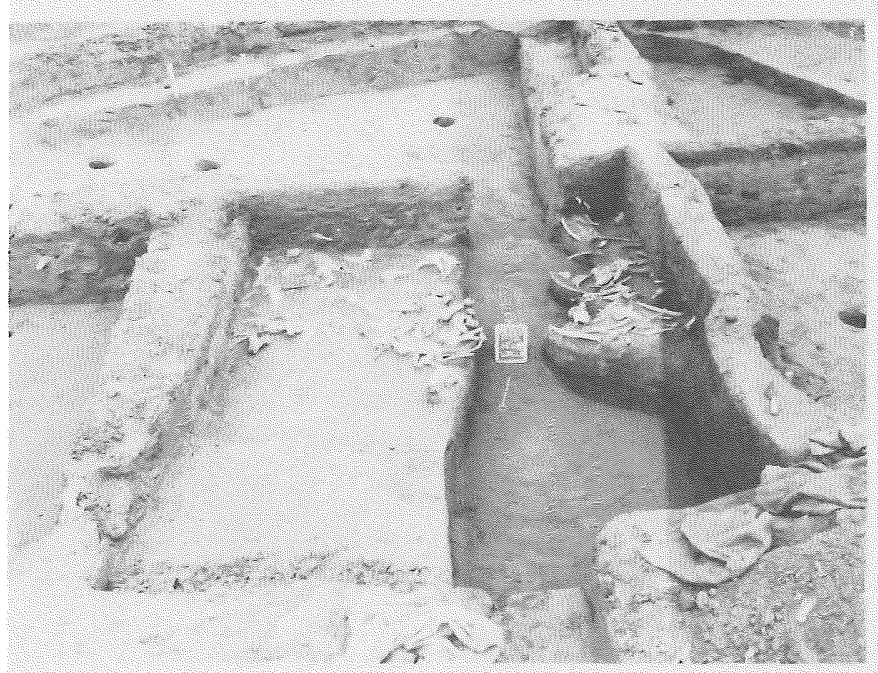

FIG. I3

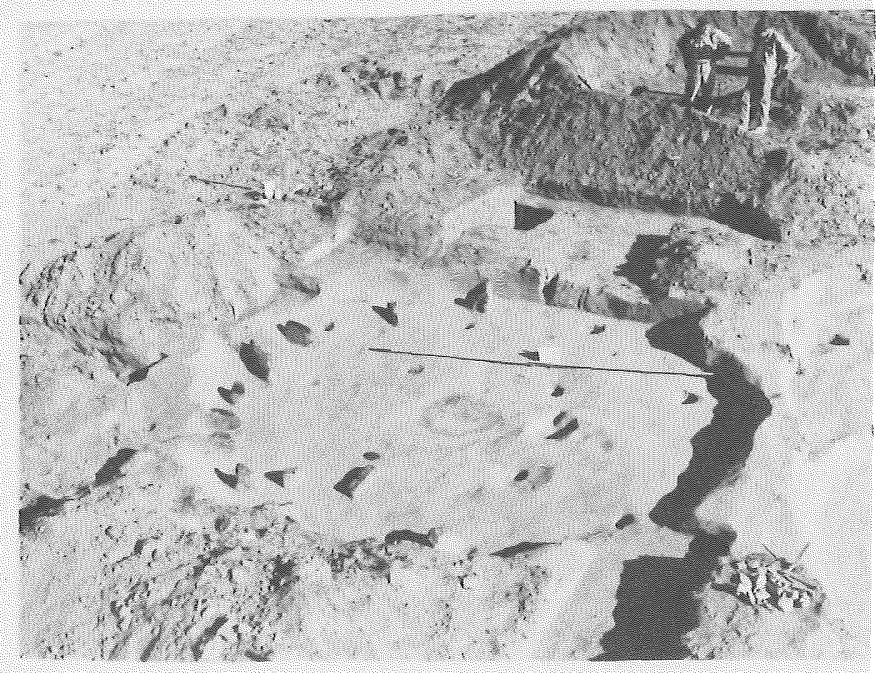

FIG. 14

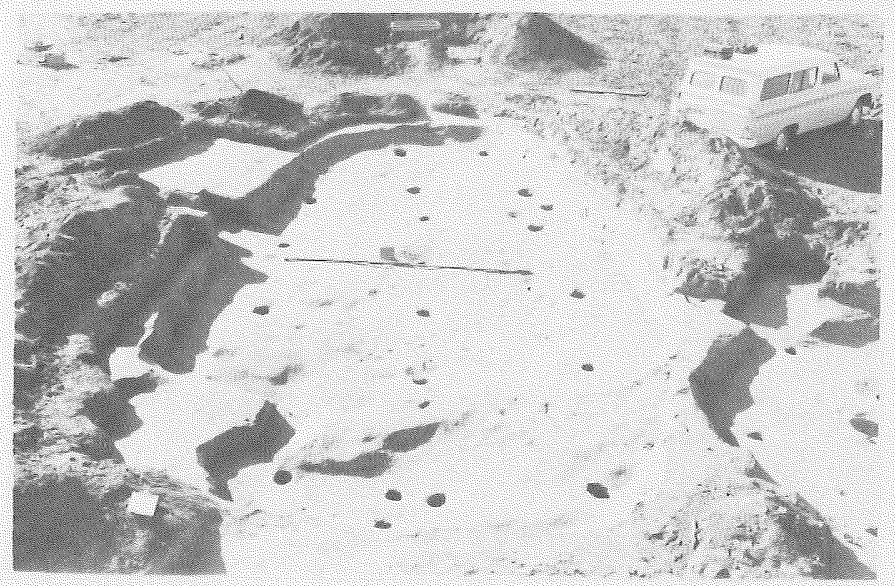

FIG. 15

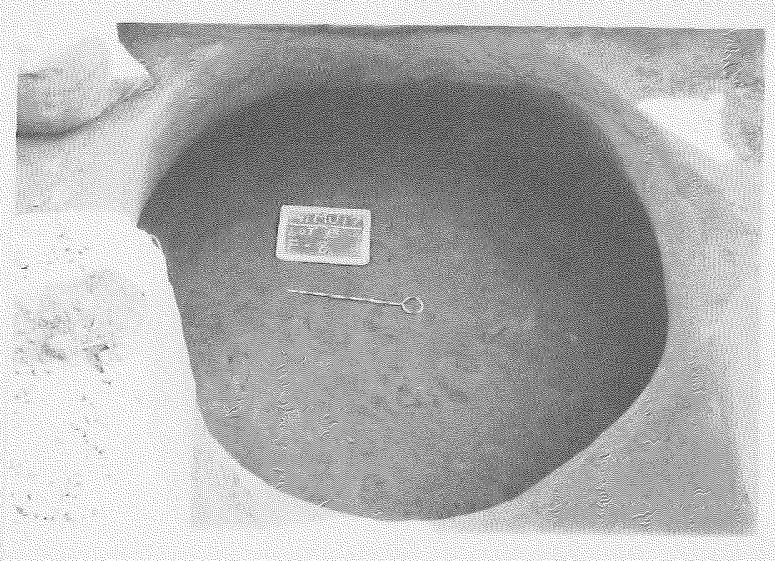

FIG. 16 



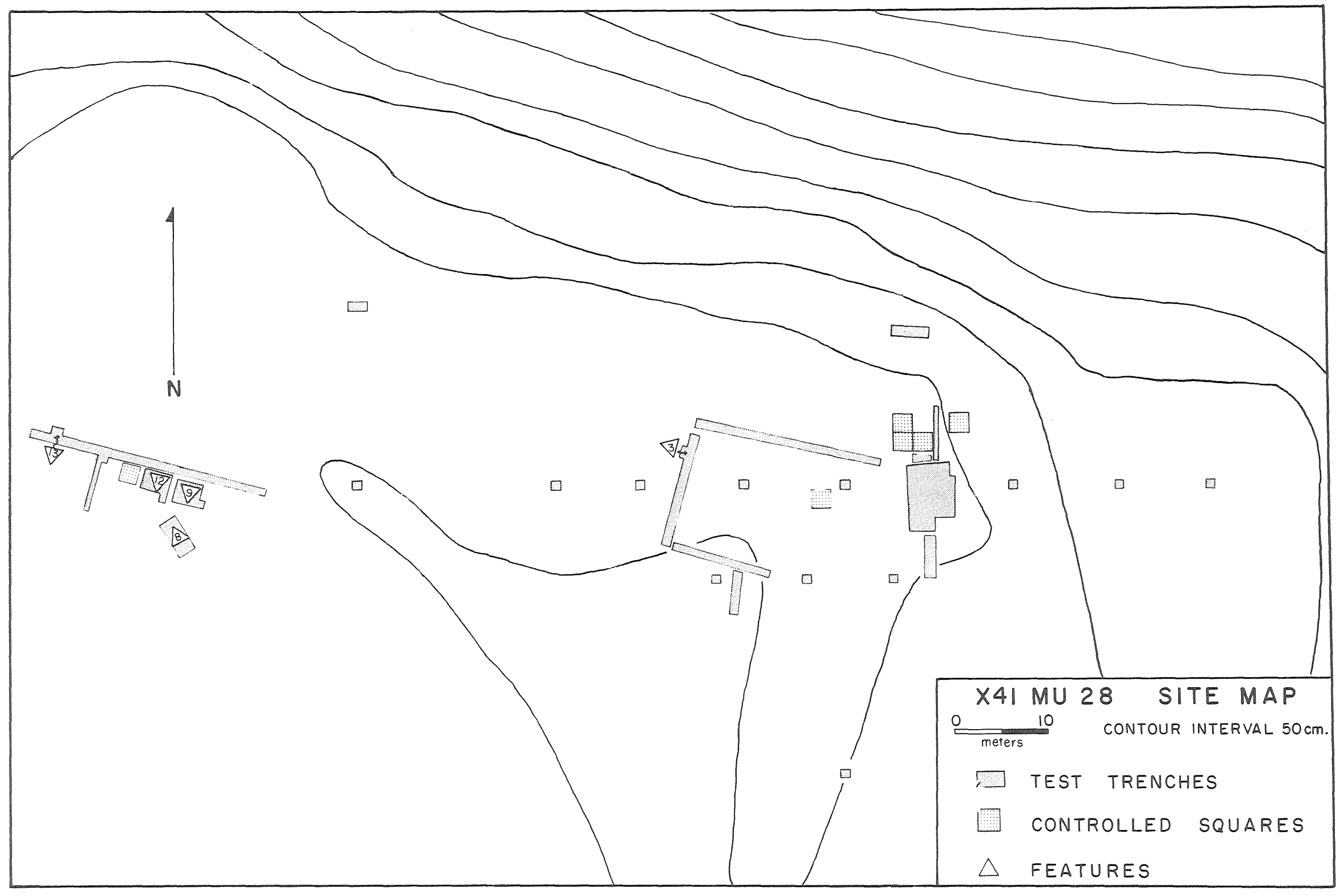

FIG. 17 



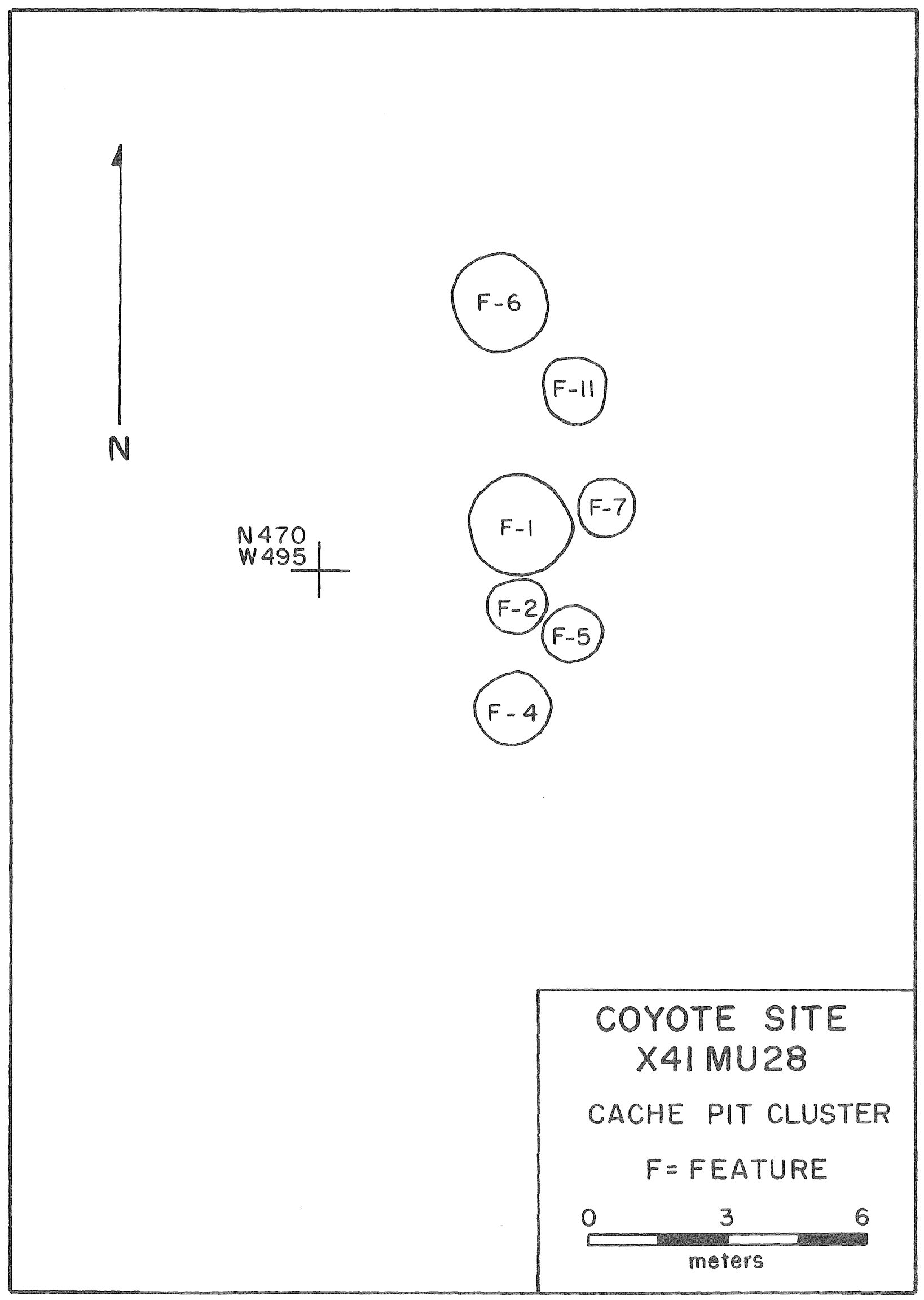

FIG. 18 


\section{SURFACE?}

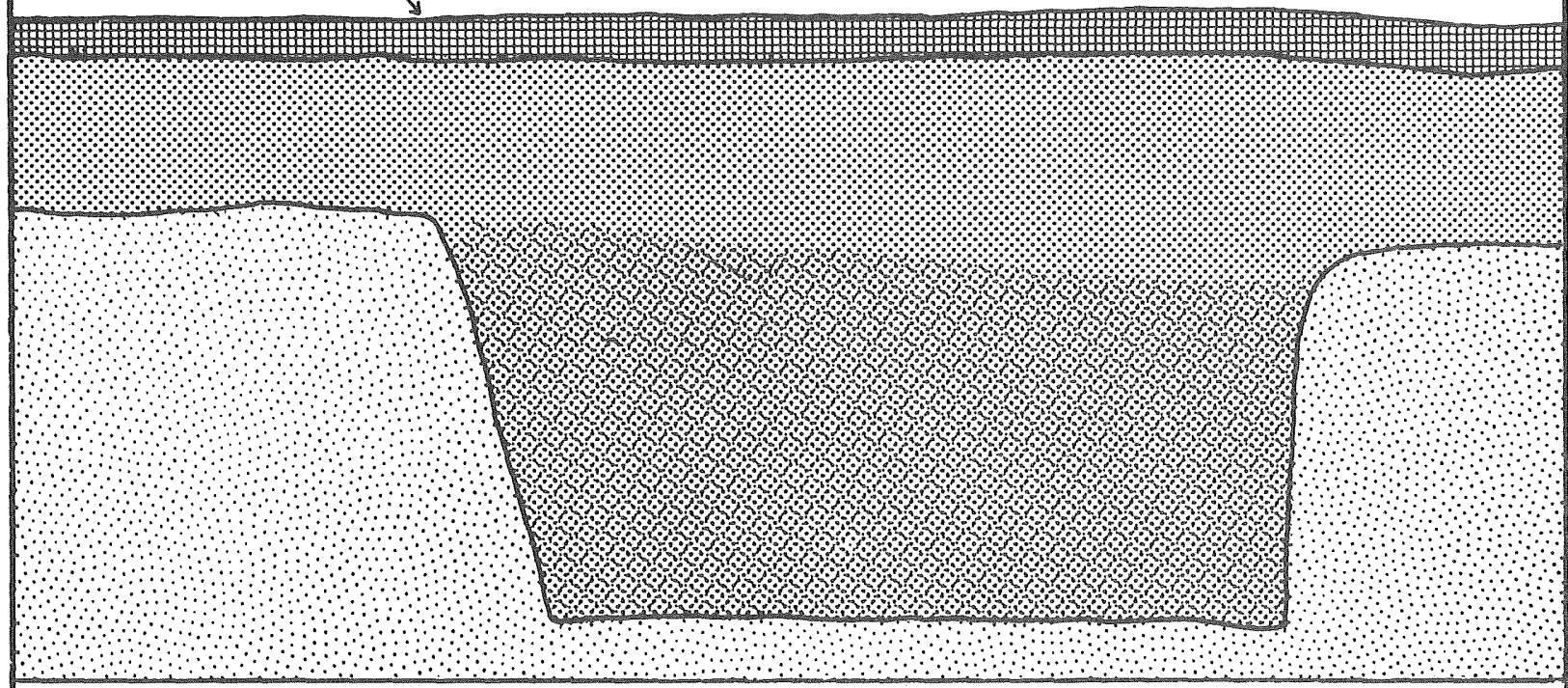

COYOTE SITE-X4IMU28

FEATURE 4-PROFILE

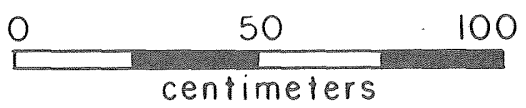

STERILE ORANGE SAND

CACHE PIT FILL

? MIDDEN ZONE

PLOW ZONE

FIG. 19 



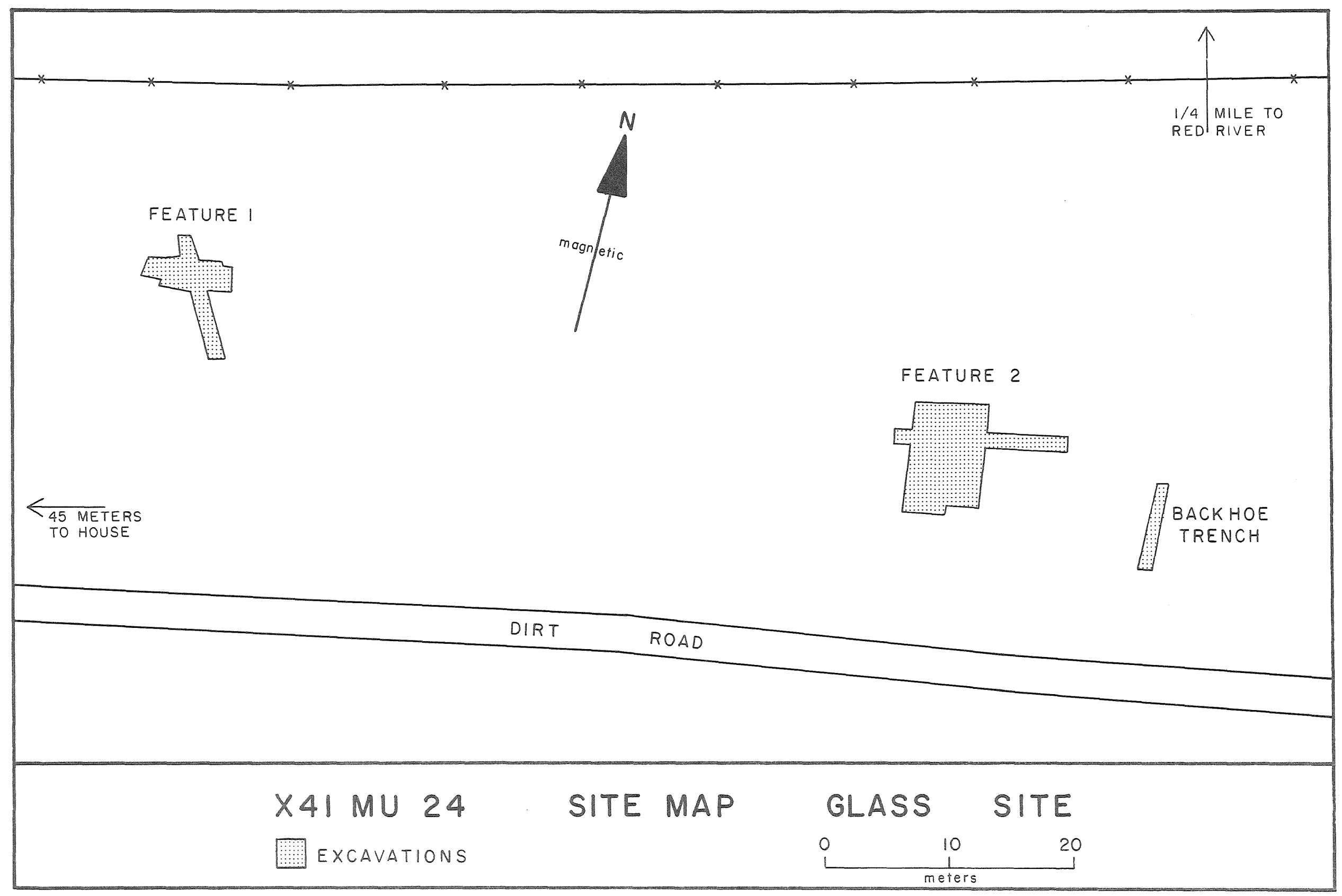

FIG. 20 



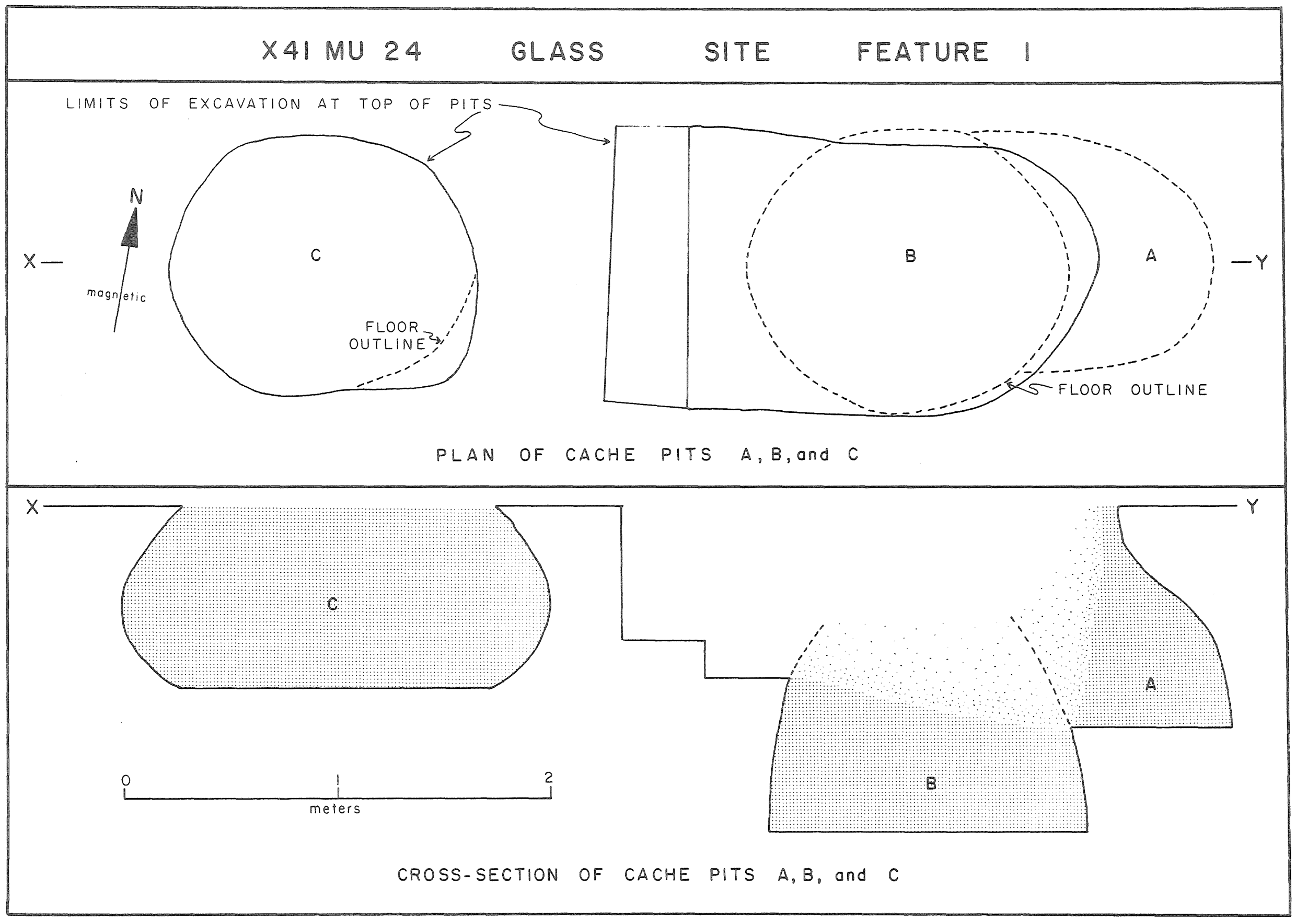

FIG. 2 I 



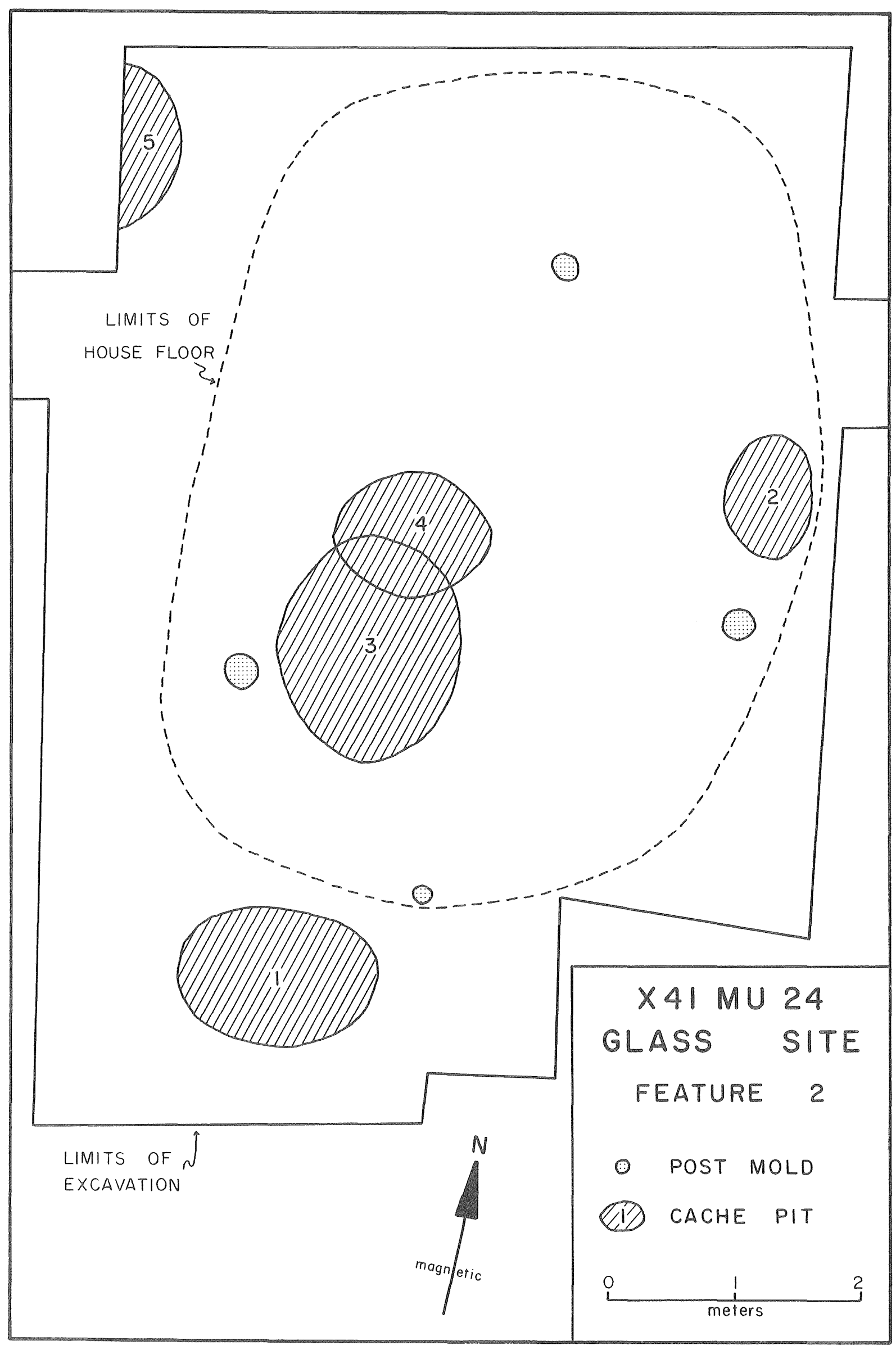

FIG. 22 


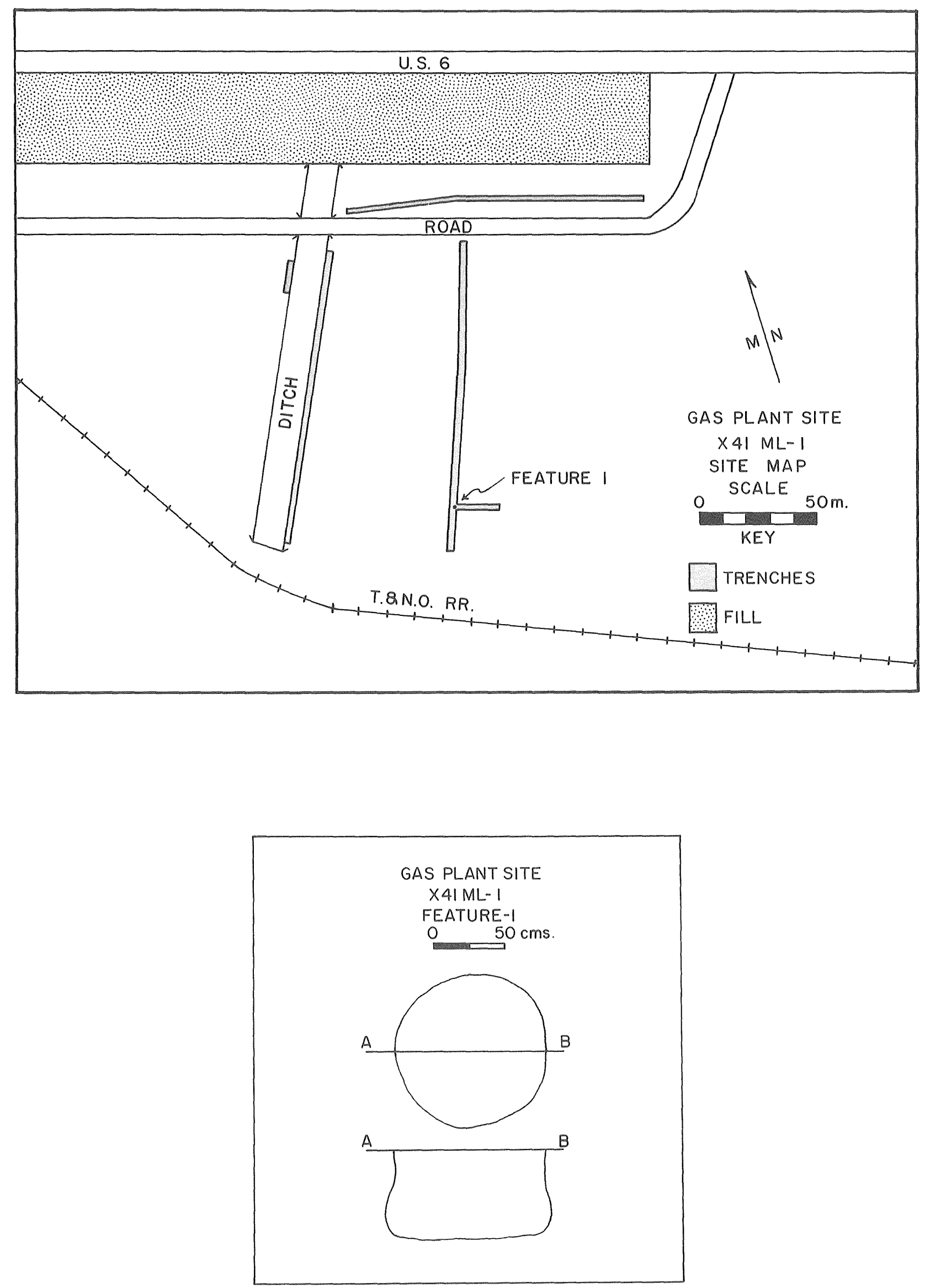

FIG. 23 



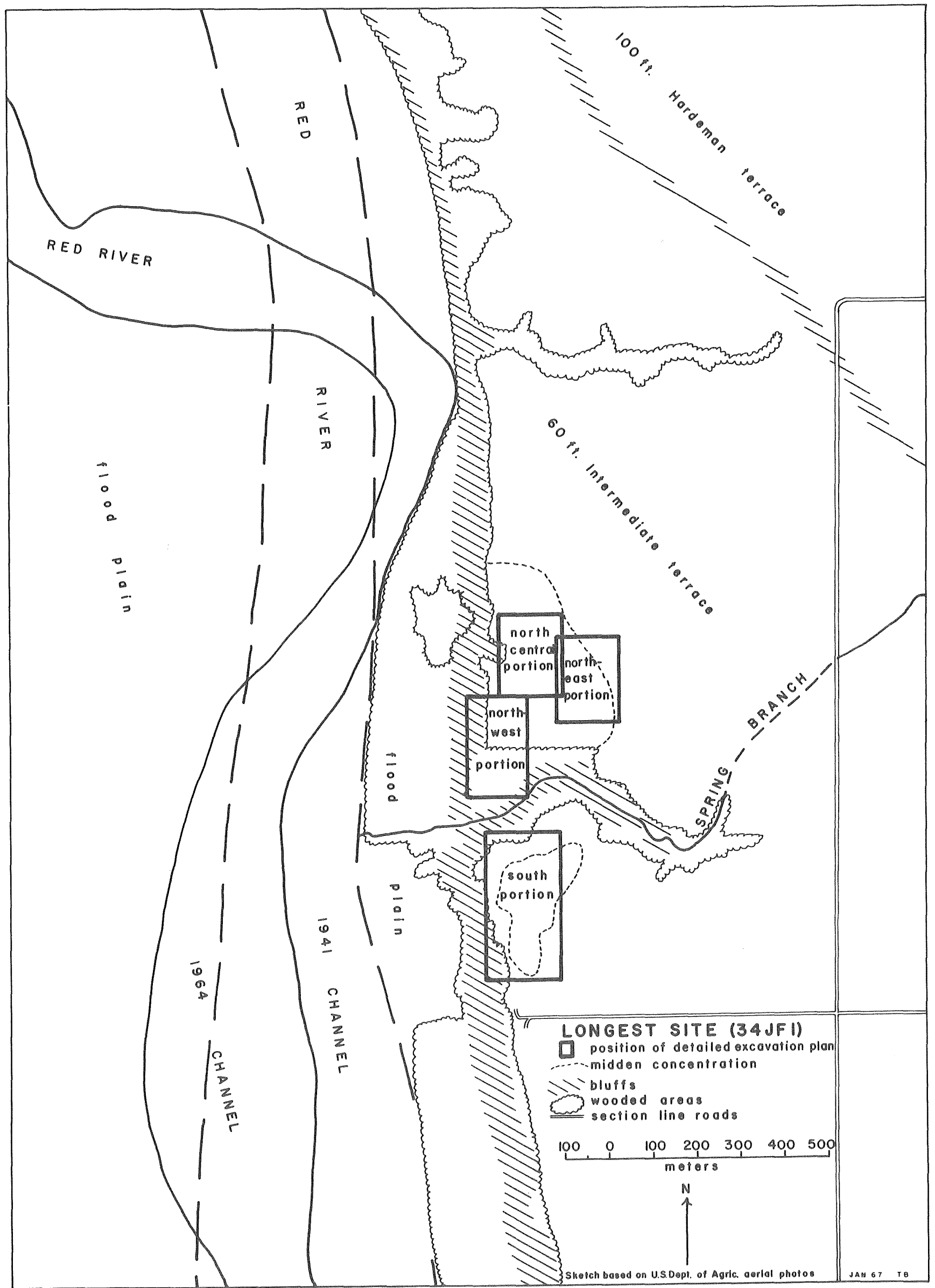

FIG. 24 



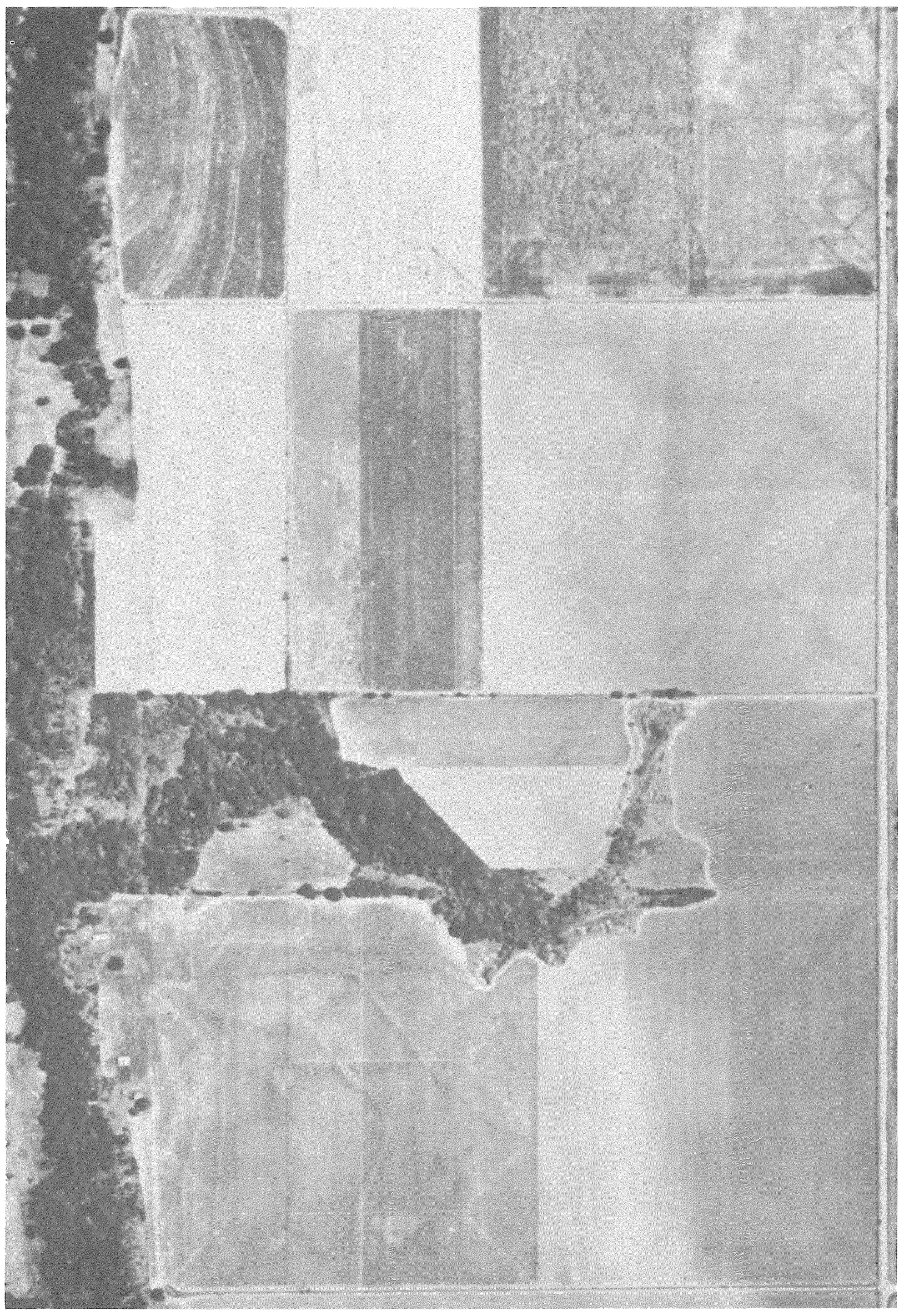

N
$\frac{0}{4}$ 



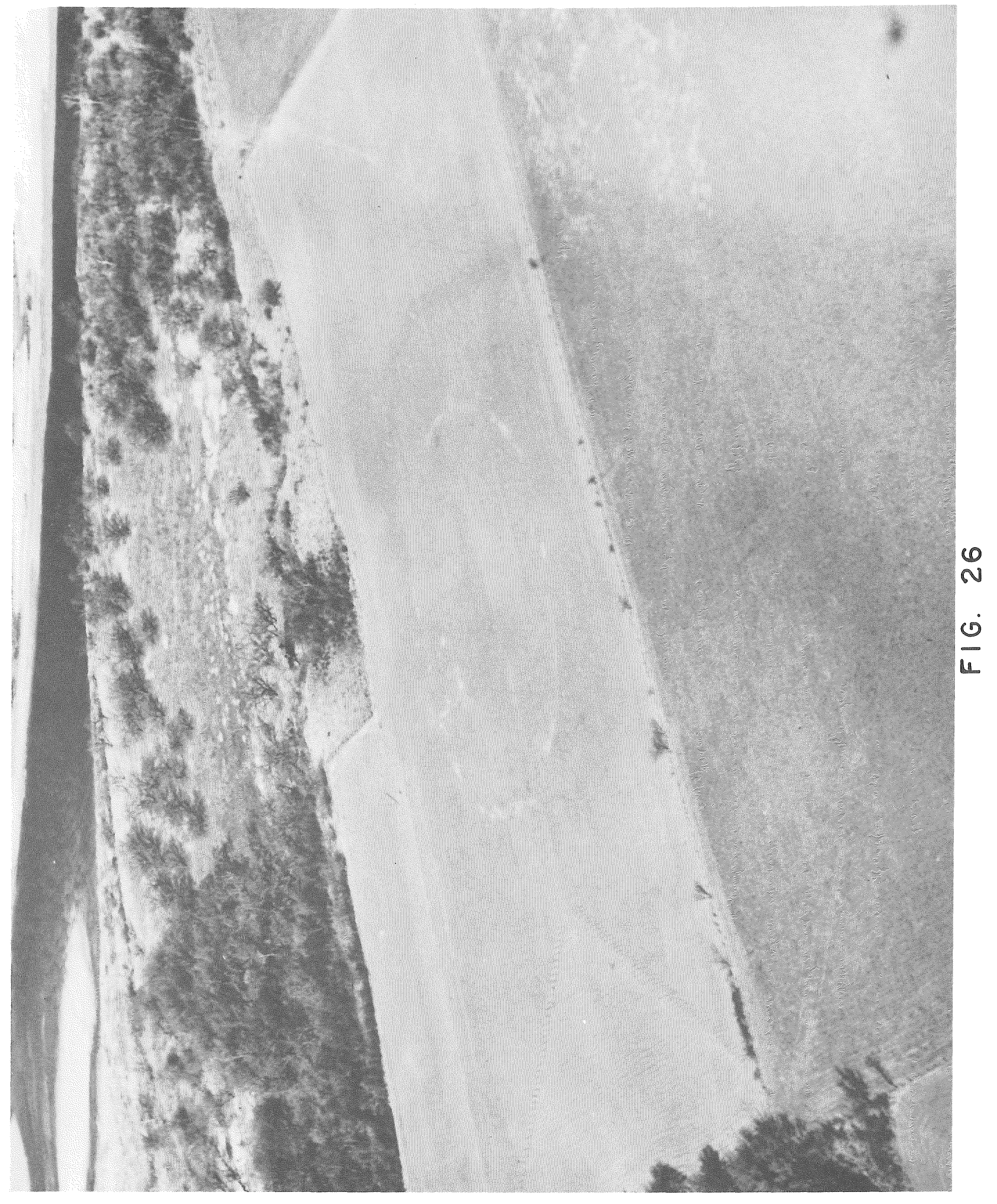





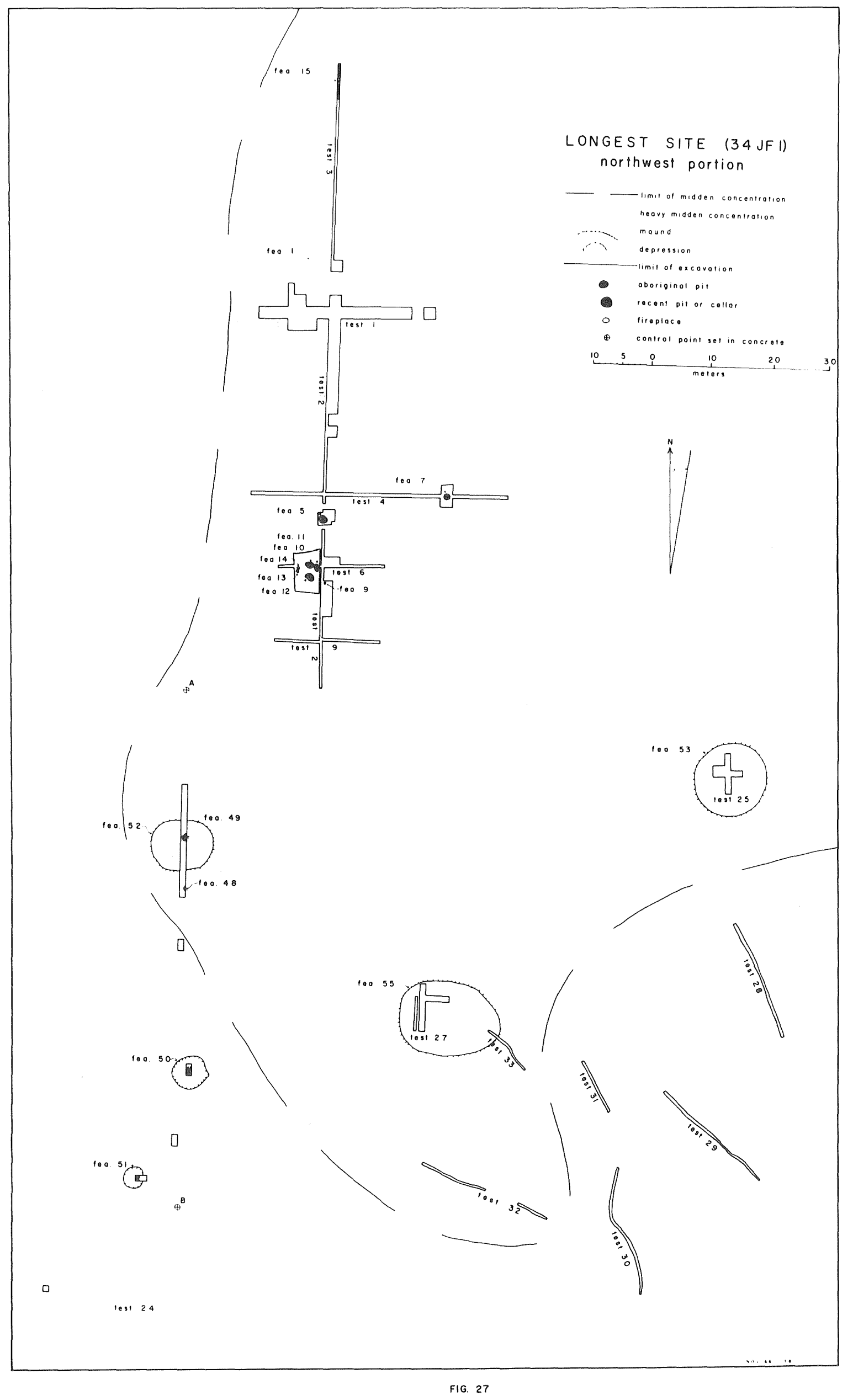





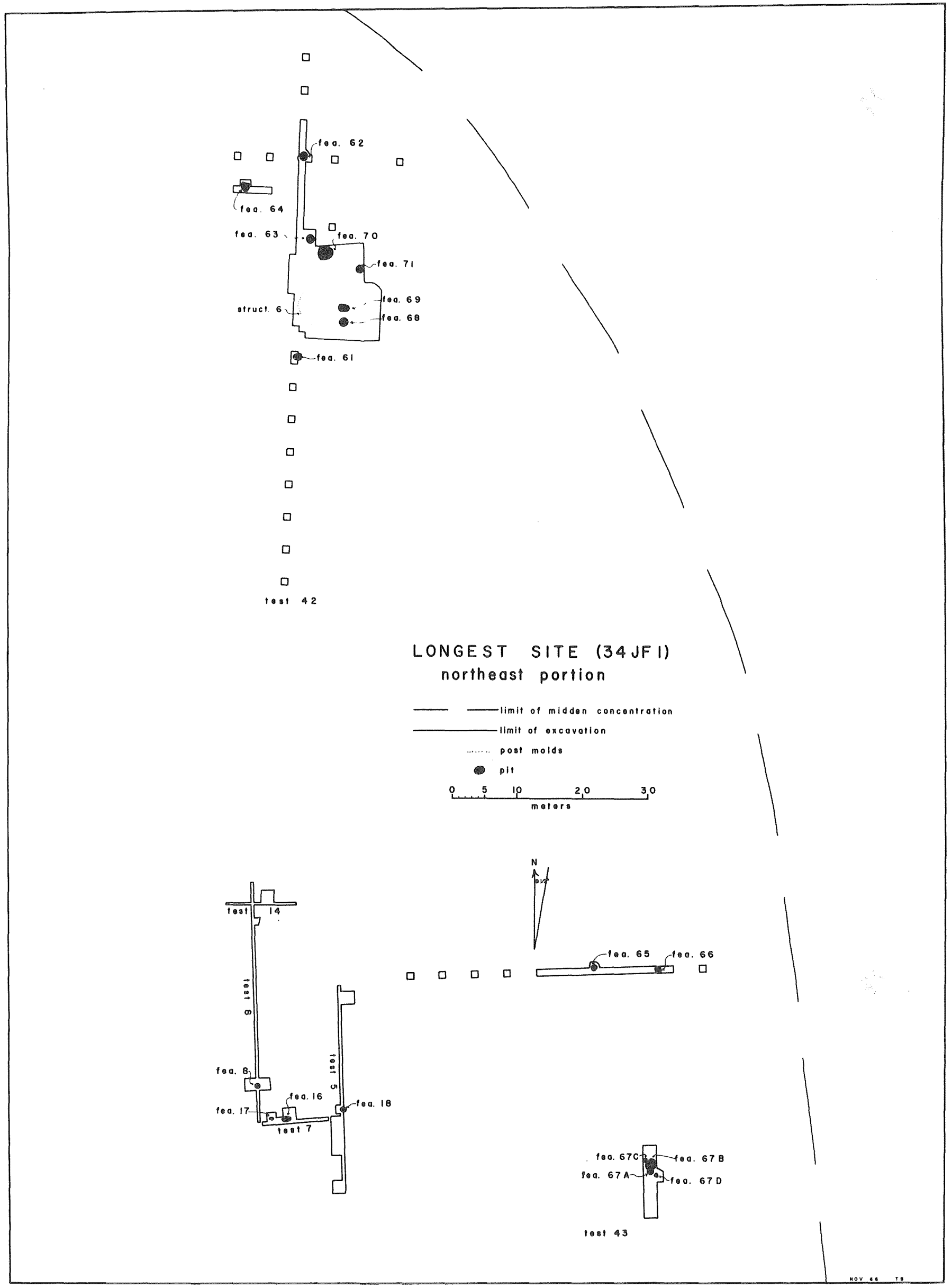

FIG. 28 



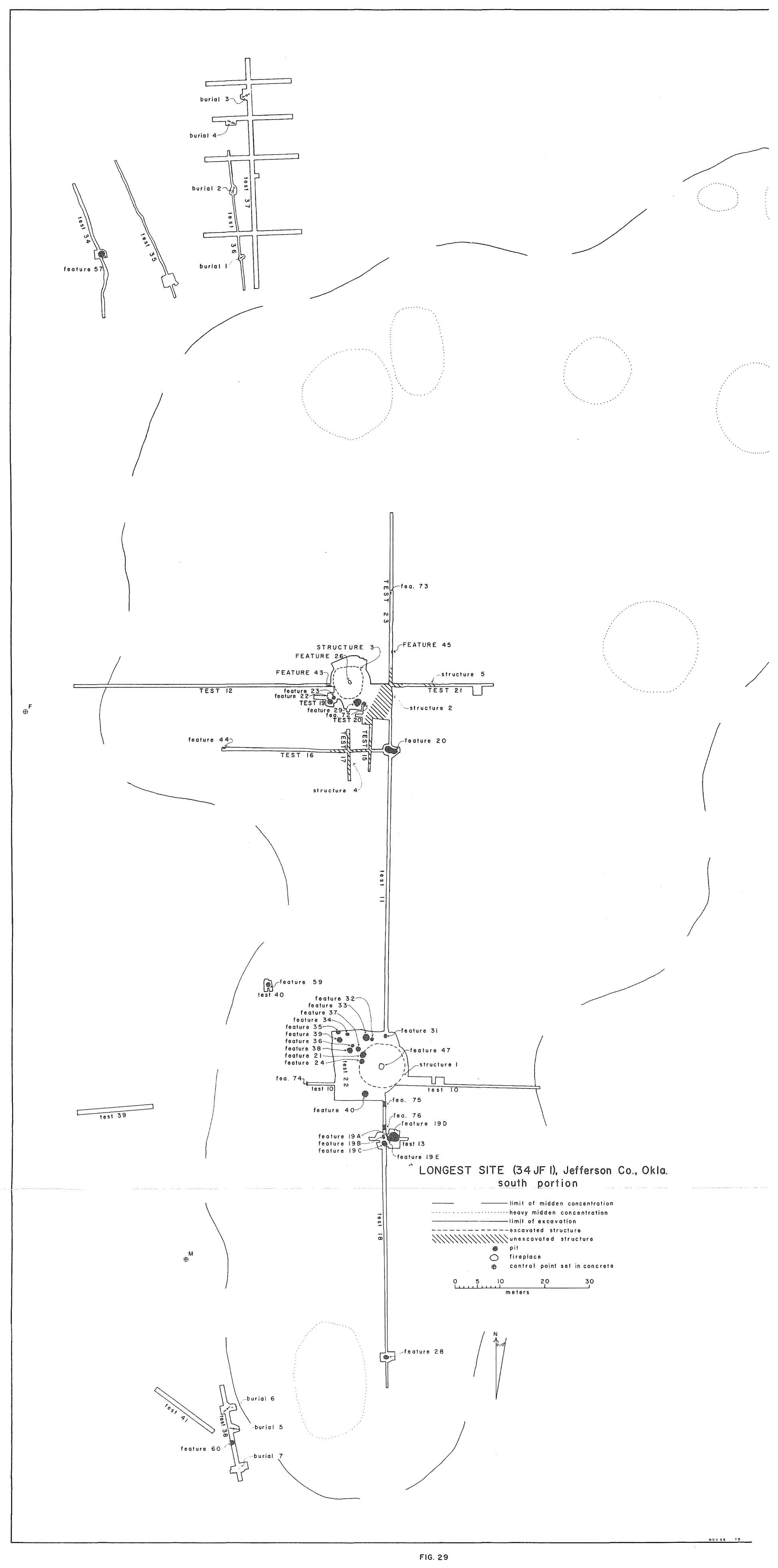




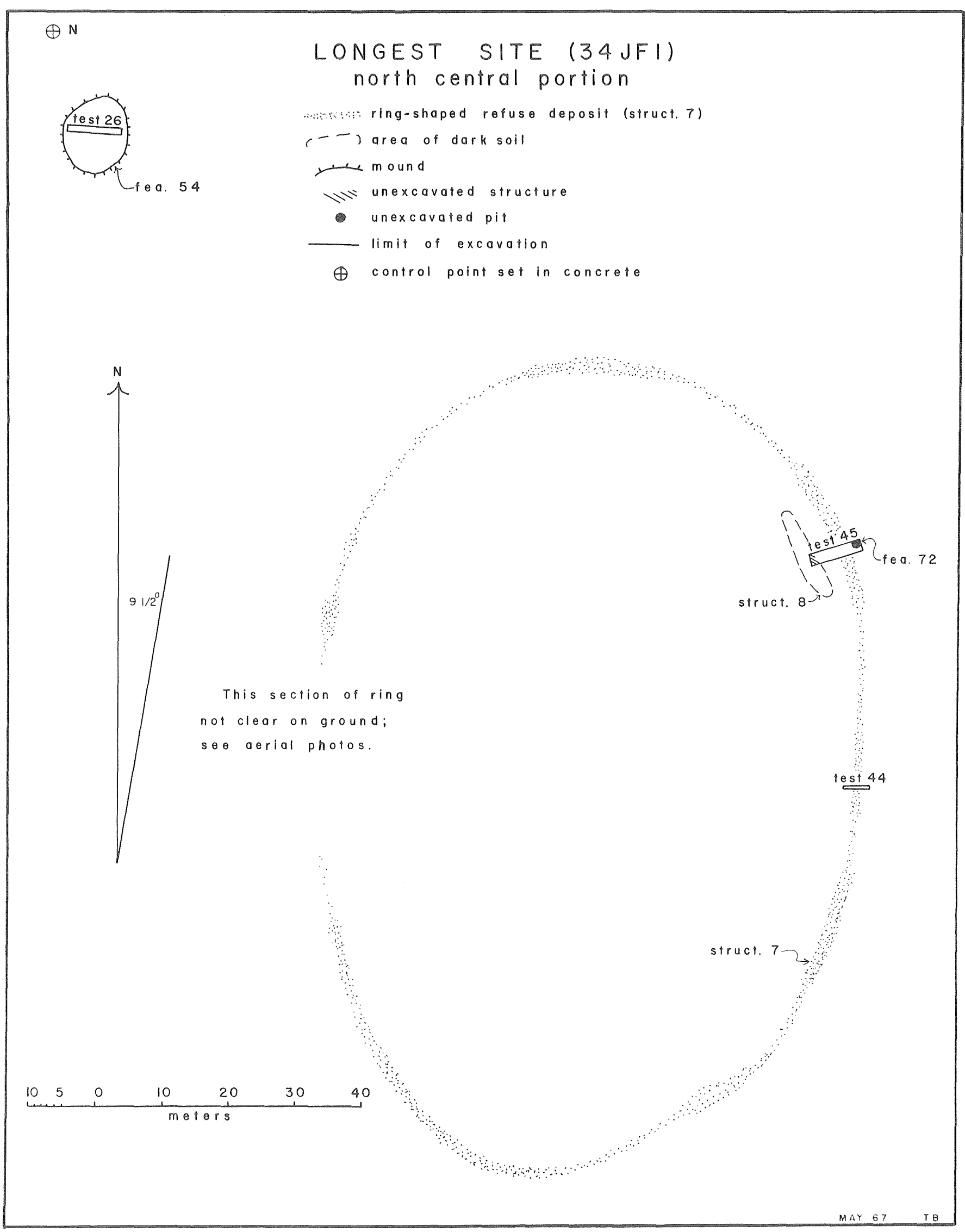

FIG. 30 


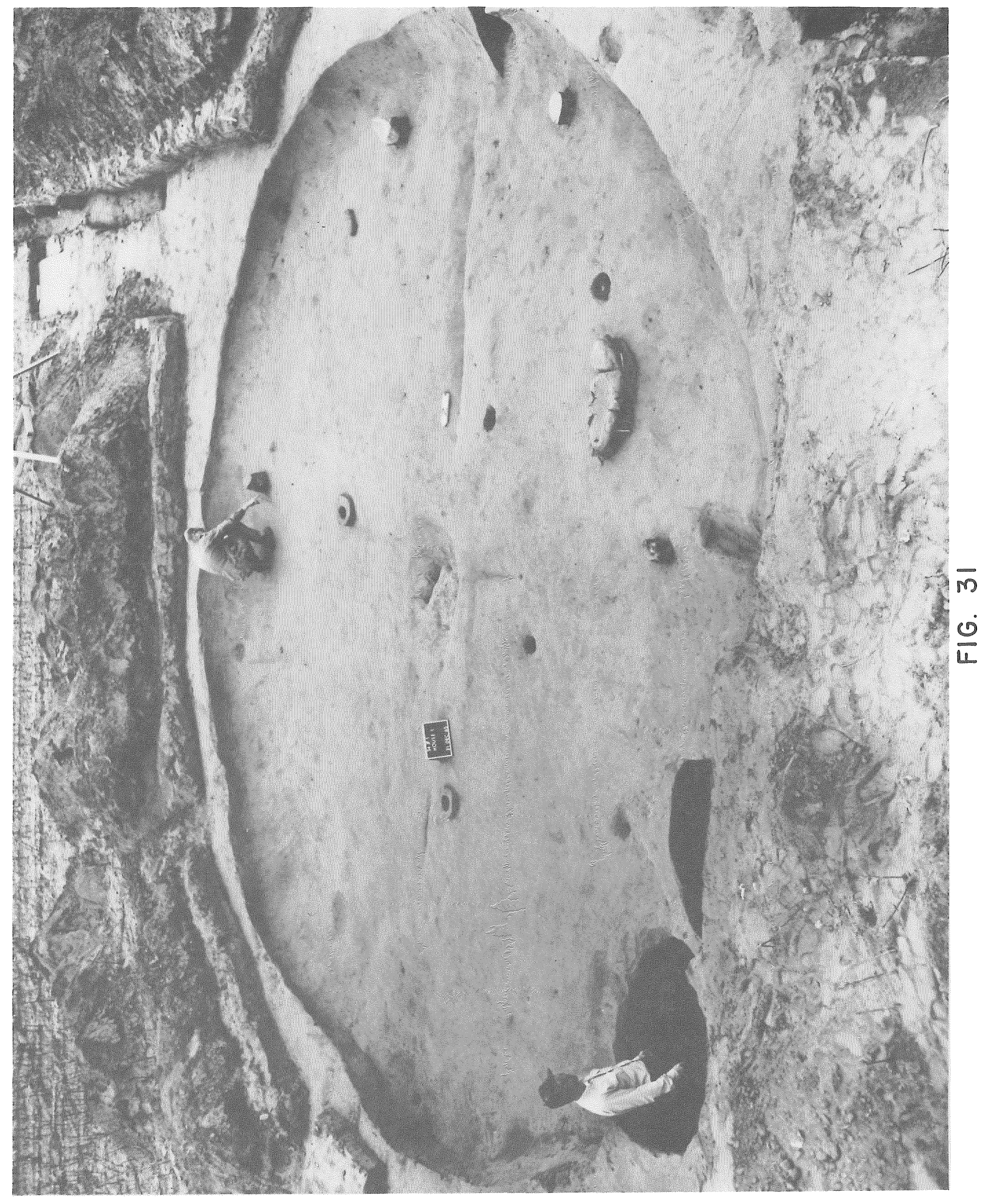




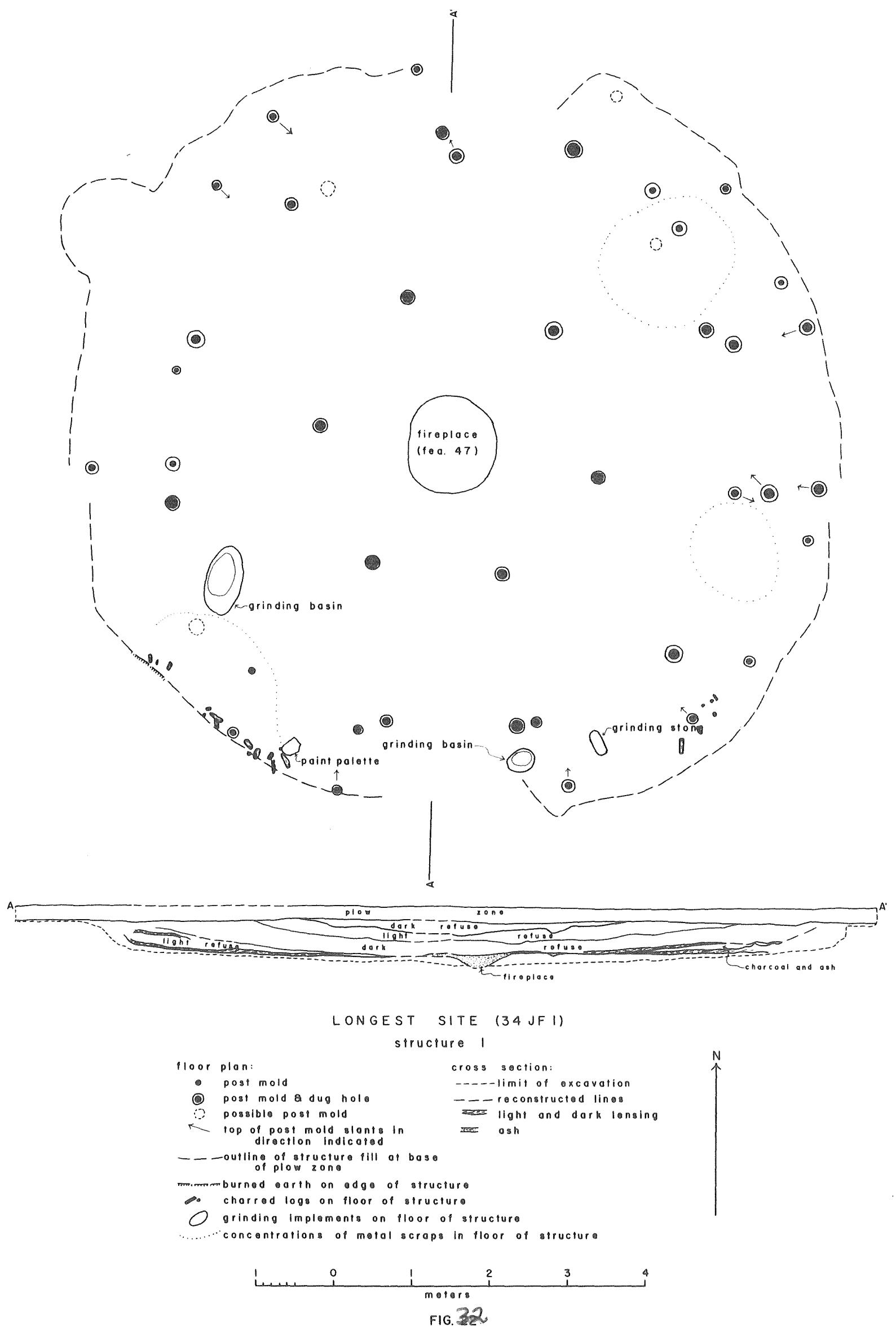




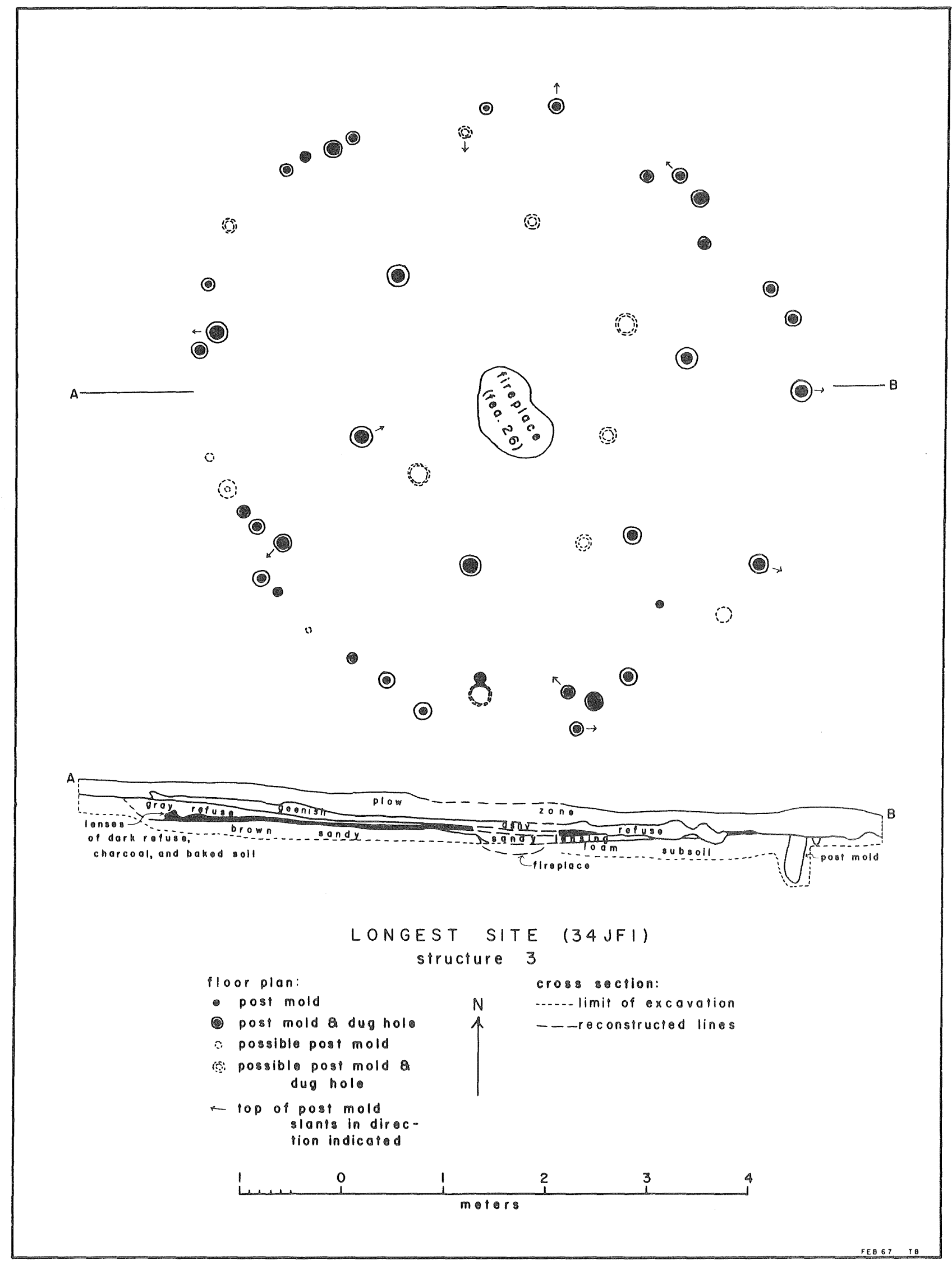

FIG. 33 


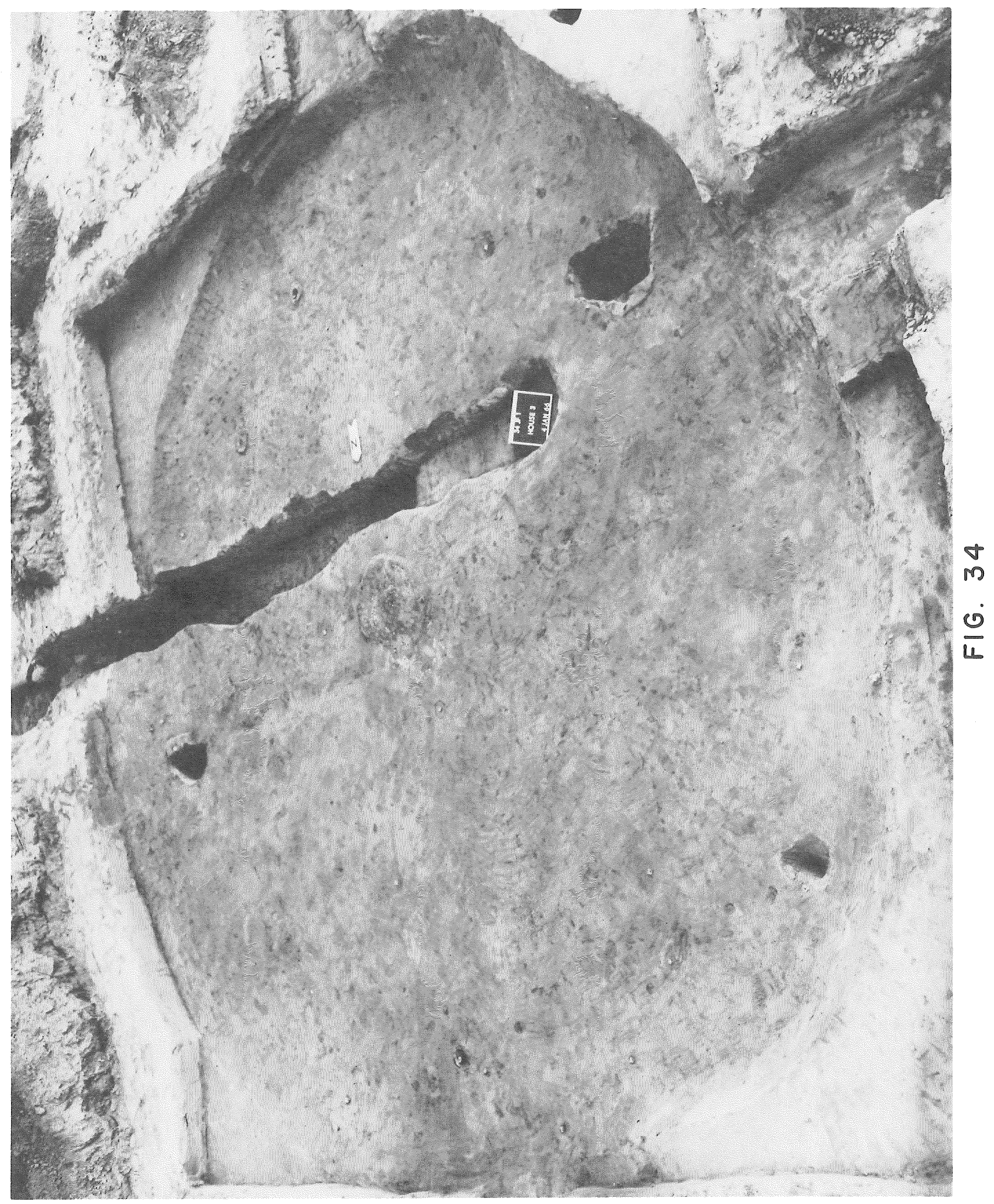









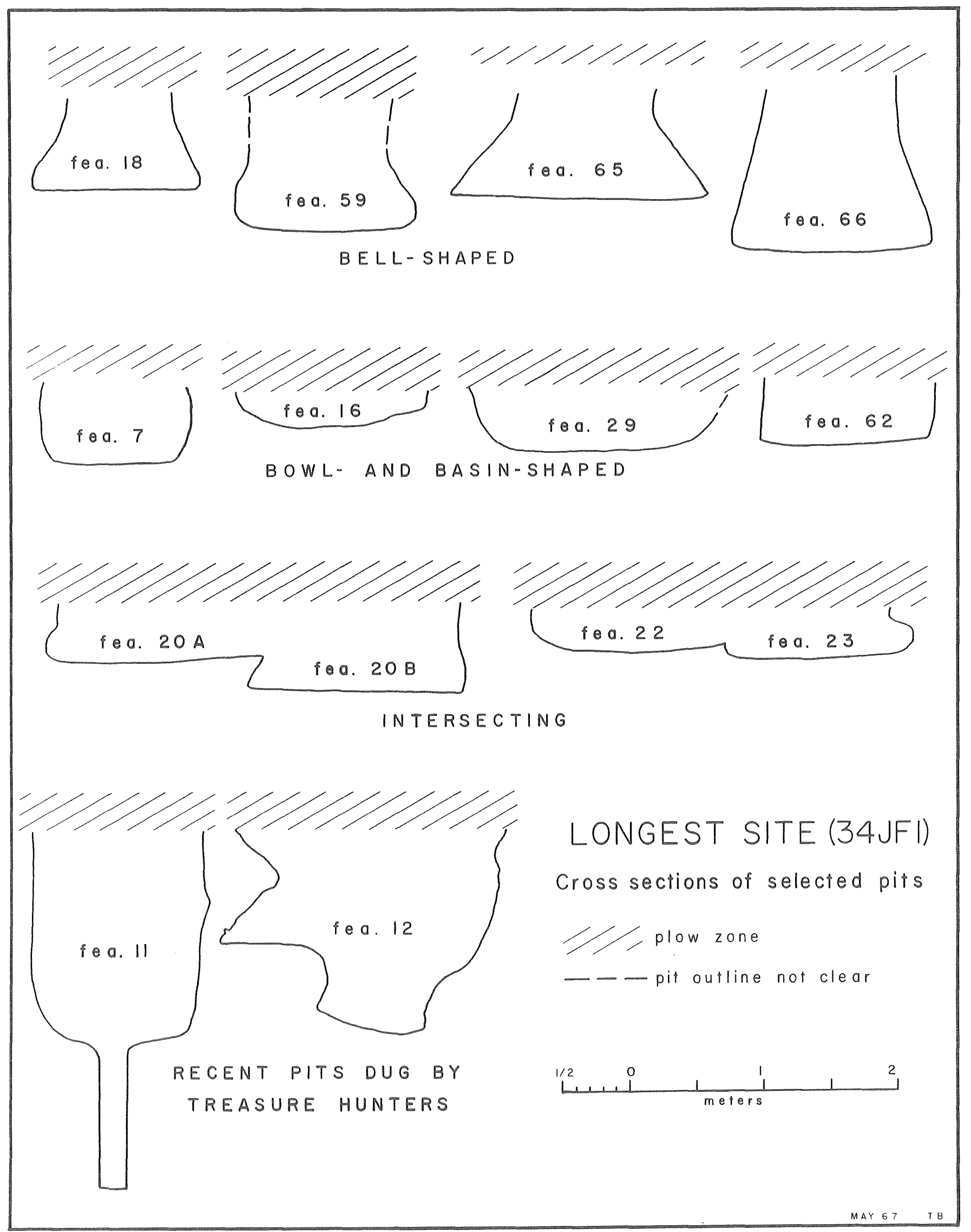

FIG. 36 


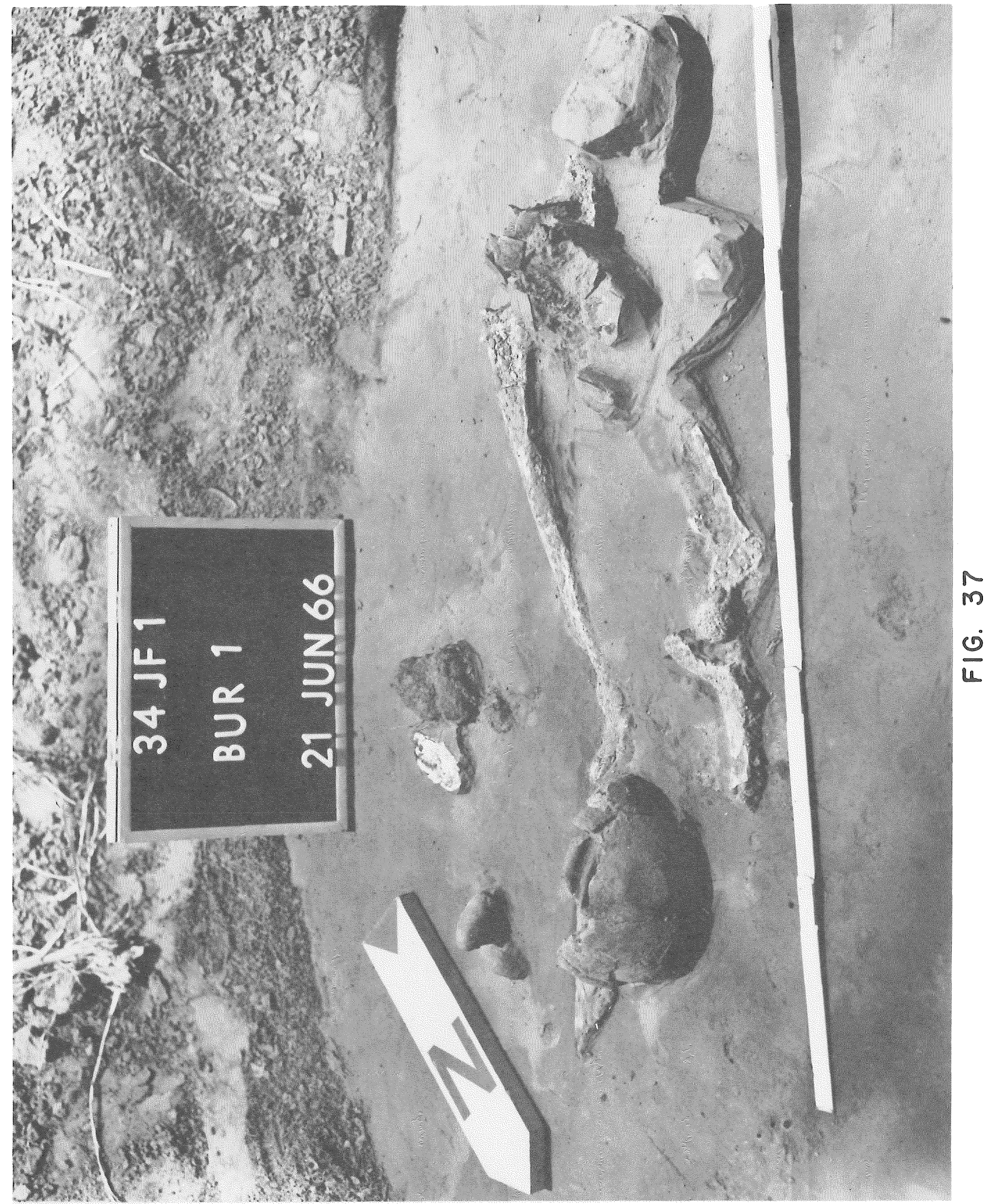




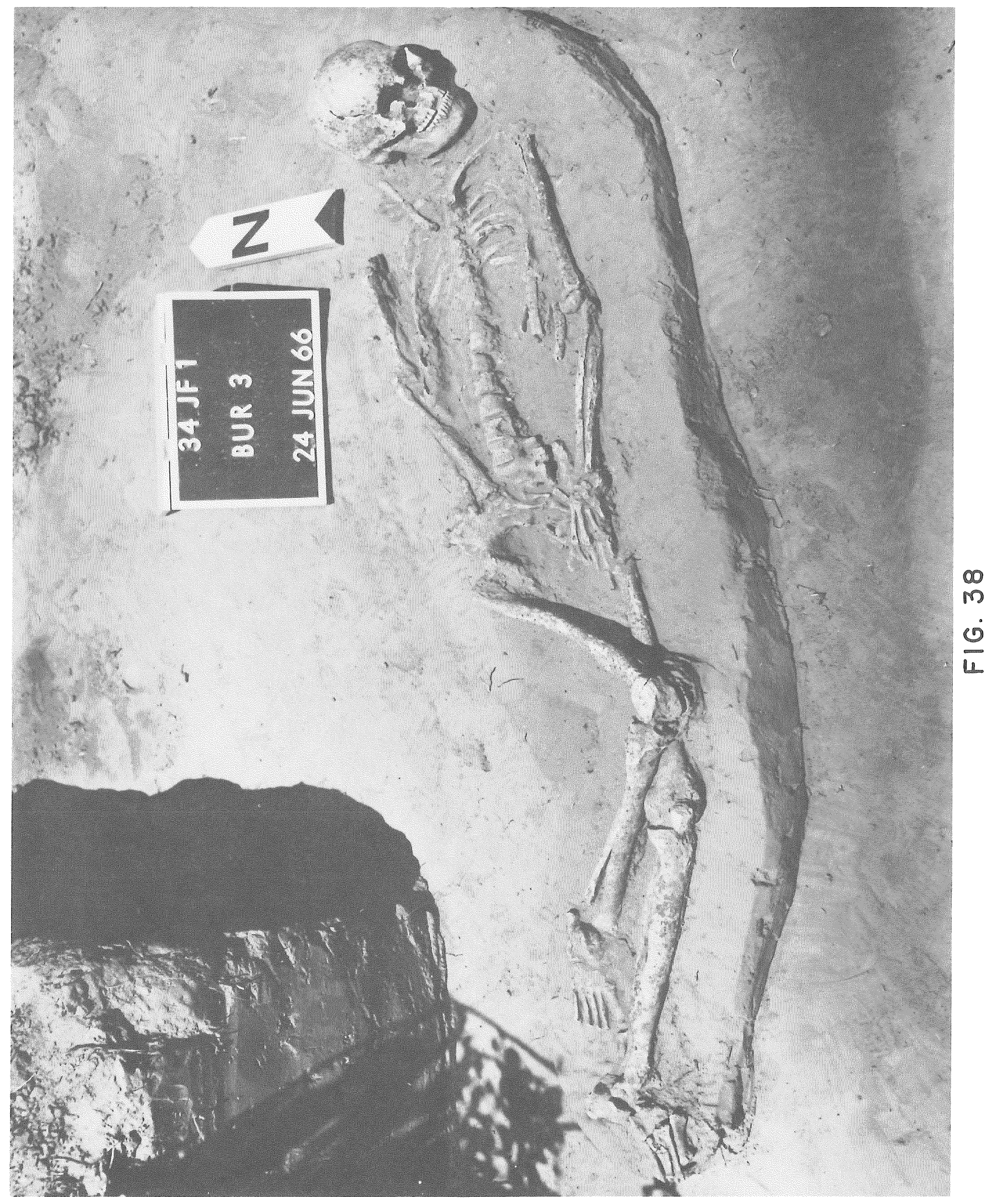




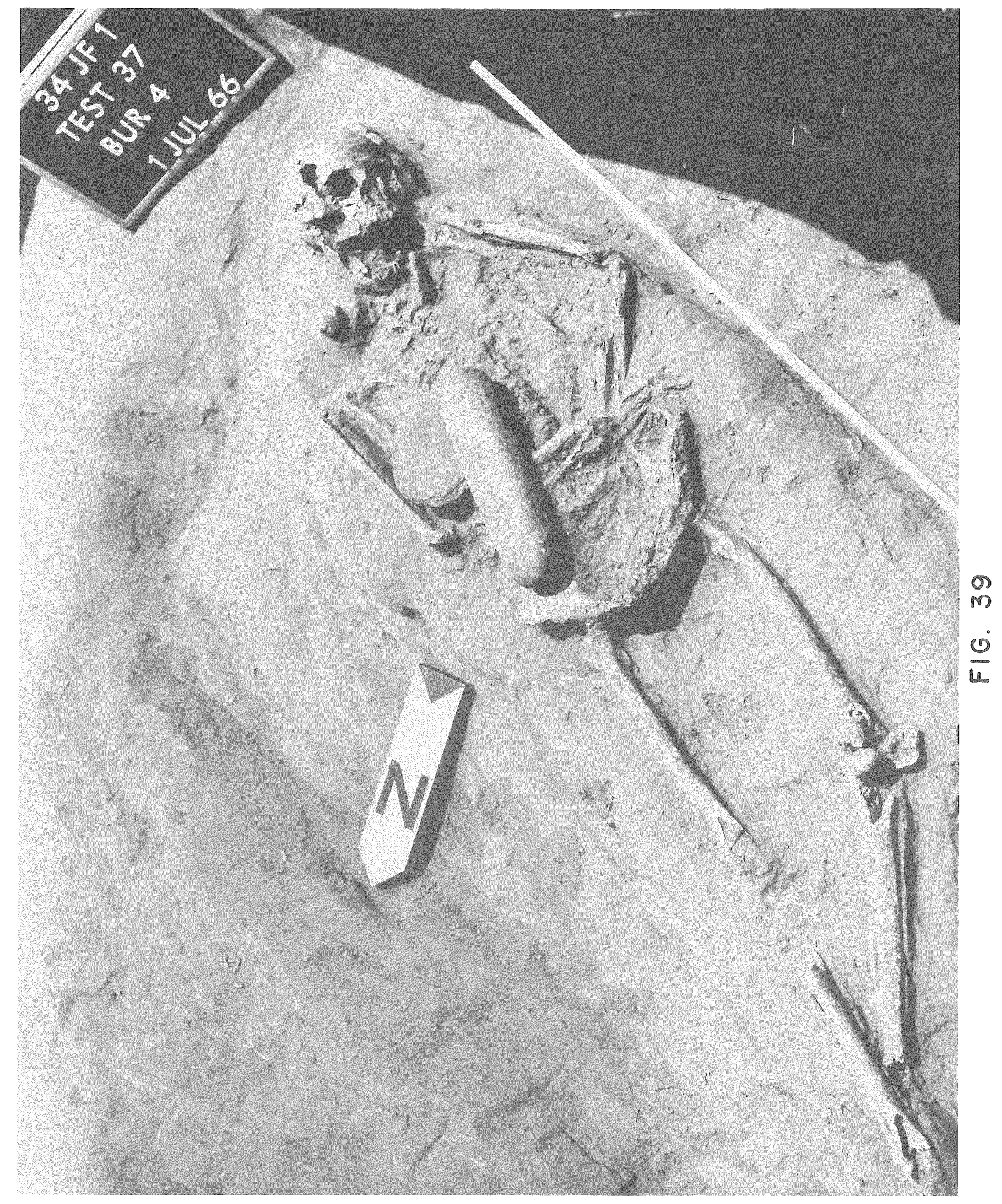









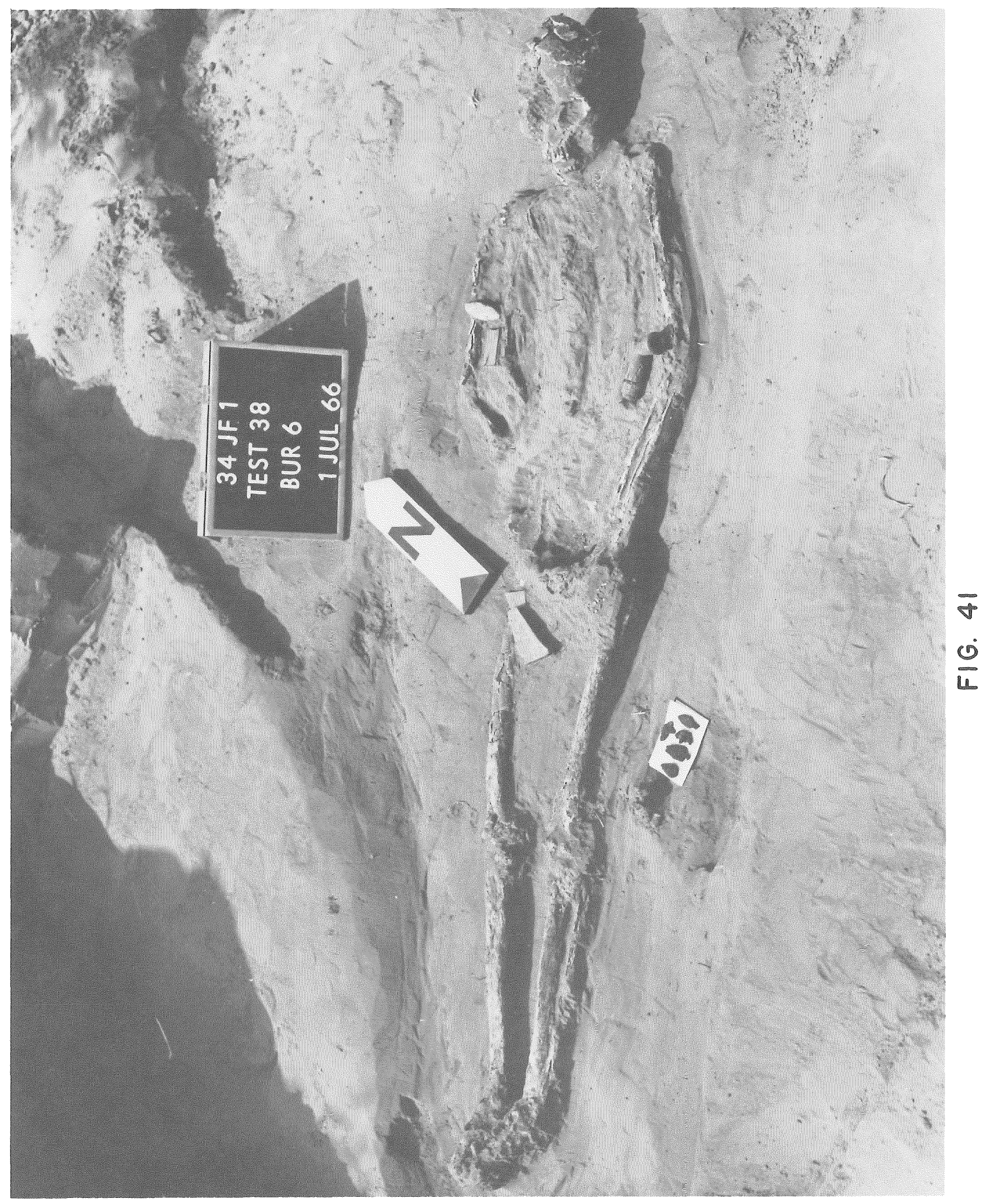




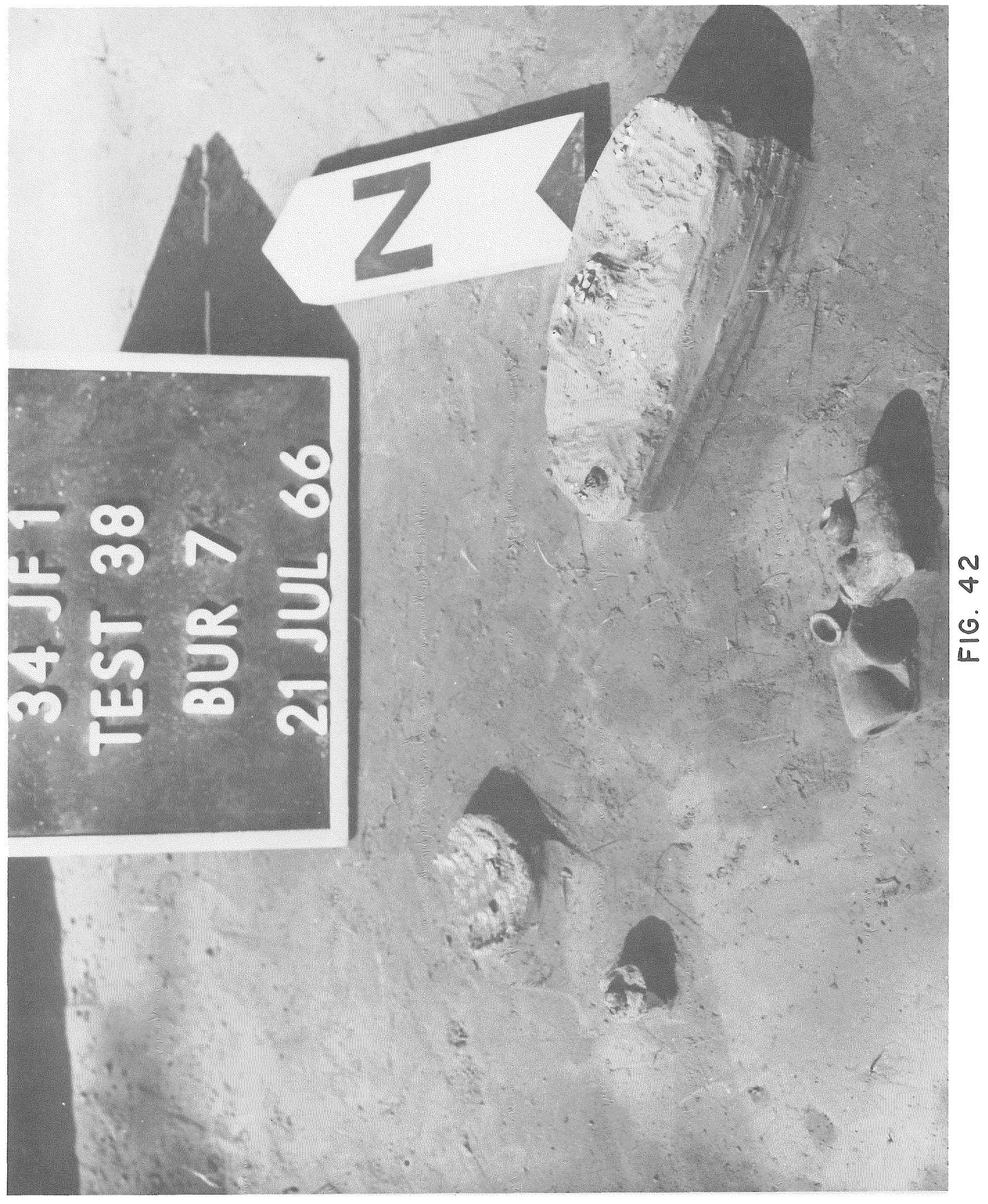




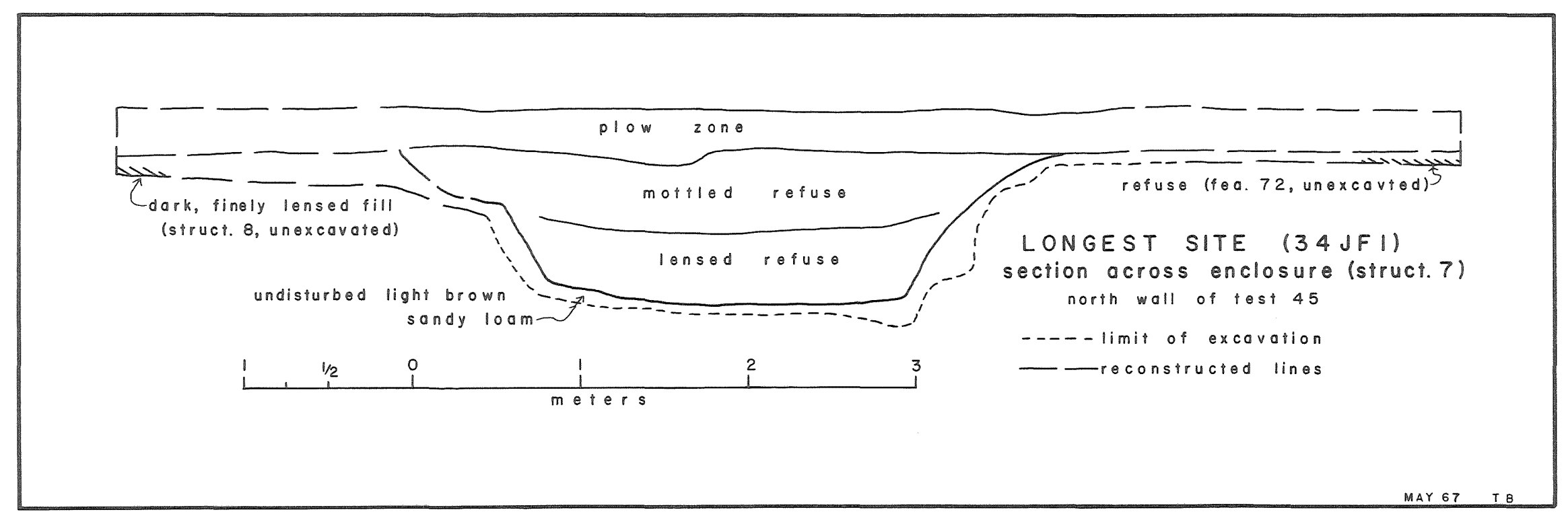

FIG. 43 
FIG. 44

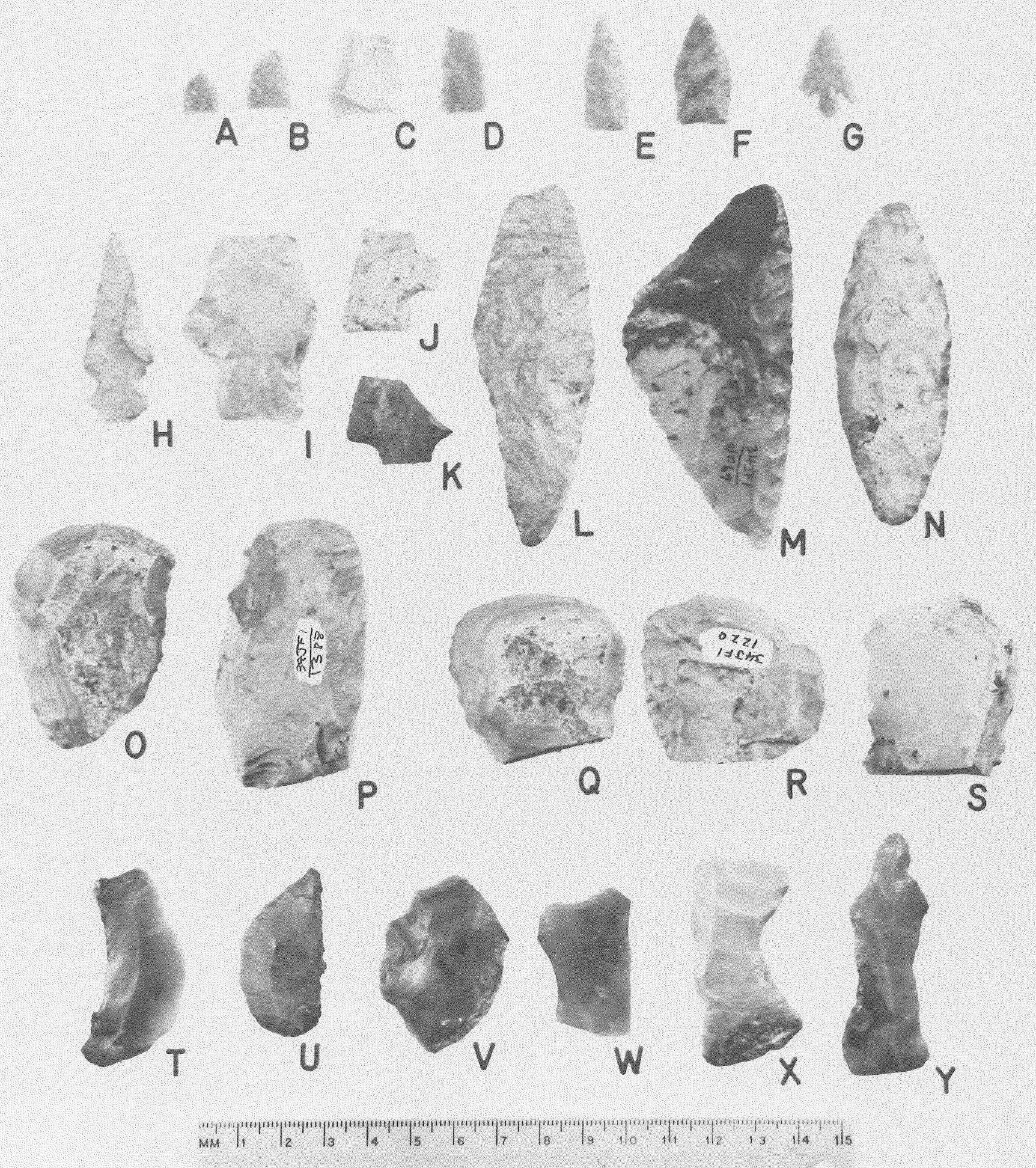




\section{ERRATA SHEET}

An Ethnohistoric Investigation of

the Wichita Indians in the South Plains

Page 249, par. I, all parentheses should be brackets.

Page 256, paragraph three, line six, should be Arkansas instead of Arkansa. Last paragraph, last line, the parentheses should be brackets.

Page 257, first paragraph, Iine two, Wichita should be in brackets instead of parentheses, ditto line four, Wichitas, Iine six, Wichitas, and line ten, Wichita. Line eighteen, remove quotes before Scholarly.

Page 260, paragraph three, line four, Kansa should be enclosed in brackets instead of parentheses.

Page 262 , paragraph four, Iine one, after word four $(1759$,$) ,$ insert page 263. Same paragraph, next to last line, at end of line, comma instead of a period. Last paragraph, line three, word six should be rancheria instead of racheria.

Page 263, paragraph three, parentheses on lines four, five, and eleven should be brackets--enclosing who were also and apparently, aitto line eighteen, enclosing emphasis ours. Last paragraph, next to last line, IScani should be Iscani.

Page 265, paragraph two, all parentheses should be brackets.

Page 266, paragraph two, line three, parentheses should be brackets.

Page 267, paragraph four, lines one, two, and five, parentheses should be brackets. Ditto last paragraph, lines four and five.

Page 270, next to last paragraph, line three, and last paragraph, line six, parentheses should be brackets.

Page 271, paragraph five, lines three and five, parentheses should be brackets.

Page 281, paragraph six, lines one, two, and eight, parentheses should be brackets.

Page 282, paragraph one, line seven, parentheses should be brackets.

Page 283, paragraph two, lines one and two, parentheses should be brackets. Last paragraph, third line from end, should be TaovayaWichita Division, page 281. 
Page two

Page 308, under Marcy, dates should be 1849-1852. brackets.

Page 310, paragraph three, Iine nine, parentheses should be

Page 311, paragraph three, lines four and five, parentheses should be brackets.

Page 314, paragraph five, line three, parentheses should be brackets. Ditto paragraph six, line five, and last paragraph, line one. brackets.

Page 318, paragraph three, line one parentheses should be

Page 323, last paragraph, lines six and seven, and line twenty, parentheses should be brackets. brackets.

Page 326 , paragraph two, Iine twelve, parentheses should be

Page 327 , last paragraph, all parentheses should be brackets.

Page 328 , paragraph eight, line two, Kichai should be enclosed in brackets, instead of parentheses.

Page 329, paragraph one, line ten, parentheses should be brackets.

Page 330, paragraph three, Iines five, six, and seven, parentheses should be brackets. Ditto last paragraph, line one.

Entries on page 362 should follow page 360 and precede page 361 .

Insert, page 362, preceding entry for Hatcher, Mattie Austin (trans.) Harris, R. K., Inus Marie Harris, Jay C. Blaine, and Jerrylee Blaine

1965 A Preliminary Archeological and Documentary Study of the Womack Site, Lamar County, Texas, Bulletin of the Texas Archeological Society, XXXVI, 287-363.

Insert, page 391, as the third entry from the end of the page (ninth entry under Anonymous) following entry beginning $n . d$.

1722 Plano del Presidio de Nuestra Señora de Loreto en la

Bahia del Spiritu Santo de la Provincia de Texas, Nuevo Reino

de Filipinos que demarco y dejo abiertas las zanjas de toda

la fortificacion el viarques de San Miguel de Aguayo (Photo-

graph). Original in AGI, Seville, No. 115.

Page 391, second entry from the bottom, first line, should be Loreto instead of Loreta.

Insert, page 392, as the first entry under Austin, Stephen F. 1820? Mapa de la Provincia de Texas by $D^{n}$ Estevan Austin.

Texas State Library, Austin. 


\section{Page three}

Page 394, first paragraph under Marcy date should be changed to 1849-1852. Add, as another entry, under liarcy:

1854 Map of the Country Upon the Brazos and Big Wichita River, Explored in the Lands Appropriated by the State of Texas for the Use of the Indians. Published by the BrazosRed River Historical Society, Museum of Midwestern University, Wichita Falls. 